Bamberger

Historische Studien

\title{
DAS BAMBERGER KOLLEGIATSTIFT ST. GANGOLF IM MITTELALTER
}

LISA WITOWSKI 
19 Bamberger Historische Studien 


\section{Bamberger Historische Studien}

hg. vom Institut für Geschichte

der Otto-Friedrich-Universität Bamberg

Band 19

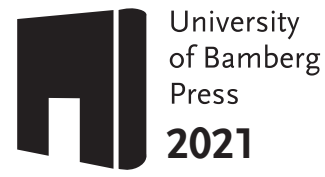




\section{Das Bamberger Kollegiatstift St. Gangolf im Mittelalter}

von Lisa Witowski 
Bibliographische Information der Deutschen Nationalbibliothek

Die Deutsche Nationalbibliothek verzeichnet diese Publikation in der Deutschen Nationalbibliographie; detaillierte bibliographische Informationen sind im Internet über http://dnb.d-nb.de/ abrufbar.

Diese Arbeit hat der Fakultät Geistes- und Kulturwissenschaften der Otto-Friedrich-Universität Bamberg als Dissertation vorgelegen.

Gutachter: Prof. Dr. Klaus van Eickels

Gutachterin: Prof. Dr. Andrea Stieldorf

Tag der mündlichen Prüfung: 07.11.2019

Dieses Werk ist als freie Onlineversion über den Publikationsserver (FIS; https://fis.uni-bamberg.de) der Universität Bamberg erreichbar. Das Werk ausgenommen Cover, Zitate und Abbildungen - steht unter der CC-Lizenz CC-BY.

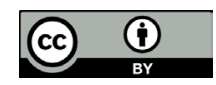

Herstellung und Druck: Digital Print Group, Nürnberg

Umschlaggestaltung: University of Bamberg Press

Umschlagbild: Ausschnitt aus dem Zweidlerplan, 1602, Staatsbibliothek Bamberg, Staatsbibliothek Bamberg. CC-BY-SA

(C) University of Bamberg Press, Bamberg 2021

http://www.uni-bamberg.de/ubp

ISSN: $1865-4622$

ISBN: 978-3-86309-815-5 (Druckausgabe)

eISBN: 978-3-86309-816-2 (Online-Ausgabe)

URN: urn:nbn:de:bvb:473-irb-509937

DOI: https://doi.org/10.20378/irb-50993 


\section{Danksagung}

Das vorliegende Buch stellt eine überarbeitete Fassung meiner Dissertation dar, die ich im Wintersemester 2019/20 an der Fakultät Geistes- und Kulturwissenschaften der Otto-Friedrich-Universität Bamberg verteidigt habe. Prof. Dr. Klaus van Eickels (Bamberg) betreute mich als mein Doktorvater und Prof. Dr. Andrea Stieldorf (Bonn) übernahm das Zweitgutachten. Prof. Dr. Mark Häberlein (Bamberg) als Herausgeber sei für die Aufnahme der Arbeit in die Reihe Bamberger Historische Studien gedankt.

Dr. Klaus Rupprecht, heute Direktor am Staatsarchiv Bamberg, danke ich besonders herzlich für seine Bereitschaft, mich in meinem Forschungsvorhaben jederzeit und voll umfänglich zu unterstützen. Er war mir durch sein umfangreiches Wissen in fränkischer Regionalgeschichte eine große Stütze in Themenfindung, Quellenrecherche und Netzwerkaufbau. Er, Dr. Stefan Nöth und das gesamte Team des Staatsarchivs Bamberg haben mir in vorweggenommener Kollegialität am Archiv die denkbar günstigsten Arbeitsbedingungen gewährt und mich mit motivierenden Gesprächen sowie Hilfestellungen unterstützt, wofür ich sehr dankbar bin. Dies hat meinen Erfahrungsschatz um zahllose Facetten erweitert und mir nicht zuletzt den Eintritt in mein heutiges Betätigungsfeld als Archivarin ermöglicht.

Freundliche Hilfe und bereitwillige Unterstützung erfuhr ich darüber hinaus bei den Bamberger Kolleginnen und Kollegen des Stadtarchivs, des Archivs des Erzbistums, der Staatsbibliothek, des Bayerischen Landesamtes für Denkmalpflege im Schloss Seehof und des Pfarramts St. Gangolf.

Meiner Familie, allen meinen Freunden und Wegbegleitern danke ich für die Ausdauer, Ruhe und Geduld, mit der sie mir zur Seite standen und mich immer wieder aufgemuntert haben. Besonders zu erwähnen ist hierbei Dr. Janis Witowski als mein Ehemann, bester Freund und strengster Kritiker.

Bayreuth, August 2021

Lisa Witowski 



\section{Inhaltsverzeichnis}

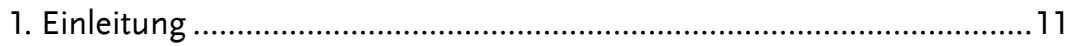

1.1 Kollegiatstifte in Mittelalter und früher Neuzeit ............................. 11

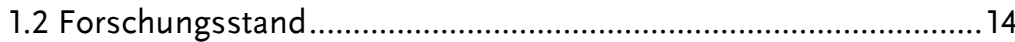

1.3 Fragestellung und Gliederung der Arbeit .......................................22

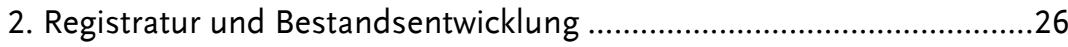

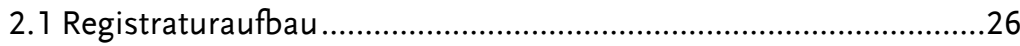

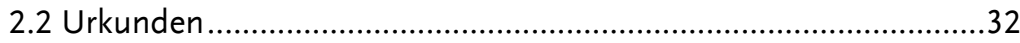

2.3 Bestand „Stift St. Gangolf, Akten und Bände“ im Staatsarchiv

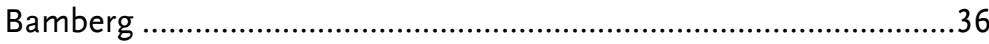

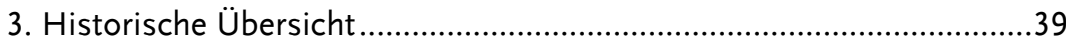

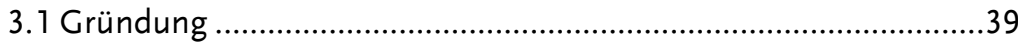

3.1.1 Quellen und Literatur zu den Gründungsdaten .........................39

3.1.2 Einordnung der Stiftsgründung in die politischen Umstände

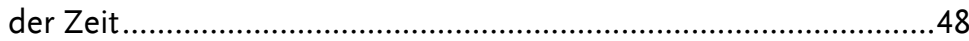

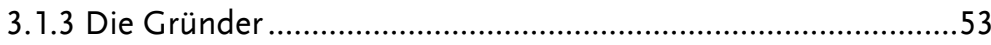

3.1.3.1 Gunther, Bischof von Bamberg ..................................53

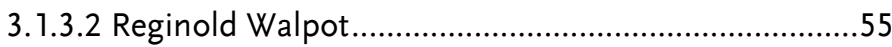

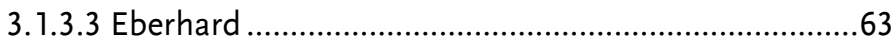

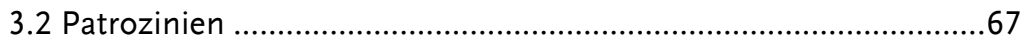

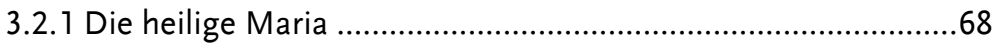

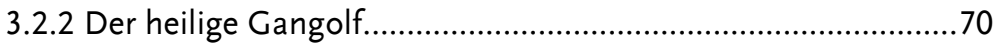

3.2.3 Der heilige Johannes der Täufer...............................................73

3.2.4 Patrozinien in den Siegeln ...................................................... 75

3.2.5 Stiftsbezeichnung in den Urkunden ........................................8 


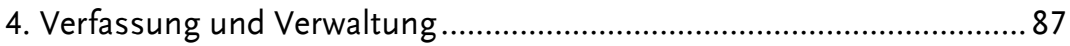

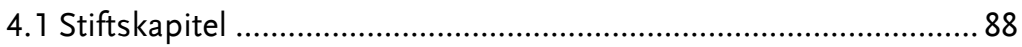

4.1.1 Statuten und Consuetudines .................................................... 90

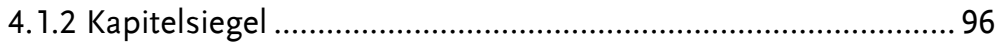

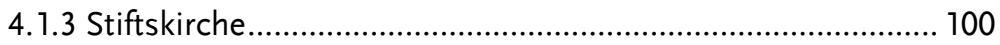

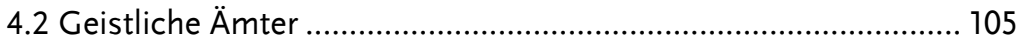

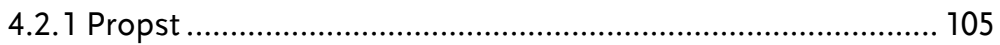

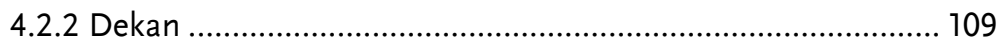

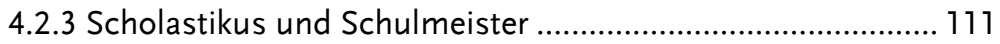

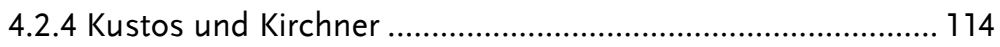

4.2.5 Keller und Immunitätsgericht.................................................. 119

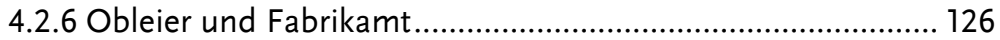

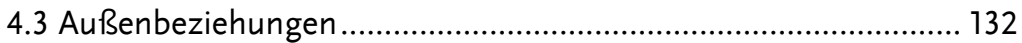

4.3.1 Das Verhältnis zum Bischof und zum Domkapitel ............... 132

4.3.2 Das Verhältnis zu den Bamberger Kirchen ........................... 136

4.3.3 Das Verhältnis zur Bürgerstadt ............................................ 140

4.3.4 Das Verhältnis zum Bürgerspital St. Katharina ..................... 143

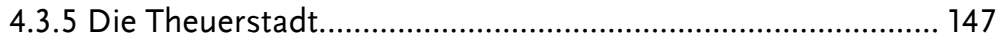

4.3.5.1 Das Verhältnis zur Kapelle St. Gertraud .................. 149

4.3.5.2 Das Verhältnis zum Heilig-Grab-Kloster ................. 151

4.3.5.3 Das Verhältnis zur Wunderburg ............................. 152

4.3.6 Das Verhältnis zum Stift Neunkirchen am Brand................. 154

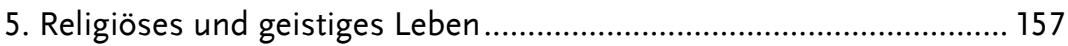

5.1 Gottesdienst und Prozessionen .................................................. 157

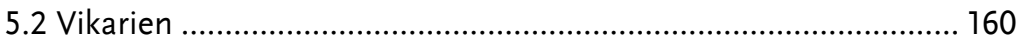


5.2.1 Vikarie St. Nikolaus senior und junior ................................... 163

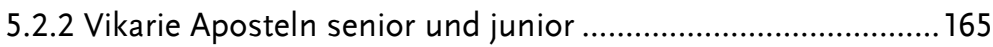

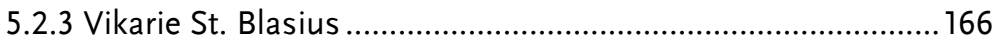

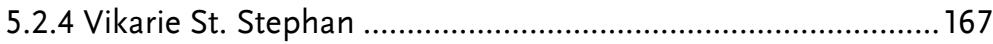

5.2.5 Vikarie St. Maria Magdalena und der heiligen drei Könige.... 168

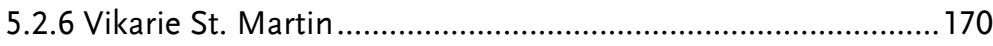

5.2.7 Vikarie St. Philipp, Jakob und Barbara .................................. 170

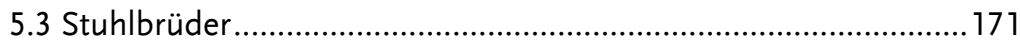

5.4 Friedhof, Bestattungen und Testamente.................................... 175

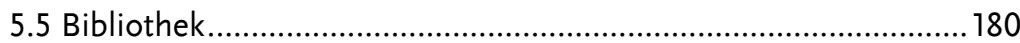

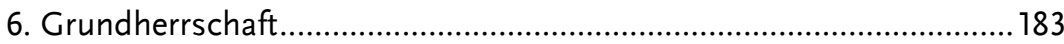

6.1. Besitzverwaltung eines Kollegiatstifts ........................................ 183

6.2 Quellen des Stifts St. Gangolf zur Besitzverwaltung .................... 186

6.3 Entwicklung des Grundbesitzes als Pfründengut ......................... 193

6.3.1 Gründungsausstattung und erste Schenkungen.................... 193

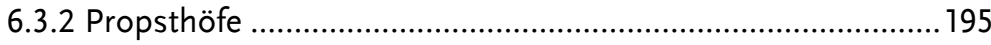

6.3.2.1 Propsthof in Hollfeld................................................... 198

6.3.2.2 Propsthof in Gesees ...................................................203

6.3.3 Verteilungsmodalitäten des Pfründenguts .............................206

6.3.3.1 Grundstock der Pfründenansprüche .......................207

6.3.3.2 Pröpstische Abgaben an den Kustos ........................208

6.3.3.3 Pröpstische Abgaben an den Keller.........................2 12

6.3.3.4 Pröpstische Abgaben an den Obleier .......................2 13

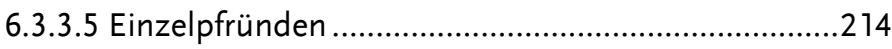

6.3.4 Kontrollmechanismen des Kapitels über den Propst.............220 
6.4 Verwaltung von Stiftungen und Schenkungen durch das Kapitel223

6.4.1 Obleibesitz 223

6.4.1.1 Quellen und begriffliche Einordnung...................... 223

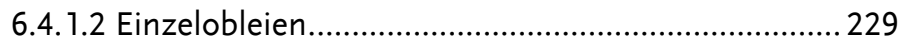

6.4.1.3 Verteilungsmodalitäten der Obleien ......................... 265

6.4.2 Andere Anniversarstiftungen und Einkünfte des Kapitels ..... 267

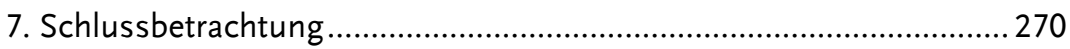

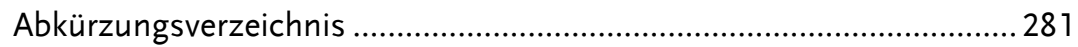

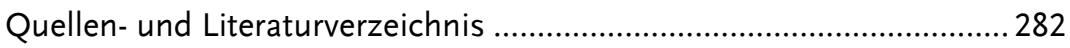

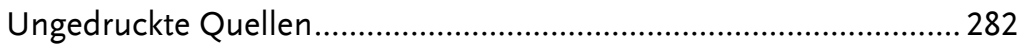

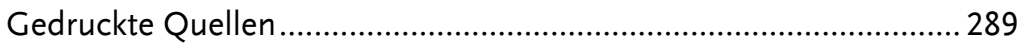

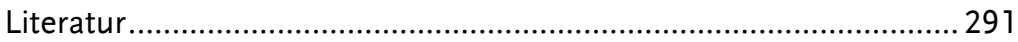

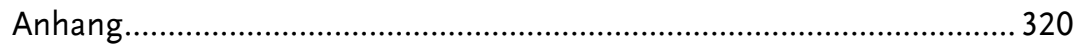

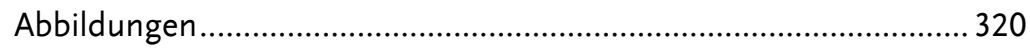

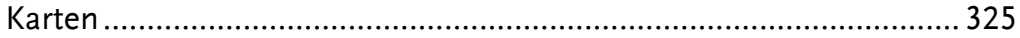

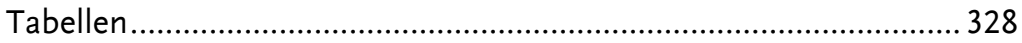

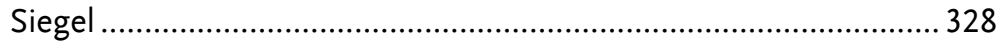

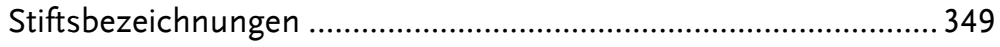

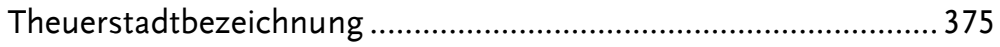

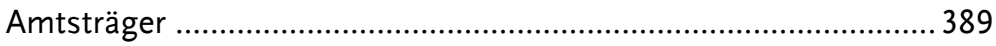




\section{Einleitung}

\subsection{Kollegiatstifte in Mittelalter und früher Neuzeit}

Kollegiatstifte fungierten wie auch Klöster als Orte der Heiligenverehrung und des Gottesdienstes und trugen durch Sicherung und Erschließung von Territorien und als Stationen, beispielsweise bei Prozessionen, zur Entwicklung und Aufwertung mittelalterlicher Städte bei. Trotzdem standen die Untersuchungen zum Thema Kollegiatstift in der Geschichtswissenschaft lange im Schatten der Klosterforschung, denn das Wirken von Säkularkanonikern wurde von anderen Rahmenbedingungen bestimmt als das der Mönche oder das der Regularkanoniker sie waren nicht zur Armut verpflichtet und gehörten keiner Ordensgemeinschaft an. ${ }^{1}$ Dies eröffnete einzelnen Kanonikern einen Handlungsspielraum auch außerhalb der Gemeinschaft, ${ }^{2}$ sodass Stifte für eine „Verflechtung von Kirche und Welt“3 ${ }^{3}$ standen und als unvollkommene Klöster galten. Die Möglichkeit, Privatbesitz anzuhäufen, bot eine Angriffsfläche für Missbilligung bereits durch mittelalterliche Zeitgenossen. Besonders Kleidung und Statussymbole der Kanoniker spielten in diesem Zusammenhang eine Rolle, da sie als von außen wahrnehmbare Kennzeichen der Zugehörigkeit Auskunft über das weltliche Selbstverständnis gaben. In den Augen der Kritiker, meist selbst aus dem Mönchtum stammend, stand dies dem Ideal des weltabgewandten Lebens entgegen.

Der Zisterzienser Caesarius von Heisterbach (1180-1240) beispielsweise kritisierte die Kanoniker offen und stellte seine eigene Lebens-

${ }^{1}$ Raymund Kottje: Claustra sine armario? Zum Unterschied von Kloster und Stift im Mittelalter. In: Consuetudines Monasticae. Festgabe für Kassius Hallinger (Studia Anselmiana, Bd. 85). Rom 1982. S. 125-144, hier: S. 128-129.

2 Peter Moraw: Über Typologie, Chronologie und Geographie der Stiftskirche im deutschen Mittelalter. In: Max-Planck-Institut für Geschichte (Hg.): Untersuchungen zu Kloster und Stift (Veröffentlichungen des Max-Planck-Instituts für Geschichte, Bd. 68. Studien zur Germania Sacra, Bd. 14.). Göttingen 1980. S. 9-37, hier: S. 12.

${ }^{3}$ Marchal, Guy P.: Was war das weltliche Kanonikerinstitut im Mittelalter? Dom- und Kollegiatstifte: Eine Einführung und eine neue Perspektive. Suit et fin. In: Katholische Universität Löwen (Hg.): Revue d'histoire ecclésiastique. Bd. 95. 1. Löwen 2000. S. 7-53, hier: S. 52. 
form als Ideal dem der Weltkleriker gegenüber. ${ }^{4}$ Dieser Konflikt war keineswegs allein eine Frage der theoretischen Auseinandersetzung mit Lebenskonzepten durch ausgewählte Intellektuelle, sondern wurde auf breiter Ebene wahrgenommen. 1277 wurde in Mainz bei einer Visitation des Erzbischofs Wernher den ansässigen Kanonikern Kleiderpracht und das Tragen von Schmuck vorgeworfen, außerdem dass sie nachts Harnisch und Schwerter in laicali habitu trugen. ${ }^{5}$

Im Zuge der Reformation stießen Reichtum und die nach außen getragene Stellung der Kanoniker nicht mehr nur auf Widerwillen, sondern wurden vehement bekämpft. Obwohl die eingeschränkten Kontrollmöglichkeiten der Gemeinschaft über den Einzelnen als Quelle des Lasters angesehen wurden, war die überregionale Bedeutung der Stifte, beispielsweise hinsichtlich der Ausbildung von Klerikern an Domschulen, ${ }^{6}$ auch den schärfsten Gegnern bewusst. In seiner Kritik an den Säkularkanonikern umriss beispielsweise Martin Luther die Aufgaben eines Kollegiatstifts als Mahnung gegen das Domstift zu Cammin in Pommern:

${ }^{4}$ So berichtete er von Gottfried, einem Schulmeister des Kanonikerstifts St. Andreas in Köln, der Besuch vom Teufel persönlich bekommen haben soll. Außerdem von einem Kanoniker des Stifts St. Kunibert in Köln, der sich aufgrund der Intervention der heiligen Maria letzendlich doch dem Mönchtum verschrieben hätte. In Heisterbach, Caesarius von: Dialogus miraculorum. hg. v. Strange, Joseph. Bd. 1-2. Köln/ Bonn/ Brüssel 1851. IV 49 und VII 8.

5 "Cum itaque honestas clericorum et vita non sine multa circumspectionis industria feliciter instituta et $\mathrm{s}$. patrum auctoritatibus et meritis roborata, tanto attentiori studio sit a corruptionis infamia preservanda, quanto maiori libertatis privilegio dinoscitur insignita, precipimus firmiter statuentes, ne clerici nutriant ammodo concos crines, qui vulgariter crulle dicuntur, nec mitras extra domos suas et curias deferant, nisi in equis constituti fuerint ad eundem et choreis laicorum in plateis et vicis se nequaquam immisceant, volumus quoque, ut loricas, gladios seu alia arma nocturno tempore in laicali habitu incedentes sub tunicis aut alias non deferant quoquo modo, ne si hoc modo fuerint deprehensi tradantur iudicio seculari, nec transitum faciant sine superpelliciis per ecclesias, eo tempore, quo divinum officium peragitur in eisdem, vestibus etiam nimia brevitate notatis, a lateribus scissis et nodatis aut cum collerio dispositis, dum superpelliciis sun induti, decetero non utantur." in Ludwig Baur (Hg.): Hessische Urkunden, Bd. 2. Darmstadt 1862. Nr. 303 S. 278-282, hier: S. 279.

${ }^{6}$ Näheres dazu in Martin Kintzinger: Stiftsschulen und Wissensvermittlung. Einführung in den Forschungsstand. In: Lorenz, Sönke/ Kintzinger, Martin/ Auge, Oliver (Hgg.): Stiftsschulen in der Region. Wissenstransfer zwischen Kirche und Territorium. Ostfildern 2005. S. 1-16. 
das erstlich der bistumb, capitel und stift fundation nicht zum bracht oder zum miessiggang gemeint sindt, sonder, das sie ein besunder zier und trost der landen sein solden, und solden dienen $z u$ bestend[ig]er, ewiger erhaltung christlicher lehr, religion, zucht und guter kunsten, nemlich, das fur und fur viel gelarter, verstendiger, geubter menner weren, bey welchen die herrschaft, ritterschaft und stet in geistlichen und vielen anderen sachen guten radt finden mochten. Item, das gemelte bischof und capitel ein ufsehen hetten uf die lehre und ceremonien in den kirchen des gantzen landes, hielten die ehegericht und handhabten gute zucht und gute sytten ?

Die Funktionen eines weltlichen Kanonikerstifts, sei es ein Dom- oder ein kleineres Kollegiatstift, waren vielfältig und die Bedeutung ihrer Arbeit für die Kirchen- und Laiengemeinde war so groß, dass Kritikpunkte wie übermäßige Prachtentfaltung oder Müßiggang im Sinne von Pflichtvernachlässigungen gravierende Auswirkungen haben mussten. Die Verbindung weltlichen und kirchlichen Auftretens in der Öffentlichkeit stellte eine Zerreißprobe für das Selbstverständnis und die Außenwirkung der Kollegiatstifte dar, musste doch eine Institution, die abhängig von der Stiftertätigkeit seiner Umgebung war, in besonderem Maße den Verlust ihres Rufs und ihres Ansehen fürchten. ${ }^{8}$ Dies geschah vor allem dann, wenn die Kanoniker den liturgischen Pflichten durch eine zu starke Orientierung auf außerkirchliche Aufgaben nicht mehr nachkamen. Da die stabilitas loci für sie nicht galt, waren die Kanoniker für geistliche und weltliche Herrscher interessant. Ausgestattet mit einer guten Ausbildung waren die Kanoniker einerseits in zahlreichen Bereichen wie Hospizwesen, Universitäten oder Pfarrseelsorge einsetzbar und andererseits durch ihren Pfründenbezug finanziell abgesichert. Diese Umstände sorgten jedoch nicht nur für die bereits erwähnten Angriffsflächen in der öffentlichen Wahrnehmung, sondern erschwerten es, ein Gemeinschaftsgefühl innerhalb der Institution zu

${ }^{7}$ Luther, Bugenhagen, Cruciger und Melanchton an die Pommerschen Räte, Wittenberg 30. Mai 1544. In: D. Martin Luthers Werke. Kritische Gesamtausgabe (Weimarer Ausgabe). Briefwechsel, Bd. 10. Weimar 1947. Nr. 3999. S. 587-590, hier: S. 588.

${ }^{8}$ Rudolf Holbach: Identitäten von Säkularkanonikern im Mittelalter. In: Kwiatkowski, Stefan/ Mallek, Janusz (Hgg.): Ständische und religiöse Identitäten in Mittelalter und früher Neuzeit. Torun 1998. S. 19-41, hier: S. 38. 
halten. Die Bindung der Kanoniker an ihr Stift musste, besonders nach der Auflösung der vita communis, ${ }^{9}$ durch Statuten und die Einführung von Präsenzgeldern sichergestellt werden, um die Durchführung der Gottesdienste mit angemessener Besetzung gewährleisten zu können. Nur so konnte der Fortbestand gesichert und das Stift als Adressat frommer Stiftungen attraktiv bleiben. Dies bildete das Spannungsfeld, innerhalb dessen sich der einzelne Kanoniker bewegte. ${ }^{10}$

\subsection{Forschungsstand}

Nach nicht unproblematischen Ansätzen einer Neueinschätzung der weltlichen Stifte in den 1960er und 1970er Jahren ${ }^{11}$ nahm sich die Germania Sacra dem Problem der fehlenden Aufarbeitung des Phänomens Kollegiatstift an. ${ }^{12}$ Das Ziel des 1917 von Paul Fridolin Kehr begründeten Projekts bestand darin, alle Bistümer auf dem Gebiet der heutigen Bundesrepublik nach aktuellem Forschungsstand aufzuarbeiten und der Öffentlichkeit zugänglich zu machen. ${ }^{13}$ Es entstanden zahlreiche Monographien, die Quellen und Literatur der kirchlichen Häuser erschlossen und auswerteten. Die Reihe der vielen Einzeldarstellungen über Dom- und Stiftskirchen wird jedoch in der aktuellen Forschung immer mehr von Arbeiten durchbrochen, die sich von der Betrachtung

9 Die „vita communis“ als Praxis des „gemeinsamen Tisches“ bezeichnet ein enges Zusammenleben der Kanoniker, bevor sich im 13. Jahrhundert eigene Kanonikerhäuser und getrennte Einkünfte herausbildeten. Näheres dazu im Kapitel 6.1. Besitzverwaltung eines Kollegiatstifts.

10 Näheres $\mathrm{zu}$ den kirchenrechtlichen Grundlagen der Institution Kollegiatstift in Wolfgang F. Rothe: Kollegiatkapitel im deutschen Sprachraum. Eine kirchenrechtliche Bestandsaufnahme. In: Zeitschrift der Savigny-Stiftung für Rechtsgeschichte, Kanonistische Abteilung 93, Bd. 124 (2007). S. 246-278, hier: S. 246.

11 Josef Siegwart: Die Chorherren- und Chorfrauengemeinschaften in der deutschsprachigen Schweiz vom 6. Jahrhundert bis 1160. Mit einem Überblick über die deutsche Kanonikerreform des 10. und 11. Jahrhunderts (Studia Friburgensia NF, Bd. 30). Freiburg 1962. und Rudolf Schieffer: Die Entstehung von Domkapiteln in Deutschland (Bonner Historische Forschung, Bd. 43). Röhrscheid 1976.

${ }^{12}$ Einen Überblick über den damaligen Ansatz der Stiftsforschung in Irene Crusius: Das weltliche Kollegiatstift als Schwerpunkt innerhalb der Germania Sacra. In: Blätter für deutsche Landesgeschichte. Neue Folge des Korrespondenzblattes 120 (1984) S. 241-253.

${ }^{13}$ Richtlinien der Germania Sacra, Dritte Folge (Stand April 2009). 
einzelner Häuser lösen und sich dem Phänomen der mittelalterlichen Kollegiatstifte in seiner Gesamtheit annähern und einen stiftsübergreifenden Ansatz verfolgen. ${ }^{14}$ Durch die Germania Sacra angeregt, widmete sich der sozialgeschichtlich orientierte Historiker Peter Moraw grundlegenden Überlegungen zur Stiftsgeschichte ${ }^{15}$ und rückte das Forschungsfeld in den Fokus der Wissenschaft.

Das Bistum Bamberg fand schon früh Eingang in die Schriftenreihe der Germania Sacra, welche mit den bearbeiteten Bischofslisten durch Dieter Weiß kürzlich seinen vorläufigen Abschluss fand. ${ }^{16}$ Eine modernen geschichtswissenschaftlichen Standards entsprechende Stadtgeschichte Bambergs fehlt zwar weiterhin, doch sind an den Lehrstühlen für Mittelalterliche und Neuere Geschichte der Otto-FriedrichUniversität Bamberg in Zusammenarbeit mit dem Stadtarchiv Bamberg zahlreiche Einzelstudien zur Geschichte der Bamberger Kirchenlandschaft und des städtischen Bürgertums entstanden. ${ }^{17}$ Ebenso macht der

\footnotetext{
${ }^{14}$ Beispielsweise Alfred Wendehorst/ Stefan Benz: Verzeichnis der Säkularkanonikerstifte der Reichskirche (Schriften des Zentralinstituts für fränkische Landeskunde und allgemeine Regionalforschung an der Universität Erlangen-Nürnberg, Bd. 35). Neustadt an der Aisch 1997; Marchal: Was war das weltliche Kanonikerinstitut im Mittelalter? 2000. S. 753; Holger Kunde (Hg.): Zwischen Kathedrale und Welt. 1000 Jahre Bistum Merseburg und Kollegiatstift Zeitz. Aufsätze (Wissenschaftlicher Begleitband zur Ausstellung). Petersberg 2005; Sönke Lorenz/ Andreas Meyer/ Dieter R. Bauer (Hgg.): Stift und Wirtschaft. Die Finanzierung geistlichen Lebens im Mittelalter. Fünfte wissenschaftliche Fachtagung zum Stiftskirchenprojekt des Instituts für Geschichtliche Landeskunde und Historische Hilfswissenschaften der Universität Tübingen 2004 (Schriften zur südwestdeutschen Landeskunde, Bd. 58). Ostfildern 2007; Sönke Lorenz/ Oliver Auge/ Sigrid Hirbodian (Hgg.): Handbuch der Stiftskirchen in Baden-Württemberg. Ostfildern 2019.

${ }_{15}$ Moraw: Über Typologie, Chronologie und Geographie der Stiftskirche im deutschen Mittelalter. 1980. S. 9-37.

${ }^{16}$ Dieter J. Weiß: Das exemte Bistum Bamberg 4: Die Bamberger Bischöfe von 1693 bis 1802 (Germania Sacra. Dritte Folge, Bd. 12). Berlin/ Boston 2015; Ders.: Das exemte Bistum Bamberg 3/1: Die Bischofsreihe von 1522 bis 1693 (Germania Sacra. Neue Folge, Bd. 38). Berlin/ New York 2000; Erich Freiherr von Guttenberg/ Alfred Wendehorst: Das Bistum Bamberg 2. Die Pfarreiorganisation (Germania Sacra. Alte Folge Abt. 2: Die Bistümer der Kirchenprovinz Mainz). Berlin/ New York 1966; Erich Freiherr von Guttenberg: Das Bistum Bamberg (Germania Sacra. Alte Folge Abt. 2: Die Bistümer der Kirchenprovinz Mainz). Berlin 1937 (ND Berlin/ New York 1963).

${ }^{17}$ Eine Auswahl aktueller Forschung:

- Aus der Reihe Stadt und Region in der Vormoderne, hg. v. Mark Häberlein: Claudia Esch: Zwischen Institution und Individuum. Bürgerliche Handlungsspielräume im mittelalterlichen Bamberg (Stadt und Region in der Vormoderne, Bd. 4. Veröffentlichungen
} 
traditionsreiche Historische Verein Bamberg (HVB) mit seinen jährlichen Berichten auf die exponierte Stellung Bambergs in Franken und im Reich aufmerksam. ${ }^{18}$ Darüber hinaus sind die geschichtstragenden Institutionen der Stadt Bamberg, namentlich die Archive, Museen, die Staatsbibliothek und die Stadtarchäologie, federführend in der Förderung stadtgeschichtlicher Untersuchungen. So entstand 2015 das Gemeinschaftsprojekt einer Sonderausstellung anlässlich des tausendjäh-

des Stadtarchivs, Bd. 23). Würzburg 2016; Mark Häberlein/ Michaela Schmölz-Häberlein (Hgg.): Handel, Händler und Märkte in Bamberg. Akteure, Strukturen und Entwicklungen in einer vormodernen Residenzstadt (1300-1800) (Stadt und Region in der Vormoderne, Bd. 3. Veröffentlichungen des Stadtarchivs Bamberg, Bd. 21). Würzburg 2015; Lina Hörl: Handwerk in Bamberg. Strukturen, Praktiken und Interaktionen in Stadt und Hochstift (1650-1800) (Stadt und Region in der Vormoderne, Bd. 2. Veröffentlichungen des Stadtarchivs Bamberg, Bd. 20). Würzburg 2015.

- Aus der Reihe Bamberger interdisziplinäre Mittelalterstudien Vorlesungen und Vorträge, hg. v. Zentrum für Mittelalterstudien der Otto-Friedrich-Universität Bamberg: Andrea Stieldorf/ Andrea Schindler (Hgg.): WeltkulturerbeN. Formen, Funktionen und Objekte kulturellen Erinnerns um und an das Mittelalter (Bamberger intersisziplinäre Mittelalterstudien. Vorlesungen und Vorträge, Bd. 6). Bamberg 2015; Stephan Albrecht (Hg.): Der Bamberger Dom im europäischen Kontext (Bamberger interdisziplinäre Mittelalterstudien Vorlesungen und Vorträge, Bd. 4). Bamberg 2015; Achim Hubel (Hg.): Neue Forschungen zur mittelalterlichen Bau- und Kunstgeschichte in Franken (Bamberger interdisziplinäre Mittelalterstudien Vorlesungen und Vorträge, Bd. 2). Bamberg 2011; Klaus van Eickels/ Christine van Eickels (Hgg.): Das Bistum Bamberg in der Welt des Mittelalters. Vorträge der Ringvorlesung des Zentrums für Mittelalterstudien der Otto-Friedrich-Universität Bamberg im Sommersemester 2007 (Bamberger interdisziplinäre Mittelalterstudien Vorlesungen und Vorträge, Bd. 1). Bamberg 2007.

- Aus der Reihe Bamberger Historische Studien, hg. v. Institut für Geschichte der OttoFriedrich-Universität Bamberg: Mark Häberlein: Testamente Bamberger Frauen des 16. und 17. Jahrhunderts (Bamberger Historische Studien, Bd. 17). Bamberg 2018; Mark Häberlein/ Michaela Schmölz-Häberlein: Stiftungen, Fürsorge und Kreditwesen im frühneuzeitlichen Bamberg (Bamberger Historische Studien, Bd. 13). Bamberg 2015; Mark Häberlein: Bamberg im Zeitalter der Aufklärung und der Koalitionskriege (Bamberger Historische Studien, Bd. 12. Veröffentlichungen des Stadtarchivs Bamberg, Bd. 19). Bamberg 2014; Mark Häberlein/ Robert Zink (Hgg.): Soziale Strukturen und wirtschaftliche Konjunkturen im frühneuzeitlichen Bamberg (Bamberger Historische Studien, Bd. 10. Veröffentlichungen des Stadtarchivs Bamberg, Bd. 17). Bamberg 2013; Johannes Hasselbeck: Die Folgen des Deutschen Bauernkriegs im Hochstift Bamberg (Bamberger Historische Studien, Bd. 7. Veröffentlichungen des Stadtarchivs Bamberg, Bd. 14). Bamberg 2012; Mark Häberlein/ Kerstin Kech/ Johannes Staudenmaier: Bamberg in der frühen Neuzeit (Bamberger Historische Studien, Bd. 1. Veröffentlichungen des Stadtarchivs Bamberg, Bd. 11). Bamberg 2008.

${ }^{18}$ Die jährlich erscheinenden Berichte des Historischen Vereins Bamberg gehen zurück bis zum Jahr 1838 und sind in ihren ältesten Ausgaben auch digital verfügbar. 
rigen Bestehens des Klosters Michelsberg mit dazugehörigen Publikationen namhafter Historiker. ${ }^{19}$

Fundierte Untersuchungen zur allgemeinen Stadtgeschichte sind essentiell, um die Kollegiatstifte angemessen einordnen zu können, und bilden daher die Grundlage für eine Erforschung der Bamberger Stiftslandschaft. Diese konnte sich bereits in der zweiten Hälfte des vorigen Jahrhunderts mit der wegweisenden Untersuchung zur wirtschaftlichen Beschaffenheit des Bamberger Domstifts niederschlagen. ${ }^{20}$ Obwohl an Quellenüberlieferung und Bedeutung weitaus bescheidener wurden auch das Kollegiatstift St. Stephan ${ }^{21}$ und das ebenfalls zum Hochstift Bamberg gehörige Kollegiatstift St. Martin in Forchheim ${ }^{22}$ durch Einzeluntersuchungen gewürdigt. Im Entstehen begriffen ist die Untersuchung zum Bamberger Kollegiatstift St. Jakob. ${ }^{23}$ Allein eine den modernen geschichtswissenschaftlichen Maßgaben entsprechende Gesamtdarstellung von Kirche und Stift St. Gangolf stand bisher aus und soll mittels dieser Monografie nachgereicht werden.

Eine historische Auseinandersetzung mit der Geschichte des mittelalterlichen Kollegiatstifts St. Gangolf setzte bereits vor dessen Säkularisation 1803 ein. Hierbei lag der Schwerpunkt überwiegend auf der

${ }^{19}$ Norbert Jung/ Holger Kempkens (Hgg.): Im Schutz des Engels. 1000 Jahre Kloster Michelsberg Bamberg 1015-2015. Begleitpublikation zur Sonderausstellung vom 26. Juni bis 4. Oktober 2015. Petersberg 2015.

20 Allen voran $\mathrm{zu}$ erwähnen: Erich Freiherr von Guttenberg: Urbare und Wirtschaftsordnungen des Domstifts zu Bamberg (Veröffentlichungen der Gesellschaft für fränkische Geschichte, Reihe 10: Quellen zur Rechts- und Wirtschaftsgeschichte Frankens, Bd. 7,1). hg. von Alfred Wendehorst. Würzburg 1969; und Stefan Nöth: Urbare und Wirtschaftsordnungen des Domstifts zu Bamberg (Veröffentlichungen der Gesellschaft für fränkische Geschichte, Reihe 10: Quellen zur Rechts- und Wirtschaftsgeschichte Frankens, Bd. 7,2). Neustadt a. d. Aisch 1986.

${ }^{21}$ Ulrike Siewert: Das Bamberger Kollegiatstift St. Stephan. Säkularkanoniker in einer mittelalterlichen Bischofsstadt. Bamberg 2007. Näheres hinsichtlich dem Einzelaspekt Architektur in Margit Fuchs: Innovation und Pragmatismus. Sankt Stephan in Bamberg als Initialbau der barocken Architektur in Franken (Gesellschaft für fränkische Geschichte, Reihe VIII: Quellen und Darstellungen zur fränkischen Kunstgeschichte, Bd. 18). Stegaurach 2017.

22 Andreas Jakob: Das Kollegiatstift bei St. Martin in Forchheim. Grundlagen zur Geschichte von Stift und Pfarrei in der zweiten Hauptstadt des Hochstiftes Bamberg 1354. 1803. Lichtenfels 1998.

${ }^{23}$ In Bearbeitung durch die Dissertation von Christine Kofer, Hauptstaatsarchiv München. 
Kunst- und Baugeschichte. Um 1600 erwähnte Martin Hoffmann als Advokat am Bamberger Hof und Leiter des fürstbischöflichen Archivs das Stift St. Gangolf im Rahmen seiner Abhandlung über die Bamberger Bischöfe. ${ }^{24}$ Im Zusammenhang mit den Leistungen des Bamberger Bischofs Gunther (amt. 1057-1065) beschrieb Hoffmann die Gründungsumstände St. Gangolfs, setzte 1063 als Jahr der Stiftsgründung fest und erwähnte Reginold Walpot und den Bürger Eberhard als Mitbegründer. Seine Quellen nannte er nicht, was jedoch die Regionalforschung viele Jahre nicht davon abhielt, seine Thesen ungeprüft zu übernehmen.

Die erste umfassende Behandlung der Geschichte des Kollegiatstifts St. Gangolf in Bamberg erfolgte in der zweiten Hälfte des 18. Jahrhunderts, als Michael Heinrich Schubert seine an der Universität Bamberg eingereichte Dissertation dem Phänomen Kollegiatstift am Beispiel St. Gangolfs widmete, ${ }^{25}$ dessen letzter Dekan er selbst war. Diese erste Beschäftigung mit der historischen Entwicklung des Stifts fiel nicht zufällig in eine Zeit der hitzig geführten Diskussion um die rechtliche und organisatorische Neuausrichtung der 1748 offiziell aufgelösten Immunitäten. Schubert verlegte die Gründung St. Gangolfs in das Jahr 1057 unter Bischof Gunther, bezeichnete Reginold und Eberhard als Mitbegründer und setzte die Weihe der Stiftskirche in das Jahr 1063. Das von Hoffmann ins Spiel gebrachte Datum 1063 griff er also auf, obwohl er die eigentliche Gründung früher ansetzte. Dass Schubert für die Rekonstruktion der außerstädtischen Besitzverhältnisse ein Lehenbuch benutzte, das auch heute noch im Bamberger Staatsarchiv die Zeit überdauert hat, ${ }^{26}$ kann an seiner fehlerhaften Interpretation desselben abgelesen werden. So werden anhand der Zwischenüberschriften des

\footnotetext{
${ }^{24}$ Martin Hoffmann: Annales Bambergensis episcopatus. In: Ludwig, Johann Peter (Hg.): Novum volumen scriptorum rerum Germanicarum. Bd. 1. Scriptores rerum episcopatus Bambergensis. Frankfurt 1718. Sp. 77.

25 Michael Heinrich Schubert: Dissertation inauguralis de origine et conditione ecclesiarum collegiatarum in genere et ecclesiae collegiatae ad B. V. M. et s. Gangolphum Bambergae in specie. Bamberg 1768.

26 „Lehenbuch Erasmussen Neusteters Sturmer genant uber die probstei s. Gangolf stift zu der Theuerstat in Bamberg 1565“ (1565-1588) in StABa Stift St. Gangolf, Akten und Bände Nr. 7.
} 
Lehenbuches Stiftsbesitzungen herausgedeutet, die jedoch bloß die Herkunft der Lehensleute bezeichnen. Laut Schubert hätte das Stift St. Gangolf demnach Grundbesitz in Nürnberg oder Weismain besessen, obwohl diese Klassifizierung nach Orten allein den Bürgerstatus der Lehensmänner bezeichnete. Liest man weiter, wird deutlich, dass in all diesen Fällen Grundbesitz in Hollfeld verliehen wurde. Daran ist zu erkennen, dass selbst hochrangige und gebildete Stiftsangehörige Mitte des 18. Jahrhunderts nur noch eine eingeschränkte Kenntnis von den mittelalterlichen Zuständen ihres Hauses hatten.

Auf Schuberts lateinische Dissertation aufbauend und diese geradezu wortwörtlich übersetzend, beschäftigte sich der 1881 im semiwissenschaftlichen „Kalender für katholische Christen“ erschienene Abriss über das zu dieser Zeit bereits säkularisierte Kollegiatstift St. Gangolf und das Leben des heiligen Gangolfs. ${ }^{27}$ Nach kleineren Erwähnungen des Stifts in Ämilian P. Ussermanns Bamberger Bischofsbeschreibung im Jahr $1802^{28}$ war dies die einzige Bearbeitung des Themas seit der Säkularisation. Der Kalender enthält einen Verweis auf eine Abhandlung über das Bamberger Kollegiatstift St. Stephan in einer vorherigen Ausgabe, sodass der Aufsatz über das Stift St. Gangolf als dessen Fortsetzung angelegt war und als Wiederentdeckung der Bamberger Kirchengeschichte zu verstehen ist. Der Autor selbst blieb anonym. Die Quellen der Abhandlung waren ein nicht näher beschriebenes Pfarrbuch „Über die Geschichte der Pfarrei“ von 1854 und die Weltchronik des Bamberger Kanonikers Heimo von St. Jakob, ${ }^{29}$ welche nach eigenen Angaben aus der königlichen Hof- und Staatsbibliothek in München bezogen wurden.

Die Aufarbeitung der Zustände rund um die säkularisierten Kircheneinrichtungen St. Gangolfs stand hingegen der statistischen Untersuchungen der Bamberger Pfarreien von 1888 vor Augen, welche sich in

27 Das Collegiatstift zu U. L. Frau und St. Gangolph in Bamberg. In: Kalender für katholische Christen. Sulzbach 1881. S. 80-91.

28 Ämelian P. Ussermann: Episcopatus Bambergensis sub sede apostolica chronologice ac diplomatice illustratus. [St. Balius] 1802. S. 270-274.

${ }^{29}$ Philipp Jaffé (Hg.): Heimo von St. Jakob: Liber de decurso temporum (Bibliotheca rerum Germanicarum, Bd. 5: Monumenta Bambergensia). Berlin 1869. S. 537-552. 
knapper Form den Kapellen, dem Friedhof und dem Pfarrhaus der 1806 errichteten Pfarrei St. Gangolf widmeten. ${ }^{30}$ Eine umfassende Betrachtung der Stiftskirche samt den sie umgebenden Kanonikerhöfen veröffentlichte 1912 der damalige Hallstadter Pfarrer Friedrich Wachter. ${ }^{31}$ Leider erwähnt auch er seine Quellen nicht oder nur indirekt. Es bleibt $\mathrm{zu}$ vermuten, dass ihm mittelalterliche Rechnungen, Gerichtsunterlagen und Urkunden vorgelegen haben, ${ }^{32}$ die sich heute im Bestand des Staatsarchivs Bamberg befinden.

Erst mit dem ehemaligen Bamberger Bürgermeister Hans Paschke wurde in den 1950er Jahren der Versuch einer Gesamtdarstellung unternommen, ${ }^{33}$ während sich die übrigen Abhandlungen vor allem mit Teilaspekten der Gangolfer Geschichte befassten. ${ }^{34}$ Paschkes Schwerpunkt lag dabei auf der Topografie des Gebietes östlich der Regnitz, wofür er sich engagiert um eine Aufarbeitung der vorhandenen Archivalien bemühte. Jedoch stellte er seine Quellenarbeit ungefiltert in die Erkenntnistraditionen der älteren Forschung und genügt daher nur

${ }^{30}$ Die Pfarreien des Erzbistums Bamberg: Statistische Notizen auf Anordnung Seiner Erzbischöfl. Excellenz revidirt. Bamberg 1888. S. 5-6.

${ }^{31}$ Friedrich Wachter: Sankt Gangolfs Ring. In: Alt-Bamberg. Rückblicke auf Bambergs Vergangenheit 12 (1912/13). S. 3-15.

32 Als eine Quelle Wachters konnte beispielsweise die bischöfliche Urkunde vom 8. November 1449 über die Neuerrichtung des Kastens von 1449 durch den Gangolfer Propst Johann Kautsch (amt. 1444-1462) identifiziert werden. In StABa A 120 L 131 Nr. 753. Näheres über die Einordnung der Urkunde im Kapitel 6.3.3.2 Pröpstische Abgaben an den Kustos.

${ }^{33}$ Hans Paschke: St. Gangolf zu Bamberg. 900 Jahre Geschichte und Topographie des Kollegiatstiftes und der Pfarrei St. Gangolf in der Theuerstadt zu Bamberg (Studien zur Bamberger Geschichte und Topographie, Heft 18) Bamberg 1959.

${ }^{34}$ Heribert Keh: Ein Beitrag zur Geschichte des ehem. Kanonikerstiftes St. Gangolf. In: Fränkische Blätter 3 (1951). S. 9; Gerd Zimmermann: Sankt Gangolfs Weg von Lothringen nach Bamberg. Studie zur Gründung und frühen Geschichte des Stiftes in der Theuerstadt zu Bamberg. In: Jahrbuch für Fränkische Landesforschung 22 (1962). S. 443-461; Alwin Reindl: Die vier Immunitäten des Domkapitels zu Bamberg. Ein Beitrag ihrer allgemeinen geschichtlichen Entwicklung, Verwaltung und Rechtsprechung. Bamberg 1969; Gerd Zimmermann: Sankt Gangolf in Bamberg. Ehem. Stiftskirche, seit 1806 Pfarrkirche (Schnell Kunstführer, Nr. 1172). Regensburg ${ }^{2} 1998$; Lothar Braun: Von der Stiftspfarrei zur Stadtpfarrei St. Gangolf in Bamberg. In: BHVB 120 (1984). S. 371-398; Lothar Braun: Musikpflege am Kollegiatstift und an der Pfarrei St. Gangolf in Bamberg im 18. und 19. Jahrhundert. In: Bericht des Historischen Vereins Bamberg, Bd. 155 (2019). S. 241-249. 
eingeschränkt modernen geschichtswissenschaftlichen Ansprüchen. Seine Studien haben bis heute keine wesentliche Erweiterung oder Überprüfung erfahren.

Dabei gibt es durchaus neuere Erkenntnisse zu dem Thema St. Gangolf, die eine Betrachtung wert sind. In den Jahren 1980, 1987 und 1988 erfolgten, getragen durch das Bayerische Landesamt für Denkmalpflege und dem Bamberger Lehrstuhl für Archäologie des Mittelalters und der Neuzeit, archäologischen Ausgrabungen an der ehemaligen Stiftskirche in der Theuerstadt. Bei Fußbodenerneuerungen wurden Bestattungen im Innenraum und bei Bauarbeiten an der Südwand der Kirche ein verschüttetes Beinhaus entdeckt. ${ }^{35}$ Die durch diese Funde gewonnenen Erkenntnisse sind jedoch aufgrund des geringen Alters der meisten Befunde nur in Teilen für die Rekonstruktion mittelalterlicher Zustände interessant. Eine Ausnahme ist die Grabungen am Chorbereich im Jahr 1988, die einen Rekonstruktionsansatz für die erste Stiftskirche aus der Gründungzeit zulässt. ${ }^{36}$ Erst jüngst wurde sich an einer umfassenden Auswertung der archäologischen Quellen der Bamberger Stadtentwicklung verdient gemacht, in der auch die Erkenntnisse zur Theuerstadt und der Stiftskirche St. Gangolf eine Rolle spielen. ${ }^{37}$ Hierbei wurden die aktuellen Grabungen oder baubegleitenden Untersuchungen einbezogen, die als Fundstellenübersicht für das Stadtgebiet seit 2011 öffentlich gemacht werden. ${ }^{38}$

35 Bayerisches Landesamt für Denkmalpflege: Grabungsbericht 1980 Ausgrabung: Untersuchung im Zuge der Verlegung einer Fußbodenheizung in der ehemaligen Sepultur der Kirche St. Gangolf, Maßnahme M-2007-31726-2_0; Bamberg, BA: St. Gangolf, G-1980 (Ü-4-6131-0137); Grabungsbericht 1987 Beobachtung bei Bodeneingriff: Fundbergung und Dokumentation im Zuge von Baumaßnahmen, Maßnahme M-200731726-3_0; Bamberg, BA: St. Gangolf, FE-1987 (Ü-4-6131-0137); Grabungsbericht 1988 Ausgrabung: Notgrabung bei Ausschachtungsarbeiten für eine Fußbodenheizung, Maßnahme M-2007-31726-1_0; Bamberg, BA: St. Gangolf, G-1988 (Ü-4-6131-0137).

${ }^{36}$ Näheres im Kapitel 4.1.3 Stiftskirche.

37 Stefan Pfaffenberger: Aspekte der Stadtentwicklung Bambergs im frühen und hohen Mittelalter aus archäologischer Sicht (Arbeiten zur Archäologie Süddeutschlands, Bd. 32; Veröffentlichungen des Stadtarchivs Bamberg, Bd. 36). Büchenbach 2020.

${ }^{38}$ Aktuell in Stefan Pfaffenberger: Stadtarchäologie in Bamberg 2018 bis 2019. In: BHVB 156 (2020). S. 9-29, zur Theuerstadt S. 23-24. 
Weitere vor allem bauhistorisch interessante Erkenntnisse wurden 1990 im Zuge der Kirchenrestaurierung unter dem damaligen Bamberger Generalvikar Alois Albrecht ${ }^{39}$ als ehemaliger Pfarrer von St. Gangolf publiziert, als es neben der Verwirklichung der Kirchenerneuerung zu einer wissenschaftlichen Auseinandersetzung mit der Stiftsgeschichte kam. Neben Untersuchungen über die Kirche und deren Chor resultierte hieraus auch eine Neuerfassung der bereits 1951 durch Heribert $\mathrm{Keh}^{40}$ besprochenen Reliquienauthentik durch Monika Schleß. ${ }^{41}$

Eine kunsttopografische Beschäftigung mit der Theuerstadt und den östlichen Stadterweiterungen Bambergs verspricht der siebente Band der Reihe Kunstdenkmäler in Bayern, der weiterhin in der Entstehung befindlich ist. ${ }^{42}$ Darin ist eine ausführliche stadt- und baugeschichtliche Einordnung des Stifts St. Gangolf zu erhoffen.

\subsection{Fragestellung und Gliederung der Arbeit}

Der Schwerpunkt der vorliegenden Arbeit liegt in der wissenschaftlichen Aufarbeitung und Untersuchung derjenigen Archivalien, die sowohl aus innerstiftischer Perspektive wie auch von außen über das Kollegiatstift St. Gangolf im Mittelalter berichten. Es ist die Aufgabe dieser Untersuchung, das zur Verfügung stehende Quellenmaterial aus den verschiedenen Archiven $\mathrm{zu}$ identifizieren, einzuordnen und im Sinne einer Institutionengeschichte auszuwerten. Erstmals werden die unedierten Quellen über das Stift in einen Kontext gestellt, ${ }^{43}$ der sie

39 Bereits 1980 hatte Alois Albrecht, damals noch amtierender Pfarrer von St. Gangolf, zusammen mit Monika Schleß über das Stift publiziert. Monika Schleß/ Alois Albrecht: Pfarrgemeinde St. Gangolf Bamberg. Bamberg 1980. Dort stützt er sich vor allem auf die Erkenntnisse von Paschke und Schimmelpfennig.

${ }^{40}$ Keh: Ein Beitrag zur Geschichte des ehem. Kanonikerstiftes St. Gangolf. 1951.

${ }^{41}$ Monika Schleß: Die älteste Urkunde von St. Gangolf im Pfarrarchiv. In: Albrecht, Alois (Hg.): Pfarrkirche St. Gangolf Bamberg. Restaurierung der ältesten Kirche der Stadt 19841990 (Festschrift zum Abschluß der Restaurierung Mai 1990). Bamberg 1990. S. 60-62.

${ }^{42}$ In Vorbereitung: Stadt Bamberg, Bd. 7: Theuerstadt und östliche Stadterweiterungen, 2. Drittelband: Stift St. Gangolf mit Oberer Gärtnerei und östlichen Stadterweiterungen (Die Kunstdenkmäler von Bayern: Regierungsbezirk Oberfranken, Bd. 3). München/ Bamberg.

43 Transkriptionsrichtlinien: wörtliche und buchstabengetreue Übertragung in geregelter 
erklären und für weitere Forschungen erschließen soll, indem wichtige Quellenbegriffe und Eigenarten des Stifts thematisiert werden.

Der Großteil der Schriftzeugnisse des Kollegiatstifts St. Gangolf findet sich in Bamberger Archiven. Die lokale Konzentration der Stiftsentwicklung hat einen größeren Niederschlag in den Beständen anderer Archive verhindert. Ausnahmen bilden vereinzelte Unterlagen im Staatsarchiv Würzburg, besonders in den Beständen des Klosters Ebrach und des Stifts Neumünster, sowie Nürnberg, in deren Urkunden Vertreter des Bamberger Stifts als Zeugen eine Rolle spielten. Die Gründe für die auf die nähere Region begrenzte Stiftsentwicklung liegen vor allem in der starken grundherrlichen Ausrichtung auf den Radenzgau, was sich in den Quellen niederschlug und auch deren Überlieferungsgeschichte beeinflusste.

Da kaum historiographische Zeugnisse Auskunft über die Bedeutung des Kollegiatstiftes St. Gangolf im Bamberger Stadtgefüge geben, stellt das stiftseigene Verwaltungsschriftgut eine unschätzbare Informationsquelle dar. Die Überlieferungsgeschichte der in der Säkularisation aufgelösten Kirchen zwingt zur Unterscheidung zwischen dem Kollegiatstift als geistlicher Institution sowie dessen durch liturgische Fragen und Pfarreiorganisation ausgerichtetem Nachlass, welcher zum Großteil im Archiv des Erzbistums Bamberg zu finden ist. ${ }^{44}$ Daneben steht die Überlieferung des Stifts St. Gangolf als weltlicher Grundbesitzer und Teil der politischen Landschaft Bambergs, ${ }^{45}$ wobei klar zu betonen ist, dass diese Trennung im Laufe der Bestandsentwicklung selten sauber gezogen wurde. Als Akteur im städtischen und außerstädtischen Gefüge

Kleinschreibung und gliedernder Interpunktion, Auflösung von diakritischen Zeichen, Auslassung von Buchstabendoppelungen.

${ }^{44}$ Das Archiv des Erzbistums Bamberg beherbergt das Pfarrarchiv des Stifts St. Gangolf aufgeteilt in den Beständen AEB Rep I Akten des Schlundrepertoriums, AEB Rep I Pfarrei St. Gangolf, Urkunden und AEB Rep. 60, Pfarrarchiv St. Gangolf. Näheres im Kapitel 2.2 Urkunden.

${ }^{45}$ Der „weltliche“ Nachlass des Stiftes St. Gangolf findet sich überwiegend im Staatsarchiv Bamberg als Archiv des Hochstifts Bamberg und seinen Nachfolgeinstitutionen. Die wichtigsten Bestände sind Stift St. Gangolf, Akten und Bände, A 120 (Urkunden nach 1400) und Bamberger Urkunden (Urkunden bis 1400). Näheres im Kapitel 2. Registratur und Bestandsentwicklung. 
hat das Stift St. Gangolf darüber hinaus Spuren im Stadtarchiv Bamberg hinterlassen. ${ }^{46}$

Die Arbeit ist nach dem Schema der Germania Sacra gegliedert. Der Handbuchcharakter der Reihe bietet sich an, um die innere und äußere Struktur des Stiftes anhand seiner Schriftzeugnisse und bauhistorischen Überreste nachzuzeichnen. Angesichts der fragmentarischen Überlieferung war eine stärker fragestellungsgeleitete Auswertung der Quellen kaum zu leisten. Die Aufarbeitung und Erschließung des Archivbestandes zum Stift St. Gangolf stehen daher im Mittelpunkt der Arbeit, was konform mit der ursprünglichen Aufgabe der Germania Sacra läuft, „das in Archiven und Bibliotheken lagernde Quellenmaterial zur Geschichte der deutschen Bistümer, Domkapitel, Stifte, Klöster, Pfarreien und Kapellen von ihrer Entstehung bis zur Auflösung [...] zu erschließen und in aufbereiteter Form zwischen Inventarisierung und Darstellung als Publikation zur Verfügung zu stellen.“47

Das Hauptaugenmerk der vorliegenden Arbeit besteht in der Klärung grundlegender stiftseigener Begriffe und dem Aufzeigen innerer und äußerer Strukturen sowie Einflüssen, denen das Stift St. Gangolf ausgesetzt war. Hieraus ergeben sich die großen Themenschwerpunkte Gründung und Patrozinien - vor allem hinsichtlich ihrer Rezeption und Bewertung in der Forschung -, innere Verwaltung, Außenbeziehungen zur Einordnung in das Stadtgefüge, geistiges und religiöses Leben sowie Grundbesitz und dessen Verwaltung. Obwohl prosopografische Studien anders als in der älteren Forschung nicht im Mittelpunkt der Betrachtung stehen, wird eine Liste der Amtsträger dieser Arbeit als Anhang angefügt. ${ }^{48}$ Sie soll weiteren Untersuchungen den Zugriff auf die Quellen erleichtern. Erwähnte Ortschaften werden zum Zwecke der Identifizierbarkeit den entsprechenden Gemeinden und Landkreisen gemäß

\footnotetext{
46 Spuren des Stifts St. Gangolf im Stadtarchiv Bamberg finden sich vor allem im Urkundenbestand A 21 und im Nachlass des Historischen Vereins D 3001 HV Rep. 1 und D 3001 HV Rep. 2.

${ }^{47}$ Richtlinien der Germania Sacra, Dritte Folge (Stand: April 2009).

${ }^{48}$ Näheres in Anhang Tabelle 3: Amtsträger.
} 
der heutigen Verwaltungsgliederung zugeordnet, welche in der Gebietsreform des Freistaates Bayern bis 1980 umgesetzt wurde.

Den Beginn des Untersuchungszeitraums markiert die Gründung des Stifts zwischen 1057 und 1059. Der zeitliche Endpunkt im 16. Jahrhundert präsentiert sich dagegen weniger einschneidend. Auf rechtsgeschichtlicher Ebene bildet das Jahr 1565 einen Einschnitt in die Immunitätsrechte St. Gangolfs und St. Jakobs, als sich die Oberrichter der beiden Stifte auf das Domstift $z u$ vereidigen hatten und dem Einfluss des eigenen Kapitels immer mehr entzogen waren. Auf politischreligionsgeschichtlicher Ebene kündigte das Jahr 1525 durch die Reformation und das Wirken des Gangolfer Kustos Johann Schwanhausen als Prediger der lutherischen Lehre einen Wandel an. Johann von Schwanhausen agierte als scharfer Kritiker des Bischofs von Bamberg sowie des Domstifts und sein Wirken bis hin zu seiner Flucht nach Nürnberg 1524 war Kennzeichen der tiefgreifenden Umbrüche der Reformationszeit in Bamberg. ${ }^{49}$ Seine kirchenkritischen Ansichten, politischen Konflikte und auch die Frage, inwieweit das Stift St. Gangolf die reformatorischen Ideen seines Kustos duldete oder gar förderte, sollen Inhalt zukünftiger Forschungen sein. Aufgrund der Eigenarten des Quellenbestandes wird das gesamte 16. Jahrhundert als Übergangsphase begriffen und betrachtet. Denn nach ersten Spuren der Quellen im 14. und schon vermehrt im 15. Jahrhundert, ballt sich die innerstiftische Überlieferung im 16. Jahrhundert. Dadurch sind viele Entwicklungen notwendigerweise aus der Rückschau zu betrachten und es müssen oftmals mittelalterliche Zustände vom spätmittelalterlichen, fast frühneuzeitlichen Standpunkt aus erschlossen werden.

\footnotetext{
49 Weiß: Das exemte Bistum Bamberg 3/1. 2000. S. 112; und Irmingard Geuder: Auch Bamberg hatte seinen Reformator. Johannes Schwanhauser, Prediger zu St. Gangolf, zum Gedächtnis. Bamberg 1973. Näheres im Kapitel 4.2.4 Kustos und Kirchner.
} 


\section{Registratur und Bestandsentwicklung}

\subsection{Registraturaufbau}

Schriftzeugnisse über das Kollegiatstift St. Gangolf sind in relativ geringer Zahl erhalten und verteilen sich über mehrere Archive, von denen jedoch das Staatsarchiv Bamberg den geschlossensten Bestand vorweisen kann. Es beherbergt als aufbewahrende Stelle der Unterlagen des 1803 von Kurpfalzbayern säkularisierten ehemaligen Hochstifts Bamberg die Überlieferung der eingezogenen Klöster und Stifte von Hochstift und Stadt Bamberg. ${ }^{50}$ Das dort liegende Schriftgut im Bestand des Stifts St. Gangolf sind die Reste der einstigen Registratur, welche sich im Stiftsgebäude in der Theuerstadt befand. In der Umbruchzeit der Säkularisation Anfang des 19. Jahrhunderts war man bestrebt, durch die Versiegelung der Stifts- und Klosterarchive das rechtlich relevante Schriftgut des Hochstifts Bamberg zu sichern. ${ }^{51}$ Durch die Anfertigung von Verzeichnissen über die vorhandene Überlieferung sollten die Besitzverhältnisse nachgezeichnet und diese als Rechtsgrundlage für die neu entstehenden Herrschaften genutzt werden. Das Unterfangen erwies sich als große Herausforderung in einer von politischen Umwälzungen und Umstrukturierungen geprägten Zeit.

So protokollierte im Dezember 1802 der Bamberger Hofkanzler Adam Joseph Pabstmann den Sturz der Kassen des Stifts St. Gangolf und stellte die schlechte Aufstellung der Stiftsregistratur fest. ${ }^{52}$ Die

${ }^{50}$ Näheres dazu in Michael Hochedlinger/ Thomas Winkelbauer (Hgg.): Herrschaftsverdichtung, Staatsbildung, Bürokratisierung. Verfassungs-, Verwaltungs- und Behördengeschichte der Frühen Neuzeit (Veröffentlichungen des Instituts für Österreichische Geschichtsforschung, Bd. 57). Wien u. a. 2010; Gerhard Hetzer: Spannungsfelder und Schnittstellen: Die staatlichen Archive im Königreich Bayern zwischen Verwaltung, Politik und Wissenschaft. In: Sächsisches Staatsarchiv (Hg.): Archivische Facharbeit in historischer Perspektive. Dresden 2009. S. 55-66.

51 Klaus Rupprecht: Die Säkularisation der Stifts- und Klosterarchive im Hochstift Bamberg. In: Baumgärtel-Fleischmann, Renate (Hg.): Bamberg wird bayerisch. Die Säkularisation des Hochstifts Bamberg 1802/03 (Sammelband zur Ausstellung im Historischen Museum Bamberg, 10. September bis 9. November 2003). Bamberg 2003. S. 223-232, hier: 224-225.

52 "Ein archiv ließ sich nicht antreffen, sondern es wurde nur in einer dem capitelszimmer ganz nahen kammer die stiftsregistratur gezeigt, die aber sehr schlecht beschaffen ist. In 
Versiegelung der Registratur, welche die Entwendung wichtiger Unterlagen verhindern sollte, wurde jedoch kurz darauf wieder aufgehoben, um dem Gangolfer Kastner namens Kaisenberg als zuständigen Verwaltungsbeauftragten die Möglichkeit zu geben, die vorhandene Überlieferung zu sichten und zu verzeichnen. ${ }^{53}$ Die Verzeichnisse wiesen große Lücken auf und gaben nur über die wichtigsten Unterlagen Auskunft. Dies stellte ein grundsätzliches Problem der zuständigen Beamten dar, auf das sie bei der Sicherung des Registraturschriftguts der mediaten Klöster und Stifte stießen. Der Kastner Kaisenberg erfüllte den Dokumentationsauftrag in kleinen Schritten und offensichtlich widerstrebend, sodass von einer Vollständigkeit der Inventarisierung nicht ausgegangen werden kann. Trotzdem liegen mehrere Verzeichnisse über die abgegebenen Unterlagen vor, von denen ein Bericht über die bey dem diesseitigen kollegiatstift $z u$ st. Gangolph vorhandenen urkunden und briefschaften den zuständigen Beamten bereits am 27. November 1802 zukam. Darin listete Kaisenberg verschiedene Urkunden oder Urkundenfaszikel über Lehensachen und Obleiangelegenheiten ${ }^{54}$ des 17. und 18. Jahrhunderts auf, außerdem zwei Lehenbücher, eins von um 1600 und eins des 18. Jahrhunderts, Verträge und Urteile über Lehenstreitigkeiten mit dem Hollfelder Rat, ein altes und neues kastenamtliches konseptbuch, Aufrisse und Beschreibungen von Zehntleistungen in Breitenlesau und Treunitz, ein Zehntbuch des stiftischen Kastenamtes aus dem 18. Jahrhundert und ein kopialbuch von verschiedenen alten urkunden,

diese registratur wurden des obleyers- und des kastners manualien mit der baarschaft des erstern, die über abzug der ihm außer verschluß gelassenen $300 \mathrm{fl}$ noch übrig war, gebracht und die thür, wodurch der eingang in die registratur ist, unter siegel gelegt." Protokoll des Bamberger Hofkanzlers Adam Joseph Pabstmann vom 1. Dezember 1802 in StABa K 202 Nr. 452.

53 „Die registraturkammer wurde darum nicht wieder mit siegeln belegt, damit das begehrte verzeichnis der archivalien, woran die zeitherige obsignatur ein hindernis gemacht hatte, hergestellt werden könne, welches auch der kastner Kaisenberg heute noch zu bewirken sich anheischig machte, weil mir sehr wenige papiere von einigem werth in der registratur vorfindlich wären." Stellungnahme des Bamberger Hofkanzlers Adam Joseph Pabstmann vom 27. Dezember 1802 in StABa K 202 Nr. 452.

${ }^{54}$ Näheres zum Begriff Oblei im Kapitel 6.4.1. Obleibesitz. 
kaufbriefen und anderen schriften. ${ }^{55}$ Im April 1803 fertigte er eine Liste der Güterverzeichnisse und Zinsbücher an, ${ }^{56}$ welche nicht ans kurfüstlich-bayerische Archiv, sondern an die zuständigen Rentämter gingen. Dort sind nicht nur kapitalbücher der heute nicht mehr existenten Annakapelle im Hauptsmoorwald genannt, sondern auch ein kustoreybuch und mehrere Aufrisse verschiedener Obleibesitzungen. Die Überlieferungen wurden erst wieder in großen Teilen zusammengeführt, als die Rentämter ihre Altunterlagen an das zuständige Staatsarchiv Bamberg als oberfränkische Nachfolgeeinrichtung des kurfürstlich-bayerischen Archivs abgaben.

Durch vereinzelte Spuren in den Quellen auf die Organisation der Gangolfer Registratur kann durch den Vergleich mit heute erhalten gebliebenen Schriftzeugnissen das Schicksal einzelner Stücke nachvollzogen werden. Die frühste Spur führt in die zweite Hälfte des 15. Jahrhunderts. Auf Betreiben des Bamberger Dompropstes Veit Truchseß von Pommersfelden gelangten mehrere Urkunden und Register der Propstei von St. Gangolf zurück nach Bamberg, die sich vorher im Besitz des Mainzer Erzbischofs befanden. ${ }^{57}$ Wie nun die Unterlagen nach Mainz gelangten, bleibt unklar. Jedoch ergab die Prüfungen der detaillierten Beschreibung der Register, dass etwa die Hälfte von ihnen heute in dem Bestand von St. Gangolf im Staatsarchiv Bamberg zu finden sind. ${ }^{58}$

55 Bericht des Kaisenberg, Kastner des Stifts St. Gangolf, über die Urkunden und Briefschaften des Kollegiatstifts vom 27. November 1802 in StABa K 202 Nr. 452.

${ }^{56}$ Bericht des Kaisenberg, Kastner des Stifts St. Gangolf, über die Zinsbücher des Kollegiatstifts vom 29. April 1803 in StABa K 210 Nr. 39.

${ }^{57}$ Abschrift einer Urkunde von 1487 des Doktor Dietrich von Plieningen als Prokuratur und Bruder des Gangolfer Propstes Johann von Plieningen (amt. 1486-1489) samt Übergabeprotokoll von 1488 der Urkunden und Register in StAWu Mainzer Ingrossaturbuch Nr. 43 fol. 67-69".

58 Laut der Urkundenabschrift trugen die besagten Register 1488 deutliche Vermerke in Form von Buchstaben A bis Q, welche wohl dem Mainzer Registratursystem zuzuschreiben sind. In StAWu Mainzer Ingrossaturbuch Nr. 43 fol. 68-69. Im Staatsarchiv finden sich dementsprechend auf denjenigen Registern, welche nicht neu eingebunden worden sind, die Registraturvermerke A sowie C bis F in StABa Stift St. Gangolf, Akten und Bände Nrr. 118 und 120 bis 123. 
Einen weiteren Hinweis darauf, wie es vor der Säkularisation um den Bestand der Lehenbücher und Akten des Stifts St. Gangolf bestellt war, gibt ein innerstiftisches Verzeichnis von $1670 .{ }^{59}$ Demnach befanden sich zu dieser Zeit folgende Lehenbücher am Stift St. Gangolf:

1. ein Buch iura praepositurae s. Gangolphi mit Zinsbuch und Urkundenabschriften (1433-1497) ${ }^{60}$

2. ein Band mit mehreren Lehenbüchern der Pröpste Stephan Beheim (amt. 1433-1441), Gumpert Fabri (amt. 1468-1478), Berthold von Henneberg (amt. 1479-1486), Melchior Truchseß (amt. 1489-1493), Eberhard Cadmer (amt. 14951507) und Erasmus Neustetter genannt Stürmer (amt. 1565-1594) (1417-1565) $)^{61}$

3. das Lehenbuch des Propstes Erasmus Neustetter genannt Stürmer (amt. 1565-1594) (1565) ${ }^{62}$

4. das Lehenbuch des Propstes Wolfgang Albert von Würzburg (amt. 1595-1610) (1595) ${ }^{63}$ und

5. das Lehenbuch des Propstes Philipp Valentin Voit von

Rieneck (amt. 1651-1658) (1652) mit Nachträgen von Propst

Franz Konrad von Stadion (amt. 1658-1685). ${ }^{64}$

Gegenüber dieser Überlieferung pröpstischer Verzeichnisse gibt eine stiftseigene Auflistung von Güterverzeichnissen über die Oblei Hundsbühl aus dem Jahr 1764 einen Einblick in das Verwaltungs-

59 „Probstey zu s. Gangolph. Ein verzeichnus deren lehenbüchern, welche 1670 bey dem collegiatstift sancti Gangolphi vorhanden gewesen, samt einen iudice darüber, dann eine verzeichnus derenjenigen büchern und akten, so dem gerichtschreiber Euchario Donhard bey dem stift s. Gangolph den 18. October 1670 eingehändigt worden“ in StABa Stift St. Gangolf, Akten und Bände Nr. 176 unfoliiert.

${ }^{60}$ Nicht identifiziert.

${ }^{61}$ Lehenprotokolle des Propteiverwaltungsamts Hollfeld durch sechs verschiedene Pröpste (1417-1576) in StABa Stift St. Gangolf, Akten und Bände Nr. 119.

62 „Lehenbuch herrn Erasmussen Neusteters Sturmer genant uber die probstei s. Gangolf stift zu der der Theuerstat“ (1565-1588) in StABa Stift St. Gangolf, Akten und Bände Nr. 7.

${ }^{63}$ Nicht identifiziert.

${ }^{64}$ Lehenbuch der Propstei angelegt durch Propst Philipp Valentin Voit von Rieneck (16521670) in StABa Stift St. Gangolf, Akten und Bände Nr. 10. 
schriftgut des Kapitels unter Führung des Dekans. ${ }^{65}$ Dort ist verzeichnet:

Designatio urbariorum ad hoc oblegium spectantium, que in registratura adservantur.

1. Liber oblegiorum d. dec. Hirsberger de anno 1538 in fol. ${ }^{66}$

2. Registrum censuum d. dec. Weishaupt de anno 1555 in fol. ${ }^{67}$

3. Urbarium oblegii collocan d. Leonis Baunach de anno 1601 in fol. ${ }^{68}$

4. Urbarium oblegii collocand. Johannis Schirmer de 1597 in klein fol. ${ }^{69}$

5. Urbarium oblegii collocan d. Nythardi Gamper de 1643 in fol. ${ }^{70}$

6. Liber oblegiorum d. Christophori Geyer de 1667 in folio. Not. hoc libro tam d. decanus Boxberger quam ego usi sumus, et plurae inscriptimus usque ad confectionem praesentus novi urbarii. ${ }^{71}$

7. Liber oblegiorum d. Wolfgangi Franscici Pymer de 1683 in fol. ${ }^{72}$

8. Urbarium oblegii collocan d. Fridericii Eppenauer de 1710 in quart. ${ }^{73}$

9. Urbarium oblegii collocan d. cell. Hönicke de 1717 in quart. ${ }^{74}$

Die hier aufgezählten Besitzverzeichnisse befinden sich fast gänzlich im heutigen Bestand Stift St. Gangolf, Akten und Bände im Staatsarchiv Bamberg und können den aktuellen Signaturen zugeordnet werden. Die einzige Ausnahme (Nr. 6) diente laut Nota dem Register von 1764 als Vorlage und es ist denkbar, dass dieses daraufhin als überholt eingestuft und vernichtet wurde.

Es wird deutlich, dass sich zu Zeiten der Säkularisation bereits keine Unterlagen mehr im Besitz des Stifts befanden, die weiter als bis in das 16. Jahrhundert zurückgingen. Der Grund hierfür findet sich nicht al-

${ }^{65}$ Register über Obleizinsen (1764-1809) in StABa Stift St. Gangolf, Akten und Bände Nr. 65.

${ }^{66}$ Register der Obleizinsen der Dekane Hirschberger und Kaspar Hartmann (1502-1620) in StABa Stift St. Gangolf, Akten und Bände Nr. 20.

${ }^{67}$ Register der Obleizinsen des Dekans Mauritio Weißhaupt (1555-1565) in StABa Stift St. Gangolf, Akten und Bände Nr. 23.

${ }^{68}$ Zinsregister der Oblei Hundsbühl des Johann Leon Baunach (1597-1646) in StABa Stift St. Gangolf, Akten und Bände Nr. 31.

${ }^{69}$ Zinsregister der Oblei Hundsbühl des Johann Schirmer (1596-1611) in StABa Stift St. Gangolf, Akten und Bände Nr. 30.

70 Zinsregister der Oblei Hundsbühl des Neithard Gamper (1643-1669) in StABa Stift St. Gangolf, Akten und Bände Nr. 41.

${ }^{71}$ Nicht identifiziert.

72 Zinsregister der Obleien des Kellers Wolfgang Franz Pymer (1642-1710) in StABa Stift St. Gangolf, Akten und Bände Nr. 40.

${ }^{73}$ Zinsregister der Obleien Hundsbühl und Dürrbrunn des Scholastikus Friedrich Eppenauer (1706-1716) in StABa Stift St. Gangolf, Akten und Bände Nr. 54.

${ }^{74}$ Zinsregister der Obleien Hundsbühl und Estuarium des Kellers Hönicke (1710-1723) in StABa Stift St. Gangolf, Akten und Bände Nr. 56. 
lein in den Schwierigkeiten einer geordneten Verwaltung während der Säkularisationszeit, denn bereits im 17. und 18. Jahrhundert lagen den Kanoniker von St. Gangolf keine älteren Register vor. Verluste von Unterlagen sind nicht in der Zeit der Säkularisation zu suchen, sondern weitaus früher. Besonders verheerend für die stiftische Besitzverwaltung hat sich der Markgrafenkrieg Mitte des 16. Jahrhunderts ausgewirkt. Zahlreiche kirchliche Einrichtungen der katholischen Hochstifte Frankens waren von den Plünderungen des Markgrafen Albrecht Alcibiades von Brandenburg-Kulmbach betroffen, was häufig eine Neusortierung der Besitzverhältnisse nötig werden ließ. So finden sich Spuren, dass sich der Gangolfer Propst nach Niederschlagung des Markgrafen 1554 die Rechte auf Teile seiner außerstädtischen Besitzungen vom Hollfelder Bürgermeister und Rat erneut bestätigen lassen musste. ${ }^{75}$

Aufgrund der Verluste von Schriftzeugnissen bereits vor der Auflösung St. Gangolfs Anfang des 19. Jahrhunderts und da die Rentämter und andere Behörden eigene Ordnungskriterien an die erhaltenen Stiftsunterlagen anlegten, ist die Rekonstruktion der Registraturordnung und ihr Umfang vor 1803 nur schwer möglich. Der Bestand des Stiftes am Staatsarchiv Bamberg wurde aus diesem Grund überwiegend anhand der in den Unterlagen repräsentierten Stiftsämter strukturiert. ${ }^{76}$ Damit ist es möglich, einen Blick in die innere Verwaltung des Stifts zu gewinnen, die die direkte Lebenswirklichkeit ihrer Entstehungszeit spiegelt. Jedoch benötigt es zur Analyse der Registraturunterlagen ein vertieftes Wissen in Struktur und Begrifflichkeiten der Güterverwaltung.

75 „In welchen orten unser probstvogt sein vogteiligkeit exeriren darf [...] in Höfen, Mochendorf, Stechendorf, Bilgendorf, Königsfelt, Brunn, Tiefenlesen, Kotzendorf, Treuntz, in probsthaus und probsthof $\mathrm{zu}$ Holfelt. Solche gerechtigkeit haben bürgermeister und rath nach dem marggräfischen krieg mit sigilirten briefen testirt zu Holfelt“ Notiz im Verzeichnis der Lehenbücher der Propstei St. Gangolf (1670) in StABa Stift St. Gangolf, Akten und Bände Nr. 176 erste Seite.

${ }^{76}$ Näheres dazu im Findbuchvorwort des Bestandes StABa Stift St. Gangolf, Akten und Bände, erstellt 2012 und aktualisiert 2014 durch Klaus Rupprecht und die Verfasserin. Einsehbar unter https://www.gda.bayern.de/findmitteldb/Findbuch/5731/ (zuletzt gesehen am 11. Mai 2021). 


\subsection{Urkunden}

\section{Die Urkunden des Stifts St. Gangolf wurden Anfang 1803 von der}

neueingerichteten kurfürstlichen Landesregierung gesondert und nachdrücklich eingefordert. ${ }^{77}$ Das scheidende Stiftskapitel antwortet daraufhin:

Eine churfürstl. preisvollste landesregierung hat uns mittels höchsten erlasses $d$. $d$. 20ten et praes. 25ten v. $m$. die weisung ertheilt, alle auf den erwerb des hochstifts Bamberg sowohl, als unseres collegiatstifts bezug habende urkunden aufzusuchen, und solche samt historischer darstellung und index bald möglichst einzubefördern. Dieser höchstem auflage würden wir so gern als schuldigst genüge leisten, allein wir müßen leider bekennen, daß wir von allen urkunden ganz verlassen sind, und daß in unserer repositur nichts vorfindlich ist, was uns zu dieser absicht dienen und licht darüber verbreiten könnte. Selbst über die art und weise des verlustes solcher urkunden haben wir keine volle gewiesheit; das einzige, was wir durch tradition und erzählungen älterer stiftsmitglieder erfahren haben, besteht darin, daß zu jenem zeitpunkte, wo margraf Albrecht in die ehemaligen hochstiftslande und hiesige residenzstadt einfiel, nicht nur allein die der ersten invasion ausgesetzten stiftshöfe ausgeplündert, sondern auch die vorhandene registratur zerstöret, und die darin befindlichen documente theils geraubt theils zerstört gröstentheils aber auf die festung Blassenburg gebracht worden seyen. Unter diesen umständen sind wir daher nicht instand, zur absicht des in dem obenbelobten höchsten erlasse angezeigten zweckes etwas an händen zu geben. ${ }^{78}$

Auch der Gangolfer Kastner Kaisenberg bestätigt 1804 den Mangel an Urkunden in der Registratur des Stifts und vermutet ähnlich dem Kapitel, dass der Großteil der Stücke im Markgrafenkrieg verloren ging. ${ }^{79}$ Es

${ }^{77}$ Im April 1803 schrieb der kurfürstliche Archivar Paul Oesterreicher (1766-1839) an die Klöster Michelsberg, Banz, Langheim, St. Klara und Heilig Grab und wies vor allem die Herausgabe der Urkunden an. In StABa Rep. K 515 Nr. 662.

${ }^{78}$ Schreiben des Kapitels von St. Gangolf an die kurfürstliche Landesregierung im Zusammenhang mit der Berichterstattung der Stifte und Klöster Bambergs über deren Registratur vom 8. Februar 1803 in StABa Hochstift Bamberg, Neuverzeichnete Akten Nr. 3799.

79 "In der registratur des ehehinnigen stifts zum hl. Gangolph befindet sich nicht eine einzige urkunde mehr von bedeutenheit. Was da vorhanden war, und gröstentheils die adelichen vasallen dieses vormaligen stifts betroffen hat, wurde bereits schon im vorigem jahre von dem kurfürstlichen lehenhof dahier von unterthänigst gehorsamsten berichtsteller überliefert. Keine stiftungsbriefe sind über dieses stift gar nicht vorhanden, und diese sollen durch den marckgrafen Albrecht von Brandenburg, welcher bekanntlich in das fürstenthum Bamberg eingefallen ist, geraubt, und noch vorfindig in dem schlosse Blassenburg ob Culmbach seyn; es scheint dies ganz wahrscheinlich zu seyn, indem dieses stift theils grose revenüre in dem fürstenthume Bayreüth selbst, theils nahe an demselben besessen hat. Mehrere verschiedene rechnungen sind zwar von aelteren seiten noch vorfindig, aber nicht geeigenschaftet in ein kurfürstliches archiv auf bewahret zu werden. 
ist schwerlich nachzuprüfen, wie gewissenhaft die scheidenden Kanoniker in diesen unsicheren Zeiten den Weisungen zur Übergabe der Urkunden und Archivalien nachkamen. Jedoch ist der immer wiederkehrende Vermerk über die Plünderung der Registratur während des Markgrafenkrieges augenfällig. Bereits wenige Jahre nach der Verheerung der stiftischen Besitzungen Mitte des 16. Jahrhunderts wird beklagt, dass Urkunden durch die Plünderung und der nachfolgenden Zerstörung verloren gegangen waren. Es findet sich in einem Einnahmeregister der Stuhlbrüder am Stift St. Gangolf aus dem 16. Jahrhundert der Vermerk:

Notandum. Johann Khurlein und Peter Schell, als stuhlbrüder, haben ihr brief und siegel einem capitel in die sacristey geben, nemblich acht und viertzig pergamene, drey papierne brief, actum 1546. In die praxedis seynd in der marggräfischen kriegsempörung anno 1553 mit andern (sambt dreyen registern) des stiftsbrifen verloren worden. ${ }^{80}$

Recherchen nach diesen möglicherweise geraubten Unterlagen im Geheimen Hausarchiv Plassenburg als Nachfolgeeinrichtung der markgräflichen Registratur blieben bisher erfolglos. ${ }^{81}$

Im Staatsarchiv Bamberg finden sich die Urkunden der hochstiftischen Institutionen nur zum Teil provenienzrein aufgestellt. Während die Urkunden nach 1401 mehr oder minder nach ausstellenden Einrichtungen geordnet sind, befinden sich die älteren Stücke überwiegend noch immer in einem Sammelbestand mit der Bezeichnung „Bamberger Urkunden“. Der Grund hierfür ist in der bayerischen Archivgeschichte zu suchen, denn das 1812 als Zentralarchiv des Königreich Bayerns aufgestellte Allgemeine Reichsarchiv (heute Bayerisches Hauptstaatsarchiv) in München extrahierte schon bald nach seiner

Daher ich mich des höchsten auftrages vom 9ten v. M. entledige, und in tiefester ehrfurcht beharrend." im Bericht Kaisenbergs, Kastner des Stifts St. Gangolf, an die Kurfürstliche Landesdirektion Bamberg über den Einzug der noch vorhandenen Urkunden des ehemaligen Stifts St. Gangolf in das Kurfürstliche Archiv vom 2. Juni 1804 in StABa K 515 Nr. 662.

${ }^{80}$ Generalregister u.a. über die Einnahmen der Stuhlbrüder aus dem 16. Jahrhundert im Urbar über die Vikarien, Obleien und Fragmente (1317-1667) in StABa Stift St. Gangolf, Akten und Bände Nr. 44.

${ }^{81}$ Recherchen erfolgten in den Unterlagen des Fürstentums im Zeitraum 1192 bis 1810 im Bestand StABa Markgraftum Brandenburg-Kulmbach-Bayreuth, Geheimes Hausarchiv Plassenburg, Akten und Bände. 
Gründung die gesamte Urkundenüberlieferung vor 1401 der ihm nun als Filialen unterstellten staatlichen Archive im bayerischen Einzugsgebiet und stellte diese als Urkundenselekt in der Hauptstadt auf. ${ }^{82}$ Eine Erschließung der eingezogenen Stücke erfolgte nicht. Erst 1993 trugen die Bemühungen Früchte, den Selekt gemäß der Archivsprengel und Zuständigkeiten an die Staatlichen Archive Bayerns zurückzugeben, sodass das Staatsarchiv Bamberg heute unter der Bestandssignatur Bamberger Urkunden (BU) eine Vielzahl an Urkunden aus der Frühzeit des Hochstifts beherbergt, aus deren Reihen nur mit großen Mühen einzelne Provenienzen herausgelöst werden können. ${ }^{83}$ Leider ist es weder durch zeitgenössische Aufzeichnungen noch durch einen stichhaltigen Registraturvermerk möglich, die Urkunden mit der Provenienz Stift St. Gangolf im Bestand BU zu identifizieren. Allein durch eine umfassende Prüfung aller Urkunden im Bestand BU auf die Erwähnung des Stifts St. Gangolf oder der Theuerstadt hin konnte durch die Verfasserin zahlreiche Urkunden identifiziert werden, die zwar keinen zwingenden Hinweis auf eine Gangolfer Provenienz boten, aber für die vorliegende Fragestellung interessant wurden. Besonders die daraus gewonnene Einsicht in die Entwicklung des Theuerstadtbegriffs ${ }^{84}$ und in die Fremd- und Selbstwahrnehmung des Stifts ${ }^{85}$ ist aufgrund der zeitlichen Nähe und quellenkundlichen Qualität als Charakteristika von Urkunden unschätzbar für die hier angestellte Untersuchung. Eine Aussage darüber, aus welcher Registratur die Urkunden stammen, kann auf diesem Wege jedoch nicht getroffen werden.

Diejenigen Urkunden des Stiftes nach 1401, welche im 19. Jahrhundert nicht nach München ausgelagert wurden, wurden durch den

${ }^{82}$ Näheres zur Geschichte des Allgemeinen Reichsarchivs in Generaldirektion der Staatlichen Archive Bayerns (Hg.): Königlich Bayerisches Allgemeines Reichsarchiv. Zur Gründung vor 200 Jahren (Beiheft der Ausstellung der Bayerischen Archivschule von Christine Kofer und Johannes Moosdiele, 23. April bis 29. Juni 2012). München 2012. S. 3.

83 Dies gelang in einem seltenen Fall bei der Provenienz Kloster Michelsberg, wo ein eindeutiger Rückvermerk Hinweise auf die Registratur des Klosters gibt. Näheres dazu in Lisa Witowski: Urkunden des Bamberger Klosters Michelsberg erschlossen und digitalisiert. In: Nachrichten aus den Staatlichen Archiven Bayerns 68 (2015). S. 50-52.

${ }^{84}$ Anhang Tabelle 3: Theuerstadtbezeichnung.

${ }^{85}$ Anhang Tabelle 2: Stiftsbezeichnungen. 
kurfürstlichen Archivaren Paul Oesterreicher, ebenfalls in Form eines Urkundenselekts, im Bestand A 120 formiert, wo die Gangolfer Urkunden zusammen mit denen des Stifts St. Stephan und des Stifts St. Jakob heute im Staatsarchiv Bamberg liegen. Die Trennung von Urkunden, Güterverzeichnissen und ungebundenem papiernen Schriftgut am Fach ist noch ein Überbleibsel des archivischen Strukturierungsverständisses des 19. Jahrhunderts. Während Registerbände und Aktengut in vielen Fällen bereits in provenienzreinen Beständen vereint sind, werden Urkunden auch in modernen Ordnungen oft noch getrennt geführt, da bestandserhalterische Überlegungen hinsichtlich Aufstellungsmöglichkeiten am Fach und ältere Verzeichnungen gegen eine Zusammenführung sprechen. Dies spiegelt sich auch in der Gangolfer Überlieferung in der Aufstellung und deren Repertorienerschließung wieder.

Das Pfarreiarchiv, das die geistlichen Hinterlassenschaften des Stiftes umfasst, ist an das Archiv des Erzbistums Bamberg gekommen. Nachdem bereits 1928 Johann Schlund, Geistlicher Rat und Pfarrer von Breitengüßbach, zahlreiche Archivalien und Urkunden aus den ehemaligen Pfarreien zusammengetragen hatte und unter der Bezeichnung „Schlundrepertorium“ verzeichnete, ${ }^{86}$ konnten in den letzten Jahren unter dem Archivleiter Andreas Hölscher auch die letzten Reste des Gangolfer Pfarrarchivs geschlossen ins Archiv übernommen und provenienzrein aufgestellt werden. ${ }^{87}$

\footnotetext{
86 AEB Rep. I. Urkunden, die das Stift St. Gangolf betreffen, finden sich unter den Ordnungskriterien „Pfarrei St. Gangolf“ und „Pfarrei St. Gertraud“. Diese Zuordnung zu konstruierten Pfarreienbezirken bezieht sich auf die stiftischen Immunitätsrechte von St. Gangolf, beziehungsweise auf die Rolle der Gertraudskapelle als Pfarrkirche seit dem 15. Jahrhundert.

${ }^{87}$ AEB Rep. 60, Pfarrarchiv St. Gangolf Bamberg. Das Pfarrarchiv in seiner heutigen Form kam durch drei Abgaben an das AEB. Bereits 2003 gelangten, erschlossen durch ein Altrepertorium von 1907, vor allem Pfarrmatrikel und Unterlagen der Pfarrverwaltung des 18. und 19. Jahrhunderts als Depositum an das Archiv, die 2014 durch Unterlagen vor allem aus dem 20. Jahrhundert ergänzt wurden. 2016 konnte auch der restliche Bestand des Pfarrarchivs an das AEB geholt und dort bereits im selben Jahr durch Holger Winkler erschlossen werden. In dem neuen Bestand sind nun auch wertvolle Stücke wie das Breviarium Eberhardi Cantoris aus dem 16.-17. Jahrhundert (Nr. 119), das Evangeliar des Stifts St. Gangolf aus dem 16. Jahrhundert (Nr. 120) und die Reliquienauthentik, datiert auf um 1060 (Nr. 436) zu finden, die mehrere Jahrzehnte als verschollen galten.
} 
Die Urkunden des Stadtarchivs Bamberg, die sich inhaltlich dem Stift St. Gangolf nähern, thematisieren hauptsächlich die Theuerstadt als städtisches Einflussgebiet und das Bürgerspital St. Katharina mit Besitzungen östlich der Regnitz. ${ }^{88}$ Darüber hinaus finden sich im Stadtarchiv die Sammlungen des Historischen Vereins Bamberg, welche vereinzelte Archivalien und Registerbände des Stifts St. Gangolf umfassen. ${ }^{89}$

Mittelalterliche Urkunden, in denen das Stift St. Gangolf eine Rolle spielt, finden sich vereinzelt im Staatsarchiv Nürnberg, aber auch im Staatsarchiv Würzburg, was wohl überwiegend mit der personalen Verbindung des Bamberger und des Würzburger Bischofamtes im Spätmittelalter zu tun hat. Vor allem die Urkunden des Klosters Ebrach enthüllen Hinweise auf Kanoniker des Stifts St. Gangolf, die seit dem 13. Jahrhundert dort als Zeugen oder Siegler in Besitzsachen auftreten oder Zollfreiheiten auf Wein durch die Stadt Würzburg erhielten. ${ }^{90}$

\subsection{Bestand „Stift St. Gangolf, Akten und Bände“ im Staats- archiv Bamberg}

Der Bestand „Stift St. Gangolf, Akten und Bände“, wie er heute im Staatsarchiv Bamberg nutzbar ist, hat einen langen Weg hinter sich. Wie bereits beschrieben, beklagten sich bereits die Kanoniker des säkularisierten Stifts Anfang des 19. Jahrhunderts über die schlechte Beschaffenheit und die Lücken, die Plünderungen und Unruhen im Laufe der Zeit in ihre Registratur gerissen hatten. Kaum ein Stück reichte schon damals über das 15. Jahrhundert hinaus, wobei sich vor allem Unterlagen des 16. und 17. Jahrhunderts erhalten haben. Die früheren Quellen sind verloren und müssen wohl als Opfer der Hussitenunruhen ${ }^{91}$ oder

${ }^{88} \mathrm{SttABa}$ A 21.

${ }^{89}$ SttABa D 3001 HV Rep. 1 und D 3001 HV Rep. 2

${ }^{90}$ Näheres dazu in StAWu Urkunden, Kloster Ebrach und besonders zu den Zollfreiheiten StAWu Geistliche Sachen 1539 aus der ersten Hälfte des 16. Jhds.

${ }^{91}$ Näheres dazu in Franz Machilek (Hg.): Die hussitische Revolution. Religiöse, politische und regionale Aspekte (Forschungen und Quellen zur Kirchen- und Kulturgeschichte Ostdeutschlands, Bd. 44). Köln u. a. 2012; Walter Tausendpfund: Oberfranken und der 
der Markgrafen- und Bauernkriege des 15. und 16. Jahrhunderts angesehen werden. Die Auflösung der stiftseigenen Registratur brachte eine Aufteilung der Überlieferung mit sich. Durch das persönliche Engagement einzelner Archivare, in Bamberg vornehmlich dem des kurfürstlichen Archivaren Paul Oesterreicher (1766-1839), ${ }^{92}$ konnten die Urkunden und einige Bände an das kurfürstliche Archiv verbracht werden und damit Verluste von Schriftgut im Zuge von Umnutzungen der Kirchengebäude oder allgemeinen Wirren entgegenwirken. Ein Großteil der Akten sowie der Registerbände, die Besitzverhältnisse dokumentieren, kamen jedoch an die zuständigen Rentämter, welche erst Ende des 19. Jahrhunderts als Abgabe wieder zurück an das staatliche Archiv gelangten, als die Aufgaben der Rentämter durch Finanzämter erfüllt wurden.

Das Königliche Kreisarchiv Bamberg, als Vorgängerinstitution des heutigen Staatsarchivs Bamberg, beherbergte Ende des 19. Jahrhunderts einen Großteil der ehemaligen Registratur des Stifts St. Gangolf. Dieser wurde im Geiste der Zeit in Selekten formiert, die sich eher an der Archivalientypologie als an der Provenienz orientierten. Dies hat sich in einigen Bereichen des Staatsarchivs bis in die heutige Zeit gehalten, wo Amts- und Geschäftsbücher als Selekt „Standbücher“, ${ }^{93}$ Rechnungen gesondert ${ }^{94}$ sowie das Verwaltungsschriftgut im Selekt „Literalien und Akten “95 vom Urkundenselekt ${ }^{96}$ getrennt am Fach stehen und in eigenständigen Repertorien geführt werden.

Hussitensturm im 15. Jahrhundert. In: Archiv für Geschichte von Oberfranken 86 (2006). S. 109-134; Thomas Krzenck: Die große Heerfahrt der Hussiten 1429-30 und der Bamberger Aufstand im Februar 1430. In: Mediaevalia historica bohemica 2 (1992). S. 119141.

92 Klaus Rupprecht: Paul Oesterreicher (1767-1839) - Archivar und fränkischer Landeshistoriker. In: Archivalische Zeitschrift 89 (2007). S. 9-43; Friedrich Leitschuh: Art. „Oesterreicher, Paul“. In: Allgemeine Deutsche Biographie, Bd. 24 (1887). S. 518-520; eine allgemeine Einordnung auch in Philipp Müller: Geschichte machen. Historisches Forschen und die Politik der Archive. Göttingen 2019.

${ }^{93}$ Standbücher des Stifts St. Gangolf waren bis 2012 im Bestand StABa A 221/IX zu finden. Heute sind sie Teil des Bestandes StABa Stift St. Gangolf, Akten und Bände.

${ }^{94}$ Rechnungen des Stifts St. Gangolf im Bestand StABa A 232.

95 Schriftgut des Stifts St. Gangolf waren bis 2012 im Bestand StABa B 98 zu finden. Heute ist es Teil des Bestandes StABa Stift St. Gangolf, Akten und Bände.

${ }^{96}$ Urkunden ab 1401 des Stifts St. Gangolf sind zusammen mit denen des Stifts St. Stephan und denen des Stifts St. Jakob im Bestand StABa A 120 formiert. 
Im Jahr 2012 konnte jedoch im Falle des Bestandes des Stifts St. Gangolf ein Erfolg hinsichtlich der Aufstellung nach modernen Gesichtspunkten erzielt werden - ein Erschließungsprojekt des Staatsarchivs Bamberg, in dessen Verlauf die Verfasserin zusammen mit Dr. Klaus Rupprecht, damals Archivoberrat am Staatsarchiv Bamberg, heute Archivleiter am Staatsarchiv Würzburg, den auf mehrere Bestände verteilten Nachlass des Stiftes St. Gangolf sichtete und neu strukturierte. Ziel war die provenienzreine Zusammenlegung des Gangolfer Bestands B 98 „Literalien und Akten“ mit Teilen des Bestands A 221/IX „Standbücher" und mit vereinzelten Archivalien anderer Selekte, woraus der Bestand „Stift St. Gangolf, Akten und Bände“ formiert wurde. Ein Untergliederungspunkt des Bestandes bildet die Überlieferung des Propsteiverwaltungsamtes Hollfeld, welches eine eigene Registratur unterhielt und erst über die Abgaben der Rentämter an das Staatsarchiv kam. Da Altrepertorien fehlen, konnte die ursprüngliche Struktur der ehemaligen Registratur nicht lückenlos ermittelt werden, sodass sich die Ordnung des Bestandes eng an den Stiftsämtern orientiert, wie sie in den Unterlagen gespiegelt werden. Es wird deutlich, dass die einzelnen Stiftsämter teilweise eine eigene Überlieferung führten. Neben dem Propst und dem Dekan sind in dem Zusammenhang der Scholastikus, der Kustos und der Keller zu nennen. Jedoch ist für das Verständnis der Quellen auch das Amt des Obleiers von Bedeutung, da dieser eine nicht unwichtige Rolle in der Besitzverwaltung spielte. ${ }^{97}$ All diese Ämter führten eigene Amtsbuchserien und Rechnungen, die in unterschiedlicher Quantität erhalten sind. Insgesamt umfasst der Bestand Stift St. Gangolf heute 234 Akten und Bände. ${ }^{98}$ Die Zuverlässigkeit dieses Verwaltungsschriftguts ist nicht selten aufgrund verschiedener Besitzansprüche beeinflusst und muss anhand von Gegenbeispielen geprüft werden. Nichtsdestotrotz bietet es einen unmittelbaren Einblick in die alltäglichen Verwaltungsabläufe und die Güterstruktur des Stifts.

\footnotetext{
${ }^{97}$ Näheres dazu im Kapitel 4.2.6 Obleier und Fabrikamt.

98 Auch online einsehbar unter https://www.gda.bayern.de/findmitteldb/Findbuch/5731/ (zuletzt gesehen am 11. Mai 2021).
} 


\section{Historische Übersicht}

\subsection{Gründung}

\subsubsection{Quellen und Literatur zu den Gründungsdaten}

Die Gründungsumstände des Kollegiatstifts St. Gangolf sind in der bisherigen Forschung naturgemäß ein wichtiges Thema gewesen, denn die Suche nach der ersten urkundlichen Erwähnung bildet das Herzstück einer jeden Institutionengeschichte. Eine Gangolfer Gründungsurkunde fehlt jedoch und ein gesichertes Gründungsdatum kann nicht benannt werden. Damit ist St. Gangolf kein Einzelfall in der Bamberger Stadtgeschichte. Während man bei der Erforschung des Domstifts Bamberg nicht zuletzt wegen der zahlreichen Konflikte rund um die Bistumsgründung im Jahr 1007 auf ein reichliches Quellenmaterial zurückgreifen kann, fehlen den anderen geistlichen Institutionen der frühen Kirchenlandschaft Bambergs meist die Zeugnisse aus ihrer Anfangszeit, sodass deren Gründung zeitlich nicht exakt bestimmt werden kann. Eine Annäherung an das konkrete Datum ist nötig. So beziehen sich die Gründungsdaten des Kollegiatstifts St. Stephan auf dessen Ersterwähnung im Jahr 1009, als das Stift bereits bestand, und des Klosters Michelsberg für das Jahr 1015 auf umstrittene Angaben späterer Schriftzeugnisse. ${ }^{99}$ Die stiftseigenen Kopialbücher von St. Gangolf aus dem 16. Jahrhundert geben keinen Aufschluss über die Gründungsumstände. Dort finden sich ausschließlich Abschriften von Urkunden, die nicht weiter als ins 13. Jahrhundert reichen und hauptsächlich Besitzverhältnisse thematisieren. ${ }^{100}$ Somit scheiden sie als Quelle für die Gründungsüberlieferung aus. Die frühen Urkunden der Bamberger

\footnotetext{
${ }^{99}$ Eine gezielte Auflistung der Ersterwähnungen des Stifts St. Stephan und des Klosters Michelsberg sowie deren Deutung als gesicherte Gründungsdaten in Bernd Schneidmüller: Ein Kloster gegen Nordwind. St. Michael, Kaiser Heinrich II. und Bamberg. In: Jung, Norbert/ Kempkens, Holger (Hgg.): 1000 Jahre Kloster Michaelsberg Bamberg 1015-2015. Im Schutz des Engels (Begleitpublikation zur Sonderausstellung vom 26. Juni bis 4. Oktober 2015). Petersberg 2015. S. 26-39. hier: S. 34.

${ }^{100}$ Kopialbücher des Stifts St. Gangolf in StABa Stift St. Gangolf, Akten und Bände Nr. 1 bis Nr. 6.
} 
Stadtgeschichte können nicht viel mehr beweisen, als dass das Stift St. Gangolf im 11. Jahrhundert bereits bestand. Die älteste Urkunde, die das Stift eindeutig erwähnt und im Original überliefert wurde, liegt im Staatsarchiv Bamberg. Sie wurde am 6. Mai 1093 von dem Bamberger Domkanoniker Ulrich ausgestellt. ${ }^{101}$ Dort übereignet er für sein Seelenheil dem Bamberger Domstift ein Gut zu Franchendorf als Oblei, bestellt den Grafen Otto von Alechbach als Vogt und benennt die Grafen Wolfram und Adelold Walpoto zu Boten des Vogtes. Von den Einnahmen werden unter anderem fünf Solidi an dem Jahrtag des Stifters jeweils den Brüdern von St. Gangolf (de sancta Maria), St. Stephan und St. Jakob übereignet. Hieraus ist ablesbar, wie weit zu jener Zeit der Ausbau der Kirchenlandschaft Bambergs schon fortgeschritten war und welche Erfolge die Stiftungstätigkeit zeigte. Hinweise auf die Gründungsumstände von St. Gangolf liefert die Urkunde jedoch nicht.

Allgemeiner Konsens über die Ursprungszeit des Kollegiatstifts St. Gangolf besteht darin, die Gründung für den Zeitraum zwischen Ostern 1057 und dem 13. April 1059 festzulegen. Die Quellen hierfür sind nicht zahlreich und lassen Raum für Spekulationen. Die historiografische Überlieferung über die Geschichte Bambergs gibt nur bedingt Einblick in die Gründungsumstände des Kollegiatstifts. ${ }^{102}$ Erst die Weltchronik des Kanonikers Heimo von St. Jakob "De decursu temporum liber" 103 von 1135, also fast 100 Jahre nach der angenommenen Stiftsgründung, weiß zu berichten:

${ }^{101}$ Urkunde des Bamberger Domkanonikers Udalrikus vom 6. Mai 1093 in StABa BU 143. 102 Als Beispiele für Quellen zur Bamberger Historiografie sind die Weltchronik des Frutolf von Michelsberg (gest. 1103) in Franz-Josef Schmale/ Irene Schmale-Ott (Hgg.): Frutolfs und Ekkehards Chroniken und die anonyme Kaiserchronik (Ausgewählte Quellen zur deutschen Geschichte des Mittelalters, Bd. 15). Darmstadt 1972; Das Preislied des Gerhard von Seeon in Klaus van Eickels: Das Preisgedicht Gerhards von Seeon auf die Bamberger Kirche. In: BHVB 138 (2002). S. 123-137; Die Lebensbeschreibung Bischof Ottos I. durch Ebo von Michelsberg (gest. 1163) in Jan Wikarjak/ Kazimierz Liman (Hgg.): Ebonis vita sancti Ottonis episcopi Babenbergensis (Monumenta Poloniae Historica. Nova Series, Bd. 7,2). Warschau 1969.; und die Lebensbeschreibung der heiligen Kunigunde in Vita sanctae Cunegundis. In: Pertz, Georg Heinrich (Bearb.): Annales, chronica et historiae aevi Carolini et Saxonici (MGH SS 4). Hannover 1841. S. 821-828.

${ }^{103}$ Jaffé (Hg.): Heimo von St. Jakob. 1869. S. 537-552. 
His tribus ecclesiis postea per Guntherum, eiusdem Babinbergensis sedis quartum praesulem, et per Reginoldum quendam virum nobilem addita est quarta ecclesia in honore sancte Mariae matris domini et sancti Gengolfi martiris extra urbem versus orientem in loco Tierstat sub ordine et professione canonica. ${ }^{104}$

Dies ist der älteste überlieferte Bericht über die Gründung des Stiftes und wurde in die Lebensbeschreibung Heinrichs II., angefertigt zwischen 1140 und 1160 durch Adalbert von Bamberg, übernommen. ${ }^{105}$ Folgt man Heimo, ergibt sich der Terminus post quem aus der Erwähnung des Bamberger Bischofs Gunther (1057-1065) als Stiftsgründer, der bald nach dem Tod des am 14. Februar 1057 verstorbenen Bischofs Adalbert als dessen Nachfolger eingesetzt wurde.

Derselbe Bischof Gunther berief am 13. April 1059 eine Diözesansynode in Bamberg ein, auf der man beschloss, gegen die slawische Bevölkerung im Maingebiet vorzugehen. In dem dazugehörigen Synodialprotokoll wurde neben dem Dompropst, dem Domdekan und anderen Personen (wohl Domkanonikern) ein Adalbero decanus de Durinstat ${ }^{106}$ erwähnt, welcher in der Forschung als Dekan des in der Theuerstadt neu gegründeten Kollegiatstifts gedeutet wurde. ${ }^{107}$ Daraus würde sich nun mit dem Jahre 1059 der Terminus ante quem ergeben, wobei die Interpretation Duristat $=$ Theuerstadt nicht immer unumstritten war. Ende des 19. Jahrhunderts gab es Stimmen, die Duristat mit der Ortschaft Döringstadt ${ }^{108}$ gleich setzten. ${ }^{109}$ Dieser Deutung wurde jedoch schon früh widersprochen, vor allem wegen der Zugehörigkeit des Ortes

104 Jaffé (Hg.): Heimo von St. Jakob. 1869. S. 546.

105 Adalberti vita Heinrici II. imperatoris. In: Pertz, Georg Heinrich (Bearb.): Annales, chronica et historiae aevi Carolini et Saxonici (MGH SS 4). Hannover 1841. S. 792-814, hier: S. 794.

${ }_{106}$ Anhang Tabelle 2: Stiftsbezeichnungen.

107 Philipp Jaffé (Hg.): Acta synodi Babenbergensis in epistolae Bambergenses cum aliis monumentis permixtae (Bibliotheca rerum Germanicarum, Bd. 5: Monumenta Bambergensia). Berlin 1869. S. 497-498, hier: S. 498.

108 Ortsteil Ebensfeld (Lk Lichtenfels).

${ }^{109}$ Bereits 1888 veröffentlichte Albert Hauck die These, dass „Duristat" als „Döringstadt“ gelesen werden müsste. In Albert Hauck: Zur Missionsgeschichte Oberfrankens. In: Blätter für bayerische Kirchengeschichte 1 (1888). S. 113-119; Übernommen in Georg Rusam: Die Einführung des Christentums in Oberfranken. In: Blätter für bayerische Kirchengeschichte 8 (1902). S. 241-256. 
Döringstadt zur Würzburger und nicht zur Bamberger Diözese, ${ }^{110}$ sodass nunmehr in der Forschung Adalbero als Dekan des Kollegiatstifts St. Gangolf und die im Jahr 1059 erste Erwähnung der Theuerstadt allgemein anerkannt sind. Dem kann sich aus der Tatsache heraus angeschlossen werden, dass Döringstadt zwar eine alte Martinskirche vorweisen kann, ${ }^{111}$ jedoch im 11. Jahrhundert keine religiöse Gemeinschaft beherbergte, die die Einsetzung eines Dekans vonnöten gemacht hätte. Außerdem kann durch gezielte Untersuchungen der Bamberger Urkunden die Annahme bestätigt werden, dass die Theuerstadt als Identifizierungspunkt des Stifts St. Gangolf galt, welcher sich sogar auf die Selbst- und Fremdbezeichnung auswirkte. ${ }^{112}$

Die vorgetragenen Argumente auf der Synode von Bamberg im Jahr 1059 hinsichtlich der Slawenmission wurden immer wieder herangezogen, um auf die Motive Bischofs Gunther zur Einrichtung des Stifts auf der anderen Seite der Regnitz schließen zu können. Gemäß der Annahme, dass ein Vertreter des Stifts St. Gangolf auf der Kirchenversammlung gewesen war, folgerte die Forschung, dass das neugegründete Stift die Stadt Bamberg nach Nord-Osten hin gegen die Slawen oder gegen den Stamm der Thüringer als moralisches Bollwerk schützen sollte. Dies überschneidet sich mit der These, die Slawenmission sei der Grund für die Gründung des Bistums Bamberg gewesen. Dass dieses Motiv schon in den zeitgenössischen Quellen zu finden ist, kann jedoch eher als Vorwand der Partei Heinrichs II. gesehen werden, um die Bistumsgründung trotz aller Widerstände auf der Frankfurter Synode im

${ }^{110}$ Erich Kolde: Beiträge, Anregungen und Gedanken zur Geschichte Frankens. Leipzig 1917. S. 37-39. und beruft sich dabei auf die bereits bestehende Deutung der „Duristat“ als Theuerstadt in Johannes Looshorn: Die Geschichte des Bisthums Bamberg, Bd. 1: Gründung und 1. Jahrhundert des Bisthums Bamberg. Bamberg 1886. S. 381.

${ }^{111}$ Friedrich Hiller: Die Kirchenpatrozinien des Erzbistums Bamberg. Bamberg 1931. S. 119.

112 Anhang Tabelle 2: Stiftsbezeichnungen. Während die erste nachweisbare Erwähnung des Kollegiatstifts St. Gangolf aus dem Jahr 1093 von den „fratres de sancta Maria“ spricht (StABa BU 143.), folgen in den Jahren darauf Fremdbezeichnungen nach dem Muster einer Amtsbezeichnung plus „Turstatensis“ (StABa BU 149.) oder „de Tuirstat“ (StABa BU 156 und BU 178.). Näheres im Kapitel 3.2.5 Stiftsbezeichnungen in den Urkunden. 
Jahr 1007 durchzusetzen. ${ }^{113}$ Die Bezeichnung „Theuerstadt“ wurde in diesem Zusammenhang auf „Thüringerstadt“ zurückgeführt. Diese Herleitung geht auf den letzten Gangolfer Dekan Schubert Mitte des 18. Jahrhunderts zurück, ${ }^{114}$ findet sich aber bereits in Ansätzen bei dem mittelalterlichen Chronisten Frutolf (gest. 1103) wieder, als er von der Gründung des Klosters Michelsberg als Zuflucht gegen den kalten Hauch des Nordens schrieb, von woher alles Schlechte stamme. ${ }^{115}$ Das blieb jedoch nicht die einzige Deutungsvariante des Theuerstadtbegriffs. Nur wenige Jahre vor der Auflösung des Stifts St. Gangolf im Zuge der Säkularisation weiß der Salzburger Universitätsprofessor Ämilian Ussermann (1737-1798) zu berichten, dass Theuerstadt soviel wie Seelgerät, also ein im Himmel angelegter Schatz, bedeute. Er leitete dies aus dem Namensbestandteil „teuer“ ab. ${ }^{116}$ Und tatsächlich ist durch die im

113 Näheres dazu bei Rudolf Endres: Das Slawenmotiv bei der Gründung des Bistums Bamberg. In: BHVB 109 (1973). S. 161-182, hier: S. 163. Endres stützt sich auf die Argumentation von Wilhelm Neukam: Das Hochstift Würzburg und die Errichtung des Bistums Bamberg. In: Würzburger Diözesangeschichtsblätter 14/15 (1952/53). S. 147-172.

114 Die Slawenmission als Gründungsmotiv des Kollegiatstifts St. Gangolf findet sich schon in Schubert: Dissertatio inauguralis. 1768. S. 57-58: "Denominatio loci vulgo Teuerstatt $\mathrm{ab}$ aliquibus controverti voluit et affirmari, olim eum vulgo die Tewerstadt oder Wehrstadt nuncupatum fuisse, est ego in nulli etiam vetustioribus documentis aliter, quam Teuerstatt legi“; und wurde später immer wieder aufgegriffen z. B. in Heinrich Mayer: Bamberg als Kunststadt (Die Kunst im alten Hochstift Bamberg und in seinen nächsten Einflussgebieten, Bd. 1). Bamberg/ Wiesbaden 1955. S. 328. und Bernhard Schimmelpfennig: Bamberg im Mittelalter. Siedelgebiete und Bevölkerung bis 1370 (Historische Studien, Bd. 391). Lübeck 1964. S. 20; Auch in Looshorn: Die Geschichte des Bisthums Bamberg, Bd. 1. 1886. S. 3: "Es ist zwar den fränkischen Königen, dem Chlodwig und besonders seinem Sohne Theodorich, gelungen, nach schweren, blutigen Kriegen die Thüringer $\mathrm{zu}$ besiegen und ihr Land $\mathrm{zu}$ erobern; allein die Thüringer behielten doch fernerhin ihr eigenes Recht und hatten eigene Herzoge. Dieses Herzogthum erstreckte sich nicht bloß über den Thüringerwald und nördlich desselben, sondern umfasste auch das Land südlich bis an den Main und weiterhin, sodass das heutige Unterfranken grossentheils und wohl auch ein Theil von Oberfranken zum Herzogthume Thüringen gehörten. Daran erinnern noch die Ortsnamen Döringstatt am Maine und vielleicht auch Turstat, Teurstat, Duristat, die alte Vorstadt von Bamberg."

115 „Contra refrigerantes flatus illius, qui in aquilone, unde malum omne pandetur, sedem ponere disposuit, refugium certum“ in Dieter J. Weiß: Das Kloster Michelsberg und die Stadt Bamberg. In: van Eickels/ van Eickels (Hgg.): Das Bistum Bamberg in der Welt des Mittelalters. 2007. 227-245, hier: S. 227.

116 "Guntherus Babenbergensium episcopus quintus ut pro insigni sua pietate honorem Dei promoveret, nova ecclesia Bambergam exornare constituit. Pro ea condenda locum in Teuerstatt seu Tewrstatt dictum selegrat, qui plurimus aedificiis et amplissima platea 
12. Jahrhundert häufig belegte Schreibweise Tuirstat eine Ableitung vom althochdeutschen Adjektiv „tiuri“ oder mittelhochdeutsch „tiur(e)“ mit der Bedeutung „wertvoll, kostbar, teuer“ denkbar, die erstmals zum Ende des 13. Jahrhunderts in Richtung Tewerstadt tendiert. ${ }^{117}$ Jedoch führte Ussermann somit nicht nur die Gründung des Stifts St. Gangolf, sondern auch die Gründung, oder zumindest Benennung, der Vorstadt Theuerstadt auf Bischof Gunther zurück, der sich auf diese Weise sein Seelenheil zu sichern suchte. Dem widerspricht, dass die Theuerstadt mit hoher Wahrscheinlichkeit schon weit vor dem Stift St. Gangolf bestanden hat. ${ }^{118}$ Andere Deutungsversuche sehen in der Bezeichnung Theuerstadt im Sinne locus tierstat einen Hinweis auf Wildtierhaltung, genauer auf ein Zentrum des königlichen Forstes Hauptsmoor unter Verwaltung der Walpoten. ${ }^{119}$ Dieser These wurde jedoch bereits vor ihrer Öffentlichmachung vehement widersprochen. ${ }^{120}$

conspicuus trans flumen Regnisium cum urbe strato ponte lapideo coniungitur." in Ussermann: Episcopatus Bambergensis. 1802. S. 270.

${ }^{117}$ Näheres dazu im Anhang Tabelle 3: Theuerstadtbezeichnung.

${ }_{118}$ Monika Schleß und Alois Albrecht datieren die Entstehung der Theuerstadt auf das 8. Jahrhundert. Als Ausgangspunkt nahmen sie die karolingische Handelsstraße, deren Verlauf heute noch streckenweise der Bamberger Königsstraße entspricht. In Schleß/ Albrecht: Pfarrgemeinde St. Gangolf Bamberg. 1980. S. 4; Näheres zur Bedeutung des karolingischen Fernhandelsweges zwischen Hallstadt und Forchheim, welcher die Grundlage für den seit dem 14. Jahrhundert nachweisbaren Steinweg in der Theuerstadt legte, in Pfaffenberger: Aspekte der Stadtentwicklung Bambergs im frühen und hohen Mittelalter aus archäologischer Sicht. 2020. S. 35-37 und S. 228; und Matthias Exner/ Peter Ruderich (Bearb.): Theuerstadt und östliche Stadterweiterungen. 1. Drittelband: Untere Gärtnerei und nordöstliche Stadterweiterung. Teil 1 und 2: Öffentliche Bauten; Straßen und Plätze (Die Kunstdenkmäler von Bayern. Regierungsbezirk Oberfranken, Bd. 9: Stadt Bamberg, Bd. 7/1). Bamberg 2019. S. 9-10.

${ }^{119}$ Ruprecht Konrad: Siedlung und Herrschaft im Hollfelder Land bis zum Hochmittelalter. In: Stadt Hollfeld (Hg.): 1000 Jahre Hollfeld Stadt und Land 1017-2017. Hollfeld 2017. S. 34-42, hier: S. 39; und Ders.: Otnant von Eschenau. Ein salischer Reichsministerialer in Nordostbayern. In: BHVB 148 (2012) S. 45-71, hier: S. 62. Ruprecht führt die Bedeutung "locus tierstat" mit den Burgennamen Zwernitz und Zwerenz zusammen und deutet sie als Zwinger oder Tiergehege, sodass er mit diesen Walpotenburgen wieder die Klammer zu Reginold Walpot als Gönner des neugegründeten Stiftes St. Gangolf aufnehmen kann. Ebenso in Zimmermann: Sankt Gangolfs Weg von Lothringen nach Bamberg. 1962. S. 448.

${ }^{120}$ Joachim Andraschke: Arianische und fränkische Missionierung im Regnitz und Obermaingebiet um 500 bis 800 n. Chr. Ein Sprachgeschichtlicher Beitrag zur Kirchenge- 
Klar ist, dass im 10. und 11. Jahrhundert eine Epoche des Landesausbau und der Rodungstätigkeit begann, was einherging mit einer weitflächigen Erschließung der Fränkischen Alb im Radenzgau. Dies sollte die Binnenkolonisation des Gebiets fördern und den Ansprüchen der konkurrierenden Schweinfurter Grafen entgegensteuern. ${ }^{121}$ Das Stift St. Gangolf wurde vermutlich deswegen in die bereits vorhandene Vorstadt des neuen Bistums gesetzt, um die fruchtbaren Böden im Umkreis des Hauptsmoorwaldes durch Landnahme zu erschließen und vor fremden Herrschaftsansprüchen zu schützen. Ob die Theuerstadt bereits zu dieser Zeit ihren Namen trug oder aufgrund der Stiftsgründung in der Form betitelt wurde, bleibt aufgrund der Quellenlage ungeklärt. Die Kolonisation der östlichen Albgebiete konnte im 11. Jahrhundert nur in Zusammenarbeit mit den slawischen Strukturen vonstattengehen. ${ }^{122}$ Die Christianisierung des fränkisch-thüringischen Raums war zu der Zeit bereits abgeschlossen, sodass eine Kirchengründung zu Missionszwecken nicht angenommen werden kann. ${ }^{123}$ Die Gründung des Stifts St. Gangolf ist daher im Zusammenhang mit dem Ausbau der Kirchenlandschaft des neuerrichteten Bistums zu sehen, welcher dem Standort liturgische Bedeutung verlieh und dem Domkapitel zugleich ein Kontingent an ausgebildeten Klerikern für seine Zwecke bescherte. ${ }^{124}$

schichte Ostfrankens. In: BHVB 135 (1999). S. 89-118, hier: S. 98. Er betont, der Name "Duristat" wäre hermundurisch und hätte nichts mit dem Wort "Tier" zu tun.

${ }^{121}$ Endres: Das Slawenmotiv bei der Gründung des Bistums Bamberg. 1973. S. 168-169.

122 Endres sieht in der Tatsache, dass auf der Bamberger Synode von 1059 von widerspenstigen und $\mathrm{zu}$ bestrafenden Slawenorten die Rede war, den Beweis, dass die Slawen bereits Teil der christlichen Gemeinschaft waren, denn Heiden hätten keine Kirchenstrafen zu fürchten. In Ebd. S. 175-176; Ein konfliktfreies Nebeneinander der zahlreichen kulturellen Einflüsse aus germanisch-fränkischen und slawischen Siedlern sieht auch Pfaffenberger bereits seit dem 9. Jahrhundert als gegeben. In Pfaffenberger: Aspekte der Stadtentwicklung Bambergs im frühen und hohen Mittelalter aus archäologischer Sicht. 2020. S. 34-35.

${ }^{123}$ Das Motiv der Slawenmission ist auch schon für die Gründung des Bistums Bamberg $1007 \mathrm{zu}$ kurz gegriffen. Näheres dazu in Klaus van Eickels: Bistumsgründungen um das Jahr 1000. In: van Eickels/ van Eickels (Hgg.): Das Bistum Bamberg in der Welt des Mittelalters. 2007. S. 33-64., hier: S. 39.

${ }^{124}$ Helmut Flachenecker: Bistum Bamberg. In: Gatz, Erwin (Hg.): Die Bistümer des Heiligen Römischen Reiches von ihren Anfängen bis zur Säkularisation. Freiburg i. B. 
In den Überlieferungen des Domkapitels vom Anfang des 15. Jahrhunderts findet sich eine Auflistung von Leistungen der Bamberger Bischöfe, die auch Gunther und seine Stiftsgründung thematisieren. Diese in der Literatur häufig als „Bischofschronik“ bezeichnete Aufzeichnung nennt das Jahr 1060 als Gründungsdatum des Stifts St. Gangolf. ${ }^{125}$ Das Datum findet sich an keiner anderen Stelle überliefert, sodass es lediglich als Versuch einer Annäherung auf Grundlage der damals vorhandenen Informationen angesehen werden kann.

Ein weiteres Datum, das im Zuge der Gründung des Stiftes St. Gangolf immer wieder auftauchte und geprüft werden muss, ist die Weihe der Stiftskirche im Jahr 1063. Diese Jahreszahl ist plausibel, aber nicht sicher nachweisbar. ${ }^{126}$ Anfang des 18. Jahrhunderts nennt der Bamberger Hofadvokat und Michelsberger Vogt Martin Hoffmann ${ }^{127}$ dieses Datum um die Kirchweihe zu datieren, erwähnt aber nicht die Quelle seiner zeitlichen Einschätzung. ${ }^{128}$ Die Zeitangabe findet sich in

\begin{abstract}
2003. S. 70-81, hier: S. 70.
125 „Guntherus [...] MLX hic episcopus quintus fuit fundator ecclesie beate Marie in Tewrstat cum quodam primore seu nobili viro Reynolt Walpoto: sepulto ibidem sub altarii sanctorum apostolorum versus locum capitularem. Ex post vero quidem Eberhardus exstruxit chorum eiusdem ecclesie et ibidem sepultus est ibidem ante summum altare beate virginis Marie et sancti Gangolfi in quorum honore fundaverat" in der Sammelhandschrift „Varia ecclesiam Bambergensem et praebendas ibidem concernentia“ in StABa B 86 Nr. 271 fol. 178.

126 Mayer: Bamberg als Kunststadt. 1955. S. 329. datierte das Querschiff und das Mittelschiff anhand der Eigenarten im Baubefund auf das 11. Jahrhundert. Eine archäologische Ausgrabung im Innenraum der Gangolfer Kirche im Jahr 1988 unter Leitung von Holger Fries konnten diese These, wenn nicht beweisen, so doch stärken, indem sie Fundamente und Reste eines Chorabschlusses freilegte, deren Bau für die Gründungsphase des 11. Jahrhunderts angenommen wurde. In Bayerisches Landesamt für Denkmalpflege: Grabungsbericht 1988 Ausgrabung: Notgrabung bei Ausschachtungsarbeiten für eine Fußbodenheizung, Maßnahme M-2007-31726-1_0; Bamberg, BA: St. Gangolf, G-1988 (Ü-4-6131-0137).

127 Näheres über die Person Hoffmanns in Konrad Arneth: M. Martin Hofmann. Ein Bamberger Späthumanist. In: BHVB 110 (1974) S. 39-165, hier: S. 138.

128 „Postero anno 1063. Guntherus episcopus Teurstadii in suburbio trans flumen orientem versus ecclesiam aedificavit eamque b. virgini Dei matri et S. Gangolpho consecravit adiuvantibus Rhinoldo Walboco comite Wolfesuvaccio et Eberhardo quodam cive Babebergensi. Quorum hic chorum eiusdem ecclesiae propriis impensis excitavit ille vero luculentissimis possessionibus ad usum et decus explere instituit. In eam uterque post mortem illatus ibi sepulturam accepit." in Hoffmann: Annales Bambergensis episcopatus. 1718 . Sp. 77.
\end{abstract}


der Literatur des gesamten 18. Jahrhunderts bis zur Auflösung des Stifts im Zuge der Säkularisation und wird auch später immer wieder aufgegriffen. ${ }^{129}$

Die Gangolfer Eigenüberlieferung selbst gibt kaum Auskunft über die Stiftsgründung. Allein eine undatierte Notiz des Hollfelder Propstvogts Johann Metzel aus dem 16. Jahrhundert thematisierte die Gründungsumstände. Johann Metzel hält darin fest, dass sein Stift 1065 von Bischof Gunther und den Grafen von Truheling gestiftet worden sei. ${ }^{130}$ Ob mit diesen Grafen die Familie von Truheding gemeint war, bleibt unklar, doch sicher scheint auf Grundlage der oben genannten Quellen, dass das Stift 1065 bereits seit einigen Jahren bestand. Sowohl das von Metzel angegebene Gründungsdatum als auch die Erwähnung des vorgenannten Grafengeschlechts als Stifter finden sich in anderen Quellen im Zusammenhang mit der Stiftsgründung nicht, während er dem Geschlecht der Walpoten keinen nennenswerten Einfluss auf die Gründung nachsagen konnte. Zwar wurde laut der Gangolfer Anniversarüberlieferung jährlich am 19. Mai ein Gottesdienst zu Ehren des Bamberger Bischofs Friedrich von Truheding (amt. 1363-1366) abgehalten, ${ }^{131}$ jedoch ist diese Erwähnung nicht überzubewerten. Auch andere Bamberger Bischöfe wurden in den Anniversarbüchern St. Gangolfs erwähnt, sodass das Gedenken an den Bischof aus der Familie der Truhedinger vor allem obligatorisch war und keine herausgehobene Stellung zum Stift vermuten lässt. Die Notiz des Propstvogtes scheidet

129 Schubert: Dissertatio inauguralis. 1768. S. 59; Christoph Gottlieb von Murr: Merkwürdigkeiten der Fürstbischöflichen Residenzstadt Bamberg. Nürnberg 1799. S. 120; Wilhelm Deinhardt: Dedicationes Bambergenses. Weihenotizen und -urkunden aus dem mittelalterlichen Bistum Bamberg (Beiträge zur Kirchengeschichte Deutschlands, Heft 1). Freiburg im Breisgau 1936. Nr. 9, S. 8.

130 „Nota. Uf einem gar alten register zu der probstey gehörig sted mit einer alten schrift verzäichnet, das die grafen von Truheling sind stifter gewest des stifts zu sanct Gangolf mit sampt bischofen Gunthers, anno 1065. So hab ich auch mehr den eines gehört, das der stift zu sanct Gangolf nicht des orts, sonder zu Holfeld, sold sein aufgericht worden, warumb er aber bey Bamberg angericht, ist nichts davon gered worden, den allein, dass solches aus anschickung bischof Gunthers villeicht beschehen sein möge. Johann Metzel Probsteyverwalther" in StABa Stift St. Gangolf, Akten und Bände Nr. 163.

${ }^{131}$ Anniversarbuch (15.-16. Jhd) in StABa Stift St. Gangolf, Akten und Bände Nr. 128 fol. 12 '. 
demnach als verlässliche Informationsquelle hinsichtlich der Gründung aus, sowohl das Datum als auch das beteiligte Grafengeschlecht betreffend. Interessant wird sie, wenn sie Hollfeld als alternativer Standort des Kollegiatstifts erwähnt. Damit gibt Metzel einen Einblick in das gesteigerte Selbstbewusstsein des Hollfelder Verwalters im 16. Jahrhundert als Vertreter der stiftischen Besitzungen außerhalb Bambergs. Dies resultiert in nicht geringem Umfang aus der Eigenständigkeit des Propstvogtes hinsichtlich seiner Aufgabenverwaltung und seiner Bedeutung in der Region. ${ }^{132}$

„Ohne geltungserhöhende Eigengeschichten haben Institutionen auf Dauer keinen Bestand. “133 schrieb Gert Melville und betont damit das, was man für das Stift St. Gangolf vermisst: einen generationenübergreifenden Gründungsmythos samt Verklärung desselben. Und doch bestand das Stift um die 750 Jahre lang.

\subsubsection{Einordnung der Stiftsgründung in die politischen Umstände der Zeit}

Sicher ist, dass sich die Gründung des Stifts St. Gangolf in eine Zeit einfügte, in der die Kirchenlandschaft Bambergs einen weitreichenden Ausbau erfuhr. Im 10. und 11. Jahrhundert setzte allgemein im Reich nördlich der Alpen eine Welle von Gründungen geistlicher Institutionen, besonders Kanonikerstiftungen, an Bischofsitzen ein, da diese sich für die Herrschaft eines Bischofs als nützlich erwiesen. Das Selbstverständnis und der Ausdruck von Herrschaft an einem Bischofssitz verlangten nach regelmäßigen Gottesdiensten von einer gewissen Größe und Qualität. Vor allem auch dann, wenn, wie in Bamberg, der Kaiser in der Person Heinrichs II. seine Aufenthalte zunehmend an Orten mit Bischofssitzen verlegte und häufig dort zugegen war. ${ }^{134}$ Die liturgische

\footnotetext{
${ }^{132}$ Näheres dazu im Kapitel 6.3.2.1 Propsthof in Hollfeld.

133 Gert Melville/ Hans Vorländer (Hgg.): Geltungsgeschichten. Über die Stabilisierung und Legitimierung institutioneller Ordnungen. Köln/ Weimar/ Wien 2002. S. V.

${ }^{134}$ Stifte als weithin wirkende „klerikale Zentren“ zur Aufwertung eines Bischofsitzes in Achim Hubel: Kaiser Heinrich II., die Idee einer Roma secunda und die Konkurrenz
} 
Ausgestaltung dieses Anspruches wurde von zahlreichen Geistlichen getragen, welche sich speziell aus Stiftskirchen rekrutierten, da diese Kleriker aufgrund ihrer finanziellen Absicherung durch Pfründen als Mitarbeiter in der diözesanen Verwaltung gut einsetzbar waren und sich nicht, wie die Mönche, den asketischen Idealen eines weltabgeschiedenen Lebens verschrieben hatten. ${ }^{135}$ Somit veränderte sich in dieser Zeit die Kirchenlandschaft nördlich der Alpen sehr zugunsten der Kanonikergemeinschaften und die Stadt wurde zum „liturgischen Raum“. ${ }^{136}$

In Bamberg begann diese Entwicklung, nachdem Kaiser Heinrich II. im Jahr 1007 aus der Burg samt Siedlung einen Bistumsitz gemacht hatte. Der Kaiser regierte wie seine Vorgänger in einem ständigen Umzug durch das Herrschaftsgebiet, in dem er bevorzugte Plätze einerseits als wiederkehrende Stationen seines Reisewegs und zum anderen zur Herrschaftsrepräsentation nutzte. Schon seine ottonischen Vorgänger bauten Orte wie Quedlinburg, Magdeburg, Frankfurt, Ingelheim oder Aachen aus und werteten sie als Pfalzen, Begräbnisstätten der Kaiserfamilie oder Orte für kirchliche Hochfeste auf. Änderungen im Machtgefüge oder Zäsuren durch Herrscherwechsel wurden im Reich nördlich der Alpen des 10. und 11. Jahrhunderts nicht selten durch die Bevorzugung bestimmter Städte deutlich. Für Kaiser Heinrich II. war

zwischen Regensburg und Bamberg im 11. Jahrhundert. In: van Eickels/ van Eickels (Hgg.): Das Bistum Bamberg in der Welt des Mittelalters. 2007. S. 103-140, hier: S. 118.

${ }^{135}$ Näheres dazu in Crusius: Das weltliche Kollegiatstift als Schwerpunkt innerhalb der Germania Sacra. 1984. S. 241-253, hier: S. 248; und Helmut Flachenecker: Lea oder Rachel? Stift oder Kloster am Bischofssitz? In: Lorenz, Sönke/ Zotz, Thomas (Hgg.): Frühformen von Stiftskirchen in Europa. Funktion und Wandel religiöser Gemeinschaft vom 6. bis zum Ende des 11. Jahrhunderts. Festgabe für Dieter Mertens zum 65. Geburtstag (Schriften zur südwestdeutschen Landeskunde, Bd. 54). Leinfelden-Echterdingen 2005. S. 377-392, hier: S. 378. Flachenecker geht noch weiter und betont, dass Kanonikerstifte außer der finanziellen Absicherung auch aufgrund ihrer weniger strengen Regeln - besonders im Vergleich zu klösterlichen Gemeinschaften - für Tätigkeiten am Bischofssitz prädestiniert waren.

${ }^{136}$ Laut Irene Crusius wurden zwischen dem 8. und 15. Jahrhundert auf dem Gebiet der deutschen Reichskirche in 34 Bischofsstädten 130 Kanonikerstifte gegründet, 76 allein im 10. und 11. Jahrhundert. Die Gründungswelle hatte demnach ihren Höhepunkt mit dem Regierungsantritt Heinrichs II. und bricht mit dem Investiturstreit ab. Crusius: Das weltliche Kollegiatstift als Schwerpunkt innerhalb der Germanica Sacra. 1984. S. 243 und S. 252. 
solch eine bevorzugte Stadt Bamberg. Diese bis dahin eher unbedeutende fränkische Siedlung erfuhr durch die Bemühungen des Kaisers um den Ausbau der römischen Kirche eine erhebliche Stärkung, und zwar auch gegen den Widerstand des Bischofs von Würzburg. Nachdem im Jahr 1012 der Dom als doppelchörige Anlage zusammen mit einer großen Pfalzanlage Gestalt annahm, folgte als wesentliches Merkmal der „ottonischen Stadt“ der Ausbau Bambergs als sakraler Ort. ${ }^{137}$

Nach dem Tod Kaiser Heinrichs II. im Jahr 1024 kam es nicht nur $\mathrm{zu}$ einem Wechsel des Herrscherhauses von den Liudolfinger zu den Saliern, sondern auch zu einer Bedeutungsverlagerung weg von Bamberg als kultisches Zentrum hin zur Domstadt Speyer. Bamberg drohten ein Bedeutungs- und damit auch ein wirtschaftlicher Besitzverlust. Laut der Chronik des Frutolf (gest. 1103), eines Mönchs des Bamberger Klosters Michelsberg, verbündeten sich Heinrichs Amtsnachfolger Konrad II. (amt. 1024-1039) und Königin Gisela mit dem Augsburger Bischof Brun (amt. 1006-1029), der zugleich auch ein Bruder Heinrichs II. war, um die privilegierte Stellung Bambergs im Reich zu unterminieren. Nur ein Traum Bruns, in dem ihm sein verstorbener Bruder ins Gewissen redete, hielt, so überliefert es Frutolf, den Bischof von seinen Plänen ab. ${ }^{138}$

Tatsächlich fiel die Gründung des Stifts St. Gangolf zwischen 1057 und 1059 in eine Zeit des Umbruchs im Reich. 1056 war Kaiser Heinrich III. (amt. 1039-1056) gestorben und hinterließ mit Heinrich IV. (amt. 1056-1105) einen minderjährigen Sohn. Dessen Unmündigkeit barg die Gefahr, dass seine Autorität im Strudel rivalisierender Fürsten untergeht. Dazu kamen Umbrüche innerhalb der kirchlichen Strukturen. Die Kirchenreform des 11. Jahrhunderts mit ihrer Kritik an Simonie, Priesterehe und den Anstrengungen, die kirchliche Autorität des

\footnotetext{
137 Van Eickels: Bistumsgründungen um das Jahr 1000. 2007. S. 60. betont, dass Bamberg um 1007 kaum städtische Züge aufwies, die eine Bistumsgründung gerechtfertigt hätten. Der rasche Ausbau der Stadt um den neuen Dom musste Heinrich II. also ein Anliegen gewesen sein.

138 Chronik des Frutolf von Michelsberg In: Schmale/ Schmale-Ott: Frutolfs und Ekkehards Chroniken und die anonyme Kaiserchronik. 1972. S. 56-57. Näheres dazu in Schneidmüller: Ein Kloster gegen Nordwind. 2015.
} 
Papsttums zu stärken, erreichte ihren Höhepunkt unter Papst Leo IX. (amt. 1049-1054) und wurde durch seinen Nachfolger Viktor II. (amt. 1055-1057) fortgesetzt. Die reformerischen Einwirkungen der Cluniazenser sind sowohl unter Papst Stephan IX. (amt. 1057-1058) als auch unter Papst Nikolaus II. (amt. 1059-1061), selbst Mönch des Klosters von Cluny, nachweisbar. ${ }^{139}$ Auf der Lateransynode von 1059 erfolgte dann der eigentliche Wendepunkt in den reformerischen Bestrebungen. Im Bistum Eichstätt entstand in dieser Zeit eine große Sammlung von Weiheformeln und es wurden Kirchenrechtssammlungen namhafter Bischöfe abgeschrieben, um den Stellenwert des Bistums Eichstätt im Heilsgeschehen zu unterstreichen. ${ }^{140}$

Doch auch in Bamberg herrschte zur Mitte des 11. Jahrhunderts Unsicherheit. In den 60er Jahren war das Verhältnis zwischen dem Bamberger Bischof Gunther und der Kaiserin-Witwe Agnes von Poitou angespannt. ${ }^{141}$ Der Grund hierfür lag in Streitigkeiten um Besitzansprüche, die im Zuge des Revindikationsprozesses Heinrichs IV. aufkamen. ${ }^{142}$ Der König bemühte sich um die Rückführung von Reichsgütern und Rechtsansprüchen, die unter seinem Vater in fremde Hände geraten waren. Heinrich IV. gab im Zuge dessen der Kirche Bambergs Güter zurück, die Heinrich III. entfremdet hatte. ${ }^{143}$ Ein Brief von 1062 ist überliefert, in dem der Bamberger Domdekan Poppo vor Bischof Gunther darüber klagt, dass die Kaiserin weder die materiellen Verluste

${ }^{139}$ Joachim Wollasch: Die Wahl des Papstes Nikolaus II. In: Fleckenstein, Josef/ Schmid, Karl (Hgg.): Adel und Kirche (Festschrift für Gerd Tellenbach). Freiburg/ Basel/ Wien 1968. S. 205-220, hier S. 219.

${ }^{140}$ Stefan Weinfurter: Eichstätt im Mittelalter. Kloster - Bistum - Fürstentum. Regensburg 2010. S. 85.

${ }^{141}$ Roman Tischer: Bischof Gunther von Bamberg (gest. 1065). Ein Pontifikat im Zeichen des Umbruchs. In: Bericht des Historischen Vereins Bamberg, Bd. 155 (2019). S. 71-94, hier S. 82-84.

${ }^{142}$ So beklagt sich 1061 Bischof Gunther von Bamberg bei dem Erzbischof Anno von Köln über dessen Beziehung zur Kaiserin Agnes. In Hans Friedrich Georg Julius Sudendorf: Registrum oder merkwürdige Urkunden für die deutsche Geschichte, Bd. 2. Berlin 1851. S. 7.; und Looshorn: Geschichte des Bisthums Bamberg, Bd. 1. 1886. S. 388.

143 Thomas Gunzelmann (Hg.): Stadt Bamberg, Bd. 1: Stadtdenkmal und Denkmallandschaft. 1. Halbband: Stadtentwicklungsgeschichte (Die Kunstdenkmäler von Bayern: Regierungsbezirk Oberfranken, Bd. 3). München/ Bamberg 2012. S. 198. 
seines Domkapitels noch die anderer Bamberger Kirchen ersetzen würde. Er schrieb:

Unsere Maria fragt sich betrübt, aufgrund welchen Verbrechens sie denn von der

Geldverteilung der Kaiserin derart ausgeschlossen und vorverurteilt sei. ${ }^{144}$

Der Bezug Poppos auf die heilige Maria als Hauptpatronin des Theuerstädter Stifts legt die Vermutung nahe, dass hier vom Stift St. Gangolf die Rede ist, ${ }^{145}$ was jedoch aufgrund der spärlichen Quellenlagen in dieser frühen Zeit des Stifts schwer zu belegen ist. Später besserte sich die Beziehung zwischen dem Bischof und der Kaiserin zwar, jedoch blieb ein stetes Misstrauen zwischen den beiden zurück. Diese Unsicherheiten für die Stadtentwicklung verschärften sich zudem noch dadurch, dass Bischof Gunther oft außerhalb Bambergs weilte, um sich auf Hoftagen, Kriegszügen und Versammlungen der Reichsfürsten zu engagieren. ${ }^{146}$

Auch anderer Widerstände und fremder Ansprüche hatte sich Bischof Gunther zu erwehren, um seine Macht im Bistum zu behaupten, was sich nicht zuletzt auch in der Ausstattung des Stifts St. Gangolf widerspiegelte. Dessen Gründungsgut umfasste Güter um Hollfeld, die nach dem Aussterben der Schweinfurter Grafen durch Ansprüche der Andechs-Meranier bedroht schienen. ${ }^{147}$ Dass diese Güter an das Kollegiatstift St. Gangolf fielen, war auf den Einfluss des Ministerialen Reginold Walpot zurückzuführen, der als einer der Gründer des Stifts gilt.

\footnotetext{
144 „Et nunc quidem omnia apud nos in suo cursu aguntur, excepto quod nostra Maria et mirando dolet et dolendo miratur, quondam suo scelere in sectione pecunie inperatricis ita exclusa et predampnata sit." Brief des Bamberger Domdekan Poppo an Bischof Gunther in Weitere Briefe Meinhards von Bamberg. In: Erdmann, Carl/ Fickermann, Norbert (Bearb.): Briefsammlung der Zeit Heinrichs IV (MGH Briefe der deutschen Kaiserzeit 5). Weimar 1950. S. 192-248, hier: S. 203. Laut kritischen Anmerkungsapperat sollten diese Geldleistungen als eine Entschädigung für Verwüstungen im Rahmen der Bamberger Fehde gedacht gewesen sein.

${ }^{145}$ Vertreter dieser These ist Erich Freiherr von Guttenberg: Die Regesten der Bischöfe und des Domkapitels von Bamberg (Veröffentlichungen der Gesellschaft für fränkische Geschichte, Bd. 6). Würzburg 1932. S. 130-131 Nr. 285 und S. 162 Nr. 337. Näheres zu der Rolle Marias als Patronin des Stifts St. Gangolf im Kapitel 3.2.1 Die heilige Maria.

${ }^{146}$ Looshorn: Die Geschichte des Bisthums Bamberg, Bd. 1. 1886. S. 390.

${ }^{147}$ Näheres im Kapitel 6.3.2.1 Propsthof in Hollfeld.
} 


\subsubsection{Die Gründer}

\subsubsection{Gunther, Bischof von Bamberg}

Während das Domstift, das Kollegiatstift St. Stephan und das Benediktinerkloster St. Michael in der Regierungszeit Heinrichs II. gegründet wurden, entstanden die Kollegiatstifte St. Gangolf und St. Jakob nach dessen Tod und unter verstärktem bischöflichen Einfluss. Besonders am Kloster Michelsberg, das sich im 12. Jahrhundert sehr um eine Umdeutung seiner Gründung als eine kaiserliche bemühte, um der bischöflichen Einflussnahme zu entkommen, entbrannte in der Forschung die Frage nach seiner Stellung als Reichskloster oder als bischöfliches Eigenkloster. ${ }^{148}$ Ebenso bot die besitzrechtliche Stellung des Stiftes St. Stephan immer wieder Grund für Diskussionen. Während in den Quellen vereinzelt Kaiser Heinrich II. oder gar Kaiserin Kunigunde als Initiatoren der Stiftsgründung angesehen wurden, vermutete die Forschung, dass nicht der Kaiser, sondern Bischof Eberhard von Bamberg Gründer von St. Stephan war. ${ }^{149}$ Jedoch muss hierbei bedacht werden, dass sich diese Frage grundsätzlich erst nach dem sogenannten Investiturstreit Ende des 11. Jahrhundert stellte. Erst durch die Beilegung dieses Streits konnten sich kirchenrechtliche Amtsbefugnisse und der damit verbundene Rang zum systemtragenden Faktor entwickeln, der durchaus auch, wie am Beispiel des Klosters Michelsberg erkennbar, instrumentalisiert werden konnte. Demgegenüber findet sich in den Quellen des Stifts St. Gangolf kein Hinweis auf die Betonung einer Rolle als Bischofsgründung oder eine bewusste Abkehr von derselben.

${ }^{148}$ Im Rahmen des tausendjährigen Gründungsjubiläum des Klosters Michelsberg neu bearbeitet im Aufsatzband von Jung/ Kempkens (Hgg.): 1000 Jahre Kloster Michaelsberg Bamberg 1015-2015. 2015.

${ }^{149}$ Arnold Faber: Die staatsrechtliche Stellung des Stifts Sankt Stephan in Bamberg. Sankt Stephan reichsunmittelbar oder bischöfliches Eigenstift? Erlangen 1950. S. 8-13; Und auf ihm aufbauend Ulrike Siewert: Die Bamberger Bistumsgründung und die Entstehung einer sakralen Landschaft. Die Bedeutung des Nebenstifts St. Stephan in der Bamberger Kirchenlandschaft. In: Jahrbuch für fränkische Landesforschung 71 (2011). S. 1-19, hier: S. 6. Letztendlich kommt Siewert zu dem Schluss, dass die „Gründung des Kollegiatstiftes eine Gemeinschaftsaktion von Bischof Eberhard und von Heinrich II. mit Kundigunde“ war. Ebd. S. 8; Dazu ebenso Karin Dengler-Schreiber: War Kaiserin Kunigunde die Gründerin von St. Stephan? In: BHVB 156 (2020). S. 89-111. 
Der Bamberger Bischof Gunther (amt. 1057-1065) war, bevor er sein Amt antrat, Domkanoniker in Bamberg, und wirkte gleichfalls als italienischer Kanzler. ${ }^{150}$ Er besaß ein großes Privatvermögen, stand in hohem Ansehen bei Kaiser Heinrich III. und wurde durch dessen Sohn und Nachfolger Heinrich IV. reich beschenkt. Gunther bemühte sich während seiner gesamten Amtszeit um die Wiederherstellung des bedrohten Bamberger Kirchenbesitzes und vermehrte ihn durch eigene Schenkungen. Grundsätzlich waren die Neuordnung und der Ausbau der Bamberger Diözese das stärkste Handlungsmotiv Bischofs Gunther, welches einen höheren Stellenwert als seine reichspolitischen Aktivitäten einnahm. ${ }^{151}$ Die Neugründung des Stifts St. Gangolf ist durchaus in diesem Zusammenhang der Stärkung des eigenen Bistums in sowohl territorialpolitsicher als auch seelsorgerischer Hinsicht $\mathrm{zu}$ verstehen, dessen Ausstattung mit Gütern in und um Hollfeld sich in den Güterverzeichnissen des Stiftes wiederspiegelt. ${ }^{152}$ In der Historiografie des Heimo von St. Jakob wird Bischof Gunther die Stiftsgründung von St. Gangolf als Verdienst zugesprochen. ${ }^{153}$ Das dort erwähnte Weihedatum der Gangolfskirche im Jahr 1063 fällt in seine Regierungszeit, jedoch hat die heutige St. Gangolfskirche mit dem Bau des 11. Jahrhunderts wenig gemein. ${ }^{154}$ Die Kirche wurde im 15. und 18. Jahrhundert weitreichend umgebaut. ${ }^{155}$ Umso erstaunlicher ist die Tatsache, dass in einschlägigen Studien immer wieder zu lesen ist, dass die heutige Pfarrgemeinde stolz sein dürfe, die älteste Kirche in Bamberg zu besitzen ${ }^{156}$ und dass Lang-

150 Tischer: Bischof Gunther von Bamberg (gest. 1065). 2019. S. 71-94; Looshorn: Die Geschichte des Bisthums Bamberg, Bd. 1. 1886. S. 370-373.

151 Eine Neubewertung Bischof Gunthers in seiner später überzeichneten Rolle als Reichsbischof in Tischer: Bischof Gunther von Bamberg (gest. 1065). 2019. S. 90-93.

152 Näheres dazu im Kapitel 6.3.1 Gründungsausstattung und erste Schenkungen.

153 Jaffé (Hg.): Heimo von St. Jakob. 1869. S. 546.

${ }^{154}$ Näheres dazu in Kapitel 4.1.3 Stiftskirche.

${ }^{155}$ Hubel: Kaiser Heinrich II. 2007. S. 118.

156 Diese These findet man immer wieder rezipiert in Mayer: Bamberg als Kunststadt. 1955. S. 328; Paschke: St. Gangolf zu Bamberg. 1959. S. 6; Franz Kohlschein: Die SanktGangolf-Kirche - ein kostbares Vermächtnis für die Pfarrgemeinde heute. In: Albrecht, Alois (Hg.): Pfarrkirche St. Gangolf Bamberg. Restaurierung der ältesten Kirche der Stadt 1984-1990. Bamberg 1990. S. 9-19, hier. S. 9; und Zimmermann: Sankt Gangolf in Bamberg. ${ }^{2} 1998$. S. 4. 
haus und Querschiff des Ursprungsbaus noch weitestgehend erhalten sein sollen. ${ }^{157}$ Denn von seinem romanischen Gesamteindruck ist kaum etwas an der heutigen Gangolfskirche erhaltengeblieben. In der stiftseigenen Überlieferung spielt Bischof Gunther eine untergeordnete Rolle. Zwar weiß der Propstvogt Johann Metzel im 16. Jahrhundert von der Gründung des Stifts unter Bischof Gunther, ${ }^{158}$ jedoch sucht man ihn in den Anniversarbüchern des Stifts St. Gangolf vergeblich. Die Rolle eines Bischofs bei der Gründung des eigenen Hauses schien für die Gangolfer Kanonikergemeinschaft im Laufe der Jahrhunderte kein sonderlich erwähnenswerter Umstand mehr zu sein. Die Konkurrenz der Bamberger Bischöfe mit ihrem Domkapitel, welches als Ideengeber für die kleineren Stifte der Stadt wirkte, kann dafür durchaus verantwortlich gemacht werden.

\subsubsection{Reginold Walpot}

Bereits Heimo von St. Jakob erwähnt 1135 einen vir nobilis Reginold, der zur Gründung des Stifts St. Gangolf beigetragen habe. ${ }^{159}$ Der Bezug zum Ministerialgeschlecht der Walpoten findet sich hier noch nicht, jedoch kann sie indirekt über die Grundausstattung des Stifts erschlossen werden. Wie bereits erwähnt, bestand die erste wirtschaftliche Ausstattung des Bamberger Stifts St. Gangolf aus Gütern und Rechten rund um die Ortschaft Hollfeld, welche sich bis dahin im Besitz des Geschlechts der Walpoten befand. Diese Familie konnte sich über die Zeit hinweg als Vertreter des Grafengerichts im Radenzgau etablieren. Die Walpoten als eines der bedeutendsten Adelsgeschlechter des mittleren Maingebiets sind erst um 1015 mit der Entstehung der Bistumskanzlei Bambergs urkundlich in Erscheinung getreten, ihre Ursprünge werden

${ }^{157}$ Zimmermann: Sankt Gangolf in Bamberg. ${ }^{2}$ 1998. S. 4.; Kohlschein: Die Sankt-GangolfKirche. 1990. S. 11; Mayer: Bamberg als Kunststadt. 1955. S. 329. Dort ist auch von der Vierzahl der Pfeilerarkaden zu lesen, die in Barockzeit umgebaut wurde, die man aber noch an der Seitenaltaranordnung ablesen könne.

${ }^{158}$ Gründungsnotiz (16. Jhd) in StABa Stift St. Gangolf, Akten und Bände Nr. 163.

${ }^{159}$ Jaffé (Hg.): Heimo von St. Jakob. 1869. S. 546. 
aber weitaus früher angesetzt. ${ }^{160}$ Nachdem das Geschlecht der Babenberger Anfang des 10. Jahrhunderts im Zuge der Babenberger Fehde seine Ansprüche auf das Herzogtum Franken verlor, konzentrierte es seine Macht auf das Gebiet um Grabfeld, Radenzgau, Volkfeld und Tullifeld. Dort erreichten sie die Grafenwürde, in welcher sie alsbald durch die Schweinfurter und die Henneberger abgelöst wurden. ${ }^{161}$ Die Stellvertretung im Grafengericht des Radenzgaus übernahmen vermutlich seit dem 10. Jahrhundert die Walpoten. Als die Schweinfurter durch Auseinandersetzungen mit Heinrich II. an Einfluss verloren, kam es zu einer Neuordnung der Kräfte, von welcher das neugegründete Bistum Bamberg profitierte, indem es den Radenzgau erhielt. Die Walpoten blieben weiterhin begüterte Stellvertreter der Grafen des Radenzgaus, welche nun nicht mehr dem König, sondern dem Bamberger Bischof unterstanden. ${ }^{162}$ Der Kern der Walpotengüter lag nördlich von Hollfeld, um den späteren Gerichtsbezirk Zwernitz, außerdem im Raum um Schönfeld, Krögelstein, Truppach und Wonsees. ${ }^{163}$ Mit dem Aussterben der Schweinfurter stiegen die Grafen von Andechs-Plassenberg auf und traten in direkte Konkurrenz mit den Walpoten um deren Besitzungen, welche die Geschlossenheit des Plassenburger Herschaftsgebietes durchlöcherte. ${ }^{164}$ In dieser Zeit politischer Wirren kam es unter den Walpoten zu zahlreichen Stiftungen und Schenkungen zur Sicherung von gefährdetem Besitz. ${ }^{165}$

Reginold wurde als Gründer von St. Gangolf stiftsintern bereits in den frühesten Nachweisen gewürdigt. So finden sich in den Annivers-

${ }^{160}$ Gustav Voit: Die Walpoten. Auf den Spuren des ältesten Adelsgeschlechtes der Fränkischen Schweiz (Die Fränkische Schweiz - Heimatkundliche Beiträge, Bd. 11). Erlangen/ Jena 1996. S. 7.

${ }^{161}$ Wilhelm Störmer: Die konradinisch-babenbergische Fehde um 900. Ursachen, Anlass, Folgen. In: Goetz, Hans-Werner (Hg.): Konrad I. auf dem Weg zum „Deutschen Reich“? Bochum 2006. S. 169-183; Erich Schneider/ Bernd Schneidmüller (Hgg.): Vor 1000 Jahren - Die Schweinfurter Fehde und die Landschaft am Obermain 1003 (Schweinfurter Museumsschriften, Bd. 118). Schweinfurt 2004.

${ }^{162}$ Voit: Die Walpoten. 1996. S. 14.

163 Ebd. S. 16.

164 Ebd. 1996. S. 24.

165 Näheres zu den Walpoten in Erich Freiherr von Guttenberg: Territorienbildung am Obermain. In: BHVB 79 (1925). S. 284-287. 
arbüchern jährlich für den 8. Februar Einträge, die Raynolt Walpot als fundator huius ecclesie ausweisen. ${ }^{166}$ Darin wird als sein Begräbnisort der Gangolfer Altar, genauer der Altar apostolorum, genannt. Einen Altar der Aposteln Petrus und Paulus hat es an der Stiftskirche St. Gangolf wohl gegeben und dieser wurde sogar mit zwei Vikariestiftungen bedacht. ${ }^{167}$ Nachrichten über diesen Altar gibt es jedoch erst seit dem 14. Jahrhundert, als die ältere der beiden Stiftungen im Jahr 1343 gegründet wurde. ${ }^{168}$ Wo genau sich dieser Altar befand, ist nicht bekannt. Archäologische Nachweise fehlen ${ }^{169}$ und der damalige Baubestand hat sich seit der Stiftsgründung naturgemäß stark verändert. Glaubt man vereinzelten Nachrichten von um 1800, konnte man zu dieser Zeit eine Tafel mit den Namen des Reginold und des Eberhard am Hauptaltar der Stiftskirche finden. ${ }^{170} \mathrm{Zu}$ bedenken ist, dass der heutige barocke Altar sowohl in der Ausstattung als auch in der Lage nicht dem erstmals vorhandenen romanischen Altar entspricht. Dieser hat sich in der Vierung der Kirche

${ }^{166}$ Eintrag in den Anniversarbüchern (15.-16. Jahrhundert) für den 8. Februar in StABa Stift St. Gangolf, Akten und Bände Nr. 128 fol. 4 "Obiit Raynolt Walpot fundator huius ecclesie et cantantur longe vigilie et missa solempnis cum tractu commonisti et cum ministris." mit dem Nachtrag am Seitenrand: „ante altare apostolorum“; in StABa Stift St. Gangolf, Akten und Bände Nr. 129 fol. 10 "Reynolt fundator ecclesie Walpot nuncupatus. Obiit Reynolt fundator ecclesie nostre et cantantur longe vigilie et missa sollemnis cum ministris, cum tractu commonisti“; und in StABa Stift St. Gangolf, Akten und Bände Nr. 130 fol. 5“ „Fundator. Ad animam Remaldi Walpot fundatoris huius ecclesie dantur principaliter consuete 4 denarii et cantantur longe vigilie“.

${ }^{167}$ Näheres im Kapitel 5.2.2 Vikarie Aposteln senior und junior.

${ }^{168}$ Abschrift der Urkunde vom 19. September 1343 im Zinsregister der Vikarie Aposteln senior (1673-1714) in StABa Stift St. Gangolf, Akten und Bände Nr. 96 fol. 33-35.

${ }^{169}$ Bei der archäologischen Grabung von 1988 wurde unter Holger Fries im Bereich der Vierung nördlich des heutigen Altars ein Sarkophag aus Sandsteinplatten gefunden, dem ein Holzkästchen mit nicht identifizierten Gegenstände aus Stoff, Leder und Metall beigegeben wurde. Eine genaue Datierung erfolgte nicht, jedoch sind die bisher näher beleuchteten Grablegen in der Stiftskirche nie vor dem 15. Jahrhundert anzusetzen. Bayerisches Landesamt für Denkmalpflege: Grabungsbericht 1988 Ausgrabung: Notgrabung bei Ausschachtungsarbeiten für eine Fußbodenheizung, Maßnahme M-2007-31726-1_0; Bamberg, BA: St. Gangolf, G-1988 (Ü-4-6131-0137).

170 "Hinter dem hohen Altare dieser Kirche zu St. Gangolph liest man unter der Gedächtnißmalerey ihres Stifters folgende Namen: Eberhardus com. fundator chori. Reinoldus Walbot fundator ecclesiae. Dieser liegt in der Mitte des Chors begraben." in Murr: Merkwürdigkeiten der Fürstbischöflichen Residenzstadt Bamberg. 1799. S. 120; Diese Nachricht wurde immer wieder aufgegriffen, beispielsweise durch Paschke: St. Gangolf zu Bamberg. 1959. S. 6. 
befunden und war Johannes dem Täufer geweiht. ${ }^{171}$ Sowohl der Auffindungsort als auch die bloße Existenz einer Tafel mit der in der älteren Literatur so häufig erwähnten Inschrift über die Gründer der Kirche sind laut Angabe der Verantwortlichen der heutigen Pfarrei St. Gangolf nicht bekannt.

Die Verbindungen der Familie Walpot zum Stift St. Gangolf sind über das Wirken des Reginold Walpot hinaus nur sehr gering gewesen. In der Zeugenreihe des sogenannten Giechburgvertrages von 1149 taucht ein Cuonradus prepositus sancte Marie (Konrad von Memmelsdorf, amt. 1147-1155) auf, der zeitgleich Domkustos und Mitglied der Familie der Walpoten war. ${ }^{172}$ Obwohl die Walpoten und Vertreter des Stifts St. Gangolf noch bis in das 13. Jahrhundert, durchaus auch zusammen, in Urkunden $\mathrm{zu}$ finden sind, scheint dies auf keiner besonderen politischen Verbindung zu gründen. Enger hingegen ist das Verhältnis zwischen den Walpoten und dem Kloster Banz. So tritt 1240 Ebo, Dekan des Stifts St. Gangolf (amt. 1240-1241), neben anderen geistlichen Würdenträgern Bambergs wie dem Kloster Michelsberg und dem Domkapitel und Laien als Zeuge auf, als Friedrich von Zwernitz genannt Walpot dem Kloster Banz Vogteirechte an verschiedenen Orten übereignete. ${ }^{173}$ Das Stift St. Gangolf spielte aber in den weiteren Walpotenurkunden kaum eine Rolle, selbst in solchen, die enge Beziehungen zu Bamberg voraussetzten. Eine Familienmemoria oder ähnliches, getragen vom Stift St. Gangolf, wurde anscheinend nicht angestrebt. Die Hinwendung der Walpoten zum Patrozinium des heiligen Gangolf war keineswegs programmatisch. In keinen der anderen zahlreichen Stiftungen der Familie tritt der heilige Gangolf als Kirchenpatron auf oder spielte anderweitig eine Rolle in der Familiengeschichte. ${ }^{174}$ Der Einfluss der Familie in der Bischofsstadt Bamberg wurde systematisch ausgebaut, was

\footnotetext{
171 Laut Ussermann wurde der Altar 1564 neu errichtet in Ussermann: Episcopatus Bambergensis. 1802. S. 271.

${ }^{172}$ Vidimus verschiedener Urkunden von Egilbert, Bischof zu Bamberg, aus dem Jahr 1149 in StABa BU 247. Besprochen in Voit: Die Walpoten. 1996. S. 25.

${ }^{173}$ Memorialvorsorge des Friedrich von Zwernitz vom 10. Juli 1240 in StABa BU 600.

174 Zimmermann: Sankt Gangolfs Weg von Lothringen nach Bamberg. 1962. S. 448.
} 
an Erwähnungen derer von Walpot in Zeugenlisten, ${ }^{175}$ Güterschenkungen ${ }^{176}$ und Teilnahme an wichtigen Hochfesten festgemacht werden kann. So stiftete beispielsweise Graf Reginboto, der als Walpote identifiziert wird, zusammen mit seiner Ehefrau Adela zahlreiche Güter, Kelche, Geld und Kännchen an das Kloster Michelsberg. ${ }^{177}$

Unklar ist, was Reginold Walpot zur Ausstattung des Stifts St. Gangolf veranlasst haben könnte. Vorbild könnte eventuell Kaiser Heinrich II. gewesen sein, der erst wenige Jahre zuvor im Zuge der Bamberger Bistumsgründung 1007 reiche Schenkungen für das Domstift tätigte. Als dessen vorrangigste Motivation wurde die Sorge um das Seelenheil wegen seiner Kinderlosigkeit angegeben. ${ }^{178}$ Es ist anzunehmen, dass das eigene Totengedenken ein Beweggrund für die Stiftung durch Reginold Walpot gewesen ist. Eine politische Motivation stellte wohl die Sicherung der territorialen Macht der Walpoten im Zuge der Schweinfurter Fehde 1003 dar, die eine territorialpolitische Neuordnung nach sich zog. ${ }^{179}$

In einigen Arbeiten zum Stift St. Gangolf aus dem 18. Jahrhundert wird Reginold Walpot mit der Familie der Wolfstriegel in Verbindung

175 Ein Adelold Walpot findet sich als Zeuge in bischöflichen Urkunden oder als Bote eines domstiftischen Vogtes und auch dessen Nachkommen Ulrich und mehrere Personen mit Namen Friedrich Walpot bis weit in das 13. Jahrhundert hinein in den Urkunden des Staatsarchivs Bamberg: BU 143 vom 6. Mai 1093; BU 149 vom 19. Mai 1108 als beglaubigte Abschrift von 1883 II 10; Kloster Michelsberg, Urkunden Nr. 20 vom 13. Juni 1136; BU 247 von 1149; BU 256 vom 8. Juli 1151; BU 264 vom 27. März 1152; BU 283 von 1157; BU 312 von um 1170; BU 473 von 1216; BU 478 um 1216; Kloster Michelsberg, Urkunden Nr. 75 von 1217; BU 618 vom 14. November 1243; BU 671 vom 21. Juli 1249; und Kloster Michelsberg, Urkunden Nr. 110 von 1255.

176 Als Beispiele dienen die ebenfalls durch Adelold Walpot getätigte Stiftung zum familiären Totengedenken an das Kloster Michelsberg in StABa Kloster Michelsberg, Urkunden Nr. 16 von 1124; und der Verkauf eines Gutes an das Bamberger Kloster St. Theodor durch Ulrich Walpot in BU 427 von 1203. Ebenso ist die hier bereits besprochene Memoriasicherung des Friedrich von Zwernitz genannt „Waltpoto“ am Kloster Banz durch großzügige Stiftungen zu nennen. In BU 660 vom 10. Juli 1240; und ebenfalls ein Friedrich Walpot stiftet an das Kloster Langheim in BU 1257 vom 26. Februar 1300.

${ }^{177}$ Looshorn: Die Geschichte des Bisthums Bamberg, Bd. 1. 1886. S. 499.

${ }^{178}$ Van Eickels: Bistumsgründungen um das Jahr 1000. 2007. S. 58.

${ }^{179}$ Ebd. S. 58. 
gebracht. ${ }^{180}$ Dies ist jedoch anachronistisch, da das Geschlecht der Wolfstriegel erst nach dem Aussterben der Walpoten, also Mitte des 14. Jahrhunderts, urkundlich nachgewiesen werden kann. Zu der Zeit waren sie Besitzer der Burg Krainach zwischen Hollfeld und Wonsees und hatten das Vogtamt von Weida inne. ${ }^{181}$ Vermutlich traten sie durch Heirat mit der Tochter des letzten Walpoten Friedrich V. (1285-1300) die Erbschaften der Walpoten in Franken an, ${ }^{182}$ was eine Erklärung für die fehlerhafte Zuordnung des Stiftsgründers Reginold sein könnte. Ausgangspunkt der genealogischen Konstruktion war Michael Heinrich Schubert als letzter Dekan des Stifts St. Gangolf, ${ }^{183}$ dessen fehlenden Quellenangaben die ältere Forschung nicht von der ungefilterten Übernahme der Familienzuordnung abhielt.

Ein hochinteressantes Zeugnis über das Wirken des Ministerialen Reginold Walpot fand keinen Eingang in die frühe Gangolfforschung, da es erst Mitte des 19. Jahrhunderts aufgefunden wurde. Die sogenannte "Reliquienauthentik“, bestehend aus zwei zusammengehefteten Pergamentblättern, soll neue Erkenntnisse über die Gründung des Stift St. Gangolf bringen. ${ }^{184}$ Eine beigegebene Notiz meldet den Fund dieses Pergaments am 12. Mai 1859 durch den damaligen Pfarrer Kaspar Schweitzer in einem Reliquienkästchen in der Sakristei der Gangolfskir-

\footnotetext{
180 Schubert nennt ihn „Wolffesuuacius Rheinoldus Wallbot“ und schreibt dazu „Comes ille Rheinoldus Wallbot reperitur etiam interfuisse synodo Babebergensi anno 1058 celebrata. Obiit hic Babebergae et post mortem ecclesiae a se dotatae illatus honorifice ante altare ss. apostolorum tumulatus fuerat, cuius anniversarius ibi singulis annis mense Februario celebratur." in Schubert: Dissertatio inauguralis. 1768. S. 58; Der Kalender für katholische Christen wiederholt diese Information "Reginold (Reinhold) von Walbott (comitem Wolffesuuacium Reinoldum Wallbot, wahrscheinlich Walpot, Besitzer von Zwernitz ob dem Gebirg, später Sanspareil genannt)" in Das Collegiatstift zu U. L. Frau und St. Gangolph in Bamberg. In: Kalender für katholische Christen. 1881. S. 81; Ussermann nennt ihn "Wolfeswrac" in Ussermann: Episcopatus Bambergensis. 1801. S. 270.

${ }^{181}$ Eckard Lullies: Die Fehde der Guttenberg gegen die Vögte und die Adelsfehde gegen Eger. Kulmbach 1999. S. 61-64.

${ }^{182}$ Voit: Die Walpoten. 1996. S. 63.

${ }^{183}$ Schubert: Dissertatio inauguralis. 1768.

${ }^{184}$ Näheres zu einer genauen Beschreibung und einer ersten Einordung des Fundes in Keh: Ein Beitrag zur Geschichte des ehem. Kanonikerstiftes St. Gangolf. 1951. S. 9; Besprochen auch von Schleß: Die älteste Urkunde von St. Gangolf im Pfarrarchiv. 1990. S. 60-62.
} 
che, das sich dort zusammen mit mehreren oft unbezeichneten Reliquien befand. ${ }^{185}$ Die Authentik wurde in der Folge in der Pfarrkirche St. Gangolf aufbewahrt und befindet sich heute im Archiv des Erzbistums Bamberg. ${ }^{186}$ Heftungsspuren am Rand des Pergamentes könnten darauf hindeuten, dass dieses Blatt an einem Behälter gehangen hat, in dem sich die erwähnten Reliquien befunden haben könnten. ${ }^{187} \mathrm{Zu}$ lesen ist, dass Papst Gregor einem Reginold und dessen Ehefrau Irmgard in Rom Reliquien von zahlreichen Heiligen übergab. ${ }^{188}$ Diese Reliquien waren nicht sonderlich charakteristisch und stammten wohl aus einem depositum reliquiarum, von denen die römische Kirche viele besaß. ${ }^{189}$ Dass hierbei keinerlei Gangolfreliquien erwähnt wurden, ist nicht verwunderlich, denn der heilige Gangolf soll - der Legende nach - nicht in Rom begraben worden sein, sodass dort auch keine Reliquienpraxis entstehen konnte. Ein Blick auf das Schriftbild der Authentik zeigt eine karolingische Minuskel, die noch weit entfernt ist von den eckig gebrochenen Rundungen und der steilen, engen Schriftführung der im 12. Jahrhundert aufkommenden gotischen Minuskel. ${ }^{190}$ Die Entstehungs-

${ }^{185}$ Keh: Ein Beitrag zur Geschichte des ehem. Kanonikerstiftes St. Gangolf. 1951. S. 9.

${ }^{186}$ Die Pergamenturkunde (datiert auf um 1060), die Mitteilung über die Fundumstände und die Publikation der Urkunde in AEB Rep. 60 Pfarrarchiv St. Gangolf Bamberg Nr. 436 .

${ }^{187}$ Heribert Keh untersuchte die in der Forschung bis dahin unbekannte Quelle und stellte eine Abmessungen von zum einen 9 x 16,5 cm fest, an dessen unterem Rand ein schmaler Streifen des gleichen Materials mit einer Abmessung von 2,5 x 15,5 cm angeheftet ist. Der schmalere Streifen wird von Keh als nachträglich angenäht betrachtet. Das Pergament ist dreimal quer gebrochen, was Keh als typisch mittelalterliche Faltung deutet. Eingestochene Löcher am Rand und ein Fadenreststück deuteten darauf hin, dass das Pergament auf einer Oberfläche aufgenäht gewesen war. Keh: Ein Beitrag zur Geschichte des ehem. Kanonikerstiftes St. Gangolf. 1951. S. 9.

188 "Horum sanctorum reliquias Gregorius papa dedit Reginoldo ac coniugi Irmingarde, quando simul Romae fuerunt: Sancti Petri videlicet principis apostolorum, sancti Stephani protomartyris, sancti Peregrini confessoris, sancti Pancracii, sancti Sebastiani et sancti Fabiani. De corporibus sanctorum Sixsti, Felicissimi et Agapiti, Laurencii, Ypoliti et quadraginta martirum." transkribiert nach Keh: Ein Beitrag zur Geschichte des ehem. Kanonikerstiftes St. Gangolf. 1951. S. 9.

189 Gerd Zimmermann: Die Gangolfskirche als Spiegel der Frömmigkeit seit über 925 Jahren. In: Albrecht, Alois (Hg.): Pfarrkirche St. Gangolf Bamberg. Restaurierung der ältesten Kirche der Stadt 1984-1990. Bamberg 1990. S. 20-33, hier: S. 22.

${ }^{190}$ Näheres dazu in Übungsbuch Deutsche Schriftkunde. Schriftbeispiele des 12. bis 20. Jahrhunderts aus bayerischen staatlichen Archiven (Sonderveröffentlichung der 
zeit des Schriftstückes wäre also durchaus für die Gründungszeit des Stifts denkbar. Bei dem erwähnten Papst Gregor könnte es sich also um Gregor V. (amt. 996-999), Gregor (VI.) (Gegenpapst, amt. 1012), Gregor VI. (amt. 1045-1046) oder Gregor VII. (amt. 1073-1085) handeln. ${ }^{191} \mathrm{Si}$ cher ist, dass 1046 auf Initiative des Bamberger Bischof Suitger ein Romzug stattfand, der von vielen Gläubigen begleitet wurde und auf dem Suitger letztendlich zu Papst Clemens II. (amt. 1046-1047) erhoben wurde. Dies jedoch erst, nachdem auf der Synode von Sutri auf Initiative Heinrichs III. der Misstand von drei gleichzeitig amtierenden Päpsten, unter ihnen Gregor VI., abgeschafft wurde. Obwohl es durchaus denkbar ist, dass Reginold Walpot und seine hier erwähnte Frau Irmgard an diesem Romzug teilnahmen und am Tiber um Reliquien für das neuzugründende Stift St. Gangolf baten, bleibt es fraglich, ob die beiden dafür einen abgesetzten Papst und nicht Clemens II. gewählt hätten. Wahrscheinlicher ist daher der Bezug zu der Fastensynode in Rom vom 17. Februar 1079, als Mitglieder der Bamberger Kirche durch Gregor VII. vorgeladen wurden, um sich wegen der Einsetzung des umstrittenen Bamberger Bischofs Herman von $1065 \mathrm{zu}$ rechtfertigen. Laut Voit war unter den Angeklagten auch ein Ulrich Walpot, dessen Bruder Adelod III. dem Kloster Michelsberg das Gut Altenhollfeld übereignen musste, um Ulrich auszulösen. ${ }^{192}$

Da nichts über den Entstehungszusammenhang des Fragmentes der Gangolfer Geschichte bekannt ist, muss seine Aussagekraft kritisch hinterfragt werden. Die Vermutung, dass es sich bei dem erwähnten Reginold um Reginold Walpot handelte, ist verlockend, und sowohl Heribert Keh als auch Monika Schleß gehen allzu selbstverständlich davon aus. Das Stift St. Gangolf oder Bamberg selbst wurden in dem Schriftstück mit keinem Wort erwähnt und auch die Identifizierung des

Staatlichen Archive Bayerns, Bd. 11). München 2015. S. 11.

${ }^{191}$ Die Päpste des 12. Jahrhunderts, die Keh noch als mögliche Kandidaten miteinbezieht, fallen nach der Schriftbildanalyse heraus. Keh: Ein Beitrag zur Geschichte des ehem. Kanonikerstiftes St. Gangolf. 1951. S. 9.

1921124 bestätigt Otto, Bischof von Bamberg (amt. 1102-1139), diese Stiftung in StABa Kloster Michelsberg, Urkunden Nr. 16 von 1124; Untersucht in Voit: Die Walpoten. 1996. S. 22. 
genannten Reginold als Mitglied der Walpotenfamilie ergibt sich nicht aus dem Wortlaut. Es muss daher in Erwägung gezogen werden, dass das Pergament ursprünglich gar nicht mit St. Gangolf in Verbindung gestanden hat, sondern erst nachträglich und vielleicht aufgrund einer Überdeutung der Erwähnung des Namens Reginold an das Stift St. Gangolf gekommen ist. Erstmals am Stift nachzuweisen ist die Authentik um das Jahr 1600, als sie zusammen mit anderen Reliquien explizit aufgelistet wurde und der Gangolfer Dekan Kaspar Hartmann (amt. 1583-1622) überraschenderweise als Urheber der Authentik ausgewiesen wurde. ${ }^{193}$ Eine spätere Anfertigung des Pergaments samt Text, um spätere Reliquienanschaffungen künstlich in den Gründungszusammenhang zu stellen, ist trotz des romanischen Schriftbildes nicht auszuschließen.

Trotzdem ist die Reliquienauthentik bei allen Unsicherheiten rund um die Einordnung der Quelle ein äußerst interessantes Zeugnis hinsichtlich der Bedeutung Reginold Walpots als Gönner des Stifts. Denn selbst wenn die Authentik erst im Laufe des Mittelalters dem Stift zugeordnet wurde, dann geschah dies im Rahmen einer gesteigerten Verehrung Reginold Walpots als Mitbegründer. Somit wurde er nicht nur aufgrund der ersten wirtschaftlichen Ausstattung rund um Hollfeld verehrt, sondern auch hinsichtlich eines Beitrags zur liturgischen Aufwertung des Stifts.

\subsubsection{Eberhard}

Die Person des dritten möglichen Stiftgründers Eberhard ist rätselhaft. Erstmals erwähnt wird er Anfang des 15. Jahrhunderts in der Über-

193 "Alia scheda reliquiarum sarcula affixa in qua sic legitur horum ss.or reliquas s. Gregorii papa dedit, Reginaldo ac eius coniungi Irmingardae, quando simul Romae fuerunt, videlicet s. Petri principi apostolorum, s. Stephani protomartyris, s. Peregrini confessoris, s. Pangratii, ss. Sebastiani et Fabiani, de corporibus ss.or Sixti, felicissimi et agapiti, Laurentii et Hippolyti et ss. quadraginta mayrtyrum. Haec praedicta omnia scheda pergamena ad scripta aperta fecit r. d. Casparus Hartmann, decanus anno 1601." Im „Index sacrarum reliquiarum quae hodie in collegiata ecclesiae sanctae Mariae virginis et sancti Gangolphi martyris in Theuerstatt extra muros Bambergenses habentur" [undat., um 1600] in SttABa D 3001 HV Rep. 2 Nr. 522 fol. 39-41, hier: fol. 40‘ 
lieferung des Bamberger Domkapitels im Rahmen der bereits erwähnten „Bischofschronik“. ${ }^{194}$ Ein nicht näher beschriebener Eberhard hätte demnach den Chor des Stifts St. Gangolf errichten lassen und wäre nach seinem Tod unter dem Altar der Maria und des Gangolfs, wahrscheinlich ist damit der Hauptaltar gemeint, bestattet worden. Und auch die Kanoniker des Stifts St. Gangolf selber nahmen ihn in die stiftseigenen Überlieferung auf. So findet sich in den Anniversarbüchern des Stifts ein Eberhard als Kirchengründer, der als Graf bezeichnet wird und dessen Begräbnisort sich im Chor befunden haben soll. ${ }^{195}$ In späteren Arbeiten über das Stift St. Gangolf ist Eberhard schnell ein fester Bestandteil des Gründungsmythos geworden, jedoch soll es sich nun um einen Bamberger Bürger gehandelt haben. Erstmals taucht diese Information in den Bamberger Annalen des Martin Hoffman aus dem 16. Jahrhundert auf. ${ }^{196}$ Dort erwähnt Hoffmann, der als Hofadvokat und Michelsberger Vogt in die Bamberger Strukturen eingebunden war, einen Eberhardus civis Babenbergensis als dritten Gründer des Stifts. Quellen nennt er keine. ${ }^{197}$ Der spätere Gangolfer Dekan Michael Heinrich Schubert (amt. 1790-1803) greift in seiner Dissertation 1768 diesen Eberhard auf und bezeichnet ihn ebenfalls als Bürger der Stadt Bamberg: „Pari modo et civis ille Eberhardus post obitum suum in eadem

\footnotetext{
194 „Ex post vero quidem Eberhardus exstruxit chorum eiusdem ecclesie et ibidem sepultus est ibidem ante summum altare beate virginis Marie et sancti Gangolfi in quorum honore fundaverat" in der Sammelhandschrift "Varia ecclesiam Bambergensem et praebendas ibidem concernentia" in StABa B 86 Nr. 271 fol. 178.

${ }^{195}$ Eintragung für den 4. April im Anniversarbuch (16. Jhd) des Stifts St. Gangolf "Eberhardus comes fundator huius ecclesie" mit der Notiz "Sepultuam est in choro" in StABa Stift St. Gangolf, Akten und Bände Nr. 128 fol. 8'; Und mit ähnlichem Wortlaut im Anniversarbuch (16. Jhd) in StABa Stift St. Gangolf, Akten und Bände Nr. 129 fol. 23.

196 „Postero anno 1063. Guntherus episcopus Teurstadii in suburbio aedificavit eamque b. virgini dei matri et s. Gangolpho consecravit adiuvantibus Rhinoldo Walboco comite Wolfesuvaccio et Eberhardo quodam cive Babebergensi." in Hoffmann: Annales Bambergensis episcopatus. 1718. Sp. 77; Übernommen in die stiftseigene Überlieferung als Einleitung der Gottesdienstordnung Breviarium Eberhardi Cantoris (14.-16. Jhd) in AEB Rep. 60 Pfarrarchiv St. Gangolf Bamberg Nr. 119.

197 Schon Erich Freiherr von Guttenberg beschwerte sich über die fehlenden Belege Hoffmanns in den Annales Bambergensis episcopatus und die damit einhergehende „nachhaltige Verwirrung in den Gründernamen [von St. Gangolf]“ in Guttenberg: Das Bistum Bamberg. 1937. S. 1-2.
} 
ecclesia intra chorum repositus in sancta pace requiescit, eiusque anniversarius in mense Aprili cuiuslibet anni haberi solet." ${ }^{198}$ Weiterhin schrieb Murr 1799: "Hinter dem hohen Altare dieser Kirche zu St. Gangolph liest man unter der Gedächtnismalerey ihres Stifters folgende Namen: Eberhardus com. fundator chori. Reinoldus Walbot fundator ecclesiae. Dieser liegt in der Mitte des Chors begraben. “199 Der Kalender für katholische Christen bringt 1881 beide Informationen zusammen, indem er einen Eberhard mit dem Beinamen Graf als reichen Bürger und Mitbegründer der Gangolfer Kirche nennt. ${ }^{200}$ Auch Looshorn nimmt Eberhard als Gründer an, nennt aber keine Quellen. ${ }^{201}$ Sicher sind sowohl die domstiftischen als auch die stiftseigenen Notizen Grundlage für den Mythos Eberhards.

Die tatsächliche Existenz des dritten Stiftsgründers bleibt jedoch fraglich. Weder Heimo von St. Jakob noch die stiftseigene Gründungsnotiz des Hollfelder Propstvogtes aus dem 16. Jahrhundert nennen einen Eberhard als Gründer. Da sowohl die Altäre heute andere sind und auch die archäologischen Befunde am Chor kein Gründergrab freilegten, bleiben die in der älteren Literatur genannten Nachweise der Existenz eines Eberhards als Gründer aufgrund seines Bestattungsortes unbestätigt. Doch wie plausibel ist die Beteiligung eines reichen Bamberger Bürgers an der Gründung und Gestaltung einer Stiftskirche im 11. Jahrhundert? Zuvorderst muss betont werden, dass der Begriff „Bürger" in diesem Zusammenhang anachronistisch ist angesichts der im 11. Jahrhundert noch wenig entwickelten städtischen Strukturen. ${ }^{202}$ Es ist freilich nicht ausgeschlossen, dass sich die Stadtbewohner durch die Stimmung des Aufschwungs und der Neugründungen zu dieser

${ }^{198}$ Schubert: Dissertatio inauguralis. 1768. S. 58.

${ }^{199}$ Murr: Merkwürdigkeiten der Fürstbischöflichen Residenzstadt Bamberg. 1799. S. 120.

${ }^{200}$ Das Collegiatstift zu U. L. Frau und St. Gangolph in Bamberg. In: Kalender für katholische Christen. 1881. S. 81.

201 "Zur Erbauung der Kirche, besonders des Chores, gab auch ein sehr reicher Bürger Bambergs, Eberhard, viel." in Looshorn: Geschichte des Bisthums Bamberg. 1886. S. 381.

202 Claudia Esch spricht davon, dass sich in der zweiten Hälfte des 13. Jahrhunderts zumindest eine kleine städtische Führungsschicht entwickelt habe, die sich ein Mitspracherecht in Bamberger Belangen erarbeitet hatte. In Esch: Institution und Individuum. 2016. S. 49. 
Zeit zu Stiftungstätigkeiten inspiriert fühlten. Jedoch ist das Bamberger Bürgertum im 11. Jahrhundert bei Weitem noch nicht ausgeprägt und die Vorstellung einer Bürgerbeteiligung erinnert eher an den Erzählduktus späterer Jahrhunderte, als das Bürgertum sich aufgrund seines Aufstiegs mehr und mehr seiner Stellung bewusst wurde. Die Tatsache, dass die Person Eberhards erstmals Anfang des 15. Jahrhunderts erwähnt wurde, festigt die Vermutung, dass er erst nachträglich in den Gründungsmytos aufgenommen wurde, als sich im sogenannten Immunitätenstreit das Verhältnis zwischen Bürgerstadt und Immunitäten neu ausrichtete. Der städtische Konflikt war gerade überwunden, in dem das Domkapitel als Interessenvertreter der drei Bamberger Kollegiatstifte seine Machtansprüche gegen Bischof und Bamberger Bürgerstadt zu sichern suchte. Die Stadtbürger unter dem Rat der Stadt bemühten sich um eine Einigung mit dem Domkapitel hinsichtlich der Auflösung der Stiftsimmunitäten, der Stadtbefestigung, der gemeinsamen Besteuerung, der Erbhuldigung vor Bischof und Domkapitel sowie der Vereidigung vor einem weltlichen Gericht. ${ }^{203}$ Erst in den 1440er Jahren gelang eine längerfristige Einigung, die zur Folge hatte, dass die Muntäter als Einwohner der Immunitäten aktiv in die städtische Verwaltung miteingebunden wurden. ${ }^{204}$ Zeigt die Einführung eines Bamberger Bürgers als Gründer eines Kollegiatstifts im 16. Jahrhundert, hundert Jahre nach dem verbissenen Konflikt um Ansprüche auf die Oberhoheit, etwa eine Befriedung der gegenseitigen Ansprüche? Was für Vorteile hatte es, einer kirchlichen Einrichtung einen bürgerlichen Stifter beizustellen? Wurde auf eine vermehrte Großzügigkeit der Bürger spekuliert, wenn einer der ihren zum Gründer stilisiert wurde? All dies bleibt unbeantwortet. Doch klar ist, dass das Stift St. Gangolf hierbei eine Sonderrolle einnahm. Keine der anderen kirchlichen Einrichtungen Bambergs pflegte die Tradition eines bürgerlichen Stifters. Dort galt es hingegen wich-

\footnotetext{
${ }^{203}$ Näheres zu Verlauf und Folgen des Immunitätenstreits in Esch: Zwischen Institution und Individuum. 2016. S. 98-113.

${ }^{204}$ Caroline Göldel: Zur Entwicklung der Bamberger Stadtverfassung im 15. Jahrhundert im Spannungsfeld Rat - Gemeinde - Klerus. In: BHVB 135 (1999). S. 7-44, hier: S. 21.
} 
tiger, Heinrich, Kunigunde oder den heiligen Otto in ihren Gründungsmythos aufzunehmen. ${ }^{205}$

\subsection{Patrozinien}

Die Praxis zur Weihe einer Kirche und zur Berufung auf einen oder mehrere Heilige als Schutzpatrone ist im Katholizismus tief verankert. Schon in der Zeit vor Konstantin dem Großen wurden Kapellen über Heiligengräber errichtet. ${ }^{206}$ Der Grundgedanke des Patroziniums ist der Schutz der Kirche durch einen eigens dazu ausgewählten Heiligen. Die Wahl der Patrone richtete sich nicht nur nach liturgischen Überlegungen, sondern war dem entsprechenden Zeitgeist und lokalen Einflüssen geschuldet. Das Patrozinium offenbart daher wichtige Hinweise über die Einbindung einer Kirche in kirchlichen, politischen, kulturellen und wirtschaftlichen Gegebenheiten.

Für das Stift St. Gangolf in Bamberg kann man aus den Quellen die Verehrung mehrerer Patrone herauslesen, von denen die heilige Maria und der heilige Gangolf schon seit den Anfängen belegt sind, während Johannes der Täufer erst später als Patron in Erscheinung trat. Die Praxis einer Mehrfachpatronage war nicht unüblich, hatte jedoch meist eine unterschiedliche Gewichtung der verehrten Reliquien als Grundlage. ${ }^{207}$ Für das Stift St. Gangolf ist jedoch die Rekonstruktion des mittelalterlichen Reliquienbestandes schwierig und obwohl die Gangolfverehrung nachgewiesen werden kann, besaß das Stift im Mittelalter vermutlich

205 Klaus Guth: Die Verehrung der Bistumspatrone im Mittelalter. In: Göller, Luitgar (Hg.): 1000 Jahre Bistum Bamberg 1007-2007. Unterm Sternenmantel (Katalog der Jubiläumsausstellung). Petersberg 2007. S. 26-41, hier: S. 37.

${ }^{206}$ Helmut Flachenecker: Patrozinienforschung in Deutschland. In: Concilium Medii Aevi 2 (1999). S. 145-163, hier: S. 147; und Franz-Heinrich Beyer: Geheiligte Räume. Theologie, Geschichte und Symbolik des Kirchengebäudes. Darmstadt 2008. S. 33. Näheres zu Patrozinien in Bamberg und Franken in Hiller: Die Kirchenpatrozinien des Erzbistums Bamberg. 1931. S. 1; Wilhelm Deinhardt: Frühmittelalterliche Kirchenpatrozinien in Franken. Studien zur Frühgeschichte der Diözesen Bamberg und Würzburg. Nürnberg 1933; und Gerd Zimmermann: Patrozinienwahl und Frömmigkeitswandel im Mittelalter. Dargestellt an Beispielen aus dem alten Bistum Würzburg. In: Würzburger DiözesanGeschichtsblätter 20 (1958). S. 24-126. und 21 (1959). S. 5-124.

${ }^{207}$ Flachenecker: Patrozinienforschung in Deutschland. 1999. S. 151. 
noch keine Reliquie des Heiligen. ${ }^{208}$ Es ist fraglich, warum das Stift in der Theuerstadt gerade diese Patrone als Beschützer der Kirche wählte, wenn doch keine Reliquienpraxis hinter der Entscheidung zu stehen schien. Die Quellenlage zur Beantwortung dieser Frage ist dünn. Jedoch bietet eine Analyse derjenigen Urkunden, die das Stift St. Gangolf erwähnen oder von ihm selbst ausgestellt wurden, eine Möglichkeit zur Annäherung an die Problematik. Denn sowohl die Siegel, die mit der Siegelumschrift und auch dem Siegelbild Bezug zu einem Heiligen nehmen, als auch die Stiftsbezeichnung selbst geben einen Einblick in den Stellenwert der Patronagen für Stiftsmitglieder und deren Zeitgenossen.

\subsubsection{Die heilige Maria}

Die heilige Maria ist eine klassische Patronin sowohl der Ost- als auch der Westkirche. Sie ist die einzige weibliche Heilige im sogenannten „Heiligenhimmel“ des Bamberger Domes und dort seit 1007 neben den Aposteln Petrus und Paulus die Hauptpatronin. ${ }^{209}$ Doch während Friedrich Hiller in seiner Untersuchung der Bamberger Kirchenpatrone aufgrund ihrer allgemeinen Verehrung keine Notwendigkeit sah, einen Grund für die Wahl Marias als Patronin zu suchen, ${ }^{210}$ sieht Gerd Zimmermann in der Entscheidung für Maria als Hauptpatronin des Stifts St. Gangolf die Nähe zur Reform der Klöster Cluny und Hirsau begründet. $^{211}$

Obwohl die Marienfrömmigkeit keineswegs erst zu Zeiten der Kirchenreformen des 11. Jahrhunderts einsetzte, erlangte ihre Verehrung doch durch die monastischen Bewegungen, die Maria und Petrus als Heilige förderten, einen ungeahnten Aufschwung. ${ }^{212}$ Maria stellte für

208 Näheres zum Reliquienbestand des Stift St. Gangolf im Kapitel 3.2.2 Der heilige Gangolf.

${ }^{209}$ Guth: Die Verehrung der Bistumspatrone im Mittelalter. 2007. S. 27-28.

${ }^{210}$ Hiller: Die Kirchenpatrozinien des Erzbistums Bamberg. 1931. S. 13.

${ }^{211}$ Zimmermann: Sankt Gangolfs Weg von Lothringen nach Bamberg. 1962. S. 457.

${ }^{212}$ Ludwig Unger: Auf der Suche nach der rechten Lebensweise. Die Hirsauer und die Bursfelder Reform auf dem Michaelsberg. In: Jung, Norbert/ Kempkens, Holger (Hgg.): 
das Christentum eine herausragende Heilige dar, die als Mutter Gottes, aber auch gelöst von dieser Rolle, beispielsweise in dem Eva-MariaVergleich oder Maria als Sinnbild der ecclesia, eine große Wirkungskraft entfaltete. ${ }^{213}$ Die zunehmende Marienfrömmigkeit seit dem 12. Jahrhundert sorgte für ein gesteigertes Auftreten der heiligen Maria auf Siegeln geistlicher Institutionen. In Bamberg bestand eine ikonografische Konkurrenzsituation zwischen dem Kloster St. Theodor und dem Stift St. Gangolf, denn auch das 1157 als Frauenkloster gegründete St. Theodor unterstand neben dem heute namensgebenden Patron der heiligen Maria als Hauptheilige und nutzte das Bildprogramm auf seinen Siegeln ${ }^{214}$ und in seiner Selbstbezeichnung. ${ }^{215}$

Die heilige Maria kann wohl zu Recht als Hauptheilige des mittelalterlichen Stifts St. Gangolf angesehen werden, obwohl Gangolf und Maria innerhalb den Stiftsbezeichnungen etwa gleichberechtigt genannt werden. ${ }^{216}$ Das Maria als Patronin einen höheren Stellenwert einnahm, kann anhand der Motivwahl des Kapitelsiegels abgelesen werden. Während die älteren Kapitelsiegel Maria als Mutter Gottes allein in exponierter Stellung zeigen, kommt um das Jahr 1400 zwar Gangolf als Ritterheiliger dazu, ist jedoch ikonografisch der Maria untergeordnet. ${ }^{217}$

1000 Jahre Kloster Michaelsberg Bamberg 1015-2015. Im Schutz des Engels (Begleitpublikation zur Sonderausstellung vom 26. Juni bis 4. Oktober 2015). Petersberg 2015. S. 94-109.

213 Arnold Angenendt: Heilige und Reliquien. Die Geschichte ihres Kultes vom frühen Christentum bis zur Gegenwart. München 1994. S. 220.

${ }^{214}$ So findet sich bereits an der Urkunde der Agnes, Äbtissin des Klosters St. Theodor, vom 13. August 1205 ein Siegel anhängend, das die thronende Maria mit Kind zeigt. In StABa BU 412. Zum Vergleich: das erste korporative Siegel des Stifts St. Gangolf, das Maria in ähnlicher Pose zeigt, ist erst für das Jahr 1295 nachweisbar. In: StaWu Kloster Ebrach, Urkunden 1295 V 25. Siegelbeschreibung im Anhang Tabelle 1: Siegel Nr. 4.

215 Ein Beispiel ist die Selbstbezeichnung des Klosters St. Theodor als „ecclesie sancte Marie Bambergensis“ um 1199 in StABa BU 412 und ebenso in den Urkunden StABa BU 415, BU 475, BU 476, BU 485, BU 607. Näheres dazu im Kapitel 3.2.5 Stiftsbezeichnung in den Urkunden.

216 Näheres dazu Kapitel 3.2.4 Patrozinien in den Siegeln und im Anhang Tabelle 2: Stiftsbezeichnung.

${ }^{217}$ Näheres dazu in Kapitel 4.1.2 Kapitelsiegel. 


\subsubsection{Der heilige Gangolf}

Die Verehrung des Ritterheiligen Gangolf nördlich der Alpen nimmt im Laufe des Hochmittelalters stetig zu und erreicht im Spätmittelalter seinen Höhepunkt. ${ }^{218}$ Im Volksglauben wird er vor allem mit Gewässern in Verbindung gebracht, was sich auf das Quellwunder bezog, das in der Legende des Heiligen eine große Bedeutung einnimmt. ${ }^{219}$ Jedoch lag im 11. Jahrhundert, zur Zeit der Gründung des Stifts St. Gangolf, der Schwerpunkt der Gangolfverehrung westlich des Rheins, vor allem im Elsaß und in Lothringen. ${ }^{220}$ Obwohl seine Popularität vereinzelt schon um das 10. Jahrhundert über den Rhein nach Osten gelangt war, ${ }^{221}$ ist es bemerkenswert, wie früh die Gangolfverehrung in Bamberg in Gestalt des Theuerstädter Stifts anzutreffen ist. In seiner Betrachtung der Kirchenpatrone im Gebiet des Bistums Bamberg stellt Friedrich Hiller den heiligen Gangolf unter die Rubrik „Fränkische Heilige“ und meint damit Kulte, deren Ausgangspunkt weit im Westen $\mathrm{zu}$ suchen sind, betont aber auch hier, dass die Gangolfverehrung bereits „bei den alten Franken“ Anklang fand. 222

Der heilige Gangolf tritt in Bamberg im 11. Jahrhundert auch unabhängig vom Theuerstädter Stift auf. So erwähnt die Weiheurkunde der Krypta vom Stift St. Jakob im Mai 1072 reliquie Gengolfi neben zahlrei-

218 Zimmermann: Patrozinienwahl und Frömmigkeitswandel im Mittelalter. 1959. S. 74.

${ }^{219}$ Eine ausführliche Auswertung des Motivs der Quellerweckung in der Heiligenlegende Gangolfs mit einem Vergleich der Hagiografie aus den Viten und Legende der Hrotsvit von Gandersheim aus dem 9. und 10. Jahrhundert in Edgar Altenhöfer: Studien zur Verehrung St. Gangolfs. Insbesondere zur Legende und Sage des Heiligen. Würzburg 1993, besonders S. 39.

${ }^{220}$ Zimmermann: Sankt Gangolfs Weg von Lothringen nach Bamberg. 1962. S. 443-461.

${ }^{221}$ Der Forschung über die Verbreitung der Gangolfverehrung im mittel- und süddeutschen Raum nimmt sich vor allem Wolfram Siegel engagiert an. Seinen jedoch größtenteils auf Hypothesen beruhenden Erkenntnissen, die Karolinger hätten den Kult nach Osten gebracht, ist aufgrund der Quellenarmut mit Vorsicht zu begegnen. Wolfram Siegel: Der Heilige Gangolf in Münchenlohra an der Hainleite. Basilika, Kloster und karolingische Vorgeschichte (Harz-Forschungen, Bd. 20). Wernigerode/ Berlin 2005; Ders.: Der heilige Gangolf im Raum um den Harz und die Zeit der Sachsenkriege Karls des Großen. In: Harz-Zeitschrift 45/2 (2000); Ders.: Der heilige Gangolf an Donau und Lech. In: Zeitschrift des Historischen Vereins für Schwaben 84 (1991). S. 7-43.

${ }^{222}$ Hiller: Die Kirchenpatrozinien des Erzbistums Bamberg. 1931. S. 108. 
chen anderen Heiligenreliquen. ${ }^{223}$ Außerdem ist für das Jahr 1120 eine Gangolfreliquie bei Altarweihen im Kloster Michelfeld nachweisbar. ${ }^{224}$ Zimmermann vermutet das Stift St. Gangolf als Ausgangspunkt der Reliquienstreuung auf die anderen Bamberger Kirchen, ${ }^{225}$ obwohl es für das gesamte Mittelalter hindurch keine Spuren von Gangolfreliquien am Stift in der Theuerstadt gibt. Erst um 1600 nennt ein Reliquienverzeichnis des Stifts zwei Armreliquien des heiligen Gangolf in seinem Bestand. ${ }^{226}$ Unklar ist, ob dem Stift im 17. Jahrhundert eine Reliquie aus dem Haupt des Heiligen geschenkt wurde, wie immer wieder zu lesen ist, ${ }^{227}$ wovon aber heute jeder Nachweis fehlt.

1155 benennt Ebo in der Vita des heiligen Bischofs Otto I. von Bamberg den Tag des heiligen Gangolf im Jahr 1106 als Tag der Bischofsweihe Ottos durch Papst Paschalis II. in Anagni. ${ }^{228}$ Dieser deutliche Hinweis auf die Verehrung des heiligen Gangolfs in Bamberg bereits im 12. Jahrhundert ist vor allem dahingehend bedeutsam, wenn man bedenkt, dass der 13. Mai 1106 in die Osterzeit fällt, womit Ebo

\footnotetext{
${ }^{223}$ Deinhardt: Dedicationes Bambergenses. 1936. S. 9, Nr. 10.

${ }^{224}$ Interessanterweise lässt sich die Gangolfverehrung hier am Altar des Johannes des Täufers nachweisen, wo mit Maria, Gangolf und Johannes die drei Patrone des Theuerstädter Stifts zusammen auftreten. In Deinhardt: Dedicationes Bambergenses. 1936. S. 11-12, Nr. 15, hier: S. 12.

225 Zimmermann: Sankt Gangolfs Weg von Lothringen nach Bamberg. 1962. S. 445.

${ }^{226}$ Neben zahlreichen Reliquien anderer Heiliger wird "bona pars de brachio S. Gangolphi martyris“ genannt. Im „Index sacrarum reliquiarum quae hodie in collegiata ecclesiae sanctae Mariae virginis et sancti Gangolphi martyris in Theuerstatt extra muros Bambergenses habentur“ [undat., um 1600] in SttABa D 3001 HV Rep. 2 Nr. 522 fol. 39-41, hier: fol. $40^{\prime}$.

${ }^{227}$ Der Kalender der katholische Christen erwähnte dies erstmals 1881: "Das Haupt des heil. Gangolph wurde von Ferdinand, Herzog von Bayern, Kurfürst und Erzbischof von Köln, dem Amtsvorgänger des Kurfürsten und Erzbischofs Maximilian nach Eichstätt geschenkt und ein Theil davon (die Hirnschale) von dem Kapuzinerprovinziale Ferdinand auf inständiges Bitten des Propstes, des Dekans und der übrigen Kanoniker der Collegiatskirche St. Gangolph in Bamberg überlassen." und bezog sich auf die Acta Sanctorum Maii Bd. 2. S. 642. In Das Collegiatstift zu U. L. Frau und St. Gangolph in Bamberg. In: Kalender für katholische Christen. 1881. S. 90; Laut Zimmermann: Sankt Gangolfs Weg von Lothringen nach Bamberg. 1962. S. 459. sei die Kopfreliquie des heiligen Gangolfs im 17. Jahrhundert von Florennes über Eichstätt nach Bamberg gekommen.

228 „Erat tertio idus maii scilicet in natalicio sancti Gangolfi martiris“ in Ebbonis vita Ottonis episcopi Babenbergensis. In: Pertz, Georg Heinrich (Bearb.): Historiae aevi Salici (MGH SS 12). Hannover 1856. S. 822-883, hier: 830.
} 
zahlreiche andere Datierungsmöglichkeiten offen gestanden hätten. Gerd Zimmermann stellt während seiner Analyse der Herkunft des Gangolfkultes fest, dass die Bischofsweihe Ottos I. bewusst auf einen Pfingstsonntag gelegt wurde und dass trotzdem im Bamberger Raum dieser Tag mit dem heiligen Gangolf in Verbindung gebracht wurde. ${ }^{229}$ Die Verbreitung der Gangolfverehrung wird ebenso durch die Betrachtung der Kalendarien des Bamberger Doms aus dem 12. Jahrhundert deutlich, wo der 13. Mai als Gangolfstag durch eine rote Markierung hervorgehoben ist. ${ }^{230}$ Die Gangolfsverehrung in Bamberg ist demnach bereits im 11. Jahrhundert nachweisbar und erfuhr im 12. Jahrhundert eine spürbare Steigerung.

Die Tatsache, dass der heilige Gangolf als beliebter lothringischer Reformheiliger bereits zu diesem frühen Zeitpunkt in Bamberg angekommen war, sieht Gerd Zimmermann in der Nähe der Gangolfer Stiftsgründung zum Reformideal des 11. Jahrhundert begründet. Dabei betont er, dass sich weder Bischof Gunther als herausragender Förderer der Reformbewegung hervorgetan hätte, noch dass sich das Stift selbst in irgendeiner Weise durch Reformnähe auszeichnete. Das Argument, dass Reginold Walpot mit seiner Frau nach Rom pilgerte und dies das Frömmigkeitsideal und die Reformverbundenheit des Stiftsgründers beweisen würde, wurde aufgrund der zweifelhaften Einordnung der Reliquienauthentik bereits relativiert. ${ }^{231}$ Die Vermutung, dass die Wahl des Heiligen Gangolf als Stiftspatron aus Sympathie zur Reform heraus passierte, ist daher mit kritischer Distanz zu betrachten.

Der heilige Gangolf war außerdem auch Patron der auf einem Bergsporn gelegenen Pfarrkirche von Hollfeld, dies jedoch erst frühestens seit dem 12. Jahrhundert. ${ }^{232}$ Dies dokumentiert weniger Missionsgedanken oder liturgische Bräuche, als die Zurschaustellung von Eigen-

\footnotetext{
${ }^{229}$ Zimmermann: Sankt Gangolfs Weg von Lothringen nach Bamberg. 1962. S. 444.

${ }^{230}$ Caspar Anton Schweitzer: Vollständiger Auszug aus den vorzüglichsten Calendarien des ehemaligen Fürstenthums Bamberg. In: BHVB 7 (1844). S. 67-319, hier: S. 69 und S. 174.

${ }^{231}$ Näheres im Kapitel 3.1.3.2 Reginold Walpot.

${ }^{232}$ Näheres zur Entwicklung Hollfelds in Konrad: Siedlung und Herrschaft im Hollfelder Land bis zum Hochmittelalter. 2017. S. 34-42.
} 
tumsrechten des Kollegiatstifts in Bamberg über ihre außerstädtischen Besitzungen mit dem Schwerpunkt in Hollfeld. ${ }^{233}$ Mit dem Aufkommen des Gangolfkultes im Spätmittelalter und der besonderen Hervorhebung des Quellwunders in der Heiligenlegende, wurde die Theuerstadt mit seiner Nähe zum Flussarm der Regnitz als Ort der Gangolfverehrung aufgrund seiner Bedeutung als Gewässerheiliger erklärbar, während die topografische Lage der Gangolfkirche in Hollfeld auf dessen Rolle als Volksheiliger von Bergkirchen gedeutet werden konnte. ${ }^{234}$ Einen Hinweis auf die ursprüngliche Intention der Patrozinienwahl gibt dies allerdings nicht.

\subsubsection{Der heilige Johannes der Täufer}

Johannes der Täufer hat im Neuen Testament eine herausragende heilsgeschichtliche Funktion als Wegbereiter Christi. Von Italien aus war er nördlich der Alpen sowohl vor der Reformbewegung des 11. Jahrhundert als auch danach beliebter Patron, der vor allem für Taufkirchen als Schutzheiliger fungierte. In Bamberg ist die Verehrung bereits im 11. Jahrhundert nachweisbar, wo 1012 eine der in den acht Altären des Bamberger Doms vorgefundenen Reliquien von Johannes dem Täufer stammen soll. ${ }^{235}$ Darüber hinaus ist eine Johanneskapelle mit Vikar seit dem 14. Jahrhundert am Stift St. Stephan belegt. ${ }^{236}$ In Würzburg ist das Stift Haug ein frühes Beispiel der Johannesverehrung in Franken. ${ }^{237}$

Dass Johannes der Täufer als dritter Patron des Stifts St. Gangolf auftrat, ist weitgehend unbekannt und aus den mittelalterlichen Quellen nicht herauszulesen. Erst im 16. Jahrhundert tauchten Nachrichten über

${ }^{233}$ Näheres dazu im Kapitel 6.3.2.1 Propsthof in Hollfeld.

${ }^{234}$ So tritt Gangolf als Patron der fränkischen Bergkirchen und Naturheiligtümer auf, z. B. der Gangolfsberg bei Ebrach, Hamelberg bei Fladungen, Gangolfsberg bei Neustadt an der Saale und Milseburg in der Rhön. Zimmermann: Patrozinienwahl und Frömmigkeitswandel im Mittelalter. 1959. S. 73.

235 Deinhardt: Dedicationes Bambergenses. 1936. S. 4-5, Nr. 2, hier: S. 5.

${ }^{236}$ Hiller: Die Kirchenpatrozinien des Erzbistums Bamberg. 1931. S. 74.

237 Enno Bünz: Stift Haug in Würzburg. Untersuchungen zur Geschichte eines fränkischen Kollegiatstifts im Mittelalter (Veröffentlichungen des Max-Planck-Instituts für Geschichte, Bd. 128. Studien zur Germania Sacra, Bd. 20). Göttingen 1998. S. 55. 
ihn und seine Funktion für die Kirche auf, als es um den Feiertag des Heiligen ging. ${ }^{238}$ Demnach gab es einen Johannesaltar an der Kirche des Stifts St. Gangolf, jedoch überraschenderweise ohne einen zuständigen Vikar. Der Johannisaltar soll liturgisch exponiert vor dem Chor gestanden haben, bis er durch den heutigen barocken Altar abgelöst wurde. ${ }^{239}$ Durch eine stiftsinterne Auflistung aller Altäre in der Gangolfskirche um 1600 zeigt sich, dass der damalige Altar des Johannis Baptiste in den späteren Altar des Karl Borromäus umgewandelt wurde. ${ }^{240}$

Zimmermann stellte die These auf, dass das Quellwunder des heiligen Gangolfs und die Täufereigenschaft des Johannes in der mittelalterlichen Patrozinienwahl zusammenspielten. ${ }^{241}$ Ein Neuaufkommen der Bamberger Johannesverehrung im Kontext seiner Rolle als Schirmherr des Johanniterordens und des damit einhergehenden Spitalwesen, ${ }^{242}$ scheint hingegen unwahrscheinlich. Zwar war die Theuerstadt durchaus Ort Bamberger Spitäler, jedoch ohne das Zutun des Stifts St. Gangolf. Möglich scheint aber, dass es sich bei Johannes dem Täufer weniger um einen der Gründungsheiligen gehandelt hat, sondern dass er als Altarheiliger auf Umwegen und erst in der Neuzeit in die Verehrung des Stiftes gelangte. ${ }^{243}$ Solch eine Patrozinienerweiterung ist nicht selten ein Hinweis auf eine Neuausrichtung des geistigen und religiösen Lebens, deren Umstände jedoch häufig nicht überliefert sind. ${ }^{244}$ Die geänderte

238 SttABa D 3001 HV Rep. 2 Nr. 264 fol. 27‘. Näheres dazu in Zimmermann: Sankt Gangolfs Weg von Lothringen nach Bamberg. 1962. S. 458.

${ }^{239}$ Ussermann: Episcopatus Bambergensis. 1802. S. 271. und Zimmermann: Die Gangolfskirche als Spiegel der Frömmigkeit seit über 925 Jahren. 1990. S. 23. Auf welche Quellen sich diese Angaben stützen, wird an beiden Stellen nicht näher ausgeführt.

240 „In collegiata ecclesia beatae Mariae virginis et sancti Gangolphi altaria“ in AEB Rep. 60 Pfarrarchiv St. Gangolf Bamberg Nr. 3 unfoliiert.

241 Zimmermann: Sankt Gangolfs Weg von Lothringen nach Bamberg. 1962. S. 458.

${ }^{242}$ Flachenecker: Patrozinienforschung in Deutschland. 1999. S. 148.

${ }^{243}$ Vergleiche dazu die Überlegungen zu dem im 8. Jahrhundert gegründeten Benediktinerkloster Wessobrunn im Herzogtum Bayern. In Flachenecker: Patrozinienforschung in Deutschland. 1999. S. 152.

244 Zimmermann geht davon aus, dass es weitaus häufiger zu Patrozienwechsel und erweiterungen gekommen ist, als man heute aufgrund fehlender Spuren nachweisen kann. Näheres dazu in Zimmermann: Patrozinienwahl und Frömmigkeitswandel im Mittelalter. 1959. S. 35. 
Ausrichtung des Stiftes könnte mit der Neuanschaffung einer Johannesreliquie zusammengehangen haben. Für diese These würde sprechen, dass die erste Erwähnung einer Reliquie von Johannes dem Täufer am Stift St. Gangolf zur Zeit einer seiner ersten nachweisbaren Erwähnungen als Stiftspatron überhaupt auftrat. ${ }^{245}$ Die Zeit der Johannisverehrung am Stift St. Gangolf vor dem 16. Jahrhundert bleibt aufgrund fehlender Quellen verborgen.

\subsubsection{Patrozinien in den Siegeln}

Mögen Patrozinien und Statuten für den inneren Zusammenhalt und die innere Verfassung des Stifts gestanden haben, so waren die Siegel ein sichtbares Zeichen nach außen und genauso rechtswahrend. Siegel und Siegelbilder sind im Fall des Stifts St. Gangolf eine wichtige Quelle, um sich der Bedeutung der Patrone für das Haus anzunähern. Bei der Praxis der Mehrfachpatrozinien stellt sich die Frage, wer an prominenter Stelle auf dem Siegelbild zu sehen ist und auf wen in der Siegelumschrift Bezug genommen wird. All das gibt Auskunft über das Selbstbild, das das Stift St. Gangolf nach außen transportieren wollte und welchem Heiligen es seine Rechtshandlungen unterstellte. ${ }^{246}$ Die ikonografischen, stilistischen und medialen Eigenschaften, hervorgehend aus seiner Rolle als Beglaubigungsinstrument, machten das Siegel

\footnotetext{
${ }^{245}$ Zusammen mit Reliquien anderer Heiliger soll sich ein nicht näher benannter Teil des Johannes des Täufers in einem Gefäß „pulvisculum aliquod rubrum sericeum auratin“ befunden haben. Im „Index sacrarum reliquiarum quae hodie in collegiata ecclesiae sanctae Mariae virginis et sancti Gangolphi martyris in Theuerstatt extra muros Bambergenses habentur" [undat., um 1600] in SttABa D 3001 HV Rep. 2 Nr. 522 fol. 39-41, hier: fol. 40.

${ }^{246}$ Siegel als Einblick in die Selbstdefinition sowohl von Institutionen als auch von Einzelpersonen untersuchte Andrea Stieldorf am Beispiel reichsfürstlicher Repräsentation in Andrea Stieldorf: Helden oder Heilige. Überlegungen zur Motivwahl reichsfürstlicher Münzen und Siegel. In: Archiv für Diplomatik 62 (2016). S. 107-136; am Beispiel von adeligen Einzelpersonen in Dies.: Die Selbstdarstellung rheinischer Hochadeliger auf Siegeln und Münzen. In: Rheinische Vierteljahresblätter 79 (2015). S. 68-103; und auch am Beispiel der Universitäten in Dies.: Heilige Patrone und weltliche Stifter. Zur Selbstdarstellung und Selbstdeutung mittelalterlicher Universitäten. In: Archiv für Diplomatik 56 (2010). S. 317-361.
} 
$\mathrm{zu}$ einem Herrschaftszeichen, welches nicht nur die rechtliche Handlungsfähigkeit einer Institution oder eines Amtes deutlich machen sollte, sondern auch dazu gedacht war, „die Präsenz des real abwesenden Ausstellers einer Urkunde bei dessen Empfänger zu erzeugen“. ${ }^{247}$

Die ersten Siegel des Stifts St. Gangolf finden sich in der Urkundenüberlieferung des Staatsarchivs Bamberg ${ }^{248}$ sowie im Archiv des Erzbistums Bamberg, ${ }^{249}$ und sind ausschließlich Heiligensiegel. ${ }^{250}$ Sie zeigen die heilige Maria meist im Brustbild mit Kind, aber auch als stehende und sitzende Ganzfigur. ${ }^{251}$ Das Bildprogramm des ersten überlieferten Siegels des Stifts St. Gangolf, ein Dekansiegel von 1242, ist durch starke Beschädigungen schwer $\mathrm{zu}$ rekonstruieren, vermutlich stellt es Maria mit Herrschaftsattributen dar. Die Siegelumschrift jedoch nimmt eindeutig Bezug zur Bamberger Theuerstadt. ${ }^{252}$ Doch auch in dieser frühen Phase der stiftischen Heiligenverehrung mit einer auffälligen Tendenz zur heiligen Maria, finden sich drei Ausnahmen aus der

${ }^{247}$ Markus Späth: Die Bildlichkeit korporativer Siegel im Mittelalter. Perspektiven eines interdisziplinären Austauschs. In: Späth, Markus (Hg.): Die Bildlichkeit korporativer Siegel im Mittelalter. Kunstgeschichte und Geschichte im Gespräch (Sensus. Studien zu mittelalterlichen Kunst, Bd. 1). Köln/ Weimar/ Wien 2009. S. 9-29, hier: S. 12; Oder auch Brigitte M. Bedos-Rezak: Medieval Identity. A Sign and a Concept. In: American Historical Review 105/5 (2000). S. 1489-1533, hier: S. 1490; Die Stellvertreterfunktion des Siegelbildes spricht auch Andrea Stieldorf den Heiligensiegeln der geistlichen Institutionen zu, bescheinigt jedoch eine „Verblassung“ der Identifikation des Sieglers mit dem Siegel durch das Aufkommen der kommunalen Siegel, z. B. Stadtsiegel, im 12. und 13. Jahrhundert. Näheres dazu in Andrea Stieldorf: Siegelkunde (Hahnsche Historische Hilfswissenschaften, Bd. 2). Hannover 2004. S. 28.

248 In den Beständen StABa BU, Urkunden des Klosters Michelsberg, Urkunden des Klosters Langheim und Urkunden der Stifte St. Stephan, St. Gangolf und St. Jakob im Bestand A 120.

${ }^{249}$ Im Bestand AEB Rep. I.

250 Näheres zur Wirkungskraft von Heiligenbildern und zur Bedeutung von Heiligensiegeln in Manfred Groten: Vom Bild zum Zeichen. Die Entstehung korporativer Siegel im Kontext der gesellschaftlichen und intellektuellen Entwicklungen des Hochmittelalters. In: Späth, Markus (Hg.): Die Bildlichkeit korporativer Siegel im Mittelalter. Kunstgeschichte und Geschichte im Gespräch (Sensus. Studien zu mittelalterlichen Kunst, Bd. 1). Köln/ Weimar/ Wien 2009. S. 70-71; und Näheres zu Reliquien und Heiligenbilder allgemein in Angenendt: Heilige und Reliquien. 1994. S. 183-189.

${ }^{251}$ Näheres im Anhang Tabelle 1: Siegel. Darin vor allem die ersten Siegel bis Anfang des 14. Jahrhunderts.

252 StABa BU 613. Anhang Abbildung 1. 
Mitte des 14. Jahrhunderts, auf denen der heilige Gangolf auf dem Siegel des Dekans Walther von Gundloch (amt. 1324-1354) abgebildet ist. ${ }^{253}$ Zeitgleich mit dem ersten Dekansiegel in der Darstellung des heiligen Gangolf, zeigt sich der Ritterheilige auf den Siegeln des Stiftskellers als Richter der Gangolfer Immunität. ${ }^{254}$ Die gemeinsame Darstellung von Maria und Gangolf findet sich dagegen nur im Kapitelsiegel ab etwa $1400 .{ }^{255}$ Der dritte Patron, Johannes der Täufer, spielt in der Siegelführung des Stifts St. Gangolf keine nachweisbare Rolle, was für eine erst frühneuzeitliche Etablierung des Johannespatroziniums sprechen würde.

Maria ist in den Siegeln als Hauptheilige zu erkennen, die bereits auf den ältesten nachweisbaren Siegeln abgebildet ist und in den meisten Siegelumschriften Erwähnung findet. Wird ein Heiligenname genannt, dann ist es der der Mutter Gottes in der Form ecclesia sancte Marie oder ecclesia beate Marie. Hinzu kommt immer der Bezug zur Theuerstadt, ${ }^{256}$ unabhängig davon, ob es sich um ein Kapitelsiegel oder ein personales Amtssiegel handelt und auch unabhängig davon, ob und welcher Heilige auf dem Siegelbild dargestellt wird. Bei dem Vergleich der in dieser Arbeit untersuchten 67 Siegel wurde deutlich, dass allein schon der Zusatz in Teuerstat genügte, um das Stift in einer Siegelum-

253 Personales Amtssiegel des Walther von Gundloch, Dekan des Stifts St. Gangolf (amt. 1324-1354), in StABa BU 2060 vom 18. Juli 1331 (Anhang Tabelle 1: Siegel Nr. 14); in StABa Kloster Michelsberg, Urkunden Nr. 294 vom 13. Dezember 1342 (Anhang Tabelle 1: Siegel Nr. 16); und in StABa Kloster Michelsberg, Urkunden Nr. 302 vom 26. April 1344 (Anhang Tabelle 1: Siegel Nr. 17). Das Siegelfeld zeigt den heiligen Gangolf (stehende Ganzfigur) mit Lanze/ Fahne in der rechten Hand und gekreuztem Schild in der linken Hand, rechts von ihm kniet betend eine Figur im Halbprofil.

${ }^{254}$ Personales Amtssiegel des Herman von Mühlhausen, Keller des Stifts St. Gangolf (amt. 1328-1344), in StABa BU 2060 vom 18. Juli 1331 (Anhang Tabelle 1: Siegel Nr. 15).

255 Erster Nachweis des neuen Typs des Gangolfer Kapitelsiegels in StABa Kloster Langheim, Urkunden 1406 VIII 28 (Anhang Tabelle 1: Siegel Nr. 31). Näheres zur Entwicklung und Einordnung des korporativen Siegels von St. Gangolf in Kapitel 4.1.2 Kapitelsiegel.

${ }^{256}$ Einzige bisher identifizierte Ausnahme ist das personale Amtssiegel des Albert Graf von Schlüsselberg, Propst des Stifts St. Gangolf (amt. 1268-1294), vom 23. April 1275 (Anhang Tabelle 1: Siegel Nr. 2), in der die Theuerstadt nicht erwähnt wird und die Umschrift „S(IGILLUM) ALB(ER)TI P(RAE)PO(SIT)I S(AN)C(T)E MARIE BABENB(ER)GEN(SIS)“ lautet. In StABa BU 881. 
schrift zu identifizieren. ${ }^{257}$ Hinsichtlich des lokalen Bezugs war es für die Siegler unwichtig, dass das Stift St. Gangolf nicht den uneingeschränkten und alleinigen Zugriff auf das Bamberger Gebiet der Theuerstadt hatte. Ähnlich wie Stadtsiegel, deren Bürgerschaft ebenso wenig das gesamte Stadtgebiet umfasste, ging es um die Abgrenzbarkeit von anderen Gruppen durch Nutzung von festen Räumen als repräsentative Elemente, die jedoch einen Personenverband und kein Territorium vertraten. ${ }^{258}$ Das Siegelbild ordnete den Siegler einem gewissen Stand, einer gewissen Ordnung zu, während die Siegelumschrift die Person oder das Kollektiv näher identifizierte.

Der heilige Gangolf hingegen findet in den Siegelumschriften keinen Nachhall, selbst wenn er im Siegelbild erscheint. Er ist in den meisten Fällen aufrecht stehend abgebildete, entweder in wallenden Gewändern oder in Rüstung mit einem Banner in der rechten Hand und einem stehenden Schild mit Kreuz in der linken Hand. ${ }^{259}$ Der Keller als Aussteller von Urkunden agierte als Richter über weltliche Angelegenheiten in der Gangolfer Immunität. Er benutzte dabei den Ritterheiligen Gangolf als obersten Zeugen seiner Rechtsprechung und unterstellte diese dem weltlicheren Heiligen anstatt der Gottesmutter. ${ }^{260}$

\footnotetext{
${ }^{257}$ Ein Beispiel von vielen ist bereits das früheste nachweisbare Siegel des Stifts St. Gangolf von 1242: Personales Amtssiegel des Ebo, Dekan des Stifts St. Gangolf (amt. 12401261), mit der Umschrift „S(IGILLUM) EBONIS D[ECA]NI IN TURSTAT“ (Anhang Tabelle 1: Siegel Nr. 1). In StABa BU 613.

${ }^{258}$ Näheres im Kapitel „Stadt und Raum“ bei Franz-Josef Arlinghaus: Konstruktion von Identität mittelalterlicher Korporationen - rechtliche und kulturelle Aspekte. In: Späth, Markus (Hg.): Die Bildlichkeit korporativer Siegel im Mittelalter. Kunstgeschichte und Geschichte im Gespräch (Sensus. Studien zur mittelalterlichen Kunst). Köln/ Weimar/ Wien 2009. S. 33-46, hier: S. 38-42; und Peter Johanek: Die Mauer und die Heiligen Stadtvorstellungen im Mittelalter. In: Behringer, Wolfgang/ Roeck, Bernd (Hgg.): Das Bild der Stadt in der Neuzeit. 1400 - 1800. München 1999. S. 26-38.

259 Damit ähnelt das Gangolfsiegel sehr dem Siegel der Stadt Bamberg, das den Stadtheiligen Georg ebenfalls als Ritterheiligen mit Banner und Schild zeigt. Im Unterschied zum Gangolfsiegel befindet sich das Kreuz des heiligen Georg auf dem Banner und auf seiner Brust, während auf dem stehenden Schild ein Adler sitzt. Näheres dazu in Karl Schnapp: Die historischen Hoheitszeichen der Stadt Bamberg. in: BHVB 109 (1973). S. 55-93.

${ }^{260}$ Anhang Abbildung 4.
} 
Während im 11. und 12. Jahrhundert neben den bisher üblichen Bischofssiegeln auch Äbte von Benediktiner- und Zisterzienserklöstern sowie Pröpste und Dekane der Domkapitel als Siegler auftraten, verbreitet sich die Praxis des Siegelns erst um 1250 auf die unteren Ebenen der Kirchenhierarchie. ${ }^{261}$ Diese Entwicklung findet sich auch in der Siegelpraxis des Stifts St. Gangolf wieder, wo das erste Siegel, ein Siegel des Dekans Ebo $1242^{262}$ überliefert ist, das erste Kapitelsiegel erst $1295^{263}$ und das erste Kellersiegel gar erst 1331. ${ }^{264}$

$\mathrm{Zu}$ unterscheiden sind die personalen Siegel einer Amtsperson von den korporativen Siegeln, die das Stift St. Gangolf als Institution oder die Kanonikergemeinschaft als Gruppe repräsentierten. Die individuellen Amtssiegel vertraten den Propst, Dekan oder ein anderes der siegelfähigen Stiftsämter, zwar mit vollem Namen und nicht selten mit Wappenschild der Herkunftsfamilie, jedoch immer als Amtsperson des Stifts. Laiensiegel, das beispielsweise der Propst von St. Gangolf als Aussteller an eine Urkunde anhängte, welches aber keinerlei Bezug zum Stift hat, sondern den Propst als Adligen ausweist, ${ }^{265}$ wurden nicht

261 Untersucht an einem norddeutschen Beispiel durch Isabelle Guerreau: Otto I. von Wohldenberg. Form und Funktion der Selbstdarstellung eines norddeutschen Weltgeistlichen im Spiegel seiner Siegel. In: Signori, Gabriela (Hg.): Das Siegel. Gebrauch und Bedeutung. Darmstadt 2007. S. 45-52, hier: S. 46.

262 Personales Amtssiegel des Ebo, Dekan des Stifts St. Gangolf (amt. 1240-1261) von 1242 in StABa BU 613 (Anhang Tabelle 1: Siegel Nr. 1).

${ }^{263}$ Korporatives Siegel des Kapitels St. Gangolf vom 25. Mai 1295 in StAWu Urkunden Kloster Ebrach 1295 V 25 (Anhang Tabelle 1: Siegel Nr. 4).

${ }^{264}$ Personales Amtssiegel des Herman von Mühlhausen, Keller des Stifts St. Gangolf (amt. 1328-1344), vom 18. Juli 1331 in StABa BU 2060 (Anhang Tabelle 1: Siegel Nr. 15).

265 Beispiele für solche Fälle sind ein Schiedsspruch vom 1. Juni 1489 des Laurentius, Domvikar und Kanoniker des Stifts St. Stephan in Bamberg, und des Heinrich Glantz, Dekan des Stifts St. Gangolf in Bamberg (amt. 1486-1491), in der Differenz zwischen dem Kloster Michelsberg und dem Kapitel des Stifts St. Jakob, in welchem Heinrich Glanz mit seinem Familiensiegel beglaubigte. In StABa Kloster Michelsberg, Urkunden Nr. 1419; Am 27. Januar 1565 bestätigte Erasmus Neustetter als Domdekan in Würzburg, Propst des Stifts Haug, Domkanoniker in Bamberg und Propst des Stifts St. Gangolf (amt. 1565-1594) gegenüber dem Dekan und dem Kapitel von St. Gangolf mehrere Pflichten und siegelte mit seinem Familiensiegel. In StABa A 120 L 131 Nr. 732; Neben dem Siegel des Bischofs von Bamberg hängt zur Beglaubigung einer bischöflichen Bestätigung vom 8. November 1449 das Familiensiegel des Johann Kautsch, Propst von St. Gangolf (amt. 1444-1462). In StABa A 120 L 131 Nr. 753; Am 30. Juli 1516 bestätigte Paul Neydecker als Propst des Stift St. Gangolf (amt. 1516-1565) gegenüber dem Dekan und dem Kapitel von St. Gangolf 
mit in die Untersuchung einbezogen. Kanoniker und kleinere Würdenträger wie Vikare verzichteten generell auf die Thematisierung ihrer Kirchenzugehörigkeit und siegelten mit ihren Familiensiegeln. ${ }^{266}$ Diese Vermischung von Amt und Familie in der Repräsentation einer Person ist nur im modernen Verständnis widersprüchlich, denn das Mittelalter kannte kein Selbstverständnis als Privatperson und definierte sich nach Stand, Rang und Zugehörigkeit zu einer Gruppe. ${ }^{267}$

Im Medium Siegel bündeln sich also Hinweise auf die Selbstbezeichnung des Stiftes, seinen Bezug zu den Stiftern durch das Siegelbild und die Gewichtung der Theuerstadt als identitätsstiftendes Element. Darüber hinaus äußert sich der Wert des Mediums Siegel als Mittel zur Selbstdarstellung des Stifts als Rechtsperson, als Gemeinschaft und als geweihte Kirche eines oder mehrerer Heiliger.

\subsubsection{Stiftsbezeichnung in den Urkunden}

Neben den Siegeln und ihrem Bildprogramm bieten die Urkunden, an deren Rechtsvorgang das Stift St. Gangolf beteiligt war, noch einen weiteren Ansatzpunkt, um die Gewichtung der Patrone nach innen und deren Bedeutung in der Außenwirkung zu erfahren und zwar ersichtlich in der Bezeichnung des Stifts innerhalb des Urkundentextes. Um Muster zu erkennen, wurden anhand stiftseigener und stiftsfremder Urkunden aus dem Staatsarchiv Bamberg, dem Archiv des Erzbistums Bamberg, dem Stadtarchiv Bamberg und dem Staatsarchiv Würzburg eine chronologischen Auflistung der Stiftsbezeichnung erstellt. ${ }^{268}$ Allein die durch die Verfasserin durchgeführte Analyse aller Bamberger Urkunden vor 1401, die im Staatsarchiv Bamberg unter der Signatur BU ohne Provenienzzugehörigkeit und gezielter Verzeichnung zu finden sind, bietet einen völlig neuen Zugang zum Selbstverständnis des Stifts

mehrere Pflichten und siegelte mit seinem Familiensiegel. AEB Rep. I Pfarrei St. Gangolf U 826.

266 Dies lässt sich als generelles Phänomen auch in Norddeutschland nachweisen in Guerreau: Otto I. von Wohldenberg. 2007. S. 50.

${ }^{267}$ Arlinghaus: Konstruktion von Identität mittelalterlicher Korporationen. 2009. S. 36.

${ }^{268}$ Anhang Tabelle 2: Stiftsbezeichnungen. 
St. Gangolf. Ziel ist die Annäherung an Identitätsfragen der Stiftsgemeinschaft, die eng mit der Verehrung von heiligen Stiftern zusammenhingen. Da sich für das Stift St. Gangolf kaum belastbare Hinweise auf eine Praxis der Reliquienverehrung im Mittelalter finden lassen, ${ }^{269}$ konnten über diesen Ansatz neue Antworten auf die Frage der Stellung der Heiligen innerhalb der Selbstwahrnehmung des Stifts gewonnen werden. Bisher fehlte ein umfassender Einblick in die Urkundenüberlieferung der betreffenden Archive, sodass sich die gängigen Forschungsmeinungen rund um den Stellenwert der stiftischen Patrone nur auf die Auswertung einzelner Stücke stützen konnten. Die hier angefertigte tabellarische Aufstellung aller Fremd- und Selbstbezeichnungen in den betreffenden Urkunden sollen Thesen stärken oder verwerfen helfen.

Die Selbstbezeichnung war von seiner Grundidee heraus eine Möglichkeit, sich auf einen Bezugspunkt auszurichten, und nicht zuletzt auch ein Profilierungsmittel gegenüber anderen Häusern. ${ }^{270}$ Dafür war der Kirchenpatron als Schutzherr der Kirche in besonderem Maße geeignet. Die Selbstbezeichnung des Stifts St. Gangolf findet sich erst in jüngeren Urkunden um $1300,{ }^{271}$ später vor allem in denen des Kellereigerichts, während sich in der älteren Überlieferung üblicherweise Fremdbezeichnungen des Stifts finden. Dies liegt darin begründet, dass in der Überlieferungsbildung der vielen Jahrhunderte überwiegend Bischofs- und Königsurkunden eine Rolle spielten und sich Urkunden kleinerer Institutionen erst spät erhalten konnten.

Bei der Analyse der Selbst- und Fremdbezeichnungen des Stifts St. Gangolf wird erkennbar, dass die Nennung des Heiligen Gangolf zwar bereits Mitte des 12. Jahrhunderts als Namensbestandteil des Stifts auf-

${ }^{269}$ Näheres im Kapitel 3.2.2 Der heilige Gangolf.

270 Rainer Berndt: „Ich habe dich beim Namen gerufen“ (Is 45 3-4). Formen der Selbstwerdung und der Identitätsbildung im lateinischen Mittelalter. In: Berndt, Rainer (Hg.): „Eure Namen sind im Buch des Lebens geschrieben“. Antike und mittelalterliche Quellen als Grundlage moderner prosopographischer Forschung (Erudiri Sapientia. Studien zum Mittelalter und zu seiner Rezeptionsgeschichte, Bd. 11). Münster 2014. S. 2539, hier: S. 34.

271 „Decanus totusque capitulum in Tiurstat Babenbergensis“ in StAWu Kloster Ebrach, Urkunden 1295 V 25; und "praepositus sancte Marie in Thuerstat extra muros Babenbergenses“ in StABa Kloster Langheim, Urkunden 1302 XI 10. 
tauchte, ${ }^{272}$ jedoch seine Nennung bis ins 15 . Jahrhundert hinein vereinzelt blieb. ${ }^{273}$ Erst dann tritt eine größere Dichte der Gangolfnennungen auf. Selbst in den Urkunden des Kellereigerichtes, das durchgehend mit dem Bild des heiligen Gangolf siegelte, ist der bloße Verweis auf das stift unser lieben frauen $z u$ Teuerstat nicht selten ausreichend für eine Identifizierung. ${ }^{274}$ Dabei ist der heilige Gangolf in Bamberg bereits seit dem 12. Jahrhundert kein Unbekannter: So wird 1179 in einer Stiftungsurkunde des Bischofs Otto von Bamberg an seine Domkanoniker und auch an die Kollegiatstifte das Fest des heiligen Gangolfs erwähnt. ${ }^{275}$ Das Stift St. Gangolf selbst wird aber in den meisten Urkunden durch den Zusatz Tiurstat oder Tuirstat ausgewiesen, ohne dass die heilige Maria oder der heilige Gangolf als Namensbestandteil bemüht worden wäre. Die Erwähnung der Theuerstadt taucht bereits in den ersten Urkunden auf, die das Stift benannten, ${ }^{276}$ und verdeutlicht, dass die Bamberger Vorstadt östlich der Regnitz eine herausragende identitätsstiftende Wirkung für St. Gangolf hatte, die weit über die der Heiligen hinausging. Die Identifizierung einer religiösen Einrichtung mit einer bestimmten Lokalität ist kein Phänomen, das sich allein auf das Stift St. Gangolf beschränkte. So ist die Bezeichnung des Bamberger Klosters

\footnotetext{
${ }^{272}$ Fremdbezeichnung „ecclesia in honore sancte Mariae matris domini et sancti Gengolfi martiris extra urbem versus orientem in loco Tierstat" von vor 1139 in Heimo von St. Jakob "De decursu temporum liber" in: Jaffé (Hg.): Heimo von St. Jakob. 1869. S. 546; Fremdbezeichnung "praepositus sancti Gangolfi“ von um 1151 in StABa Kloster Michelsberg, Urkunden Nr. 38; Fremdbezeichnung „praepositus sancti Gingolfi Babenbergensis" vom 14. Februar 1152 in StABa Kloster Michelsberg, Urkunden Nr. 39; Fremdbezeichnung "praepositus sancti Gingulfi“ von 1178 in StABa BU 335; und Fremdbezeichnung „praepositus sancti Gingolfi“" von 1187 in StABa BU 376.

273 Fremdbezeichnung "de sancto Gangolfo“ von 1271 in StAWu Kloster Langheim, Urkunden 1271 XI 10; Fremdbezeichnung „rector scolarum sancti Gangolfi“ von 1290 in StAWu Kloster Ebrach, Urkunden 1290 III 21/II; Selbstbezeichnung „korhere zu sant Gangolf zu Teurstat zu Babenberch“ von 1349 in StABa BU 2651 und in StABa BU 2670.

${ }^{274}$ Ein Beispiel ist die Fremdbezeichnung „kelner zu Tuerstat" von 1344 in StABa BU 2498.

${ }^{275}$ Stiftungsurkunde des Otto, Bischof von Bamberg (amt. 1177-1196), von 1179 in StABa BU 339. Näheres dazu im Kapitel 3.2.2 Der heilige Gangolf.

${ }^{276}$ Fremdbezeichnung „decanus de Duristat“ von 1059 im Synodialprotokoll vom 13. April 1059 (Zeugenliste) in Jaffé: Acta synodi Babenbergensis. 1869. S. 498. Nr. 8; Fremdbezeichnung „fratres de sancta Maria“ von 1093 in StABa BU 143; Fremdbezeichnung „prepositus Turstatensis“ von 1108 in StABa BU 149.
} 
Michelsberg in den Quellen als monasterium montis monachorum schon früh auf dessen Lage zurückzuführen und die Bezeichnung der Anhöhe oberhalb des Domes wurde durch die Anlage des Klosters beeinflusst. ${ }^{277}$

$\mathrm{Zu}$ unterscheiden ist bei der Analyse der Urkunden zwischen dem ausführlichen Namen des Stiftes, den man in der Intitulatio des Ausstellers findet, ${ }^{278}$ und dem Kurznamen, der gebraucht wird, wenn innerhalb der Urkunde das Stift zum wiederholten Male Erwähnung findet und nicht selten nachdem der offizielle Name schon genannt wurde. Bei diesem Kurznamen ist zu beobachten, dass er in den meisten Fällen auf die Theuerstadt verweist, selbst wenn im offiziellen Namen in derselben Urkunde sowohl beide Heilige als auch die Theuerstadt als erwähnungswürdig eingestuft wurden. ${ }^{279}$ Dies ist vor allem deshalb interessant, da anzunehmen ist, dass diese Kurznamen in den allgemeinen Sprachgebrauch eingingen und somit identitätsstiftend waren.

Wie bedeutsam die Erwähnung der Theuerstadt zur Identifizierung und Selbstdarstellung des Stifts St. Gangolf war, wird bei der näheren Betrachtung der Selbstbezeichnung des Frauenklosters St. Theodor deutlich, welches sich ebenso wie das Stift St. Gangolf auf die heilige Maria als Patronin stützte. Während die Schwestern des Klosters St. Theodor zum Stift St. Jakob aufgrund der Lage und Besitzverflechtun-

\footnotetext{
${ }^{277}$ Näheres dazu im Bestand StABa Kloster Michelsberg, Urkunden.

278 Beispielsweise die Selbstbezeichnung „chorherr und obirster kelner des stifts zu unser lieben frawn und sanct Gangolfs kirchen zu Teurstat asserhalben der mawrn der stat zu Bamberg und richter in der munthat doselbst" von 1452 in SttABa A 21 20-03-1452.

${ }^{279}$ Als Beispiele in den Urkunden: Um 1190 „praepositus sancte Marie in Duorstat“ und als Kurztitel „vicarius de Tuorstat“ in StABa BU 387; 1242 „sancte Marie in Tyrstat decanus" und als Kurztitel "custos in Tyrstat" in StABa BU 613; Am 2. Juli 1285 „prepositus sancte Marie in Tewerstat" und als Kurztitel "prepositus in Tewerstat" in StAWu Kloster Ebrach, Urkunden 1285 VII 2/I; Am 13. Dezember 1318 „probst des gotzhaus ze Tewerstat auzzerhalb der mawer der stat ze Babemberch" und als Kurztitel "chorhere ze Tewerstat“ in StABa BU 1716; und am 24. August 1468 „probst des stifts unser lieben frauwen und sant Gangolfs zu Tewerstadt bey Bamberg" und als Kurztitel „stift zu Tewerstat“ in StABa A 120 L 133 Nr. 878; Als Beispiele für Ausnahmen: Am 9. Dezember 1336 „ecclesie sancte Marie in Teuerstat extra muros civitatis Babnbergensis” und als Kurztitel „ecclesia sancte Marie“ in AEB Rep. I, Pfarrei St. Gangolf U 818; und am 21. Mai 1474 „brobst unser liben frawen und sant Gangolfs zu Thewerstat bey Bamberg“ und als Kurztitel „probstey unser lieben frawen und sant Gangolfs“ in StABa A 120 L 133 Nr. 881.
} 
gen enge Kontakte unterhielten, ${ }^{280}$ waren die Beziehungsverflechtungen zwischen dem Kloster und den Stiften St. Stephan und St. Gangolf eher gering. Und doch lassen sich häufig genug Kontakte zwischen St. Gangolf und St. Theodor finden, die eine Unterscheidung der beiden Häuser in ikonografischer oder hinsichtlich der Bezeichnung der Institutionen nötig machten. Bereits um 1199 ist eine Urkunde der Äbtissin und des Konvents des Klosters St. Theodor überliefert, in welcher sich die Schwesterngemeinschaft selbst als ecclesie sancte Marie Bambergensis bezeichnete. ${ }^{281}$ Und auch in späteren Fällen tritt das Stift St. Gangolf als Zeuge in Angelegenheiten des Frauenklosters St. Theodor auf und unterstellte sich der heiligen Maria: 1216 kaufte Eckbert, Bischof zu Bamberg, beispielsweise ein Gut zu Kotzendorf und übereignete verschiedene Güter dem Kloster St. Theodor (sorores de monte sancte Marie virginis), während die Zeugen neben dem Dompropst, dem Domdekan, dem Domkustos und anderen Kanonikern und Laien aus Sifridus praepositus in Tuoerstat bestand. ${ }^{282}$ Auch hier diente die Theuerstadt als ein auf das Stift St. Gangolf beschränktes Unterscheidungsmerkmal.

Doch auch das Kloster St. Theodor wird nicht nur mit der heiligen Maria als namensgebender Patronin in Verbindung gebracht: 1249 übereignete der Bamberger Bischof Heinrich dem Kloster St. Theodor einige Güter und bezeichnete es als sanctimonalium St. Theodoru. ${ }^{283}$ Und ebenfalls als sanctimonialium sancti Theodori in Babenberch wurde das Kloster 1255 in einer Verkaufsurkunde des Heinrich, Bischof zu Bamberg, bezeichnet, in der neben einem Domkanoniker und einem Kanoniker des Stifts St. Stephan auch der magister C. canonicus Tirstatensis als

280 Robert Zink: St. Theodor in Bamberg 1157-1554. Ein Nonnenkloster im mittelalterlichen Franken. Bamberg 1978. S. 78-79.

${ }^{281}$ Urkunde der Äbtissin und des Konvents des Klosters St. Theodor von um 1199 in StABa BU 412.

${ }^{282}$ Urkunde des Eckbert, Bischof von Bamberg (amt. 1203-1237), von 1216 in StABa BU 473. Ebenfalls die Selbstbezeichnung des Klosters St. Theodor als „monasterium sancte Marie“ in einer bischöflicher Urkunde von etwa 1217 in StABa BU 485; als „sorores in monte sancte Marie“ in einer bischöflichen Urkunden von 1216 in StABa BU 475 und BU 476; oder als „coenobium sancte Marie“ in einer Urkunde der Agnes, Äbtissin von St. Theodor, von 1240 in StABa BU 607.

${ }^{283}$ Urkunde des Heinrich, Bischof von Bamberg (amt. 1242-1257), vom 21. Juli 1249 in StABa BU 671. 
Zeuge auftrat. ${ }^{284}$ Weitaus seltener, aber doch nachweisbar, ist der Gebrauch der beiden Heiligen Maria und St. Theodor im Verbund, wie es am 28. Januar 1280 Gerdrud, Äbtissin von St. Theodor zu Bamberg, in einer Urkunde über eine Übertragung eines Weinbergs zu Ochsenfurt an zwei Bürger tat, als sie ihr Haus ecclesia sancte Marie virginis sanctique Theodori in Babenberch nannte. ${ }^{285}$ Die vollständige Heraushebung des heiligen Theodor als namensgebender Patron erfolgte, ähnlich wie bei dem Stift St. Gangolf, erst im Laufe des Mittelalters.

Damit kann festgehalten werden, dass der heilige Gangolf erst ab der Mitte des 15. Jahrhunderts gängiger Bestandteil des Stiftsnamens wurde und vorher nur vereinzelt auftrat. Doch auch diese wenigen frühen Spuren des Heiligen in der Stiftsbezeichnung widerlegen bereits die ältere Forschungsmeinung, dass das Gangolfpatrozinium erst in der Spätzeit des Stifts zum Marienpatrozinium hinzukam. Bereits ab der Mitte des 12. Jahrhunderts trat Gangolf in der Stiftsbezeichnung auf. Die Benennungen für das Stift St. Gangolf variieren sehr stark und das von Beginn an, während die anderen beiden Kollegiatstifte St. Stephan und St. Jakob kaum Varianzen in ihrem Stiftsnamen aufzeigen und sich sehr früh auf ihre Hauptheiligen beriefen.

Der Namenszusatz extra muros, der auf den ersten Blick wie eine Bestätigung der Sonderrolle Theuerstadts als Vorbezirk Bambergs erscheinen mag, stellt sich ziemlich schnell als eine häufig benutzte Bezeichnung verschiedenster Bamberger Institutionen heraus. So werden das Kloster Michelsberg, ${ }^{286}$ das Stift St. Stephan ${ }^{287}$ und das Stift St.

\footnotetext{
${ }^{284}$ Urkunde des Heinrich, Bischof von Bamberg(amt. 1242-1257), vom 9. Januar 1255 in StABa BU 720.

${ }^{285}$ Urkunde der Gerdrud, Äbtissin von St. Theodor zu Bamberg, vom 28. Januar 1280 in StABa BU 935.

286 Stellvertretend die Bezeichnung „monasterium sancti Michahelis ordinis sancti Benedicti montis monachorum extra muros Bambergenses" in einer Michelsberger Urkunde vom 10. Februar 1350 in StABa Kloster Michelsberg, Urkunden Nr. 321; oder „montis monachorum prope muros Bambergenses“ für das Kloster Michelsberg in einer Urkunde vom 22. August 1420 in StABa Kloster Michelsberg, Urkunden Nr. 682.

${ }^{287}$ So spricht bereits Heimo von St. Jakob vom Stift St. Stephan als "loco extra urbem" in Jaffé (Hg.): Heimo von St. Jakob. 1869.
} 
Jakob $^{288}$ nicht selten ebenfalls mit diesem Namenszusatz bezeichnet oder bezeichnen sich selbst derart. Selbst die Pfarrkirche St. Martin ${ }^{289}$ und auch das Katharinenspital, ${ }^{290}$ welche heute mitten auf der Inselstadt thronten, werden als extra muros Bambergenses bezeichnet. Bemerkenswert ist die konstante Betonung der Lage innerhalb oder außerhalb der Mauer dahingehend, wenn man bedenkt, dass Bamberg nie eine geschlossene Mauer hatte. ${ }^{291}$ Diese Beobachtungen verstärken die von Guy P. Marchal aufgestellte These, dass es sich bei der Bezeichnung extra muros nicht um eine enge lokale Beschreibung handelt, sondern die betreffenden Kirchen, im Kranz um die Bischofsstadt gelegen, als eine spirituelle Mauer mit einer „sakrale Schutzfunktion“ verstanden wurden. ${ }^{292}$

${ }^{288}$ Stellvertretend die Bezeichnung "ecclesia sancti Jacobi extra muros Bambergensis" in einer Bamberger Kaufurkunde vom 14. August 1242 in StABa BU 1110; oder ebenso in einer bischöflichen Urkunde vom 16. November 1356 in StABa BU 2913.

289 "Allzuoft sind Kirchen außerhalb der Mauern höheren Alters als die städtischen Siedlungen, die, bei ihrer Gründung ihnen zugeordnet, in ihnen eine Pfarrkirche schon vorfanden." in Tilmann Breuer/ Reinhard Gutbier: Stadt Bamberg. Teil 5/1: Innere Inselstadt (Die Kunstdenkmäler von Bayern. Regierungsbezirk Oberfranken, Bd. 7). München 1990. S. 30-31.

${ }^{290}$ Wolfgang F. Reddig: Bürgerspital und Bischofsstadt. Das St. Katharinen- und das St. Elisabethspital in Bamberg vom 13.-18. Jahrhundert (Spektrum Kulturwissenschaft, Bd. 2). Bamberg/ Frankfurt (Oder) 1998. S. 49.

${ }^{291}$ Eine Aufarbeitung des Verlaufs der Bamberger Stadtmauer in Roman Schöpplein: Die hochmittelalterliche Stadtmauer der Bamberger Inselstadt unter besonderer Berücksichtigung der Ergebnisse der Ausgrabung „Am Kranen 14“ (Forschungen des Instituts für Archäologie, Denkmalkunde und Kunstgeschichte - Bereich Archäologie, Bd. 3. Veröffentlichungen des Stadtarchivs Bamberg, Bd. 26). Bamberg 2016.

${ }^{292}$ Marchal: Was war das weltliche Kanonikerinstitut im Mittelalter? 2000. S. 38. 


\section{Verfassung und Verwaltung}

Im Zuge der Kanonikerreform des 11. und 12. Jahrhunderts formten sich zwei Typen von Kanonikerstiften heraus: einerseits die regulierten Stifte, die sich eine neue Strenge des Zusammenlebens auferlegten und sich einer Ordensregel, meist der des heiligen Augustinus, unterstellten; und zum anderen die weltlichen Kollegiatstifte, die im Gegensatz dazu weiterhin Privatbesitz des einzelnen Kanonikers zuließen und kein Ordensgelübde verlangten. ${ }^{293}$ Während sich erstere aufgrund ihrer Orientierung an der Kanonikerreform in ihrer Regelaufstellung weitgehend ähnlich entwickelten, wiesen die weltlichen Kollegiatstifte schon bald eine große Vielfalt von inneren Verfassungen auf. Das gemeine Recht bildete zwar eine gemeinsame Grundlage, jedoch wurden durch die jeweiligen Kapitel eigene Akzente gesetzt. So gab es einen allgemeinen Usus zur Einrichtung von Stiftsämtern, wobei aber nicht alle Ämter in allen Stiften $\mathrm{zu}$ finden waren oder diese von Haus zu Haus unterschiedliche Funktionen innehatten. Besonders in den Gewohnheiten (consuetudines), Aufnahmebedingungen oder Anwesenheitspflichten war eine große Varianz zu beobachten. Personelle Verhältnisse oder wirtschaftliche Begebenheiten beeinflussten die Ausbildung der Rechtsverhältnisse ebenso wie örtliche Gegebenheiten, sodass es große Unterschiede in der Normgebung von Stift zu Stift in ein und derselben Stadt geben konnte. ${ }^{294}$ Um also die innere Verwaltung des weltlichen Kollegiatstiftes St. Gangolf nachvollziehen zu können, genügt nicht allein eine Zusammenfassung aller Kollegiatstifte Bambergs, sondern es ist eine gesonderte Betrachtung vonnöten.

${ }^{293}$ Werner Goez: Kirchenreform und Investiturstreit 910 - 1122. Stuttgart ${ }^{2} 2008$.

294 Näheres zur Typenvielfalt von Statuten und Gemeinschaftsnormen in Gisela Drossbach: Haec sunt statuta. In: Drossbach, Gisela (Hg.): Von der Ordnung zur Norm: Statuten in Mittelalter und Früher Neuzeit. Paderborn 2010. S. 369-385. 


\subsection{Stiftskapitel}

Das Kapitel war der Ort der Zusammenkunft der vollbepfründeten Kanoniker und daher der Mittelpunkt des Stifts. Eine kirchliche Institution wie Kollegiatstift oder Kloster, welche sich auf das Abhalten von Gebeten spezialisierte und für memoriale Dienste - Rainer Berndt nennt dies den „Gedächtnisauftrag“ ${ }^{295}$ der geistlichen Gemeinschaften Einkünfte bezog, schuf sich erst dadurch eine Gemeinschaft, dass sie sich durch die Pflicht zum Fürgebet zusammenschloss. Die gemeinsamen Gebete und Gesänge in der Stiftskirche waren besonders für die weltlichen Stifte ein einendes Element, da dies seit dem 13. Jahrhundert nach der Auflösung der vita communis neben den Kapitelsitzungen die wenigen Gelegenheiten waren, an denen sich die Kanoniker versammelten. Daher hatte das Kapitel des Stifts eine doppelte Funktion, denn einerseits verstand man darunter die regelmäßige Zusammenkunft zum Gottesdienst, bei dem die täglichen liturgischen Pflichten erfüllt wurden, und andererseits hatte es die Rolle einer juristischen Person inne, die ein eigenes Siegel führte, Dokumente ausstellte und Gerichtsrechte wahrnahm. Daher waren vor allem Kapitelsitzungen sichtbarer Ausdruck der rechtlichen Handlungsmacht eines Kollegiatstifts und ihrer liturgischen Leistungsfähigkeit. Die sechs Kapitelprotokolle, die für das Stift St. Gangolf überliefert sind, sind ausschließlich neuzeitlich, sodass die mittelalterlichen Zustände rund um die stiftsinterne Rechtssprechung schwer zu rekonstruieren sind. ${ }^{296}$

Dem Stiftskapitel wurde durch den Entwurf und die Umsetzung von Statuten eine innere Verfassung gegeben, deren Einhaltung durch ein Kapitelgericht garantiert werden sollte. Besonders die Rekrutierung von Nachwuchs und die Regelung der Aufnahme von Kanonikern stellte

295 Rainer Berndt: „Tuet dies zu meinem Gedächtnis“. Die Eucharistie als Grundlage christlicher memoria in Kirche und Theologie des Mittelalters. In: Berndt, Rainer (Hg.): Wider das Vergessen und für das Seelenheil. Memoria und Totengedenken im Mittelalter (Erudiri Sapientia. Studien zum Mittelalter und zu seiner Rezeptionsgeschichte, Bd. 9). Münster 2013. S. 21-39, hier: S. 24.

296 Protokolle der Kapitelsitzungen (1624-1681) in StABa Stift St. Gangolf, Akten und Bände Nr. 156; (1682-1694) Nr. 157; (1695-1709) Nr. 158; (1730-1739) Nr. 159; (1740-1750) Nr. 160; und (1750-1761) Nr. 161. 
eine wichtige Aufgabe der Gemeinschaft dar. Dabei waren auf dem Weg zum Kapitularkanoniker, also zu einem Stiftsmitglied mit Stimme bei den Kapitelsitzungen und voller Pfründe, einige Stufen $\mathrm{zu}$ nehmen. Ähnlich wie am Domkapitel ${ }^{297}$ kann für das Stift St. Gangolf ein dreifacher Stand der Kanoniker nachgewiesen werden: zum einen die non emancipati, also Aufnahmewillige, welche in den Schulen vom Scholastikus auf ihre Mitgliedschaft im Stift vorbereitet wurden. Ab dem 14. Jahrhundert ist am Stift St. Gangolf die Praxis nachweisbar, vier Chorschüler durch eigene Pfründen zu versorgen. ${ }^{298}$ Ihre Aufgaben bestanden unter anderem in der täglichen Anwesenheit im Chor sowie dem stündlichen Singen und Lesen. ${ }^{299}$ Zur zweiten Gruppe von Kanonikern zählten die emancipati, deren Ausbildung abgeschlossen war und die höhere Weihen erfahren hatten. Diese waren dem Dekan unterstellt, ${ }^{300}$ hatten jedoch weder im Chorbereich der Kirche, noch im Kapitel einen eigenen Platz und damit auch keine Vollpfründe inne. Zur dritten Kanonikergruppe gehörten die vollbepfründeten Kapitularkanoniker, die volles Mitspracherecht in den Versammlungen genossen und Ämter wahrnehmen konnten. Die Aufnahme als Kanoniker und die Verleihung der Pfründen wurden über den Dekan und das Kapitel geregelt. ${ }^{301}$

297 Bestimmungen über den dreifachen Kanonikerstand am Domkapitel in einer Urkunde des Domkapitels vom 26. September 1326 in StABa BU 1904.

${ }^{298}$ So stiftet der Gangolfer Kustos Konrad (amt. 1307-1331) im Jahr 1329 die vier Pfründen für Chorschüler, um sein Seelenheil zu sichern. Im Vidimus des Bamberger Bischofs von 1329 in StABa BU 1988.

${ }^{299}$ Bestätigung der Stiftung des Kustos durch den Bischof und das Domkapitel 1336 in AEB Rep. I Pfarrei St. Gangolf U 818.

${ }^{300}$ Schiedsspruch des Bamberger Domdekans vom 23. August 1339 im Kopialbuch StABa Stift St. Gangolf, Akten und Bände Nr. 3 Teil III S. 43-45.

301 Beispiele: Am 3. Juni 1439 empfängt Dietrich von Redwitz als Kanoniker von dem Kapitel unter Vorsitz des Seniors Hans Phere, als Vertreter des Dekans, nach dem Tod des Kanonikers Hugo vom Lichtenstein, aufgrund eines päpstlichen Briefes, nach Zustimmung des Georgius Rephun, Keller des Stifts (amt. 1441-1481), und nach der Berufung durch das Konzil von Basel die vakante Pfründe, was vom Domdekan samt Kapitel bestätigt wurde. In StABa A 120 L 131 Nr. 721; Am 10. Januar 1517 empfängt der Kanoniker Johann Wilhelm von Hieronimus Hirschberger, Dekan des Stifts (amt. 15121542), und dem Kapitel eine durch Tod vakant gewordene Pfründe. In StABa A 120 L 131 Nr. 720; Am 7. Mai 1556 bürgt Johannes Seligmann als Kanoniker des Stifts dem Dekan und dem Kapitel von St. Gangolfs über die Verleihung einer durch die „ubergebung“ des Pangraz Gries, Tagmessner am Domstift, vakant gewordene Pfründe. In StABa A 120 L 
Ein Mindestalter von 24 Jahren, Abstammung aus einer legitimen ehelichen Verbindung und ein ausreichendes Vermögen waren Voraussetzungen zum Eintritt in das Stift. ${ }^{302}$ Eine adelige Zugehörigkeit, wie es am Domstift üblich war, ${ }^{303}$ war im Stift St. Gangolf kein Aufnahmekriterium, womit es sich in die Reihen anderer kleinerer Kanonikerstifte einfügte. Für das 15. und 16. Jahrhundert sind höchstens 12 vollbepfründete Kanoniker gleichzeitig am Stift St. Gangolf nachweisbar. ${ }^{304}$ Damit lässt sich ein Einblick in die Größenordnung der Gemeinschaft im 15. Jahrhundert gewinnen: Das Bamberger Domstift hatte in seinen Statuten die Anzahl der Pfründen auf 20 beschränkt ${ }^{305}$ und die tägliche Brotration, die der Propst des Stifts St. Stephan an seine Kanoniker vergab, wurde in 17 Teile geteilt. ${ }^{306}$ Das Stift St. Gangolf gehörte also zu den kleineren Bamberger Häusern.

\subsubsection{Statuten und Consuetudines}

Die heute noch zugängliche Statutenüberlieferung des Stifts St. Gangolf besteht aus sechs Bänden, welche im Gangolfer Bestand im Staatsarchiv Bamberg, ${ }^{307}$ im Bestand des Archiv des Erzbistums Bam-

131 Nr. 731.

302 Statut Nr. 13 "De cappa chorali novi capitularis canonici et carentia vocis capitularis" im Statutenbuch StABa Stift St. Gangolf, Akten und Bände Nr. 130 fol. 67'-68.; oder das Statut Nr. 23 „De tempore quo quis se absentare poterit preter fructum subtractionem” im Statutenbuch StABa Stift St. Gangolf, Akten und Bände Nr. 130 fol. 75'-76'; Zum Vergleich: 1611 legte das Domkapitel für die drei Kollegiatstifte Bambergs fest, dass niemand unter 21 Jahren eine Pfründe erhalten soll. In StABa B 86 Nr. 380a.

303 Näheres zur Praxis des Abstammungsnachweises im Bamberger Domstift in Lisa Witowski: Adlige Exklusivität. Aufschwörbuch des Bamberger Domkapitels. In: Original! Pracht und Vielfalt aus den Staatlichen Archiven Bayerns (Ausstellung der Staatlichen Archive Bayerns im Bayerischen Hauptstaatsarchiv). München 2017. S. 146-149.

304 Näheres zu den 14 Vollpfründen, von denen der Dekan und Keller jeweils zwei erhielten, im Kapitel 6.3.3.5 Die Frage nach den Einzelpfründen.

${ }^{305}$ Nöth: Urbare und Wirtschaftsordnungen. 1986. Anm. 29. S. 12. Als frühesten Nachweis dieser Beschränkung nennt Nöth ein Statut von 1390, wohl aus dem Statutenbuch Liber albus in StaBa Rep. B 86 Nr. 230.

${ }^{306}$ Siewert: Das Bamberger Kollegiatstift St. Stephan. 2007. S. 213.

${ }^{307}$ StABa Stift St. Gangolf, Akten und Bände Nr. 130, Nr. 131 und Nr. 132. 
berg ${ }^{308}$ und in der Sammlung des Historischen Vereins Bambergs ${ }^{309} \mathrm{zu}$ finden sind. Die Versionen haben alle diejenigen Statuten als Grundlage, die am 17. Januar $1433^{310}$ von Bischof Anton von Rotenhan (amt. 1431-1459) dem Stift, vertreten durch Dekan Johann Schank (amt. 14331441), den Scholastikus Konrad Ruthardt (amt. 1432-1434) und den Keller Johann Fere (amt. 1414-1440), verliehen worden waren. Nach innerstiftischen Streitigkeiten wurden sie am 2. Dezember 1444 unter dem Dekan Heinrich Klinghart (amt. 1442-1449) neu angelegt und wiederum vom Bischof bestätigt. ${ }^{311}$ Nach einigen Vernachlässigungen erfolgte die Wiederherstellung der Statuten im Jahr 1523, sodass sie in dieser Version bis zur Auflösung des Stifts hinein benutzt werden konnte. ${ }^{312}$ Auf eine frühere Statutenversion gibt es keinen Hinweis. ${ }^{313}$

Mit der Verleihung der Statuten an das Stift St. Gangolf im Jahr 1433 wurde Stefan Beheim Propst des Stifts (amt. 1433-1441), in dessen eigens angelegtem Lehenbuch sich bezeichnenderweise eine Abschrift des Statuts über die Aufgaben des Propstes findet. ${ }^{314}$ Seinen Amtsvorgängern kann man diese Wertschätzung der stiftseigenen Verfassung nicht nachsagen: Während der Amtszeit von Thomas Graf von Wertheim (amt. 1417-1431), der ein Neffe des Bamberger Bischofs Albrecht von Wertheim war, nahm nicht er, sondern sein Bruder lange die Auf-

${ }^{308}$ AEB Rep. I Akten des Schlundrepertoriums, A 121; Auszüge aus den Statuten des Stifts außerdem in AEB Rep. 60 Pfarrarchiv St. Gangolf Bamberg Nr. 2.

${ }^{309}$ SttABa D 3001 HV Rep. 2 Nr. 264 fol. 54-73‘ und Nr. 265.

310 Datierung nach einem modernen Bleistiftvermerk im Statutenbuch StABa Stift St. Gangolf, Akten und Bände Nr. 132 fol. 2. Bestätigt durch Ussermann: Episcopatus Bambergensis. 1802. S. 272.

311 Undatierte Abschrift einer bischöflichen Urkunde vom 2. Dezember 1444 in StABa A 120 Nr. 722. Auch in Ussermann: Episcopatus Bambergensis. 1802. S. 274.

312 Auf Grundlage der Version von 1523 hat der Mainzer Kirchengeschichtler Stephan Alexander Würdtwein im Jahr 1771 die Gangolfer Statuten publiziert. In Stephan Alexander Würdtwein: Nova subsidia diplomatica ad selecta juris ecclesiastici Germaniae et historiarum capita elucidanda ex originalibus et authenticis documentis, Bd 1. Heidelberg 1771. S. 197-270. mit dem Verweis auf das Jahr 1523 auf S. 269.

${ }^{313}$ Die ersten Statutenbücher des Bamberger Stifts St. Stephan stammen ebenfalls erst aus dem 15. Jahrhundert, wobei es im Gegensatz zum Stift St. Gangolf einzelne Spuren auf frühere Statuten des 13. und 14. Jahrhunderts gibt. Siewert: Das Bamberger Kollegiatstift St. Stephan. 2007. S. 71.

314 Lehenprotokolle des Propteiverwaltungsamts Hollfeld (1417-1576) in StABa Stift St. Gangolf, Akten und Bände Nr. 119 fol. 24'-26. 
gaben des Gangolfer Propstes wahr, welcher wegen schlechten Lebenswandels seines Amtes enthoben wurde. ${ }^{315}$ Die Vernachlässigung des Propstamtes ging mit zahlreichen Konflikten mit dem Stiftskapitel einher, die wie eine Fortsetzung der Differenzen des Bamberger Domstifts mit dem Dompropst erscheinen. Bereits zwischen 1392 und 1394 klagte das Domkapitel seinen Dompropst Johann von Heideck wiederholt der Veruntreuung der Pfründeneinkünfte an. Dieser rechtfertigte sich mit Einkunftseinbußen seiner Propsteigüter aufgrund feindlicher Übergriffe, allen voran der aktuellen Hussiteneinfälle, denen das Hochstift ausgesetzt gewesen sei, sodass er nicht zu Zahlungen imstande gewesen wäre. Johann von Heideck zahlte auch dann nicht, als nach einer Prüfung durch zwei Mitglieder des Domkapitels die Schwächung der Güter zwar bestätigt, aber die Einkünfte als ausreichend deklariert wurden, ${ }^{316}$ und auch nicht, als Bischof Lamprecht (amt. 1374-1398) ihn in seinem Urteil zur Zahlung mahnte. ${ }^{317}$

1398 bestätigten der Dompropst, der Domdekan, alle Domämter, Domkanoniker (einschließlich des Propstes von St. Martin in Forchheim und des Propstes von St. Gangolf) und mehrere Erzdiakone die Statuten und Gewohnheiten des Domkapitels, welche gleichzeitig auch auf die anderen Kollegiatstifte angewandt wurden. ${ }^{318}$ In den Jahren 1406 bis 1408 verschärften sich die Auseinandersetzungen zwischen dem Dompropst und dem Domkapitel trotz aller Schlichtungsversuche, welche erst mit einem Statut von 1409 beigelegt werden konnten, das allgemein eine Emanzipation des Domkapitels zum Inhalt hatte. ${ }^{319}$ Dass

315 So ist er wohl bischöflichen Visitationen ferngeblieben, hat dem Gangolfer Kapitel Getreide und Pfründen vorenthalten, das Propsthaus verfallen lassen, eine Konkubine unterhalten und jahrelang keiner Messe beigewohnt. Näheres dazu in der kopial überlieferten Urkunde des Bamberger Bischofs Friedrich III. von Aufseß (amt. 1421-1431) von 1431 im Kopialbuch StABa Stift St. Gangolf, Akten und Bände Nr. 3 Teil II S. 311 und Johannes Looshorn: Die Geschichte des Bistums Bamberg, Bd. 4: Das Bistum Bamberg von 1400 - 1556. Bamberg 1900. S. 212-213.

${ }^{316}$ Urkunde des Domkapitels vom 15. Juli 1394 in StABa BU 4442.

317 Bischöfliche Urkunde vom 17. Oktober 1394 in StABa BU 4451.

318 „Statuta et consuetudines [...] pro nobis et nostris successoribus et pro omnibus dicte ecclesie Bambergensis canonicis“ in Urkunde des Domkapitels von 27. November 1398 in StABa BU 4665.

${ }^{319}$ Der gesamte Fall in Johannes Looshorn: Die Geschichte des Bisthums Bamberg, Bd. 3: 
das Stift St. Gangolf 1433 ebenfalls Statuten verliehen bekam, welche unter anderem die Pfründenverwaltung durch den Propst regelte, scheint da kein Zufall zu sein.

Bischof Anton von Rotenhan förderte nicht nur im Stift St. Gangolf die Verfassungsentwicklung. Seine Amtszeit fiel in die Zeit des Immunitätenstreits, in dem er sich, anders als viele seiner Vorgänger, für die Belange des Klerus, besonders des Domkapitels, einsetzte. ${ }^{320}$ Als 1435 der Abt des Klosters Michelsberg starb, bestimmte der Bischof nicht nur Johann Fuchs als Propst von St. Jakob zum neuen Abt, sondern er machte dem Kloster Vorgaben, wie sie ihre Abtswahl durchzuführen hatten. ${ }^{321}$ Unter den Zeugen dieses Vorgangs ist auch der Gangolfer Dekan Johann Schank, welcher zwei Jahre zuvor die Statuten für sein Stift von ebenjenem Bischof entgegennahm. Der Bischof konnte aufgrund seines Bestätigungsrechtes starken Einfluss auf die Statuten einer kirchlichen Einrichtung nehmen. ${ }^{322}$ Die institutionelle Grundlage eines Kollegiatstifts waren seine Statuten, wie Bischof Anton 1449 treffend formulierte:

und vor allen dingen den corheren die das tage und nacht mit gotesdinste verdinen dovon nach laute und inhalde irer statut oder briefe ausrichten und bezalen. ${ }^{323}$

Es sind 26 Statuten des Stifts St. Gangolf überliefert, welche thematisch in drei Kategorien unterteilt werden können: ${ }^{324} 1$. Ordnungen, die die

Das Bistum bamberg von 1303-1399. Bamberg 1891. S. 468-470; Näheres dazu in Nöth: Urbare und Wirtschaftsordnungen. 1986. S. 6-7; Der Streit zwischen Kapitel und Propst mit dem Vorwurf, der Propst würde zu viele Einkünfte für sich behalten, war kein seltener Fall und trat beispielsweise im Domstift von Xanten schon in der ersten Hälfte des 13. Jahrhunderts auf, was in der Trennung der Güter des Propstes und des Kapitels 1296 gipfelte. Näheres dazu in Heike Hawicks: Xanten im späten Mittelalter. Stift und Stadt im Spannungsfeld zwischen Köln und Kleve. Köln 2007. S. 66 und S. 68.

${ }^{320}$ Egon Johannes Greipl: Art. "Rotenhan, Anton von (um 1390-1459)”. In: Gatz, Erwin (Hg.): Die Bischöfe des Heiligen Römischen Reiches 1448 bis 1648. Ein biographisches Lexikon. Berlin 1996. S. 596.

321 "Instrumentum electionis abbatis Johannis Fuchs electi per dominum Antonium episcopum babenbergensem" vom 25. April 1435 im Kopialbuch StABa Kloster Michelsberg, Akten und Bände Nr. 46 fol. 203‘-207‘, hier: fol. 203‘.

322 Als Beispiel die Würzburger Kirchen in Alfred Wendehorst: Stadt und Kirche. In: Wagner, Ulrich (Hg.): Geschichte der Stadt Würzburg. Bd. 1: Von den Anfängen bis zum Ausbruch des Bauernkrieges. Stuttgart 2001. S. 255-271, hier: S. 264.

${ }^{323}$ Bischöfliche Urkunde vom 8. November 1449 in StABa A 120 L 131 Nr. 753.

324 Bei der folgenden Unterteilung dient Marchals Erfassung der Statuten des 
Rechte und Pflichten der Ämter behandeln; ${ }^{325}$ 2. Ordnungen, die das Stiftsleben regeln (Aufnahmemodalitäten, Residenzpflichten, Pfründen, Kanonikerhöfe); ${ }^{326}$ und 3. Ordnungen, die Gottesdienst und Kirchenunterhalt thematisieren (Gebete, Messen, Prozessionen, Altarschmuck). ${ }^{327}$ Die Regelungen rund um das Stiftsleben überwiegen auffällig, besonders sind es die Bezüge und Geldzuwendungen, die die größte Aufmerksamkeit erfuhren. Dies erklärt sich aus den Entstehungsumständen der Statuten als Schlichtungsmittel zwischen Propst und Kapitel und sind auch in den Statuten anderer Kollegiatstifte in diesem Umfang $\mathrm{zu}$ finden.

Die Regelungen rund um den Gottesdienst finden sich hingegen verstärkt in den Consuetudines, den Gewohnheiten, welche sich in den

Kollegiatstifts St. Peter in Basel als Orientierung. In Guy P. Marchal: Die Statuten des weltlichen Kollegiatstifts St. Peter in Basel (Quellen und Forschungen zur Basler Geschichte, Bd. 4). Basel 1972. S. 108.

${ }^{325}$ Kapitel 2: de preposito et praepositure ecclesie nostre administratione et de juramento et cautione praepositi; Kapitel 3: de decano ecclesie nostre eiusque officio et iuramento praestando; Kapitel 4: de scholastico ecclesie nostre et eius officio; Kapitel 5: de custode ecclesie nostre et eius officio; Kapitel 6: de cellerario ecclesie nostre et eius officio; Kapitel 7: de oblegiario vel magistro fabrice ecclesie nostre et eius officio.

${ }^{326}$ Kapitel 1: de ordinatione divini cultus ibidem; Kapitel 8: de computationibus annualibus officialium praedictorum; Kapitel 8: de computationibus annualibus officialium praedictorum; Kapitel 9: de sigilli nostri capitularis custodia; Kapitel 10: de non dando canonicatu necnon de collatione canonicatuum praebendarum et vicariarum ac dispossitione officiorum ecclesie nostre; Kapitel 11: de statutis dandis in admissione canonici et iuramento praestando; Kapitel 12: de emancipatione et receptione ad capitulum et iuramento canonici capitularis; Kapitel 13: de cappa chorali novi capitularis canonici et carentia vocis capitularis; Kapitel 15: de distributione et receptione fructuum prebendalium; Kapitel 16: qualiter fructus praebendare absentium distribuantur et actus chori pro eisdem disponantur; Kapitel 17: de fructibus deservitis obeuntius canonicorum et vicariorum ecclesie nostre disponens; Kapitel 18: de corpore prebendali absentum exemptorum nostro capitularium ac obeuntium canonicorum et de duplo decani et cellerarii; Kapitel 19: de dispositione fructuum praebendarum vacantium; Kapitel 20: quibus canonicis fructus annigratie succedere quique eis carere debeant; Kapitel 21: de perceptione oblagiorum solutione canonum et peractione anniversariorum ac obedientia vicariorum; Kapitel 22: de infirmis quid cuilibet infirmitate durante debeatur; Kapitel 23: de tempore quo quis se absentare poterit preter fructum subtractionem; Kapitel 24: quomodo a debitoribus canonicis creditoribus eorum per capitulum requi rentibus disponatur satisfieri; Kapitel 25: de dispositione quo ad curias canonicates; Kapitel 26: de executoribus testamentorum; Kapitel 27: qualiter bona ecclesie cum ad judicia trabuntur debeant defensari; Kapitel 28: de prohibitione alienationum bonorum et clenodiorum ecclesie et registro generali procurando.

${ }^{327}$ Kapitel 14: de sacerdotis in choro installatione. 
meisten Quellen direkt an die Statuten anschließen und mit ihnen zusammen einen Corpus bilden. Sie stellten eine andere Art der Normgebung dar, denn es waren innerstiftische Regelungen, die vom Kapitel verabschiedet wurden und, anders als die Statuten, ohne den Einfluss des Bischofs entstanden. ${ }^{328}$ Für St. Gangolf sind 17 Consuetudines überliefert. Sie stellten eine Ergänzung zu den Statuten dar, die bestimmte Aspekte der Disziplin und des Gottesdienstes regelten. ${ }^{329}$ So werden das Verhalten bei Prozessionen und im Chor ebenso wie Regelungen der Bekleidung, der Verbeugungen und des Schweigens, sowie Vikarien und Präsenzgelder thematisiert. ${ }^{330}$ Die überlieferten Consuetudines des Stifts St. Gangolf stammen alle von 1523, als auch die Stau-

328 Kassius Hallinger: Consuetudo. Begriff, Formen, Forschungsgeschichte, Inhalt. In: Max-Planck-Institut für Geschichte (Hg.): Untersuchungen $\mathrm{zu}$ Kloster und Stift (Veröffentlichungen des Max-Planck-Instituts für Geschichte, Bd. 68. Studien zur Germania Sacra, Bd. 14). Göttingen 1980. S. 140-166, hier: S. 143.

${ }^{329}$ Näheres dazu im Kapitel 5.1 Gottesdienst und Prozessionen.

330 „Consuetudines ecclesie beate Marie in Teuerstat von Dekan Johannes Schank von 1523:

- De vicariis officandis et missis pro defunctus

- De ceteris consuetudinibus

- De pulsum ad primissariam

- Quando cappis utendum sit

- De inclinationibus

- De statione vel sessione

- De silentio

- De genuflexionibus

- De introitum vel exitum

- De portione presentiarum

- De introitum

- De inclinatione in exitum

- De vestibus

- Qualiter pertranseat chorus

- De processionibus consuetis

- De processionibus solemnibus in ecclesia maiori

- Qualiter agendum sit circa sepulturam et exequias defunctorus."

im Statutenbuch StABa Stift St. Gangolf, Akten und Bände Nr. 130 fol. 87‘-92‘. Die gleichen Consuetudines im Statutenbuch StABa Stift St. Gangolf, Akten und Bände Nr. 131 fol. 35-39‘; AEB Rep. I Akten des Schlundrepertoriums Akt 121 unfoliiert; SttABa D 3001 HV Rep. 2 Nr. 264 fol. 54-73‘ und Nr. 265 unfoliiert. Außerdem findet sich eine Abschrift der Consuetudines ohne Statuten im Besoldungsbuch des Gangolpher Kirchners von 1601 in SttABa HV Rep. 2 Nr. 522 fol. 43-48،. 
ten neu aufgelegt wurden. Frühere Consuetudines sind nicht überliefert.

\subsubsection{Kapitelsiegel}

Das Kapitelsiegel authentifizierte Urkunden und Rechtsakte, die im Namen der Gemeinschaft geschlossen wurden, also einen überpersönlichen Aussteller repräsentierten. Das Siegel manifestierte das Kapitel als rechtsfähige Einrichtung, die sich als einmütige Gemeinschaft verstand und als solche handelte. Jedoch konnten laut mittelalterlichem Kirchenrecht Körperschaften nicht eigenständig siegeln, sondern mussten sich durch eine natürliche Person vertreten lassen - für Dom- oder Kollegiatstifte waren dies meist deren Propst oder Dekan. ${ }^{331}$ Ein korporatives Bewusstsein, das die Siegel von Domdignitären überflüssig machte und die Ausbreitung von Kapitelsiegeln bestärkte, entwickelte sich erst im Laufe des 12. Jahrhunderts. Auch für das Stift St. Gangolf sind die ersten überlieferten Siegel die des Dekans und des Propstes. ${ }^{332}$ Das erste nachweisbare Auftreten eines Kapitelsiegels im Jahr 1295 erfolgte in Verbindung mit dem Siegel des Marquard, Dekan des Stifts St. Gangolf (amt. 1294-1303), sodass das Kapitelsiegel lediglich ergänzend anhing, gemäß dem Wortlaut in der Urkunde decanus totusque capitulum in Turstat Babenbergensis. ${ }^{333}$ Erst 1376 siegelte das Kapitel des Stifts St. Gangolf erstmals nachweislich unabhängig von Propst oder Dekan, als es zusammen mit dem Abt des Klosters Michelsberg und den Kapiteln des

331 Für Augsburg untersuchte dies Thomas Michael Krüger: Zeugen eines Spannungsverhältnisses? Die mittelalterlichen Siegel des Augsburger Domkapitels und der Augsburger Bürgerschaft. In: Späth, Markus (Hg.): Die Bildlichkeit korporativer Siegel im Mittelalter. Kunstgeschichte und Geschichte im Gespräch. Köln/ Weimar/ Wien 2009. S. 239-260, hier: S. 240.

332 Siegel des Ebo, Dekan des Stifts St. Gangolf (amt. 1240-1261), von 1242 in StABa BU 613 (Anhang Tabelle 1: Siegel Nr. 1); Siegel des Albert Graf von Schlüsselberg, Propst des Stifts St. Gangolf (amt. 1268-1285), vom 23. April 1275 in StABa BU 881 (Anhang Tabelle 1: Siegel Nr. 2); und Siegel des Leupold von Grindlach, Propst des Stifts St. Gangolf (amt. 1285-1302) vom 2. Juli 1285 in StAWu Kloster Ebrach, Urkunden 1285 VII 2/I (Anhang Tabelle 1: Siegel Nr. 3).

${ }^{333}$ Urkunde des Kapitels von St. Gangolf vom 25. Mai 1295 in StAWu Kloster Ebrach, Urkunden 1295 V 25. 
Stifts St. Stephan und St. Jakob von Bamberg ergänzend zu Lamprecht, Bischof zu Bamberg (amt. 1374-1398), und dem Domkapitel den Verkauf der Güter, Festungen und Schlösser Frankenberg, Friedburg, Atersee und Osterhofen bestätigte. ${ }^{334}$ In den folgenden Jahrhunderten sind die Rechtsvorgänge, die durch das Kapitelsiegel beglaubigt wurden, zwar weiterhin durch Propst oder Dekan in Verbund mit dem Kapitel als Aussteller beurkundet, jedoch siegelten die Amtsträger in den meisten Fällen nicht. ${ }^{335}$ Der Auftritt des Kapitels als eigenständiger Siegler seit Ende des 14. Jahrhunderts und das damit ausgedrückte korporative Selbstverständnis fällt in die Zeit der Ausbildung der Stiftsstatuten Anfang des 15. Jahrhunderts samt der Emanzipation gegenüber dem Propst zur Sicherung des Stiftsvermögens.

Als allgemeines Phänomen bei der Wahl von Siegelbildern durch geistliche Konvente und Kapitel griff auch das Kapitel des Stifts St. Gangolf auf die Darstellung der Patrone der Kirche zurück. ${ }^{336}$ Für das Kapitelsiegel von St. Gangolf sind zwei Typen nachweisbar, die zeitlich aufeinanderfolgen: Der ältere Typ findet sich in dem Zeitraum zwischen $1295^{337}$ bis etwa zum Jahr $1400^{338}$ und zeigt eine auf einer schlichten

\footnotetext{
${ }^{334}$ Bischöfliche Urkunde von 1376 in StABa BU 3726.

335 Als Mitsiegler einer bischöflichen Urkunde vom 5. August 1390 ist zwar Heinrich, Dekan von St. Gangolf (amt. 1387-1395), genannt, angehängt wurde aber das Kapitelsiegel. In StABa BU 4261; Am 28. August 1406 beurkunden Dekan und Kapitel des Stifts den Verkauf von Güter in Kirchleus, aber der Dekan tritt nicht als Siegler auf. In StABa Kloster Langheim, Urkunden 1406 VIII 28; Zwar tritt am 8. November 1449 in einer bischöflichen Urkunde auch der Gangolfer Propst neben dem Kapitel als Siegler auf, jedoch wird über sein Siegel keine Zugehörigkeit zum Stift St. Gangolf deutlich, welche allein durch das Kapitelsiegel vermittelt wird. In StABa A 120 L 131 Nr. 753; und ebenso für den 16. Juni 1466 in StABa A 120 L 131 Nr. 757; Am 30. Mai 1466 werden Dekan und Kapitel als Aussteller genannt, aber nur das Kapitel siegelt. In A 120 L 131 Nr. 724; In einer Streitbeilegung zwischen dem Propst von St. Gangolf und der Stadt Hollfeld vom 22. August 1468 siegelt das Kapitel wieder im Verbund mit dem Propst. In StABa A 120 L 133 Nr. 879; Am 25. April 1526 werden Dekan und Kapitel als Aussteller genannt, aber nur das Kapitel siegelt. In A 120 L 131 Nr. 726; und ebenso am 31. Mai 1534 in AEB Rep. I Pfarrei St. Gangolf U 822.

${ }^{336}$ Näheres im Kapitel 3.2.4 Patrozinien in den Siegeln.

${ }^{337}$ Das erste nachweisbare Kapitelsiegel älteres Typs in StAWu Kloster Ebrach, Urkunden 1295 V 25 (Anhang Tabelle 1: Siegel Nr. 4).

338 Das letzte nachweisbare Kapitelsiegel des älteren Typs in StABa BU 4261 von 1390 (Anhang Tabelle 1: Siegel Nr. 23).
} 
Bank sitzende Maria mit Kind und einem Gegenstand in der Hand, vielleicht dem symbolträchtigen Granatapfel oder einer Taube. ${ }^{339} \mathrm{Ab}$ 1400 ist ein neuer Typus des Gangolfer Kapitelsiegels nachweisbar. ${ }^{340}$ Der sitzenden Maria mit Kind im oberen Siegelfeld wird ein stehender Gangolf mit Lanze und Schild im unteren Segment beigestellt. ${ }^{341}$ Kunsthistorisch interessant sind die architektonischen Hintergründe, welche das Siegelfeld nun strukturieren und den zwei Heiligen jeweils einen eigenen Raum zugestehen, wobei die Maria als Mutter Gottes den renommierteren Platz oberhalb des heiligen Gangolfs einnimmt und ihre Stellung der seinen übergeordnet ist. Diese gestalterische Darstellung von Architekturen ist als Auswirkung eines neuen Kunstgeschmacks der Zeit zu sehen und präsentiert die Kirche als Hauptgebäude des Stifts pars pro toto für die Gemeinschaft. ${ }^{342}$ Das Kapitel des Stifts St. Gangolf zeigt sich durch die innerhalb des Kirchengebäudes greifbar werdenden Patrone und nutzt architektonische Bezüge zur Umschreibung seiner Wirkungsstätte. Die Identifizierung mit dem Kirchengebäude, oder vielleicht Kapitelsaal, wird dann bedeutend, wenn man sich bewusst macht, dass mit der Auflösung der vita communis ein gemeinsamer Raum der Kanoniker nur noch in Form des Kapitel- oder Chorsaals bestand. Er bildete also das Herzstück der Gemeinschaft, sodass seine Darstellung auf dem Kapitelsiegel als zentrales Rechtsmittel des Stiftes gerechtfertigt scheint.

Die Mikroarchitektur ist im Falle der Gangolfer Kapitelsiegel nicht sehr detailliert ausgeformt und eher schlicht gehalten. Trotzdem ist der neuere Typ des korporativen Siegels weitaus detailreicher als der ältere, dessen Bildtradition der sitzenden Maria, anstatt einer einfachen Bank, nun einen verzierteren Thron zuweist. Der dargestellte Heilige Gangolf

${ }^{339}$ Anhang Abbildung 2.

340 Das erste nachweisbare Kapitelsiegel neueren Typs in StABa Kloster Langheim, Urkunden 1406 VIII 28 (Anhang Tabelle 1: Siegel Nr. 31).

${ }^{341}$ Zur Illustration das Kapitelsiegel von 1534 im Anhang Abbildung 3.

${ }^{342}$ Markus Späth: Mikroarchitektur zwischen Repräsentation und Identitätsstiftung. Die Siegelbilder englischer Klöster und Kathedralkapitel im 13. Jahrhundert. In: Albrecht, Uwe/ Kratzke, Christine (Hgg.): Mikroarchitektur im Mittelalter. Ein gattungsübergreifendes Phänomen zwischen Realität und Imagination. Leipzig 2008. S. 253-277. hier: S. 255. 
erinnert in Haltung und Ausstattung stark an den bisher im Kellersiegel vorkommenden Ritterheiligen mit Fahne und gekreuztem Schild. Die ältere Forschung war sich dieser zwei Typen des Gangolfer Kapitelsiegels nicht bewusst und erwähnte bloß den jüngeren. ${ }^{343}$

Die Wahl des Siegelbildes war keineswegs eine willkürliche, sondern unterstellte dem Heiligen in gewisser Weise die Siegelführerschaft. Mit dem Übergang des Kapitelsiegels von der alleinigen Abbildung Marias hin zur Abbildung der beiden Hauptheiligen Maria und Gangolf zeigt sich nicht zuletzt die Entwicklung einer eigenen Bildtradition, die durch die Aufnahme des heiligen Gangolfs als Repräsentant der Kanonikergemeinschaft eine Identität der Gruppe schafft. Das Stift Haug in Würzburg beispielsweise kann ein Kapitelsiegel vorweisen, das sich über all die Jahrhunderte in seiner Ikonografie kaum veränderte. ${ }^{344}$

Laut den Gangolfer Statuten waren für die Verwahrung des Kapitelsiegels zwei Kapitularkanoniker zuständig, und zwar der älteste und der jüngste. ${ }^{345}$ Diese zwei Kanoniker übernahmen mit der Siegelführung die Befugnisse, Rechtsakte über Güter, Einnahmen und Ausgaben des Stifts $\mathrm{zu}$ besiegeln und stellvertretend Reverse zu beglaubigen. ${ }^{346}$ Die Nebeneinanderstellung von Maria und Gangolf findet sich in den Bildern der Amtssiegel nicht. Dies war ausschließlich ein Phänomen des Kapitelsiegels ab 1400 und blieb der Repräsentation der Gemeinschaft vorbehalten. Die Amtspersonen, die am Stift St. Gangolf anhand der

\footnotetext{
343 "Das Kapitelssiegel stellte die Bildnisse der Jungfrau Maria als den ersten und St. Gangolphs als zweiten Kirchen- und Schutzpatron dar; in einem zweispitzigen Siegel v. J. 1528 steht die Muttergottes oberhalb dem heil. Gangolph; in späterer Zeit stellte man diese beiden Kirchenpatrone in gleicher Linie nebeneinander." in Das Collegiatstift zu U. L. Frau und St. Gangolph in Bamberg. In: Kalender für katholische Christen. 1881. S 85.

${ }^{344}$ Dargestellt werden die beiden Heiligen Johannes der Evangelist und Johannes der Täufer. In Bünz: Stift Haug in Würzburg. 1998. S. 184.

345 "Sigillum vero nostrum capitulare debet per duos canonicos e nobis hoc ordine fideliter custodiri, videlicet que senior post decanum et iunior canonici capitulares per illum annum primum debeant." in Statut Nr. 9 über das Kapitelsiegel im Statutenbuch StABa Stift St. Gangolf, Akten und Bände Nr. 130 fol. 64‘.

346 "Contractus vero cuiuscumque locationis bonorum censuum seu reddituum quarum libet personarum ecclesie nostre qui sigillo capitulari debent roborari non tradantur alicui expediti, nisi littera vulgariter reversa nunccupata etiam a personis locationis recipientibus fuerit“ in Statut Nr. 9 über das Kapitelsiegel im Statutenbuch StABa Stift St. Gangolf, Akten und Bände Nr. 130 fol. 65.
} 
überlieferten Siegel neben dem Kapitel als unabhängige siegelnde Kräfte gesichert nachgewiesen werden konnten, waren der Propst, der Dekan und der Keller. Eine interessante Ausnahme im Bildprogramm der Siegel des Stifts St. Gangolf stellt ein Siegel des Kustos von 1329 dar. ${ }^{347}$

\subsubsection{Stiftskirche}

Der Bau der Stiftskirche von St. Gangolf fällt in die Frühzeit des Bamberger Bistums. Umso bedauerlicher ist es, dass sich von den Kirchenbauten des 11. Jahrhunderts nur wenige erhalten haben. Allein die Stiftskirche von St. Jakob ist in ihrer ursprünglichen Bauform zu erahnen. ${ }^{348}$ Die These, dass man mit der Gangolfskirche noch heute eine der ältesten Gebäude Bambergs bewundern kann, ist dahingehend kritisch zu betrachten. ${ }^{349}$ Wann die Kirche von St. Gangolf fertiggestellt wurde, kann nicht sicher festgestellt werden. Das einzige Zeugnis, das das Datum 1063 als Weihedatum der Kirche erwähnt, ist ein Eintrag in den Bischofsannalen des Martin Hoffmann, welche erst um 1600 entstanden und als verlässliche Quelle generell zu hinterfragen ist, da die Herkunft seiner Informationen im Dunkeln bleiben. ${ }^{350}$ Doch selbst wenn die genauen Hintergründe unklar sind, kann man sich aufgrund der Überschneidungen in der Quellenlage der Vermutung anschließen, dass die ursprüngliche Stiftskirche noch im 11. Jahrhundert fertiggestellt wurde. Leider hat das heutige Gebäude mit dem ursprünglichen Bau wenig gemein, denn es wurde im Laufe der Jahrhunderte weitgehend verändert. ${ }^{351}$ Bereits im 12. Jahrhundert wurden unter dem Bamberger Bischof Otto I. Baumaßnahmen an der Gangolfskirche vorgenommen. So

\footnotetext{
${ }^{347}$ Anhang Abbildung 5. Näheres dazu im Kapitel 4.2.4 Kustos und Kirchner. 348 Näheres dazu in Hubel: Kaiser Heinrich II. 2007. S. 103-140. hier: S. 118.

${ }^{349}$ Diese These findet man immer wieder rezepiert und ursprünglich aus Mayer: Bamberg als Kunststadt. 1955. S. 328-329; Paschke: St. Gangolf zu Bamberg. 1959. S. 6; Kohlschein: Die Sankt-Gangolf-Kirche. 1990. S. 9; Zimmermann: Sankt Gangolf Bamberg. 1982. S. 4. 350 „Postero anno 1063. Guntherus, episcopus, Teurstadii in suburbio, trans flumen orientem versus, ecclesiam aedificavit eamque b. virgini, Dei matri et S. Gangolpho, consecravit“ in Hoffmann: Annales Bambergensis episcopatus. 1718. Sp. 77. Eine Einordnung der Quelle im Kapitel 3.1.1 Quellen und Literatur zu den Gründungsdaten.

${ }^{351}$ Hubel: Kaiser Heinrich II. 2007. S. 118.
} 
sollen die zwei Kirchtürme auf eine Initiative Ottos zurückgehen. ${ }^{352}$ Diese wurden im 17. Jahrhundert in welsche hauben umgebaut. ${ }^{353}$ Gesichert ist, dass 1117 Bamberg ein großes Erdbeben ereilte, durch welches vor allem die Michelsberger Klosterkirche Schaden erlitt. ${ }^{354}$ Denkbar wäre, dass die Baumaßnahmen Ottos an der Gangolfskirche ebenfalls auf Schäden durch das Erdbeben zurückgingen. Wahrscheinlicher ist hingegen ein Feuer als Ursprung dringend nötiger Baumaßnahmen an der Gangolfskirche: Laut der Überlieferung des Domstiftes hat es im Jahr 1185 im August an der Domkirche und anderen wichtigen Stadtgebäuden einen großen Brandschaden gegeben, nachdem schon im April des Jahres die Kirche von St. Gangolf gebrannt hatte. ${ }^{355}$ Um 1400 wurden wohl die gotischen Obergeschosse der Türme errichtet und die älteren Aufbauten ersetzt. ${ }^{356} 1488$ wurde der Kreuzgang umgebaut, wobei unter dem Dekan Heinrich Glantz (amt. 1486-1491) drei der vier Seiten abgerissen wurden und an der vierten Seite zur Stiftsschule hin auf Höhe der bereits vorhandenen sechs Fenster ein siebentes Fenster eingebaut wurde. Dies erfolgte mit Beratung des alten statmeister ${ }^{357}$ Kon-

352 „Ad sanctum Gangolphum turres edificavit et fratribus iuxta flumen Rada [Rodach] quinque mansos et duo molendina tribuit." in Excerpta de Ottone ex libris Andreae abbatis s. Michaelis Babenbergensis. In: Pertz, Georg Heinrich (Bearb.): Historiae aevi Salici (MGH SS 12). Hannover 1856. S. 903-909, hier: S. 909; und in Oswald Holder-Egger (Bearb.): Relatio de piis operibus Ottonis episcopi Bambergensis (MGH SS 15/2). Hannover 1888. S. 1151-1166, hier: S. 1163.

353 „Im J. 1671 veränderte man die zwey spitzigen thürme unserer kirche zu U. L. frau und sct. Gangolph in die jetzigen welschen hauben - welches $443 \mathrm{f} 33 / 4$ x frk. kostete. " in AEB Rep. 60 Pfarrarchiv St. Gangolf Bamberg Nr. 3.

354 „1117 Terremotus maximus factus est 3. Non. Ianuar.” in Annales S. Michaelis Babenbergensis. In: Pertz, Georg Heinrich (Bearb.): Annales et chronica aevi Salici (MGH SS 5). Hannover 1844. S. 9-10, hier: S. 10; „1117. Terrae motus factus est.“ in Philipp Jaffé (Hg.): Annales s. Michaelis Bambergenses (Bibliotheca rerum Germanicarum, Bd. 5: Monumenta Bambergensia). Berlin 1869. S. 553-554, hier: S. 553.

355 „1185. Aprilis monasterium sancte Marie in Twerstat combustum est.“ in Jaffé (Hg.): Annales s. Michaelis Bambergenses. 1869. S. 554.

${ }^{356}$ Mayer: Bamberg als Kunststadt. 1955 S. 330. Quellen gibt Mayer nicht an.

357 Das Amt des Stadtmeisters als ausführender Bausachverständiger des städtischen Bauhofs veränderte sich in der zweiten Hälfte des 15. Jahrhunderts hin zu einem Verwaltungsposten zur Unterstützung des administrativ wirkenden Baumeisters. Das eigentliche Bauwesen unterhielt seitdem der Werkmeister. Näheres dazu in Caroline Göldel: Der Bamberger Bauhof und dessen Schriftwesen im 15. Jahrhundert. In: BHVB 123 (1987). S. 223-282, hier: S. 236. 
rad Zimmermann und unter der Ausführung des Baumeisters Paul Steinmetz, der für seine Arbeit 38 Gulden, einen Altarstein und die übriggebliebenen Steine des Kreuzganges erhielt. ${ }^{358}$ Das hier zitierte Rechnungsbuch der Thesaurare von St. Gangolf, ${ }^{359}$ das eine Laufzeit von 1511 bis 1570 hat, beinhaltet jedoch nicht nur den Hinweis auf den Umbau des Kreuzganges im Jahr 1488. Das Rechnungsbuch ist 1511 angelegt worden, ${ }^{360}$ um den Thesauraren als Bauherren und Geldverwalter als Arbeitsinstrument zu dienen, sodass dort die Ausgaben (exposita) und der finanzielle Grundstock (percepta) zu finden sind. ${ }^{361}$ Damit wurden die Angaben über den Umbau des Kreutzganges erst frühestens

358 „Creutzgang belangendt. $\mathrm{Zu}$ wissen das sich die wirdigen und ehrwirdigen hern Heinrich Glantz dechant und das gemein capitel des stiefts unser lieben frauen und s. Gangolfs $\mathrm{zu}$ Theuerstat mit dem ersamen meister Paulus Steinmetz vereindt haben und mit ihme uber einkomen sundt also das er ihn die viren seiten an den kreutzgang desselben stiefts an der schule mit sechs fenstern ihn allerweise und form der andern dreier fensterseiten, darum mit ghauen steinwerk und ihn der mitte derselben seiten an des siebenden fensters stat einen ausschus in den creutzgang gegen der hinten, mit einen altar einen pogen ihn der hohe der andern fenster darneben mit einen gewelblein vorn hin ein zirlichen fenster mit einem pfosten und furm stuck und darneben mit zweien schlitz fensterlein und darob unter dem tag mit einen ghauenen simslein mit weisen stein, alles auf sein eigen koste und verlegen mit steinkalg abbrechen und mauern nach noturft zwischen hie und sant Walpurgtag schirst komendt ungeuerlich machen und fertigen soll, und fur solchen bau, arbeit, gost und alles darlegen, sollen die vorbemelten dechant und capitel dem genantem meister Paulussen Steinmetz geben und bezalen achtunddreissig gulden reinischer landeswerung dartzu sollen sie ihme ein altarstein ihn dem obgnanten ausschlus schicken und ihme auch von den stein der mauer die abgebrochen wirt dartzu volgen lassenn, sowohl er der uber gehauenen stein noturftig wirdt und so der genante meister Paulus solchen pau nach der genanten hern gfallen verfertigen und gmachen hat, setzet er zu ihren eheren und erkentnus was sie ihme uber die achtunddreissig gulden zu schenck und er mus geben und meister Cunradi Zimmerman der ält statmeister hat den obgnanten heren geret und versprochen gut dafür zu sein, das der vorgenanter meister Paulus dem gmelten hern solch paw vorkeruch masst und zogeulich thun ausrichten und volbringen soll alle geverde und argelist herinne ausgeschlossen. Geschehen am montag nach Briccii [13. November] im LXXXVIII Jar." in Thesaurarsrechnung (1511-1570) auf Rückseite des Deckblattes in StABa Stift St. Gangolf, Akten und Bände Nr. 191.

359 Thesaurarsrechnung (1511-1570) in StABa Stift St. Gangolf, Akten und Bände Nr. 191 unfoliiert.

${ }^{360}$ Durch den Eintrag in der Spalte Exposita im Jahr 1511 sind nicht nur die Ausgaben für diverse Bauarbeiten belegt, sondern selbst die Kosten, nämlich fünf Groschen, für das Buch selbst: „V grosch fur ein register solche rechnung darein zuschreiben“ in StABa Stift St. Gangolf, Akten und Bände Nr. 191. Näheres zu dieser Quelle im Kapitel 4.2.6 Obleier und Fabrikamt.

${ }^{361}$ Näheres dazu im Kapitel 4.2.6 Obleier und Fabrikamt. 
13 Jahre später in dieser Schrift niedergeschrieben und sind eventuell Abschriften früherer Aufzeichnungen.

Auch der Chor der Stiftskirche von St. Gangolf ist mehreren Bauphasen unterworfen gewesen. Dies überrascht nicht, jedoch stellt sich die Frage, ob, wie Franz Kohlschein und nach ihm Gerd Zimmermann annahmen, der Chor wirklich zu Zeiten der Kirchengründung kurz und fast rechteckig gewesen war. ${ }^{362}$ Stütze dieser These sind die Befunde einer Ausgrabung vom Herbst 1988, durchgeführt vor Ort durch Holger Fries unter der Zuständigkeit des Bayerischen Landesamtes für Denkmalpflege, Außenstelle Schloß Seehof. ${ }^{363}$ Dabei wurden in der Pfarrkirche ältere Baubefunde und Grablegen entdeckt, als für die Verlegung einer Fußbodenheizung Ausschachtungen in Teilen des Mittelschiffes, der Vierung und im Chorbereich vorgenommen wurden. Als aussagekräftig stellten sich Sandsteinmauerreste im Chorbereich heraus, die sowohl eine halbrunde Apsis, als auch Indizien für einen rechteckigen Chorabschluss lieferten. Holger Fries berichtete damals: „Beide Fundamente haben eine gemeinsame Estrichlage; es könnte sich bei diesem Baubefund um einen fast rechteckigen Chorabschluß handeln, welcher der Gründungskirche von 1063 zugerechnet werden könnte, während die Rundapsis eine durch Wachstum des Kollegiatstifts notwendig gewordene jüngere Bauphase wäre. “364 Diese sehr aufschlussreiche Deutung der Befunde würde bedeuten, dass die Kirche, zumindest vorübergehend, einen Chor gehabt hätte, der allerdings aufgrund seiner geringen Größe diesen Namen kaum verdient. Die Bedeutung und auch die Anzahl der Stiftsmitglieder zu dieser Zeit müsste demnach recht klein gewesen sein. Denkbar wäre jedoch auch die Deutung als provisorischer

362 Kohlschein: Die Sankt-Gangolf-Kirche. 1990. S. 11; Zimmermann: Sankt Gangolf Bamberg. 1982. S. 4.

${ }^{363}$ Grabungsunterlagen samt Grabungsbericht von Holger Fries und der Auswertung der Textilanalyse in Bayerisches Landesamt für Denkmalpflege: Grabungsbericht 1988 Ausgrabung: Notgrabung bei Ausschachtungsarbeiten für eine Fußbodenheizung, Maßnahme M-2007-31726-1_0; Bamberg, BA: St. Gangolf, G-1988 (Ü-4-6131-0137); Eine Auswertung der Grabungsergebnisse mit ersten Rekonstruktionsversuch in Pfaffenberger: Aspekte der Stadtentwicklung Bambergs im frühen und hohen Mittelalter aus archäologischer Sicht. 2020. S. 232-234.

364 Ebd. 
Chor, der alsbald durch die halbrunde Apsis ersetzt wurde, schließlich befand sich sowohl auf der rechteckigen Sandsteinmauer, als auch auf der halbrunden eine gemeinsame Estrichlage. ${ }^{365}$ Jedoch wird völlig übersehen, dass es sich bei dem beschriebenen Baubefund um ein nicht vollständig rechteckiges Fundament handelt, was eine Deutung als Fundament des repräsentativen Chores ausschließen müsste. Diesem Zweifel ging auch Holger Fries selbst nach, als er anmerkte: „Bei der Quermauer könnte es sich aber auch um eine für die Einwölbung der Apsis nötige Spannmauer handeln. Klarheit kann letztendlich nur eine umfassende Grabung erbringen. “366

Der Chor in seiner heutigen Ausdehnung als gotisches Bauwerk ist Mitte des 15. Jahrhundert entstanden. ${ }^{367}$ Dies ist deshalb erwähnenswert, da sich die Stadt und seine Kirchenlandschaft zu dieser Zeit unter massivem finanziellen Druck befanden, als die Hussiten vor den Stadttoren standen. Im Zuge dieser Bedrohung kam die Stadt überein, Geld $\mathrm{zu}$ sammeln und sich von der drohenden Plünderung freizukaufen. Darüber hinaus waren Zahlungen nötig, um die aufgrund der Plünderung entstanden Schäden zu reparieren. ${ }^{368}$ Daher waren nach 1430 die Institutionen Bambergs gezwungen, durch Abgaben und Steuern Geldmittel zu beschaffen. Von dieser wirtschaftlichen Notlage, in der sich Bamberg daraufhin befand, erholte sich die Stadt nur langsam. Vor allem auch deswegen, weil der sogenannte Immunitätenstreit das Verhältnis zwischen der Stadt und der Kirchenlandschaft trübte.

Das Stift St. Gangolf muss davon ebenso betroffen gewesen sein. Trotzdem ist es dem Gangolfer Propst Johann Kautsch (amt. 1444-1462) möglich gewesen, einen romanischen Chor an der Stiftskirche durch einen gotischen Neubau zu ersetzen, dessen Schlussstein neben der Maria und dem Ritter St. Gangolf mit Fahne die Inschrift ebenjenes Propstes zierte. So findet man im Chor noch heute die Schlussteine mit dem Wappen des Propstes Kautsch (1458), des Stifts (heiliger Gangolf)

\footnotetext{
365 Ebd.

366 Ebd.

${ }^{367}$ Zimmermann: Sankt Gangolf in Bamberg. 1982. S. 5.

${ }^{368}$ Esch: Zwischen Institution und Individuum. 2016. S. 159-160.
} 
und des Propstes Neudecker (1564). ${ }^{369}$ Der Letztere soll den Chor nach einem Einsturz wieder aufgebaut haben. ${ }^{370}$ Der Schlussstein trägt angeblich noch heute die Inschrift anno dni MCCCCLVIII Johannes Kautsch praepositus. ${ }^{371}$ Der, laut Mayer, vierte Schlussstein mit der Inschrift Ruina chori facta anno 1563 et reaedificata per capitulum 64 um das Wappen des Propstes gibt Zeugnis von einem Ereignis, als ein Teil des Chores 1563 einstürzte, weil wahrscheinlich die Strebepfeiler zwischen den ersten beiden Chorjochen fehlten. ${ }^{372}$

\subsection{Geistliche Ämter}

\subsubsection{Propst}

Die Pröpste der drei kleineren Stifte Bambergs hatten für ihre Häuser die Entscheidungskompetenzen in weltlichen Belangen inne und waren neben der Verwaltung des Pfründenguts für die Vertretung in allen äußeren Angelegenheit zuständig. ${ }^{373}$ Außerdem zeichnete der Propst für die Eintreibung aller fälligen Abgaben der Immunitätsbewohner und der Erträge der niederen Gerichtsbarkeit verantwortlich, also Gerichtsgebühren oder Bußgelder. ${ }^{374}$ So war er laut seinem in den Gangolfer Statuten festgelegten Eid verpflichtet, die vereinbarten Abgaben in Form von Geld- und Naturalleistungen dem Kapitel fristgerecht zukommen zu lassen und keinerlei Gewinne aus seinen Amtsbesitzungen zu veräußern. ${ }^{375} \mathrm{Ihm}$ oblag es, die Kirche und das Propstamt zu

\footnotetext{
${ }^{369}$ Zimmermann: Sankt Gangolf in Bamberg. 1982. S. 13.

${ }^{370}$ Kohlschein: Die Sankt-Gangolf-Kirche. 1990. S. 11.

${ }^{371}$ Mayer: Bamberg als Kunststadt. 1955. S. 332.

372 Mayer: Bamberg als Kunststadt. 1955. S. 332. Quellen nennt Mayer nicht.

${ }^{373}$ So sind beispielsweise Beziehungen zur Reichsstadt Nürnberg vor allem über das Amt des Propstes greifbar: 1440 war der Gangolfer Propst Zeuge, als der Bamberger Bischof Anton (amt. 1431-1459) die Pfarrstelle St. Lorenz in Nürnberg überträgt. In: StANu Rep. 8 Reichstadt Nürnberg, Urkunden der Kirchen in Nürnberg Nr. 58 a; und 1503 war der Gangolfer Propst neben dem Abt von St. Egidius in Nürnberg Zeuge bei der Ernennung des Bischofs von Nocera durch Papst Julius II. In: StANu Rep. 1 b Reichsstadt Nürnberg, Päpstliche und fürstliche Privilegien Nr. 429.

${ }^{374}$ Göldel: Zur Entwicklung der Bamberger Stadtverfassung. 1999. S. 7-8.

375 „Nec bona immobilia quecumque et decimas ipsius praepositure vendere permutare
} 
beschützen und zu verteidigen. ${ }^{376}$ Außerdem hielt er die Rechte an allen stiftseigenen Immobilien. ${ }^{377}$

Der erste Propst von St. Gangolf ist 1108 nachweisbar. ${ }^{378}$ Dieser Eberhardus prepositus Turstatensis ${ }^{379}$ (amt. 1108-1115) tritt als Zeuge in einer Güterübertragung des domstiftischen Vogts von Bamberg auf, wo er in den Reihen der Domkanoniker gleich nach Dompropst und Domdekan genannt wird. Ebenso verhält es sich mit dem zweiten sicher nachweisbaren Gangolfer Propst, der 1142 als Udalricus praepositus sancte Marie (amt. 1140-1144) ebenfalls in der Zeugenliste einer diesmal bischöflichen Urkunde inmitten der Domkanoniker und den anderen Stiftspröpsten auftaucht. ${ }^{380}$ Die Positionierung in den Zeugenlisten deutet darauf hin, dass sich die Stiftspröpste bereits zu diesem frühen Zeitpunkt aus den Reihen der Domkanoniker rekrutierten und das Propstamt an einem der kleineren Stifte eine einträgliche Pfründe, zusätzlich zu den Einkünften eines Domkanonikers, versprach. Obwohl die Verpflichtung zur Ahnenprobe für Anwärter auf einen Sitz im Bamberger Domkapitel erst 1390 schriftlich fixiert worden war, ${ }^{381}$ gehörte

impignorare aut alienare“ in Statut Nr. 2 über den Propst samt Propsteid im Statutenbuch StABa Stift St. Gangolf, Akten und Bände Nr. 130 fol. 58 .

376 „Iura ecclesie et praepositure pro posse meo protegam et defendam." in Statut Nr. 2 über den Propst samt Propsteid im Statutenbuch StABa Stift St. Gangolf, Akten und Bände Nr. 130 fol. 58 ؛

377 "Edificia et officinas in consueto edificio habebo et tenebo." in Statut Nr. 2 über den Propst samt Propsteid im Statutenbuch StABa Stift St. Gangolf, Akten und Bände Nr. 130 fol. $58^{\text {c }}$

378 Friedrich Wachter nennt für das Jahr 1100 einen Friedrich als,,abbas St. Mariae in Turstatt“ in Friedrich Wachter: General-Personal-Schematismus der Erzdiözese Bamberg 1007 - 1907. Bamberg 1908. Nr. 2729. Da sowohl die ungeklärte Herkunft der Information als auch die genaue Deutung des Stiftsproptes als Abt Zweifel an der Existenz des Propstes lassen, soll er hier nicht näher thematisiert werden.

${ }^{379}$ Abschrift von 1883 einer vogteiliche Besitzübertragung vom 19. Mai 1108 in StABa BU 149.

${ }^{380}$ Bischöfliche Urkunde von 1142 in StABa BU 223.

${ }^{381} \mathrm{Im}$ Jahr 1390 wurde die Adligkeit als Vorraussetzung zur Aufnahme in das Domkapitel durch die Wahlkapitulation festgeschrieben. Näheres dazu in Esch: Zwischen Institution und Individuum. 2016. S. 38. Im Juramentenbuch des Domkapitels von 1572 wurde die adlige Abstammung eines neuen Mitgliedes festgelegt: "Ein jeglicher, der auf den stift zu Bamberg zu einer pfrundt komen will, der sol zuvoran benennen seinen vater und seins vatersmutter, sein mutter und seiner mutter mutter, und sol vier haben, die rittermessig und des stiftsgenossen sein, und ir vier anen auch benennen sollen, die da globen und 
die adlige Abstammung im Domkapitel schon weitaus früher zum Merkmal der meisten seiner Mitglieder. So sind ab Ende des 12. Jahrhunderts Gangolfer Pröpste mit adligem Hintergrund nachweisbar, welche überwiegend den Adelsfamilien der Region entstammten. ${ }^{382}$ Jedoch schien die Adelszugehörigkeit keine grundsätzliche Voraussetzung für die Bestallung als Gangolfer Propst gewesen zu sein, wie sich beispielhaft am Propst Johann Kautsch (amt. 1444-1462) zeigt, der seinem Namen zufolge wohl aus einer einflussreichen Bamberger Bürgerfamilie stammte. ${ }^{383}$ Die Untersuchung der Gangolfer Stiftsmitglieder in hohen Ämtern ergab, dass sich der Propst von St. Gangolf nicht selten neben seinen Aufgaben als Domkanoniker in Bamberg auch als Domkanoniker in Würzburg aber auch in Speyer, Augsburg oder Passau betätigte. ${ }^{384}$ Die Verschränkung des Amtes des Gangolfer Propstes und dem des Domkustos zu Bamberg lässt sich bereits für das 12. Jahrhundert greifen. ${ }^{385}$ Ebenso waren Gangolfer Dekane häufig gleichzeitig

schweren, das derselb von den gnanten seinen vier anen geborn sei, und das dieselben sein vier anen rittermessig und des stiftsgenossen sein." in StABa B 86 Nr. 263 fol. 1'. Näheres zur Praxis des Abstammungsnachweises im Bamberger Domstift in Lisa Witowski: Adlige Exklusivität. Aufschwörbuch des Bamberger Domkapitels. In: Original! Pracht und Vielfalt aus den Staatlichen Archiven Bayerns (Ausstellung der Staatlichen Archive Bayerns im Bayerischen Hauptstaatsarchiv). München 2017. S. 146-149.

${ }^{382}$ Laut einer stiftseigenen Auflistung aller Gangolfer Pröpste aus dem 18. Jhd, sind diese von Anfang an adlig. In Protokolle der Kapitelsitzungen (1740-1750) in StABa Stift St. Gangolf, Akten und Bände Nr. 160 fol. 77‘.

383 Die Familie Kautsch wurde von Claudia Esch als durchaus einflussreich in der Funktion der Bamberger Stadtgerichtsschöffen identifiziert. In Esch: Zwischen Institution und Individuum. 2015. S. 249.

384 Auswahl von Gangolfer Pröpsten samt ihren Amtzeiten und zusätzlichen Ämtern: Konrad von Scheinfeld (amt. 1158-1174), Domkanoniker von Bamberg und Würzburg; Albert von Kastell (amt. 1248-1258), Domkanoniker von Bamberg und Würzburg; Heinrich von Brunn (amt. 1380-1388), Domkanoniker in Bamberg und Speyer; Thomas Graf von Wertheim (amt 1417-1431), Domkanoniker in Bamberg und Würzburg; Stephan Beheim, (amt. 1433-1441), Kanoniker am Stift St. Stephan und Domkanoniker in Passau; Melchior Truchsess von Pommersfelden (amt. 1489-1493), Domkanoniker in Würzburg und Domkantor in Speyer; Andreas Fuchs von Dornheim (amt. 1512-1515), Domkanoniker in Bamberg, Augsburg und Würzburg; Erasmus von Neustetter gen. Stürmer (amt. 1565-1594), Domdekan in Würzburg und Propst im Würzburger Stift Haug; Wolfgang Albrecht von Würtzburg (amt. 1595-1610), Domkanoniker in Bamberg und Würzburg und Propst im Bamberger St. Stephan.

${ }^{385}$ In den Zeugenlisten der bischöflichen Urkunden für das Jahr 1152 in StABa BU 264; für das Jahr 1187 in StABa BU 376; und für das Jahr 1190 in StABa BU 387. 
auch Bamberger Domkanoniker, Kanoniker in den Häusern von Nürnberg und Feuchtwangen oder Vikare an verschiedenen Bamberger Kirchen. ${ }^{386}$ Bei den anderen geistlichen Ämtern am Stift St. Gangolf ist die Verflechtung mit weiteren Einrichtungen nicht in dieser Ausprägung zu beobachten. Ihre funktionale Fächerung reichte vielfach nicht über die Region hinaus.

Die Belange des Stiftes standen in der Wahrnehmung des Inhabers des Propstamtes jedoch in der Konkurrenz zu den Pflichten an anderen Häusern. Die Kluft zwischen Propst auf der einen Seite und Dekan als Wortführer der Kapitelmitglieder auf der anderen Seite zeigte sich durch die starke Ausrichtung des Propstes auf das einträglichere Domstift im Gegensatz zum kleineren Kollegiatstift. Bereits die unterschiedliche Standeszugehörigkeit erhöhte die Möglichkeit der Differenzen. Der Propst residierte nicht in einem Kanonikerhaus nahe des Stifts. In vielen Häusern ging die Spaltung zwischen den Funktionsträgern zu ihrem Propst so weit, dass letzterer seinen Aufgaben zur Vertretung der Stiftsgemeinschaft nicht mehr nachkam und sich einträglicheren Diensten und Aufgaben widmete. Das hatte nicht selten hinsichtlich der hauseigenen Verfassung eine Trennung von Propsteigut und Stiftsgut, sowie eine Abdrängung des Propstes aus stiftsinternen Angelegenheiten zur Folge. ${ }^{387}$ Der Propst von St. Gangolf behielt demgegenüber das gesamte Mittelalter hindurch Einflussmöglichkeiten auf sein Stift, jedoch war es vor allem der Dekan, der den Vorsitz des Kapitels als ausführender Amtmann innehatte. Die Beziehung zwischen dem Propst und dem Stiftskapitel von St. Gangolf war von wechselseitigen Beeinflussungen und Kontrollrechten geprägt. Während also beispielsweise die Besetzung der Stiftämter Kustorei, Scholasterei und Kellerei beim Propst lag, ${ }^{388}$ hatte das Kapitel ein gewisses Mitspracherecht bei der

${ }^{386}$ Näheres im Anhang Tabelle 4: Amtsträger.

${ }^{387}$ Marchal: Was war das weltliche Kanonikerinstitut im Mittelalter? 2000. S. 19.

388 "Auch sollen und wolln wir die drey officia mit namen custorey, scolasterey und kelnerey des benanten stifts keinem anderen nicht leyhen dann canonico capitulari der do stimm hat" in Abschrift einer Urkunde des Propstes Melchior Truchseß (amt. 1489-1493) von 1489 in dessen Lehenbuch (1489-1494) in StABa Stift St. Gangolf, Akten und Bände Nr. 123 fol. 3; und mit ähnlichem Wortlaut in der Cautio des Propstes Paul Neydecker 
bischöflichen Einführung des Stiftpropstes in sein Amt, was sich in dem erforderlichen Schwur des Propstes vor dem Kapitel und die daraufhin erfolgende Bestätigung zur Aufnahme des Propstes durch die Kanonikergemeinschaft ausdrückte. ${ }^{389}$

Seit dem Einsetzen einer gewissen Quellendichte im 15. Jahrhundert ist die Trennung von Propstei-, Kapitels- und Obleibesitz zu beobachten, deren Einrichtung jedoch bereits früher vermutet werden kann. ${ }^{390}$ Der Besitzkomplex um Hollfeld und die pröpstischen Vogteirechte darauf bildeten als Gründungsgut eine besonders einträgliche und prestigeträchtige Gütermasse, sodass der Gangolfer Propst mit dem $40 \mathrm{~km}$ entfernten Hollfeld durchweg in engem Kontakt stand: Er hatte vor dem Rat Eidesleistungen $\mathrm{zu}$ verrichten und demonstrierte seine Ansprüche, indem er bei seiner Amtseinsetzung feierlichen Einzug hielt. ${ }^{391}$ Außerdem hatte der Propst das Besetzungsrecht für die Kapelle von Hollfeld inne, welches er ab dem 15. Jahrhundert ausschließlich an einen Kapitularkanoniker des Stifts St. Gangolf vergeben durfte. ${ }^{392}$

\subsubsection{Dekan}

Der erste vermutete Dekan von St. Gangolf trat bereits im Zusammenhang mit der Stiftsgründung in Erscheinung, als ein Adalbero decanus de Duristat auf der Diözesansynode des Bischofs Gunter von Bam-

(amt. 1516-1565) vom 30 Juli 1516 in AEB Rep. I Pfarrei St. Gangolf U 826; und in der Cautio des Propstes Erasmus Neustetter (amt. 1565-1594) vom 27 Januar 1565 in StABa A 120 L 131 Nr. 732; Ebenso im Statutenbuch StABa Stift St. Gangolf, Akten und Bände Nr. 130 fol. 58 .

${ }^{389}$ In der Urkunde StABa A 120 L 131 Nr. 753 vom 8. November 1449 legte Anton, Bischof zu Bamberg (amt. 1431-1459), fest "wir wollen auch, das solchs hinfur von einem ieglichen probst der nach im kumet also unverbrochenlich gehalten werde, des ein yeglicher probst der nu hinfur doselbst probst wirdert, solch zu tun, ee dann er von den corheren aufgenomen wirt, sweren sol".

${ }^{390}$ Näheres dazu im Kapitel 6.3 Entwicklung des Grundbesitzes als Pfründengut.

${ }^{391}$ Schubert: Dissertatio inauguralis. 1768. S. 83.

392 „Et cappelanatum sancti Gangolphi in Holfelt nulli alteri quod canonicis praebendatis capitularibus praefate ecclesie quotiens ea vacare contigerit“" in Statut Nr. 2 über den Propst samt Propsteid im Statutenbuch StABa Stift St. Gangolf, Akten und Bände Nr. 130 fol. $58^{\prime}$. 
berg am 13. April 1059 greifbar wird. ${ }^{393}$ Diese frühe Nennung eines Gangolfer Amtsträgers ist eine Ausnahme. Die nächsten Vertreter des Amtes lassen sich erst wieder im 12. Jahrhundert fassen. ${ }^{394}$

Der Dekan besaß eine herausgehobene Stellung im Stift, leitete den Gottesdienst und die Kapitelversammlungen. Darüber hinaus hatte er die Gerichtsbarkeit sowohl über die Stiftsmitglieder als auch die Immunitätsbewohner inne. So besaß er das Recht, Angehörige der Gangolfer Kanonikergemeinschaft wegen Ausschweifungen und Sorglosigkeit festzusetzen, musste dazu jedoch die Einwilligung des Kapitels einholen. ${ }^{395}$ Die Immunitätsbewohner hingegen fügten sich seinem Urteil als Vorstand des Lehengerichts. ${ }^{396}$ Das Stifts St. Gangolf genoss in dieser Sache freilich keine Sonderstellung - die Disziplinargewalt des Dekans lässt sich ebenfalls für das Stift St. Stephan ${ }^{397}$ und das Bamberger Domstift ${ }^{398}$ nachweisen. Die Kompetenzen des Domdekanatsgerichts überstiegen dabei weit die der kleineren Stifte, da es für die geistliche Gerichtsbarkeit der Diözese sowie die Zivilgerichtsbarkeit über Kirchenangehörige im gesamten Bistum zuständig war. ${ }^{399}$ Die Blutgerichtsbarkeit über Geistliche hingegen, beispielsweise bei Streitigkeiten mit Stadtbürgern, hatte der Bischof, nicht der Zentrichter, als regelnde Instanz inne.

393 Jaffé (Hg.): Acta synodi Babenbergensis. 1869. S. 498. Näheres zur Einordnung dieser Quelle im Kapitel 3.1.1 Quellen und Literatur zu den Gründungsdaten.

394 "Gerunc decanus de Tuirstat" 1127 in StABa BU 156 und StABa BU 178; "Gotescalcus decanus sancte Marie in Tuwerstat" 1199 in StABa BU 411.

395 "Quodque ego non velim aliquem canonicum capitularem absque dicti capituli vel majoris ejus partis ejusdem precedente consenu inclaustrare nec aliqua alia insolita pena punire, ac quod in frustibus reditibus ac proventibus quos predecessores mei habuerunt et habere consueverunt, contentus esse velim." im Eid des Dekans abgedruckt im Statutenbuch bei Würdtwein: Nova subsidia diplomatica. 1771. S. 210.

${ }^{396}$ Als einzige überlieferte Quelle ist das Gerichtsbuch des Lehen- und Kapitelsgericht (1527-1536) greifbar in StABa Stift St. Gangolf, Akten und Bände Nr. 211.

${ }^{397}$ Siewert: Das Bamberger Kollegiatstift St. Stephan. 2007. S. 96-97.

398 Heinrich Straub: Die geistliche Gerichtsbarkeit des Domdekans im alten Bistum Bamberg von den Anfängen bis zum Ende des 16. Jhds. Eine rechtsgeschichtliche Untersuchung (Münchener theologische Studien, Bd. 3, 9). München 1957.

399 Wilhelm Neukam: Immunitäten und civitas in Bamberg von der Gründung des Bistums 1007 bis zum Ende des Immunitätenstreits 1440. In: BHVB 78 (1922/24). S. 189369, hier: S. 242. 
Gewählt wurde der Dekan des Stifts St. Gangolf aus den Reihen der Kapitularkanoniker und seine Bestätigung erfolgte durch den Bischof. Um sein Stimmrecht im Kapitel beizubehalten, bezog der Dekan auch nach seiner Wahl weiterhin seine Pfründe als Kapitularkanoniker, sodass er, ebenso wie der Propst, doppeltbepfründet war. ${ }^{400}$ Jedoch hatte er dadurch eine strengere Anwesenheitspflicht als die anderen Kanoniker zu erfüllen. ${ }^{401}$ Bei Abwesenheit wurde er sowohl in seinen weltlichen wie auch in seinen geistlichen Aufgaben durch den ältesten Kapitularkanoniker vertreten. ${ }^{402}$ Die Bedeutung des Dekans für die Gemeinschaft war erheblich, sodass intern Vorsorge getragen wurde, dass dieses wichtige Amt nicht durch Resignation vakant werden konnte. ${ }^{403}$

\subsubsection{Scholastikus und Schulmeister}

Der Scholastikus wurde vom Kapitel gewählt und führte die Oberaufsicht über die Stiftsschule. Außerdem versah er Schreibertätigkeiten. ${ }^{404}$ Ursprünglich war ein Scholastikus an den Kathedralkirchen des Bischofs für die Ausbildung des Nachwuchses zuständig. Bereits früh nach der Trennung von Bischofsamt und Domklerus bildete sich das Amt eines Schulherren heraus, dessen Bedeutungsentwicklung im 12.

\footnotetext{
400 Näheres zum Vergleich mit dem Domkapitel in Nöth: Urbare und Wirtschaftsordnungen. 1986. S. 10.

401 „Ad hoc mentium nostrarum aciem convertimus qualiter decanum ecclesie nostre pro tempore existentem ad residentiam personaliter in ecclesia nostra faciendum pro meliori regimine ecclesie nostre modis convenientibus et rationabilibus inducamus." in Statut Nr. 3 über den Dekan im Statutenbuch StABa Stift St. Gangolf, Akten und Bände Nr. 130 fol. 59.

402 „Ex tunc senior canonicus capitularis praesens pro tempore vices ipsius decani in eius absentia in spirtualibus et temporalibus fideliter supplebit.” in Statut Nr. 3 über den Dekan im Statutenbuch StABa Stift St. Gangolf, Akten und Bände Nr. 130 fol. 60.

${ }^{403}$ Am 9. November 1397 wurde vor der Wahl des neuen Dekans Konrad Reben (amt. 1397-1410) in einer Kapitelssitzung beschlossen, dass der erwählte Dekan ohne Zustimmung des Kapitels seine Amt nicht aufgeben oder tauschen dürfe. Im Kopialbuch StABa Stift St. Gangolf, Akten und Bände Nr. 3 Teil I S. 33-33‘.

404 "Atque singulas ecclesie nostre litteras cum opus fuerit legat et conscribat." in Statut Nr. 4 über den Scholastikus im Statutenbuch StABa Stift St. Gangolf, Akten und Bände Nr. 130 fol. 61'.
} 
Jahrhundert seine Blütezeit fand. ${ }^{405}$ Stiftsschulen boten, vor allem außerhalb der Domstifte, aufgrund der großen Konkurrenz durch die Universitäten nicht mehr als die Elementarausbildung der angehenden Kleriker an. ${ }^{406}$

Für das Stift St. Gangolf sind die ersten scholastici erst für das 13. Jahrhundert nachweisbar. ${ }^{407}$ Eine Bedeutung über das Stift hinaus erlangte dessen Scholastikus Leupold von Hirschberg, der 1314 das Augustinerchorherrenstift an der Pfarrkirche des Marktes Neunkirchen am Brand mit Hilfe des Bamberger Bischofs stiftete. ${ }^{408}$

Am Stift St. Gangolf gehörte die Scholasterei zu einem der drei vom Propst eingesetzten Stiftsämter, wodurch ihm eine ausreichende Bepfründung gesichert war. ${ }^{409}$ Davon hatte der Scholastikus einen Schulmeister, in den Quellen als rector scholarum bezeichnet, $\mathrm{zu}$ unterhalten. ${ }^{410}$ Bereits seit dem frühen 14. Jahrhundert ging die Tendenz dahin, dass der Inhaber der Scholasterei nicht mehr selbst unterrichtete, sondern einen Vertreter anstellte, der seine Aufgaben in Unterricht und Lehre wahrnahm. ${ }^{411}$ Die Verantwortung im personellen wie auch im rechtlichen Sinne lag weiterhin beim Scholastikus. Ein Universitätsabschluss wurde von dem Schulmeister nicht verlangt, sondern allein

\footnotetext{
${ }^{405}$ Marchal: Was war das weltliche Kanonikerinstitut im Mittelalter? 2000. S. 23.

${ }^{406}$ Näheres zur Konkurrenz der Stiftsschulen zu Universitäten aber auch zu bürgerlichkommunalen Stadtschulen in Kintzinger: Stiftsschulen und Wissensvermittlung. 2005. S. 1.

407 "Berhtoldus scolaricus in Twerstat" am 8. November 1246 in StABa BU 645; "Dietericus scolasticus" am 25. Mai 1295 in StAWu Urkunden Kloster Ebrach 1295 V 25.

${ }^{408}$ Näheres dazu im Kapitel 4.3.6 Das Verhältnis zum Stift Neunkirchen am Brand.

${ }^{409}$ Kintzinger: Stiftsschulen und Wissensvermittlung. 2005. S. 14.

410 „Quod scholasticus ecclesie nostre pro tempore schole eisdem ecclesie de idoneo rectore scholarum pro tempore et eidem rectori de expensis aut de salario iuxta decani et capitulari nostri vel maioris eius partis dictamen competenter provideat." in Statut Nr. 4 über den Scholastikus im Statutenbuch StABa Stift St. Gangolf, Akten und Bände Nr. 130 fol. 61 .

411 Martin Kintzinger: Scholaster und Schulmeister. Funktionsfelder der Wissensvermittlung im späten Mittelalter. In: Schwinges, Rainer Christoph (Hg.): Gelehrte im Reich. Zur Sozial- und Wirkungsgeschichte akademischer Eliten des 14. bis 16. Jahrhunderts (Zeitschrift für Historische Forschung, Beiheft 18). Berlin 1996. S. 349374, hier: S. 350.
} 
Grundkenntnisse in Lesen, Schreiben und Singen. ${ }^{412}$ Obwohl die Anstellung als Schulmeister meist von einem Leben am Existenzminimum und von geringer überregionaler Bedeutung gekennzeichnet war, hat es ein Gangolfer Vertreter zu Berühmtheit gebracht: Hugo von Trimberg, der bereits in den Jahren 1260 bis 1306 als Schulmeister am Stift St. Gangolf wirkte und in seinem bekanntesten Werk „Der Renner“ folgenden Vermerk hinterließ:

Der diz buoch getihtet hât, der pflac der schoul ze Tiurstat wol vierzic jâr vor Babenberc und hiez Hûc von Trimperc. ${ }^{413}$

Aufgrund dieser Notiz, die einen eindeutigen Bezug auf das Stift St. Gangolf enthält und damit einen selten Einblick in die Stiftsgeschichte vor dem 15. Jahrhundert gewährte, wurde die Person Hugo von Trimbergs in der älteren Gangolfforschung allzu sehr überbewertet. Zwar hält „Der Renner“ gezielt Beobachtungen zum Kanonikat allgemein fest, jedoch sind seine Spuren am Stift St. Gangolf über seinen gedichteten Zweizeiler hinaus weitgehend verwischt. Allein 1290 ist ein Hugo rector scolarum sancti Gangolfi als Zeuge in einer Bestätigungsurkunde des Bamberger Stifts St. Jakob an das Kloster Ebrach greifbar. ${ }^{414}$ Da Hugo von Trimberg als Schulmeister mit nur geringen Einkünften aus den Zuwendungen des Scholastikus und anderen Schulgeldern rechnen konnte, und schon gar nicht mit einer sicheren Pfründe, werden Klage über seine materiellen Sorgen in seinen Werken gerne als Zeugnisse seiner Zeit als Gangolfer Schulmeister gedeutet. ${ }^{415}$ Sie bleiben jedoch die einzigen Belege dieser These. Die Funktion des „Renners“, den Laien fremdsprachliche, das heißt lateinische, Bildung nahezubrin-

${ }^{412}$ Helmut Flachenecker: Der Zusammenhang zwischen Stiftsschule und Studentenzahlen anhand fränkischer und bayerischer Beispiele. In: Lorenz, Sönke/ Kintzinger, Martin/ Auge, Oliver (Hgg.): Stiftsschulen in der Region. Wissenstransfer zwischen Kirche und Territorium. Ostfildern 2005. S. 167-183, hier: S. 170.

${ }^{413}$ Rudolf Kilian Weigand: Der 'Renner' des Hugo von Trimberg. Überlieferung, Quellenabhängigkeit und Struktur einer spätmittelalterlichen Lehrdichtung (Wissensliteratur im Mittelalter, Bd. 35). Wiesbaden 2000. Anhang "Inhaltsübersicht zu den 'Renner'-Teilen".

${ }^{414}$ StAWu Kloster Ebrach, Urkunden 1290 III 21/II.

${ }^{415}$ So finden sich im Renner Vers 23135 Klagen über Schulden bei den Juden und in den Versen 18919 und 18920 Sorgen über die Versorgungspflicht des Autors über 12 Menschen. Näheres dazu in Weigand: Der 'Renner' des Hugo von Trimberg. 2000. S. 21. 
gen, ${ }^{416}$ wobei er die Bibel als Grundlage aller Weisheit verstand, kann freilich als Reflektion seiner Aufgaben als Schulmeister verstanden werden. Viel mehr erfährt man im „Renner“ über seine weitere Lehrtätigkeit jedoch nicht, sodass die Person Hugo von Trimberg nur bedingt zur Klärung der Gangolfer Stiftsgeschichte beiträgt.

\subsubsection{Kustos und Kirchner}

Der Kustos war mit der Sorge um den Kirchenunterhalt, die Beleuchtung und den Kirchenschatz betraut. ${ }^{417}$ Er war zuständig für die Anlegung und Pflege der Anniversarbücher ${ }^{418}$ und hatte die Verantwortung über die Sakristei, deren Schlüssel er verwahrte. ${ }^{419}$ Außerdem zeichnete er zusammen mit zwei weiteren Kanonikern des Stifts für die Verwahrung des Kapitelsiegels verantwortlich und hatte unter Zeugen eigenhändig eine Inventarliste über alle ihm anvertrauten Kirchenschätze anzufertigen. ${ }^{420}$ Leider ist keine solche Inventarliste erhalten, würde

${ }^{416}$ Verse 24543-24551 „Swa diz bouch vert durch diu lant, in Swaben, in Düringen, in Beiern, in Franken da süln tiutsche liute danken miner sele mit irm gebete, mit almousen, mit andere guotete, daz ich vil fremder lere in han in tiutscher zungen kunt getan, die manic jar vor und dennoch hiure in tiutscher sprache waren tiure." in Ebd. S 23.

417 „Ut res ecclesie et sacristie nostre diligentius ac utilius conserventur.“ in Statut Nr. 5 über den Kustos im Statutenbuch StABa Stift St. Gangolf, Akten und Bände Nr. 130 fol. 61'.

418 Näheres zum Vergleich mit dem Kloster Michelsberg in Johannes Nospickel: Das Michelsberger Necrolog. In: Nospickel, Johannes (Hg.): Das Necrolog des Klosters Michelsberg in Bamberg (Monumenta Germaniae Historica: Libri Memoriales et Necrologia Nova Series, Bd. 6). Hannover 2004. S. 51-186; Dazu auch Elmar Hochholzer: Kloster Michaelsberg und sein Totengedenken. In: Jung, Norbert/ Kempkens, Holger (Hgg.): 1000 Jahre Kloster Michaelsberg Bamberg 1015-2015. Im Schutz des Engels (Begleitpublikation zur Sonderausstellung vom 26. Juni bis 4. Oktober 2015). Petersberg 2015. S. 82-93.

419 „Claves quoque sacristie nostre posterioris in nullu casu alteri quam canonico ecclesie nostre committet" in Statut Nr. 5 über den Kustos im Statutenbuch StABa Stift St. Gangolf, Akten und Bände Nr. 130 fol. 61'.

420 „Et sibi pro parte capituli nostri per duos canonicos sigillum nostrum capitularem habentes assignandis ante plenariam et completam adeptionem, possessionis eiusdem custodie inventarium de propria sua manu conscriptum. " in Statut Nr. 5 über den Kustos im Statutenbuch StABa Stift St. Gangolf, Akten und Bände Nr. 130 fol. 61‘. 
sie doch wichtige Einblicke in die Besitzverhältnisse und stiftische Vermögenswerte liefern.

Ein Kuriosum ist das einzige überlieferte Siegel eines Gangolfer Kustos vom Anfang des 14. Jahrhunderts. ${ }^{421}$ Dieses nimmt durch die Umschrift S(IGILLUM) CINR(ADUI) CUSTODI DE TUERSTAT eindeutig Bezug auf das Stift St. Gangolf, hat jedoch darüber hinaus ikonographisch keinerlei Bezug zu anderen Stiftssiegeln. Siegelführer war der Gangolfer Kustos Konrad Pfaffenhofer (amt. 1307-1331), dessen Siegel einen laufenden, langhälsigen Vogel und Geäst zeigt, während ein Wappenschild völlig fehlt. Erwähnenswert ist das Siegel nicht nur, da es durch seine ungewöhnliche Ausgestaltung auf eine Umnutzung eines stiftsfremden Typars oder einer Gemme hindeutet, ${ }^{422}$ sondern weil ein Kustos am Stift St. Gangolf als Verwahrer des Kapitelsiegels selbst gar keine Siegelgewalt besaß. ${ }^{423}$ Die Urkunde, an der dieses Siegel zu finden ist, ist eine bischöfliche Bestätigung (Vidimus) einer Stiftung von vier Präbenden für die Chorschüler (scholarium choralium) durch den Kustos Konrad, welche 1329 mit Zustimmung des Propstes Friedrich von Hohenlohe (amt. 1323-1351) vollzogen wurde. ${ }^{424}$ Dass neben dem Bamberger Domkapitel und dem Gangolfer Propst der Gangolfer Kustos selbst siegelte, stellt eine Ausnahme dar, und ist im Zusammenhang mit der Stiftung von Privatbesitz zu sehen. Seine Beteiligung an der Legitimierung des Vorgangs stützte sich zweifelsfrei auf seine Rolle als Stifter in diesem einen Rechtsvorgang, und trotzdem wird durch die Siegelumschrift betont, dass er als Kustos des Stifts St. Gangolf siegelte und nicht als Mitglied seiner Familie oder seines weltlichen Standes. Es ist anzunehmen, dass die Familie des sicherlich aus bürgerlichen Verhältnissen stammenden Konrad nicht siegelführend war und er sich aus seiner Stellung als Kustos heraus ein Siegel anfertigen ließ, das er eventuell auch nur dieses eine Mal zum Einsatz brachte. Damit zeigen sich

\footnotetext{
${ }^{421}$ Anhang Tabelle 1: Siegel Nr. 13; und Anhang Abbildung 5.

${ }^{422}$ Näheres zum Typ des Gemmensiegels in Stieldorf: Siegelkunde. 2004. S. 23.

423 "Cui etiam recognitiones tradant de reddendo manibus propriis scriptas vel sigillis ipsorum sigillatas." in Statut Nr. 5 über den Kustos im Statutenbuch StABa Stift St. Gangolf, Akten und Bände Nr. 130 fol. 62.

${ }^{424}$ Bischöfliche Urkunde von 1329 in StABa BU 1988.
} 
umso deutlicher die fließenden Grenzen zwischen Privatsiegel und Amtssiegel im Mittelalter.

Der Kustos hatte neben seinen Aufgaben als Kirchenpfleger die Stellung des Stiftspfarrers inne, also die geistliche Betreuung der Stiftsangehörigen. Der Sprengel der mittelalterlichen Stiftspfarrei ist schwer nachzuzeichnen und umfasste neben dem engeren Stiftsgebiet, bestehend aus den Kapitelhäusern, den Kanonikerhöfen und Vikariatsgebäuden, Teile des Immunitätsgebietes. ${ }^{425}$ Eine interessante Quelle bezüglich des Pfarrsprengels der Gangolfer Kustorei findet sich in einem Zinsregister einer Einzeloblei, in welchem anhängend von um 1600 eine Reihe Häuser in der Zuständigkeit des Gangolfer Kustos als Pfarrer aufgelistet sind. ${ }^{426}$ Darin sind 60 Anwesen aufgeführt, wovon zehn als Kanonikerhöfe (curia canonicorum) ausgewiesen sind, sieben als Vikarierhäuser (domus vicariae), eines zur Stuhlbrüderpfründe gehörig und fünf als Michelsberger Besitzungen in der Theuerstadt - einschließlich dem domus kirchhaus s. Gertrudis und dem domus vicariae s. Gertrudis. ${ }^{427}$ 37 Anwesen sind als domus bezeichnet und mit dem Namen des Bewohners versehen. Die Tatsache, dass die Kanonikerhöfe nicht hintereinander aufgelistet sind, spricht dafür, dass die eingepfarrten Höfe nach einer geografischen Ordnung anhand der Straßen aufgezählt wurden und Exklaven anderer wirtschaftlicher Zuständigkeiten wie selbstverständlich miteinbezogen wurden. So gehörte beispielsweise der Katharinenhof in der Theuerstadt ${ }^{428}$ nicht in den Pfarrsprengel des Gangolfer

${ }^{425}$ Noch der letzte Gangolfer Dekan Schubert (amt. 1790-1803) beschrieb Pfarrrechte des Stifts, die über die Stiftsangehörigen hinaus auf „nahegelegene Distrikte, worin einige hundert Seelen sich befinden“ übergreifen. In Michael Heinrich Schubert: Historischer Versuch über die geistliche und weltliche Staats- und Gerichtsverfassung des Hochstifts Bamberg. Ein Beytrag zur deutschen insonderheit ostfränkischen Geschichte. Erlangen 1792. S. 58.

${ }^{426}$ „Verzeichnis der hauser, so in das stift zu s. Gangolph der custorei die pfarliche gerechtigkeith habe und ein verleibt sind wie folget." abschriftlich vom Anfang des 17. Jahrhunderts im Zinsregister einer Einzeloblei (1703-1748) in StABa Stift St. Gangolf, Akten und Bände Nr. 53 fol. 62 .

${ }^{427}$ Näheres zur Rechtsstellung der Kapelle St. Gertraud in der Theuerstadt im Kapitel 4.3.5.1 Das Verhältnis zur Kapelle St. Gertraud.

${ }^{428}$ Braun: Von der Stiftspfarrei zur Stadtpfarrei. 1984. S. 375; Näheres dazu im Kapitel 4.3.4 Das Verhältnis zum Bürgerspital St. Katharina in Bamberg. 
Kustos, sondern, wie auch das Haupthaus des Spitals, in die Pfarrei St. Martin, sodass der Hof an dieser Stelle nicht mit aufgelistet wurde. Dass sich die neuzeitliche Stiftspfarrei St. Gangolf aus den mittelalterlichen Zuständigkeiten der Kustorei heraus entwickelte, zeigt sich an der Tatsache, dass die Pfarrei noch im 18. Jahrhundert kein eigenes Vermögen hatte und vom Kollegiatstift abhängig war. ${ }^{429}$

Die ersten Inhaber des Kustodenamtes sind für das 13. Jahrhundert belegt. ${ }^{430}$ Der bekannteste Kustos des Stifts St. Gangolf ist Johann Schwanhausen (amt. 1510-1524), dessen reformatorisches Wirken in Bamberg Spuren hinterließ und der zahlreiche Anhänger bei Bürgern und Geistlichen fand. ${ }^{431}$ Nachdem er in Wittenberg zusammen mit Luthers Freunden Spalatin und Amsdorf Theologie studiert hatte, wurde er 1508 Vikar des Maria-Magdalena-Altars am Stift St. Gangolf. 1509 wurde er als Kanoniker aufgenommen und bald darauf zum Kustos ernannt. Dabei war er in Bamberg gut vernetzt und hatte neben Verbindungen zum Hof des Bischofs Georg von Limburg (amt. 1505-1522) auch verwandtschaftliche Beziehungen zum Bürgertum Bambergs. ${ }^{432}$ Während seiner Lutherischen Predigten wuchs seine Anhängerschaft so rasant, dass angeblich eine Kanzel auf dem Kirchplatz von St. Gangolf aufgestellt werden musste, weil die Stiftskirche die zahlreichen Zuhörer nicht mehr aufnehmen konnte. ${ }^{433}$ Im Jahr 1522 wurde ihm mit dem neuen Bamberger Bischof Weigand von Redwitz (amt. 1522-1556) jedoch ein starker Verfechter des katholischen Glaubens entgegengesetzt, sodass er 1524 sein Amt als Kustos verlor und einen Landesverweis erhielt. Er begab sich nach Nürnberg und wurde dort Prediger für die Nonnen des St. Katharinen Klosters, wo er 1528 starb. Er war als Prediger der lutherischen Ideen durchaus kein Einzelfall in der Region und die Unzufriedenheit der Bürgerschaft mündete 1525 im Bauernkrieg. Die Rolle, die das Stift St. Gangolf bei diesen Prozessen gespielt hat, ist

\footnotetext{
${ }^{429}$ Braun: Von der Stiftspfarrei zur Stadtpfarrei. 1984. S. 378.

430 "Ulricus custos in Tyrstat" von 1242 in StABa BU 613 und BU 614; "Egelolfus custor" von 1295 in StAWu Urkunden Kloster Ebrach 1295 V 25.

${ }^{431}$ Geuder: Auch Bamberg hatte seinen Reformator. 1973. S. 1.

${ }^{432}$ Ebd. S. 2.

${ }^{433}$ Ebd. S. 2.
} 
unklar. Der damalige Dekan Hieronymus Hirschberger versuchte wohl durch restriktive Maßnahmen die katholische Ordnung in der Gemeinschaft wiederherzustellen, indem er beispielsweise die Rechtesammlung des Stifts in Kopialbücher zusammenfassen ließ und auf die strenge Einhaltung der Statuten pochte. ${ }^{434}$

In der Verwaltung des Stifts unterstand dem Kustos ein Kirchner, der die Instandhaltung der Kirchenanlage verantwortete und die Gottesdiensten vorbereitete. Jedoch ist ein Gangolfer Kirchner das gesamte Mittelalter hindurch nicht erwähnt. Neben einer kurzen Notiz von 1590 im Zusammenhang mit den Aufgaben des Kustos, ${ }^{435}$ findet sich erstmals die detaillierte Aufgabenbeschreibung eines Kirchners in dessen Besoldungsbuch von $1601 .{ }^{436}$ Der Kirchner war demnach für die Beleuchtung des Kirchengebäudes zuständig, das Kircheninnere aber auch den Kirchhof sauber und von pösen gerüchs ${ }^{437}$ freizuhalten und unbefugte Personen des Gebäudes zu verweisen. Er sollte die Messgewänder, Chormäntel und Fastentücher nach dem vom Kustos aufgestellten Inventar verwahren, sauber halten und bereitstellen ${ }^{438}$ und diesem an Allerseelen beim Seelamt helfen. ${ }^{439}$ Dabei unterstand er immer den Anweisungen des Kustos:

Der kirchner soll kainen todten leuten noch begraben ohne verwissen und bewilligung des custors. Es sey reich oder arm, klain oder groß. Und wan eins bey disem stieft in die kirchen, creutzgang oder kirchhof begraben wird, soll der kirchner das bainhaus aufsperren, dem todtenbegraber sagen, das er die bainer so er im grabmachung findet, mit vleis in das bainhaus zu den anderen ordenlich leg, wan das gescheen, soll er

\footnotetext{
${ }^{434}$ Ohne Angaben von Quellen spricht dies Wachter: General-Personal-Schematismus der Erzdiözese Bamberg. 1908. S. 212. an. Tatsächlich findet sich im Kopialbuch StABa Stift St. Gangolf, Akten und Bände Nr. 1 für das gesamte 16. Jahrhundert der Eintrag "Concordat ego Hieronimus decanus Hirschberger" unter den betreffenden Urkundenabschriften.

435 Regelwerk des Obleiamtes vom 22. Mai 1590 als Anhang eines Registers über Anniversarien und Fabrikzinsen von 1584 bis 1607 in StABa Stift St. Gangolf, Akten und Bände Nr. 29 fol. 186-187. Näheres $\mathrm{zu}$ dieser Quelle im Kapitel 4.2.6 Obleier und Fabrikamt.

436 "Sanct Gangolphs stieftkirchners besoldung” von 1601 in SttABa D 3001 HV Rep. 2 Nr. 522.

${ }^{437}$ Ebd. fol. 5.

${ }^{438}$ Ebd. fol. 9.

${ }^{439}$ Ebd. fol. 12‘.
} 
widerumb zusperren und gute fursehung haben, das nichts unsaubers dahin gewor-

fen werdt, alles sauber und rain halten. ${ }^{440}$

Der Kirchner gehörte dem Laienstand an und soll auch mit seinem weib, kindern, knechten und maiden ein gotzförtchtigs ehelichs leben führen, friedlich und aynig sein, kain zankh, neyd noch unaynigkeidt unter den chorbrudern, nachbarn und andern personen durch sich noch die seynigen nicht berursachen. ${ }^{441}$ Außerdem heißt es, dass er als Schöffe am Immunitätsgericht zu wirken hatte. ${ }^{442}$

Das hier abgesteckte Aufgabenfeld des Kirchners findet sich ebenso in einem Urbar des 17. Jahrhundert, welches die Vikarien und Obleien thematisierte. Dort ist die Rolle des Kirchners als Gerichtsschöffe festgelegt:

Item ein yeder kirchner des stifts zu sanct Gangolf hat einen schopfenstul und man-

zal, so dem ampt incorporit, und im gericht $z u$ sitzen schuldig. ${ }^{443}$

Darüber hinaus verwahrte er laut dem Besoldungsbuch den Kirchenschlüssel, wartete regelmäßig den Uhrturm samt Uhr und war für das Läuten der Glocken zuständig. Dass sich in den Gangolfer Quellen vereinzelt auch ein campanarius, also ein Glöckner, finden lässt, deutet wohl weniger auf ein gesondertes Amt, sondern nur erneut auf den Kirchner hin. Auch ihm ist der Kustos vorgesetzt. ${ }^{444}$

\subsubsection{Keller und Immunitätsgericht}

Der Keller zeichnete verantwortlich für die Verwaltung der Einkünfte, welche das Kapitel vom Propst erhielt. Diese hatte er einzutreiben, zu

${ }^{440}$ Ebd. fol. 12‘-13.

${ }^{441}$ Ebd. fol. 16 .

${ }^{442}$ „XVI summra korn Bamberger mas giebt jerlich dominus praepositus ecclesiae nostrae gleich einem anderen scabinus Martini dem kirchner zu sanct Gangolph stiefft von dem schöpfenstuhl und manzahl so dem ambt incorporirt und im gericht zu sitzen schuldig“ in Ebd. fol. 2 .

${ }^{443}$ Urbar der Vikarien, Obleien und Fragmente (1317-1630) in StABa Stift St. Gangolf, Akten und Bände Nr. 32 fol. 49.

${ }^{444}$ Ein „campanarius“ wird erst für das 16. Jahrhundert erwähnt, als er verpflichtet wurde, sechs Schillinge Heller von Einkünften aus der Oblei Hundsbühl an den Kustos zu zahlen. Im Register der Obleizinsen (1555-1565) in StABa Stift St. Gangolf, Akten und Bände Nr. 23 fol. 65; und im Urbar der Vikarien, Obleien und Fragmente (1317-1630) in StABa Stift St. Gangolf, Akten und Bände Nr. 32 fol. 3، 
lagern und an das Kapitel und seine Ämter in Einzelpfründen auszugeben. ${ }^{445}$ Durch Eid verpflichtete er sich, nur hochwertiges und gereinigtes Getreide, welches durch das Kapitel als sogenanntes Kaufmannsgut klassifiziert werden musste, an die betreffenden Personen zu verteilen. ${ }^{446}$

Darüber hinaus stand der Keller dem Gericht vor, das über die Einwohner der Immunität verfügte, - das Immunitätsgericht, oder in den Quellen häufiger das kellereigericht genannt - wofür er auch ein eigenes Siegel führte. ${ }^{447}$ Unter einer Immunität wird in diesem Zusammenhang ein Sonderbezirk verstanden, in dem die betreffende Gemeinschaft das Recht zur Ausübung der Niedergerichtsbarkeit besaß. Anfangs umfasste dieser Bezirk nur die Kanonikerhöfe, weitete sich dann jedoch auf die Laienbevölkerung aus, die in Beziehung mit der kirchlichen Einrichtung standen. ${ }^{448}$ Die Immunität bezeichnete also das weltliche Herrschaftsgebiet der Stifte, welches von den Einflüssen der domvogteilichen Niedergerichtsbarkeit unabhängig war. Während die Geistlichkeit per se Immunität, das heißt die Befreiung von der weltlichen Gerichtsbarkeit, besaß, war es ein neuer Gedanke, dass die der Kirche

\footnotetext{
445 „Debeatque ipse cellerarius noster pro tempore omnes et singulos praebendales et alios fructus redditus et proventus canonicorum officiorum et personarum ecclesie nostre in quantum sibi ratione officii cellerarie incumbit a domino preposito et aliunde diligenter petere in locis per capitulum deputandis colligere simul reponere ac illis quibus pertinet fideliter distribuere temporibus debitis, dolo et fraude seclusis quibuscunque." in Statut Nr. 6 über den Keller im Statutenbuch StABa Stift St. Gangolf, Akten und Bände Nr. 130 fol. 62 '.

446 "Illos predictos iam fructus prebendales ullo mudo distribuere aut mensurare presumam nisi inprimis et ante omnia dominis meis de capitulo vel iudicibus quibusdam per ipsos dominos ad hoc specialiter deputatis quod sint mercantile venditi debiti et placibiles vulgariter gut Kauffmannsgut nuncupati, probentur.” in Würdtwein: Nova subsidia diplomatica. 1771. S. 215.

447 "Quod cellerarius ecclesie nostre pro tempore super bonis immobilibus ecclesie nostre vel canonicorum vicariorum aut personarum eius sive super feudis censibus et redditibus eorundem quoscumque contractus seu litteras sigillare nec quicumque in praeiudicum eiusdem ecclesie et personarum sive etiam bonorum huiusmodi in iudicio seculari emunitatis ecclesie nostre quod fideliter et iuste exercendum eius officium attinet" in Statut Nr. 6 über den Keller im Statutenbuch StABa Stift St. Gangolf, Akten und Bände Nr. 130 fol. 62 .

${ }^{448}$ Esch: Zwischen Institution und Individuum. 2016. S. 29.
} 
benachbarten Laien von der vogteilichen Rechtsprechung ebenso befreit waren.

Mitte des 12. Jahrhunderts sind erste Nachrichten über die bereits etablierten Bamberger Immunitäten überliefert, als 1154 Bischof Eberhard (amt. 1146-1170) dem Kloster Michelsberg ebendiese gerichtliche Freiheit gewährte. ${ }^{449}$ Im Jahr 1201 ließ sich das Domstift vom Bischof zusichern, dass die Vogteirechte in Bamberg nicht mehr als Lehen übertragen werden sollen. ${ }^{450}$ An die Stelle des Grafenvogts trat nun der Zentgraf als absetzbarer Beamter, der bis ins 15. Jahrhundert hinein die Blutgerichtsbarkeit in Stadt und Immunitäten ausübte. ${ }^{451}$ Immunitätsrichter waren in der Strafgerichtsbarkeit für kleinere Verbrechen, einschließlich Verwundungen, zuständig. Einnahmen entstanden durch die Geldbußen. Ebenso waren die Immunitätsrichter verantwortlich für die Zivilgerichtsbarkeit, welche Streitigkeiten von Privatleuten, Schuldforderungen, Kauf- und Erbzinsverträge umfasste. Ab dem 14. Jahrhundert lag das Richteramt der Immunitäten bei einem Kanoniker der jeweiligen Bamberger Stifte, ${ }^{452}$ in den meisten Fällen beim Keller. Die Kellereigerichte stellten eine Kompetenz der Stifte hinsichtlich eigenständiger Rechtsprechung dar. Dass dies als Konkurrenz zum Machtverständnis des Domkapitels aufgefasst wurde, wird daran deutlich, dass der Keller der Immunitäten ab dem 16. Jahrhundert auf das Domkapitel vereidigt wurde, um diesem die Oberaufsicht zu sichern. ${ }^{453}$

\footnotetext{
${ }^{449}$ Neukam: Immunitäten und civitas in Bamberg. 1922/24. S. 197.

${ }^{450}$ Esch: Zwischen Institution und Individuum. 2016. S. 34.

${ }^{451}$ Neukam: Immunitäten und civitas in Bamberg. 1922/24. S. 231.

452 Ebd. S. 237.

453 "Aidt der kelner oder oberrichter in munteten: Ich, N., gelobe und schwere, nach dem ich von den erwirdigen und edlen N.N., meinem probst, mit der kelnerei sanct N. stifts versehen und darauf den erwirdigigen wolgebornen edlen und hochgelarten hern dechant und capitel des thumstifts zu Bamberg presentirt, auch von inen angenomen worden, das ich wolermelten meinen gnedigen herren, einem erwirdigen thumcapitel, getreu und gewere sein, iren schaden warnen und frommen werben, irer münteten und derselben rechten und gerechtigkeiten, und das daran nichts entzogen, getreulich nach besten meinem vermögen handhaben, darob sein, das die gericht zu gewonlicher zeit und tägen jedes maln vleissig gehalten, die munteter an das stat oder andere gericht nit ziehen lasen, keinen inwoner der munteten one ir vorwissen in die muntet einnemen oder hingegen austreiben in massen das ausgangene mandat solchs mitbringt, auch meinen unterrichter und gerichtsknecht mit irem vorwissen annemen, und do dieselben also von mir angeno-
} 
Schriftzeugnisse über das Gangolfer Kellereigericht sind zum einen die Urkunden, die vom Keller als Richter ausgestellt wurden, und zum anderen die Gerichtsbücher, von denen nur wenige überliefert sind. ${ }^{454}$ Trotzdem geben sie Auskunft darüber, dass das Gericht üblicherweise am Montag gehalten wurde und zwar in Anwesenheit des Kellers als obersten Richters, eines Unterrichters, eines Gerichtsschreibers und der vier Schöffen. Diese hatten vor dem Dekan und dem Kapitel Rechenschaft abzulegen. ${ }^{455}$ Da aus den Urkunden des Kellers als Richter dessen Zuständigkeitsbereich herausgelesen werden kann, dient eine Analyse der darin benannten Häuser, Höfe und Grundstücke als Annäherung an die ungefähre Ausdehnung des Gangolfer Immunitätsgebietes. ${ }^{456}$ Dies muss als Schätzung betrachtet werden, die darüber hinaus aufgrund der schwachen Quellenlage keine Aussage über die Entwicklung der Gebietsausdehnung geben kann. Aber durch einen umfassenden Einblick in die Urkunden des Gangolfer Kellereigerichts im Staatsund Stadtarchiv Bambergs sowie im Archiv des Erzbistums ist diese Schätzung fundiert genug, um eine Diskussionsgrundlage geben zu können.

Die erste Urkunde des Gangolfer Immunitätsgerichts mit dem Keller als Richter findet sich für die Mitte des 14. Jahrhunderts ${ }^{457}$ und bezeichnet den Beginn des Untersuchungszeitraums, welcher im 16. Jahrhundert endete. Nach einer Identifizierung der mittelalterlichen

men, in irer capitelstuben und nirgent anders de gewonliche pflicht von inen begern oder nemen, keine appellation von beiutheiln zulasen, und do mir etwas beschwerlichs, welches etwa $\mathrm{zu}$ schmelerung irer obrigkeiten und herligkeiten gelangen möchte, furfiele, alweg mit irem rate handeln, und uber iren mandaten, wie die iedesmals angeschlagen halten und sonsten durchaus das wenig leisten sol und will, so bishieher von einem oberkelner gelaistet, und einem kelner geburt, und zustehet, getreulich und ungeuerlich. Also helf mit gott und sein heliges evangelium." im Juramentenbuch des Domkapitels 1572 in StABa B 86 Nr. 263 fol. 17-17‘.

${ }^{454}$ Gerichtsbuch des Kellereigerichts (1520-1523) in StABa Stift St. Gangolf, Akten und Bände Nr. 210; und Gerichtsbuch des Kellereigerichts (1589-1595) in StABa Stift St. Gangolf, Akten und Bände Nr. 212.

455 „Darnach Ieronimus Hirsperger dechant und einem erwirdigen capitel nach alter gewonheyt presentirt“ im Gerichtsbuch des Kellereigerichts (1520-1523) in StABa Stift St. Gangolf, Akten und Bände Nr. 210 fol. 1.

${ }^{456}$ Anhang Karte 1: Immunitätsgebiet.

${ }^{457}$ Urkunde des Kellers von St. Gangolf vom 18. März 1347 in StABa BU 2583. 
Straßenbezeichnungen im heutigen Stadtbild, können in Rechtsstreitigkeiten eingebundene Grundstücke lokalisiert werden. Daraus ergibt sich ein Gebiet mit der Gangolfskirche im Zentrum, das sich vom Heiliggrabkloster ${ }^{458}$ bis zur Wunderburg hin erstreckte, ${ }^{459}$ ohne jedoch diese beiden Gebiete einzuschließen. ${ }^{460}$ Die Gertraudkapelle lag inmitten des Gangolfer Immunitätsgebietes, sodass Ewiggeldspenden an die Kapelle nicht selten über das Gangolfer Kellereigericht eingezahlt wurden. ${ }^{461}$ Es werden die Straßenzüge Hundsbühl, ${ }^{462}$ Egelsee, ${ }^{463}$ Hinter St. Gangolf, ${ }^{464}$ Mittelgasse $^{465}$ und der Steinweg mit der Gertraudenkapelle ${ }^{466}$

${ }^{458}$ Urkunde des Immunitätsgerichts St. Gangolf über den Verkauf eines Gartens „gelegen hinter dem Heiligen Grab der einseit stost [...] vorn an dy wegstraß daselbst als man zu den Heiligen Grab hin aus get" vom 1. Juni 1439 in AEB Rep. I Pfarrei St. Gertraud U 101; Ähnlicher Wortlaut in Ebd. U 103 bis U 105 von 1440 bis 1443; und in AEB Rep. I Pfarrei St. Martin U 17 von 1403.

459 Urkunde des Immunitätsgerichts St. Gangolf über den Verkauf eines Hauses mit Garten „auf dem Huntzpuhel gelegen und stözt vorn an dy strazzen do selbenst [...] und hinten an das geßlein das an dy Wunderburg get und an der Wunderburg graben" vom 23. April 1391 in StABa BU 4287; Ähnlicher Wortlaut in A 120 L 131 Nr. 760 von 1475.

${ }^{460}$ Die Grenze zwischen Immunitätsbereich und Stadtgerichtsbereich am Kloster Heilig Grab verlief im 16. Jahrhundert nachweislich entlang der Färbergasse "nördlich davon gehörte der westliche Teil der heutigen Heiliggrabstraße und des Spiegelgrabens zum Stadtgericht, der östliche Teil zur Immunität St. Gangolf." in Christian Chandon: Die Bevölkerung der Stadt Bamberg um 1525. Eine sozialtopographische Skizze. In: Häberlein, Mark/ Zink, Robert (Hgg.): Soziale Strukturen und wirtschaftliche Konjunkturen (Bamberger Historische Studien, Bd. 10). Bamberg 2013. S. 17-51, hier: S. 38.

461 Dies traf immer dann zu, wenn die belasteten Grundstücke in der Gangolfer Immunität lagen. Näheres dazu in den Urkunden des Immunitätsgerichts St. Gangolf von 1439 bis 1453 in AEB Rep. I Pfarrei St. Getraud U 101 bis U 105 sowie U 108 und U 109.

${ }^{462}$ Urkunde des Immunitätsgerichts St. Gangolf über den Verkauf eines Hauses mit Hof und Garten „uf dem Hundspöhel“ vom 18. Mai 1360 in StABa BU 3075; Ähnlicher Wortlaut in StABa BU 4693 von 1399; und in AEB Rep. I Pfarrei St. Gertraud U 109 von 1453. Entspricht der heutigen Nürnberger Straße.

${ }^{463}$ Urkunde des Immunitätsgerichts St. Gangolf über den Verkauf eines Hauses mit Hof „auf dem Hundspuhel und in diser muntat gelegen [...] hinten an den Egelse und vorn an den gemeynen wege stossend“ vom 27. Februar 1492 in AEB Rep. I Pfarrei Unserer lieben Frau U 121; Ähnlicher Wortlaut in A 120 L 131 Nr. 750 und Nr. 751 von 1424 bis 1445. Entspricht der heutigen Egelseestraße.

${ }^{464}$ Urkunde des Immunitätsgerichts St. Gangolf über den Verkauf eines Hauses „hinter sant Gangolf gelegen das einseyt an des brobsthove und mit den andern orten an den wege stossend ist" vom 31. Oktober 1491 in A 120 L 131 Nr. 761; Ähnlicher Wortlaut in A 120 L 131 Nr. 762 von 1493. Entspricht der heutigen Josephstraße.

${ }^{465}$ Urkunde des Immunitätsgerichts St. Gangolf über den Verkauf eines Hauses mit Hof 
umfasst. Dies entspricht in den Grundzügen auch dem Umfang des Immunitätsgerichts St. Gangolfs, das das Bamberger Domkapitel Ende des 16. Jahrhunderts beschrieb, um in einem Rechtsstreit mit der Stadt die Zuständigkeit über die Wunderburg zu klären. ${ }^{467}$ Das Immunitätsgebiet ist demnach um einiges größer, als es Lothar Braun in seiner Untersuchung angenommen hatte. ${ }^{468}$ Isolde Maierhöfer ist in Sachen Ausdehnung des Immunitätsbezirks schon großzügiger, hält sich jedoch an eher allgemeinen Eckpunkten fest. ${ }^{469}$ Zur Rekonstruktion der neuzeitlichen Verhältnisse hingegen können die bis dahin erschlosse-

„hinter sant Gangolf in der Mittelngassen gelegen [...] vorn an die wegstrassenn derselben gassen“ vom 14. April 1477 in AEB, Rep. I Pfarrei Unserer lieben Frau U 114. Entspricht der heutigen Mittelstraße.

466 Urkunde des Immunitätsgerichts St. Gangolf über Verkauf eines Gartens mit Fischgrube „stoßt [...] anderseit an sand Gerdrawtengaße genant so man da selbst an daz wasser get mit der virden seyten hynten an die spitalpewnt" vom 21. Mai 1408 in AEB Rep. I Pfarrei St. Gertraud U 97; Ähnlicher Wortlaut in den Urkunden 1419 bis 1445 in AEB Rep. I Pfarrei St. Gertraud U 98 bis U 100 und U 107. Die Gertraudenkapelle samt aller sie umgebenden Gassen und Wege sind aufgrund des Ausbaus der Eisenbahnstrecke und der Anlage von Luitpoldstraße und -brücke im 19. Jahrhundert heute nicht mehr im Stadtbild zu finden. Sie würde an der heutigen Königsstraße liegen.

467 „Capitliche iurisdiction. Erstlichen von dem steg an uber den anger, so in s. Martinsspital gehörig, und dem stift s. Gangolf zu lehen rüret, bis hinüber in die gassen zum schrancken und am wasser hinaufwarts an die lilgenstauden, nit weit von dem Erlach gelegen, und von dannen hinüber zue dem beichtheusle bey dem hochgericht, und volgendts bis zum Haudtmors an die Lietzendorferstrassen und verners hinumb bey dem Heilgen Grab an der mauer und hinein bis an mehr benanten schranken [...] das die förderstuben des angezogenen closters in dem stattgericht, die cammer aber daran in der mundeten liege, und dieweilen auch incidenter des galgenhofs, so in dem capitlichen gezircks liegt." im Rezessbuch des Domkapitels vom 19. September 1597 in StABa B 86 Nr. 22 fol. 218 '-220, hier: fol. $219^{\prime}$.

${ }^{468}$ Näheres dazu in der Karte über das Immunitätsgebiet von St. Gangolf bei Braun: Von der Stiftspfarrei zur Stadtpfarrei. 1984. S. 377. Auch er orientiert sich an Straßenzügen und schließt die Getraudkapelle in das Gangolfer Immunitätsgebiet mit ein. Jedoch fehlen in seiner Interpretation die gesamte Kaimsgasse sowie die Grundstücke an Egelsee und Hundsbühl.

469 „Die weitgespannte Gangolfiter Immunität erstreckte sich zwischen Regnitz und Hauptsmoorwald, von ,den Siechen' im Norden bis zum Gereuth im Süden.“ in Isolde Maierhöfer: Bambergs verfassungstopographische Entwicklung vom 15. bis zum 18. Jahrhundert. In: Petri, Franz (Hg.): Bischofs- und Kathedralstädte des Mittelalters und der frühen Neuzeit (Städteforschung, Reihe A: Darstellungen, Bd. 1). Köln 1976. S. 146-162, hier: S. 154. mit Verweis auf Schimmelpfennig: Bamberg im Mittelalter. 1964. S. 31-33. und Neukam: Immunitäten und civitas in Bamberg. 1922/24. S. 86-88. 
nen Hauptmannschaften herangezogen werden, wie Christian Chandon richtig erkannte. ${ }^{470}$

Der erste Keller von St. Gangolf ist im 13. Jahrhundert nachweisbar, ${ }^{471}$ das erste Kellersiegel jedoch erst im 14. Jahrhundert. ${ }^{472}$ In den Gangolfer Statuten war festgelegt, welche Kompetenzgrenzen es zwischen dem Siegelrecht des Kellers zum Siegelrecht des Kapitels gab. So stand es ihm oder einem seiner Vertreter in der Rechtssprechung nicht zu, über Verträge oder Urkunden zu entscheiden, die von höherer Stelle oder vom Kapitel ausgestellt worden waren. ${ }^{473}$ Immer ist auf dem Bild des Kellersiegels der heilige Gangolf zu sehen und Maria bewusst ausgespart. Bei den ersten überlieferten Kellersiegeln sieht man Gangolf auf Knien betend mit einer zum Schlag ausholenden Person mit spitzem Hut (Judenhut?) zu seiner Linken, was an die Märtyrerrolle des Heiligen in der Gangolflegende erinnert. ${ }^{474}$ Später ist Gangolf als Ritter, also als weltliche Person dargestellt, ${ }^{475}$ was der Funktion des Kellers als

\footnotetext{
${ }^{470}$ Chandon: Die Bevölkerung der Stadt Bamberg um 1525. 2013. S. 37.

471 "Egelolfus cellerarius in Tuwerstat" von 1242 in StABa BU 614.

472 Erstes nachweisbares Gangolfer Kellersiegel von 1331 in StABa BU 2060 (Anhang Tabelle 1: Siegel Nr. 15).

473 „Seu occasionem eiusdem iudicii facere per se vel aliud seu alios eius nomine quovismodo presumat sed huiusmodi qui desuper fierit contractus seu littere sigillandi vel sigillande capitulari sigillo ecclesie nostre si capitulo nostro expedire videbitur munientur, nisi capitulum nostrum eidem cellerario aliud expresse duxerit committendum." in Statut Nr. 6 über den Keller im Statutenbuch StABa Stift St. Gangolf, Akten und Bände Nr. 130 fol. 62 '.
}

${ }^{474}$ Personales Amtssiegel des Herman von Mühlhausen, Keller des Stifts St. Gangolf (amt. 1329-1344), in StABa BU 2060 vom 18. Juli 1331 (Anhang Tabelle 1: Siegel Nr. 15); personales Amtssiegel des Heinrich, Keller des Stifts St. Gangolf (amt. 1345-1356), in StABa BU 2583 vom 18. März 1347 (Anhang Tabelle 1: Siegel Nr. 18); und personales Amtssiegel des Heinrich, Keller des Stifts St. Gangolf (amt. 1345-1356), in StABa BU 2670 vom 23. November 1349 (Anhang Tabelle 1: Siegel Nr. 19). „Analog zur Verbreitung der hagiographischen Literatur zeigt sich auch bei den Siegelbildern eine Hinwendung zur Heiligenvita mit der Aufnahme von szenischen Darstellungen.“ in Beatrice MarnettéKühl: Vom Abt zum Konvent. Eine Etappe in der Geschichte des Ordenssiegels. In: Signori, Gabriela (Hg.): Das Siegel. Gebrauch und Bedeutung. Darmstadt 2007. S. 65-74, hier: S. 73.

${ }^{475}$ Auf dem personalen Amtssiegel des Otto von Aufseß, Keller des Stifts St. Gangolf (amt. 1367-1381), von 1374 ist Gangolf in wehenden Gewändern mit Fahne und gekreuztem Schild dargestellt. In AEB Rep. I Pfarrei St. Martin U 4 (Anhang Tabelle 1: Siegel Nr. 21); Jedoch schon auf dem personalen Amtssiegel des Herman Willich, Keller des Stifts St. Gangolf (amt. 1381-1414), von 1391 ist er in Rüstung mit Schwert und Fahne abgebildet. 
Richter in weltlichen Fragen der Immunität und Niedergerichtsbarkeit entspricht. ${ }^{476}$ Dieses Bildprogramm hielt sich bis in das 16. Jahrhundert hinein. Die Figur eines Ritterheiligen im Siegelbild ist dabei nicht allein dem Stift St. Gangolf vorbehalten. Die Stadt Bamberg führte mit dem heiligen Georg ebenso eine gerüstete Figur im Siegel, die der Darstellung im Gangolfsiegel erstaunlich ähnelt. Da das Stadtsiegel auf den Drachen als Erkennungszeichen des heiligen Georg verzichtete, steht dem Betrachter nun der Ritterheilige mit Fahne und Schild gegenüber, der sich durch das einfache Georgskreuz auf Brust und Fahne auszeichnet. Dieses einfache Kreuz findet sich ebenfalls im Kellersiegel des Stifts St. Gangolf, jedoch immer nur auf dem Schild des Heiligen.

\subsubsection{Obleier und Fabrikamt}

Um den umfangreichen und weit verstreuten Obleibesitz ${ }^{477} \mathrm{zu}$ organisieren, nutzte das Stift St. Gangolf das Obleiamt, dem der Obleier, in den Quellen auch oblegiarius genannt, vorstand. Dieser unterstand direkt dem Kapitel und seine Bestellung wurde nicht, wie die Ämter des Scholastikus, Kustos und Kellers, durch den Propst mitbestimmt. Geldbeträge, die ab dem 14. Jahrhundert die Naturalienabgaben ablösten, flossen direkt an den Obleier und wurden durch ihn an die Kanoniker verteilt, wobei er einen Teil der Einkünfte für sich behielt. ${ }^{478}$ Die Einrichtung eines Obleiamts war eine gängige Praxis im Hochstift Bamberg und konnte bereits für das Domstift ${ }^{479}$ und das Stift St. Stephan ${ }^{480}$ nachgewiesen werden. Für das Kollegiatstift bei St. Martin in Forchheim erfüllten, laut den Statuten, der Dekan und andere Kanoniker die Auf-

In StABa BU 4287 (Anhang Tabelle 1: Siegel Nr. 24).

476 Die „Militarisierung von Heiligen“, also die bewusste Übertragung ritterlicher Eigenschaften auf Heilige, erfolgte bereits seit dem 11. Jahrhundert. Der heilige Gangolf reiht sich damit in bekannte Beispiele wie Mauritius oder Georg ein. Näheres dazu in Stieldorf: Helden oder Heilige. 2016. S. 135.

${ }^{477}$ Näheres zur Charakterisierierung der Gangolfer Obleien in Kapitel 6.4.1 Obleibesitz.

478 Diese Praxis ist schon für das Bamberger Domkapitel nachweisbar. Näheres dazu in Nöth: Urbare und Wirtschaftsordnungen. 1986. S. XI.

${ }^{479}$ Ebd. S. 60.

${ }^{480}$ Siewert: Das Bamberger Kollegiatstift St. Stephan. 2007. S. 221. 
gaben des Obleiers. ${ }^{481}$ Guttenberg stellte für das Domstift Bamberg die Vermutung auf, dass bis zum 12. Jahrhundert der Domkustos die Obleieinnahmen des Domkapitels verwaltet haben könnte. ${ }^{482}$ Danach, mit Auflösung der vita communis und der Umwandlung der Naturalien- in Geldabgaben, sorgte der Obleier im Auftrag des Domstifts für die Verteilung der Obleigelder. ${ }^{483}$

In den Statuten des Stifts St. Gangolf wird noch vor dieser klassischen Aufgabe der Obleiorganisation die enge Verknüpfung des Obleiamtes mit dem Fabrikamt erwähnt. ${ }^{484}$ Außerdem finden sich in den Obleirechnungen auch die Einnahmen und Ausgaben des Fabrikamtes. ${ }^{485}$ Damit zeichnete der Gangolfer Obleier in erheblichen Maße für die Bausubstanz der stiftseigenen Gebäude verantwortlich. Daraus lässt sich wiederum lesen, dass die Einnahmen, die sich aus Anniversarstiftungen frommer Gönner speisten, sowohl für das liturgische Totengedenken als auch für den Erhalt der Kirchengebäude verwendet wurden. In beiden Fällen war das Obleiamt für die Verteilung der Subventionen zuständig. Obwohl zahlreiche Aufstellungen über die Einnahmen des Fabrikamtes überliefert sind, ${ }^{486}$ bleiben Informationen über die Verwendung derselben oder das Aufgabenfeld des Fabrikamtes rar. Allein ein Rechnungsbuch der Thesaurare als Verwalter des Fabrikgutes mit einer Laufzeit von 1511 bis 1570 gibt Auskunft über Einnahmen, Ausgaben und Verwendung der für das Fabrikamt gedachten Gelder sowie

\footnotetext{
${ }^{481}$ Jakob: Das Kollegiatstift bei St. Martin in Forchheim. 1998. S. 294.

${ }^{482}$ Guttenberg: Urbare und Wirtschaftsordnungen. 1969. S. 18.

${ }^{483}$ Nöth: Urbare und Wirtschaftsordnungen. 1986. S. 61.

484 „Et ut officiis oblegiarie et fabrice ecclesie nostre que connexa sunt utilius provideatur.” in Statut Nr. 7 über den Obleier und Fabrikmeister im Statutenbuch StABa Stift St. Gangolf, Akten und Bände Nr. 130 fol. 63-64.

${ }^{485}$ StABa A 232/III Hochstift Bamberg, Ämterrechnungen Stifter R. 22560 (1560/61). Und losgelöst vom Obleiamt die Rechnungen der Stiftsfabrik „Computus fabricae“ in StABa A 232/III Hochstift Bamberg, Ämterrechnungen Stifter R. 24762 (1562/63), R. 24790 (1590/91) und R. 24795 bis R. 24800 (1595 bis 1601).

${ }^{486}$ Vor allem in den Register der Anniversarien und Fabrikzinsen in StABa Stift St. Gangolf, Akten und Bände Nr. 27, Nr. 29 und Nr. 34 mit Laufzeiten von 1573 bis 1673. Der Fabrikzins wird aber schon in der Obleimatrikel (1433-1663) für das Jahr 1433 erwähnt in StABa Stift St. Gangolf, Akten und Bände Nr. 192 fol. I; und im Anniversarbuch des Stifts St. Gangolf für das Jahr 1542 in StABa Stift St. Gangolf, Akten und Bände Nr. 129 fol. 1.
} 
über die Besetzung der Thesaurarsämter. ${ }^{487}$ Aus diesen Rechnungen lässt sich ersehen, dass es im 16. Jahrhundert immer zwei Thesaurare gab, von denen einer in der Regel der Keller des Stifts war. Die Verwendung der Fabrikeinnahmen wurde an dieser Stelle ebenfalls anschaulich beschrieben. So findet sich in der Abschrift einer Urkunde vom 13. November 1488 ein Bericht über den umfassenden Umbau des Kreuzganges der Gangolfskirche ${ }^{488}$ und unter der Rubrik Ausgaben der Thesaurarsrechnungen für das Jahr 1511 Einträge wie: vier Pfund und fünf Pfund um den poden zu kleyben, 22 Pfennige fur negel die pretter uf dem poden auf zunageln, drei Pfund und 22 Pfennige dem zigler fur 200 preyszigel zum thurn und 12 Pfennige die zygel zu füren, 32 Pfennige für negel die büen am thürn aufzuschlagen und fur rättel das tach zu ferben und drei Gulden geben dem glockenhengker die chorglocken zu hengken. ${ }^{489}$ Das Aufgabenspektrum der Thesaurare umfasste also nicht nur die Bezahlung der Handwerker für Reparatur- und andere Baumaßnahmen, sondern auch die Sorge um Beschaffung und Transport der Materialien. Die enge Verbindung von Obleiamt und Fabrikamt bedeutete eine gemeinsame Verwaltung der Einnahmen, jedoch wurde die praktische Ausführung, zumindest im 16. Jahrhundert, nicht vom Obleier übernommen. Dessen Hauptaufgabe blieb die Verwaltung der Obleieinnahmen, bei welcher er, laut den Statuten, unter der Aufsicht des Dekans und des Kapitels stand. ${ }^{490}$ Dies beinhaltete die Einnahme und Verteilung, aber auch die Kontrolle der Kanoniker und Vikare hinsichtlich der Vernachlässigung von Obleigütern. ${ }^{491}$ Auch die Kontrolle von Amtsantritten und Eintritten der Stiftsangehörigen für die Stellung als

487 Thesaurarsrechnungen (1511-1570) in StABA Stift St. Gangolf, Akten und Bände Nr. 191.

${ }^{488}$ Eintrag in den Thesaurarsrechnungen (1511-1570) unter der Notiz „creutzgang belangendt" in Ebd.

${ }^{489}$ Eintrag in den Thesaurarsrechnungen (1511-1570) für das Jahr 1511 unter den Thesauraren Konrad Lebenter und Erhard Getzendorffer in Ebd.

490 "Quod oblegarius eiusdem ecclesie nostre pro tempore omnes et singulos redditus et proventus [...] petat colligat [...] et voluntate decani et capituli ecclesie nostre convertat" in Statut Nr. 7 im Statutenbuch StABa Stift St. Gangolf, Akten und Bände Nr. 130 fol. 63.

491 „De inquisitione negligentiarum circa bona ecclesiae per oblegario“ als Randnotiz im Statut Nr. 7 über den Obleier und Fabrikmeister im Statutenbuch StABa Stift St. Gangolf, Akten und Bände Nr. 130 fol. 63. 


\section{Kanoniker und den damit einhergehenden Pfründenbezug übernahm laut Statuten der Obleier. ${ }^{492}$}

Ergänzend zu den Statuten liefert ein Regelwerk, beruhend auf einem Kapitelerlass unter dem Dekan Kaspar Hartmann (amt. 1583-1622) aus dem Jahr 1590, Einblicke in das Aufgabenfeld des Gangolfer Obleiers:

De officio oblegarii ecclesiae collegiatae ad s. Gangolphum extra muros Bambergenses.

1. Er solle alle praesentz durch das ganze jar ordentlich zu rechter geburender zeit, ohne vortheil, schreiben und im chor anschlagen.

2. Soll er die praesentz durch das ganze jar recht, billich unde gleich dem kleinsten als dem grösten, nach deme ein iztwedere persohn verdient, austheilen.

3. Er soll auch mit vleis aufschreiben eines ietwedern chorhern hinwegreisen und sein wiederkunft.

4. Das er alle zeit wöll aufzaigen den tag und das alter eines newen chorhern, so zu einem canonicat und prebende zugelassen wirdt.

5. Wan einem chorhern wirdt absentz gegeben, zu welcher zeit und wie lang, soll er solches vleisig einschreiben.

6. Und do der eltesten chorhern einer stirbt, soll er allzeit vleisig aufzeichen wer unter dem capitulhern primus vel secundus in oblegii recipiendis sey.

7. Was das die obley belanget, als kleine mistivlein und quitantzen, so geldt abgelost werdt, das geburth einen obleyern zu schreiben, und was fur geldt er einnembt so ad fabricam gehörig, soll er nicht daheim behalten, sondern alspalden denn herrn thesaurariis zustellen, die dan solches nimerzugenlich in die sacristey ad thesaurum legen sollen.

8. Die kirchen und stiftsgebeuhe soll er auch im jar etlichmahl vleissig besichtigen, und wo es mangel hat oder gewinnen will, dasselmig in dem capitul anmelden.

9. Wiewol dieser punct eines custodi geburdt, so aber kein verus da ist, soll ein obleyer alle quartal in der sacristey der kleinoder und ornata besichtigen, was dan zerbrochen, verwust oder durch hinlessigkeit des kirchners verlohren, aufzeichnen, was aber sonst $z u$ den gottesdienst mangelt, es sey mit waschen oder besserung der ornate, dasselmig vleisig anordnen und verschaffen, das es verricht werde.

10. So von stifts wegen, es sey vor dem consistorio oder einem anderen gericht, oder was anders zuverrichten ist, soll er solchen willig und mit allen vleis nachkhommen und darinnen nicht nachlessig, versaumblich oder verhinderlich sein.

11. Wan dan ein lehen geliehen wird, soll er dasselmig vleisig im beysein des $h$. dechants oder seniorn aufzeichnen, auch fragen nach den anstössen, und wo solches verners hinzinset in das lehenbuch schreiben, das gefallene handlohn denn capitularibus praesentibus vocem habentibus alsbalden austheilen.

12. Er soll auch in alleweg die obleizehenten zu und bey Holveldt nach allen besten vleis und vermögen auf das höchst verlassen und das getraidt, zins und andere gefell der obley mit hochsten vleis alles einfordern und einbringen.

492 "Que oblegarius notabit dies admissionis ad praebendas“ als Randnotiz im Statut Nr. 7 über den Obleier und Fabrikmeister im Statutenbuch StABa Stift St. Gangolf, Akten und Bände Nr. 130 fol. 63، 
13. Nach verlassung der zehendten soll ein obleyer ein iedem capitularheren ein specification solcher verlassung, und was einen in der austheilung wirdt, zustellen.

14. Und do getraidt, denn h. capitularibus gehörig, gewerdt worden, soll er dasselmig vleisig warten und lasen wenden, umbschlahen auch wolverwahren, damit es keinen schaden empfange, und vor der austheilung soll er alles getraide, waitz, korn, gersten und habern ein jedes insonderheit einmal 3 oder 4 mal wol durcheinander zihen lassen, damit es gleich werde, und darin soll er keinen vortheil brauchen.

15. Ein obleyer soll auch nach vollendung seines jhar einen jeden capitularherren unverzugentlich und ungemahndt sein rechenzettl mitsampt den rechengelt zustellen, den supernumerarium erlegen, alle rechnung so ein obleyer zuthun schuldig ist, auf das fuderlichste unverzogentlich ordentlicher weis im capitel thun, und was er dan in ein yede rechnung schuldig bleibt, daselmig erlegen unde zalen wie unten.

$\mathrm{Zu}$ diesen soll auch ein obleyer in einen monat nach Walpurgis (nach vollendung seines jhars) dominis capitularibus praesentibus et vocem habentibus ihr reichen remanentz und hunergeldt zustellen, auch alle seine obley, vicarey und fabricarechnung, zwischen Walpurgis und Jacobi immediate hernach folgendte, volscha[...]lich vor capitul thun und verrichten.

16. Item von den hingeliehen geldt sol er vleisig nachfragen haben, ob die burgen abgestorben oder aber newe possessores seindt, dasselmig wo es an nachtheil ist, vleisig einschreiben und die zalen austhun, solches aber zuvorn ein capitul anzeigen.

17. Er soll auch, wan geldt hingeliehn wirdt oder aber abgelöst wirdt, dasselmig vleisig aufzeichnen und von dem original ein copey davon in das new briefbuch schreiben, davon dan derjenig, so das geldt entlehet, $12 \mathrm{~d}$ zu schreiben geben solle.

Hierauf soll ein angehendter obleyer mit handtgebendter trew, loco praestiti juramenti promitiren und angeloben, solches alles vleisig zu halten und zuverrichten ohne geverde.

Sic capitulgelass in stuba capitulari, praesentibus dominis de capitulo, domino Casparo Hartman decano, Joanne Sparwasser seniore, Alberto Gampert, Georgio Juda, Joanne schultero, Heinrico Eselio, Andrea Schwartz cellario et magistro Christophoro Schonfeld. 22 die mensis May anno 1590.

Es soll auch herr obleyer seine diener oder hausgenosen auf den capitulcasten nicht gehn lassen auch in solchen ambt mit gethraidt einnehemen und ausmessen niht gestatten, in seinem abwesen soll er das seiner gebrüder einem bevelhen. ${ }^{493}$

Neben der erwähnten Zusammenarbeit mit den zwei Thesauraren (Punkte 7 und 8), der Einbringung und Verteilung der Obleizehnte samt ordnungsgemäßer Lagerung (Punkte 6, 12, 13 und 14) und der Kontrolle der Eintrittsfristen in den Kanonikerstand samt Anspruch auf eine Pfründe (Punkt 4), hatte der Obleier laut dem Regelwerk von 1590 zahlreiche andere Verpflichtungen, die die Statuten nicht thematisierten. Dies umfasste zum einen die Aufstellung, Kontrolle und Öffentlichmachung der Präsenzen (Punkte 1, 3 und 5). Das hatte durchaus praktische

493 Regelwerk des Obleiamtes vom 22. Mai 1590 als Anhang eines Registers der Anniversarien und Fabrikzinsen (1584-1607) in StABa Stift St. Gangolf, Akten und Bände Nr. 29 fol. 186-187. 
Bedeutung, stellte doch die dauernde Abwesenheit vieler Kanoniker eine elementare Bedrohung für die Stellung des Stifts dar, das damit seiner Hauptaufgabe, die Sicherung der liturgischen Zeremonien an den Jahrtagen der Stifter, nicht nachkommen konnte. Sanktionsmaßnahmen wurden für säumige Stiftsangehörige eingeführt, von denen vor allem das Ausbleiben der sogenannten Präsenzgelder die effektivste zu sein schien und für deren Verteilung der Obleier zuständig gewesen war (Punkt 2). Umso erstaunlicher ist es, dass sich für das Stift St. Gangolf nur ein Präsenzbuch aus dem Jahr 1608 überliefert hat, ${ }^{494}$ das darüber hinaus eher einem Anniversarbuch ähnelt und keine Auskünfte über das Problem der Abwesenheit von Kanonikern gibt. Ebenfalls federführend ist der Obleier in der Anlage der Lehenbücher und der Obleiregister (Punkt 11), dessen praktische Umsetzung sich aber nur selten und auch eher in den Zins- und Lehenregister nachweisen lässt, welche im zeitlichen Umfeld der Bestimmungen von 1590 entstanden sind. ${ }^{495}$ Diese Übung im Protokollieren, Auflisten und ein sicherer Umgang mit Zahlen und Werten sorgten sicher auch dafür, dass der Obleier eine gern gesehene Gerichtshilfe (Punkt 10) sowie eine verantwortliche Stelle für die jährliche Rechnungslegung (Punkt 15) und Geldleihe (Punkte 16 und 17) gewesen ist. Der erwähnte Eingriff in die Kompetenzen des Kustos samt Kontrollfunktion über den Kirchner durch den Obleier (Punkt 9) darf nicht überinterpretiert werden und war wohl den besonderen Umständen am Ende des 16. Jahrhunderts geschuldet, als sich in den Quellen vom Tod des Johann Zwirner (amt. 1560-1577) bis hin zum Amtsantritt des Johann Hartmann (amt. 1609-1612) kein Kustos am Stift St. Gangolf greifen lässt. Jedoch überschneiden sich die Aufgabenfelder des Obleiers dennoch mit denen des Kustos hinsichtlich Überwachung der Bausubstanz und Kontrolle der Sakristei samt Kirchenschatz.

Das Amt eines Obleiers umfasste also nicht nur eine Vielzahl an unterschiedlichen Aufgaben. Seine Verantwortung für hohe Geldbeträge

494 „Praesentsbuch“ oder „Ordo anniversario ecclesiae s. Gangolphi per circulum anni iuxta regulam oblegarii“ (1608-1738) in StABA Stift St. Gangolf, Akten und Bände Nr. 133. ${ }^{495}$ Zinsregister von 1584, 1600 und 1612 angelegt durch den Kanoniker und Obleier Heinrich Esel in StABa Stift St. Gangolf, Akten und Bände Nr. 29, Nr. 34 und Nr. 36. 
und wichtige Dokumentationsarbeiten schien groß. Es bedurfte daher eines Obleiers, der sich durch Zuverlässigkeit und fehlerfreies Arbeiten auszeichnete. Besonders das Rechnen, Schreiben und die Buchführung musste er beherrschen, um die Versorgung der Kanoniker durch Obleieinahmen zu sichern. Umso erstaunlicher ist es, dass sich kein Hinweis auf Besetzungsmodalitäten in den Quellen finden lässt, der eine gezielte Ausbildung oder eine gewisse Zeit am Stift zur Voraussetzung für das Amt des Obleiers machte.

\subsection{Außenbeziehungen}

\subsubsection{Das Verhältnis zum Bischof und zum Domkapitel}

Da es sich bei dem Stift St. Gangolf um eine bischöfliche Gründung handelte, gab es für den Stadtherrn durchaus Möglichkeiten zur Intervention. ${ }^{496}$ An der Entwicklung der inneren Stiftsverwaltung war er beispielsweise über sein Bestätigungsrecht der Statuten beteiligt. ${ }^{497}$ Liturgisch vereinigte der Bischof alle Bamberger Kirchen, was sich, für die gesamte Gemeinde sichtbar, in der Praxis der Prozessionen zeigte. ${ }^{498}$ Darüber hinaus band er die einzelnen Kirchen in die Vorsorge seines und seiner Vorgänger Seelenheil mit ein. So bedachte Lupold, Bischof von Bamberg (amt. 1353-1363), im Jahr 1356 nicht nur die von ihm neugegründete Domvikarie St. Barbara mit Gütern in Hersbruck, sondern auch die Stifte St. Stephan, St. Gangolf, St. Jakob und das Kloster St. Theodor mit Geldleistungen für Memorialleistungen. ${ }^{499}$ Auch beim Kauf verschiedener Güter von den Grafen von Truhedingen und dem Kloster Fulda im Jahr 1390 wurden durch den Bamberger Bischof Lampert (amt. 1374-1398) die Kollegiatsifte insofern eingebunden, dass er alle diese Güter dem Domkapitel übertrug und festlegte, dass die

496 Grundsätzlich hatte ein Bischof das „Kontroll- und Eingriffsrecht“ auf seine Kollegiatstifte, wodurch diese sich von klösterlichen Einrichtungen unterschieden. In Marchal: Was war das weltliche Kanonikerinstitut im Mittelalter? 2000. S. 33.

${ }^{497}$ Näheres im Kapitel 4.1.1 Statuten und Consuetudines.

${ }^{498}$ Näheres im Kapitel 5.1 Gottesdienst und Prozessionen.

${ }^{499}$ Bischöfliche Urkunde vom 16. November 1356 in StABa BU 2913. 
gesamte Bamberger Kirchenlandschaft (Kloster Michelsberg, Kloster St. Theodor, Kloster St. Klara, Kloster Heilig Grab sowie die Stifte St. Stephan, St. Gangolf und St. Jakob) den Jahrtag des Bischofs zu feiern hatten. ${ }^{500}$ Die Jahrtage einzelner Bischöfe aus dem 14. bis 16. Jahrhundert finden sich durchaus in der Anniversarüberlieferung des Stifts St. Gangolf, ${ }^{501}$ was die typische Verzahnung der kirchlichen Einrichtungen einer Stadt untereinander widerspiegelte.

Die Tatsache, dass sich aus den Reihen der Domkanoniker sowohl die Bischöfe als auch die Pröpste der Kollegiatstifte rekrutierten, sorgte dafür, dass zahlreiche Bamberger Bischöfe im Laufe ihrer kirchlichen Karriere durchaus auch das Propstamt von St. Gangolf bekleideten: beispielsweise Bischof Egilbert (amt. 1139-1146), der Nachfolger des später heiliggesprochenen Ottos I., ${ }^{502}$ oder Eckbert (amt. 1203-1237) aus dem Geschlecht der Andechs-Meranier, der vor seiner Berufung als Bamberger Bischof Propst von St. Gangolf war. ${ }^{503}$

Das Domstift widersetzte sich das gesamte Mittelalter hindurch dem bischöflichen Einfluss über die Kollegiatstifte in Bamberg. Es wuchs seit

\footnotetext{
${ }^{500}$ Bischöfliche Urkunde vom 5. August 1390 in StABa BU 4261.

${ }^{501}$ Es finden sich neun Bamberger Bischöfe in den Anniversarbüchern des Stifts St. Gangolf: Wulfing von Stubenberg (amt. 1304-1318) mit seinem Totengedenken am 14. März in StABa Stift St. Gangolf, Akten und Bände Nr. 128 fol. 7 und Nr. 130 fol. 10; Heinrich II. von Sternberg (amt. 1324-1328) am 1. April in StABa St. Gangolf, Akten und Bände Nr. 128 fol. 8“ und Nr. 129 fol. 22'; Leupold II. von Egloffstein (amt. 1335-1343) am 27. Juni in StABa Stift St. Gangolf, Akten und Bände Nr. 128 fol. 16 und Nr. 129 fol. 41; Friedrich von Hohenlohe (amt. 1344-1352) am 21. Dezember in StABa Stift St. Gangolf, Akten und Bände Nr. 128 fol. 30‘, Nr. 129 fol. 82‘ und Nr. 130 fol. 45; Leopold III. von Bebenburg (amt. 1353-1363) am 28. Oktober in StABa Stift St. Gangolf, Akten und Bände Nr. 128 fol. 26 und Nr. 129 fol. 69; Friedrich von Truhendingen (amt. 1363-1366) am 19. Mai in StABa Stift St. Gangolf, Akten und Bände Nr. 128 fol. 12' und Nr. 129 fol. 33; Lamprecht von Brunn (amt. 1374-1398) am 17. Juli in StABa Stift St. Gangolf, Akten und Bände Nr. 128 fol. 17 ' und Nr. 129 fol. 45'; Albrecht von Wertheim (amt. 1398-1421) am 20. Mai in StABa Stift St. Gangolf, Akten und Bände Nr. 128 fol. 12‘, Nr. 129 fol. 33‘ und Nr. 130 fol. 18‘; und Weigand von Redwitz (amt. 1522-1556) am 6. Juni in StABa Stift St. Gangolf, Akten und Bände Nr. 129 fol. 37.

502 Klaus van Eickels: Bamberger Bischofswahlen im Mittelalter. In: Göller, Luitgar (Hg.): 1000 Jahre Bistum Bamberg 1007-2007. Unterm Sternenmantel (Katalog der Jubiläumsausstellung). Petersberg 2007. S. 126-133, hier: S. 130.

503 Johannes Looshorn: Die Geschichte des Bisthums Bamberg, Bd. 2: Das Bistum Bamberg von 1102-1303. Bamberg 1888. S. 591; und als "Ekcebrecth praepositus s. Marie" 1192 in StABa BU 391.
} 
seiner Gründung schnell über seine ursprüngliche Rolle zur Sicherstellung des Chordiensts am Dom hinaus und wurde zu einer eigenständig handelnden Einrichtung mit privatem Vermögen und selbstgewählten Statuten. Ihm oblag nach den Beschlüssen des Wormser Konkordats von 1122 und des IV. Laterankonzils von 1215 das Bischofswahlrecht, ${ }^{504}$ was letztendlich auf die Praxis der Wahlkapitulationen hinauslief. ${ }^{505}$ Diese Entwicklung eines selbstbewussten Domkapitels ist nicht allein in Bamberg zu beobachten, sondern findet sich auch in anderen Bischofsstädten wie Eichstätt und Würzburg. ${ }^{506}$ Jedoch war Bamberg eine der ersten Städte, die ein Domkapitel herausbildeten, was beispielhaft für andere Bistümer wurde. ${ }^{507}$ Der Einfluss des Bamberger Domkapitels wuchs und stützte sich auf die Entscheidungsgewalt, die es über die drei Stifte ausübte. So wählte es die Vertreter der vier wichtigen innerstädtischen Kirchen zur Bestätigung der kaiserlichen Schenkung des Ortes Fürth, welcher als eigenes Amt für das Domstift in den darauffolgenden Jahrhunderten erhebliche ökonomische Bedeutung besaß. ${ }^{508}$ Die Machtposition des Domstifts musste gegen die Einmischung des Bischofs und der Bürgerstadt verteidigt werden, um seine Entscheidungsfreiheit und die Befreiung der stiftischen Immunitätsgebiete von allgemeinen Steuern und Abgaben zu sichern. Während die Kollegiatstifte bei der Ausübung der niederen Gerichtsbarkeit und der Verwaltung des Immunitätsgebietes eigenständig agierten, regelte das Domstift die Angelegenheiten der Kollegiatstifte nach außen. So setzte es beispielsweise 1432 die Huldigung der Bewohner der Stiftsimmunitäten auf das

\footnotetext{
${ }^{504}$ Van Eickels: Bamberger Bischofswahlen im Mittelalter. 2007. S. 128.

505 Näheres dazu in Georg Weigel: Die Wahlkapitulationen der Bamberger Bischöfe 13281693. Eine historische Untersuchung. Bamberg 1909.

${ }^{506}$ In Würzburg ist die Verselbständigung des Domklerus gegenüber dem Bischof und dessen Rolle als Mitregent erst nach dem Investiturstreit greifbar. In Wendehorst: Stadt und Kirche. 2001. S. 255.

${ }^{507}$ Bernd Schneidmüller: "Tausend Jahre sind für dich wie der Tag, der gestern vergangen ist". Die Gründung des Bistums Bamberg 1007. In: van Eickels/ van Eickels (Hgg.): Das Bistum Bamberg in der Welt des Mittelalters. 2007. S. 15-32, hier: S. 25.

508 Der Abt des Klosters Michelsberg, der Dekan des Stifts St. Stephan, der Dekan des Stifts St. Gangolf und der Dekan des Stifts St. Jakob vidimieren um 1250 eine Urkunde von 1007 über die kaiserliche Schenkung des Ortes Fürth samt Vogtei an die Bamberger Domkanoniker. In StABa BU 689.
} 
Domkapitel durch, nachdem diese bisher nur ihrem eigenen Propst zu huldigen hatten. ${ }^{509}$ Das führte $\mathrm{zu}$ Spannungen mit dem Bamberger Bischof, der als Stadtherr durchaus eigene Interessen verfolgte. Der Konflikt gipfelte in dem Immunitätenstreit, der alle Parteien samt der Bürgerstadt betraf und bereits ausführlich durch die Forschungen besprochen wurde. ${ }^{510}$ Der Immunitätenstreit entwickelte sich aus einem Konflikt um die städtische Vermögenssteuer seit dem Ende des 14. Jahrhunderts und wurde durch die Hussitenbedrohung in den 1430er Jahren noch verschärft. Der Stadtrat verlangte eine Auflösung der vielen stiftischen Gerichtsbezirke als Gegenleistung für die Huldigung der Stadt nicht nur, wie üblich, gegenüber dem Bischof, sondern auch gegenüber dem Domkapitel. Damit stieß er auf Widerstand und eine Einigung erfolgte erst 1440, in dem man sich darauf verständigte, eine gemeinsame Steuer zur Tilgung der städtischen Schulden zu erheben. Die Grundstruktur der Bamberger Immunitäten als Sonderbezirk wurde dadurch aber nicht angetastet. In den schriftlichen Zeugnissen des Stifts St. Gangolf ist der Widerhall dieser Ereignisse gering, ${ }^{511}$ da vor allem das Domkapitel den Konflikt trug, um seine Oberherrschaft über die Bamberger Kirchen zu sichern. Zudem setzen die überlieferten Quellen des Stifts St. Gangolf überwiegend erst nach dem Immunitätenstreit ein. Zwar reichen zumindest die Gangolfer Stiftsstatuten bis in das Jahr 1433 zurück, jedoch widmen sie sich inhaltlich eher der Beziehung des Kapitels zu seinem Propst. ${ }^{512}$ Das Bamberger Domstift hatte nicht nur politisch einen beherrschenden Einfluss auf die kleineren Kollegiatstifte, sondern auch in liturgischer Hinsicht. So orientierte sich die Gottesdienstordnung des Stifts St. Gangolf nachweislich an den Gebräuchen des Domstifts. ${ }^{513}$

${ }^{509}$ Esch: Zwischen Institution und Individuum. 2016. S. 39.

${ }^{510}$ Neu aufgearbeitet vor allem in Ebd; Und klassisch in Reindl: Die vier Immunitäten des Domkapitels zu Bamberg. 1969; Schimmelpfennig: Bamberg im Mittelalter. 1964; und Neukam: Immunitäten und civitas in Bamberg. 1922/24.

511 Allein eine Abschrift der Goldenen Bulle des Königs Sigismund von 1431 befindet sich im Bestand des Gangolfer Pfarrarchivs. In AEB Rep. 60 Pfarrarchiv St. Gangolf Bamberg Nr. 1.

512 Näheres im Kapitel 4.1.1 Statuten und Consuetudines.

${ }^{513}$ Näheres im Kapitel 5.1 Gottesdienst und Prozessionen. 


\subsubsection{Das Verhältnis zu den Bamberger Kirchen}

Das Kollegiatstift St. Gangolf reihte sich in die Bamberger Kirchenlandschaft ein, von der sich aber vorrangig die Beziehungen zu den beiden Kollegiatstiften St. Stephan und St. Jakob und zum Kloster Michelsberg in den Quellen niedergeschlagen haben. Innerhalb der drei Kollegiatstifte, die im Einflussgebiet des Domkapitels agierten, hatte das Stift St. Stephan eine Vorrangstellung gegenüber den anderen zwei Kollegiatstiften. ${ }^{514}$ So konnte Ulrike Siewert feststellen, dass das Stift St. Jakob seine Statuten in großen Teilen von St. Stephan übernommen hatte. ${ }^{515}$ Die Rangfolge anhand des Gründungsalters findet sich auch in der Stellung innerhalb der Zeugenlisten gespiegelt. In der Regel stand der Propst von St. Gangolf in den Zeugenlisten der bischöflichen Urkunden hinter dem Propst von St. Stephan und vor dem Propst von St. Jakob, ${ }^{516}$ was sich mit der Abfolge der Gründungsjahre deckte und somit auch Einblick in Stellung des Stiftes St. Gangolf innerhalb des Bamberger Stadt- und Kirchengefüges gewährt. ${ }^{517}$ Die Bedeutung eines Amtes innerhalb des Stifts wog dabei schwerer als das Alter der Institution. So stand ein Kanoniker von St. Stephan im Rang nach dem Dekan

\footnotetext{
${ }^{514}$ Luitgar Göller: Domstift und Kollegiatstifte. In: Göller, Luitgar (Hg.): 1000 Jahre Bistum Bamberg 1007-2007. Unterm Sternenmantel (Katalog der Jubiläumsausstellung). Petersberg 2007. S. 42-49, hier: S. 44.

${ }^{515}$ Siewert: Das Bamberger Kollegiatstift St. Stephan. 2007. S. 196.

516 Beispiele sind die bischöflichen Urkunden vom 28. Oktober 1142 in StABa Kloster Michelsberg, Urkunden Nr. 27; von 1142 in StABa BU 223; und von 1143 in StABa BU 226. Dies lässt sich bis zum Ende des 16. Jahrhunderts und darüber hinaus in den Bamberger Urkunden beobachten. Beispiele für Ausnahmen von dieser Regel, ebenfalls in den Zeugenlisten der bischöflichen Urkunden Bambergs: Der Propst von St. Gangolf steht um 1150 vor dem Propst von St. Stephan in StABa Kloster Michelsberg, Urkunden Nr. 38; der Propst von St. Gangolf und der Propst von St. Jakob stehen um 1180 vor dem des Stifts St. Stephan in StABa BU 347; der Propst von St. Gangolf findet sich 1192 erst nach dem Propst von St. Jakob in StABa BU 391; oder der Propst von St. Gangolf steht 1275 vor dem Propst von St. Stephan in StABa BU 878.

${ }^{517}$ Die Reihenfolge Dom, St. Stephan, St. Gangolf und St. Jakob findet sich ebenso in den Bamberger Prozessionsordnungen wieder. In Siewert: Das Bamberger Kollegiatstift St. Stephan. 2007. S. 197.
} 
von St. Jakob, ${ }^{518}$ der Dekan von St. Stephan wiederum nach dem Propst von St. Gangolf. ${ }^{519}$ Dies ist vor allem dann bedeutsam, wenn man die Mehrfachbepfründungen einzelner Kanoniker und die damit einhergehende Verflechtung der Stifte bedenkt.

Die Zusammenarbeit zwischen den Kollegiatstiften war eng. So gab es Festlegungen, sich bei innerstiftischen Auseinandersetzungen untereinander abzusprechen, was sich sogar in den Statuten des Stifts St. Gangolf niederschlug. Konnten sich Dekan und Kapitel von St. Gangolf im Streitfall untereinander nicht einigen, sollten Vertreter der Stifte St. Stephan und St. Jakob vermitteln. ${ }^{520}$ Schon 1395 wurde eine Verpflichtung untereinander eingegangen, im Falle einer Appellation, also einer Berufung gegen ein Urteil in erster Instanz, den Vorgaben des Domstifts zu folgen. ${ }^{521}$ Diese gegenseitige Einbindung zur Klärung strittiger Rechtsfragen blieb keine diplomatische Floskel, sondern ist in zahlreichen Urkunden praktisch nachvollziehbar. ${ }^{522}$ Die enge Kooperation und

\footnotetext{
${ }^{518}$ Schenkungsurkunde an das Stift St. Jakob von 1214 in StABa BU 467.

${ }^{519}$ Bischöfliche Urkunde von 1217 in StABa Kloster Michelsberg, Urkunden Nr. 75.

520 „Statuimus ut si quod absit inter decanum ecclesie nostre ex una et capitulum nostrum partibus ex altera dissensio contraversio seu discordia ex orta fuerit et concordia per nos seu inter nos fieri bono modo non valeret super huiusmodi dissensionibus contraversiis et discordiis ad venerabiles vires ac dominos sanctos Stephani et Jacobi ecclesiarum collegiatarum intra et extra muros Bambergense decanos et capitula recursus esset habenda" in Statut Nr. 3 über den Dekan im Statutenbuch StABa Stift St. Gangolf, Akten und Bände Nr. 130 fol. 60".

521 Appellationsverpflichtung der Nebenstifte gegenüber dem Domstift vom 23. August 1395 in StABa BU 4488.

522 Am 17. Januar 1400 urteilte Friedrich Stieber als Bamberger Domherr und Gangolfer Propst (amt. 1397-1410) in dem Streit zwischen Wilhelm, Abt des Klosters Michelsberg zu Bamberg, mit den Fürsprechern Arnolt von Sparnek, Bamberger Domherr, und Konrad Seybot, Bürger von Bamberg, gegen den Dekan und das Kapitel von St. Jakob in Bamberg mit den Fürsprechern Konrad Raben als Dekan von St. Gangolf (amt. 1397-1410), und Johann Naszach als Kanoniker von St. Stephan, wegen des Lehenrechts über fünf Häuser in Bamberg. In StABa Kloster Michelsberg, Urkunden Nr. 605; 1442 schlichtete Johann Kautsch als Dekan von St. Stephan und Generalvikar, und die Kapitel der Stifte St. Stephan und St. Jakob einen Streit zwischen dem Dekan, dem Kellner und dem Kapitel von St. Gangolf auf der einen Seite mit Stephan Beheim als Propst von St. Gangolf (amt. 14421444) auf der anderen Seite wegen ausstehender Zahlungen aus dem Propsteigut. Im Gangolfer Kopialbuch in StABa Stift St. Gangolf, Akten und Bände Nr. 2 fol. 300‘-303; 1489 erfolgte der Schiedsspruch des Laurentius, Domvikar und Kanoniker von St. Stephan, und des Heinrich Glantz, Dekan von St. Gangolf (amt. 1486-1491), in der Differenz zwischen Andreas, Abt des Klosters Michelsberg in Bamberg, und dem Kapitel des Stifts
} 
ein geschlossenes Auftreten der kirchlichen Einrichtungen Bambergs in Rechtsfragen boten Vorteile hinsichtlich der Konkurrenz durch die Bürgerstadt und den Machtansprüchen des Domkapitels.

Und auch besitzrechtlich arbeitete man zuweilen zusammen. Im Jahr 1468 gab es Differenzen zwischen St. Jakob und einer Frau namens Gerhaus Zollner wegen eines Zinses über 14 Pfennigen und einem Huhn, welche die Frau auf eine Oblei in der Theuerstadt an das Stift zu zahlen hatte. Obwohl es sich offensichtlich um eine Jakobsche Oblei handelte, war das Stift St. Gangolf involviert, indem von Seiten des Domstifts angeordnet wurde, dass die Abgaben trans pontem Sesprucken zu dem Stift St. Gangolf transportiert werden sollten. ${ }^{523}$

Außerdem bot sich eine Zusammenarbeit auf Ebene des Totengedächtnisses an. So verfügte die Kirche von St. Stephan über einen Gangolfaltar ${ }^{524}$ und drei Anniversarien wiesen auf Personen aus St. Gangolf hin. ${ }^{525}$ In den Gangolfer Anniversarbüchern finden sich Eintragungen über Pröpste, Dekane, Scholastiki und andere Kanoniker der Stifte St. Stephan ${ }^{526}$ und St. Jakob. ${ }^{527}$ Andere kirchliche Einrichtungen sind,

St. Jakob wegen des Kaufs mehrerer vom Stift St. Jakob zu Lehen gehender Güter durch das Kloster. In StABa Kloster Michelsberg, Urkunden Nr. 1419; Als der Gangolfer Kanoniker Heinrich Neydecker 1534 aus dem bischöflichen Gefängnis entlassen wurde, schwor er vor dem Dekan von St. Stephan Urfehde und nannte als Bürgen einen Kanoniker von St. Stephan, den Domkaplan und einen Bürger von Bamberg in A 120 L 131 Nr. 728.

${ }^{523}$ Urteil des Offizials des Bamberger Domdekans vom 9. November 1468 in A 120 L 135 Nr. 1016.

${ }^{524}$ Siewert: Das Bamberger Kollegiatstift St. Stephan. 2007. S. 50.

525 Ebd. S. 148.

${ }^{526}$ Vertreter des Stifts St. Stephan in den Gangolfer Anniversarbüchern: Johann Zufras als Propst (gest. 1387) mit seinem Totengedenken am 20. Februar in StABa Stift St. Gangolf, Akten und Bände Nr. 129 fol. 13 und am 21. Februar in Nr. 128 fol. 5 und Nr. 130 fol. 7; Berthold von Henneberg als Propst (gest. 1495) am 23. April in Nr. 128 fol. 10 und Nr. 129 fol. 27'. Salbertus als Propst am 3. August in Nr. 128 fol. 19 und am 5. August in Nr. 130 fol. 28; Gangolf Ringer als Dekan am 3. Mai in 128 fol. 11 und Nr. 129 fol. 30; Und desweiteren Kanoniker des Stifts St. Stephan: Heinrich Lust (gest. 1402) am 8. April in Nr. 128 fol. 9, Nr. 129 fol. 24 und Nr. 130 fol. 13; Johann Nassau (gest. 1418) am 29. Dezember in Nr. 128 fol. 31', Nr. 129 fol. 84' und Nr. 130 fol. 46'; Heinrich Kilian (gest. 1451 oder 1461) am 18. Dezember in Nr. 128 fol. 30‘ und Nr. 129 fol. 81‘; Konrad Vachdorf (gest. 1456 oder 1461) am 14. November in Nr. 128 fol. 27' und Nr. 129 fol. 73; Johann Bessler (gest. 1461 oder 1466) am 9. Oktober in Nr. 128 fol. 24' und am 10. Oktober in Nr. 129 fol. 66 und Nr. 130 fol. 36; Eberhard Kadmer aus Hollfeld, später Propst von St. Gangolf (amt. 14951507), am 1. Januar in Nr. 128 fol. 1, Nr. 129 fol. 2 und Nr. 130 fol. 1; Heinrich Lebenter 
abgesehen vom Domkapitel, dort nicht erwähnt. Dies überrascht vor allem für das Kloster Michelsberg, in dessen eigener Memorialüberlieferung durchaus Vertreter des Stifts St. Gangolf zu finden sind, deren Wirken sich teilweise bis ins 11. Jahrhundert zurückverfolgen lassen. ${ }^{528}$ Die Attraktivität des Stifts St. Gangolf als Träger eines Memorialauftrages war demnach eher gering und ging nicht über die Bamberger Stiftslandschaft hinaus.

Auch in anderen Bereichen sind Abstufungen in den Beziehungen zueinander bemerkbar. So waren das Kloster Michelsberg und das Stift St. Jakob nicht nur durch ihre lokale Nähe verbundener als mit den anderen Kirchen. Im Jahr 1123 wurde das Ägidienspital aus dem Besitz des Stifts St. Jakob herausgelöst und dem Kloster unterstellt, jedoch waren weiterhin Kanoniker von St. Jakob als Priester am Spital tätig. ${ }^{529}$ Johannes Nospickel vermutet aufgrund geringer Schenkungen an das Kloster Michelsberg durch die Stifte St. Stephan und St. Gangolf ein gewisses Konkurrenzdenken wegen der besonderen Gunst des Klosters, in der es bei den Bamberger Bischöfen stand. ${ }^{530}$

(gest. 1503) am 17. September in Nr. 128 fol. 23, Nr. 129 fol. 60 und am 18. September in Nr. 130 fol. 33'; Johann Zollner am 4. Mai in Nr. 128 fol. 11 und am 5. Mai in Nr. 129 fol. 30' und Nr. 130 fol. 16'. Berenger am 16. Mai in Nr. 128 fol. 12, Nr. 129 fol. 32' und Nr. 130 fol. 18; Johann Wernher am 26. August in Nr. 128 fol. 21 und Nr. 129 fol. 55; und Gottfried am 12. November in Nr. 128 fol. 27‘, Nr. 129 fol. $72^{\prime}$ und Nr. 130 fol. 40`.

${ }^{527}$ Kanoniker des Stifts St. Jakob in den Gangolfer Anniversarbüchern: Seufried de Hallis als Dekan am 8. März in Nr. 128 fol. 6', Nr. 129 fol. 16' und Nr. 130 fol. 9; Nikolaus Hertlein als Dekan am 14. Oktober in Nr. 128 fol. 25, Nr. 129 fol. 67 und Nr. 130 fol. 37; Walther Gusbach als Scholastikus (gest. 1424) am 9. Dezember in Nr. 128 fol. 29' und Nr. 129 fol. 79; Johann Senft als Scholastikus und Senior am 17. Januar in Nr. 128 fol. 2 und Nr. 29 fol. 5; Konrad am 8. Januar in StABa Stift St. Gangolf, Akten und Bände Nr. 128 fol. 1'; und Konrad Schwab am 9. Januar in Nr. 128 fol. 1' und Nr. 129 fol. 3.

528 Johannes Nospickel: Kalendarische Folge der Einträge und Provenienzregister. In: Nospickel, Johannes (Hg.): Das Necrolog des Klosters Michelsberg in Bamberg (Monumenta Germaniae Historica: Libri Memoriales et Necrologia Nova Series, Bd. 6). Hannover 2004. S. 187-519, hier: 445.

${ }^{529}$ Nospickel: Das Michelsberger Necrolog. 2004. S. 170.

${ }^{530}$ Ebd. 


\subsubsection{Das Verhältnis zur Bürgerstadt}

Mit dem Begriff „Bürgerstadt“ ist die Zugehörigkeit zum Zuständigkeitsbereich des Stadtgerichts impliziert. ${ }^{531}$ Der Bürgerbegriff unterlag einer starken sozialen Differenzierung und ist in seinem zeitgenössischen Gebrauch unscharf definiert. Oftmals umfasste die Bezeichnung ausschließlich die führende, politisch handlungsfähige Gruppe innerhalb der städtischen Laiengemeinschaft, die das Bürgerrecht innehatte. ${ }^{532}$ In Bamberg traten die Vertreter der Stadt 1263 erstmals als rechtliche Körperschaft auf, indem sie ein eigenes Siegel benutzten. ${ }^{53}$ $\mathrm{Ab}$ dem Jahr 1306 ist die Existenz eines Stadtrats nachweisbar. ${ }^{534}$ Doch trotz solcher verfassungsrechtlichen Entwicklungen stand die Bürgergemeinde in Bamberg weiterhin unter der Herrschaft des Bischofs und war während des gesamten Mittelalters nicht imstande, sich davon zu emanzipieren. ${ }^{535}$ Der Tatsache, dass das Domstift die Verhandlungen mit der Bamberger Bürgerstadt auch im Namen der kleineren Stifte dominierte, waren ebenso die rechtlichen Beziehungen des Stifts St. Gangolf $\mathrm{zu}$ ihr unterworfen. Jedoch ging es bei den Verhandlungen zwischen Stadt und Domstift vorrangig um die rechtliche Sonderstellung der Stiftsimmunitäten zum Erhalt deren eigenständiger Niedergerichtsbarkeit. Außerhalb dieser Trennung von Rechtsbereichen waren die Gebiete der Immunität und der Bürgerstadt durchaus räumlich

\footnotetext{
${ }^{531}$ Näheres zur Problematik der Bamberger Stadttopografie in Esch: Zwischen Institution und Individuum. 2016. S. 30-31; und darüber hinaus hinsichtlich der Begrifflichkeit "Altstadt" und „Neustadt" Bambergs in Frankfurter Quellen des 16. Jahrhunderts und dem damit einhergehenden Problem der Topografie Bambergs in Claudia Esch: Topografie und Wirtschaft. Das Verhältnis von Stadtgericht und Immunitäten im mittelalterlichen und frühneuzeitlichen Bamberg im Spiegel der Markt- und Handelsrechte. In: Häberlein, Mark/ Schmölz-Häberlein, Michaela (Hgg.): Handel, Händler und Märkte in Bamberg. Akteure, Strukturen und Entwicklungen in einer vormodernen Residenzstadt (1300-1800) (Stadt und Region in der Vormoderne, Bd. 3. Veröffentlichungen des Stadtarchivs Bamberg, Bd. 21). Würzburg 2015. S. 21-50, hier: S. 38-39.

532 Näheres dazu in Esch: Zwischen Institution und Individuum. 2016. S. 232-235.

533 Ebd. S. 50.

534 Wobei der Bamberger Stadtrat während des gesamten Mittelalters nicht politisch unabhängig agieren konnte. In Ebd. S. 54.

535 Ebd. S. 44.
} 
verzahnt. Bewohner der Immunitäten hatten Funktionen in städtischen Institutionen, beispielsweise als Genannte ${ }^{536}$ oder im Stadtgericht, inne und beteiligten sich auf diesem Weg an städtischen Entscheidungen. ${ }^{537}$ Außerdem wurden die Sonderabgabe des Bamberger Bischofs Weigand von Redwitz (amt. 1522-1556) zur Beseitigung der Zerstörungen infolge des Bauernkrieges 1525 sowohl den Einwohnern des Stadtgerichtes als auch denen der Immunitäten auferlegt. ${ }^{538}$ Bereits davor gab es eine rege Zusammenarbeit zwischen der Stadtgemeinde und den Immunitäten, die sich insbesondere in Krisenzeiten bewährte. Die Laienbewohner der Immunitäten waren ebensowenig von Steuern befreit wie die Stadtbewohner, und auch Zünfte und andere Handwerkervereinigungen bezogen Mitglieder sowohl aus der Bürgerstadt wie auch aus den Immunitätsgebieten. ${ }^{539}$ Eine dauernde Konfliktsituation zwischen Bürgerstadt und Immunitäten, wie sie eine Bevorzugung der Sonderbezirke bewirkt hätte, muss daher angezweifelt werden. Die politischen Bestrebungen der Vertreter der Bürgerstadt liefen darauf hinaus, die rechtlichen Sonderbezirke der Stifte in das Stadtgebiet einzubinden. Jedoch ging es dabei um die Integration der Immunitätsbewohner, also der Laien im Umfeld des Stifts St. Gangolf, nicht aber um das Stift oder seine Kanoniker selbst. Daher und weil sich dieser Frage bereits in aktuellen Forschungen angenommen wurde, ${ }^{540}$ soll es hier um die Beziehung zwischen Stift und Bürgerstadt gehen und die Einbindung der Immunitätsbewohner in die politischen und rechtlichen Strukturen der Bürgerstadt außer Acht gelassen werden. In diesem Zusammenhang darf nicht unerwähnt bleiben, dass die maßgeblichen Veränderungen in der Stadtverfassung nach Beendigung des Immunitätenstreits und die damit einhergehende stärkere Einbindung der Immunitätsbewohner in die

${ }^{536}$ Das Amt der Genannten sieht Claudia Esch als ein Gruppe von Beratern des Stadtrats aus der städtischen Oberschicht. In Ebd. S. 272.

${ }^{537}$ Ebd. S. 314-315.

538 Chandon: Die Bevölkerung der Stadt Bamberg um 1525. 2013. S. 21.

${ }^{539}$ Esch: Topografie und Wirtschaft. 2015. S. 30-34.

${ }^{540}$ Näheres zur Frage nach der politischen, rechtlichen, finanziellen und militärischen Einbindung der Immunitätsbewohner Bambergs in die städtischen Strukturen in Esch: Zwischen Institution und Individuum. 2016. S. 110-113. 
städtischen Strukturen nicht nur für das Domkapitel eine Bedrohung deren Machtmonopols bedeutete. Sie betrafen auch den Einfluss der Stifte auf ihre Immunitäten, schließlich strebte die Bürgerstadt weiterhin nach einer Auflösung der Niedergerichtsbarkeitsbezirke der Stifte zugunsten einer einheitlichen städtischen Rechtsprechung.

Die personelle Verknüpfung von Gangolfer Stiftsangehörigen mit den bürgerlichen Familien Bambergs war gering. Die Namen bedeutender patrizischer Familien wie Tockler, Usmer und Zollner fehlen in der Reihe der Stiftskanoniker ganz und auch im Stift nachweisbare Familien sind häufig nur einmalig anzutreffen. ${ }^{541}$ Vereinzelt finden sich jedoch Vertreter von Bamberger Bürgerfamilien in hohen stiftischen Ämtern, wie es bei der Familie Kautsch der Fall war, deren Mitglieder im 15. Jahrhundert nicht nur einen Dekan, ${ }^{542}$ sondern sogar einen Propst $^{543}$ stellten. Das Amt des Gangolfer Dekans bekleidete ein Vertreter der Familie Raben, ${ }^{544}$ ein Kustos entstammte der Familie Kohler ${ }^{545}$ und gleiches betraf einen Scholastikus, der wahrscheinlich der Familie Gundeloch angehörte. ${ }^{546}$ Einzelne Kanoniker ohne näher beschriebenes Amt am Stift stammten seit dem 15. Jahrhundert aus den Familien Holzschuh, ${ }^{547}$ Schwab ${ }^{548}$ und Esel. ${ }^{549}$ Diese doch überschaubare Menge

541 Grundlage zur Frage nach den wichtigsten Bamberger Bürgerfamilien war die Identifizierung der Stadtgerichtsschöffen und deren Herkunft in Ebd. S. 249.

${ }^{542}$ Michael Kautsch, Dekan (amt. 1474-1482) und seit 1468 am Stift belegbar.

${ }^{543}$ Johann Kautsch, Propst (amt. 1444-1462), auch Dekan von St. Stephan.

${ }^{544}$ Konrad Raben, Dekan (amt. 1397-1410).

545 "Iohannis Koler custor" (gest. 1490) in einer bischöflichen Urkunde vom 16. Juni 1466 in StABa A 120 L 131 Nr. 757.

${ }^{546}$ Burkard Gundeloch, Scholastikus (gest. 1401). Spuren von ihm ohne Quellenangaben finden sich nur in Wachter: General-Personal-Schematismus der Erzdiözese Bamberg. 1908.

547 Pangraz Holzschuh, laut Wachter: General-Personal-Schematismus. 1908. war er Gangolfer Dekan (amt. 1571-1577), als Kanoniker in den 1560er Jahren nachweisbar in den Thesaurarsrechnungen (1511-1570) in StABa Stift St. Gangolf, Akten und Bände Nr. 191 unfoliiert.

548 Johann Schwab (1), als Gangolfer Kanoniker nachzuweisen für 1452-1479, wo sein Totengedenken am 21. Oktober Eingang in eines der Gangolfer Anniversarbücher fand. In StABa Stift St. Gangolf, Akten und Bände Nr. 129 fol. 68; Johann Schwab (2), als Gangolfer Kanoniker für das Jahr 1583 nachzuweisen in der Obleimatrikel (1433-1663) in StABa Stift St. Gangolf, Akten und Bände Nr. 192 fol. 22'; und Heinrich Schwab, als Keller von 1580- 
lässt die Vermutung aufkommen, dass das Stift St. Gangolf generell als wenig attraktive Versorgungsinstitution für die Söhne der städtischen Oberschicht angesehen wurde.

Besitzrechtlich dürfte eher von einer geringen Verzahnung der Stiftsbesitzungen mit dem Stadtgebiet auszugehen sein. Der innerstädtische Obleibesitz des Stifts befand sich vorrangig im Bereich der Theuerstadt, also in den engen Grenzen zwischen Regnitz und Hauptsmoorwald. Nur wenige Besitzkomplexe befanden sich im Stadtgerichtsbezirk, welche aufgrund der Zusammenarbeit des Stifts mit dem Bamberger Bauhof durch letzteren verwaltet wurde. ${ }^{550}$

\subsubsection{Das Verhältnis zum Bürgerspital St. Katharina}

Im Jahr 1203 wurde das Spital St. Katharina erstmals erwähnt, als es zu Beginn der franziskanischen Armutsbewegung nahe der Pfarrkirche St. Martin auf der Bamberger Inselstadt gegründet wurde und als Bürgerspital unter starker stadtherrlicher Abhängigkeit stand. ${ }^{551}$ Es bildete zusammen mit dem 1330 gegründeten Spital St. Elisabeth im Sand unterhalb des Doms den Schwerpunkt der spätmittelalterlichen Krankenversorgung außerhalb der Kirche unter einer bürgerlichen Trägerschaft. In dieser Zeit konnte besonders in kleinen Städten ein rasanter Anstieg der Spitalgründungen beobachtet werden, die zugleich auch Ausdruck der sozialen Probleme des 14. Jahrhunderts waren. ${ }^{552}$ Die

1588 nennt Paschke in den Dignitätenlisten ohne Quellenangaben. In Paschke: St. Gangolf zu Bamberg. 1959.

${ }^{549}$ Heinrich Esel, als Kanoniker nachweisbar im Register der Anniversarien und Fabrikzinsen des Kanonikers Heinrich Esel (1584-1607) in StABa Stift St. Gangolf, Akten und Bände Nr. 29 fol. 187; und eventuell derselbe Heinrich Esel (gest. 1620) als Senior in der Obleimatrikel (1433-1663) in StABa Stift St. Gangolf, Akten und Bände Nr. 192 fol. 27'; Es ist durchaus denkbar, dass das Selbstzeugnis im Gangolfer Statutenbuch ebenfalls von diesem Heinrich Esel stammt: „Als man zalt 1552 iahr umb aller heytigen tag bin ich Heinrich Esel geborn worden, ist mein tauftod gewesen Heintz Bischof ein schefer zu Wisentfels nahent bei Holvelt. Mein schwester Anna hat mirs also gesagt.“ in StABa Stift St. Gangolf, Akten und Bände Nr. 131 fol. 1'.

${ }^{550}$ Näheres zur Oblei Wattlauben im Kapitel 6.4.1.2 Einzelobleien.

${ }^{551}$ Reddig: Bürgerspital und Bischofsstadt. 1998. S. 28.

552 Ebd. S. 41. 
Bemühungen rund um eine angemessene Krankenversorgung fand sowohl in bürgerlichen wie auch in kirchlichen Kreisen Unterstützung, sodass die Lehenbücher des Katharinenspitals neben den Stiftungen von Bürgertum und Adel auch die Lehensabhängigkeiten von den Bamberger Kirchen, ${ }^{553}$ vor allem vom Stift St. Gangolf, auflisteten. ${ }^{554}$ Denn während das Elisabethspital seinen Besitzschwerpunkt im Sand beibehielt, orientierte sich das Katharinenspital Richtung Osten der Stadt, wo es zur Ausformung von zwei Kerngebieten kam: zum einen der städtische Besitz auf der Regnitzinsel rund um sein Haupthaus bei St. Martin, und zum anderen in der Theuerstadt rund um den sogenannten Katharinenhof, der als Wirtschaftsmittelpunkt für die Besitzungen jenseits der Regnitz fungierte. ${ }^{55}$ Dieser Hof am Hundsbühl führte eine eigene Verwaltung, innerhalb der der Hofmann mit seiner Ehefrau den Vorstand innehatte, und sorgte für die Bewirtschaftung der Theuerstädtischen Besitzungen. ${ }^{556}$ Nachweisbar ist der Katharinenhof seit dem Jahr 1333, nämlich als ein Konrad von Limbach sein Haus, Hof und Garten in der Theuerstadt dem Spital überlies. ${ }^{557}$ Das Katharinenspital hatte schon bald zahlreiche Besitzungen rechts der Regnitz - allen voran im Hundsbühl, in der Siechengasse, Mittelgasse, Litzendorferstraße, vor dem Langen Tor, am Sendelbach, Gereuth und bei dem Heiligen Grab, ${ }^{558}$ aber auch mit Land im Hauptsmoor apud Teuerstat, ${ }^{559}$ was es zu einem direkten Nachbarn des Stifts St. Gangolf machte.

553 Schenkung des Bamberger Bischofs an das Katharinenspital vom 14. Dezember 1308 über 16 Tagwerk Feld, die im Hauptmoorwald bei der Theuerstadt neu angelegt werden sollten. Im Lehenbuch des Katharinenspitals (1247-1526) in SttABa B 11 Nr. 100 fol. 4; Auch das Stift St. Stephan unterhielt eine nicht unbedeutende Beziehung zum Katharinenspital, welche sich auf Grundbesitz in der Immunität St. Stephan stützte. In Siewert: Das Bamberger Kollegiatstift St. Stephan. 2007. S. 199.

${ }^{554}$ Lehenbuch des Katharinenspitals (1247-1526) in SttABa B 11 Nr. 100 fol. 20-44; und Nr. 101 fol. 2‘-3, fol. 10-10‘, fol. 20-20` und fol. 23-23‘.

${ }^{555}$ Reddig: Bürgerspital und Bischofsstadt. 1998. S. 56.

${ }^{556}$ Ebd. S. 174.

557 Lehenbuch des Katharinenspitals (1247-1526) in SttABa B 11 Nr. 100 fol. 101'-102; Hans Paschke: Der Katharinenhof. Beiträge zur Bamberger Häusergeschichte. In: Fränkischer Tag 10 und 12 (1954).

558 Reddig: Bürgerspital und Bischofsstadt. 1998. S. 55.

559 Bereits oben erwähnt wurde die bischöfliche Schenkung 1308 von 16 Äckern im Hauptmoor apud Teuerstat im Lehenbuch des Katharinenspitals (1247-1526) in SttABa B 
Besonders lukrativ erschien ein großes unbebautes Stück Land direkt am Fluss, genannt die Peunt oder Spitalpeunt, welches aus der gemeinschaftlichen Dreifelderwirtschaft herausgenommen war und gesondert genutzt wurde. Bereits zu Beginn des 14. Jahrhunderts wird erwähnt, dass der Dekan und das Kapitel von St. Gangolf im Jahr 1335 einen Acker in der Teurstat bei der spitalbeunt an den Spitalmeister und das Spital verliehen haben. ${ }^{560}$ Die Ausdehnung der Theuerstadt erfolgte auf Kosten des sandigen und feuchten Hauptsmoorwaldes, sodass eine Entwässerung eingerichtet werden musste. Einer dieser künstlichen Bäche und Kanäle folgte dem Verlauf der heutigen Kunigundenruhstraße und wurde Lausach genannt. ${ }^{561}$ Die Lausach diente als Wiesenentwässerung für die damalige, nach Norden ausgreifende Regnitzflussschleife, der sogenannten Peunt, deren Ausdehnung heute noch am gebogenen Verlauf der Gangolfstraße abgelesen werden kann. ${ }^{562}$ Diese unbebaute Fläche entstand aus der Urbarmachung von Sumpfwaldflächen und diente als Maßnahme gegen Hochwasser, als Viehweideland oder zum Anbau für landwirtschaftliche Sonderkulturen. ${ }^{563} \mathrm{Um}$ das Gebiet bearbeiten zu können, erhielt das Spital 1340 ein Wegerecht, das

11 Nr. 100 fol. 4; Zeuge ist unter anderem auch ein Gangolfer Kanoniker; ebenfalls im Jahr 1308 erfolgte die bischöfliche Schenkung an das Katharinenspital über 60 Joch Acker Waldes des Hauptmoores bei Theuerstadt zur Kultivierung in SttABa A 21 14-12-1308.

${ }^{560}$ Urkunde des Gangolfer Dekans und Kapitels vom 28. August 1335 in StABa BU 2179; Ebenso in SttABa A 21 28-03-1335; und in der innerstiftischen Überlieferung findet sich das Revers des Spitalmeister vom 26. August 1335 im Kopialbuch (16. Jhd) StABa Stift St. Gangolf, Akten und Bände Nr. 3 Teil 3 S. 36.

561 Näheres zu der Rolle der Gewässer in der historisch-topografischen Entwicklung Bambergs in Schöpplein: Die hochmittelalterliche Stadtmauer der Bamberger Inselstadt. 2016. S. 15; Das Gewässernamensforschung einen Beitrag zur Siedlungsgeschichte leisten kann, zeigt Albrecht Greule: Gewässernamensgeschichten im Main-Donau-Raum. In: Rolf Bergmann/ Stefanie Stricker (Hgg.): Römer - Baiern - Franken. Archäologie, Namensforschung, Sprachgeschichte im Main-Donau-Raum (Bamberger interdisziplinäre Mittelalterstudien. Vorlesungen und Vorträge, Bd. 7). Bamberg 2016. S. 9-23.

562 Exner/ Ruderich: Theuerstadt und östliche Stadterweiterungen. 2019. S. 8.

${ }^{563}$ Ebd. S. 406; Erich Freiherr von Guttenberg: Peunten in Oberfranken, im Allgäu und in der Steiermark. In: Korrespondenzblatt der Deutschen Gesellschaft für Anthropologie, Ethnologie und Urgeschichte 39 Nr. 4/5 (1908). S. 25-33, hier: S. 25 und S. 30. 
den Hof des Ottweyn Peyer und seiner Ehefrau Kungunt betraf. ${ }^{564}$ Dieser Weg führte durch das Hoftor der Familie Peyer an den Peuntfeldern, dem wiederum ein Tor zur Straße und zur Teuerstadt vorgelagert war. Die Schlüsselgewalt lag sowohl beim Katharinenspital als auch bei der besagten Familie Peyer. Der beschriebene Weg diente dem ungehinderten Zugang zu den Peuntfeldern. Der Einfluss des Stifts St. Gangolf wird daran deutlich, dass die Regelung ausdrücklich in Anwesenheit des Gangolfer Dekans vereinbart und gesiegelt wurde. Außerdem wohnten dieser Übereinkunft neben mehreren bürgerlichen Vertretern auch nicht näher benannte Gangolfer Kanoniker als Zeugen bei.

Die besitzrechtliche Verknüpfung von Spital und Stift in der Theuerstadt war streng geregelt und ist für das 16. Jahrhundert gut dokumentiert. ${ }^{565}$ So hatte die Spitalleitung, bestehend aus zwei Pflegern, einem Meister und einem Schreiber, strenge Vorgaben was Lehenrechte und Abgaben betraf. Der älteste der Spitalpfleger war der Lehensmann von zwei Gangolfer Morgen Wiesen auf der Peunt, von welchen er Abgaben an das Stift zu leisten hatte. Diese Wiesen wurden immer wieder dem nächstältesten Pfleger verliehen. Andere Gangolfer Güter in der Theuerstadt wurden hingegen nur dem Spitalmeister verliehen, welche er wiederum unter bestimmten Bedingungen weiterverleihen durfte. Der Spitalschreiber war für die ordnungsgemäße Auflistung und Einhaltung der Zahlungsfristen verantwortlich. Beide, Spitalmeister und Spitalschreiber, wurden auf das Gangolfer Kapitel vereidigt. Dass diese Regelung schon vor ihrer Niederschrift praktisch umgesetzt wurde, zeigt ein Schriftzeugnis aus dem Jahr 1537, in dem es heißt:

Ist der ersam und weyse Hans Franck, burger zu Bamberg und derzeit eltester pfleger sant Katherinaspital zu Bamberg bey sant Martins pfarkirchen gelegen, sampt dem spitalschreiber und dem spitalmeister vor uns dechant und capitelherrn in unser

\footnotetext{
${ }^{564}$ Urkunde des Ehepaars Peyer in Anwesenheit und mit Siegel des Gangolfer Dekans vom 18. Februar 1340 im Kopialbuch des Katharinenspitals (1247-1526) in SttABa B 11 Nr. 100 fol. $27^{\prime}-28$.

565 Lehenprotokolle des Obleiamtes (1410-1598) in StABa Stift St. Gangolf, Akten und Bände Nr. 126 fol. 104-105; Ebenso die Gegenüberlieferung im Lehenbuch des Katharinenspitals (1448-1576) in SttABa B 11 Nr. 101 fol. 13-14; Verwaltungsschriftgut über die Spitallehen vom 16. Jahrhundert an in AEB Rep. 60 Pfarrarchiv St. Gangolf Bamberg Nr. 328.
} 
capitel capitelstuben erschinen und anzaigt nach dem der erbar und fursichtig Dackler, diser zeit der eltest erbpfleger gedachts spitals, mit tod verschiden und byshero sich keiner desselbigen geschlechts erfunden, derhalben sy dazumal von wegen der lehen, dy sy von uns und unserm stift (von des Gempels seligen gutern) zulehen hetten, nach hant eins spruchs daruber brif und sigel ausgangen, ansuchten und paten ine $d y$ selbigen nach verunge des spruchs zuleihen. Welche ich Ieronimus Hirschperger decahnt aus bevelh meiner herrn des capitels nach prauch unsers stifts und inhalt des spruchs gelihen hab und theten alspald lehenspflicht. ${ }^{566}$

\subsubsection{Die Theuerstadt}

Die Theuerstadt als abseits der Insel- und Domstadt liegende Vorstadt war wichtiger Bestandteil der Gangolfer Selbst- und Fremdwahrnehmung. ${ }^{567}$ Dort fanden sich sowohl das Immunitätsgebiet ${ }^{568}$ als auch der Großteil des stiftischen Obleibesitzes. ${ }^{569}$ Dabei darf nicht übersehen werden, dass das Stift St. Gangolf in dem Gebiet östlich der Regnitz durchaus nicht allein präsent war, denn die Theuerstadt umfasste ein Konglomerat an unterschiedlichen Besitz-, Gerichts- und Pfarreirechten. Städtische Einrichtungen wie der Wirtschaftshof des bereits erwähnten Bürgerspitals St. Katharina oder die Wunderburg waren ebenso prägend für den Stadtteil Theuerstadt, wie das Kloster Heilig Grab und die Gertraudkapelle. Auch der Liebfrauen-Siechhof hatte seine Spuren in der Theuerstadt hinterlassen, erkennbar bis heute an der heutigen „Siechengasse“. ${ }^{570}$ Jedoch finden sich in den Quellen nur wenige Hinweise auf etwaige Beziehungen des Siechhauses zum Stift St. Gangolf, die einer näheren Betrachtung wert wären. Die Präsenz dieser zahlreichen Einrichtungen sorgte für eine Vielzahl von Grundherrschaften und Leiheverhältnissen in der Theuerstadt, in denen das Stift St. Gangolf einen festen Platz einnahm.

566 Lehenprotokolle des Obleiamtes (1410-1598) in StABa Stift St. Gangolf, Akten und Bände Nr. 126 fol. 31'.

${ }^{567}$ Näheres im Kapitel 3.2.5 Stiftsbezeichnungen in den Urkunden.

${ }^{568}$ Näheres im Kapitel 4.2.5 Keller und Immunitätsgericht.

${ }^{569}$ Näheres im Kapitel 6.4.1 Obleibesitz.

${ }^{570}$ Bis heute erhalten ist das barocke Liebfrauen-Siechenhaus in der Siechenstraße 88/92. 1308 erstmals urkundlich erwähnt, gehörte es im 16. Jahrhundert zur St. Martinspfarrei. Näheres dazu in Exner/ Ruderich: Theuerstadt und östliche Stadterweiterungen. 2019. S. 249-284, hier: 249-252; Mayer: Bamberg als Kunststadt. 1955. S. 348 und 352. 
Die Pfarrseelsorge in der Theuerstadt wurde größtenteils unabhängig vom Stift St. Gangolf bestritten. Generell teilte sich die Stadt Bamberg in zwei Pfarrbezirke: in den der Oberen Pfarre (auch Unsere Liebe Frau genannt), und in den der Unteren Pfarre (auch St. Martin genannt), welche unabhängig von Rechtsgrenzen verschiedene Gebiete umfassten. ${ }^{571}$ Durchbrochen wurden diese Stadtpfarreibezirke durch die Pfarreigebiete der kirchlichen Einrichtungen. Die Bewohner der Theuerstadt wurden daher, ausgenommen der Pfarreibezirk des Gangolfer Kustos, ${ }^{572}$ seelsorgerisch durch die Pfarrei St. Martin betreut. ${ }^{573}$ Auch bezüglich der Gerichtsrechte war die Theuerstadt ein Flickenteppich. Außerhalb des Immunitätsgebiets von St. Gangolf, wo der Keller des Stifts die Niedergerichtsbarkeit ausübte, ${ }^{574}$ fiel die Siechengasse beispielsweise vollständig in die Zuständigkeit des Stadtgerichts, während die Bereiche Steinweg und Heilig Grab, zumindest im 16. Jahrhundert, in einen Stadtgerichts- und einen Immunitätsgerichtsbereich unterteilt waren. ${ }^{575}$ Durch Ausbau des Stadtgebiets entwickelte sich auch die Theuerstadt bereits im Laufe des 12. Jahrhunderts ähnlich dem Sandgebiet. So konnte durch die Grabung am Deutschen Haus in der Oberen Königsstraße 4 die Entwicklung von Holz- zu Steinbauten nachgezeichnet werden, womit bereits sehr früh eine Straßensiedlung mit teilweisen massiven Haupthäusern nachzuweisen ist. ${ }^{576}$ Seit Anfang des 14. Jahrhunderts bildete die Seesbrücke eine Anbindung des Marktes auf der Inselstadt zur Altstraße in der Theuerstadt, welche, aufgrund ihrer Befestigung als steinweg bezeichnet, die Bedeutung der Theuerstadt für den Ausbau Bambergs als Handelsstadt aufzeigt. ${ }^{577}$ In dieser Zeit war die Theuerstadt ähnlich dem Kaulberg von drei Tortürmen, perfriede genannt, gesichert, welche eine Ummauerung ersetzte und zur Kontrolle

\footnotetext{
${ }^{571}$ Guttenberg/ Wendehorst: Das Bistum Bamberg 2. 1966. S. 76-87.

${ }^{572}$ Näheres im Kapitel 4.2.4 Kustos und Kirchner.

573 Braun: Von der Stiftspfarrei zur Stadtpfarrei. 1984. S. 375.

${ }^{574}$ Näheres im Kapitel 4.2.5 Keller und Immunitätsgericht.

575 Chandon: Die Bevölkerung der Stadt Bamberg um 1525. 2013. S. 38.

576 Pfaffenberger: Aspekte der Stadtentwicklung Bambergs im frühen und hohen Mittelalter aus archäologischer Sicht. 2020. S. 286; Näheres zur Grabungsbeschreibung am Deutschen Haus in den 1990er Jahren auf S. 235-254.

${ }^{577}$ Exner/ Ruderich: Theuerstadt und östliche Stadterweiterungen. 2019. S. 17.
} 
des Personen- und Warenverkehrs sowie als Gefängnisse genutzt wurden. ${ }^{578}$ Die Sozialstruktur östlich der Regnitz unterschied sich jedoch ziemlich bald von der der Insel- und Domstadt. Christian Chandon konnte deutlich machen, dass die Theuerstadt zu Beginn des 16. Jahrhunderts von einer eher ärmeren Bevölkerungsschicht geprägt war und die Besiedelung auf engem Raum erfolgte. ${ }^{579}$ Die Betreiber der in dem Gangolfer Obleibesitz organisierten Theuerstädter Höfe waren also überwiegend Bauern und Gärtner und seltener Handwerker oder Händler. ${ }^{580}$

\subsubsection{Das Verhältnis zur Kapelle St. Gertraud}

Die bereits im 12. Jahrhundert erwähnte Gertraudkapelle lag in unmittelbarer Nachbarschaft zum Stift St. Gangolf in der Theuerstadt am Steinweg und fungierte anfangs als Spital unter bischöflicher Oberaufsicht. ${ }^{581}$ Später diente es als Anlaufpunkt für Pilger, deren Herberge 2007 archäologisch nachgewiesen werden konnte. ${ }^{582}$ Im Jahr 1137 bekam das Kloster Michelsberg die Rechte über das Spital St. Gertraud durch den später heiliggesprochenen Bischof Otto verliehen, die 1251 durch Papst Innozenz IV. bestätigt wurden. ${ }^{583} \mathrm{Im}$ 15. Jahrhundert wurde St. Gertraud, inzwischen zur Pfarrkirche erhoben, dem Kloster Mi-

\footnotetext{
578 Ebd. S. 221-223.

${ }^{579}$ Chandon: Die Bevölkerung der Stadt Bamberg um 1525. 2013. S. 47.

580 Dies bestätigen auch die mittelalterlichen Befunde einer jüngeren stadtarchäologischen Grabungen, die in der Färbergasse einen Ackerhorizont, in der Siechenstraße 21 ein Mistbeet und in der Tocklergasse 23-29 einen gärtnerisch genutzten Humusboden nachweisen konnten. $\mathrm{Zu}$ finden unter den Katalognummern 6, 38 und 42 in Stefan Pfaffenberger: Stadtarchäologie in Bamberg 2016 bis 2017. In: BHVB 154 (2018). S. 7-36.

581 Karl Geyer: Die öffentliche Armenpflege im kaiserlichen Hochstifts Bamberg mit besonderer Rücksicht der Stadt Bamberg. Bamberg 1909. S. 168.

582 Kirche, Friedhof und Herberge über drei Parzellen hinweg wurden während eines Neubaus samt Tiefgarage zwischen Tränkgasse, Ludwigstraße und Obere Königstraße, heute Obere Königstraße 18, ergraben. In Pfaffenberger: Aspekte der Stadtentwicklung Bambergs im frühen und hohen Mittelalter aus archäologischer Sicht. 2020. S. 254-262.

${ }^{583}$ Rainer Braun: Das Benediktinerkloster Michelsberg 1015 - 1525. Eine Untersuchung zur Gründung, Rechtsstellung und Wirtschaftsgeschichte, Bd. 2. (Die Plassenburg. Schriften für Heimatforschung und Kulturpflege in Ostfranken, Bd. 39). Kulmbach 1977. S. 15.
} 
chelsberg inkorporiert. ${ }^{584}$ Die päpstliche Erlaubnis zur Verteilung von Ablassbriefen ermöglichten der Kapelle Einnahmen, die zum Erhalt der Kirche und, im besonderen Fall, auch zur Reparatur von Schäden nach einem großen Brand im 13. Jahrhundert verwendet werden konnten. ${ }^{585}$

Das Stift St. Gangolf hatte also keinerlei Zuständigkeit über die Kapelle, und doch sorgte die Tatsache, dass St. Gertraud inmitten des Gangolfer Immunitätsbezirkes lag, für zahlreiche Verknüpfungen auf rechtlicher Ebene. So agierte das Gangolfer Kellereigericht als legitimierende Instanz bei Stiftungen zugunsten der Gertraudkapelle, sobald die gestifteten Güter auf Gangolfer Gebiet lagen. ${ }^{586}$ Trotzdem blieb der Bischof weiterhin oberster Lehnsherr. ${ }^{587}$

Auch die Ausübung der Pfarrrechte über die Kapelle war nicht unumstritten. 1470 erhob das Stift St. Gangolf Ansprüche gegenüber dem Kloster Michelsberg auf die Seelsorge über die Angehörigen der Kapelle St. Gertraud - ein Streit, der bis vor den Bischof getragen wurde. ${ }^{588}$ Dass diese Bemühungen von einigem Erfolg für das Stift gekrönt gewesen sein mussten, lässt die Tatsache vermuten, dass um 1600 das domus kirchhaus s. Gertrudis stiftsintern zum Pfarrsprengel des Gangolfer Kustos gezählt wurde. ${ }^{589}$

Liturgisch bestand die Zusammenarbeit vor allem aus einer Einbindung der Gangolfer Stiftsmitglieder in den Gottesdienst in der Kapelle. Im Nachlass des Klosters Michelsberg findet sich ein verzeichnis was ein

\footnotetext{
584 Hannah Hien: Das Beginenwesen in fränkischen und bayerischen Bischofsstädten (Veröffentlichungen der Gesellschaft für fränkische Geschichte, Reihe IX: Darstellungen aus der fränkischen Geschichte, Bd. 59). Würzburg 2013. S. 213.

${ }^{585}$ Päpstliche Indulgenz an die Kirche St. Gertraud aus dem Jahr 1288 in StABa BU 1039; und aus dem Jahr 1299 in StABa BU 1241.

586 Nachzuweisen für einige Fälle ab der ersten Hälfte des 15. Jahrhunderts in den Urkunden des Kellereigerichts in AEB Rep. I Pfarrei St. Gertraud U 101-105, 107-110.

587 „Georg bischov zu Bamberg unsers gnedigen herren als lehenherrn bemelter capellanei“ in AEB Rep. I Pfarrei St. Gertraud U 116 vom 18. August 1513.

${ }^{588}$ Notariatsinstrument einer bischöflichen Urkunde von 1470 in AEB Rep. I Pfarrei St. Gertraud U 111.

589 „Verzeichnis der hauser, so in das stift zu s. Gangolph der custorei die pfarliche gerechtigkeith habe und ein verleibt sind wie folget." vom Anfang des 17. Jahrhunderts im Zinsregister einer Einzeloblei (1703-1748) in StABa Stift St. Gangolf, Akten und Bände Nr. 53 fol. 62‘. Näheres zu dieser Quelle im Kapitel 4.2.4 Kustos und Kirchner.
} 
prister und schulmeister bei st. Gangolph wegen Gertraudis des jahr über zu singen und zur bestallung hat, ${ }^{590}$ aus dem deutlich wird, dass der Gangolfer Scholastikus und nicht selten auch seine Schüler, ${ }^{591}$ am Tag der heiligen Gertraud (17. März), zur Kirchweih der Kapelle, in der Woche nach Pfingsten (in octav corporis Christi) und während des Advents im Dezember durch das Abhalten von Gottesdiensten eingebunden waren. Außerdem flossen aus den Einnahmen der Gertaudkapelle neben Zahlungen an die Gangolfer Vikarie Philipp und Jakob 15 Pfennige direkt an den Kustos von St. Gangolf, was sich wohl auf dessen Tätigkeit als Pfarrer in der Gertraudkapelle zurückführen lässt. ${ }^{592}$

\subsubsection{Das Verhältnis zum Heilig-Grab-Kloster}

Als bürgerliche Stiftung wurde das Dominikanerinnenkloster laut Legende im Jahr 1314 durch den Bamberger Bürger Franz Münzmeister und seine Ehefrau Katherina nach deren Reise nach Jerusalem zu Ehren des Grabmales Christi gestiftet und 1356 mit Nonnen besetzt. ${ }^{593}$ Gemäß der Volkssage spielte eine fromme Magd des Stifts St. Gangolf hinsichtlich der Klostergründung eine Rolle, indem sie eine durch Diebe achtlos ins Feld geworfenen Hostien fand und daraufhin an jenem Fundort das Kloster errichtet wurde. ${ }^{594} \mathrm{Im}$ Jahr 1525 wurde das Kloster geplündert und auch während des 30jährigen Krieges und 1803 im Zuge der Säkularisation stark in Mitleidenschaft gezogen. ${ }^{595}$ Das bereits von Münzmeister gestiftete Ölbild „Göttliche Hilfe“ findet sich heute in der Pfarr-

\footnotetext{
590 Zins- und Lehenbüchlein „über des einkomen zu der pfründt s. Gertrauten“ (15901610) in StABa Kloster Michelsberg, Akten und Bände Nr. 979 unfoliiert.

591 „Einem jeden schuelknaben, der sindt viel oder wenig, ein pretzen und ein heiße milch“ im Zins- und Lehenbüchlein „über des einkomen zu der pfründt s. Gertrauten“ (1590-1610) in StABa Kloster Michelsberg, Akten und Bände Nr. 979 unfoliiert.

592 Zins- und Lehenbüchlein „über des einkomen zu der pfründt s. Gertrauten“ (1590$1610)$ in StABa Kloster Michelsberg, Akten und Bände Nr. 979 unfoliiert.

${ }^{593}$ Exner/ Ruderich: Theuerstadt und östliche Stadterweiterungen. 2019. S. 78-80; Mayer: Bamberg als Kunststadt. 1955. S. 344.

594 Die Sage vom Heiligen Grab in Andreas Haupt: Bamberger Legenden und Sagen. Bamberg 1842. S. 167-185, hier: S. 180.

${ }^{595}$ Mayer: Bamberg als Kunststadt. 1955. S. 344.
} 
kirche von St. Gangolf. ${ }^{596}$ Die Legende rund um die Gründung des Heilig-Grab-Klosters ging in die stiftseigene Überlieferung ein:

Den 7. Juni 1356 bekundet Franz Münzmeister, bürger zu Bamberg, und seine frau Kunigunda um das newe closter $z u$ dem Heilgen Grab zu Teurstat auswendig Babenberg, das wir anheben sein zu stiften und zu bawen, und wann wir hofstät, die dabey und darumb liegen, darzu haben und kaufen müssen, da ein theil zinschaft waren und sein den herren zu s. Gangolf zu Teurstat, an der willen wir darzu kommen mochten und die durch unser bitt willen ihr gunst darzu gegeben haben, so haben wir ihn denselben ihren zins des sind siben und zweintzig schilling heller und zwey vaßnachthüner ewiger güldt zu ein mehrer sicherheit gegeben. ${ }^{597}$

Ungeachtet dessen, dass das Kloster territorial an die Immunität von St. Gangolf grenzte, war die Stadt Bamberg alleiniger Vermittler und bestätigende Instanz von Rechtsgeschäften und Leiheverhältnisse. ${ }^{598}$ Allein ein Gütertausch zwischen Stift und Kloster Ende des 14. Jahrhunderts bedingt durch die nahe Nachbarschaft zeigt eine gewisse Beziehung über die legendenhafte Gründungsgeschichte hinaus. ${ }^{599}$

\subsubsection{Das Verhältnis zur Wunderburg}

Der Rechtsstatus der dörflichen Siedlung Wunderburg sorgt bis heute für Diskussionen in der stadtgeschichtlichen Forschung. Während Isolde Maierhöfer das Gebiet als Kammerlehen zwar unter der Gerichtsbarkeit des Bischofs verortete, ${ }^{600}$ konnte Christian Chandon anhand der Sonderstellung der Wunderburg in den Steuerlisten von 1525 feststellen, "dass diese Siedlung noch nicht zum unmittelbaren Stadtgebiet gezählt wurde, sondern den Status einer direkt an das Stadt-

\footnotetext{
${ }^{596}$ Ebd. S. 345.

${ }^{597}$ Kopialbuch StABa Stift St. Gangolf, Akten und Bände Nr. 3 Teil 2 S. 220-221, hier: S. 220.

${ }^{598}$ Beispiele für von der Stadt Bamberg besiegelte Kaufgeschäfte des Klosters Heilig Grab sowie Gerichtsurteile des Schultheißen in StABa BU 2985 vom 22. März 1358; in BU 3115 vom 29. April 1361; BU 3130 vom 5. August 1361; BU 3599 vom 9. Februar 1374; BU 3787 vom 7. Mai 1378; BU 3860 vom 14. Februar 1380; BU 4001 vom 8. Februar 1384; und BU 4091 vom 9. April 1386.

599 Tausch eines Hauses am Steinweg mit einem Haus mit Hof in der Langgasse in der Bürgerstadt in einer Gangolfer Urkunde vom 4. April 1385 im Kopialbuch in StABa Stift St. Gangolf, Akten und Bände Nr. 3 Teil 2 S. 110-112.

${ }^{600}$ Maierhöfer: Bambergs verfassungstopographische Entwicklung. 1976. S. 154.
} 
gebiet anschließenden Vorstadt hatte. " ${ }^{601}$ In der stiftseigenen Überlieferung von St. Gangolf nimmt die Wunderburg nicht viel Platz ein. Dass sie um 1600 nicht zum Gangolfer oder Theuerstädter Gebiet gezählt wurde, zeigt ein Einnahmenregister von Anniversarstiftungen und Fabrikzinsen. Dort werden die abgabepflichtigen Personen den angegrenzten Gebieten immunitatis in der Theuerstadt, Wunterburg, civitatis Teuerstadianae und civitatis Bambergensis zugeordnet. ${ }^{602}$ Das verdeutlicht, dass die Wunderburg außerhalb der Immunität St. Gangolf lag. Trotzdem spielte sie besitzrechtlich für das Stift eine Rolle, da einzelne Höfe in der Wunderburg Teil der Gangolfer Oblei Hundsbühl waren. ${ }^{603}$

Unzweifelhaft ist diese dörfliche Siedlung im Südosten Bamberg ein gutes Beispiel, um zu verdeutlichen, wie dem Domkapitel daran gelegt war, die Immunitätsgebiete der Bamberger Kollegiatstifte nicht nur zu sichern, sondern sie darüber hinaus zu erweitern. Seit dem Jahr 1565 festigte sich das Domkapitel endgültig als Gerichtsherr der Immunitäten. ${ }^{604}$ Die Wunderburg war dabei immer wieder Streitthema zwischen dem Bischof und dem Domkapitel: Gehörte die Wunderburg zur Immunität St. Gangolf, womit sie auch der Gerichtsbarkeit des Stifts unterläge, oder zum städtischen Gebiet, dass wiederum zum Einflussbereich des Bischofs gehörte? ${ }^{605}$ Auch wenn zum Ende des 16. Jahrhunderts das Domkapitel die Grenzen der Gangolfer Immunität rund um die Wunderburg festlegte, ${ }^{606}$ fand dazu erst 1672 eine abschließende Regelung

${ }^{601}$ Chandon: Die Bevölkerung der Stadt Bamberg um 1525. 2013. S. 50.

${ }^{602}$ Register der Anniversarien und Fabrikzinsen (1601-1673) in StABa Gangolf, Akten und Bände Nr. 34. fol. 288'-295.

${ }^{603}$ Urbar über die Vikarien, Obleien und Fragmente (1317-1630) in StABa Stift St. Gangolf, Akten und Bände Nr. 32. Näheres zur Oblei in Kapitel 6.4.1.2 Einzelobleien - Oblei Hundsbühl.

${ }^{604}$ Reindl: Die vier Immunitäten des Domkapitels zu Bamberg. 1969. S. 326.

${ }^{605}$ Klaus Rupprecht: Der „Fall“ Wunderburg. Zur Beziehung Bischof Georgs von Bamberg (1459-1475) mit Kaiser Friedrich III. (1440-1493). In: Bielmeier, Horst (Hg.): Festgabe Gerd Zimmermann zum 65. Geburtstag (BHVB, Beiheft 23). Bamberg 1989. S. 111-138; Reindl: Die vier Immunitäten des Domkapitels zu Bamberg. 1969. S. 250.

606 Unter dem Vermerk „Domcapitlische iurisdiction der Wunderburg“ vom 19. September 1597 betonte das Domkapitel zwar seine Ansprüche auf die Wunderburg, räumte aber ein, dass der Schultheiß das Gebiet zum Stadtgericht zählte und dass „solcher Wunderburg halber vor unerdenklichen iahren in possessione gewesen, auch die darin verübten frevel vom dem richter obangeregter mundaten [Stifts St. Gangolf] verbüst 
statt. Danach gehörte die Wunderburg zwar insgesamt zur Gangolfer Immunität, jedoch wurden darin befindliche Häuser und Höfe vereinzelt der bischöflichen Gerichtsbarkeit unterstellt. ${ }^{607}$

\subsubsection{Das Verhältnis zum Stift ${ }^{608}$ Neunkirchen am Brand}

Das Stift des Augustiner-Chorherren-Ordens in Neunkirchen am Brand bestand im Zeitraum von 1314 bis 1554 und lag während seiner Wirkungszeit weitab von Bamberg, nämlich in der Nähe von Erlangen. ${ }^{609}$ Bereits vor seiner Gründung als Reformkanonikerstift gab es eine Pfarrkirche an gleicher Stelle, deren Oberpfarrer Leupold die Aufwertung der Kirche als Stift vorangetrieben hatte. ${ }^{610} \mathrm{Im}$ Jahr 1314 bestätigt Wulfing von Stubenberg als Bischof von Bamberg (amt. 1304-1318)

worden“. im Rezeßbuch des Domkapitels StABa B 86 Nr. 22 fol. 218'-220, hier: fol. 218 '. ${ }^{607}$ Rezeßbuch des Domkapitels StABa B 86 Nr. 42 fol. 147-149; Originalurkunde in StABa A 85 L 343 Nr. 1396.

${ }^{608}$ Häufig wird irreführend die Bezeichnung Kloster für die Kirche Neunkirchen am Brand verwendet - nicht nur in der Literatur, sondern auch als Quellenbegriff („monasterium canonicorum regularum“). Bei dem Gotteshaus in Neunkirchen am Brand handelte es sich um einen Zusammenschluss von Regularkanonikern unter dem Orden der Augustiner-Chorherren. Damit ist die Rede von Weltgeistlichen, die sich jedoch auf die mönchischen Werte des Gehorsams, Keuschheit und - und das unterscheidet sie von den unregulierten Kanonikern wie denen von St. Gangolf in Bamberg - auf Armut beriefen. Damit hatte diese kirchliche Einrichtung den Status eines Stifts und nicht den eines Klosters. Näheres dazu in Michael Schmid: Augustiner-Chorherren. In: Theologische Realenzyklopädie, Bd. 4. Berlin/ New York 1979. S. 723-728.

609 Horst Miekisch: Das Augustiner-Chorherrenstift Neunkirchen am Brand als Musterkonvent der Raudnitzer Reform in Franken und seine Auflösung in der Reformationszeit. In: Wüst, Wolfgang/ Machilek, Franz (Hgg.): Neunkirchen am Brand. Die Geschichte einer fränkischen Marktgemeinde. St. Ottilien 2019. S. 82-91; Ders.: Das Augustinerchorherrenstift Neunkirchen am Brand. Seine Geschichte und seine Bedeutung für die Verbreitung der Raudnitzer Reform. Dissertation, Universität Bamberg 2005.

${ }^{610}$ Bischöfliche Urkunde vom 14. Juli 1313 in StABa BU 1562 und kopial überliefert im Fundationsbuch des Stifts Neunkirchen am Brand in StABa B 113 Nr. 1 S. 8. bestätigt diese erste Stiftung des Leupold, die aus Gütern zu „Syglen“, „Slanhof bei Schellenberch“ und „Nanchendorf bei Höhstet“ bestand; Die Stiftungsurkunde vom 10. August 1313 in StABa BU 1568 fertigte Bischof Wulfing aus und bestätigt darin die Frühmesse, durchgeführt durch Pfarrer Leupold. Näheres dazu in Horst Miekisch: Pfarrer Leupold - der Gründer des Chorherrenstiftes. In: Wüst, Wolfgang/ Machilek, Franz (Hgg.): Neunkirchen am Brand. Die Geschichte einer fränkischen Marktgemeinde. St. Ottilien 2019. S. 423-424. 
die Stiftung des Augustiner-Chorherrenstiftes Neunkirchen am Brand. ${ }^{611}$ Der besagte Oberpfarrer Leupold bezog gleichzeitig eine Pfründe als Scholastikus am Stift St. Gangolf in Bamberg und wurde in der Literatur häufig der Familie von Hirschberg zugerechnet. ${ }^{612}$ Bereits im Jahr 1303 erwarb er Besitzungen in der Region und gründete das Spital St. Katharina in Forchheim. ${ }^{613}$ Bei all seinen Bemühungen um die religiösen Pflichten an verschiedenen Häusern hatte das Stift Neunkirchen am Brand für Leupold aber wohl die größte Bedeutung, da er sich dort letztendlich auch begraben ließ. ${ }^{614}$

Die Verbindung zwischen dem Stift St. Gangolf zum Stift Neunkirchen am Brand, die sich in Leupold personifizierte, wirft die Frage auf, inwieweit auch eine Verbindung zwischen den beiden Häusern beziehungsweise Gemeinschaften bestand. Während die Einkünfte der Pfarrkirche Neunkirchen am Brand nicht nur Leupold als Pfarrer, sondern auch seinem Kapitel in Bamberg zustanden, flossen sie nach der Neuerrichtung als Stift im Jahr 1314 als Unterhalt an die acht Priester und sechs Scholaren des Regularkanonikerstifts. ${ }^{615}$ Auch nach der Umwandlung der Pfarrkirche in eine Stiftskirche blieben Leupold sowohl seine Stellung als Pfarrer als auch seine Pfründe, die er als Scholastikus von St. Gangolf bezog, erhalten. ${ }^{616}$

611 Bestätigungsurkunde des Wulfing, Bischof von Bamberg (amt. 1304-1318), vom 8. Januar 1314 in StABa BU 1578; Auch im Fundationsbuch des Stifts Neunkirchen am Brand in StABa B 113 Nr. 1 S. 8.

${ }^{612}$ Miekisch konnte nachweisen, dass in den Quellen keinerlei Beweise für eine Zugehörigkeit $\mathrm{zu}$ der Familie von Hirschberg zu finden sind und diese Bezeichnung durch die Regionalforschung des 19. Jahrhunderts, allen voran Franz Wenceslaus Goldwitzer: Geschichte des Marktes Neunkirchen am Brand und des ehemaligen Klosters mit Rücksicht auf die Pfarrei daselbst nebst einer Topographie. Erlangen 1814. geprägt wurde. In Miekisch: Pfarrer Leupold. 2019. S. 423; und Ders.: Das Augustinerchorherrenstift Neunkirchen am Brand. 2005. S. 13 Anm. 39.

${ }^{613}$ Reddig: Bürgerspital und Bischofsstadt. 1998. S. 42.

${ }^{614}$ Miekisch: Das Augustinerchorherrenstift Neunkirchen am Brand. 2005. S. 16.

${ }^{615}$ Bestätigungsurkunde des Wulfing, Bischof von Bamberg (amt. 1304-118), vom 8. Januar 1314 in StABa BU 1578. Näheres dazu in Ebd. S. 11.

${ }^{616}$ So wird ihm noch 1318 als Leupolt, "dem pfarrer des closters zu Newnkirchen und schulmayster zu Tewerstat ze Babemberg“ ein Gut verkauft. Im Fundationsbuch des Stifts Neunkirchen am Brand in StABa B 113 Nr. 1 S. 15 und S. 17; In einem Schiedsspruch des Heinrich Ritter von Marloffstein vom 13. Juni 1328 in einer Differenz zwischen Leupold und Konrad Holzman um einen an das Kloster übereigneten „hof zu dem bade“ in StABa 
Hinweise über weitere bestehende Verbindungen zwischen dem Kollegiatstift St. Gangolf zum Stift Neunkirchen am Brand sind rar. In Konflikten, wie der im Jahr 1317 um die Ausübung der Archidiakonalgerichtsbarkeit zwischen dem Stift Neunkirchen am Brand und dem Domkapitel, in der Friedrich von Truhendingen als amtierender Propst von St. Gangolf (amt. 1302-1318) unter den Vertretern des Domkapitels auftauchte, ${ }^{617}$ ist dieser eher als Domkanoniker statt als Gangolfer Propst tätig. Miekisch konnte darüber hinaus nachweisen, dass es keinerlei Spuren einer Gebetsverbrüderung zwischen dem Stift Neunkirchen am Brand und dem Bamberger Stift St. Gangolf gab. ${ }^{618}$

Nichtsdestotrotz behielt das Stift seinen Scholastikus Leupold nicht zuletzt aufgrund seiner Stiftungsleistungen in Neunkirchen am Brand in ehrenvoller Erinnerung, sodass sein Todestag am 11. September Eingang in die Gangolfer Anniversarsüberlieferung fand. ${ }^{619}$ Darüber hinaus ist im Kopialbuch des Stifts St. Gangolf eine Urkunde vom Januar 1330 überliefert, in der Friedrich, Propst des Stifts Neunkirchen, das Jahrtagsgedenken des dominus Leupoldus canonicus et scholasticus ecclesiae s. Mariae in Teurstat extra muros Bambergense mit der Stiftung von einem Pfund jährlich für das Abhalten von Gottesdienstleistungen bestätigte. ${ }^{620}$ Der Vikar des Altars St. Nikolai iunioris an der Stiftskirche St. Gangolf in Bamberg hatte alljährlich den Jahrtag des Leupoldi sacerdotis de Neunkirchen de curia in Swinbach zu begehen. ${ }^{621}$

Die Beziehung des Stifts St. Gangolf zum Stift Neunkirchen am Brand war also sehr personalisiert und auf das Engagement des Leopold beschränkt. Es sind sowohl vor dessen Wirken als auch nachher keine weiteren Verbingungslinien zwischen den zwei Häusern auszumachen.

BU 1947 wird Leupold als „Leupold korher ze Teuerstat weilent fparer ze Newenkirchen“ betitelt.

${ }^{617}$ Auf Beschluss vom Bamberger Bischof und Domkapitel wurde das neue Stift gegen Zahlungen von der Archidiakonalgerichtsbarkeit losgesprochen. Im Fundationsbuch des Stifts Neunkirchen am Brand in StABa B 113 Nr. 1 S. 13-14; und in StABa BU 1682.

${ }^{618}$ Miekisch: Das Augustinerchorherrenstift Neunkirchen am Brand. 2005. S. 230.

${ }^{619}$ StABa Stift St. Gangolf, Akten und Bände Nr. 128 fol. 22' und Nr. 129 fol. 58'.

${ }^{620}$ Kopialbuch Gangolf, Akten und Bände Nr. 3 Teil 2 S. 277.

621 Urbar über die Vikarien, Obleien und Fragmente (1317-1667) in StABa Stift St. Gangolf, Akten und Bände Nr. 44 fol. 53. 


\section{Religiöses und geistiges Leben}

\subsection{Gottesdienst und Prozessionen}

Die Quellen über die liturgische Ausgestaltung der Gottesdienste am Stift St. Gangolf sind wenig zahlreich und reichen nicht weiter als bis in das 16. Jahrhundert. Vor allem die Gangolfer Consuetudines, deren früheste überlieferte Version aus dem Jahr 1523 stammt, geben Einblick in die Regelungen rund um Gottesdienst und Chorgebet. ${ }^{622}$ Demnach hatte der Dekan die liturgische Leitung inne. Bei Abwesenheit wurde er von dem ältesten Kanoniker vertreten. ${ }^{623} \mathrm{Um}$ die Disziplin während der Chorgebete zu gewährleisten, wurden strenge Vorgaben über das Verhalten des Einzelnen gemacht. Die Verbeugung nach Osten während des Offiziums beispielsweise sollte ehrerbietig und synchron geschehen, ${ }^{624}$ Gesang und Lesungen waren ohne Geschwätz und mit Sorgfalt zu absolvieren. ${ }^{625}$ Bei Geflüster während der Gottesdiente wurden die Schüler dafür verantwortlich gemacht, die Ruhe untereinander wiederherzustellen. ${ }^{626}$ Diese Regelungen, welche letztendlich als Ermahnung zur Frömmigkeit verstanden werden müssen, waren keine Seltenheit in stiftischen Regelwerken und dienten der Sicherung des

622 "Consuetudines laudabiles disciplinam, silentium, ceremonias chori et divinorum officiorum cencernentes in ecclesia nostra” im Statutenbuch StABa Stift St. Gangolf, Akten und Bände Nr. 130 fol. 87`. Näheres zu den Consuetudines im Kapitel 4.1.1 Statuten und Consuetudines.

623 „Volentes, precipientes, consuetudines, ceremonias et observantias huiusmodi ab omnibus ecclesie nostre personis inviolabiliter observari sub pena transgresseribus neglectoribus seu violatoribus eorundem per decanum nostrum si prius fuerit alias per seniorem canonicum capitularem presentem arbitraria imponenda." im Statutenbuch StABa Stift St. Gangolf, Akten und Bände Nr. 130 fol. 87‘.

624 Consuetudo „De inclinationibus: Item regentes chorum, antequam incipiant invitatorium, ambo reverenter et simul se inclinent ad orientem." im Statutenbuch StABa Stift St. Gangolf, Akten und Bände Nr. 130 fol. 89'.

${ }^{625}$ Consuetudo „De silentio: Item nullus tempore divinorum cum altero confabulationes presertim in choro habeat, sed quilibet legat, cantet aut lectionibus vel cantibus aliorum, dum ille silere debet, diligenter intendat" im Statutenbuch StABa Stift St. Gangolf, Akten und Bände Nr. 130 fol. 90'.

${ }^{626}$ Consuetudo „De introitum et exitum: Item nullus intret, exeat aut pertranseat chorum infra silentium vel uno solo legente vel canente, nec quisquam eo tempore sibilet, scholarem vocet sive mittat, ut debitum silentium observetur." im Statutenbuch StABa Stift St. Gangolf, Akten und Bände Nr. 130 fol. 91. 
makellosen Auftritts nach außen. In diesem Zusammenhang ist auch die Bestimmung zu sehen, dass die Kleidung und Kopfbedeckung der Kanoniker während der Gottesdienste weder unangebracht, nachlässig angelegt oder gar zu kurz sein durften. ${ }^{627}$

Eine mittelalterliche Gottesdienstordnung aus dem Nachlass des Gangolfer Pfarrers Friedrich Wunder (geb. 1775), welche im Pfarrarchiv des Stifts zu finden ist, ${ }^{628}$ ergänzt das Bild der liturgischen Ausgestaltungen des stiftischen Alltags um einige interessante Aspekte. Es handelte sich um eine Version der frühesten Gottesdienstordnung des Bamberger Domstifts, welche in seiner Urform im 12. Jahrhundert entstand und im 15. Jahrhundert durch den Gangolfer Dekan Heinrich Forstmeister (amt. 1416-1428) an das Kollegiatstift gelangte. ${ }^{629}$ Dort wurde sie durch Texttilgungen und Überarbeitungen den Ansprüchen des Stifts St. Gangolf angepasst. Die Grundstruktur der domstiftischen Gottesdienstordnung blieb, jedoch wurden liturgische Besonderheiten St. Gangolfs, wie die Regelungen rund um die Beteiligung der Gangolfer Kanoniker an der domstiftischen Liturgie zu hohen Festtagen, hinzugefügt. Hier finden sich die wenigen überlieferten Informationen über die Prozessionen, an denen das Stift mitwirkte: ${ }^{630}$ Vorgeschrieben war die Teilnahme Gangolfer Kanoniker an der Palmprozession während der Fastenzeit hin zum Kloster Michelsberg, an der Prozession des ersten Bitttages vor Christi Himmelfahrt vom Dom aus hin zum Stift St. Stephan, am zweiten Bitttag an der Prozession über das Kloster St. Theodor hin zur Pfarrkirche Unserer Lieben Frau und am dritten Bitttag

${ }^{627}$ Consuetudo „De vestibus: Item nullus indecentibus vestibus chorum neque capatus vel cum mitra aut sine religione monasterium tempore divinorum intrare nec omnino aliquid inibi brevibus vestibus indutus legere, cantare aut quidquam facere officiando presumat.“ im Statutenbuch StABa Stift St. Gangolf, Akten und Bände Nr. 130 fol. 91'.

${ }^{628}$ Als Dispositum im Archiv des Erzbistums Bamberg unter der Signatur AEB Rep. 60 Pfarrarchiv St. Gangolf Bamberg Nr. 119.

${ }^{629}$ Näheres über das "Breviarium St. Gangolphi” in Edmund Karl Farrenkopf: Breviarium Eberhardi Cantoris. Die mittelalterliche Gottesdienstordnung des Domes zu Bamberg. Münster 1969; und Otto Meyer: Breviarium Eberhardi Cantoris. Zur Überlieferungsgeschichte der mittelalterlichen Gottesdienstordnung des Doms zu Bamberg. In: Monumentum Bambergense (Bamberger Abhandlungen und Forschungen, Bd. 3). München 1955. S. 413-429.

${ }^{630}$ Meyer: Breviarium Eberhardi Cantoris. 1955. S. 426-427. 
vom Stift St. Gangolf aus hin zur Pfarrkirche St. Martin. Außerdem erfolgte am Markustag (25. April) eine Prozession vom Dom aus zur Stiftskirche St. Gangolf und es finden sich Spuren einer eigenen Prozession des Stifts St. Gangolf zur Präsentation der stiftsinternen Reliquien $^{631}$ an der Kapelle St. Gertraud vorbei. Die Gangolfer Vikare waren darüber hinaus in die Fronleichnamsprozession des Domstifts mit eingebunden, an der auch die Vertreter des Theuerstädter Immunitätsgerichts in Person der Richter und Schöffen beteiligt waren. ${ }^{632}$ Diese Vorgaben zu den religiösen Aufzügen werden ergänzt durch Passagen in den Consuetudines, welche bestimmten, dass das Stift St. Gangolf bei der Hochamtsprozession des Domstifts vertreten zu sein hatte. ${ }^{633} \mathrm{Au}$ ßerdem galt dort wie auch bei den anderen Prozessionen, dass möglichst alle Kanoniker des Stifts anwesend sein sollten und dass diejenigen, die nicht rechtzeitig vor Beginn der Prozession am Chor eintrafen, sich still an einem Nebeneingang aufzuhalten hatten, um die geordneten Reihen der Prozessierenden nicht zu stören. ${ }^{634}$

Ein interessantes Detail, das in der Gangolfer Gottesdienstordnung des 16. Jahrhunderts festgelegt wurde, ist die Pflege des Brauchs eines Kinderbischofs ${ }^{635}$ am Tag des heiligen Nikolaus (6. Dezember). Bis dahin in Bamberg nur am Stift St. Stephan nachweisbar, ${ }^{636}$ wählten sich die Scholaren einmal im Jahr einen der ihren zum Bischof, mit dem sie in die Kirche der Stadt zogen. ${ }^{637}$ Dieses Bischofsspiel stellte durch den

\footnotetext{
${ }^{631}$ Näheres zu den Reliquien des Stifts im Kapitel 3.2 Patrozinien.

${ }^{632}$ Meyer: Breviarium Eberhardi Cantoris. 1955. S. 427.

633 Consuetudo „De processionibus solemnibus in ecclesia maiori.” im Statutenbuch StABa Stift St. Gangolf, Akten und Bände Nr. 130 fol. 91.

${ }^{634}$ Consuetudo „De processionibus consuetis: Item cum processiones consuete fuerint omnes intersint et nullus in monasterio extra processionem compareat, sed volens in processione congredi festinet prius chorum intrare aut secus ianuam stare et alias retrocedat et processioni inordinate se non immisceat." im Statutenbuch StABa Stift St. Gangolf, Akten und Bände Nr. 130 fol. 91'.

${ }^{635}$ Näheres zu diesem Brauch in Tanja Skambraks: Das Kinderbischofsfest im Mittelalter. Florenz 2014.

${ }^{636}$ Erich Freiherr von Guttenberg: St. Nikolaus im alten Bamberg. In: Bamberger Blätter für fränkische Kunst und Geschichte (Beilagen zum Bamberger Volksblatt) 5 (1928). S. 85 87, hier: S. 85.

${ }^{637}$ Meyer: Breviarium Eberhardi cantoris. 1955. S. 428.
} 
szenischen Rollentausch ein anschauliches Beispiel der Gangolfer Frömmigkeitspraxis und mittelalterlichen Festkultur dar. Außerdem beteiligte sich das Stift St. Gangolf, wie auch die anderen Bamberger Stifte, durch die Bereitstellung von sogenannten Ölpriestern an der Ölprozession am Gründonnerstag. Die Ölprozession war seit Ende des 15. Jahrhunderts ein fester Bestandteil der Liturgie am Bamberger Dom. ${ }^{638}$

Eine rätselhafte Quelle hinsichtlich der liturgischen Praxis am Stift St. Gangolf ist ein reich illustriertes Evangeliar aus dem 15. Jahrhundert, welches sich in der Überlieferung der Gangolfer Pfarrei findet. ${ }^{639}$ Die Prachthandschrift umfasst Musikalien mit Noten und Texten zu den jährlichen Festen sowie Auszüge aus den Evangelien, entbehrt jedoch jeden Hinweis auf seine Entstehungsgeschichte. Trotzdem festigen die dem Evangeliar vorgesetzte Darstellung des Wappens des Heinrich von Rotha, Dekan des Stifts St. Gangolf (amt. 1412-1416), und der besonders hervorgehobene Eintrag am Gangolftag mit Darstellung des Ritterheiligen $^{640}$ die Vermutung, dass es sich um ein speziell für das Stift St. Gangolf angefertigtes Stück handelt.

\subsection{Vikarien}

Zur Abhaltung der allgemeinen Gottesdienste an den Altären des Stifts St. Gangolf waren Vikarien, auch Altarpfründen genannt, eingerichtet, welche Stifungen mit gesondertem Vermögen und ohne seelsorgerische Pflichten darstellten. Sie wurden jeweils mit einem Vikar ${ }^{641}$ besetzt, der als Stellvertreter des Pfründners den liturgischen Dienst am Altar wahrnahm und, ähnlich wie die Kanoniker des Stifts, Präsenzgel-

638 Xaver Haimerl: Das Prozessionswesen des Bistums Bamberg im Mittelalter (Münchener Studien zur historischen Theologie, Bd. 14). München 1937 (ND Hildesheim 1973). S. 121-122.

${ }^{639}$ AEB Rep. 60 Pfarrarchiv St. Gangolf Bamberg Nr. 120.

${ }^{640}$ AEB Rep. 60 Pfarrarchiv St. Gangolf Bamberg Nr. 120 S. 22.

${ }^{641}$ Kirchenrechtlich ist hier der "vicarius minor“ gemeint. Näheres dazu in Marie-Luise Heckmann: Art. „Vikar,- iat“. In: LexMA Bd. 8 (1997). Sp. 1662-1664; und Michael Kaiser: Art. „Vikar“. In: LThK Bd. 10 (1965). Sp. 791. 
der erhielt. Unterhalten wurden die Vikare durch die Einnahmen aus zinspflichtigen Grundstücken, die sich auf Stiftungen an den von ihnen betreuten Altar gründeten und vom Kapitel verwaltet wurden. Durch die Eigenart der stiftseigenen Überlieferung sind in den Quellen überwiegend Spuren der Einkommensverwaltung der Vikarien zu finden, wohingegen ihre erhebliche liturgische Bedeutung nur sehr schwer herauszulesen ist.

Die Erschließung der ältesten Nennungen der Vikarien ist fast ausschließlich über die Zinsregister des 16. Jahrhunderts $\mathrm{zu}$ leisten. ${ }^{642}$ Leider geben diese Schriftzeugnisse kaum Informationen über die bloße Erwähnung der Güter hinaus, sodass sich kein umfassendes Bild über die Verwaltung und Bedeutung der einzelnen Vikariestiftungen gewinnen lässt. Die Abhängigkeit der unter einer Vikarie zusammengefassten Grundstücke und Güter betrafen die Abgabepflichten an das Stift St. Gangolf und den speziellen Vikar. Die Pfarreizugehörigkeit oder andere geistliche Zuständigkeiten waren davon nicht betroffen und lagen üblicherweise an anderer Stelle.

Nachweisbar sind Vikarien des Stifts St. Gangolf bereits im 14. Jahrhundert, als der Bamberger Domdekan die Gangolfer Vikare dazu anhielt, sich an den allgemeinen Brauch in Bamberg zu halten. ${ }^{643}$ Das Stift St. Gangolf regelte die Vikariepraxis in seinen Consuetudines. In ihnen ist von acht stellvertretenden Priestern die Rede, ${ }^{644}$ die wohl dem Hauptaltar und den sieben Unteraltären zugeordnet waren. Jedoch betonen die Consuetudines an anderer Stelle wiederum die Doppelbesetzung einer Vikarie, wenn diese sowohl eine Senior- und eine Juniorstif-

${ }^{642}$ Das älteste ist dabei das Urbar mit einer Vikarienauflistung für die Jahre 1516 bis 1566 in StABa Stift St. Gangolf, Akten und Bände Nr. 32 fol. 1-59'.

643 Schiedspruch des Domdekans von Bamberg als Generalvikar zur Klärung von Streitigkeiten rund um die Chorwoche, Lesung der Lektionen und Singen der Responsorien durch die Gangolfer Vikare. Als Abschrift der Urkunde vom 30. Juni 1320 in Looshorn: Die Geschichte des Bisthums Bamberg, Bd. 3. 1891. S. 51.

644 „Item summa missa in altari maiori ipsius ecclesie hora consueta per octo ex nobis canonicos seniores, qui presbiteri nuncupantur, secundum ordinem in canonicatibus et prebendis eorundem per singulos dies alternatis hebdomadis celebriari et cantari debebit, quorum etiam quilibet septimana sua expleta in hebdomada sequenti cum due misse in choro cantande sunt, priorem cantare." im Statutenbuch StABa Stift St. Gangolf, Akten und Bände Nr. 130 fol. 88. 
tung, also eine ältere und eine jüngere innehatte. ${ }^{645}$ Der Vikar des Stephanaltars von St. Gangolf beschrieb im 16. Jahrhundert im Rahmen einer Eidesleistung vor dem Stiftskapitel seine Aufgaben wie folgt:

In possession und gewerde solcher vicarei gunstiglich kommen und eingelasen haben derhalben gerede ich und vorsprich bei meinen gut waren treuen di selben vicarei selbst personlich bezihen mit messen singen und lesen durch mich nach meinen vermögen, auch sonst niemandt und keinen andern an mein stat stellen an sonder willen und wissen eines capitels. ${ }^{646}$

Während die Übertragung einer Vikarie zur Besetzung einer vakanten Stelle und zur Sicherung der Pfarrdienste an dem Altar in den meisten Fällen allein Sache des Stiftskapitels war, erfolgte die Besetzung der Vikarie St. Stephan durch den Bamberger Bischof, jedoch mit ausdrücklicher Zustimmung des Dekans und des Gangolfer Kapitels. ${ }^{647}$

Die Besitzungen, auf die sich die Vikariestiftungen beriefen, lagen ähnlich den Obleistiftungen über mehrere Orte verteilt, sodass auch hier die Eintreibung der Einkünfte mit Schwierigkeiten verbunden war. Ein beredtes Zeugnis davon gibt eine Urkunde aus dem Jahr 1406, in der der Dekan und das Kapitel des Stifts St. Gangolf auf ausdrückliche Bitten ihres Vikars des Altars St. Nikolaus senior Güter zu Kirchleus (Lk Kulmbach, Kirlewbs) verkauften, mit der Begründung:

wy daz im der obgenant erbezins ungelegen sey und daz er den in etlichere iar nutze mit muwe und erbeit einbrengen als uns auch wol kuntlich ist. Und er hat uns gebeten, daz wir dy obgenanten guter wollen vorkaufen und daz gelt daz dafur gevalle seinen obgenannt vicarei anlegen wollen an gelegnern nehern steten. ${ }^{648}$

Die heutigen Altarbezeichnungen ${ }^{649}$ sind nicht identisch mit denen des Mittelalters. Eine stiftseigene Auflistung der Altäre um das Jahr 1600 verzeichnet 12 Altäre und ordnet diese sogar den späteren Altären zu: 1. der Hauptaltar der heiligen Maria und des heiligen Gangolf, 2. s. Trini-

${ }^{645}$ Näheres dazu in den Kapiteln 5.2.1 Vikarie St. Nikolaus senior und junior und 5.2.2 Vikarie Aposteln senior und junior.

${ }^{646}$ Urkunde von 1536 in AEB Rep. I Pfarrei St. Gangolf U 823.

${ }^{647}$ Urkunde vom 1. Januar 1554 in AEB Rep. I Pfarrei St. Gangolf U 825.

${ }^{648}$ Urkunde des Klosters Langheim vom 28. August 1406 in StABa Kloster Langheim, Urkunden 1406 VIII 28.

${ }^{649}$ Links von Ost nach West: Altäre der Heilgen Johannes Nepomuk, Joseph und Sebastian; und rechts von Ost nach West: Altäre der Dreifaltigkeit, der Unbefleckten Empfängnis und des Heiligen Karl Borromäus. Näheres dazu in Mayer: Bamberg als Kunststadt. 1955. S. 334. 
tatis, 3. b. Mariae virginis, 4. s. Johannis baptistae (der spätere Altar des Karl Borromäus), 5. s. apostolorum, 6. s. Stephani protomartyris (der spätere Altar des Johannes Nepomuk), 7. s. Martini episcopi, 8. s.s. Philippi et Jacobi (der spätere Altar des heiligen Joseph), 9. s. Mathiae apostoli (der spätere Altar des heiligen Sebastian), 10. s. Katharinae et Blasii (der spätere Gotthelf-Altar), 11. s. Mariae Magdalenae et trium regum und 12. s. Nicolai episcopi (der spätere Altar der heiligen Anna). ${ }^{650}$

Durch die Untersuchungen von Vikariestiftungen und den ihnen zugeordneten Altären ist es häufig möglich, in die frühesten Anfänge der Altargeschichte eines Hauses vorzudringen und dort Präferenzen in der frühen Heiligenverehrung auszumachen. ${ }^{651}$ Die Entscheidung, Altarpatrozinien $\mathrm{zu}$ ändern, konnte sich auf verschiedene Umstände gründen: Sie konnten gewissen Moden folgen oder ging mit neuerworbenen Reliquien einher. So wurde 1806 die heutige Göttlich-Hilf-Kapelle in der mittelalterlichen Sepultur der Gangolfer Kirche eingerichtet, nachdem ein Kruzifix aus der säkularisierten Heiliggrabkirche dem ehemaligen Stift übereignet wurde. ${ }^{652}$ Die mittelalterlichen Altäre samt Vikarien, die sich aus den Quellen herausfiltern lassen, belaufen sich auf insgesamt sieben, wobei zwei Altäre sowohl eine Senior- und eine Juniorvikarie besaßen.

\subsubsection{Vikarie St. Nikolaus senior und junior}

Eine der frühesten Vikariestiftungen ist die des Altars St. Nikolaus, ${ }^{653}$ der in den Zinsregistern des 16. Jahrhunderts sowohl durch eine vicaria st. Nicolai senioris und vicaria st. Nicolai iunioris besetzt wurde, und sich an der Stelle der heutigen Annakapelle befand. Der Nikolausal-

650 „In collegiata ecclesia beatae Mariae virginis et sancti Gangolphi altaria“ in AEB Rep. 60 Pfarrarchiv St. Gangolf Bamberg Nr. 3 unfoliiert.

${ }^{651}$ Zimmermann: Die Gangolfskirche als Spiegel der Frömmigkeit seit über 925 Jahren. 1990. S. 23.

652 Mayer: Bamberg als Kunststadt. 1955. S. 336.

${ }^{653}$ Gerd Zimmermann sieht die ältere Nikolausvikarie im Jahr 1307 und die jüngere 1317 sowohl durch den Kustos als auch durch den Keller gegründet. Zimmermann: Die Gangolfskirche als Spiegel der Frömmigkeit seit über 925 Jahren. 1990. S. 24. 
tar war demnach mit zwei Vikaren besetzt, die abwechselnd ihren Gottesdienst versahen. ${ }^{654}$

Nach Interpretationen der Fundamentlage und der dendrochronologischen Daten aus dem Dachstuhl konnte nach jüngeren Erkenntnissen eine Erbauung der Kapelle bereits für das 12. oder 13. Jahrhundert in die Diskussion gebracht werden. ${ }^{65}$ Die ältere Nikolausvikarie selbst ist erstmals 1406 fassbar, als Konrad Raben, Dekan von St. Gangolf (amt. 1398-1407), auf Bitten des Vikars Güter zu Kirchleus verkaufte, da diese durch ihre entfernte Lage nur schwer zu verwalten wären. ${ }^{656}$ Hier erscheint der Gangolfer Dekan als Lehensherr der Nikolausvikarie. Dies wird zum einen durch die Rolle des Dekans bei der Verleihung der vakanten Vikarie bestätigt, ${ }^{657}$ und zum anderen durch den Vermerk collator dominus decanus bei den Eintragungen über die ältere der beiden Nikolausvikarien in den Zinsregistern des 16. Jahrhunderts bekräftigt, worin Einnahmen aus Gütern in Pünzendorf (Gde Scheßlitz, Lk Bamberg), Weiden (n. ident., vermutlich Gde Weismain, Lk Lichtenfels, Weyden), ${ }^{658}$ Neundorf (Gde Mitwitz, Lk Kronach, Neundorf bey Kulmbach), Hallstadt (Lk Bamberg) sowie in Bamberg in der Theuerstadt, in der Wunderburg und im Abtswörth verzeichnet sind. ${ }^{659}$ Die jüngere Vikarie St. Nikolaus speiste sich hingegen aus Einkünften aus Steinbach [am Wald?] (Lk Kronach), Schönfeld (Gde Hollfeld, Lk Bayreuth) und Störnhof (Gde Wiesenttal, Lk Forchheim, Stornhove). ${ }^{660}$

654 Consuetudo „De vicariis officiandis et missis pro defunctis: Duo vicarii s. Nicolai singulis diebus in altari suo celebrabuntur quilibet vicissim per integram septimanam." im Statutenbuch StABa Stift St. Gangolf, Akten und Bände Nr. 130 fol. 89.

${ }^{655}$ Pfaffenberger: Stadtarchäologie in Bamberg 2018 bis 2019. 2020. S. 24.

${ }^{656}$ StABa Kloster Langheim, Urkunden 1406 VIII 28.

${ }^{657}$ Der Vikar des Altars St. Nikolaus senior bürgte für den Dekan bei dem Verleihungsakt. In der Urkunde des Stifts St. Gangolf vom 30. Juni 1531 in StABa A 120 L 131 Nr. 727; und vom 30. April 1539 in StABa A 120 L 131 Nr. 729.

658 Dieter George: Lichtenfels. Der Altlandkreis (Historisches Ortsnamensbuch von Bayern, Bd. 6). München 2008. S. 164-165.

659 „Vicaria sancti Nicolai senioris“ im Zinsregister von 1516 in StABa Stift St. Gangolf, Akten und Bände Nr. 44 fol. 23-27‘; „vicaria sancti Nicolai senioris“ im Zinsregister von 1555 in StABa Stift St. Gangolf, Akten und Bände Nr. 23 fol. 17-20; „vicaria sancti Nicolai senioris“ im Zinsregister um 1566 in StABa Stift St. Gangolf, Akten und Bände Nr. 32 fol. 14-16:

${ }^{660}$ „Vicaria sancti Nicolai iunioris“ im Zinsregister von 1516 in StABa Stift St. Gangolf, 


\subsubsection{Vikarie Aposteln senior und junior}

Auch die Vikariestiftung, die den heiligen Aposteln geweiht wurde, unterteilte sich wohl bereits im 14. Jahrhundert in eine jüngere und eine ältere. ${ }^{661}$ Dadurch war eine Besetzung mit zwei Vikaren geboten, welche in einer festen Reihenfolge ihren wöchentlichen Verpflichtungen am Altar nachgingen. ${ }^{62}$ Die ältere bezog ihre Einkünfte aus Gütern in Neuhaus (Gde Aufseß, Lk Bayreuth), Königsfeld (Lk Bamberg), Traindorf (Gde Heiligenstadt in Oberfranken, Lk Bamberg), Teuschnitz (Lk Kronach), Gundelsheim (Lk Bamberg), Hallstadt (Lk Bamberg) sowie in Bamberg in der Theuerstadt und am Sand. ${ }^{663}$ Laut den Zinsregistern des 16. Jahrhunderts stand diese Vikarie unter die Obhut des Gangolfer Scholastikus, der als procurator dieser vicarey fungierte. ${ }^{664}$ Die Gründungsurkunde der älteren Vikariestiftung am Altar der Aposteln Petrus und Paulus von 1343 ist abschriftlich überliefert und weist einen Gottfried, Kanoniker des Stifts St. Gangolf, als dessen Stifter ad perpetuam rei memoriam aus, der sie mit Gütern in Königsfeld, Traindorf, Teuschnitz, Gundelsheim und im Bamberger Hundsbühl ausgestattet hatte. ${ }^{665}$ Damit zeigt sich, dass sich das Stiftungsgut seit der Einrichtung der Vika-

Akten und Bände Nr. 44 fol. 28-33; „vicaria iunioris sancti Nicolai“ im Zinsregister von 1559 in StABa Stift St. Gangolf, Akten und Bände Nr. 23 fol. 57-60; „vicaria sancti Nicolai iunioris“ im Zinsregister um 1566 in StABa Stift St. Gangolf, Akten und Bände Nr. 32 fol. 17-20.

${ }^{661}$ Gerd Zimmermann erwähnt eine Vikarie der heiligen Apostel am Altar des heiligen Kreuzes und der Apostel Petrus und Paulus von 1343 und eine, die spätestens 1388 eingerichtet wurde. Zimmermann: Die Gangolfskirche als Spiegel der Frömmigkeit. 1990. S. 24.

662 Consuetudo „De vicariis officiandis et missis pro defunctis: Duo vicarii altaris apostolorum similiter singulis diebus in suo altari alternatis ebdomadis celebrabuntur." im Statutenbuch StABa Stift St. Gangolf, Akten und Bände Nr. 130 fol. 89.

663 „Vicaria senioris apostolorum“ im Zinsregister von 1516 in StABa Stift St. Gangolf, Akten und Bände Nr. 44 fol. 64‘-69'; „vicaria senioris apostolorum“ im Zinsregister um 1566 in StABa Stift St. Gangolf, Akten und Bände Nr. 32 fol. 39-42.

${ }^{664}$ Zinsregister von 1516 in StABa Stift St. Gangolf, Akten und Bände Nr. 44 fol. 67; und Zinsregister um 1566 in StABa Stift St. Gangolf, Akten und Bände Nr. 32 fol. 40،

${ }^{665}$ Abschrift der Urkunde vom 19. September 1343 im Zinsregister von 1678 in StABa Stift St. Gangolf, Akten und Bände Nr. 96 fol. 33-35. 
rie bis hin zu den Zinsregistern des 16. Jahrhunderts kaum verändert hatte und somit eine gewisse Konstanz besaß. Die jüngere der beiden Vikariestiftungen um die heiligen Apostel speiste sich dagegen aus Gütern in Burggrub (Gde Heiligenstadt in Oberfranken, Lk Bamberg, Niderngrub), Königsfeld (Lk Bamberg), Voitmannsdorf (Gde Königsfeld, Lk Bamberg), Drosendorf (Gde Hollfeld, Lk Bayreuth) und Bamberger Gütern am Kaulberg und in der Theuerstadt. ${ }^{666}$

\subsubsection{Vikarie St. Blasius}

Die unter dem Namen vicaria sancti Blasii geführte Vikariestiftung ist unter den Patrozinien des heiligen Blasius und der heiligen Katharina gegründet worden und damit ein typisches Beispiel der Mehrfachpatrozinien des 14. Jahrhunderts. ${ }^{667}$ Die Stiftung war eng mit dem Amt des Propstes verbunden, der sich in den Cautiones ${ }^{668}$ an das Kapitel zu einer Zahlung von jährlich drei Pfund an den Vikar des Altars St. Blasius verpflichtete, welche er aus dem Hollfelder Zoll bezog. ${ }^{669}$ In den Zinsregistern des 16. Jahrhunderts wurde die Vikarie darüber hinaus mit dem Zusatz collator praepositus ecclesiae sancti Gangolphi versehen und berief sich auf Einkünfte in Bamberg in der Theuerstadt, Hollfeld (Lk Bayreuth), Kotzendorf (Gde Königsfeld, Lk Bamberg), Ebensfeld (Lk

666 „Vicaria iunoris apostolorum“ im Zinsregister von 1516 in StABa Stift St. Gangolf, Akten und Bände Nr. 44 fol. 15'-22; „vicaria apostolorum iunioris“ im Zinsregister von 1557 in StABa Stift St. Gangolf, Akten und Bände Nr. 23 fol. 73-77; „vicaria iunioris apostolorum" im Zinsregister um 1566 in StABa Stift St. Gangolf, Akten und Bände Nr. 32 fol. 9'-13.

${ }^{667}$ Die Heiligen Katharina und Blasius gehören zu den 14 Nothelfern, die charakteristisch für Heiligenhäufung sind. Zimmermann: Die Gangolfskirche als Spiegel der Frömmigkeit. 1990. S. 25.

${ }^{668}$ Näheres zu der Einordnung der Quellengattung der Cautiones und Remissiones im Kapitel 6.2 Quellen des Stifts St. Gangolfs zur Besitzverwaltung.

669 "Auch sollen wir dem vicarier zu zeiten $\mathrm{zu}$ sandt Blasien altar in dem genanten stift ierlich drey pfundt heller landeswerung ye auf sandt Michaelis tag geben, ongeverde" in der abschriftlich überlieferten Cautio des Propstes Melchior Truchseß (amt. 1489-1493) von 1489 in StABa Stift St. Gangolf, Akten und Bände Nr. 123 fol. 2‘-3; in der Urkunde vom 30. Juli 1516 in AEB Rep. I Pfarrei St. Gangolf U 826; in der Urkunde vom 27. Januar 1565 in StABa A 120 L 131 Nr. 732; und ein Eingangsvermerk dieser Zahlungen im Zinsregister von 1516 in StABa Stift St. Gangolf, Akten und Bände Nr. 44 fol. 73. 
Lichtenfels), Oberleiterbach (Gde Zapfendorf, Lk Bamberg) und Treunitz (Gde Königsfeld, Lk Bamberg). ${ }^{670}$

\subsubsection{Vikarie St. Stephan}

Die wohl ebenfalls im 14. Jahrhundert gegründete Vikarie des heiligen Stephan ist bisher nur vage lokalisiert und daher oft mit dem Altar des heiligen St. Blasius in Verbindung gebracht worden. ${ }^{671}$ Von einer Verbindung der zwei Altäre ist jedoch in den Zinsregistern des 16. Jahrhunderts keine Rede. Dieser Widerspruch wird in den Consuetudines des Stifts geklärt, in denen festgelegt wurde, dass der Stephansaltar mit zwei Vikaren zu besetzen war, die zugleich den Gottesdienst am Blasiusaltar zu verrichten hätten. ${ }^{672}$ In der Altarauflistung von um 1600 wird der frühere Stephansaltar mit dem späteren Altar des Johannes Nepomuk gleichgesetzt. ${ }^{673}$

Die Vikarie wird immer wieder mit dem Amt des Bamberger Bischofs als collator revenderissimus episcopus Bambergensis in Verbindung gebracht und damit auch die Einkünfte aus den Gütern in Freienfels (Gde Hollfeld, Lk Bayreuth), Treppendorf (Gde Hollfeld, Lk Bayreuth), Herzogenreuth (Gde Heiligenstadt i. Ofr., Lk Bamberg), Hollfeld (Lk Bayreuth), Tiefenpölz (Gde Heiligenstadt i. Ofr., Lk Bamberg), Teuschnitz (Lk Kronach), Dippach (Gde Burgebrach, Lk Bamberg), Neudorf (Gde Kasendorf, Lk Kulmbach), Ketschendorf (Gde Buttenheim, Lk Bamberg), Kirchehrenbach (Lk Forchheim, Erapach bey Eber-

670 „Vicaria sancti Blasii“ im Zinsregister von 1516 in StABa Stift St. Gangolf, Akten und Bände Nr. 44 fol. 70-77‘; „vicaria sancti Blasii“ im Zinsregister von 1556 in StABa Stift St. Gangolf, Akten und Bände Nr. 23 fol. 21-28; „,vicaria sancti Blasii“ im Zinsregister um 1566 in StABa Stift St. Gangolf, Akten und Bände Nr. 32 fol. 43-48،

${ }^{671}$ Zimmermann legt die Ersterwähnung der Vikarie St. Stephan auf das Jahr 1354. In Zimmermann: Die Gangolfskirche als Spiegel der Frömmigkeit. 1990. S. 24.

${ }^{672}$ Consuetudo „De vicariis officiandis et missis pro defunctis: Item duo vicarii altaris s. Stephani celebrabuntur singulis diebus in ara predicta quilibet per integram ebdomadam. Quare etiam senior in fundatione in ebdomada sua vacante unam missam in altaris $\mathrm{s}$. Blasii sextis feriis celebrare teneatur." im Statutenbuch StABa Stift St. Gangolf, Akten und Bände Nr. 130 fol. 89.

673 „In collegiata ecclesia beatae Mariae virginis et sancti Gangolphi altaria“ in AEB Rep. 60 Pfarrarchiv St. Gangolf Bamberg Nr. 3 unfoliiert. 
mannstat), Bamberg in der Theuerstadt, Ethausen prope Kunsperg (n. ident.) ${ }^{674}$ und Kerfeldt (n. ident.). ${ }^{675}$ Die Masse an Einzelgütern machte diese Vikarie zu einer der einträglichsten.

\subsubsection{Vikarie St. Maria Magdalena und der heiligen drei Könige}

Die Vikarie der heiligen Maria Magdalena und der heiligen drei Könige wurde bereits im Jahr 1355 gestiftet ${ }^{676}$ und vereinte mit ihren Patrozinien die Zeugen der Auferstehung Christi. ${ }^{677} \mathrm{Ihr}$ ist nach den Gangolfer Consuetudines ein Vikar zugeordnet, dem ebenso das Totengedenken im Chor aufgetragen worden war. ${ }^{678}$ Die Einkünfte, die der Vikar dieser Stiftung bezog, stützten sich auf Güter in Hainbach (Gde Hollfeld, Lk Bayreuth, Heympuch), ${ }^{679}$ Buckendorf (Gde Weismain, Lk Lichtenfels), Kaltenhausen (Gde Untereisenheim, Lk Würzburg), Königsfeld (Lk Bamberg), Mursreudt (n. ident.), ${ }^{680}$ Frensdorf (Lk Bamberg), Buttenheim (Lk Bamberg), Traindorf (Gde Heiligenstadt in Oberfranken, Lk Bamberg), Steinbach (Gde Ebelsbach, Lk Haßberge) sowie Bamberg in der Theuerstadt, im Zinkenwörth, der Kesslergasse, bey dem

${ }^{674}$ Eventuell Aidhausen (Lk Haßberg), jedoch ohne den Bezug zu Kunsberg, was sich auf Altenkünsberg (Gde Creußen, Lk Bayreuth) beziehen könnte.

675 „Vicaria altaris sancti Stephani“ im Zinsregister von 1516 in StABa Stift St. Gangolf, Akten und Bände Nr. 44 fol. 33'-47‘; „vicaria altaris sancti Stephani“ im Zinsregister um 1566 in StABa Stift St. Gangolf, Akten und Bände Nr. 32 fol. 20‘-28‘.

676 Die Gründungsurkunde der Vikarie am 25. Mai 1355 durch Leopold, Bischof von Bamberg (amt. 1353-1363), ist im Kopialbuch der Vikarie Maria Magdalena (1615) überliefert in StABa Stift St. Gangolf, Akten und Bände Nr. 235 fol. 1-4‘.

677 Gerd Zimmermann setzt sie mit den Patronen der heutigen Gangolfer Dreifaltigkeitskapelle gleich. Zimmermann: Die Gangolfskirche als Spiegel der Frömmigkeit. 1990. S. 25.

${ }^{678}$ Consuetudo „De vicariis officiandis et missis pro defunctis: Item vicarius s. Marie Magdalene onmes et singulas missas defunctorum per chorum nostrum in loco capitulari cantandas per totum annum cantabit seu per alterum idoneum cantari procurabit demptis missis pro fundatoribus“ im Statutenbuch StABa Stift St. Gangolf, Akten und Bände Nr. 130 fol. $88^{\prime}-89$.

679 Näheres zum Wandel des Ortsnamens Hainbach in Dorothea Fastnacht: Ebermannstadt. Ehemaliger Landkreis Ebermannstadt (Historisches Ortsnamensbuch von bayern, Bd. 4). München 2000. S. 102-103.

${ }^{680}$ Es bleibt unklar, ob eine Verbindung zu Mürsbach (Gde Rattelsdorf, Lk Bamberg) oder Niedermirsberg (Gde Ebermannstadt, Lk Forchheim) besteht. 
Seehof, in der Wunderburg und im Pfaffengeheid. ${ }^{681}$ Die Vikarie ist die einzige, für die sich eine kopiale Überlieferung erhalten hat. Im Jahr 1519 hielt Johann Schwanhausen als Gangolfer Kustos (amt. 1510-1524) und als Inhaber der Vikarie Maria Magdalena die wichtigsten Urkunden, einschließlich Gründungsurkunde und Nachweise von Schenkungen, in einem kleinen Kopialbuch fest, welches in einer Version von 1615 erhalten geblieben ist. ${ }^{682}$ Das ist ein seltener Glücksfall, da aus dem Büchlein die genauen Gründungsumstände herausgelesen werden können. So ging die Aufstellung eines Altars für Maria Magdalena und der drei Könige auf die Initiative des Walter Gundloch als Dekan des Stifts St. Gangolf (amt. 1331-1354) zurück, ${ }^{683}$ der auf diese Weise sein Totengedenken sichern wollte und auf den die Einkünfte der Vikarie aus Hainbach, Steinbach, Frensdorf und das pfaffengeheid in Bamberg zurückgingen. Außerdem wird Näheres über die Unterbringung des Vikars im sogenannten hinterhaus oder gatterhaus erwähnt, welches sich neben der Gangolfer Kirche befunden haben musste - zwischen den Kanonikerhäusern des Johann Schank und des Burckhard von Aschaffenburg. ${ }^{684}$

681 „Vicaria Mariae Magdalenae et trium regum“ im Zinsregister von 1566 in StABa Stift St. Gangolf, Akten und Bände Nr. 44 fol. 53'-64; „vicaria Mariae Magdalenae et trium regum“ im Zinsregister um 1566 in StABa Stift St. Gangolf, Akten und Bände Nr. 32 fol. 32-38.

682 „1519 praesens liber continet copias litterarum super bonis, censibus et feudis vicariae beatae Mariae Magdalenae, quas ego Joannes Schwanhausen custos et vicarius eiusdem vicariae feci conscribi“ im Kopialbuch der Vikarie Maria Magdalena (1615) in StABa Stift St. Gangolf, Akten und Bände Nr. 235.

${ }^{683}$ Kopialbuch der Vikarie Maria Magdalena (1615) in StABa Stift St. Gangolf, Akten und Bände Nr. 235 fol. 1. In der Dekanliste bei Ussermann: Episcopatus Bambergensis. 1802. S. 276 wird er als "Walterus Gundloc fundator beneficii trium Regum et S. Magdalenae a. 1333." bezeichnet.

684 "Quod nos matura deliberatione praehibita domum illam das hinterhaus, videlicet nuncupata, quae a dominus dicta das gatterhaus apud ecclesiam nostram sita et domui fratrum sedium contigua ecclesiae nostrae existit separata seu divisa ac retro curiam hon. viri Joannis Schanckh, concanonici nostri, et quondam Burchardi de Aschaffenburg fere situata" in der Bestätigungsurkunde des Heinrich Klinghart und des Kapitels von St. Gangolf 1344 im Kopialbuch der Vikarie Maria Magdalena (1615) in StABa Stift St. Gangolf, Akten und Bände Nr. 235 fol. 5. 


\subsubsection{Vikarie St. Martin}

Auch die Vikarie St. Martin hatte eine enge Verbindung zum Dekan des Stifts St. Gangolf, der in den Zinsregistern des 16. Jahrhunderts als collator angegeben wurde. Die Besitzungen, aus deren Einkünften sich die Vikarie speiste, lagen in den Orten Forchheim, Feulersdorf (Gde Wonsees, Lk Kulmbach), Pausdorf (Gde Scheßlitz, Lk Bamberg) und in der Bamberger Theuerstadt. ${ }^{655}$ Davon wurde der Unterhalt für einen Vikar am Martinsaltar bestritten, welcher mehrmals wöchentlich Gottesdienste abzuhalten hatte. ${ }^{686}$ Die früheste Erwähnung des Martinsaltars findet sich in einer Urkunde aus dem Jahr $1460,{ }^{687}$ in der der Bamberger Bischof Georg I. von Schaumberg (amt. 1459-1475) einen Altar zu Ehren des heiligen Martin, des heiligen Erhard und aller Bekenner weihte und ihn mit den Reliquien des heiligen Bischofs Martin, des heiligen Bischofs Erhard, des Märtyrers Sebastian, des Laurentius, des Märtyrers Probus, der heiligen Königin Helene und des Bekenners Wunibald ausstattete.

\subsubsection{Vikarie St. Philipp, Jakob und Barbara}

Die Orte, auf die sich die Vikariestiftung St. Philipp, Jakob und Barbara gründeten, waren Dürrbrunn (Gde Unterleinleiter, Lk Forchheim), Feulersdorf (Gde Wonsees, Lk Kulmbach), Sachsendorf (Gde Aufseß, Lk Bayreuth), Zeckendorf (Gde Scheßlitz, Lk Bamberg), Bamberg in der

685 „Vicaria sancti Martini“ im Zinsregister von 1516 in StABa Stift St. Gangolf, Akten und Bände Nr. 44 fol. 12-15; „vicaria sancti Martini“ im Zinsregister von 1555 in StABa Stift St. Gangolf, Akten und Bände Nr. 23 fol. 12-15; „vicaria sancti Martini“ im Zinsregister um 1566 in StABa Stift St. Gangolf, Akten und Bände Nr. 32 fol. 7‘-9.

${ }^{686}$ Consuetudo „De vicariis officiandis et missis pro defunctis: Vicarius s. Martini singulis septimanis secunda feria pro defunctis ad ordinatione quondam domini Heinrici de Rottenburg [n. ident.] dicti pater noster et alias tres missas in altari predicto celebret aut procuret celebrari.“ im Statutenbuch StABa Stift St. Gangolf, Akten und Bände Nr. 130 fol. 89.

${ }^{687}$ AEB Rep. 60 Pfarrarchiv St. Gangolf Bamberg Nr. 436 unfoliiert. In der beiliegenden Abschrift und dem Repertorium des AEB wurde das Datum fälschlicherweise als 1409 gelesen. 
Theuerstadt, in der Wunderburg und hinter sanct Jacob. ${ }^{688}$ Als seltener Fund ist in der jährlichen Ausgabenauflistung der Vikarie eine Spur zum Gründer der Stiftung überliefert, in der es heißt:

Ad anniversario domini Heinrici Pletzners decani huius ecclesiae, fundatoris huius vicaria. $^{689}$

Dadurch kann die Gründung auf die Mitte des 14. Jahrhunderts eingegrenzt werden, da das Todesjahr des Dekans Heinrich Bletzner für 1386 belegt ist. ${ }^{690}$ Die erste Erwähnung der Vikarie Philipp, Jakob und Barbara kann durch eine abschriftlich überlieferte Urkunde für das Jahr 1387 gefasst werden, als Bürgerinnen von Bamberg der Vikarie Güter in Sachsendorf übereigneten. ${ }^{691}$ Besetzt war der Altar mit einem Vikar, der wöchentlich fünf Messen zu lesen hatte. ${ }^{692}$

\subsection{Stuhlbrüder}

Bei den Stuhlbrüdern handelte es sich um eine Laienbruderschaft, welche durch das Abhalten von Messen oder Andachten die Quantität der Gottesdienste an einer Kirche erhöhte. Ursprünglich nur an den großen Domkirchen ansässig, leitete sich die Bezeichnung „Stuhlbruder" von dem ihnen vorbehaltenen Chorgestühl nahe der Herrschergräber ab, wo sie ihre Gebete verrichteten. Sie waren als Laien kein direkter Bestandteil der Kirchenorganisation, standen aber in einem Abhängigkeitsverhältnis zu einer bestimmten Kirche und arbeiteten dieser zu, um

688 „Vicaria Philippi et Jacobi et Barbarae“ im Zinsregister von 1516 in StABa Stift St. Gangolf, Akten und Bände Nr. 44 fol. 1-11; „vicaria Philipp et Jacobi et sanctae Barbarae“ im Zinsregister um 1566 in StABa Stift St. Gangolf, Akten und Bände Nr. 32 fol. 1-7.

${ }^{689}$ StABa Stift St. Gangolf, Akten und Bände Nr. 44 fol. 11; und StABa Stift St. Gangolf, Akten und Bände Nr. 32 fol. 7.

${ }^{690}$ Eintrag im Anniversarbuch in StABa Stift St. Gangolf, Akten und Bände Nr. 128 fol. 21 '.

${ }^{691}$ Abschrift einer Urkunde vom 25. Mai 1387 im Zinsregister von 1628 in StABa Stift St. Gangolf, Akten und Bände Nr. 89 fol. 52‘-54.

${ }^{692}$ Consuetudo „De vicariis officiandis et missis pro defunctis: Item vicarius ad altare Philippi et Jacobi in eodem altari singulis septimanis quinque missas celebrare tenebtur." im Statutenbuch StABa Stift St. Gangolf, Akten und Bände Nr. 130 fol. 89. 
die Erfüllung der liturgischen und karitativen Verpflichtungen zu gewährleisten. ${ }^{693}$

Bereits im Jahr 1146 sind Stuhlbrüder am Bamberger Domstift im Zusammenhang mit der Kanonisation Kaisers Heinrich II. nachweisbar. ${ }^{694}$ Nachdem sich die Einkünfte der Stuhlbrüder anfangs aus dem Obleivermögen der Domkanoniker speisten, um damit Memorialleistungen zu erfüllen, bildete sich im 13. und 14. Jahrhundert ein Pfründensystem heraus, das Bamberger Bürgern in Diensten des Bischofs und des Domkapitels eine Altersversorgung bot. ${ }^{695}$ Eine Stuhlbruderpfründe war dabei sowohl adligen wie auch nichtadligen Bambergern zugänglich. ${ }^{696}$

Nach dem Beispiel des Domkapitels leisteten sich auch die Bamberger Kollegiatstifte Stuhlbrüder zur Sicherung ihrer gottesdienstlichen Pflichten. Am Stift St. Gangolf saßen seit dem 14. Jahrhundert vier Stuhlbrüder, welche ihre Einkünfte aus der Stiftung eines Bamberger Bürgers namens Arnold Blemser bezogen, welche er zu sein und seiner eltern seel und heyl zu gut stiftete. ${ }^{697}$ Zwar waren sie dem Dekan und Kapitel zu Gehorsam verpflichtet, der Lehensherr ihrer Pfründe aber

${ }^{693}$ Näheres zum Wandel des Memorialbedürfnisses im 14. Jahrhundert und der Etablierung des laikalen Bruderschaftswesens in Werner Scharrer: Laienbruderschaften in der Stadt Bamberg vom Mittelalter bis zum Ende des Alten Reiches. Geschichte - Brauchtum Kultobjekte. In: BHVB 126 (1990). S. 21-392, hier: S. 49.

${ }^{694}$ Ebd. S. 69.

${ }^{695}$ Ebd. S. 69 und S. 71.

${ }^{696}$ In seinen Wahlkapitulationen vom 18. Mai 1459 schwört der designierte Bamberger Bischof Georg von Schaumberg (amt. 1459-1475): "Ich will auch kein stuhlbruder pfründe in meinem stifte verleyhen, noch gnade oder brieste darauf geben. Sie seyend dann eine oder mehre ledig worden, und so eine ledig würdet, soll ich die keinem anderen dann einen ehrbährn, frommen und armen edelmann darzu tuglich leyhen, ob aber derselben keiner in einem monath funeden wurde, so soll ich die andern tüglichen und ehrbähren personen, so often das noth geschieht, leyhen und ihr keinem absens geben und sie mit der gehorsambe weisen an dechand und capitel meines stifts, doch das sie ihren habitum ordentlich tragen“. In "Iuramentum Georgii de Schaumberg episcopi bambergensis" in StABa A 25 L 30 Nr. 42 \ 15.

${ }^{697}$ Bestätigungsurkunde des Gangolfer Propstes Friedrich von Hohenlohe (amt. 13231351) mit Dekan und Kapitel vom 29. Januar 1324 in StABa BU 1844; und ebenso in SttABa D 3001 HV Rep. 1 Nr. 281. 
war der Gangolfer Propst. ${ }^{698}$ In den nachfolgenden Jahren wurden die Pfründen durch verschiedene Stiftungen, vor allem im Bamberger Hauptsmoorwald, angereichert. ${ }^{699}$ Untergebracht wurden die Brüder in eigenen Häusern in der Theuerstadt. ${ }^{700}$

Nach den großen Umbrüchen des Hussiteneinfalls und des Immunitätenstreits im 15. Jahrhundert war aufgrund der desolaten Finanzsituation der Stifte eine Reformation der Bamberger Stuhlbrüder vonnöten. Die Folge war eine Beschränkung der Gangolfer Stuhlbrüder auf zwei Personen, wobei es keine Vorrangstellung des einen Laienbruders vor dem anderen gab. ${ }^{701}$ Vor allem das Gangolfer Statutenbuch bietet Einblicke in die Neuaufstellung der Stuhlbrüder. ${ }^{702}$ Nach der Präsentation vor dem Propst erfolgte die Aufnahme durch das Kapitel, dem beide

698 „Item bischof Johannes hat die vier stulpruder pfrundt confirmirt, welche alhie ein burger Arnoldus dictus Blemser von seinen gutern von newen gestift, sein und seiner eltern seel und heyl zu gut, und das dise stulpruder sollen haben eben dise freyheyten, als die stulpruder im thumbstift, und das ein yder der zeyt probst zu Theuerstat solche vier stulpruder pfrundt so sie ledig, leyhen solle, datum 1324 dominicam ante purificatione Marie. Item die fundation der gestiften pfrundt der stulpruder die ist hinterlegt hinter den probst Paulus Neydecker als lehenhern. Ferners haben die stulpruder presentz, wie dan des obleyers regula von den gestiften jartagen aufweist, doch das sie solche wie andere stiftspersonen verdinen. " im Urbar über die Vikarien, Obleien und Fragmente (1317-1630) in StABa Stift St. Gangolf StABa Stift St. Gangolf, Akten und Bände Nr. 32 fol. 51.

${ }^{699}$ In den Jahren 1333 und 1345 stiftete der designierte Bamberger Bischof Wernther (amt. 1329-1335) Neubrüche im Hauptsmoorwald an die Gangolfer Stuhlbrüder. Im Kopialbuch StABa Stift St. Gangolf, Akten und Bände Nr. 3 Teil 3 S. 170 und S. 45.

700 „Census et proventus fratrum sedium in ecclesia collegiata beatae Mariae et sancti Gangolphi in Thewerstat extra muros Bambergenses. Zum ersten so haben iede stulpruder ein yder sein aigen behausung $\mathrm{zu}$ der stulpruder pfrundt fundirt und geseht." im Urbar über die Vikarien, Obleien und Fragmente (1317-1630) in StABa Stift St. Gangolf StABa Stift St. Gangolf, Akten und Bände Nr. 32 fol. 51.

701 „Item es solle auch bede stulbruder einer dem andern beystand thun, die stulbruderpfrundt betreffend in oder anfert der rechten mit halber expens zuverfechten. Es solle auch keiner mehr zins noch gult in registu haben dan der ander soll einer als vil geniest haben als der ander. [...] Item es solle auch bede stulbruder, wie sich dan wol gepurt, vor einem erwirdigen capitel einer dem andern geloben, bruderlich trew zubeweisen stat und vest einer ob dem andern zuhalten, nichts an wollen und wissen des andern zuhandlen, dadurch den pfrundten schmehlerung oder encherlei abzug geschehen mochte." im Statutenbuch StABa Stift St. Gangolf, Akten und Bände Nr. 130 fol. 85 und fol. 86.

702 „Reformatio der stulbruder zu sand Gangolf wie sich ein ieglicher halten soll und zuthun gepürt wie hernachvolgt“ im Statutenbuch StABa Stift St. Gangolf, Akten und Bände Nr. 130 fol. 83‘-86. 
Stuhlbrüder Gehorsam zu schwören hatten. ${ }^{703}$ Ihre Aufgaben bestanden im Ministrieren während der Gottesdienste zu allen hohen Feiertagen, in der Anwesenheit bei Prozessionen und Umgängen, im Läuten zur Frühmesse und in der Sorge um den Altaraufbau. Die Bedeutung der Stuhlbrüder für die Gewährleistung der Gottesdienste war nicht zu unterschätzen. So wurde im Statutenbuch festgelegt, dass sich keiner der Stuhlbrüder unerlaubt über Nacht vom Stift entfernen durfte. War ein Bruder aus irgendeinem Grund verhindert und konnte seine Aufgaben nicht erfüllen, musste er einen Ersatz finden. ${ }^{704}$ Die enge Orientierung an den Gebräuchen des Domstiftes zeigte sich an der Regelung, dass die Gangolfer Stuhlbrüder sich im gleichen Habit wie die Stuhlbrüder am Domstift zu kleiden hatten. ${ }^{705}$

Bemerkenswert ist der Verweis auf die intellektuelle Eigenleistung eines jeden Stuhlbruders bei der Verrichtung seiner Gebete - zwar sollten die Anweisungen des Kapitels beachtet werden, jedoch waren durchaus eigene Auslegungen der Gebetsleistungen möglich. ${ }^{706}$ Auch

703 „Zum andern, soll ein ieglicher stulbruder von einem erwurdigen probst zu sand Gangolf angenomen werden, durch sich selbst oder seinen gewalthabern einem erwurdigen capitel presentiern, darnach soll er von einem capitel ufgenomen und zugelassen werden, er soll auch einem erwurdigen dechant oder eltisten capitelherrn geloben gehorsamkeit und er erpittung, wie ander glider unsers stiefts sand Gangolfs und der pfrumdt wonlichen vorzusteen und dem stieft seinen nutz zusuchen und den schaden zuwendten." sowie der Eid „Forma Juramenti si opus fuerit: Das ich mit trewen gelobt hab und mit worten unterweist bin, das will ich stat vest unverpruchenlich halten, also hat mir got zuhelfen und die heiligen." im Statutenbuch StABa Stift St. Gangolf, Akten und Bände Nr. 130 fol. $83^{‘}-84$ und fol. 86.

704 „Item es solle auch dem stulbruder on erlaubnis eins dechants oder eltisten capitelshern uber nacht aus Bamberg bleiben, und ob einer ausbleiben wollte, solle er einen andern an sein stat bestellen zu ministiren, damit der prister nit verseumpt werden, dardurch der gotsdinst verhindert werden mocht und so einer mit kranckheit beladen were, solle der ander dester vleissiger sein. Item es soll auch dem stulbruder vier oder mer tag [nit] aus Bamberg sein, er hab dan vor angesagt und verlaub begert von seiner oberhandt als dechant.“ im Statutenbuch StABa Stift St. Gangolf, Akten und Bände Nr. 130 fol. 84.

705 „In allen umbgengen und processionen nemlich in der fasten so mal station pflegt zuhalten in iren habiten in allergestalt und prauch der stulpruder des hohenstiefts erzeigen.“ im Statutenbuch StABa Stift St. Gangolf, Akten und Bände Nr. 130 fol. 84‘

706 „Item es solle auch ein ieglicher stulbruder bei der gehorsam, so er einem dechant und capitel gethan hat, sein gepet alle tag sprechen, was im dan uferlegt wirdt, doch mit eins capitels und seiner selbs erkantnus kund und aufsagung anzunemen, und seins gewissens 
bei der Verwaltung ihrer Unterlagen hatten die Stuhlbrüder weitgehend freie Hand. Sie verwahrten diese in eigener Verantwortung, standen dabei aber unter Oberaufsicht des Kapitels. ${ }^{707}$ Im Jahr 1553 sollen 48 Pergament- und drei Papierurkunden der Gangolfer Stuhlbrüder den Verwüstungen des zweiten Marktgrafenkrieges zum Opfer gefallen sein, welche bis zu diesem Zeitpunkt in der Kapitelsakristei des Stifts aufbewahrt wurden. ${ }^{708}$ Die Abschaffung der Bruderschaft am Stift erfolgte kurz darauf im 16. Jahrhundert. ${ }^{709}$

\subsection{Friedhof, Bestattungen und Testamente}

An einer kirchlichen Institution, deren Hauptaufgabe in der Sicherung von Memorialgedenken bestand, war der Umgang mit dem Tod auf geistiger Ebene ein selbstverständlicher. Die Bestattung von Stiftsangehörigen stellte den letzten Dienst der Mitbrüder an dem Verstorbenen dar. Die wenigsten wurden direkt unter einem Altar, ${ }^{710}$ sondern vielmehr in der Sepultur bestattet. ${ }^{711}$ Auch einen Friedhof musste es

und vermogens nach der person." im Statutenbuch StABa Stift St. Gangolf, Akten und Bände Nr. 130 fol. 85-85'.

707 „Es sollen die bede stulbruder ein verschlossne truhen, darin ir brif, register, geriechtigkeiten und ander ding zustendig iren pfrundten, darzu zwen schlussel. Einen soll ein capitel den andern die stulbruder haben." im Statutenbuch StABa Stift St. Gangolf, Akten und Bände Nr. 130 fol. 85.

708 Generalregister u.a. über die Einnahmen der Stuhlbrüder aus dem 16. Jahrhundert im Urbar über die Vikarien, Obleien und Fragmente (1317-1667) in StABa Stift St. Gangolf, Akten und Bände Nr. 44.

${ }^{709}$ Scharrer: Laienbruderschaften in der Stadt Bamberg. 1990. S. 77.

${ }^{710}$ Laut dem Gangolfer Anniversarbuch soll der Stiftsgründer Reginold Walpot unter dem Altar der Aposteln Petrus und Paulus begraben wurden sein. In StABa Stift St. Gangolf, Akten und Bände Nr. 128 fol. 4; Und ebenso im Anniversarbuch findet sich der Hinweis, dass 1564 der Keller Eustach Schwanhausen zwischen den beiden Kirchtürmen unter einem Altar begraben sein soll. In StABa StABa Stift St. Gangolf, Akten und Bände Nr. 129 fol. 52'. Bei einer Notgrabung im Jahr 1988 wurde unter dem zuständigen Archäologen Holger Fries Grablegen in der Südwesthälfte des Mittelschiffes und im Vierungsbereich nördlich des heutigen Altars gefunden, die frühestens in das 17. Jahrhundert datiert werden konnten. In Grabungsbericht in Bayerisches Landesamt für Denkmalpflege: Grabungsbericht 1988 Ausgrabung: Notgrabung bei Ausschachtungsarbeiten für eine Fußbodenheizung, Maßnahme M-2007-31726-1_0; Bamberg, BA: St. Gangolf, G-1988 (Ü4-6131-0137).

7111980 wurde im Rahmen einer Notgrabung bei der Verlegung einer Fußbodenheizung 
nahe der Stiftskirche gegeben haben, jedoch ist dessen genaue Lage ohne archäologische Untersuchungen nicht leicht zu ermitteln. In dem Kapitel des Statutenbuchs, das die Beisetzungen regelte, wird erwähnt, dass sich der Friedhof nach altem Brauch apud ecclesie nostre befand. ${ }^{712}$ Laut der älteren Forschung sei dieser Friedhof westlich und südlich der Kirche angelegt und 1801 aufgelöst worden, ${ }^{713}$ jedoch fehlen dafür jegliche Belege. Was hingegen archäologisch lokalisiert werden konnte, war ein Beinhaus, worin gewöhnlich die älteren Knochen aus den neubelegten Gräbern aufbewahrt wurden. Unter der örtlichen Leitung von Magnus Wintergerst wurde 1987 im Rahmen einer archäologischen Grabung des Bayerischen Landesamtes für Denkmalpflege unter der östlichen Kapelle des Gangolfer Südseitenschiffes nach einem bis dahin verfüllten Treppenabgang eine Kammer mit rundbogigem Zugang und einem kleinen Fenster entdeckt. Diese Kammer wurde von den konsultierten Fachleuten Heyse, Prof. Zimmermann, Prof. Sage und Losert als Beinhaus gedeutet. ${ }^{714}$

Alle verstorbenen Stiftsmitglieder, einschließlich des Propstes, Dekans und der Vikare, sollten im Rahmen ihrer Bestattung laut den Gangolfer Consuetudines eine Messe unter Oberaufsicht des Obleiers am Altar der heiligen Maria Magdalena erhalten. ${ }^{715}$ Für die praktische Um-

in der ehemaligen Sepultur (seit 1806 Göttlich-Hilf-Kapelle) mehrere Grablegen und Sarkopharge entdeckt, die von der zuständigen Textilrestaurator M. Th. Worch in das späte Drittel 17. und 18. Jahrhundert datiert wurde. Eine dieser Bestattungen konnte sicher als die eines Klerikers ausgewiesen werden. In Grabungsbericht in Bayerisches Landesamt für Denkmalpflege: Grabungsbericht 1980 Ausgrabung: Untersuchung im Zuge der Verlegung einer Fußbodenheizung in der ehemaligen Sepultur der Kirche St. Gangolf, Maßnahme M-2007-31726-2_0; Bamberg, BA: St. Gangolf, G-1980 (Ü-4-6131-0137).

712 Consuetudo "Qualiter agendum sit circa sepulturam et exequias defunctorus“ im Statutenbuch StABa Stift St. Gangolf, Akten und Bände Nr. 130 fol. 92-92'.

${ }^{713}$ Kohlschein: Die Sankt-Gangolf-Kirche. 1990. S. 13.

${ }^{714}$ Grabungsbericht in Bayerisches Landesamt für Denkmalpflege: Grabungsbericht 1987 Beobachtung bei Bodeneingriff: Fundbergung und Dokumentation im Zuge von Baumaßnahmen, Maßnahme M-2007-31726-3_0; Bamberg, BA: St. Gangolf, FE-1987 (Ü-46131-0137).

715 „Demum cum aliqua persona in ecclesia nostra beneficiata sive prepositus, decanus aut vicarius diem suum clauserit extremum et corpus illius apud ecclesiam nostram tumulandum fuerit [...] tenebitur quilibet superstes in ecclesia nostra beneficiatus nulla penitus dempto unam missam in salutare remedium anime cuiuslibet sic defuncti secundum ordinem ad requisitionem et ordinationem oblegarii nostri pro tempore in 
setzung des Leichentransports und der Bestattung waren die Stuhlbrüder zuständig. ${ }^{716}$ In späteren Regelwerken wurde der Kirchner unter Anleitung des Kustos für die Bestattungen verantwortlich erklärt. ${ }^{717}$

Die Bedeutung, die die Regelung der eigenen Bestattung schon zu Lebzeiten hatte, zeigt das Bemühen, ebendiese testamentarisch vorauszuplanen. Neben floskelartigen Formulierungen, die die Sicherung des Seelenheils und die Ehrung der Patrone als Motivation des Schriftstücks verdeutlichten, wurden in Testamenten Festlegungen zur Bestattung, zum Ablauf und Umfang des Totengedenkens sowie zur Verteilung der weltlichen Habe des Betroffenen getroffen. Leider sind Testamente von Gangolfer Kanonikern erst seit dem 16. Jahrhundert überliefert: Hieronimus Hirschberger, Dekan des Stifts St. Gangolf (amt. 1512-1542), und das Kapitel reversierten im Jahr 1526 die Stiftung eines Ewigzinses auf verschiedene Güter durch Amandus Korber, Kanoniker und Senior des Stifts, mit genauen Anweisungen, wie das Totengedenken abzulaufen habe. ${ }^{718} \mathrm{Zu}$ anderer Gelegenheit bestätigten Hieronimus Hirschberger als Dekan sowie das Kapitel im Jahr 1534 das Testament des Konrad Freyerer, Kanoniker des Stifts, über die Stiftung eines Ewiggeldes für dessen Jahrtag:

Davon wir gemelten hern Cunraten Freyerer jerlich und ein jdes jars besondere einem jartag halten wollen mit gesungen vigilien und seelmessen nach gewonheit und gebrauch unsers stiefts, und die obbemelten zwen gulden zins zugedachten anniversario unter die person der kirchen zu sambt den beneficaten. Als nemblichn legentibus missaz cuiliber zehen pfennig custodi zehen pfennig pro candelas seelmissario acht pfennig pro candelas cuiliber chorali sechs pfennig edituo drey pfennig residuum vero inter canonicis et vicaris gleich austheylen. ${ }^{719}$

altari b. Marie Magdalene celebrare” im Consuetudo „Qualiter agendum sit circa sepulturam et exequias defunctorus" im Statutenbuch StABa Stift St. Gangolf, Akten und Bände Nr. 130 fol. 92-92'.

716 „Item so ein chorherr oder vicarier unsers stiefts mit todt verschid, alsdan sollen die stulbruder geschickt sein, die leich zutragen und zu der erden bestaten aus bruderlicher pflicht und christlicher lieb.“ im Statutenbuch in StABa Stift St. Gangolf, Akten und Bände Nr. 130 fol. 84'.

717 "Sanct Gangolphs stieftkirchners besoldung” von 1601 in SttABa D 3001 HV Rep. 2 Nr. 522. Näheres dazu im Kapitel 4.2.4 Kustos und Kirchner.

${ }^{718}$ Urkunde des Gangolfer Dekans und Kapitel vom 25. April 1526 in StABa A 120 L 131 Nr. 726.

${ }^{719}$ Urkunde des Gangolfer Dekans vom 31. Mai 1534 in AEB Rep. I Pfarrei St. Gangolf U 822. 
Der Gangolfer Kanoniker Johann Wilhelm legte vor seinem Tod 1528 fest, dass er gemäß dem üblichen Vorgehen seines Stifts in der Sepultur der Gangolfer Kirche beigesetzt werden soll. ${ }^{720}$

Die Quellen können, was die Bestimmungen von Stiftungen anbelangt, zweideutig sein. So ist in den testamentarischen Festlegungen des Gangolfer Kanonikers Georg Judas, welche über die Geistliche Regierung des Bamberger Hochstifts überliefert wurden, zwar die Bestimmung des Dekans und des Kustos als zwei seiner Testamentarier enthalten, ohne jedoch weiterhin eine Stiftung oder andere Bindung an das Gangolfer Stift über seinen Tod hinaus festzulegen. ${ }^{721}$ Wie umfangreich die Seelmessstiftung desselben Georg Judas an das Stift St. Gangolf tatsächlich war, lässt sich erst über andere Schriftzeugnisse ermitteln. ${ }^{722}$ Ein detaillierteres Bild von der jeweiligen Nachlassregelung wird also erst spät im 16. Jahrhundert gegeben, als in manchen Fällen sogar die darauf resultierenden rechtlichen Streitigkeiten und Folgen dokumentiert sind. ${ }^{723}$

Dass Gangolfer Kanoniker trotz ihrer Stiftszugehörigkeit ihre Nachlässe über andere Häuser regelten und Zuwendungen nicht an das Stift St. Gangolf richteten, war keine Seltenheit. Bereits für das Jahr 1318 ist

\footnotetext{
720 „Corpus vero sed tamquam canonicis ecclesie s. Gangolphi me decedere contingat in medio sepulture nostre iuxta solitis et laudabilem consuetudinem conmitto sepelie mihi." und „Item beger und ist meyn letzter will dass meyn testamentarii sollen erkawfen eyn anniversaren fur mich und meyene eltern und alle guttheten in dem stieft zw sant Gangolf da ich begrabt gewesen“ im Testament des Kanonikers Johann Wilhelm, Kanoniker des Stifts St. Gangolf, vom 29. Februar 1528 in StABa Geistliche Regierung, Akten und Bände Nr. 4567. Dort empfiehlt er sich neben der Fürsprache Gottes der Heiligen „Jesu Christi, beate Marie virginis, sancto angelo meo, beato Andree apostulo meo, necnon sancto Gangolpho singulari patrono meo totique curie celesti“.

${ }^{721}$ Hingegen sind Geldstiftungen an die Bamberger Einrichtungen Kloster Heilig Grab, das Bamberger Almosenamt, das Franziskanerkloster und das Dominikanerkloster in dem Vorgang rund um die testamentarischen Festlegungen des Georg Judas (gest. 1591), Kanoniker des Stifts St. Gangolf, von 1588-1597 festzumachen. In StABa Geistliche Regierung, Akten und Bände Nr. 4568.

${ }^{722}$ Die reichverzierte Ausgabe der an St. Gangolf getätigten Seelmessstiftung von 1596 des Georg Judas mit Ertragsrechnungen bis 1625 und Texte der Messen in StABa Stift St. Gangolf, Akten und Bände Nr. 134.

${ }^{723}$ Testament des Eustachius Schwanhausen (gest. 1564), Kanoniker des Stifts St. Gangolf, und darauffolgender Prozess in den Jahren 1569-1574 in StABa Geistliche Regierung, Akten und Bände Nr. 5488.
} 
der Fall überliefert, dass Konrad, Kustos des Stifts St. Gangolf (amt. 1307-1331), nach seinem Tod ein halbes Pfund Pfennige jährlichen Zins auf ein Haus mit Hof bei der Leonardkapelle, das mit dem Beinamen applonis beschrieben wird, an Eberhard, Dekan des Bamberger Stifts St. Jakob, für sein Totengedenken stiftete und sich unter den Zeugen auch zwei Gangolfer Vikare befanden. ${ }^{724}$

Auch die Einrichtung des Stifts Neunkirchen am Brand durch den Gangolfer Scholastikus Leupold (amt. 1298-1328) ist vor allem deswegen so aussagekräftig, da in dem Urkundenbuch des 1314 gegründeten und dem Bamberger Bischof unterstellten Stiftes ${ }^{725}$ keinerlei Bezug auf das Stift St. Gangolf als Patronageeinrichtung oder eine irgendwie geartete Verbindung der zwei Häuser erwähnt ist. Das Totengedenken des Gangolfer Scholastikus Leopold kann jedoch sowohl im Stift Neunkirchen als auch im Stift St. Gangolf nachgewiesen werden. ${ }^{726}$ In einem anderen Fall tätigte ein Gangolfer Kanoniker namens Paul im Jahr 1349 eine durch den städtischen Schultheiß und die Schöffen bezeugte Stiftung an das Bamberger Kloster St. Theodor mit einem Seelgerät an ein Theresienkloster. ${ }^{727}$ Im Jahr 1479 bestätigte Petrus, Vizethesaurus des Bischofs von Calahorra, die Stiftung von 55 Gulden für die Jahrtagsfeier des Bartholdus ex comitibus de Henneberg prepositus ecclesie beate Marie virginis

\footnotetext{
724 „Heinricus et Chunradus vicarii ecclesie in Thuerstat“ in der Urkunde des Konrad, Kustos des Stifts St. Gangolf (amt. 1307-1331), am 25. Februar 1318 in StABa BU 1698.

7251314 bestätigt Wulfing von Stubenberg, Bischof von Bamberg (amt. 1304-1318), dem Leupold von Hirschberg, Scholastikus von St. Gangolf (amt. 1298-1328) und Oberpfarrer von Neunkirchen, die Stiftung des Augustiner-Chorherrenstiftes Neunkirchen am Brand. Im Fundationsbuch des Stifts Neunkirchen am Brand in StABa B 113 Nr. 1. Näheres im Kapitel 4.3.6 Das Verhältnis zum Stift Neunkirchen am Brand.

${ }^{726}$ Urkunde (kopial überliefert) des Friedrich, Propst des Stifts Neunkirchen, von 1330 bestätigt das Jahrtagsgedenken des "dominus Leupoldus canonicus et scholasticus ecclesiae s. Mariae in Teurstat extra muros Bambergenses" mit der Stiftung von einem Pfund jährlich für das Abhalten mehrerer Messen in der Klosterkirche. In StABa Stift St. Gangolf, Akten und Bände Nr. 3 Teil 2 S. 277; Außerdem verzeichnete der Vikar des Altars St. Nikolai iunioris des Stifts St. Gangolf als jährliche Ausgabe die Begehung des Jahrtages des "Leupoldi sacerdotis de Neunkirchen de curia in Swinbach". Im Zinsregister von 1516 in StABa Stift St. Gangolf, Akten und Bände Nr. 44 fol. 53. Näheres dazu im Kapitel 4.3.6 Das Verhältnis zum Stift Neunkirchen am Brand.

${ }^{727}$ Urkunde des Schultheiß`von Bamberg samt Schöffen vom 3. April 1349 in StABa BU 2651.
} 
in Teuerstat Bambergensis diocesis an der Kammer in Rom. ${ }^{728}$ All diese Fälle zeigen, wie verwoben ein einzelner Kanoniker durch seine Memoriapflege innerhalb der ihn umgebenden Kirchenlandschaft sein konnte, was nicht allein als ein Phänomen des Stifts St. Gangolf angesehen werden darf. ${ }^{729}$ Die Motivation ist die Sicherung des Seelenheils über den Tod hinaus durch die mehrfache Absicherung an verschiedenen Institutionen.

\subsection{Bibliothek}

Zusammen mit zwei weiteren Kanonikern war der Gangolfer Kustos laut Statut für die Verleihung von kapitelseigenen Büchern zuständig, verlangte dafür einen Pfand und hatte dem Kapitel über säumige Zahler oder entfremdete Bücher Rechenschaft abzulegen. ${ }^{730}$ Diese Praxis war auch beim Stift St. Stephan üblich. ${ }^{731}$ Jedoch muss bezweifelt werden, dass St. Gangolf eine ähnlich große Bibliothek wie St. Stephan besaß, denn Spuren eines größeren Buchbestandes finden sich nicht. Als in den Jahren 1803 bis 1805 die Säkularisation der kirchlichen Bibliotheken von 20 Institutionen in Bamberg und im Umland - darunter auch St. Gangolf - erfolgte, wurde kein einziges Buch des Theuerstädter Stifts erwähnt. ${ }^{732}$ Durch die fehlende Abgrenzung von Archivgut und

\footnotetext{
${ }^{728}$ Urkunde des Petrus, Vizethesaurus des Bischofs von Calahorra, vom 16. März 1479 in StABa A 120 L 131 Nr. 725.

${ }^{729}$ So sind im Bamberger Stift St. Stephan drei Anniversarstiftungen von Personen aus dem Stift St. Gangolf nachweisbar. Näheres dazu in Siewert: Das Bamberger Kollegiatstift St. Stephan. 2007. S. 148; Auch für das Stift Haug in Würzburg lässt sich ein enges liturgisches Beziehungsgeflecht vor allem mit dem Domkapitel und dem Kollegiatstift Neumünster nachweisen. In Bünz: Stift Haug in Würzburg. 1998. S. 399.

730 „Libri quoque ecclesie nostre nemini nobiscum non beneficiato concedantur, nisi is cui concedentur, pignus sufficiens dederit aut cautionem ydoneam praestiterit de restituendo. Aliqum custos ecclesie nostre pro tempore sine cuius voluntate alii canonici inhaec parte nil disponent, tenebitur satisfacere ad dictamen capituli nostri vel maioris eius partis pro libris alienatis vel alteri concessis per capitulum nostrum requisitus. " im Statutenbuch StABa Stift St. Gangolf, Akten und Bände Nr. 130 fol. 62.

${ }^{731}$ Siewert: Das Bamberger Kollegiatstift St. Stephan. 2007. S. 100.

${ }^{732}$ Bernhard Schemmel: Die Säkularisation der Stifts- und Klosterbibliotheken. In: Baumgärtel-Fleischmann, Renate (Hg.): Bamberg wird bayerisch. Die Säkularisation des Hochstifts Bamberg 1802/03. Bamberg 2003. S. 239-250, hier: S. 241.
} 
Bibliothekserbe in den Wirren der Säkularisationsverwaltung und durch die Konzentration der Überlieferung auf den Domschatz der heutigen Staatsbibliothek ist die Rekonstruktion einer Gangolfer Bibliothek schwierig. ${ }^{733}$ Nur von wenigen Büchern, die mit dem Stift in Verbindung gebracht werden können, sind Nachrichten erhalten. So ist neben „Der Renner“ von Hugo von Trimberg, was wahrlich nicht sein einziges Werk war, ein lateinisches Kalenderheiligengedicht laurea sanctorum erhalten, das wohl als Lesebuch für den Schulunterricht am Stift St. Gangolf im Gebrauch war. ${ }^{734}$ Wobei nicht geklärt ist, ob es auch über Hugos Tätigkeiten hinaus am Stift verblieb. Ein Eintrag im Gangolfer Anniversarbuch aus dem 15. Jahrhundert deutet eventuell auf eine Bücherstiftung hin, als im Jahr 1462 für das ewige Gedenken des Pfarrers Johann Spieß aus Etzelskirchen 12 Bände an St. Gangolf gestiftet wurden. Für diese wurde bestimmt, dass sie offen in einem Regal im Chor aufbewahrt werden sollten. ${ }^{735}$

Von einem stiftseigenen Buchbestand in einem gewissen Umfang kann also ausgegangen werden. Trotzdem hatte der Scholastikus laut den Gangolfer Statuten eigenständig für Gesangsbücher zu sorgen, um damit die Jugend $\mathrm{zu}$ unterweisen. ${ }^{736}$ Scheinbar konnte er auf keine vorhandenen Bestände zurückgreifen. Dass der Kustos im 15. Jahrhundert die Verantwortung für Buchverleihungen trug, lässt sich schwer in

\footnotetext{
733 "Von den Nebenstiften St. Stephan, St. Jakob und St. Gangolf hatte offenbar nur St. Jakob einen umfangreicheren Bestand. St. Stephan hatte als nennenswerte Stücke nur die Bamberger Apokalypse ohne Einband und das Evangelistar“. Ebd. S. 242. In den Unterlagen über die Umverteilung der Stifts- und Klosterbibliotheken im Zuge der Säkularisation findet das Sift St. Gangolf keine Erwähnung. In StABa K 3 F VIII Nr. 181.

${ }^{734}$ Näheres in Otto Meyer: Bambergs Heilige in Hugo von Trimbergs Kalendergedicht. In: Fränkische Blätter für Geschichtsforschung und Heimatpflege 7 (1955). S. 53-55, hier: S. 54.

735 "Anno domini 1462 die sabati post diem sancti Valentini que fuit vicesima mensis Februarii obiit magister Joannes Spis quondam rector polis ecclesie in Etzelskirchen Herbipolensis diocesis pro cuius anniversario perpetuo donatur ecclesie nostre duodecim volumina librorum in pulbtis chori eiusdem ecclesie nostre repositis per quos quidem libros quilibet loco presentiarum accedat" im Anniversarbuch StABa Stift St. Gangolf, Akten und Bände Nr. 129 fol. 11.

736 „Libros cantuales ad scolas pro iuvenum informatione pertinentes procuret et quotiens necessarium fuerit reformet." im Statutenbuch StABa Stift St. Gangolf, Akten und Bände Nr. 130 fol. 61.
} 
eine Schätzung des tatsächlichen Bibliotheksbestandes umdeuten. Dies ist vor allem deswegen bedauerlich, da mit der Frage nach einer Bibliothek die Frage nach der Bedeutung des Stifts St. Gangolf als geistiges Zentrum einhergeht. ${ }^{737}$

${ }^{737}$ Die Bedeutung von Bibliotheken für geistliche Insitutionen mit einem eher abschätzigen Blick auf weltliche Stifte in Kottje: Claustra sine armario? 1982. S. 131. 


\section{Grundherrschaft}

\subsection{Besitzverwaltung eines Kollegiatstifts}

Die Besitzverwaltung der Kollegiatstifte ist nur im Zusammenhang mit deren Verfassungsentwicklung zu verstehen, denn so werden die Praxis verschiedener Gütergruppen und das daraus resultierende Verwaltungsschriftgut verständlich. Die Verfassung der Kollegiatstifte wurde maßgeblich durch die Domstifte beeinflusst, deren Beispiel nicht selten in Teilen übernommen wurde. Jedoch sind die Kollegiatstifte nicht als verkleinerte Versionen der dominierenden Domstifte anzusehen. Besonderheiten in Entwicklung und stiftsinterne Regelungen erfordern einen gesonderten Blick auf die einzelnen Häuser.

Ein grundlegender Vorgang für die Ausrichtung der stiftischen Besitzverwaltung des Mittelalters bestand in der Gütertrennung zwischen Bischof und Domkapitel und der Ausformung des Bischofsgutes (mensa episcopi), auch Mensalgut genannt, und eines vom Dompropst verwalteten Sondergutes für die Versorgung der Domkapitulare (mensa fratrum). Die Anfänge dieser Entwicklung finden sich bereits im 9. Jahrhundert in den Emanzipationsbestrebungen des Kölner Domkapitels. ${ }^{738}$ An dem Besitzkomplex des Bischofgutes orientierte sich die Organisation des Vermögens der Domkanoniker als Pfründengut, ${ }^{739}$ das Grundlage für

\footnotetext{
738 Näheres dazu in Enno Bünz: Oblatio - oblagium - Oblei. Zur Güterorganisation und verwaltung mittelalterlicher Dom- und Kollegiatstifte. In: Lorenz, Sönke/ Meyer, Andreas/ Bauer, Dieter R. (Hgg.): Stift und Wirtschaft. Die Finanzierung geistlichen Lebens im Mittelalter. Fünfte wissenschaftliche Fachtagung zum Stiftskirchenprojekt des Instituts für Geschichtliche Landeskunde und Historische Hilfswissenschaften der Universität Tübingen 2004. Ostfildern 2007. S. 19-44, hier: S. 21; und Peter Landau: Art. „Kirchengut“. In: ThRE Bd. 18 (1989). S. 656.

${ }^{739}$ Als Pfründengut wird hier, synonym zum Begriff „Präbendalgut“, der Grundbesitz und die Rechte eines Stiftes verstanden, welche Grundlage der Einzelpfründen bilden und zum Gegenstück des späteren Obleigut herausbildet. Näheres dazu in Peter Landau: Art. „Beneficium, Benefizium“. In: LexMA Bd. 5 (1980). Sp. 1906. Näheres zur Entwicklung dieser Verwaltungsform in Andreas Meyer: Das Aufkommen des Nummerus Certus an Dom- und Stiftskirchen. In: Lorenz, Sönke/ Meyer, Andreas/ Bauer, Dieter R. (Hgg.): Stift und Wirtschaft. Die Finanzierung geistlichen Lebens im Mittelalter. Fünfte wissenschaftliche Fachtagung zum Stiftskirchenprojekt des Instituts für Geschichtliche Landeskunde und Historische Hilfswissenschaften der Universität Tübingen 2004.
} 
die Pfründenbezüge der gemeinsam lebenden Domkanoniker (vita communis) war. ${ }^{740}$

Im 13. Jahrhundert änderte sich die Stiftslandschaft grundlegend, als es zur Auflösung der Vita communis kam und das gemeinsame Zusammenleben der Kanoniker abgelöst wurde durch nunmehr eigenbewirtschaftete Kanonikerhöfe (curiae) rund um die Stiftskirche. Es entstanden dem einzelnen Kanoniker nun Kosten für Bautätigkeiten, Unterhalt und Verwaltung, sodass der Ruf nach der Eigenverwaltung von Pfründen laut wurde, entweder durch die Kanoniker selbst oder unter der Ägide des Propstes. ${ }^{71}$ Die erforderliche Neuregelung wurde von Region zu Region, von Stift zu Stift anders gehandhabt, sodass sich unterschiedliche Verwaltungsmodelle herausbideten. Stifte, die nach der Auflösung der Vita communis gegründet wurden, weisen nicht selten gar kein gemeinsames Pfründengut mehr auf $\mathrm{f}^{742}$ oder wurden ohne die Einrichtung eines Propstamtes gegründet. ${ }^{743}$ Andere behielten das Amt durchaus bei, trennten den Propst jedoch völlig von seiner Rolle als Verwalter des Pfründengutes. ${ }^{74}$ Letzteres geschah im Zuge der allgemeinen Entwicklung der Kollegiatstiften seit dem 13. Jahrhundert, als

Ostfildern 2007. S. 1-17.

740 Die „vita communis“ ist bereits im 8. Jahrhundert für die nicht klösterlichen Klerikergemeinschaften als verbindendes Element synodal festgelegt worden und als Idee aus der Benediktinerregel übernommen. Näheres $\mathrm{zu}$ dieser Entwicklung in Bernd Schneidmüller: Verfassung und Güterordnungen weltlicher Kollegiatstifte im Hochmittelalter. In: Zeitschrift der Savigny-Stiftung für Rechtsgeschichte. Kanonistische Abteilung (1986) 103. S. 118-119.

${ }^{741}$ Bünz: Oblatio - oblagium - Oblei. 2007. S. 22. Näheres zu den Bamberger Verhältnissen am Domstift in Nöth: Urbare und Wirtschaftsordnungen. 1986. S. 4.

${ }^{742}$ Das Stift bei St. Martin in Forchheim beispielsweise wurde 1354 gegründet und pflegte nie eine Vita communis. Stattdessen verfügte der einzelne Kanoniker von Anfang an frei über seinen Anteil des Gesamtvermögens. In Jakob: Das Kollegiatstift bei St. Martin in Forchheim. 1998. S. 218.

743 Als Ausnahmen erscheinen das Stift St. Burkhard in Würzburg, aber auch die Bamberger Stifte. Näheres dazu in Wendehorst: Stadt und Kirche. 2001. S. 265.

${ }^{744}$ Am 15. Juni 1296 erfolgte im Domstift Xanten nach langer Streitigkeit die Einigung zwischen Propst und Kapitel zur Trennung des Propstes von der Verwaltung der Pfründen, die seit der Gründung in dessen Zuständigkeit gefallen war. Näheres dazu in Hawicks: Xanten im späten Mittelalter. 2007. S. 148. 
der Propst als Domkanoniker nur noch stiftsfern agierte und daher aus den internen Geschäften herausgedrängt wurde. ${ }^{745}$

Die Schaffung von durch die Kanoniker eigenverwalteten Gütern als Einzelpfründen wurde begleitet durch die Entstehung eines Sondervermögens, das weder dem Mensalgut noch dem Pfründengut angehörte und unter dem Begriff „Obleigut“ zusammengefasst wurde. ${ }^{746}$ Über diese auf kleinere und größere Jahrtagsstiftungen zurückgehenden Besitzkomplexe konnte nur der vollberechtigte Kapitularkanoniker verfügen, die somit seiner uneingeschränkten Verwaltung unterstanden. Der Propst hatte keinerlei Zugriff auf diese Einkünfte.

Die vielfältigen Entwicklungslinien und verwinkelten Verwaltungszustände hatten zur Folge, dass in der Forschung nicht immer sauber zwischen Pfründengut, Obleigut und anderen Kapitelgütern, wie Benfizien, Vikariaten und Anniversarstiftungen, getrennt wurde. ${ }^{747}$ Betrachtet man die Verhältnisse am durch die Forschung gut erschlossenen Domstift in Bamberg, ${ }^{748}$ dann fällt auf, dass dort nach Abschaffung der Vita communis der vom Dompropst verwaltete Pfründenbesitz bestehen blieb. Der Dompropst erhielt sich seine Rolle in der Pfründenverwaltung. ${ }^{749}$ Auch am Bamberger Stift St. Stephan verwaltete der Propst das Pfründengut bis weit in die Neuzeit hinein. ${ }^{750}$

\footnotetext{
745 Marchal: Was war das weltliche Kanonikerinstitut im Mittelalter? 2000. S. 19.

${ }^{746}$ Näheres dazu in Bünz: Oblatio - oblagium - Oblei. 2007. S. 28.

${ }^{747}$ Als Beispiel soll die umfangreiche Arbeit von Stephan Acht über das Kollegiatstift der Alten Kapelle in Regensburg dienen, welche seit Kaiser Heinrich II. dem Bistum Bamberg angehörte. Trotz einer methodisch einwandfreien Herangehensweise, verwendet Acht die Begriffe Pfründe oder Pfründengut nicht und die Trennung der Besitzgruppen bleibt er schuldig. Stephan Acht: Studien zum Besitz des Kollegiatstifts Unserer Lieben Frau zur Alten Kapelle in Regensburg. In: Mai, Paul (Hg.): Kollegiatstift Unserer Lieben Frau zur Alten Kapelle in Regensburg 1002-2002. Katalog zur Ausstellung in der Bischöflichen Zentralbibliothek Regensburg, 15. Juli bis 11. Oktober 2002 (Kataloge und Schriften. Bischöfliches Zentralarchiv und Bischöfliche Zentralbibliothek Regensburg, Bd. 17). Regensburg 2002. S. 35-42.

748 Näheres dazu in Guttenberg: Urbare und Wirtschaftsordnungen. 1969; und Nöth: Urbare und Wirtschaftsordnungen. 1986.

749 „So steht fest, daß das Präbendalvermögen der Domkanoniker tatsächlich niemals in einzelne persönliche Pfründen aufgeteilt wurde, sondern stets als geschlossene Vermögensmasse in der Verwaltung des Dompropstes verblieb." in Guttenberg: Urbare und Wirtschaftsordnungen. 1969. S. 15.

${ }^{750}$ Siewert: Das Bamberger Kollegiatstift St. Stephan. 2007. S. 94 und S. 212.
} 


\subsection{Quellen des Stifts St. Gangolf zur Besitzverwaltung}

Zur Beurteilung der Besitzstruktur und -verwaltung eines Kollegiatsstiftes wie der des Stifts St. Gangolf ist die Recherche in unterschiedlichsten Quellenarten vonnöten. Während die frühesten Spuren in der Urkundenüberlieferung zu finden sind, ist die systematische Aufarbeitung der Besitzverwaltung über die Güterverzeichnisse möglich. Diese blieb in der Forschung im Gegensatz zur Urkundenüberlieferung oft weitgehend unbeachtet, ermöglicht aber erst mit dieser im Verbund ein umfassendes Verständnis für die Güterverwaltung des Stifts St. Gangolf. Obwohl sie nur bruchstückhaft erhalten sind und zeitlich eher spät einsetzen, geben die Güterverzeichnisse Einblick in den Umfang der Besitzungen, gliedern diese durch ihren Registercharakter nach Verwaltungsgruppen und führen in vielen Fällen Einkünfte und Nutzung derselben auf. Darüber hinaus werden notizhafte Erwähnungen in frühen Urkunden über Abgaben oder Rechtstitel nicht selten erst durch die Einbettung in den großen Zusammenhang eines Güterverzeichnisses verständlich.

Für das Stift St. Gangolf waren die Güterverzeichnisse im Bestand der Standbücher A 221/IX des Staatsarchivs Bamberg zu finden. Hierbei handelte es sich nicht um eine provenienzreine Aufstellung, sondern die Standbücher aller hochstiftischer Einrichtungen wurden im 19. Jahrhundert aufgrund ihrer gattungsspezifischen Eigenheiten zusammengebracht. In einem großen Verzeichnungsprojekt des Staatsarchivs Bamberg konnte seit dem Jahr 2012 dieser Missstand beseitigt werden. Nun wurde durch den damaligen stellvertretenden Archivleiter Dr. Klaus Rupprecht und der Autorin der Bestand B 98 „Stift St. Gangolf. Literalien und Akten“ mit den Gangolfer Standbüchern aus A 221/IX sowie einzelnen Nummern aus A 226 vervollständigt, umnummeriert und provenienzrein unter der Bestandsbezeichnung „Stift St. Gangolf. Akten und Bände“ neu aufgestellt. ${ }^{751}$ In diesem Bestand sind 127

751 Näheres dazu im Kapitel 2.3 Bestand „Stift St. Gangolf. Akten und Bände“ im 
Standbücher der Provenienz des Stifts St. Gangolf bis zu dessen Auslösung im Jahr 1803 zu finden. Sie machen mehr als die Hälfte des gesamten Bestandes „Stift St. Gangolf. Akten und Bände“ im Staatsarchiv Bamberg aus, was den Eigenarten von Nachlässen solcher Institutionen entspricht, deren Rechtsnachfolgern vor allem die Wahrung von Grundrechten am Herzen lag. Rund 50 Standbücher fallen in den untersuchten Zeitraum bis 1600. Die Güterverzeichnisse behandeln zum Großteil Obleigüter und sind als solche in den meisten Fällen eindeutig gekennzeichnet. Von den wenigen bis zum Jahr 1600, die solch eine Zuordnung zum Obleigut nicht zeigen, sind 13 Nummern der Propstei zugeordnet und behandeln das Pfründengut unter pröpstlicher Verwaltung. Sie unterscheiden sich zum einen in Zins- und Zehntverzeichnisse ${ }^{752}$ und zum anderen in Verzeichnisse über an Adel, Bürger oder Bauern verliehene Güter in Form von Lehenbüchern. ${ }^{753}$ Doch trotz dieser Typologisierung darf die Vielfalt der güterverzeichnenden Quellen nicht übersehen werden, die entgegen ihres standardisierten Eindrucks viele

Staatsarchiv Bamberg.

752 Den hier interessanten Zeitraum betreffen folgende Abgabenverzeichnisse: Zinsregister des Propstes Paul Neydecker (1560-1566) in StABa Stift St. Gangolf, Akten und Bände Nr. 11; „Urbarium und zinsregister herrn Erasmus Neusteters sturmer genant uber die probstei s. Gangolffs stifts in der Theuerstat bey Bamberg" (1562-1578) in StABa Stift St. Gangolf, Akten und Bände Nr. 12; „Zinsbuch der probstey s. Gangolph“ (15951604, 1627 in StABa Stift St. Gangolf, Akten und Bände Nr. 13; und Getreideverzeichnis des Kellers Johann Wilhelm (1521) in StABa Stift St. Gangolf, Akten und Bände Nr. 18.

${ }^{753}$ Den hier interessanten Zeitraum betreffen folgende Lehenbücher: Lehenprotokolle des Propsteiverwaltungsamts Hollfeld durch Propst Graf Thomas von Wertheim (1417-1429) in StABa Stift St. Gangolf, Akten und Bände Nr. 118; Lehenprotokolle des Propteiverwaltungsamts Hollfeld durch sechs verschiedene Pröpste (1417-1576) in StABA Stift St. Gangolf, Akten und Bände Nr. 119; Lehenprotokolle des Propteiverwaltungsamts Hollfeld durch Propst Johann Kautsch und Propst Gumpert Fabri (1466-1480) in StABa Stift St. Gangolf, Akten und Bände Nr. 120; Lehenprotokolle des Propsteiverwaltungsamts Hollfeld durch Propst Bertholt Graf von Henneberg (1479-1482) in StABa Stift St. Gangolf, Akten und Bände Nr. 121; Lehenprotokolle des Propsteiverwaltungsamts Hollfeld durch drei Pröpste (1479-1565) in StABa Stift St. Gangolf, Akten und Bände Nr. 122; „Lehenbuch der probstei des stifts s. Gangolf“ (1489-1494) in StABa Stift St. Gangolf, Akten und Bände Nr. 123; „Liber feudorum venerabilis domini Pauli Neideckers praepositi in Teuerstat extra muros Bambergenses“ (1554-1598) in StABa Stift St. Gangolf, Akten und Bände Nr. 124; „Lehenbuch herrn Erasmussen Neusteters Sturmer genant uber die probstei s. Gangolf stift zu der Theuerstat" (1565-1588) in StABa Stift St. Gangolf, Akten und Bände Nr. 7; und „Lehenbuch zu der s. Gangolfs probstey zu Teuerstat bey Bamberg gehorig“ (15781590) in StABa Stift St. Gangolf, Akten und Bände Nr. 125. 
Misch- und Übergangsformen aufweisen. Es bedarf einer gezielten Betrachtung der einzelnen Grundherrschaften samt Zuständigkeiten. Die Eigenbezeichnungen der Verzeichnisse sind nur bedingt belastbar, denn diese folgen keiner einheitlichen Systematik. ${ }^{754}$ Die Bezeichnung als lehenbuch oder lehenprotokoll gibt die tatsächlichen rechtlichen Begebenheiten und Inhalte der Register nicht immer korrekt wieder, da dort durchaus keine Lehen sondern niedere Leihen, also Grundleihen, an Bauern oder an das städtische Bürgertum aufgelistet sein können. Für das Stift St. Gangolf sind nur wenige wirkliche Lehenakte als echtes Mannlehen an Adlige vorgekommen. Diese sind in der Regel an exponierter Stelle gleich zu Beginn eines Verzeichnisses zu finden. ${ }^{755}$ Darüber hinaus sind die vorliegenden Güterverzeichnisse häufig später zusammengeheftete Einzelstücke oder ältere Verzeichnisse, die durch Notizen oder Abschriften von Urkunden oder Statuten ergänzt wurden. ${ }^{756}$ Damit ist es schwierig, sowohl zeitlich als auch sachlich ein Ordnungssprinzip für einzelne Stücke herauszulesen. Trotzdem wurde sich im Folgenden bei der Bezeichnung der betreffenden Stücke weitgehend an den Quellenbegriffen orientiert, um eine Idenfizierung des Originals zu erleichtern.

Die Güterverzeichnisse halfen dem Stiftskapitel durch die darin enthaltene umfangreiche Dokumentation, die Einkünfte und Ansprüche bis in die Neuzeit hinein aufrechtzuerhalten. Beispielsweise werden aus den Lehenprotokollen des Propsteiverwaltungsamts Hollfeld die Beziehung zwischen Propst, Propstvogt in Hollfeld und der Stadt Hollfeld ersichtlich, vorrangig anhand von Regelungen des Handlohns oder

754 Enno Bünz: Probleme der hochmittelalterlichen Urbarüberlieferung. In: Rösener, Werner (Hg.): Grundherrschaft und bäuerliche Gesellschaft im Hochmittelalter (Veröffentlichungen des Max-Planck-Instituts für Geschichte, Bd. 115). Göttingen 1995. S. 31-75, hier: S. 33.

${ }^{755}$ Lehenverzeichnis (1565-1588) in StABa Stift St. Gangolf, Akten und Bände Nr. 7 fol. 2325.

${ }^{756}$ So besteht beispielsweise das Güterverzeichnis (1417-1576) in StABa Stift St. Gangolf, Akten und Bände Nr. 119, das als Lehenprotokolle des Propteiverwaltungsamt Hollfeld diente, aus zusammengehefteten Verzeichnissen von insgesamt sechs Pröpsten, denen Abschriften von Urkunden und Statuteneinträgen über die Rolle des Propstes beigestellt wurden. 
Streitigkeiten über Zollrechte. Die große Zahl der Güterverzeichnisse im Bestand des Stifts St. Gangolf zeigt trotz aller Lückenhaftigkeit der Überlieferung, dass die Fortführung der Listen zur Aufrechterhaltung der Besitzansprüche den Großteil der stiftischen Verwaltungsarbeit darstellte, um einen Überblick über alte wie auch neue Rechte zu behalten.

Es ist auffällig, dass die Güterverzeichnisse der Propstei selten vor dem 15. Jahrhundert einsetzten. Der Grund dafür liegt zum einen in den Überlieferungsumständen, denn mit den Hussiteneinfällen, den politischen Wirren des Immunitätenstreits und den Plünderungen im Markgrafenkrieg ${ }^{757}$ war Mitte des 15. Jahrhunderts eine Neuaufstellung der Güterverzeichnisse und Anpassung an die neuen Verhältnisse notwendig geworden. Zum anderen ist die Ursache hierfür in dem Charakter der Überlieferung zu finden. Die Auflösung der Vita communis im 13. Jahrhundert erfolgte etwa zeitgleich, wenn auch von dieser Entwicklung unabhängig, mit einer Veränderung in der Strukturierung des Grundbesitzes, nämlich von einem Villikationssystem zu einem Pachtund Leihesystem. ${ }^{758} \mathrm{Zu}$ Zeiten der Villikationsstruktur wurde der Grundbesitz von abhängigen Bauern bewirtschaftet, die einem größeren, unmittelbar vom Grundherrn bewirtschafteten Fronhof unterstanden. Die Leitung eines solchen Fronhofs führte ein hofmann oder villicus aus, der die festgelegten Abgaben in den umliegenden Ortschaften eintrieb und sie zu festgelegten Terminen im Jahr ${ }^{759}$ an das Stift abzulie-

\footnotetext{
${ }^{757}$ Näheres zu den Auswirkungen der Unruhen im 15. Jahrhundert auf die Registratur des des Stifts St. Gangolf im Kapitel 2.1 Registraturaufbau.

758 Eine allgemeine Übersicht über die Wandlung der Grundherrschaft findet sich in Werner Rösener: Agrarwirtschaft, Agrarverfassung und ländliche Gesellschaft im Mittelalter (Enzyklopädie deutscher Geschichte, Bd. 13). München 1992. S 22-23 und S. 8183; sowie in Adriaan Verhulst: Aspekte der Grundherrschaftsentwicklung des Hochmittelalters aus westeuropäischer Sicht. In: Rösener, Werner (Hg.): Grundherrschaft und bäuerliche Gesellschaft im Hochmittelalter (Veröffentlichungen des Max-PlanckInstituts für Geschichte, Bd. 115). Göttingen 1995. S. 16-30; Näheres zu den Bamberger Verhältnissen in Nöth: Urbare und Wirtschaftsordnungen. 1986. S. 4; oder auch Rainer Braun: Das Benediktinerkloster Michelsberg 1015 - 1525. Eine Untersuchung zur Gründung, Rechtsstellung und Wirtschaftsgeschichte, Bd. 1 (Die Plassenburg. Schriften für Heimatforschung und Kulturpflege in Ostfranken, Bd. 39). Kulmbach 1978. S. 87.

${ }^{759}$ Ein Beispiel für Spuren dieser alten Regelungen ist das „Verzaichnus der zehenden so
} 
fern hatte. ${ }^{760}$ Die Aufzeichnung darüber wurde in Güterverzeichnissen, oftmals vorschnell als Urbare angesprochen, festgehalten, die jedoch für die Anfangsphasen eines Stifts nur in Ausnahmen überliefert sind. ${ }^{761}$ Die frühen Verzeichnisse bildeten aber die Grundlage für die spätere Wirtschaftsverwaltung auf Grundlage des Pacht- und Leihesystems, sodass die Zinsbücher des 15. Jahrhunderts durchaus Aussagen über die Zustände der Anfangszeit des Stifts bieten können. Als die Besitzungen kirchlicher Institutionen frei verliehen wurden, nachdem sie sich vor der Auflösung der Villikationen in Eigenbewirtschaftung befanden, wurden vermehrt Urkunden ausgestellt ${ }^{762}$ und die älteren Aufzeichnungen gingen in umfangreicheren Güterverzeichnissen auf. Das verkomplizierte die Verwaltung, sodass in dieser Zeit die Verzeichnisüberlieferung schlagartig anstieg, um den neuen Ansprüchen an Dokumentation gerecht zu werden. Nun halfen sogenannte Propsthöfe bei der Eintreibung der Einkünfte, deren Standort sich nicht selten an der Lage der einstigen Zentralhöfe der Villikationen orientierte. Die Propsthöfe waren, wie es für das Domstift bereits nachgewiesen werden konn-

in die probstey gehörig unnd jerlich den 11. Juli in Hollveldt verlassen werde." von 1592, das jedoch nicht geführt wurde. Zu finden im Zinsregister $(1595-1604,1627)$ in StABa Stift St. Gangolf, Akten und Bände Nr. 13 fol. 24.

${ }^{760}$ Nöth: Urbare und Wirtschaftsordnungen. 1986. S. 4.

${ }^{761}$ Es ist ein allgemeines Phänomen der Stiftsforschung, dass die frühen Aufzeichnungen der mittelalterlichen Urbarsüberlieferung nur in sehr geringer Zahl überliefert sind, diese jedoch in vielen Fällen erschlossen wurden. Da die Überlieferung der hoch- und spätmittelalterlichen Urbare in ihrer Quantität sprunghaft ansteigen, stellt ihre Erschließung hingegen ein logistisches Problem dar. Die Unterscheidung zwischen Urbar und Zinsverzeichnis wird häufig nicht sauber gezogen. Näheres dazu in Bünz: Probleme der hochmittelalterlichen Urbarüberlieferung. 1995. S. 32; und zur Frage „Was ist ein Urbar?"“ in Enno Bünz/ Dieter Rödel/ Peter Rückert/ Ekhard Schöffler (Bearb.): Fränkische Urbare. Verzeichnis der mittelalterlichen urbariellen Quellen im Bereich des Hochstifts Würzburg (Veröffentlichungen der Gesellschaft für fränkische Geschichte. Reihe 10: Quellen zur Rechts- und Wirtschaftsgeschichte Frankens, Bd. 13). Neustadt a. d. Aisch 1998. S. 11-17.

${ }^{762}$ Matthias Thiel hat diesen Sachverhalt für das Regensburger Kloster St. Emmeran herausstellen können, was trotz aller Schwierigkeit bei der Anwendbarkeit klösterlicher Verhältnisse auf Kollegiatstifte hier einen interessanten Hinweis auf die Deutung der Überlieferung bietet. Näheres dazu in Matthias Thiel: Das St. Emmeraner Register von 1275 in Clm 12992, seine Vorstufen und Nachläufer. Ein Beitrag zum klösterlichen Registerwesen und dessen Anfängen. In: Zeitschrift für bayerische Landesgeschichte 33 (1970). S. 85-134 und S. 542-635, hier: S. 577-578. 
te, ${ }^{763}$ mit vom Propst unmittelbar unterstellten Verwaltern oder Kastnern besetzt, die die Einkünfte sammelten und nach Bamberg lieferten. Das neue Agrarsystem mit zahlreichen Leiheformen, Stiftungsmodalitäten und Abgabeformen machte zusätzliche Besitzübersichten nötig, die neben dem bloßen Leiheakt auch die genauen Abgabeleistungen festhalten mussten.

Auch die Gangolfer Güterverzeichnisse der Oblei- oder Vikariatsgüter reichen nicht weiter als bis in das 15 . Jahrhundert zurück, was seine Ursache ebenfalls in den Verlusten während der Unruhen in und um Bamberg während des 15. und 16. Jahrhunderts hatte. Während dieser Zeiten erlitten die geistlichen Institutionen der Region erhebliche Schädigungen an Land, Leuten und Registratur. Trotzdem sind die Verzeichnisse, die Obleigut organisierten, im Bestand des Stifts St. Gangolf weitaus umfangreicher überliefert, als es Verzeichnisse über die Pfründengüter sind. Dies hat mit dem häufigen Wechsel der Obleiinhaber zu tun, die eine umfangreichere Dokumentation erforderten. Das Obleigut veränderte sich häufiger, es verlagerte sich und lag weitaus verstreuter als das Pfründengut. Die Verwaltung dieser Güter bedurfte daher weitaus mehr Schriftgut.

Neben den Güterverzeichnissen ist die Sichtung von Schriftzeugnissen aus politischen und verfassungsbildenden Zusammenhängen unerlässlich, um das Verwaltungsschriftgut einordnen zu können. Dies sind zum einen die Statutenbücher des Stifts, ${ }^{764}$ welche theoretische Normen ohne Aussage über die tatsächliche praktische Umsetzung liefern. Erst im Verbund mit den aus den in den Güterverzeichnissen herauszulesenden Herangehensweisen in der Güterverwaltung können Aussagen über tatsächliche Herrschaftsstrukturen getroffen werden. Zum anderen ist eine Heranziehung der Urkundenüberlieferung zur Rekonstruktion der Güterorganisation nötig. Für das Stift St. Gangolf

${ }^{763}$ Nöth: Urbare und Wirtschaftsordnungen. 1986. S. 5.

${ }^{764}$ Für das Stift St. Gangolf sind sechs Statutenbücher aus dem 16. Jahrhundert überliefert in StABa Stift St. Gangolf, Akten und Bände Nr. 130, Nr. 131 und Nr. 132; in AEB Rep. I Akten des Schlundrepertoriums, A 121; Auszüge aus den Statuten des Stifts außerdem in AEB Rep. 60 Pfarrarchiv St. Gangolf Bamberg Nr. 2.; sowie in SttABa D 3001 HV Rep. 2 Nr. 264 fol. 54-73‘ und Nr. 265. Näheres im Kapitel 4.1.1 Statuten und Consuetudines. 
liegen Originale sowohl aus den bereits erwähnten Beständen des Staatsarchivs Bamberg ${ }^{765}$ vor als auch aus dem Archiv des Erzbistums Bamberg ${ }^{766}$ und dem Stadtarchiv Bamberg. ${ }^{767}$ Abschriftliche Überlieferungen finden sich in den Kopialbüchern ${ }^{768}$ aber auch in lose überlieferten Urkundenabschriften ${ }^{769}$ des Stifts sowie in den Arbeiten von Johannes Looshorn ${ }^{770}$.

Besonders aussagekräftig für die Rekonstruktion von Besitzverhältnissen erweisen sich die Zugeständnisse des Propstes an das Kapitel bei dessen Amtsantritt, in den Quellen cautio ${ }^{771}$ genannt, und dessen Bestätigung durch das Kapitel, genannt remissio. ${ }^{772}$ Darin versprach der neue Propst dem Dekan und dem Kapitel seine althergebrachten Rechte und versicherte sich gewisse Sicherheiten bei Zahlungsunfähigkeit. Der Vorteil der Cautiones und Remissiones als Quellengattung hinsichtlich ihrer Auswertung besteht darin, dass sie im Gegensatz zu der Statutenüberlieferung aufgrund ihrer Zweckgebundenheit ein aktives Vorgehen

${ }^{765}$ Näheres zur Gangolfer Urkundenüberlieferung im Staatsarchiv Bamberg im Kapitel 2.2 Urkunden.

766 Die für diese Fragestellung interessanten Urkunden im Archiv des Erzbistums Bamberg finden sich in den Beständen AEB Rep. I Pfarrei St. Gangolf, Urkunden.

${ }^{767}$ Einen eigenen Bestand des Stifts St. Gangolf findet sich im Stadtarchiv nicht, jedoch sind durch die umfangreiche Aufbereitung der Urkunden des Bestandes SttABa A 21 mittels Urkundenregesten über die archiveigenen Auftritt www.stadtarchiv-bamberg.de durch eine Suche nach Schlagwörtern gute Ergebnisse zu erzielen.

${ }^{768}$ Die Kopialbücher des Stifts St. Gangolf sind in mehreren Versionen aus dem 16. und 17. Jahrhundert überliefert in StABa Stift St. Gangolf, Akten und Bände Nr. 1 bis Nr. 6.

${ }^{769}$ Beispielsweise der Sammelakt von 1600 bis 1610 in StABa Stift St. Gangolf, Akten und Bände Nr. 168 über Streitigkeiten zwischen dem Propst von St. Gangolf und der Stadt Hollfeld über Propsteilehen mit Urkundenabschriften aus dem 14. und 15. Jahrhundert.

${ }^{770}$ Looshorn: Die Geschichte des Bisthums Bamberg, Bd. 3 1891. Zu bedenken ist jedoch die Tatsache, dass nicht alle seine Abschriften dem entsprechenden Original zuzuordnen sind.

${ }^{771}$ Für das Stift St. Gangolf überlieferte Cautiones für den 17. Mai 1489 abschriftlich im Lehenbuch (1489-1494) des Propstes Melchior Truchsess (amt. 1489-1493) in StABa Stift St. Gangolf, Akten und Bände Nr. 123 fol. 2‘-3; Cautio vom 30. Juli 1516 des Propstes Paul Neydecker (amt. 1516-1565) in AEB Rep. I Pfarrei St. Gangolf U 826; und Cautio vom 27. Januar 1565 des Propstes Erasmus Neustetter (amt. 1565-1594) in StABa A 120 L 131 Nr. 732.

772 Für das Stift St. Gangolf ist solch eine Remissio nur einmal überliefert vom 11. November 1466: Original in StABa A 120 L 131 Nr. 758; und abschriftlich in den Lehenprotokollen den Propsteiverwaltungsamts Hollfeld (1417-1576) in StABa Stift St. Gangolf, Akten und Bände Nr. 119 fol. 53‘-54. 
der Verhandlungspartner dokumentieren. Zwar gehörten stereotype Formeln und floskelartige Wiederholungen ganzer Passagen zum gängigen Vorgehen, jedoch vermitteln sie durch ihre Unmittelbarkeit eine hohe Aussagekraft und spiegeln die damalige Praxis der Konfliktlösung zwischen Propst und Stiftskanoniker wieder. Grundsätzlich erinnern die Cautiones des Stiftspropstes an die Praxis der Wahlkapitulationen des Domkapitels, worin der Bischof gegenüber seinem Stift zahlreiche Zugeständisse machte und welche die große Machtfülle der Domkapitel im Spätmittelalter festigte. ${ }^{773}$ Auch der Propst des Stifts St. Gangolf hatte vor seinem Amtsantritt einen Schwur vor seinem Kapitel zu leisten. ${ }^{774}$ Der Unterschied bestand darin, dass es sich nicht um sein Wahlgremium handelte - der Propst eines Bamberger Kollegiatstifts wurde vom Domkapitel eingesetzt - sondern ihn der Schwur sichtbar als Vorsteher der Gemeinschaft präsentierte. ${ }^{775}$

\subsection{Entwicklung des Grundbesitzes als Pfründengut}

\subsubsection{Gründungsausstattung und erste Schenkungen}

Die erste wirtschaftliche Ausstattung des Stifts St. Gangolf erfolgte durch Reginold Walpot im Zuge der Stiftsgründung Mitte des 11. Jahrhunderts. ${ }^{776}$ Aus dem Ministerialadel stammend, war er besonders im

773 Näheres zur Entwicklung des Bamberger Domkapitels als zweiten Stadtherrn im Kapitel 3.1.2 Einordnung der Stiftsgründung in die politischen Umstände der Zeit.

${ }^{774}$ „Des ein yeglicher probst der nu hinfur doselbst probst wirdert solch zu tun, ee dann er von den corheren aufgenomen wirt, sweren sol“ in dem Urteil des Anton, Bischof zu Bamberg (amt. 1431-1459), vom 8. November 1449 in StABa A 120 L 131 Nr. 753.

775 So beschreibt die ältere Forschung, dass der Propst des Stifts St. Gangolf nach seiner Ernennung durch einen bischöflichen Kommissar nach Hollfeld geführt wurde, wo er nach einem feierlichen Einzug einen Eid vor dem Rat in Hollfeld leisten musste und damit die Vogteirechte über die Stadt erlangte. In Schubert: Dissertatio inauguralis. 1768. S. 81; und Das Collegiatstift zu U. L. Frau und St. Gangolph in Bamberg. 1881. S. 80-91, hier: S. 83. In den Statuten des Stifts St. Gangolf findet sich dazu nichts. Dass der Bischof die Propsteien der verschiedenen Stifte nur Mitgliedern des Domkapitels übertragen durfte, ist auch für die Würzburger Stifte nachweisbar. In Bünz: Stift Haug in Würzburg. 1998. S. 190.

776 Guttenberg: Die Regesten der Bischöfe und des Domkapitels von Bamberg. 1932. Nr. 285; Guttenberg: Territorienbildung am Obermain. In: BHVB 79 (1925). S. 284-287. 
Radenzgau und um Zwernitz begütert, ${ }^{777}$ und auch weit nach seiner Gründung konzentrierte sich der stiftische Grundbesitz in diesem Gebiet, vor allem um die Stadt Hollfeld herum. ${ }^{778}$

Die Siedlung Hollfeld ist bereits 1017 nachzuweisen, als der Bischof von Würzburg Kirchenzehnten neben anderen Ortschaften um Hollfeld an den Bamberger Bischof abtrat. ${ }^{779} \mathrm{Im}$ Jahr 1057 erlosch das Geschlecht der Markgrafen von Schweinfurt im Mannesstamm und den Walpoten als deren Ministerialen drohte der Verlust ihrer Ländereien im neuen Machtgefüge. Dass das zwischen 1057 und 1059 neugegründete Stift St. Gangolf mit umfangreichen Walpotenbesitz bedacht wurde, scheint daher kein Zufall zu sein und kann wohl als Maßnahme der Walpoten gewertet werden, das mittlerweile unsicher gewordene Gebiet um Hollfeld und einige Höfe in der Stadt abzustoßen und als Ausstattungsgut dem Stift St. Gangolf zu übereignen. ${ }^{780}$ Hollfeld bot mit seiner Lage an Handelsstraßen und mit einem reichen landwirtschaftlich genutzten Umland viele Ausbaumöglichkeiten. Dies nutzte nicht nur das Stift St. Gangolf, sondern ebenso das Bamberger Hochstift und die Reichsritterschaft. Günther Hofman bezeichnet das Hollfeld des 14. Jahrhunderts gar als „bischöfliche Landesburg“, die mit der in der

Näheres zur Rolle der Walpoten bei der Stiftsgründung im Kapitel 3.1.3.2 Reginold Walpot.

777 Zimmerman: Sankt Gangolfs Weg von Lothringen nach Bamberg. 1962. S. 447.

778 Im Rahmen der Inkorporation der Kaplanei von Hollfeld im Jahr 1449 wurde dementsprechend festgestellt: „Und wann nu der mererteil der guter des genant stifts bey und umb unser stat Holvelt gelegen sind“ in einer bischöflichen Urkunde vom 17. November 1449 in StABa A 120 L 133 Nr. 876.

${ }^{779}$ Caroline Göldel-Kaupper: Die Jubiläumsurkunde von 1017. In: Stadt Hollfeld (Hg.): 1000 Jahre Hollfeld Stadt und Land 1017-2017. Hollfeld 2017. S. 9-12; Guttenberg: Die Regesten der Bischöfe und des Domkapitels von Bamberg. 1932. Nr. 141.

${ }^{780}$ Günther Hofman: Hollfeld - Holvelt. Ein geschichtlicher Überblick. In: Stadt Hollfeld (Hg.): St. Gangolf. Das Wahrzeichen der Stadt Hollfeld zu neuem Leben erweckt. Hollfeld 2001. S. 5-8, hier: S. 5; Wolfram Siegel stellt darüber hinaus in derselben Veröffentlichung die These auf, dass die Walpoten vom Bischof von Bamberg zur Stiftung gezwungen wurden, da sie Auseinandersetzungen mit den Erben der Schweinfurter Markgrafen um die Besitzverhältnisse fürchteten. In Wolfram Siegel: Der heilige Gangolf in Hollfeld und das Geschlecht der Walpoten. In: Stadt Hollfeld (Hg.): St. Gangolf. Das Wahrzeichen der Stadt Hollfeld zu neuem Leben erweckt. Hollfeld 2001. S. 9-12, hier: S. 10. Näheres zu den Gründungsumständen des Stifts St. Gangolf im Kapitel 3.1.2 Einordnung der Stiftsgründung in die politischen Umstände der Zeit. 
Stadtmauer integrierten Gangolfskirche ein Bollwerk gegen den Einfluss der Andechs-Meranier bilden sollte. ${ }^{781}$ Obwohl dies wohl etwas zu weit greift, ist die Bedeutung Hollfelds für das Stift St. Gangolf bis in die Neuzeit hinein unbestritten. Es nahm als Verwaltungsstützpunkt und als Zentrum des außerstädtischen Besitzes des Stifts St. Gangolf eine wichtige Rolle in der Grundherrschaft des Stifts ein. Die Gangolfer Güter um Hollfeld unterstanden dabei fast ausschließlich dem Propst und wurden dort als Außenstelle mit zentraler Funktion in der Region verwaltet.

Da die Quellen zum Stift St. Gangolf erst überwiegend im 15. Jahrhundert einsetzen und daher nur die spätmittelalterlichen Spuren überliefert sind, muss die Rekonstruktion der stiftischen Gründungsausstattung auf die lückenhafte Urkundenüberlieferung und auf Rückschlüsse in den Güterverzeichnissen gestützt werden. Außerdem sind Parallelen zur Besitzverwaltung des Bamberger Domstifts durchaus aussagekräftig, um die Verhältnisse des kleineren Stifts St. Gangolf nachzuzeichnen. Wie bereits erwähnt, konnte von Guttenberg schon für das 11 . Jahrhundert nachweisen, dass das domstiftische Gründungsgut nicht nur vom Dompropst verwaltet wurde, sondern dass dieses auch nach der Auflösung der Vita communis als Pfründengut geschlossen verblieb und nicht in Einzelpfründen aufgeteilt wurde. ${ }^{782}$ Ähnlich dem Domstift wurde auch das Gangolfer Gründungsgut durch sogenannte Propsthöfe mit einer zentralen Verwaltungsfunktion in der Region verwaltet.

\subsubsection{Propsthöfe}

Im 15. und 16. Jahrhundert lassen sich aus den Güterverzeichnissen mehrere als Propsthöfe bezeichnete Güter des Stifts außerhalb Bam-

\footnotetext{
${ }^{781}$ Hofman: Hollfeld - Holvelt. 2001. S. 6.

782 „Das wesentliche aber ist, daß diese alten Pfründengüter des Domstifts [...] ausdrücklich als Dompropsteigüter gelten und an die Stelle der Domstiftsvillikation nunmehr das ,Dompropsteiamt' tritt.“ In Guttenberg: Urbare und Wirtschaftsordnungen. 1969. S. 17; Näheres dazu in Nöth: Urbare und Wirtschaftsordnungen. 1986. S. 5. Näheres dazu im Kapitel 6.1 Besitzverwaltung eines Kollegiatstiftes.
} 
bergs herauslesen: neben Hollfeld ${ }^{783}$ sind solche Verwaltungseinheiten in Tiefenellern (Gde Litzendorf, Lk Bamberg), ${ }^{784}$ in Ebensfeld (Lk Lichtenfels) ${ }^{785}$ und in Gesees (Lk Bayreuth), ${ }^{786}$ auch in Brunn (Gde Heiligenstadt, Lk Bamberg) ${ }^{787}$ und Laibarös (Gde Königsfeld, Lk Bamberg) ${ }^{788}$ zu finden. Diese auf der im 12. Jahrhundert abgelösten Villikationsstruktur beruhenden Verwaltungshöfe hatten eine zentrale Funktion für

783 Für das Jahr 1565 „der probstbauer zu Holveldt von dem probsthof daselbst“ im Zinsregister (1562-1578) in StABa Stift St. Gangolf, Akten und Bände Nr. 12 fol. 104; „Hollveldt. [...] von dem probsthof daselbsten“ im Zinsregister $(1595-1604,1627)$ in StABa Stift St. Gangolf, Akten und Bände Nr. 13 fol. 9; auch „fronhof“ genannt. Näheres dazu in den Lehenprotokollen des Propsteiverwaltungsamts Hollfeld (1417-1429) in StABa Stift St. Gangolf, Akten und Bände Nr. 118 fol. 9 Nr. 21.

784 "Tiefenellern. Und ist der pauer aufm hof schuldig die ayer zu ostern bey den zinsleuten daselb einzufoderrn und dem probst zuzubringen." im Zinsregister (15601566) in StABa Stift St. Gangolf, Akten und Bände Nr. 11 fol. 1; „Nota. Dieser besitzer des hofs ist schuldig alle zins und gult $\mathrm{zu}$ Tifenellern einzubringen, und einem brobst zuuberantworten, soll auch alle jhar einem brobst ein prunmal geben, zwee fuhr holz zu weinachten in eine mit sechs pferden, zwei fuder hew in eins mit sechs pferden und auch gewohnliche fron zinsen schuldig sein." im Zinsregister (1562-1578) in StABa Stift St. Gangolf, Akten und Bände Nr. 12 fol. 24; „ein hof zu Tiefenellern den probsthof genanndt" im Lehenverzeichnis (1565-1588) in StABa Stift St. Gangolf, Akten und Bände Nr. 7 fol. 98; und im Zinsregister $(1595-1604,1627)$ in StABa Stift St. Gangolf, Akten und Bände Nr. 13 fol. 14 '.

785 "Ebensfeld. So ist der pauer oder peuerin auf diesem hof auch schuldig bey den anderen zinsleuten daselb der probstey gehorig alle denselben zins an geldt, eyern, kesen und huener yder zeit einzuforderrn und eynem probst hereinzubringen." im Zinsregister (1560-1566) in StABa Stift St. Gangolf, Akten und Bände Nr. 11 fol. 5'; unter der Kategorie „Ebensfeld“ für das Jahr 1565 „und ist besitzer dieses brobsthofs schuldig alle zins und gult nichts davon ausgenommen einzubringen und gein Bamberg der brobstey zugewehren, ist auch schuldig gewonliche fron zu thun. "im Zinsregister (1562-1578) in StABa Stift St. Gangolf, Akten und Bände Nr. 12 fol. 26; am 7. Oktober 1448 urteilte Anthon, Bischof zu Bamberg (amt 1431-1459), in der Klage der „armeleute“ des „probst unser lieben frawen stieftes zu Tewerstat bey unser stad Bamberg“ in Ebensfeld gegen Jorg Truchses, bischöflicher Amtmann aus Lichtenfels, über die Pfändung einer „blocherfure“. In StABa A 120 L 133 Nr. 851.

786 „Summarum des jerlichen einkommens und zins der probstey s. Gangolfs stieft in der Teuerstat bey Bamberg ufm gebirg, in der stat Holveldt auf dem lande dobey, sampt dem drithail bau zu Geses bey Bareudt, alles vermoge des registers zuhauf gezogen." für das Jahr 1565 im Zinsregister (1562-1578) in StABa Stift St. Gangolf, Akten und Bände Nr. 12 fol. 103:

787 "Brun beym Greiffenstain. Hans Herbst hat empfangen den probsthof" im Lehenverzeichnis (1565-1588) in StABa Stift St. Gangolf, Akten und Bände Nr. 7 fol. 99.

788 „Probsthof zu Laubrös“ im Lehenverzeichnis (1565-1588) in StABa Stift St. Gangolf, Akten und Bände Nr. 7 im „index locorum“. 
die ihnen zugeordneten Ortschaften, welche jedoch nie als gesamte Orte im Besitz einer Institution waren, sondern eher als sogenanntes Streugut aus einzelnen Höfen, Häusern, Gärten, Wiesen, Wäldern, Feldern und vereinzelt auch Wirtschaftseinheiten wie Mühlen bestanden. Der jeweilige Verwalter hatte regelmäßig Abgaben an den Gangolfer Propst nach Bamberg zu liefern, der davon seinen Pflichtteil an das Kapitel verteilte.

Die Bezeichnung als Propsthof wurde nicht systematisch benutzt. Es sind Größen- und Bedeutungsunterschiede zwischen den einzelnen Verwaltungseinheiten zu erkennen, die von der Anzahl und Wirtschaftskraft der ihnen unterstellten Ortschaften abhingen. Die Orte Hollfeld und Gesees werden durch die Güterverzeichnisse geradezu als Zentralorte außerhalb Bambergs ausgewiesen, denen eine feste Anzahl von Ortschaften unterstellt waren, während für die kleineren Propsthöfe meist nicht mehr als die bloße Erwähnung zu finden sind. Eine Rekonstruktion der Orte, die zum Pfründengut des Stiftes St. Gangolf gezählt wurden, ist erst für das 16. Jahrhundert möglich. ${ }^{789}$ Hierfür ist das Zinsregister der Propstei von 1562 bis 1578 ausschlaggebend, ${ }^{790}$ welches erstmals mit einem Anspruch auf Vollständigkeit an die Aufzählung aller dem Propst unterstellten Orte heranging. Frühere Zinsregister ${ }^{791}$ und Lehenbücher der Propstei ${ }^{792}$ sowie Lehenprotokolle des Propsteiverwaltungsamtes Hollfeld ${ }^{793}$ lassen sich durch die Analyse dieses einen

\footnotetext{
${ }^{789}$ Anhang Karte 2: Pfründengut.

790 „Urbarium und zinsregister herrn Erasmus Neusteters Sturmer genant uber die probstei s. Gangolfs stifts in der Theuerstat bey Bamberg 1565. Auch probstzehent.“ im Zinsregister (1562-1578) in StABa Stift St. Gangolf, Akten und Bände Nr. 12.

${ }^{791}$ Im Zinsregister (1560-1566) in StABa Stift St. Gangolf, Akten und Bände Nr. 11.

792 Das umfangreichste Lehenbuch der Propstei „Lehenbuch Erasmussen Neusteters Sturmer genant uber die probstei s. Ganngolf stift zu der Theuerstat in Bamberg 1565“ (1565-1588) in StABa Stift St. Gangolf, Akten und Bände Nr. 7. ist zeitgleich mit dem Zinsregister (1562-1578) in StABa Stift St. Gangolf, Akten und Bände Nr. 12 entstanden, wurde jedoch nicht nach den Orten des Pfründenguts strukturiert, sondern nach den Herkunftsorten der Zinspflichtigen.

${ }^{793}$ Lehenprotokolle des Propsteiverwaltungsamts Hollfeld sind bereits von Anfang des 15. bis Ende des 16. Jahrhunderts überliefert. In StABa Stift St. Gangolf, Akten und Bände Nrr. 118-122. Transkription und Besprechung des frühesten Lehenprotokolls des Propsteiverwaltungsamts Hollfeld von Anfang des 15. Jahrhunderts (StABa Stift St. Gangolf, Akten
} 
Zinsregisters einordnen, indem die Ortschaften des Kaplanatszehnten in Hollfeld beispielsweise von Ortschaften in der Zuständigkeit des Propsthofes zu Gesees unterschieden werden können. Auch nicht leicht $\mathrm{zu}$ identifizierende Ortschaften lassen sich dadurch eindeutiger zuordnen. ${ }^{794}$ Insgesamt konnen so 39 Orte nachgewiesen werden, aus denen der Propst Einkünfte bezog.

\subsubsection{Propsthof in Hollfeld 795}

Der dem Propst unterstellte Hof in Hollfeld, gelegen in der Nachbarschaft zur Kirche St. Gangolf in Hollfeld, ${ }^{796}$ erfüllte nicht nur die Funktion eines Außenpostens, sondern ist auch als Verwaltungseinheit $\mathrm{zu}$ verstehen, die eigene, von den Propstbesitzungen unabhängige Einkünfte unterhielt. ${ }^{797}$ Anders als für die anderen Propsthöfe kann für den Propstvogt in Hollfeld eine eigenständige Verwaltung mit eigenen Zinsund Zehntbüchern nachgewiesen werden. Die Sonderstellung mit eigener Buchführung ist der Grund dafür, dass im Bestand „Stift St. Gangolf, Akten und Bände“ des Staatsarchivs Bamberg eine Teilprovenienz „Propsteiverwaltungsamt Hollfeld“ angelegt wurde, um diesem Umstand auch archivisch gerecht zu werden. Obwohl mit Recht vermutet werden kann, dass die Güter in Hollfeld eine der frühesten Besitzungen

und Bände Nr. 118) in Caroline Göldel: Der Liber feudalis ecclesiae St. Gangolphi 14171432. Das älteste Lehnbuch des Kollegiatstiftes St. Gangolf in Bamberg. [o. O.] 1996.

${ }^{794}$ Beispielsweise ist die Unterscheidung der Orte Welkendorf (Gde Hollfeld, Lk Bayreuth) unter der Quellenbezeichnung „Welckendorf“ oder „Welckendorf am wasser“ von der Ortschaft Wölkendorf (Gde Stadelhofen, Lk BA) unter der Quellenbezeichnung "Welchendorf“ vonnöten. Ein ähnlicher Fall ist die Unterscheidung der Orte Draisendorf (Gde Wiesenttal, Lk Forchheim) unter der Quellenbezeichnung „Dreysendorf“, "Dreusendorf“ oder „Dreisendorf“ von der Ortschaft Drosendorf (Gde Hollfeld, Lk Bayreuth) mit der Quellenbezeichnung „Drosendorf“.

795 Näheres dazu Lisa Witowski: Die Bedeutung Hollfelds für das mittelalterliche Kollegiatstift St. Gangolf in Bamberg. In: Stadt Hollfeld (Hg.): 1000 Jahre Hollfeld Stadt und Land 1017-2017. Hollfeld 2017. S. 48-52.

796 „Probsteyhoefstadt auch daselbst zu Hollfeldt nebn sanct Gangolphs capelen umb seines hofs und sanct Gangolphsberge an der Keynach gelegen“ in Abschrift einer Urkunde vom 3. November 1434 angefertigt um 1600 im Sammelakt über Streitigkeiten zwischen dem Propst von St. Gangolf und der Stadt Hollfeld über Propsteilehen in StABa Stift St. Gangolf, Akten und Bände Nr. 168 fol. 30.

${ }^{797}$ Rechnung Propstei Hollfeld in StABa A 232/III R. 25268 (1568/69). 
des Stiftes St. Gangolf waren, ${ }^{798}$ lassen sich erste Spuren eines Gangolfer Propsthofes in Hollfeld in den stiftseigenen Quellen erst für das 14. Jahrhundert ausmachen. Diese betrafen Streitigkeiten zwischen Otto von Gauberstadt als Propst von St. Gangolf (amt. 1385-1397) und der Stadt Hollfeld, in denen es um die die Deutung des Propsthofes und der Lehengüter in Hollfeld als Mann- oder Propstlehen ging. ${ }^{799}$ Geschlichtet wurde schließlich zugunsten des Propstes, sodass dieser bei der Auswahl des Propstvogtes nicht an die Erblinien seiner Lehensmänner gebunden blieb.

Beinahe 100 Jahre früher, jedoch ohne die direkte Erwähnung eines Propsthofes, entschied Wulfing, Bischof von Bamberg (amt. 1304-1318), in der Differenz zwischen dem Pfarrer von Hollfeld und dem Stift St. Gangolf wegen des Neubruchtzehnts von jährlich sechs Scheffeln Getreide auf Stiftsgüter in Hollfeld, Stechendorf (Gde Hollfeld, Lk Bayreuth), Sachsendorf (Gde Aufseß, Lk Bayreuth), Tiefenlesau (Gde Hollfeld, Lk Bayreuth), Zochenreuth (Gde Aufseß, Lk Bayreuth), Drosendorf (Gde Hollfeld, Lk Bayreuth), Breitenlesau (Gde Waischenfeld, Lk Bayreuth) und Hochstahl (Gde Aufseß, Lk Bayreuth) zugunsten des Stifts, und zählt in diesem Zusammenhang einen Großteil der Güter auf, die später das Einflussgebiet des Gangolfer Propstvogtes umfassten. ${ }^{800}$

Das Stift St. Gangolf hatte darüber hinaus Zugriff auf zahlreiche Höfe in der Stadt Hollfeld selbst, deren Zahl jedoch erst mit Einsetzen der Güterverzeichnisse ab dem 15. Jahrhundert ermittelt werden können. Caroline Göldel konstatierte im Zuge ihrer Analyse der Lehensprotokolle des Propsteiverwaltungsamtes Hollfeld von 1417 bis 1432, ${ }^{801}$ dass sich in diesem einen Güterverzeichnis „Angaben zu mehr als 90 Prozent der damals bestehenden Anwesen“ zu Hollfeld fänden. ${ }^{802}$ Diese

798 Näheres im Kapitel 3.1. Gründung.

${ }^{799}$ Abschrift einer Urkunde vom 3. November 1393 angefertigt um 1600 im Sammelakt über Streitigkeiten zwischen dem Propst von St. Gangolf und der Stadt Hollfeld über Propsteilehen in StABa Stift St. Gangolf, Akten und Bände Nr. 168 fol. 26.

800 Looshorn: Die Geschichte des Bisthums Bamberg, Bd. 3. 1891. S. 50, jedoch ohne Herkunftsangabe der Urkunde.

${ }^{801}$ In den Lehenprotokollen des Propsteiverwaltungsamts Hollfeld (1417-1429) in StABa Stift St. Gangolf, Akten und Bände Nr. 118.

802 Göldel: Der Liber feudalis. 1996. S. 9. 
Güter in der Stadt fielen in die direkte Zuständigkeit des Propstvogts zu Hollfeld, der die Abgaben sammeln ließ und zu festen Terminen an den Kasten des Propstes in Bamberg zu liefern hatte. ${ }^{803}$

Während die Ausrichtung der Verwaltung auf die ehemaligen Villikationshöfe samt deren abhängigen Güter im Umkreis durchaus dem üblichen Bild der mittelalterlichen Gutsverwaltung entsprach, ist die Konzentration auf ein eng begrenztes Gebiet für eine geistliche Institution selten zu beobachten. Für das Domstift von Bamberg ist beispielsweise eine weit auseinanderliegende Streulage des Pfründenbesitzes nachgewiesen, der sich „in Österreich, Baiern und Franken, am oberen und unteren Main wie an der Regnitz, in Hessen und im Rheinland“ findet. ${ }^{804}$ Der Pfründenbesitz des Stifts St. Gangolf, natürlich weitaus eingeschränkter als der des reichen Domstifts, war auch im kleineren Maßstab beiweitem nicht so breit gefächert und begnügt sich mit einer Ausdehnung zwischen Bamberg und Bayreuth. ${ }^{805}$

Eine Auflistung inmitten eines Zins- und Zehntverzeichnissen der Propstei aus dem Jahr 1565 stellt einen Glücksfall dar, um die Zuständigkeit des Hollfelder Propstvogtes zu rekonstruieren. Deutlich wird die praktische Umsetzung der vögtischen Aufgaben nachgezeichnet, indem es wörtlich heißt:

Item die jerlichen zins so zu der probstey s. Gangolfs stieft ufm gebirge gehorig hat hie vor der zeit ein probstverwalter zu Holveldt dieselbigen in acht tagen gesamlet, rainbgefaren und einbracht wie volgt.

803 Guttenberg benutzt für diese Abgabenpflichten der ehemaligen Villikationshöfe die Bezeichnung „Serviten“ in Anlehnung an regelmäßigen Leistungen der Königshöfe und kann sich auf ganze Servitenordnungen für das Domstift Bamberg stützen. Für das Stift St. Gangolf sind weder solche Ordnungen, noch der Begriff „Serviten“ überliefert, jedoch ähnelt sich die Praxis des Dom- und des Kollegiatstiftes auffällig. Näheres dazu in Guttenberg: Urbare und Wirtschaftsordnungen. 1969. S. 16; In der Urkunde StABa A 120 L 134 Nr. 899 vom 31. Juli 1527 zeigt sich, dass die Gangolfer Höfe in den umliegenden Dörfern zuerst nach Hollfeld ablieferten und der Propst zusätzliche Abgaben zu zahlen hatten. Dort musste Weigand, Bischof von Bamberg (amt. 1522-1556), eine Regelung finden, die die Vergütung eines Kainacher „armenmans“ des Propstes von St. Gangolf, der für diesen die Abgaben auf seinen Hof „gein Holvelt furet und seinem verweser dieselben daselbsten antwortet“, in Form von Roggenbroten betrafen.

${ }^{804}$ Guttenberg: Urbare und Wirtschaftsordnungen. 1969. S. 14.

${ }^{805}$ Anhang Karte 2: Pfründengut. 
Den ersten tage ferdt man auf das gebirg gen Schederndorf, ${ }^{806}$ Welckendorf, ${ }^{807}$ Stadelhofen ${ }^{808}$ und Eichenhull ${ }^{809}$ und wartet den zins 17 seck.

Den andern tag ferdt man gen Reuaperg, ${ }^{810}$ Dreusendorf ${ }^{811}$ und Habstall ${ }^{812}$. Suppen 18 seck.

Den dritten tage ferdt man gen Braitenlesa ${ }^{813}$ und Zochareuth ${ }^{814}$ suppen 18 seckh.

Den virten tage ferdt man gen Durnhof ${ }^{815}$ und Tiefenlosa ${ }^{816}$ suppen 18 seckh.

Den funften tag ferdt man gen Schressendorf ${ }^{817}$ suppen 18 seck.

Den sechsten tage ferdt man gen Welchendorf ans wasser ${ }^{818}$ nach mittag gen Hoefen ${ }^{819}$ und Mochadorf ${ }^{820}$ kein supp 12 seckh.

Den siebenden tage ferdt man gen Dreunitz ${ }^{821}$ und Wiesendtfels ${ }^{822} 6$ seck.

Den achten tage ferdt man gen Pilgadorf ${ }^{823} 10$ seck. ${ }^{824}$

In diesem „Hollfelder-8-Tage-Programm“ als Zeugnis des praktischen Ablaufs der Propsthofverwaltung folgt der Leser dem Verwalter beinah lückenlos durch die Umgebung Hollfelds. Die Reihenfolge der aufgezählten Orte wird anschließend in den Registern, die die Einkünfte aufzählen, strikt eingehalten. Dadurch konnten Ortschaften allein an ihrer Lage innerhalb der relativen Nachbarschaft zu anderen Ortschaften identifiziert werden. Der Propstvogt agierte als selbständiger Verwalter, der nach den in den Güterverzeichnissen festgelegten Bestimmungen die Einzelerträge einnahm. Jedoch werden hier, ganz nach der Eigenart der urbariellen Aufzeichnungen, ausschließlich die Ablieferungspflichten der einzelnen Ortschaften, jedoch nicht die Gesamter-

\footnotetext{
${ }^{806}$ Schederndorf (Gde Stadelhofen, Lk Bamberg).

${ }^{807}$ Wölkendorf (Gde Stadelhofen, Lk Bamberg).

${ }^{808}$ Stadelhofen (Lk Bamberg).

${ }^{809}$ Eichenhüll (Gde Stadelhofen, Lk Bamberg).

${ }^{810}$ Rauhenberg (Gde Wiesenttal, Lk Forchheim).

${ }^{811}$ Draisendorf (Gde Wiesenttal, Lk Forchheim).

${ }^{812}$ Hochstall (Gde Aufseß, Lk Bayreuth).

${ }^{813}$ Breitenlesau (Gde Waischenfeld, Lk Bayreuth).

${ }^{814}$ Zochenreuth (Gde Aufseß, Lk Bayreuth).

${ }^{815}$ Dörnhof (Gde Aufseß, Lk Bayreuth).

816 Tiefenlesau (Gde Hollfeld, Lk Bayreuth).

${ }^{817}$ Schressendorf (Gde Plankenfels, Lk Bayreuth).

${ }^{818}$ Welkendorf (Gde Hollfeld, Lk Bayreuth).

${ }^{819}$ Höfen (Gde Hollfeld, Lk Bayreuth).

${ }^{820}$ Moggendorf (Gde Hollfeld, Lk Bayreuth).

821 Treunitz (Gde Königsfeld, Lk Bamberg).

822 Wiesentfels (Gde Hollfeld, Lk Bayreuth).

${ }^{823}$ Pilgerndorf (Gde Hollfeld, Lk Bayreuth).

${ }^{824}$ Im Zinsregister (1562-1578) in StABa Stift St. Gangolf, Akten und Bände Nr. 12 fol. 78 78'.
} 
zeugnisse der Höfe wiedergeben. ${ }^{825}$ Es wird damit nicht deutlich, wieviel von diesen Einnahmen der Propstvogt an die Propstei in Bamberg abzuliefern hatte und wieviel von den Einnahmen er als seine eigenen Einkünfte einbehalten konnte.

Die Versorgung des Propstvogtes wird aus anderen Verzeichnissen ersichtlich. Eine Urkunde des Anton, Bischofs von Bamberg (amt. 14311459), aus dem Jahr $1449^{826}$ gibt Einblick in die praktische Verwaltung des Propsthofes in Hollfeld. So lag diese mit all seinen Zuständigkeiten für das Umland in der Hand von zwei Amtsleuten, also Laien, die die Abgaben einnahmen und notfalls einforderten. Laut den Ausführungen des Bischofs wurden aber die Einnahmen des Propsthofes infolge der Zerstörung des Gebietes durch die Hussiteneinfälle geschmälert, sodass die regelmäßigen Gottesdienste in der Hollfelder Gangolfkirche wie auch im Stift in Bamberg gefährdet waren. Daran wird die Bedeutung des Hollfelder Propsthofes und die Konzentration der Gangolfer Besitzungen in diesem Raum deutlich. Bischof Anton inkorporierte dem Stift in Bamberg nun also die Kaplanei von Hollfeld und bestimmte einen Priester aus der Mitte der Gangolfer Kanoniker zum Inhaber des Kaplanatamts, der die Aufgaben der beiden Amtsleute zu übernehmen hatte. Deren Einnahmen kamen nun direkt dem Stift zugute. Diese Inkorporation der Kaplanei wurde in einem Statut festgehalten, das die Besetzung des Kaplans von Hollfeld durch den Propst von St. Gangolf regelte. ${ }^{827}$

Die Versorgung des Verwalters eines Propsthofes, in den Quellen auch Kaplanatszehnt genannt, kann für Hollfeld im 16. Jahrhundert aufgrund eines „Urbars“ des Propstes Erasmus Neustetters (amt. 15651594) nachvollzogen werden. So zog der Hollfelder Propstvogt seine

\footnotetext{
${ }^{825}$ Näheres dazu in Guttenberg: Urbare und Wirtschaftsordnungen. 1969. S. 16.

${ }^{826}$ Bischöfliche Urkunde vom 17. November 1449 in StABa A 120 L 133 Nr. 876.

827 „Decanatum vero scholastriam, custodiam, cellerariam ecclesie nostre et capellanatum sancti Gangolphi in Holveld nullis quam canonicis capitularibus eiusdem ecclesie habere nec alicui possidenti alterum eorum permutare licebit preter consensus capituli nostri vel maioris eius partis.“ im Statut Nr. 10 „De non dando canonicatu necnon de collatione canonicatuum praebendarum et vicariarum ac dispossitione officiorum ecclesie nostre" im Statutenbuch in StABa Stift St. Gangolf, Akten und Bände Nr. 130 fol. 65‘.
} 
Einkünfte aus den Orten Wohnsdorf (Gde Hollfeld, Lk Bayreuth), Hainbach (Gde Hollfeld, Lk Bayreuth) und Meuschlitz (Gde Plankenfels, Lk Bayreuth) sowie Einnahmen aus einem einzelnen Hof, genannt curia lochnerin, in Hollfeld. ${ }^{828}$ Er bezog die Hälfte dieser Einnahmen. ${ }^{829}$ Die Einnahmenmenge des Propstvogts, angegeben in Hollfelder Maß, bewegte sich in den Jahren 1562 bis 1568 zwischen 66 Sümmer $^{830}$ und 82 Sümmer für Roggen, Gerste, Hafer und Weizen, wovon Hafer den größten und Weizen den kleinsten Teil ausmachten. Es ist auffällig, dass die Orte des Kaplanatzehnts sich nicht in der obenzitierten Auflistung des „Hollfelder-8-Tage-Programms“ wiederfinden. Diese Trennung zwischen Einnahmen für die Propstei und eigenen Einkünften des Hollfelder Propstvogtes birgt aufschlussreiche Informationen für die Analyse der verschiedenen Besitzkomplexe des Stiftes, denn die Erwähnung der Orte Wohndorf, Hainbach und Meuschlitz deuten dem folgend immer auf das Propstverwaltungsamt Hollfeld hin, wodurch eine Zuordnung zu der betreffenden Teilprovenienz möglich wird.

\subsubsection{Propsthof in Gesees}

Ebenfalls als größerer Propsthof des Stifts St. Gangolf fungierte der Ort Gesees (Lk Bayreuth). Diese Ortschaft findet sich weit außerhalb des Hollfelder Einzugsgebiets und gehörte in das Einflussgebiet der Stadt Bayreuth. ${ }^{831}$ Während der Großteil der vom Propst verwalteten Besit-

\footnotetext{
${ }^{828}$ Im Zinsregister (1562-1578) in StABa Stift St. Gangolf, Akten und Bände Nr. 12 fol. 118-118‘ (das Jahr 1562), fol. 121'-122 (1563), fol. 125-125‘ (1564), fol. 128‘-129 (1565), fol. 124'-125 (1566), fol. 139-140 (1567), und fol. 144-145 (1568).

829 „Caplanat zehendt. Daran ein probstverwalter zu Holveldt den halbentheil han“ im Zinsregister (1562-1578) in StABa Stift St. Gangolf, Akten und Bände Nr. 12 fol. 118.

${ }^{830}$ Als Sümmer oder auch Scheffel wurde ein Hohlmaß zur Messung von Schüttgütern bezeichnet, welches auf das dazu verwendete Gefäß, meist einen Korb, zurückgeht. In Deutsches Wörterbuch von Jakob und Wilhelm Grimm: Art. „Sümmer“. Bd. 20 (1942). Sp. 1077.

${ }^{831}$ Wilhelm Müller lässt sich sogar zu der fragwürdigen Behauptung hinreißen, dass die Bamberger Gärtner der Theuerstadt in Bamberg und die Bauern des Hummelgaus, zu dem Gesees gehörte, eine "volksmäßige Sonderstellung” teilten. Wilhelm Müller: Der Hummelgau. Ein Beitrag zur geschichtlichen Landschaftskunde Oberfrankens. In: Archiv für Geschichte von Oberfranken 36,1 (1952). S. 81-128, hier: S. 124. Außerdem setzt er den „Hummelgau“ und „Hundsbühl“ semantisch in Verbindung. Ebd. S. 106.
} 
zungen um Hollfeld herum gruppiert waren und auch von dort aus organisiert wurden, lag der Ort Gesees mit seinen beyligenden dorfern daselbsten ${ }^{832}$ namens Forkendorf (Gde Gesees, Lk Bayreuth), Gosen (Gde Haag, Lk Bayreuth), Obernschreez (Gde Haag, Lk Bayreuth) und Rödensdorf (Gde Bayreuth) ausserhalb des Besitzschwerpunkts um Hollfeld. Wohl auch aus logistischen Überlegungen heraus wurde Gesees daher als eigener Propsthof ausgebaut. Die Verwaltung der Güter um Gesees erfolgte über die Propstei, jedoch diente Hollfeld als Zwischenstation. So wurden die Einnahmen aus Gesees, die laut den Zinsregistern des 16. Jahrhundert ausschließlich aus Getreidelieferungen (Erbsen, ${ }^{833}$ Gerste, Weizen und Hafer) bestanden, in Hollfeld gesammelt und anschließend von dem Propstvogt mit anderen Einnahmen nach Bamberg verbracht. ${ }^{834}$ Die Abgaben an Weizen standen dem Dekan und dem Kapitel zu, was aus der Cautio des Propstes Melchior Truchseß von 1489 hervorgeht:

Wir sollen und wolln auch die genanten dechant, capitel, chorherrn und personen des obgenanten stiefts in gemeyn und besunder ungehindert lassen an allen iren zehenden, zynsen, gulten und obleyen die sie in unser probstey dorfern und gutern haben, und sunderlich an allem weytzs der ierlich an einem dritteyl zum Gesess und anderswo in unser probstey gefellet und mag gesamet werden, der ine auch zu ken pfrundtn in gemein zugehort. 835

Dies wurde bereits 1466 in der Remissio des Kapitels an den Propst Gumprecht Fabri (amt. 1468-1478) angesprochen:

Auch uns lassen volgen allen weiz der auf der genanten propstey man gesamet werden, zuvordn der da gefellet uff den dritteil zum Geses und allen andern zehenten der oftgenanten probsteyen. ${ }^{836}$

Nicht immer war diese Vereinbarung unumstritten. Paul Neydecker, Propst des Stifts St. Gangolf (amt. 1516-1565), beispielsweise erklärte

832 Zinsregister (1562-1578) in StABa Stift St. Gangolf, Akten und Bände Nr. 12 fol. 98-98'. 833 "Erbes“.

${ }^{834}$ Näheres dazu in „summarum des jerlichen einkommens und zins der probstey s. Gangolfs stieft in der Teuerstat bey Bamberg ufm gebirg, in der stat Holveldt auf dem lande dobey, sampt dem drithail bau zu Geses bey Bareudt, alles vermoge des registers zuhauf gezogen“ im Zinsregister (1562-1578) in StABa Stift St. Gangolf, Akten und Bände Nr. 12 fol. $103^{\prime}$.

${ }^{835}$ Im Lehenverzeichnis (1489-1494) in StABa Stift St. Gangolf, Akten und Bände Nr. 123 fol. 3 .

${ }^{836}$ In den Lehenprotokollen des Propteiverwaltungsamts Hollfeld (1417-1576) in StABa Stift St. Gangolf, Akten und Bände Nr. 119 fol. 53’. 
sich in der Cautio zu seinem Amtsantritt vor dem Kapitel mit dem althergebrachten Inhalt einverstanden, die jährlichen Weizenabgaben aus dem Drittel der Güter in Gesees und anderen Propsteigütern an das Stift abzugeben und den Dekan und das Kapitel an diesen Rechten weiterhin ungehindert teilhaben $\mathrm{zu}$ lassen. ${ }^{837}$ Jedoch klagte derselben Propstes vor Weigand, Bischof von Bamberg (amt. 1522-1556), im Jahr 1528:

Auch des waytz so von dem dritteil pau etlicher veldung oder hofs des dorfs zum Gesees bey Bayreut gelegen jerlichen gefallen, er probst inen dechant und capitel volgen zulassen schuldig were, des aber er probst zu volstrecken und thun nit schuldig vorgehabt, sich auch mit brieflichen urkhunden und des waytz halben auch mit langherekomender possession und gewerhe auch prescription des bede, korn ${ }^{838}$ und waytz, ime seiner probstey und nachkomen allein gehorig und von recht zugepuren sollten. $^{839}$

Während jedoch das bischöfliche Urteil an der Zahlung des Korns an den Kustos nach althergebrachter Gewohnheit festhielt, sollten die Passagen in den zukünftigen Cautiones der Pröpste ausgelassen und der Propst von diesen Zahlungen an das Kapitel befreit werden. ${ }^{840}$ Doch schon Neydeckers Nachfolger im Propstamt, Erasmus Neustetter genannt Stürmer (amt. 1565-1594), versprach in seiner Cautio zu seinem Amtsantritt im Jahr 1565 erneut, die Weizenabgaben aus dem Drittel der Güter in Gesees an das Kapitel wieder einzuführen. ${ }^{841}$

Die Sonderstellung der bayreuthischen Orte als Güter des Bamberger Stifts St. Gangolf spiegelte sich auch in der Bayreuthischen Überlie-

\footnotetext{
${ }^{837}$ AEB Rep. I Pfarrei St. Gangolf U 826.

838 Gemeint sind die Kornabgaben an den Kustos zur Nutzung des Gangolfer Getreidekastens, gegen welche Paul Neydecker in seiner Klage ebenfalls aufbegehrt. Näheres zu diesen Abgaben im Kapitel 6.3.3.2 Pröpstische Abgaben an den Kustos.

${ }^{839}$ Urkunde vom 25. September 1528 in StABa A 120 L 133 Nr. 867. Die Differenzen darüber schwelten schon länger. So findet sich im Kopialbuch des Stifts St. Gangolf die Abschrift einer Urkunde vom 26. Februar 1527, worin dokumentiert wird, dass sich das Kapitel in dieser Sache mit den Kanonikern der Bamberger Stifte St. Stephan und St. Jakob abgesprochen hat. StABa Stift St. Gangolf, Akten und Bände Nr. 3 fol. 207-207‘

840 „Nemblich das oftgedachter waytz so von dem dritteil paw zum Geses jerlichen gefallen wurde oder machte, sollte inen dechant und capitel alleyn volgen und zusteen, gantz untrefftig und unpundtlich auch tod und abesein und in kunftigen dergleichen cautionibus der nachkomenden probst ausgelassen werden“ in StABa A 120 L 133 Nr. 867. ${ }^{841}$ Urkunde vom 27. Januar 1565 in StABa A 120 L 131 Nr. 732.
} 
ferung wieder, wo in einem Landbuch aus dem 15. Jahrhundert unter der Kategorie „Gesees“ Folgendes zu lesen ist:

Item die brobstey von Tewerstat ze Bamberg hat aus etlich den pesten eckern des obgenanten dorfes ein driteil, die sein pisher in eins erber mans stadel, genant gampeler ${ }^{842}$, gefürt und gesamet worden. ${ }^{843}$

Wie Caroline Göldel anhand von Vergleichen der Güterbeschreibungen im Landbuch des Amts Bayreuths und der Güterverzeichnisse des Stifts St. Gangolf in Bamberg feststellte, beschränkte sich dieser driteil nicht nur auf vom Stift selbst verliehene Güter. Der Propst schien vielmehr zusätzlich Ansprüche auf Einnahmen aus Gütern der markgräflichen Verwaltung gehabt zu haben. ${ }^{844}$

\subsubsection{Verteilungsmodalitäten des Pfründenguts}

Aufgrund der identifizierten Propsthöfen des Stifts St. Gangolf konnte die Bedeutung des Propstes für die Verwaltung des Pfründengutes deutlich gemacht werden. Doch wie wurden die Einnahmen aus diesem Besitzkomplex verwendet? Wieviele Einzelpfründen gab es und welche Größenordnung hatten sie?

Die Verteilungsmodalitäten werden in den Güterverzeichnissen nicht thematisiert und wichtige Überlieferungen zur Rekonstruktion der Verteilungspraxis, wie Pfründenordnungen oder eine Aufstellung der Präbendalserviten, fehlen in der Überlieferung des Stifts St. Gangolf. Jedoch enthalten die Güterverzeichnissen vereinzelt Urkundenabschriften, die Einblicke in die Praxis der pröpstlichen Cautiones und der kapitlischen Remissiones bieten und somit die Überlieferung aus Originalurkunden bereichern.

${ }^{842}$ Von Thomas Pöhlmann als Hans Gampler identifiziert, der um 1400 den halben Zehnt über das Dorf Gesees innehatte und davon neben der Propstei des Stifts St. Gangolf auch der markgräflichen Herrschaft abgabepflichtig war. In Thomas Pöhlmann: Das Amt Bayreuth im frühen 15. Jahrhundert. Das Landbuch B von 1421/24, eine spätmittelalterliche Quelle mit Erläuterungen (Bayreuther Arbeiten zur Landesgeschichte und Heimatkunde, Bd. 9). Bayreuth 1992. S. 326-327.

${ }^{843}$ Ebd. S. 326.

${ }^{844}$ Göldel: Der Liber feudalis. 1996. S. 13-14. 


\subsubsection{Grundstock der Pfründenansprüche}

Bereits in den Jahren 1307 und 1328 sind Streitigkeiten zwischen dem Gangolfer Propst und seinem Kapitel überliefert, die die Pfründenansprüche des Stifts thematisierten. ${ }^{845}$ In beiden Fällen bestätigte der Bischof dem Kapitel Ansprüche auf Zahlungen von 53 Pfund Denare weniger vier Schillingen zweimal jährlich, jährliches Kornbrot, 19 Scheffel Weizen, 143 1/2 Scheffel Hafer, den gesamten Zehnt zu Hohenstat ${ }^{846}$ als Ersatz für wohl ansonsten anstehende Weinlieferungen, von dem das Kapitel dem Propst vier Pfund trinkgeld retour schuldete. Im Jahr 1328 erkämpfte sich das Kapitel zusätzlich noch Ansprüche auf 28 Fastnachtshühner und 28 Käseleiber.

Besonders was die Geldzahlungen und die Abgaben an Käse und Hennen betraf, fällt eine Konstanz der Werte bis ins 16. Jahrhundert hinein auf. 53 Pfund Pfennige zweimal jährlich (beziehungsweise 106 Pfund Heller zweimal jährlich oder 212 Pfund Heller einmal jährlich) ${ }^{847}$ sowie 28 Fastnachtshennen und 28 Weihnachtskäse finden sich für den 11. November $1466,{ }^{848}$ für den 17. Mai $1489,{ }^{849}$ für den 30. Juli $1516^{850}$ und für den 27. Januar 1565. ${ }^{851} \mathrm{Im}$ Falle des Getreides sind die Konstan-

${ }^{845}$ Urteil des Wulfing, Bischof von Bamberg (amt. 1304-1318), vom 21. Februar 1307 in der Differenz zwischen Friedrich von Truhendingen, Propst des Stifts St. Gangolf (amt. 1302-1318), gegen den Dekan und das Kapitel des Stifts wegen Abgaben von Geld, Getreide und Wein. In Looshorn: Die Geschichte des Bisthums Bamberg, Bd. 3. 1891. S. 49; und Urteil des Heinrich, Bischof von Bamberg (amt. 1324-1328), und Herman, Abt des Klosters Michelsberg, vom 23. März 1328 in der Differenz zwischen Friedrich von Hohenlohe, Propst des Stifts St. Gangolf (amt. 1323-1351), gegen den Dekan und das Kapitel wegen Abgaben von Geld, Getreide, Wein, Hühnern und Käse in Ebd. S. 127-128.

${ }^{846}$ Gemeint ist wohl Höchstadt am Main (Lk Lichtenfels), das jedoch in späteren Jahren weder als Propst- noch als Obleigut des Stifts St. Gangolf erwähnt wird.

${ }^{847}$ Ein Heller hatte in diesem Zusammenhang den Wert eines halben Pfennigs.

${ }^{848}$ Remissio des Kapitels und Dekan Konrad Hartung (amt. 1453-1474) vom 11. November 1466 in den Lehenprotokollen des Propteiverwaltungsamts Hollfeld (1417-1576) in StABa Stift St. Gangolf, Akten und Bände Nr. 119 fol. 53; Hier fehlen jedoch die Ansprüche auf Käse und Hennen.

849 Cautio des Propstes Melchior Truchsess (amt. 1489-1493) vom 17. Mai 1489 im Lehenverzeichnis (1489-1494) in StABa Stift St. Gangolf, Akten und Bände Nr. 123 fol. 2.

${ }^{850}$ Cautio des Propstes Paul Neydecker (amt. 1516-1565) vom 30. Juli 1516 in AEB Rep. I Pfarrei St. Gangolf U 826.

851 Cautio des Propstes Erasmus Neustetter (amt. 1565-1594) vom 27. Januar 1565 in StABa A 120 L 131 Nr. 732. 
ten weniger augenfällig. Bis ins 16. Jahrhundert hinein wurden die Weizenabgaben ausschließlich als ein Drittel der Propsteinkünfte, besonders aus Gesees, beziffert, ohne genaue Maßangaben zu nennen. Die Haferkontigente beliefen sich noch in den Jahren 1516 und 1565 auf 144 Scheffel $^{852}$ und entsprachen damit der Größenordnung des 14. Jahrhunderts. Das in den Quellen des 14. Jahrhunderts erwähnte Kornbrot, also Brot aus Roggen, ${ }^{853}$ wird in den späteren Jahrhunderten durch Roggenkontingente von 94 Scheffel Roggen jährlich ersetzt. ${ }^{854}$ Diese Abgaben aus Propstgütern von 53 Pfund Pfennig, 28 Weihnachtskäse, 28 Fastnachtshennen, größere Weizenabgaben, 144 Scheffel Hafer und 94 Scheffel Roggen bildeten den Grundstock der Gangolfer Pfründen vom 14. bis zum 16. Jahrhundert, welcher offensichtlich quantitativ keinen großen Schwankungen unterlag.

\subsubsection{Pröpstische Abgaben an den Kustos}

Bis zum 16. Jahrhundert wurde der Grundstock der pröpstischen Abgaben an das Kapitel erweitert und durch Sonderregelungen angereichert, meist um Misstände zu beseitigen oder auf Streitigkeiten zu reagieren. Am deutlichsten wird dies in den Regelungen rund um den Getreidekasten des Stifts in Bamberg. Am 8. November 1449 reagierte Anton, Bischof von Bamberg (amt. 1431-1459), auf die Klage des Gangolfer Kapitels, wonach der Hof am Kreuzgang des Stift, welcher vom

852 „Hundert vier und vierzigk scheffel haberns auf sand Merteins tag ode ehe“ in der Cautio des Propstes Melchior Truchsess (1489-1493) vom 17. Mai 1489 im Lehenverzeichnis (1489-1494) in StABa Stift St. Gangolf, Akten und Bände Nr. 123 fol. 2; und in ähnlichem Wortlaut in der Cautio des Propstes Paul Neydecker (amt. 1516-1565) vom 30. Juli 1516 in AEB Rep. I Pfarrei St. Gangolf U 826; und der Cautio des Propstes Erasmus Neustetter (amt. 1565-1594) vom 27. Januar 1565 in StABa A 120 L 131 Nr. 732.

${ }^{853}$ Deutsches Wörterbuch von Jakob und Wilhelm Grimm: Art. „Kornbrot“. Bd. 11 (1868). Sp. 1821.

854 „Vir und newnzigk scheffell korns ye auf sand Michels tag oder davor" in der Cautio des Propstes Melchior Truchsess (amt. 1489-1493) vom 17. Mai 1489 im Lehenverzeichnis (1489-1494) in StABa Stift St. Gangolf, Akten und Bände Nr. 123 fol. 2; und in ähnlichem Wortlaut in der Cautio des Propstes Paul Neydecker (1516-1565) vom 30. Juli 1516 in AEB Rep. I Pfarrei St. Gangolf U 826; und in der Cautio des Propstes Erasmus Neustetter (amt. 1565-1594) vom 27. Januar 1565 in StABa A 120 L 131 Nr. 732. 
Propst als Kasten zur Einlagerung des Gertreides genutzt wurde, baufällig wäre, der Propst daher das Getreide an anderer Stelle lagere und so der Kontrolle des Kapitels bei der Pfründenvergabe entging. ${ }^{855}$ Johann Kautsch, Propst des Stifts St. Gangolf (amt. 1444-1462), verpflichtete sich daraufhin zum Neubau des verfallenen Hofes mit Kosten über 300 Gulden und erklärte sich nach Intervention des Bischof bereit, diesen Neubau samt dessen Gewinnen der Kustorei des Stifts St. Gangolf zu unterstellen, um die bisher mangelhafte Beleuchtung des Chores zur Winterzeit und den damit einhergehenden Beschränkungen für den Gottesdienst entgegenzuwirken. ${ }^{856}$ Der Propst hatte dem Kustos des Stifts also nun jährlich fünf Scheffel Roggen ${ }^{857}$ als Extraration zu zahlen, damit er den Getreidekasten nutzen durfte. Die Verwendung dieser Sondereinkünfte war streng vorgeschrieben und sollten dazu dienen Wachslichter von Michaelis bis Ostern zu kaufen. Obwohl im Jahr 1449

855 „Wir Anthonius von gotes gnaden bischove zu Bamberg bekennen offenlichen mit disem briefe gen allermeniglichen, als vortzeiten bey unserm stifte zu Tewrstad ein probst bey und an dem creutzgange doselbst einen hofe und behausunge gehabt. Darein das korn und getreyde, das im von des stifts wegen $\mathrm{zu}$ gestanden, hat geschutet und gelegt und dovon den korheren doselbst vor allen dingen ir pfrunde gegeben und bezalt hat. Dasselb haus nu vor langentzeiten zu gangen und zunicht worden ist, do dourch dem stifte berlicher schade geschehen zwischen ietzutzeiten dem probst und den corheren vil unwillens aufgestanden ist, indem das ein yegliche probst der ietzutzeiten gewesen ist, solche getreid und korn nicht bey dem stifte, sunder anderswo, wo im das fuglichen gewesen ist, gefurt und geschutet hat und den corheren ir pfrunde bezalt und gegeben vom dem, das im gevallen hat. Doran sie dann kein genugde gehabt, sunder einen probst in solchem oft und dick geverlichkeit zugemessen haben“ in StABa A 120 L 131 Nr. 753.

856 „Als wir des wol unterrichtet sind, hat uns der genant probst zuversteen geben, wie sunder gros breche und mangel in dem genanten stift zu Teurstad sey. Nemlichen an dem das die custerey, die den chor beleuchten sol, wintertzeit so viel nicht hab noch vermuge, das sie zu der metten den heren, die do singen und lesen sollen, liechter geben mocht. Von solchs mangels wegen ir manicher ungesungen und ungelesen in der metten sitzen bleiben muss, do mit der gotisdinst gar sewmlich volbracht wirt und darumb in ewigen zeiten zuverkomen, hat uns der oftgenant probst aus sunder andacht mit fleis gebeten, das wir im vergonnt haben, als wir im auch das vergonnen in craft ditz briefs, das er das genant haus, das er also pawen sol und will, ubergeben muge des genanten sifts custrey“ in StABa A 120 L 131 Nr. 753.

${ }^{857}$ Es lag in dem Ermessen des Propstes, ob er statt der fünf Scheffel Roggen 110 Gulden an den Kustos bezahlte: „doch behalt wir einem yeglichen probst, der nach disem kumt, die wilkur und freiheit, das er mogen und macht hat, alle iar die obgenanten funf scheffel korns von der custrey ab zukaufen umb hundert und zehen gulden“ in StABa A 120 L 131 Nr. 753. 
festgelegt wurde, das solchs hinfur von einem ieglichen probst, der nach im kumet, also unverbrochenlich gehalten werde, ${ }^{858}$ wurde die Vereinbarung schon wenige Jahre später angefochten. In einem Urteil des Bamberger Bischofs Georg (amt. 1459-1475) vom 16. Juni 1466 konnte Gumpert Fabri, Propst von St. Gangolf (amt. 1468-1478), ein Abrücken des Kapitels von der Regelung einfordern. Zu seiner Begründung führte er die hohen Kosten des Neubaus von mehr als 300 Gulden an, die Johann Kautsch zwar verbraucht, den Bau jedoch nicht zuende gebracht hätte. Daher befürchtet er, Gumpert Fabri, nun ohne erwartbare Einkünfte zu veramen und bat daher den Bischof um Nachsicht. ${ }^{859}$ Dieser sah die pröpstlichen Sorgen als begründet an und befreite ihn von der Zahlung der fünf Scheffel Roggen an die Kustorei von St. Gangolf. ${ }^{860}$ Interessant ist, dass sich ebenjener Gumpert Fabri laut der Remissio des Konrad Hartung, Dekan von St. Gangolf (amt. 1453-1474), und des Kapitels vom 11. November 1466 im Rahmen seines Amtsantritts nach laut und inhaldt einer caution, die wir von dem genanten unsern herrn dem probst haben, daruber sagend, auch jerlichen ausrichten und bezalen soll, funf gulden $z u$ einem jartag, maister Johansen Kautschen seeligen, etwan auch probst daselbst ${ }^{861}$ bestätigen ließ. Hier ist zwar nicht die Rede von einer Zahlung zur Nutzung des Getreidekastens, jedoch stimmen sowohl der Betrag als auch die Verwendung durch die Kustorei, welche die Nekrologe und damit die Begehung von Jahrtagen betreute, überein.

${ }^{858}$ StABa A 120 L 131 Nr. 753.

859 „Hat uns der obgenant unser probst berichtet, das solch empfremden und beswerunge des obgemelten hawse der probsteye ein groser abgangk und geringerunge sey, nach dem der genanten probsteye dargegen kein erstattung noch ergetzunge sey geschehen, so hette auch der genant Kautsch die drewhundert guldein, der er sich nach laut der gemelten brives verpflichtet hat, nicht sunder vast mynder verbawet mit ertzelunge ander mer ursachen und uns als den obersten fursten und bischove des landes und lehenherren solcher probsteye angerufen und ersucht, im dorfune widerbrengung und versehung $\mathrm{zu}$ tun“ in StABa A 120 L 131 Nr. 757.

860 „Das derselbe brive im furbasser weder craft noch macht haben und dem obgenanten unserm probst und seiner probsteye an iren gerechtigkeiten keinen schaden fugen noch bringen und auch derselbe probst hinfure nicht pflichtig sein sol, die obgenanten fonf scheffel korns also ierlich zugeben“ in StABa A 120 L 131 Nr. 757.

${ }^{861}$ In den Lehenprotokollen des Propteiverwaltungsamts Hollfeld (1417-1576) in StABa Stift St. Gangolf, Akten und Bände Nr. 119 fol. 53’. 
Eine rege Bautätigkeit am Kreuzgang, in dessen Nachbarschaft sich der Kautschhof befand, bestärkt den Eindruck, dass nach einem allgemeinen Verfall der Stiftsgebäude nun deren Erneuerung angestrebt wurde. So ist unter der Wirkung von Heinrich Glantz, Dekan des Stifts St. Gangolf (amt. 1486-1491), eine Notiz aus dem Umfeld der Thesaurarsüberlieferung überliefert, die die genauen Anweisungen des Kapitels an einen Paul Steinmetz zur Ausgestaltung des neuen Kreuzganges belegt. ${ }^{862}$ In den Cautiones des Nachfolgers im Propstamt Melchior Truchsess (amt. 1489-1493), Paul Neydecker (amt. 1516-1565) und Erasmus Neustetter genannt Stürmer (amt. 1565-1594) findet sich die ursprüngliche Regelung über den Kautschhof unverändert wieder, ${ }^{863}$ obwohl Paul Neydecker einige Jahre nach seinem Amtsantritt versuchte, aus der Verpflichtung zur Abgabe der fünf Scheffel Roggen entbunden zu werden. Dies wurde ihm jedoch durch das Urteil des Bischofs Weigand (amt. 1522-1556) am 25. September 1528 verweigert. ${ }^{864}$

Der Getreidekasten an der Stiftskirche in Bamberg war nicht die einzige Möglichkeit des Kapitels, Getreide zu lagern. So versprach der Propst seit Ende des 15. Jahrhunderts in seiner Cautio, dass er auf

${ }^{862}$ Diese Notiz findet sich undatiert und unfoliiert am Anfang der Thesaurarsrechnungen (1511-1570) in StABa Stift St. Gangolf, Akten und Bände Nr. 191. Näheres zur Auswertung der Quelle im Kapitel 4.2.6 Obleier und Fabrikamt.

863 „Wir sollen und wollen auch ierlich solich getreyde von der brobstey gefallende und hievor bermelt ist auf und in das haws das meister Johann Kawtsch, unser vorfare seliger von newen gepawet hat, schutten das der custorey, des obgemelten stiefts zusteet und gehoret, also das wir alle iare ierlichen einem custor zu zeyten funf scheffel korns von demselben haws reichen und geben sollen, davon der chor von Michaelis bis auf Ostern mit wachslichten genugsamlich belewcht soll werden. Doch soll es zw unser wilkure steen, ierlich solich obgenant funf schoffel korns mit hundert und zehen gulden abzulosen, das alles in einem briefe damit herrn Anthonius seligen bischofs meister Johanns Kawtschen seligen und des vorgenanten capitels insigel versigelt ist" im Lehenverzeichnis (1489-1494) in StABa Stift St. Gangolf, Akten und Bände Nr. 123 fol. 2; und mit ähnlichem Wortlaut in der Cautio des Propstes Paul Neydecker (amt. 1516-1565) vom 30. Juli 1516 in AEB Rep. I Pfarrei St. Gangolf U 826; und in der Cautio des Propstes Erasmus Neustetter (amt. 1565-1594) vom 27. Januar 1565 in StABa A 120 L 131 Nr. 732.

864 „Nemblich das nun hinfuro zu ewigen zeiten der Paulus Neydecker ytz und seine nachkomende probst oftgemelter probstey und stifts sant Gangolfs sollen von solcher probstey renten, gulten und zinsen jerlichen in ydes jars besonder reichen und geben yezuzeiten einem custor sant Gangolfs stift zu beleuchtung der metten zu winterzeit, wie auch hievor gescheen funf schoffell korns Bamberger mas dasselbig auch also zu leyten und volstrecken schuldig sein" in StABa A 120 L 133 Nr. 867. 
Wunsch der Kanoniker auch einen Kasten in Hollfeld oder eine Lagerstätte in dessen Nähe bedienen könne. ${ }^{865}$ Diese Flexiblität mit Ausrichtung auf die Stadt Hollfeld spricht dafür, dass der Prosptvogt in Hollfeld für die Anlieferung des Getreides an die Kanoniker zuständig war.

\subsubsection{Pröpstische Abgaben an den Keller}

Weitere Sonderzahlungen hatte der Propst an den Keller des Stifts St. Gangolf zu zahlen. Von dem gesamten Getreidekontingent von über 94 Scheffel Roggen und 144 Scheffel Hafer standen dem Keller 20 Sümmer zu. ${ }^{866}$ Es ist zu vermuten, dass diese 20 Scheffel ursprünglich als Bezahlung seiner Dienste als Immunitätsrichter aufgestellt wurden, was den Verweis auf die freie Ausübung seiner rechte und gewonheyten erklären würde.

865 „Das wir den erbern und geistlichen hern, dem dechant, capitel und chorherrn desselben stiefts von allen und iglichen derselben unser brobsteyzehenden, gulten, renten, zynsen hinfur dieweyl wir bey leben und brobst daselbst sein, alle iare und ydes iare besunder gein Bamberg auf iren casten, do sie uns hinbescheiden, an alle ir scheden antworten reichen und bezalen sollen [...] wer aber sach, das dy genanten dechant, capitel und chorhern von redlicher mercklicher sache und irer noturft wegen die egenanten summ getreides gult anderswohin haben wolten, und sie oder der mererteyl under ine uns das verkundigen, und des ermanen wurden auf sand Peters und Pauls tag oder ehe, so sollen und wollen wir ine soliche ire getreydgult aber an alle ir scheden antworten und schigken gein Holfelt oder ungeverlich in vier meylen darumb, dahin sie die haben wollen auf casten, die sie uns beweisen" in der Cautio des Melchior Truchsess (amt. 1489-1493) vom 17. Mai $1489 \mathrm{im}$ Lehenverzeichnis (1489-1494) in StABa Stift St. Gangolf, Akten und Bände Nr. 123 fol. 2; und mit ähnlichem Wortlaut in der Cautio des Propstes Paul Neydecker (amt. 1516-1565) vom 30. Juli 1516 in AEB Rep. I Pfarrei St. Gangolf U 826; und in der Cautio des Propstes Erasmus Neustetter (amt 1565-1594) vom 27. Januar 1565 in StABa A 120 L 131 Nr. 732.

866 „Und irem kelner ye in zweyntzigk summer ein summer fur geyßen von dem genanten getreyde und auch castensummer von allen zehenden $\mathrm{zu}$ der genanten brobstey gehorende, ausgenommen von zweien zehenden Cotzendorf und Stechendorf genant, davon man keyn castensummern pfligt zugeben, auch wollen wir denselbenn iren kelnern bey allen rechten und gewonheyten lassen bleyben, als vor alter herkommen ist" in der Cautio des Melchior Truchsess (amt. 1489-1493) vom 17. Mai 1489 im Lehenverzeichnis (1489-1494) in StABa Stift St. Gangolf, Akten und Bände Nr. 123 fol. 2; und mit ähnlichem Wortlaut in der Cautio des Propstes Paul Neydecker (amt. 1516-1565) vom 30. Juli 1516 in AEB Rep. I Pfarrei St. Gangolf U 826; und in der Cautio des Propstes Erasmus Neustetter (amt 1565-1594) vom 27. Januar 1565 in StABa A 120 L 131 Nr. 732. 
Während die Hennenlieferungen an Fastnacht und die Käselieferungen an Weihnachten erfolgten, empfing der Keller am Gründonnerstag Wein und Mandatbrot ${ }^{867}$ oder als Ersatz dafür 30 Schillinge, um das Mandatum durchzuführen. ${ }^{868}$ Die Art der Abgaben weist darauf hin, dass die heilige Messe an diesem Tag gesichert werden sollte.

\subsubsection{Pröpstische Abgaben an den Obleier}

Dem Obleier standen vom Propst dreieinhalb Pfund Pfennige zur Feier der Jahrtage des Stifts zu. Bei dieser Sonderregelung wird vage festgelegt, aus welchen Einnahmen sich das Geld speisen sollte: es handelt sich hier um den Zoll aus Hollfeld. ${ }^{869}$ Die Zolleinnahmen ergaben sich daraus, dass Hollfeld im Grenzgebiet zwischen dem Hochstift Bamberg und dem Markgraftum Bayreuth lag und zugleich als grenznaher Handelsstützpunkt Einnahmen generieren konnte. Die Zolleinnahmen beanspruchte der Propst des Stifts St. Gangolf und leitete einen Teil davon an das Stiftskapitel in Person des Obleiers weiter.

867 „Abgabe für die mit der Fußwaschung am Gründonnerstag und mit anderen Feiertagen verbundene Armenspeisung“ in Deutsches Rechtswörterbuch: Art. „Mandatbrot, Mandatenbrot“. Bd. 9 (1996). Sp. 103.

868 „Auch sollen und wollen auf den grundonerstag ierlichen $\mathrm{zu}$ dem mandat in demselben stieft irem kelner geben und antworten ein gross virteyl oder sechzehen mass des besten franckenweins, den man zu den zeyten zu Bambergk zu dem zapffen schenckt und feyl vindet, und darzu mandatbrot nach herkomender gewonheit oder dreyssig schilling heller" in der Cautio des Melchior Truchsess (amt. 1489-1493) vom 17. Mai 1489 im Lehenverzeichnis (1489-1494) in StABa Stift St. Gangolf, Akten und Bände Nr. 123 fol. 2-2'; und mit ähnlichem Wortlaut in der Cautio des Propstes Paul Neydecker (amt. 15161565) vom 30. Juli 1516 in AEB Rep. I Pfarrei St. Gangolf U 826; und in der Cautio des Propstes Erasmus Neustetter (amt. 1565-1594) vom 27. Januar 1565 in StABa A 120 L 131 Nr. 732.

869 „Wir sollen und wollen von dem zoll zu Holfelt oder ander der brobstey gulten und renten dem obleyer zu zeyten desselben stiefts jerlichen geben und ausrichten auf sand Michels tag, vierthalb pfundt Bamberger pfennig oder dafur vierzehen pfundt heller, die dafur angeslagen und gewirdet sein auf solich iartag, die dann in des genanten stiefts regeln begriffen sind“ in der Cautio des Melchior Truchsess (amt. 1489-1493) vom 17. Mai $1489 \mathrm{im}$ Lehenverzeichnis (1489-1494) in StABa Stift St. Gangolf, Akten und Bände Nr. 123 fol. 2; und mit ähnlichem Wortlaut in der Cautio des Propstes Paul Neydecker (amt. 1516-1565) vom 30. Juli 1516 in AEB Rep. I Pfarrei St. Gangolf U 826; und in der Cautio des Propstes Erasmus Neustetter (amt. 1565-1594) vom 27. Januar 1565 in StABa A 120 L 131 Nr. 732. 


\subsubsection{Einzelpfründen}

Die Cautiones und Remissiones geben keinerlei Auskünfte über die Aufteilung der oben beschriebenen pröpstischen Abgaben an das Kapitel des Stifts St. Gangolf in Einzelpfründen. Mit der Bezeichnung pfrunde war vielmehr die Gesamtheit der pröpstischen Abgaben an das Kapitel gemeint. ${ }^{870}$ Die Verteilung der pröpstischen Abgaben unter den einzelnen Kanonikern spielte für die Cautiones der Pröpste keine Rolle. Denn, obwohl der Wortlaut der betreffenden Statuten eine Aufteilung der Abgaben an Einzelpersonen hätten vermuten lassen, ${ }^{871}$ war der Propst nicht für die Zuteilung der Einzelpfründen zuständig. Für das Domkapitel stellte Guttenberg ganz und gar fest, dass das Pfründenvermögen der Domkanoniker generell nicht in Einzelpfründen aufgeteilt wurde, sondern als "geschlossene Vermögensmasse“ zu Händen des Propstes verblieb, der daraus den Kanonikern „Rentenbezüge“ zahlte. ${ }^{872}$

In der älteren Forschung wird allgemein angenommen, dass das Stift St. Gangolf 14 Einzelpfründen unterhielt. ${ }^{873}$ Jedoch bleibt die Herkunft der Information unklar. Tatsächlich wurde die Einteilung der

870 „Davon den korheren doselbst vor allen dingen ir pfrunde gegeben und bezalt hat“ sowie „und den corheren ir pfrunde bezalt und gegeben“ im Urteil des Anton, Bischofs zu Bamberg (amt. 1431-1459), vom 8. November 1449 in StABa A 120 L 131 Nr. 753; „das unser herr der probst nicht verkommern, verkaufen oder sonst empfrembden soll, bis uns ein gantz gengen beschehen sey unser pfrundt halben“ in der Remissio des Konrad Hartung, Dekan des Stifts St. Gangolf (amt. 1453-1474), und des Kapitels vom 11. November 1466 in den Lehenprotokollen des Propteiverwaltungsamts Hollfeld (1417-1576) in StABa Stift St. Gangolf, Akten und Bände Nr. 119 fol. 54.

871 „Statuimus perpetuo observandum quod praepositus ecclesie nostre pro tempore de singulis bonis decimis fructibus redditibus et proventibus praepositure ipsius ecclesie nostre tradere debeat et exolvere realiter singulos redditus capitulo et personis eiusdem ecclesie nostre dari solidos et persolvi ad praebendas nostras spectantes." im Statut Nr. 2 über den Propst im Statutenbuch StABa Stift St. Gangolf, Akten und Bände Nr. 130 fol. 56; und im Statutenbuch StABa Stift St. Gangolf, Akten und Bände Nr. 131 fol. 3-3“

${ }^{872}$ Guttenberg: Urbare und Wirtschaftsordnungen. 1969. S. 15.

873 Alle späteren Untersuchungen stützten sich auf die Aussage "In ea praeter praepositum quatuordecim praebendae pro totidem canonicis fundatae erant, quos inter etiam decanus caeterique dignitatibus conspicui numerabantur." in Ussermann: Episcopatus Bambergensis. 1802. S. 271. 
pröpstischen Abgaben an das Kapitel in Einzelpfründen auch von den Zeitgenossen selten thematisiert. Genaue Zahlen sind beispielsweise aus den Gangolfer Statuten nicht herauslesbar, obwohl es ein Statut gibt, das dezidiert die Verteilungspraxis der Pfründen behandelt. ${ }^{874}$ Darin werden zwar die genauen Termine zur Verteilung am Fest Philippi et Jacobi (1. Mai) und die Anwesenheitspflichten geregelt, jedoch keine Angaben zur Anzahl der Einzelpfründen gemacht.

Dass das Stift St. Gangolf tatsächlich 14 Einzelpfründen unter seinen Kanonikern verteilte, wird anderweitig deutlich, beispielsweise in der Obleimatrikel matriculum oblegiorum für die Jahre 1443 bis 1663 in Form einer Rechnung des Gangolfer Dekans Johann Schank (amt. 14321441) für das Jahr $1432 .{ }^{875}$ Dort führte er die Einnahmen von Roggen und Hafer des Kapitels durch pröpstische Abgaben und durch Zinseinnahmen, die der Keller einnahm, auf und stellte diesen die Verteilung der Einnahmen in Form von Pfründen und anderen Ausgaben gegenüber. Als Einnahmen berechnete Johann Schank 100 Scheffel und zweieinhalb $\AA^{876}$ Roggen, wovon 76 Scheffel vom Propst Thomas Graf von Wertheim (amt. 1417-1433) kamen und 24 Scheffel zweieinhalb ß durch den Keller von Propstgütern eingenommen wurden, und 101 Scheffel und drei Vierling Hafer, wovon 68 einhalb Scheffel vom Propst und 32 Scheffel zwei $ß$ und drei Vierling vom Keller kamen. ${ }^{877}$ Diese Angaben

874 "Capitulum decimum quintum de distributione et receptione fructuum prebendalium.“ als Statut Nr. 15 im Statutenbuch StABa Stift St. Gangolf, Akten und Bände Nr. 130 fol. 68 '.

875 Obleimatrikel (1433-1663) in StABa Stift St. Gangolf, Akten und Bände Nr. 192 fol. 2.

${ }^{876}$ Die Maßeinheit konnte nicht sicher identifiziert werden. Zu überlegen ist, ob es sich hierbei um ein Sümmer handeln könnte. Dieser hätte in dem Zusammenhang eine Wertigkeit gleich einem Vierling (nämlich ein Viertel Scheffel). Die Unterscheidung zwischen Sümmer und Vierling ist dadurch jedoch nicht geklärt. Außerdem ist die allgemeine Auffassung eher von einer Gleichwertigkeit des Scheffels und des Sümmers geprägt. Näheres dazu im Deutschen Wörterbuch von Jakob und Wilhelm Grimm: Art. „Sümmer“. Bd. 20. Leipzig 1942. Sp. 1077: „,nach der menge wird es meist dem scheffel gleichgesetzt“.

877 „Korn XXXII ${ }^{\circ}$ anno. Item LXXVI sch korns hat grave Thomas geben. Item XXIIII sch IIi $ß$ korns hat her Hans Fere kelner eingenumen von zehend und gutern der probstey. Summa $I^{\mathrm{c}}$ sch IIi $ß$ korns. Habern XXXII ${ }^{\circ}$ anno. Item LXVIIIi sch habern hat grave Thomas geben. Item XXXII sch II $§$ III virdling hat der genante kelner eingenumen von der probstey. Summa I'I sch III virdling." in der Obleimatrikel (1433-1663) in StABa Stift 
decken sich nicht mit den Kontingenten von 94 Scheffel Roggen und 144 Scheffel Hafer, die in den Cautiones genannt werden. Von den Einnahmen veranschlagte daraufhin der Dekan Johann Schank (amt. 14301441) neuneinhalb Scheffel Roggen als Ersatz für 15 Gulden an den Propst, wahrscheinlich zur Schuldentilgung, drei Gulden Kastenmiete und 16 Scheffel Roggen an die amptlewten. ${ }^{878}$ Der Rest von über 75 Scheffel und zwei Vierling Roggen sowie 101 Scheffel und drei Vierling Hafer werden nun in 14 Pfründen zu je fünf Scheffel, ein $§$ und eineinhalb Vierling Roggen sowie sieben Scheffel und dreieinhalb Vierling Hafer aufgeteilt, welche jedoch auch in Geld ausgezahlt werden konnten. ${ }^{879}$ Von diesen 14 Pfründen erhielten der Dekan und der Keller jeweils zwei, weiterhin bekamen fünf namentlich genannte Kanoniker jeweils eine Pfründe, das Amt der Fabrik war doppeltbepfründet und drei Pfründen konnten aufgrund von Abwesenheit der Kanoniker nicht verteilt werden. ${ }^{880}$

Wenn man bedenkt, dass man es hier mit einer Obleimatrikel zu tun hat, die also die Zuteilung der einzelnen Obleien an die Kanoniker nach Freiwerden durch Tod oder Amtsaufgabe eines Stiftsmitgliedes behandelte, wird deutlich, warum sich diese Notiz gerade dort finden lässt, während die Cautiones der Pröpste kein Wort darüber verlieren: Es lag nicht im Aufgabenbereich des Propstes, die vertraglich vereinbarten Abgaben an das Kapitel in Einzelpfründen aufzuzeilen. Dies wurde innerkapitlisch geregelt. Trotzdem behielt der Propst die Verwaltung des

St. Gangolf, Akten und Bände Nr. 192 fol. 2.

878 „Item VIIIIi sch korns gen ab fur die XV gulden die man graven Thomas widergeben müst, und fur III gulden an castenmiet dem münch. Item XVI sch korns den amptlewten leyen." in der Obleimatrikel (1433-1663) in StABa Stift St. Gangolf, Akten und Bände Nr. 192 fol. 2.

879 „Item von den uberigen LXXV sch II virdling korns und I'I sch III virdling habern geburt unter XIIII pfrund yeder pfrund V sch I ß Ii virdling korns und VII sch IIIi virdling habern oder an gelt [...]“ in der Obleimatrikel (1433-1663) in StABa Stift St. Gangolf, Akten und Bände Nr. 192 fol. 2.

880 „Nemlich dem genanten techant und kelner IIII pfrund, Ruthart [identifiziert als Scholaster Konrad Rudhart (amt.1432-1434)], Vipech [identifiziert als späterer Keller Nikolaus von Viepech (amt. 1440-1443), nachweisbar als Kanoniker seit 1419], Rampusch, Vachdorf, Grewlich, II pfrund der fabricken und III pfrund absentium die geteilt sein." in der Obleimatrikel (1433-1663) in StABa Stift St. Gangolf, Akten und Bände Nr. 192 fol. 2. 
Propsteiguts in seiner Hand und sicherte so, ähnlich wie am Domstift, das weitere Bestehen seines Amtes. Es ist interessant, dass die Einzelpfründen, wie sie hier beschrieben werden, grundsätzlich gleich groß waren, jedoch eine Doppelbepfründung möglich war. Die Doppelbepfründung von Dekan und Keller ist in den Statuten, die ebenfalls unter dem Einfluss des Dekans Johann Schank angelegt wurden, im Kapitel 18 über die Verteilung des Pfründenguts bei Abwesenheit und die Doppelbefründung von Dekan und Keller geregelt. ${ }^{881}$ Dies hat mit der besonderen Rolle der beiden Ämter in der Pfründenverteilung zu tun, deren Zuständigkeit zwar beim Dekan lag, jedoch die praktische Ausführung, also Verhandlungen mit dem Propst, Sammlung der Erträge und Verteilung unter den Kanonikern, vom Keller ausgeführt wurde. ${ }^{882}$

Ein weiterer Hinweis, der die Aufteilung der pröpstischen Abgaben an das Kapitel in 14 Einzelpfründen stützt, findet sich als Notiz auf dem Deckblatt eines der Statutenbücher des Stifts, undatiert, aber wohl ins 16. Jahrhundert zu verorten. Die Notiz lautet wie folgt:

Praepositus s. Gangolphi de praepositura solvere tenet. 422 summera, ${ }^{883} 3$ virling, ${ }^{884}$ 2 gaisen korn werden unter 14 prebenden, custoden und 4 gerichts schopfen distribuirt: 366 summera korn vergaist machen die 14 prebenten einer 24 summera korn. 2 summera, 3 virling, 2 gaisen stemanenten korn inter capitulares vocem habentes. 20 summera korn d custodi vergaist. 64 summera korn vergaist den 4 gerichts schop-

881 „Capitulum decimum octavum de corpore prebendali absentum exemptorum non capitularium ac obeuntium canonicorum et de duplo decani et cellerarii." als Statut Nr. 8 im Statutenbuch in StABa Stift St. Gangolf, Akten und Bände Nr. 130 fol. 72-72'.

${ }^{882}$ Statut über den Dekan: „Fructibus tamen et proventibus praebende eidem decano ratione canonicatus competentis si alias iuxta statuta infra scripta sibi debentur pro eodem decano reservatis. De quibus actus ipsum ratione huiusmodi canonicatus in esslesia nostra concernentes sicut ceteri canonici disponere teneatur." im Statut Nr. 3 über den Dekan im Statutenbuch StABa Stift St. Gangolf, Akten und Bände Nr. 130 fol. 59'-60; "Debeatque ipse cellerarius noster pro tempore omnes et singulos praebendales et alios fructus redditus et proventus canonicorum officiorum et personarum ecclesie nostre in quantum sibi ratione officii cellerarie incumbit a domino preposito et aliunde diligenter petere in locis per capitulum deputandis colligere simul reponere ac illis quibus pertinet fideliter distribuere temporalibus debitis, dolo et fraude seclusis quibuscunque." im Statut Nr. 6 über den Keller im Statutenbuch in StABa Stift St. Gangolf, Akten und Bände Nr. 130 fol. 62 '.

883 Ein Sümmer als Hohlmaß zur Messung von Schüttgütern ist schwer in Litern umzurechnen, da seine genaue Abmessung unterschiedlich sein kann.

${ }^{884}$ Als Vierling wird der vierte Teil eines Scheffels bezeichnet. In Deutsches Wörterbuch von Jakob und Wilhelm Grimm: Art. „Vierling. 2c“. Bd. 26 (1951). Sp. 305. 
fen einem 16 summera. Summa 422 summera, 3 virling, 2 gaisen. 604 summera habern vergaist und 3 virling, 2 gaisen. 885

In dieser Aufstellung wird ebenfalls zwischen der Verteilung des Kontingents Roggen und Hafer unterschieden, wobei nur die Verteilungsmodalitäten für Roggen näher thematisiert werden. Schwierigkeiten ergeben sich bei der genauen Deutung der Maßeinheiten: Der Begriff gaise, in Varianten auch geise, geisel oder geischel, meint wörtlich „eine hohle Hand voll“ oder „einen Arm voll“ als ungefähres Maß, ${ }^{886}$ sodass man mit der bloßen Zusammenzählung der aufgelisteten Posten schnell auf Lücken stößt. Aufgrund der regionalen Unterschiede in den Getreidemaßen und der schlechten Quellenlage können mit der vorliegenden Arbeit diese Lücken nicht geschlossen werden. Das muss weiteren Forschungsarbeiten vorbehalten bleiben. ${ }^{887}$

Weitere pröpstische Abgaben an das Kapitel, die sich in den Cautiones finden, wie Weizen, Fastnachtshennen oder Weihnachtskäse, fehlen hier völlig, wobei auch dort die Roggen- und Haferabgaben die größten Posten ausmachten. Die Lücken, die die Notiz auf dem Deckblatt des einen Statutenbuches aufweist, schließen sich jedoch durch eine weitere Notiz in einem anderen Gangolfer Statutenbuch. Dort vermerkte ein nicht näher benannter Kanoniker um das Jahr 1550, was er jährlich als einfache Pfründe zu erwarten hatte:

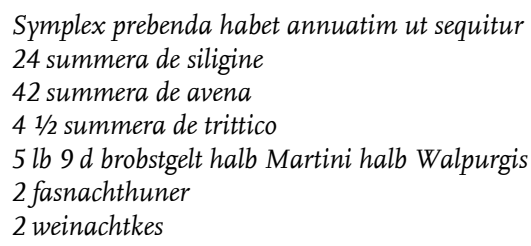

${ }^{885}$ Statutenbuch StABa Stift St. Gangolf, Akten und Bände Nr. 131 fol. 1.

${ }^{886}$ Deutsches Wörterbuch von Jakob und Wilhelm Grimm: Art. „Geischel“, Art. „Geise“, Art. „Geisel“. Bd. 5 (1897). Sp. 2607, Sp. 2608, Sp. 2618.

887 Für das Untersuchungsgebiet interessant sind die Arbeiten von Gabriele Hendges: Maße und Gewichte im Hochstift Würzburg vom 16. bis 19. Jahrhundert. München 1989; und Wilhelm Fickert: Geldwesen, Kaufkraft und Maßeinheiten im Bereich des Fürstentums Kulmbach-Bayreuth (Gesellschaft für Familienforschung in Franken, Bd. 21). Nürnberg 1989. Unbearbeitet ist bisher eine genaue Umrechnungstabelle von Getreidemaßen im Gangolfer Zinsregister (1562-1578) in StABa Stift St. Gangolf, Akten und Bände Nr. 12 fol. 152'-156', die umfangreiche Antworten auf Fragen zur Behandlung von Getreidemaßen bieten könnte. 
Quadragesimalgelt zwischen pfingsten und ostern

Lemmergelt Johannis Baptiste

$9 \mathrm{fl}$ aliquando 10 bis in $12 \mathrm{fl}$ zehentgelt Hersprück

De trittico in Baireut vendito Martini zubezallen

steingelt. ${ }^{888}$

Die 24 Sümmer Roggen (siligo) decken sich mit der Angabe auf dem Deckblatt des ersten Statutenbuchs, wie auch das Größenverhältnis der Roggen- und Haferangaben: so sind die 42 Sümmer Hafer (avena), auf die der unbekannte Kanoniker 1550 Anspruch zu haben schien, etwa der vierzehnte Teil der 604 Sümmer, drei Vierling und zwei Gaisen Hafer, die als Gesamtkontigent des zu verteilenden Hafers auf dem Deckblatt des ersten Statutenbuchs aufgelistet sind. Da beide Notizen zur gleichen Zeit entstanden sind, können die hier besprochenen Angaben ergänzend zueinander betrachtet werden.

Solche Gegenrechnungen zeigen die Übereinstimmungen mit den Cautiones-Angaben. Die 422 Scheffel, drei Vierling und zwei Gaisen Roggen und die 604 Scheffel, drei Vierling und zwei Gaisen Hafer, welche laut der Deckblattnotiz des Statutenbuchs verteilt wurden, entsprechen grob einem Vierfachen der Angaben von 94 Scheffel Roggen und 144 Scheffel Hafer, welche dem Dekan und dem Kapitel laut den Cautiones jährlich zustanden. ${ }^{889}$ Die Vervierfachung der geforderten Getreideabgaben innerhalb eines Jahrhunderts findet sich in beiden Quellen auch in Bezug auf die Einnahmen des Kustos, dem, obwohl bereits durch sein Amt vollbepfründet, eine Sonderration seitens des Propstes zustand: während Melchior Truchseß im Jahr 1489 fünf Scheffel Roggen für den Kustos errechnete, ${ }^{890}$ spricht die Statutennotiz von 20 Scheffel Roggen.

Ebenso schienen Geldbeträge eine Werterhöhung um den Faktor Vier erfahren zu haben: Das Verhältnis von vier Bamberger Heller zu

${ }^{888}$ Statutenbuch StABa Stift St. Gangolf, Akten und Bände Nr. 130 fol. 48.

${ }^{889} 94$ mal 4 = 376 Scheffel Roggen (Vergleich: 422 Scheffel 3 Vierling 2 Gaisen laut der Statutennotiz in StABa Stift St. Gangolf, Akten und Bände Nr. 131 fol. 1) und 144 mal $4=$ 576 Scheffel Hafer (Vergleich: 604 Scheffel 3 Vierling 2 Gaisen laut der Statutennotiz in StABa Stift St. Gangolf, Akten und Bände Nr. 131 fol. 1).

890 „Also das wir alle iare ierlichen einem custor zu zeyten funf scheffel korns von demselben haws reichen und geben sollenn" im Lehenverzeichnis (1489-1494) in StABa Stift Gangolf, Akten und Bände Nr. 123 fol. 2‘. 
einem Bamberger Pfennig wird in derselben Urkunde erwähnt, in der der Anspruch des Obleiers auf 3,5 Pfund Bamberger Pfennige oder 14 Pfund Heller angesetzt wird. ${ }^{891}$ Außerdem fehlt hier, trotz der Ausführlichkeit, die Erwähnung von Ansprüchen der vier Gerichtsschöffen. Jedoch können unabhängig der Kürze der Statutennotiz aus dem 16. Jahrhundert eindeutige Parallelen zu der in den Cautiones erkennbaren Praxis der pröpstischen Abgaben an das Kapitel festgestellt werden. Bei beiden Quellenarten passen die Größenverhältnisse der Getreidekontingente und die angesprochenen Getreidearten zusammen. Bei beiden wird eindeutig die Verteilung von Gütern an die Kanoniker des Stifts St. Gangolf durch ihren Propst thematisiert.

\subsubsection{Kontrollmechanismen des Kapitels über den Propst}

Die Ansprüche des Kapitels auf ihre Pfründenbezüge mussten immer wieder neu verteidigt und eingeklagt werden, und auch der Propst bemühte sich, seine Interessen gegenüber dem Kapitel zu wahren. Die bischöflichen Urteile in Streitfällen zwischen Propst und Kapitel des Stifts St. Gangolf vom Beginn des 14. Jahrhundert bis hin zur Mitte des 16. Jahrhundert, die an anderer Stelle bereits besprochen wurden, ${ }^{892}$ zeichnen davon ein deutliches Bild. Die Statuten boten dem Kapitel schließlich eine Möglichkeit, die erkämpften Zugeständnisse des Propsts festzuhalten und ihn darauf bei Amtsamtritt einen Schwur ablegen zu lassen. Das Statut über den Propst verpflichtet ihn $\mathrm{zu}$

solvere et dare canonicis et personis ipsius ecclesie praebendas fructus redditus et proventus iura et obventiones et quas solventios per praepositum et praeposituram debi-

\footnotetext{
891 "Wir sollen und wollen von dem zoll zu Holfelt oder ander der probstey gulten und renten dem obleyer zu zeyten desselben stiefts jerlichen geben und ausrichten auf sand Michelstag, vierthalb pfundt Bamberger pfennig oder dafur vierzehen pfundt heller die dafur angeslagen und gewirdet sein auf solich jartag, die dann in des genanten stiefts regeln begrifen sind ongeverde“ im Lehenverzeichnis (1489-1494) in StABa Stift St. Gangolf, Akten und Bände Nr. 123 fol 2'; Näheres dazu in Wolfgang Krug: Die Münzen des Hochstifts Bamberg 1007 bis 1802 (Süddeutsche Münzkataloge, Bd. 9). Stuttgart 1999. ${ }^{892}$ Näheres im Kapitel 6.3.3.1 Grundstock der Pfründenansprüche.
} 
tas et solvendus debitos et solvendos temporibus et solidis et censuetis provit in anti-

qua habitum ac in regulis, litteris et registris ecclesie praedicte annotatum est ${ }^{893}$

und erinnert ihn damit an die zahlreichen schriftlichen Fixierungen der kapitlischen Rechte durch Statuten, bischöfliche Urteile und pröpstische Cautiones. Die Grenzen zwischen Propstgut und Pfründengut sollten durch die Stiftsverfassung schärfer gezogen werden, um Konflikte über Ansprüche zu vermeiden. Die Praxis der Kontrolle des Propstes durch vom Kapitel entsandte Kanoniker zur Sicherung ihrer Ansprüche ist durch die Cautiones überliefert. Jedoch wird an deren Wortlaut deutlich, dass es sich dabei nicht nur um eine Absicherung des Kapitels, sondern auch des Propstes handelte. Eine beträchtliche Einkommenseinbuße durch unvorhergesehene Geschehnisse, wie Unwetter, feindliche Überfälle, aber auch große Ausgaben durch Königsumritte, schien eine reelle Gefahr zu sein, vor deren Folgen sich der Propst absichern musste. Schon 1466 erwähnte Dekan Konrad Hartung (amt. 1453-1474) in der Remissio des Stifts an Propst Gumpert Fabri (amt. 1466-1478), dass er dem Propst in bestimmten Fällen eine Minderung seiner Abgaben an das Kapitel zugestehe unter der Bedingung, dass dieser anschließend keinerlei größere Ausgaben und Besitzverschiebungen tätige, bevor er nicht seine Schulden gegenüber dem Kapitel beglichen habe. ${ }^{894} \mathrm{Ob}$ dies

${ }^{893}$ Statutenbuch StABa Stift St. Gangolf, Akten und Bände Nr. 130 fol. 58‘; Auch der Keller hatte Aufgaben in der Pfründenverwaltung zu erfüllen: „Debeatque ipse cellerarius noster pro tempore omnes et singulos praebendales et alios fructus redditus et proventus canonicorum officiorum et personarum ecclesiae nostrae in quantum sibi ratione officii cellerarie incumbit a domino praeposito et aliunde diligenter petere in locis per capitulum deputandis colligere simul reponere ac illis quibus pertinere fideliter distribuere temporibus debitis, dolo et fraude seclusis quibiscumque." im Statutenbuch StABa Stift St. Gangolf, Akten und Bände Nr. 130 fol. 62'; und StABa Stift St. Gangolf, Akten und Bände Nr. 131 fol. 12; Weiterhin über die Pfründenverwaltung in StABa Stift St. Gangolf, Akten und Bände Nr. 130 fol. 65, fol. 68‘, fol. 70‘, fol. 72, fol. 72‘.

894 „Wenn nun die oftgenanten probstey mercklich und treffendtliche schaden vom prandt und herteisn an iren guetern empfangen hat, also das ir an renthen, zend, zinsen grosser abgang geschehen ist, solche auch viel andere mercklich redlich und erbare ursach angeschen, bekennen wir obgenanter dechant und capitel fur uns und unser nachkommen in craft und macht ditz briefs, das wir von dem oftgenanten unsern herrn probst, die weil er unser probst und als obgerurt ist, nachlassung gethan haben und thun ime auch die in craft und macht ditz brifs [...], in der obgenanten caution, ist auch mit artickel lautendt, das unser herr der probst nichts verkommern, verkaufen oder sonst empfrembden soll, bis uns ein gantz gengen beschehen sey unser pfrundt halben, mit viel 
wirklich eingehalten wurde, musste jedoch aufgrund zahlreicher Missbräuche seitens des Propstes eingehend geprüft werden. In seiner Cautio legte sich Propst Melchior Truchseß (amt. 1489-1493) wie folgt fest:

Und ob es geschehe, das konigshern stet oder ander reyse durch das landt gingen oder swerlich und unfride im lande gemeinglich auferstundenn oder das hagelschawer oder getreydesversess komen davon der genant unser probstey zehendt und gudter schaden nemen und so swerlich beschedigt wurden, das wir dem obgenanten dechant und capitel ir gult, rent und zins als oben geschriben stet von allen der egenanten probstey zehenden, gutern, renten, gulten und nutzunge nicht gantz ausgericht konnten werden das gott nit verhenge, sunder gnediglich behüten wolle, so sollen die vorgenanten dechant und capitel uns, ob wir das an sie begern, an solichen gülten und schuld als obgeschriben stet, die wir ine desselben iars zugeben schuldig wurden, sengknus und nachlassung thun, nach erkenthnus zweyer capitelherrn, die wir aus irem capitel darzu benennen und geben die sich dann umb solich scheden und gelegenheyt der sache eygentlich und getrewlich erfaren, und bderseiten in der frewntschaft ob sie mugen darumb vereynen sollen, mochten die aber freuntlichen nicht geeynen, so sollen sie vor dem genanten capitel in unser gegenwurtigkeit, ob wir da bey sein wollen, leyplich eyde swern ob wir oder dasselbig capitel die von ine begern und auf dieselben eyde zwischen uns bederseyten aussprechen wievil uns auf das selbig iare an der bezalung derselben schulde, und gulte als obengeschriben stet soll abgeen und nachgelasen werden, das soll dann also von uns bederseyten gehalten werden ongeverde, wir sollen und wolln auch die genanten dechant, capitel, chorherrn und persone des obgenanten stiefts in gemeyn und besunder ungehindert lassen an allen iren zehenden, zynsen, gulten und obleyen die sie in unser probstey dorfern und gutern haben, und sunderlich an allem weytzs der ierlich an einem dritteyl zum Geses und anderswo in unser probstey gefellet und mag gesamet werden, der ine auch $z u$ ken pfrundtn in gemein zugehort on alles geverde. ${ }^{895}$

Die Absicherung galt für den Fall massiver Einkommenseinbußen durch unvorhergesehene Belastungen oder Beschädigungen der Propstgüter. Zur Prüfung der pröpstischen Behauptungen wurden zwei Kanoniker des Stifts St. Gangolf ausgesandt, um sich Klarheit über den Zustand der Güter zu verschaffen. Der Propst nahm jedoch Einfluss auf diese Prüfung dergestalt, dass er die zwei zur Prüfung vorgesehenen Kanoniker bestimmte. Auch war seine Anwesenheit bei der Anhörung der beiden Kanoniker vor dem Kapitel vorgesehen. Der Propst behielt

andern wordten inhaldt.“ in den Lehenprotokollen des Propteiverwaltungsamts Hollfeld (1417-1576) in StABa Stift St. Gangolf, Akten und Bände Nr. 119 fol. 53'-54.

${ }^{895} \mathrm{Im}$ Lehenverzeichnis (1489-1494) in StABa Stift St. Gangolf, Akten und Bände Nr. 123 fol. 2'-3; und in ähnlichem Wortlaut in der Cautio des Propstes Paul Neydecker (amt. 15161565) vom 30. Juli 1516 in AEB Rep. I Pfarrei St. Gangolf U 826; und der Cautio des Propstes Erasmus Neustetter (amt. 1565-1594) vom 27. Januar 1565 in StABa A 120 L 131 Nr. 732. 
also die gesamte Pfründenverwaltung in seiner Hand und sorgte dafür, dass Neuregelungen nicht ohne seinen Einfluss erfolgten.

Das Stift St. Gangolf orientierte sich bei der Kontrolle ihres Propstes am Vorgehen des Domkapitels, welches in eigenen Konfliktfällen ebenfalls zwei Kanoniker zur Visitation der Propstgüter bestellte und den Bischof als oberste Instanz zur Klärung von Veruntreuungen benannte. ${ }^{896}$ Die zahlreichen bischöflichen Urteile rund um die Cautiones der Pröpste zeichnen davon ein deutliches Bild und betonen, dass die Pröpste immer wieder versuchten, ihre Interessen und Einkünfte vor dem Einfluss des Kapitels zu schützen.

\subsection{Verwaltung von Stiftungen und Schenkungen durch das Kapitel}

\subsubsection{Obleibesitz}

\subsubsection{Quellen und begriffliche Einordnung}

Der Begriff Oblei (oblegium) bezeichnete eine Verwaltungseinheit, deren Grundlage die Anniversarstiftungen waren. Solche Stiftungen zur Begehung des Jahrtages eines Verstorbenen stellten Rechtsgeschäfte mit wechselseitiger Verpfichtung dar, die die Erlösung der Stifterseele durch eine Totenmesse zum Ziel hatten. Der Stifter erkaufte sich Gebete der Kanoniker für sein Seelenheil und das seiner Familie, um deren himmlische Aufnahme vorzubereiten. Die jährlichen Gedenktage wurden in diesem Rahmen weniger von der Familie, sondern von einer geistlichen Gemeinschaft getragen - „der Totenkult wurde damit gemeindeöffentlich“ in Form von Almosenvergabe und Gebeten im Rahmen einer Messe betrieben. ${ }^{897}$ Die Anniversarstiftungen stellten den Kern der Aufga-

896 Näheres zu Differenzen des Bamberger Domstifts mit seinem Dompropst in den Jahren 1392 bis 1394 im Kapitel 4.1.1 Statuten und Consuetudines.

${ }^{897}$ Arnold Angenendt: Die liturgische memoria: Hilfe für das Fortleben im Jenseits. In: Berndt, Rainer (Hg.): Wider das Vergessen und für das Seelenheil. Memoria und Totengedenken im Mittelalter (Erudiri Sapientia. Studien zum Mittelalter und zu seiner Rezeptionsgeschichte, Bd. 9). Münster 2013. S. 199-226. hier: S. 201. 
benzuteilung an ein Kollegiatstift dar, dessen Hauptaufgabe das Totengedenken war. Die häufigste Form der Anniverarstiftungen bildete gestifteter Grundbesitz, von dessen Einnahmen die Präsenzgelder an die an der jeweiligen Totenmesse teilnehmenden Kanoniker und Vikare bezahlt wurden. Die kalendarisch angelegten Anniversarbücher des Stifts St. Gangolf geben rege Auskunft über die große Anzahl an Gedenkleistungen, die über das Jahr zu begehen waren. Präsenzgelder bildeten den Anreiz für die Kanoniker, den Gottesdienst an diesen Tagen durch ihre Anwesenheit zu garantieren. Dies war nötig, da die Kanoniker aufgrund ihrer organisatorisch geringen Bindung an das Stift eher zu auswärtigen Beschäftigungen tendierten, wodurch die Kollegiatstifte fortwährend mit der Gefahr der Unterbesetzung zu kämpfen hatten. ${ }^{898}$ Die Gelder oder Naturalabgaben zur Ausgabe an die die Messe bestreitenden Kanoniker und Vikare wurden mit Auflagen versehen, nach denen die Kanoniker einen Teil ihrer Obleieneinnahmen an das Kapitel des Stifts, genauer an den Obleier, abzugeben hatten. Diese Auflagen wurden als canones bezeichnet. Die restlichen Einkünfte der Obleien sicherten zusammen mit den Pfründengeldern den Lebensunterhalt des Kanonikers.

Die Zehnt- und Zinsverzeichnisse der Obleiverwaltung nehmen im Gangolfer Bestand des Staatsarchivs Bamberg einen weitaus größeren Teil ein, als die über die vom Propst verwalteten Güter. Zum einen war diese Aufzeichnungsfülle notwendig, um die kontinuierlich wechselnden Obleiinhaber zu dokumentieren, während sich das Propsteigut durch eine gewisse personelle Konstanz auszeichnete, und zum anderen kamen jährlich neue Stiftungen dazu, vor allem Jahrtagsstiftungen, über welche eine Übersicht gewahrt werden musste. ${ }^{899}$ Hinsichtlich der

898 Näheres zur Gefährdung des Sinnmusters eines Kollegiatstiftes durch die Nebentätigkeiten seiner Kanoniker in Guy P. Marchal: Weltliches Kollegiatstift und Universität. In: Lorenz, Sönke/ Kintzinger, Martin/ Auge, Oliver (Hgg.): Stiftsschulen in der Region. Wissenstransfer zwischen Kirche und Territorium. Dritte wissenschaftliche Fachtagung zum Stiftskirchenprojekt des Instituts für Geschichtliche Landeskunde. Ostfildern 2005. S. 17-33, hier: S. 20.

${ }^{899}$ Näheres zum Vergleich mit dem Domstift in Nöth: Urbare und Wirtschaftsordnungen. 1986. S. XI. 
Quellengruppen der Obleiverzeichnisse sind drei Kategorien zu unterscheiden: Urbarähnliche Obleiregister, in denen alle Obleien des Stifts mit Zinsabgaben und Canonesbelastungen aufgelistet wurden; 900 Obleiregister der einzelnen Kanoniker über die ihnen zur Leistung verpflichteteten Einzelobleien mit Abschriften von Lehenurkunden und den fälligen Canones; ${ }^{901}$ sowie Lehenbücher der Obleien mit näheren Beschreibungen von Einzelgütern. ${ }^{902}$ Trotz ihrer Fülle reichen auch diese Güterverzeichnisse des Stifts St. Gangolf nicht weiter als bis in das 15. Jahrhundert zurück und spiegeln in ihrer Mehrzahl die Zustände des 16. Jahrhunderts wieder. Die Entwicklung des Gangolfer Obleibesitzes in früheren Jahrhunderten wird damit schwer nachvollziehbar. Weitere Quellen, die das Bild der Obleien vervollständigen, sind Obleimatrikel, Anniversarbücher und Hinweise aus Urkunden.

Für das Stift St. Gangolf ist nur eine der Obleimatrikel mit einer Laufzeit von 1433 bis 1663 überliefert, ${ }^{903}$ die bereits oben aufgrund einer vorangestellten Notiz des Dekans Johann Schanck über die Verteilung von Pfründengut erwähnt wurde. ${ }^{904}$ Dieses Schriftzeugnis ist für die Frage nach der Organisation von Obleigut bedeutend, da sie ausgehend vom Tod, Ämtertausch oder der Amtsresignation eines Kanonikers des Stifts die nun freigewordenen Obleien in einem festgelegten Prozedere $^{905}$ an die übrigen Kanoniker zu verteilen hatte. Neben prosopogra-

\footnotetext{
900 Urbar über die Vikarien, Obleien und Fragmente (1317-1630) in StABa Stift St. Gangolf, Akten und Bände Nr. 32; und Urbar der Vikarien, Obleien und Fragment (13171667) in StABa Stift St. Gangolf, Akten und Bände Nr. 44.

${ }^{901}$ Näheres für den hier interessanten Zeitraum in den Registern für einzelne Obleizinsen (16. Jhd) in StABa Stift St. Gangolf, Akten und Bände Nr. 20; Nr. 22; Nr. 23; Nr. 24; Nr. 25; und Nr. 28.

${ }^{902}$ StABa Stift St. Gangolf, Akten und Bände Nr. 126; und Nr. 127. Die Obleilehenbücher eignen sich nicht als Quelle für die Fragestellung. Zwar gehen sie teilweise bis ins 15 . Jahrhundert zurück, jedoch stehen dort nicht die gesamten Obleien im Mittelpunkt, sondern die Frage, unter welchem Obleier welchem Lehensmann welches Haus, Garten oder Wiese verliehen wurde. Eine Ordnung nach Gesamtzinsen, Canones oder Obleizugehörigkeit fehlt.

903 Obleimatrikel (1433-1663) in StABa Stift St. Gangolf, Akten und Bände Nr. 192.

${ }^{904}$ Näheres im Kapitel 6.3.3.5 Einzelpfründen.

${ }^{905}$ Näheres zur Praxis des „tukken“ im Kapitel 6.4.1.3 Verteilungsmodalitäten der Obleien.
} 
fischen Informationen gewährt die Obleimatrikel somit auch Einblicke in die Verteilungsmodalitäten und die Obleianzahl.

Unter Anniversarbücher werden kalendarische Aufzeichnungen von Stiftern mit Todestag, der Stiftung und der Gedenkleistung verstanden, die diese wiederkehrend einem bestimmten Tag im Jahr zuordnen, an dem ein Gottesdienst in einem festgelegten Umfang absolviert wurde. Obwohl die Bezeichnung Anniversarbuch oder liber anniversariorum als Quellenbegriff im Bestand St. Gangolf nicht zu finden ist, ${ }^{906}$ wird entsprechend der geläufigen Forschungsterminologie trotzdem im Folgenden der Begriff „Anniversarbuch“ verwandt. ${ }^{907}$

Die Anniversarbücher des Stiftes St. Gangolf sind in drei verschiedenen Ausführungen überliefert: Das älteste enthält Eintragungen aus dem 14. bis 16. Jahrhundert in unterschiedlichen Handschriften ${ }^{908}$ und ist durch einen Eisenring am hinteren Buchdeckel als ein festgekettetes Nachschlagewerk zum Zwecke der öffentlichen Nutzung erkennbar. ${ }^{909}$ Daneben findet sich eine nur leicht abweichende Abschrift dieses frühesten Anniversarbuches aus dem 17. Jahrhundert ${ }^{910}$ und eine verkürzte Version aus dem 16. Jahrhundert, die im Überlieferungszusammenhang mit einem der Statutenbücher steht. ${ }^{911}$

906 Sie erhielten entweder keine nachweisbare Bezeichnung oder wurden als „calendarium“ bezeichnet z. B. „Statuta cum calendario insignis ecclesiae collegiatae ad beate virginis Marie et Gangolphum“ als Titel des Statutenbuchs StABa Stift St. Gangolf, Akten und Bände Nr. 130.

907 Die Begriffe Anniversar, Jahrzeitbuch, Totenbuch oder Kalender werden hier synonym verstanden, müssen jedoch vom Nekrolog unterschieden werden, das weniger die Jahrtage der frommen Stifter, als die der eigenen Ordensangehörigen verzeichnete, und aus dem seit dem 12. Jahrhundert die Anniversare hervorgegangen sind. Näheres dazu in Hieronymus Frank: Art. „Anniversarium“. In: LThK Bd. 1 (1957). Sp. 577-579; Joachim Wollasch: Art. „Nekrologien“. In: LThK Bd. 7 (1998) Sp. 720-721; und Joachim Wollasch: Art. „Necrolog“. In: LexMA Bd. 6 (1993). Sp. 1078-1079. Die Forschung über Nekrologe und andere Quellen des Totengedächtnisses in Deutschland wurde von Gerd Tellenbach eingeleitet und neben Joachim Wollasch durch Karl Schmid und Otto Gerhard Oexle fortgeführt.

908 Anniversarbuch (15.-16. Jhd) in StABa Stift St. Gangolf, Akten und Bände Nr. 128.

${ }^{909}$ Ein ebenso verwendetes Amtsbuch wird beschrieben in Claus Brügmann: Das älteste Nekrolog des Stifts St. Peter und Alexander zu Aschaffenburg (Veröffentlichungen des Geschichts- und Kunstvereins Aschaffenburg, Bd. 30). Aschaffenburg 1989. S. 6.

${ }^{910}$ Anniversarbuch (16. Jhd) in StABa Stift St. Gangolf, Akten und Bände Nr. 129.

911 Statutenbuch StABa Stift St. Gangolf, Akten und Bände Nr. 130; und ebenfalls im 
Damit blickt das Stift St. Gangolf auch in diesem Fall auf eine weitaus kleinere und jüngere Überlieferung als das Bamberger Domstift zurück, dessen Forschung auf Anniversarbücher ab dem 13. Jahrhundert und darüber hinaus auf ältere Nekrologüberlieferungen ab 1040 zurückgreifen kann. ${ }^{912}$ Dazu kommt, dass die Anniversarbücher nur in seltenen Fällen Stiftungen einer Oblei zuordneten, sodass sich diese Quellengattung eher zu prosopografischen Studien der Stiftsangehörigen aber auch der Stifter eignet, als für die nähere Betrachtung der Besitzentwicklung. Bisher ungeklärt ist die Tatsache, warum in den Anniversarbüchern allein die Oblei Drosendorf und darüber hinaus keine weiteren Obleien genannt werden. ${ }^{913}$

Während die Pfründen stark auf den gestifteten Grundbesitz der Anfangszeit fußen, geht der Obleibesitz auf die im Laufe der Zeit an das Stift geleisteten zahlreichen Stiftungen und Schenkungen zurück. Diese Zuwendungen unterschieden sich sowohl in ihrer Größe und Qualität, als auch in der Lage. Dadurch ergab sich im Laufe des Mittelalters und der Neuzeit bis zur Auflösung des Stifts im Jahr 1803 eine verzweigte, schwer durchschaubare Besitzgemengelage, die unabhängig vom Propstgut als Obleibesitz organisiert wurde. Die Eintreibung der Einnahmen war durchaus mit Schwierigkeiten verbunden. ${ }^{914}$ Gestiftet von Geistlichen oder Laien aus frommen Beweggründen, berechtigte die Grundherrschaft über eine Oblei den Obleiinhaber zur Eintreibung grundherrlicher Abgaben, anfangs ausschließlich als Naturalien-, später aber auch als Geldabgaben. Diese konnten großen Schwankungen unterliegen. Wie unterschiedlich die Zinszahlungen pro Jahr letztendlich ausfallen konnten, zeigt die Notiz eines nicht näher benannten Kanonikers des Stifts St. Gangolf, welche sich in einem der Statutenbücher des Stifts findet:

Wievil mir yeder iars vom zehendten zu Herspach geburt hat und worden ist Anno [15] 42 Jar - 12 1/2 gulden

Verbund mit einem Statutenbuch in SttABa D 3001 HV Rep. 2 Nr. 264 fol. 6-51‘.

912 Guttenberg: Urbare und Wirtschaftsordnungen. 1969. S. 7; und Schweitzer: Vollständiger Auszug. 1844. S. 67-319.

${ }^{913}$ Näheres dazu im Kapitel 6.4.1.2 Einzelobleien.

${ }^{914}$ Nöth: Urbare und Wirtschaftsordnungen. 1986. S. 59. 


$$
\begin{aligned}
& \text { Anno [15]43 Jars - } 10 \text { guldein } \\
& \text { Anno [15]44 - } 12 \text { guldein } \\
& \text { Anno [15]45 - } 91 / 2 \text { guldein } \\
& \text { Anno [15]46 - } 11 \text { gulden } \\
& \text { Anno [15]47 - } 10 \text { gulden } \\
& \text { Anno [15]48 - } 9 \text { gulden } \\
& \text { Anno [15]49 - 8 gulden } \\
& \text { Anno [15]50 - [9 ?] gulden } \\
& \text { Anno [15]51 - } 11 \text { gulden. }{ }^{915}
\end{aligned}
$$

Ein anderes Beispiel, das den Wandel der Zahlungspraxis während des 16. Jahrhunderts dokumentiert, findet sich im Zusammenhang mit den Abgaben von Wein, die das Stift St. Jakob an das Domstift von Bamberg zu liefern hatte. So beliefen sich die Abgaben anfangs auf einen Eimer Wein im Wert von acht Gulden, dann um Wein, den das Stift St. Jakob um acht Gulden ankaufte, und schließlich wurden Naturalienabgaben unüblich, sodass das Stift acht Gulden zahlte, welche für die Anschaffung des Weins bestimmt waren. ${ }^{916}$

Die Verfügungsgewalt des Obleiinhabers über eine Einzeloblei umfasste meist ausschließlich grundherrschaftliche Rechte und schloss Gerichtsherrschaft für gewöhnlich nicht mit ein. Die rechtliche Struktur von Hof zu Hof selbst im gleichen Ort konnte sich stark unterscheiden. ${ }^{917}$ Obwohl auf einen Kanoniker mehrere Obleien kamen und diese zahlreiche Orte, Ortsteile und Güter umfassen konnte, blieben die Einkünfte aus den Obleien für den Einzelnen wohl hinter den Pfründengeldern zurück. Dies konnte Stefan Nöth für das Domstift bereits nachweisen. Er sieht den Grund dafür sowohl in der schwierigen Verwaltung durch die weit auseinanderliegenden Besitzungen, als auch in der Bezahlung der Verwalter vor Ort und die fehlende Überwachung derselben, was die Einkünfte schmälerte. ${ }^{918}$

Für die nun folgende Untersuchung der Einzelobleien spielen die genauen Einkünfte der Besitzungen keine Rolle, da diese Schwankun-

\footnotetext{
${ }^{915}$ Statutenbuch StABa Stift St. Gangolf, Akten und Bände Nr. 130 fol. 49.

${ }^{916}$ Nöth: Urbare und Wirtschaftsordnungen. 1986. S. 65; Er verweist auf StABa Standbuch 3478 fol. 21'; und StABa Standbuch 3480 S. 148.

${ }^{917}$ Ebd. S. 59.

918 Ebd. S. 61. Enno Bünz hingegen vermutet die Obleierträge generell größer als die Pfründenbezüge, nennt jedoch keine Gründe für seine Annahme. Näheres dazu in Bünz: Oblatio - Oblagium - Oblei. 2007. S. 43.
} 
gen unterworfen waren und schwer zu vergleichen sind. Für einen aussagekräftigen Vergleich über die Größe und Einträglichkeit der Obleibesitzungen sind die Belastungen der Einzelobleien mit Canones, also Abgaben, die der Kanoniker als Obleiherr aus den Einkünften seiner Oblei an das Kapitel des Stiftes St. Gangolf zu zahlen hatte, eher tauglich. Diese Canones blieben in den meisten Fällen über die Jahrzehnte hinweg erstaunlich konstant und waren nicht selten mit interessanten Bedingungen und Zahlungsmodalitäten verknüpft.

\subsubsection{Einzelobleien}

Die Obleigüter des Stifts St. Gangolf bestanden oft aus zahlreichen kleinen und kleinsten Gütern wie einzelnen Höfen, Wiesen, Feldern, Gärten und selten aus ganzen Ortschaften. Um die unübersichtliche Besitzmasse zu organisieren, wurde sie in Einzelobleien unterteilt und diese meist nach den Ortschaften benannt, in denen sich vermutlich der Ursprung der Stiftung befand. Jedoch beschränkte sich die Oblei selten auf diese Ortschaft, sondern breitete sich territorial, häufig unzusammenhängend, auch auf andere Gebiete aus, sodass eine Einzeloblei in der Regel keine geschlossene Fläche bildete. Aber nicht jede Oblei wurde nach einer Ortschaft benannt. Nach der Aufteilungen von ehemals gemeinsam genutzten Gütern erhielten die Besitzgruppen oftmals neue Bezeichnungen. Diese Praxis ist für das Domstift nicht nachweisbar. ${ }^{919}$ So ist die Herkunft mancher Gangolfer Obleibezeichnungen heute schwer nachzuverfolgen und deren historische und örtliche Herleitung nur anhand der Auflistungen in den Obleiverzeichnissen möglich. Die für das Mittelalter typische Besitzverteilung in Streulage verdeutlicht sich gut am Phänomen des Fragments. Sprechen die Quellen nicht von einer Oblei sondern von einem Fragment, dann ist der dahinterstehende Besitz entweder aus einer Teilung oder Minderung einer Oblei hervorgegangen oder die Stiftung bestand von vornherein aus einem wenig

${ }^{919}$ Michel Hofmann: Die Bamberger Stifts-Obleien und ihre Namenswelt. In: Fränkische Blätter für Geschichtsforschung und Heimatpflege 9 (1962). S. 33-36, hier: S. 34. 
ertragreichen Gut. ${ }^{920}$ Das Fragment Königsfeld des Stifts St. Gangolf beispielsweise umfasste laut den Obleiverzeichnissen des 16. Jahrhunderts nur noch Teile eines vormals zusammenhängenden Hofs, ${ }^{921}$ jedoch stand im Zentrum der Bildung dieses Fragment nicht allein der genannte Kautschenhof. Mit der Zeit kam zu dem Fragment noch ein holz, also ein Waldstück, zu Huppendorf und ein weiteres Gut in Königsfeld hinzu. Möglich war auch die Existenz einer Oblei neben einem Fragment in ein und derselben Ortschaft, die trotz dieses territorialen Nebeneinanders nicht zum Zwecke der vereinfachten Verwaltung zusammengelegt wurden, sondern als Einzelbesitzungen jeweils eigenständig verwaltet wurden. So können für das Stift St. Gangolf im 16. Jahrhundert beispielsweise in dem Ort Dürrbrunn (Lk Forchheim) zwei Obleien und zwei Fragmente nachgewiesen werden. ${ }^{922}$

Nachfolgend werden nun die vom Kapitel verwalteten Einzelobleien und Obleifragmente betrachtet, von denen für das Stift St. Gangolf anhand der Güterverzeichnisse 36 Verwaltungseinheiten festgestellt werden konnten. ${ }^{923}$

\section{Oblei Hundsbühl}

Die Oblei Hundsbühl, oder auch als wörtliche lateinische Übersetzung collocan (lat. collis - Hügel, lat. canis - Hund) genannt, war eine der größeren und daher bedeutenderen Einzelobleien des Stifts St. Gangolf, die ausschließlich Bamberger und vor allem Theuerstädter Gebiete umfasste. Hundsbühl bezeichnet dabei den Bamberger Straßenzug, der seit dem Ende des 19. Jahrhunderts als Nürnberger Straße bekannt ist. In den Obleiregistern des 16. Jahrhunderts, in denen erstmals ausführliche Obleibeschreibungen überliefert sind, ist die Oblei Hundsbühl

\footnotetext{
${ }^{920}$ Nöth: Urbare und Wirtschaftsordnungen. 1986. S. 99.

921 „Ist vor zeyten eyn hof gewesen, vor etlich vil jahren aber zertheilt worden und ist der Kautschenhof genandt, und alle nach folgende stuck darein gehört, seind alle des obleyhern lehen“ im Urbar über die Vikarien, Obleien und Fragmente (1317-1630) in StABa Stift St. Gangolf, Akten und Bände Nr. 32 fol. 24'.

922 Urbar über die Vikarien, Obleien und Fragmente (1317-1630) in StABa Stift St. Gangolf, Akten und Bände Nr. 32.

${ }^{923}$ Anhang Karte 3: Obleigut.
} 
vorrangig vor allen anderen Obleien aufgelistet und bis ins 17. Jahrhundert hinein lassen sich mehrere Dekane als Obleibesitzer nachweisen. ${ }^{924}$ Dies spricht für eine gewisse Gewichtung der Obleien untereinander, abhängig von deren Lage und Einkünften. Nur für die Oblei Hundsbühl ist anhand der Zinsregister eine lückenlose Verzeichnung aller Besitzer seit 1457 möglich, ${ }^{925}$ während für die anderen Obleien nichts dergleichen überliefert wurde. Dies zeigt, dass die stiftseigene Überlieferung schon im 17. Jahrhundert außerstande war, die Entwicklung ihres Obleibesitzes weiter zurück als bis ins 15. Jahrhundert zurückzuverfolgen. Der Grund hierfür lag wohl in den Raubzügen des Brandenburger Markgrafen Albrecht Alcibiades, welche verheerende Auswirkungen auf die Registratur des Stifts St. Gangolf aber auch auf die anderen Einrichtungen Bambergs hatten. ${ }^{926}$

Erste Stiftungen, die zur Oblei Hundsbühl gehörten, sind bereits für das Jahr 1357 nachweisbar, als drei Ehepaare dem Stift und besunder dem herren, der dieselbe obley leihet und innehat mehrere Äcker die do gelegen sindt inwendig den Sichen ihn der awe die do heist ihn den Pigen stifteten, ${ }^{927}$ und für das Jahr 1460, als das Gangolfer Kellereigericht eine Stiftung des Heinz Holzapfel und dessen Ehefrau Catherin an die obley des

\footnotetext{
${ }^{924}$ Dekane des Stifts St. Gangolf als Besitzer der Oblei Hundsbühl: Heinrich Konrad Jäger (amt. 1450) und Heinrich Glantz (amt. 1486-1491) laut dem Zinsregister des Scholastikus Neithard Gamper (amt. 1650-1653) von 1653 in StABa Stift St. Gangolf, Akten und Bände Nr. 41 fol. 28; Hieronimus Hirschberger (amt. 1512-1542) laut Urkunde vom 14. Dezember 1526 im Kopialbuch StABa Stift St. Gangolf, Akten und Bände Nr. 3 Teil 1 fol. 27-28‘; ebenso im Zinsregister von 1538 in StABa Stift St. Gangolf, Akten und Bände Nr. 20 fol. 4'-6; und Zinsregister des Scholastikus Neithard Gamper (amt. 1650-1653) von 1653 in StABa Stift St. Gangolf, Akten und Bände Nr. 41 fol. 28; sowie Moritz Weißhaupt (amt. 1542-1569) laut Zinsregister von 1555 in StABa Stift St. Gangolf, Akten und Bände Nr. 23 fol. 4-6' und fol. 61-63.

${ }^{925}$ Auflistung aller Besitzer seit 1457 im Zinsregister des Scholastikus Neithard Gamper von 1653 in StABa Stift St. Gangolf, Akten und Bände Nr. 41 fol. 28; und im Zinsregister von 1764 in StABa Stift St. Gangolf, Akten und Bände Nr. 65 Rückseite Titelblatt.

${ }^{926}$ Näheres dazu in Kapitel 2.2 Urkunden.

${ }^{927}$ Abschrift einer Urkunde vom 4. November 1357 im Kopialbuch StABa Stift St. Gangolf, Akten und Bände Nr. 3 Teil 2 S. 373-375 mit einer späteren Randnotiz „ad obleg. collocan“.
} 
Hundspühls Collocanum genant über ein Haus mit Hof und Garten an der Lausach bestätigte. ${ }^{928}$

Die Oblei Hundsbühl umfasste laut den Obleiregistern aus den Jahren $1555^{929}$ und $1567^{930}$ eine unbebaute Fläche genannt die Peunt zwischen Egelsee und der Kirche St. Gertraud, welche als Stiftung des Spitals Katharina ausgeschrieben wurde, ${ }^{931}$ weiterhin drei Häuser auf dem Hundsbühl, ${ }^{932}$ Güter in der Wunderburg, ${ }^{933}$ vier Häuser mit Hof an der Lausach, mehrere Häuser mit Höfen bei dem Kloster Heilig Grab ${ }^{934}$ und an der Litzendorfer Straße, sowie Äcker, Wiesen und Weiden in der Gaustadter Mark und nahe des Bamberger Stadtgebiets namens Piegen. ${ }^{935}$

Als Canones wurden an den Obleier zwei Pfund und siebeneinhalb Pfennigen sowie sechs Fastnachtshühnern gezahlt. Dem Kustos standen ebenfalls zwei Pfund und siebeneinhalb Pfennige zu und an das Amt des campanator ${ }^{936}$ waren sechs Schillinge Heller zu zahlen. ${ }^{937}$ Weiter hatte der Besitzer der Oblei Hundsbühl zahlreiche Obleibrote ${ }^{938}$ an verschiedene Stellen auszuteilen: Vier Obleibrote standen dem Dekan des Stifts St. Gangolf zu, zwei Obleibrote den Kanonikern des Stifts, die zur Zeit der Verteilung am Stift weilten, ein Brot an die Vikare, ein Brot dem campanator, 18 Brote dem Stift St. Stephan, 12 Brote dem Stift St.

\footnotetext{
${ }^{928}$ Abschrift einer Urkunde vom 1. Dezember 1460 im Kopialbuch StABa Stift St. Gangolf, Akten und Bände Nr. 3 Teil 2 fol. 244-247.

${ }^{929}$ Register der Obleizinsen (1555-1565) in StABa Stift St. Gangolf, Akten und Bände Nr. 23 fol. 4-6' und 61-63.

930 "Oblegium collocanum hundspuhel nuncupatur" im Urbar über die Vikarien, Obleien und Fragmente (1317-1630) in StABa Stift St. Gangolf, Akten und Bände Nr. 32 fol. 2-3".

${ }^{931}$ Näheres zur Peunt im Kapitel 4.3.4 Das Verhältnis zum Bürgerspital St. Katharina in Bamberg.

932 „Drey heuser neben am spitalhof nacheinander hinten an der mauer“.

933 "Als man uf Nornberg gehet“.

934 "Gegen dem Heiligen Grab uber an der Hohenstras als man gen Halstat gehet“.

935 „Wissen, eckern, paumfeldern und weyden gelegen unter der stat Bamberg im Bigen“.

936 Dieses Amt ist in sonst keinem anderen Schriftzeugnis beschrieben, bezeichnet nach seiner Wortbedeutung (lat. campana - Glocke) den Glöckner. Näheres im Kapitel 4.2.4 Kustos und Kirchner.

${ }^{937}$ Die Canones im Zinsregister von 1555 in StABa Stift St. Gangolf, Akten und Bände Nr. 23 fol. 63; und im Zinsregister von 1567 in StABa Stift St. Gangolf, Akten und Bände Nr. 32 fol. 3 .

938 „Panes primarios vulgariter obleyprot“.
} 
Jakob, 20 Brote dem Karmeliterkloster und zehn Brote an die Bamberger Franziskaner (fratres minores). Der Umfang der Besitzungen, die durch die Oblei Hundbühl verwaltet wurden, blieb bis zur Auflösung des Stifts konstant, wie dies aus dem Register der Oblei von 1764 hervorgeht. ${ }^{939}$ Dort ist auch eine Notiz über die Übernahme der Erbzinserträge in das Grundbuch der neuen Herrschaft vom 25. Januar 1820 überliefert.

\section{Oblei Estuarium}

Die Oblei Estuarium bestand aus rein Theuerstädter Besitzungen. Diese umfassten laut den Obleiregistern des 16. Jahrhunderts ein Haus mit Platz und Garten neben der badstuben am Steinweg in der munthat und weitere zwei Häuser in dessen Nachbarschaft, worauf Canones von sieben Pfennigen zweimal jährlich lagen. ${ }^{940}$ Eine zusätzliche im Obleiregister von 1567 hinzugefügte Notiz von 1571 gibt darüber hinaus Auskunft, dass zum Besitzstand der Oblei Estuarium außerdem ein Haus mit Garten in der Mitelgassen und eine Hofstat daneben gehörte. ${ }^{941}$ Zwei dieser Häuser mit Hof und Garten ihn der muntät $z u$ Teurstat zwischen der badstuben und [...] hinab bis an die Hintergas können bereit für das Jahr 1403 gefasst werden, als der Dekan von St. Gangolf und das Kapitel gegen die Witwe des Konrad Treppendorfer und deren Söhne Fritz und Konrad wegen ausstehender Zinsen klagten und betont wurde, also des derselbe heuser, hofstet und gärten mit ihren zugehören waren ein obley. ${ }^{942}$ Woher die Bezeichnung oblegium Estuarium (lat. aestuarium = Bucht,

\footnotetext{
${ }^{939}$ Register über Obleizinsen (1764-1809) in StABa Stift St. Gangolf, Akten und Bände Nr. 65 fol. 1.

940 Oblei „Estuarium“ im Zinsregister von 1538 in StABa Stift St. Gangolf, Akten und Bände Nr. 20 fol. 7; Oblei „Estuarium“ im Zinsregister von 1548 in StABa Stift St. Gangolf, Akten und Bände Nr. 22 fol. 14; „oblegium Estuarium“ im Zinsregister von 1555 in StABa Stift St. Gangolf, Akten und Bände Nr. 23 fol. 10; „oblegium Estuarium alias officialis genandt“ im Zinsregister von 1567 in StABa Stift St. Gangolf, Akten und Bände Nr. 32 fol. 11.

${ }^{941}$ Zinsregister von 1567 in StABa Stift St. Gangolf, Akten und Bände Nr. 32 fol. 11.

${ }^{942}$ Urkunde vom 8. Juli 1403 im Kopialbuch in StABa Stift St. Gangolf, Akten und Bände Nr. 3 Teil 3 S. 156-158; Eine spätere Randnotiz ordnet diesen Rechtsvorgang der „oblegiis Aestuariis vel officialis“ $\mathrm{zu}$.
} 
Flussmündung) stammt, ist bisher ungeklärt. Denkbar wäre ein Zusammenhang mit der relativen Nähe der Häuser und Höfe zum Fluss Regnitz. ${ }^{943}$

\section{Oblei Scriniatricis}

Ebenfalls aus Gütern in der Bamberger Theuerstadt bestand die Oblei Scriniatricis. Drei Häuser am Steinweg bei der Kirche St. Gertraud bildeten zusammen mit dazugehörigen Gärten und Höfen die Verwaltungseinheit, von deren Einnahmen der Obleiherr 25 Schillinge an das Stift St. Gangolf zu bezahlen hatte. ${ }^{944}$

Auf eines dieser Häuser mit Hof und Garten ihn der muntat zu Teurstat gegen s. Gerdrauten uber verkaufte Anna Hoffman und ihre Tochter Else bereits im Jahr 1456 ein Ewiggeld an den Dekan und das Kapitel des Stifts St. Gangolf und besonders an den Scholastikus Engelhard von Güßbach (amt. 1435-1463)

der des obgenanten erbes ein rechter lehenherr ist, als von eines obleys wegen Scriniatricis ihn des genanten stieftsbuchern genant. ${ }^{945}$

Diese Oblei existierte also bereits weit vor der Mitte des 15. Jahrhundert. Jedoch wird auch an dieser Stelle in keinen der mittelalterlichen Quellen der Ursprung der Obleibezeichnung „Scriniatricis“ angesprochen oder gar geklärt. ${ }^{946}$

943 Michel Hofmann deutet ein „estuarium“ als eine Art Sauna und sieht die Namensherkunft in Anlehnung an die benachbarte Badstube begründet. Auf welche sprachliche Grundlage er diese Vermutung stützt, bleibt jedoch offen. In Hofmann: Die Bamberger Stifts-Obleien und ihre Namenswelt. 1962. S. 36.

944 Oblei „Scriniatricis“ im Zinsregister von 1548 in StABa Stift St. Gangolf, Akten und Bände Nr. 22 fol. 12-12“; „oblegium Scriniatricis“ im Zinsregister von 1555 in StABa Stift St. Gangolf, Akten und Bände Nr. 23 fol. 15'; „oblegium Scriniatricis“ jedoch mit Canones von 30 Schillingen im Zinsregister von 1567 in StABa Stift St. Gangolf, Akten und Bände Nr. 32 fol. 11.

${ }^{945}$ Urkunde vom 29. Oktober 1456 im Kopialbuch in StABa Stift St. Gangolf, Akten und Bände Nr. 3 Teil 3 S. 111-113.

946 Denkbar wäre eine Ableitung von lat. scrinium - Schrein, Kapsel, Behälter zu Aufbewahrung von Büchern oder Papieren, was jedoch die Bedeutung der Oblei weiterhin unklar ließe. Michel Hofmann versuchte sich an der Deutung als „Oblei der schreinerin“ nach dem Genitiv von lat. scriniatrix - Schreinerin. In Hofmann: Die Bamberger StiftsObleien und ihre Namenswelt. 1962. S. 36. Doch obwohl es durchaus denkbar wäre, dass sich der Grundstock der Oblei aus dem Hof einer Schreinerswitwe heraus gebildet hat, existiert der Begriff „scrinatrix“ im Lateinischen nicht, sodass höchstens an eine, im Latein 


\section{Oblei Anshelmi}

Die Oblei Anshelmi umfasste ausschließlich einen Garten in der Theuerstadt am genglein gelegen so man zum Heiligen Grab gehet. ${ }^{947}$ Ihre Bezeichnung hatte die Oblei aufgrund eines Hofes erhalten, der einem Mann namens Anshelm gehörte und an den sich der besagte Garten anschloss. ${ }^{948}$ Die an dieser Stelle im Obleiregister von 1567 genannten sieben Schillinge, 21 Pfennige und zwei Hühner Abgaben bezeichneten vermutlich, auch aufgrund des Vergleichs mit Angaben in den kopial überlieferten Urkunden, die Zinsbelastung des Gutes und weniger die Canones der Oblei. Dies wirft jedoch die Frage auf, ob der Obleiherr der Oblei Anshelmi keine Canones zu bezahlen hatte und falls doch, warum es das Obleiregister nicht vermerkte. Da jedoch auch die früheren Obleiregister die Canonesbelastung des Gartens nicht erwähnen, muss die Frage vorerst unbeantwortet bleiben. ${ }^{949}$

Aus dem 15. Jahrhundert sind zwei Klagen überliefert, in denen die jeweiligen Obleiherren vorgeführt wurden, Abgaben nicht geleistet zu haben. Dies ist zum einen Konrad Wurm, Kustos von St. Gangolf (amt. 1444-1448), der 1446 gegen einen Seyfrid Schmid wegen ausstehender Zinsen über sieben Schillinge und zwei Fastnachtshühner auf einen Garten

derselb garten sey ein obley des vorgenanten stifts [klagte] und sey auch genant nemlich unter andern obleyen ihres stiefts der gart hinter des Anshelms hof und gehe von ihme und von eine itzlichen der do sey ein besitzer desselben obleyes zu lehen. 950

Obwohl ein Garten in der Nähe des Klosters Heilig Grab durch seine unmittelbare Nachbarschaft zum Stift St. Gangolf wohl leicht zu verwal-

des Spätmittelalters nicht unübliche, Bedeutungsübertragung von Schrein auf Schreiner in Betracht gezogen werden könnte.

947 Zinsregister von 1567 in StABa Stift St. Gangolf, Akten und Bände Nr. 32 fol. 19‘.

948 „Nota dise obley wirt also genant das diser garten gelegen hinter des Anshelms hofreyt [...] und gibt jerlich VII schilling pfennig alter Bamberger muntz, thut $21 \mathrm{~d}$ und 2 pulles“ im Zinsregister von 1567 in StABa Stift St. Gangolf, Akten und Bände Nr. 32 fol. 19‘.

949 „Oblegium Anshelmi“ im Zinsregister von 1564 in StABa Stift St. Gangolf, Akten und Bände Nr. 25 fol. 57; „oblegium Anshelmi“ im Zinsregister von 1567 in StABa Stift St. Gangolf, Akten und Bände Nr. 32 fol. 19'.

${ }^{950}$ Urkunde vom 31. Februar 1446 im Kopialbuch in StABa Stift St. Gangolf, Akten und Bände Nr. 3 Teil 2 S. 279-282. 
ten und die Abgabenleistungen leicht $\mathrm{zu}$ kontrollieren gewesen sein mussten, klagte im Jahr 1474 der Gangolfer Keller Georg Rephuhn (amt. 1441-1481) als Obleiherr der Oblei Anshelmi gegen einen Heinz Treiser wegen nicht erfolgter Abgaben von zwei Fastnachtshühnern und 21 Pfennigen auf einen Garten, der durch spätere Randnotizen ad oblegium Anshelmi zugeordnet wurde. ${ }^{951}$

\section{Fragment Hintergass genannt Huppendorferin}

Das Fragment mit dem Namen Hintergass genannt Huppendorferin kann bei der Quellenlektüre aufgrund der Namensähnlichkeit durchaus mit der Gangolfer Oblei Huppendorf verwechselt werden. Jedoch haben diese beiden Besitzkomplexe nicht viel miteinander zu tun, da sich die Oblei Huppendorf nahe der Gemeinde Königsfeld (Lk Bamberg) befand, während sich das hier behandelte Fragment nach der Hintergasse in der Bamberger Theuerstadt (die heutige Heiliggrabstraße) beziehungsweise nach dem Familiennamen einer vermuteten, aber durch die Quellen nicht nachgewiesenen, Vorbesitzerin namens Huppendorfer benannte.

Das Fragment Hintergass genannt Huppendorferin bestand aus drei Häusern, wovon eines an der Straße zum Kloster Heilig Grab und zwei in der Mittelgasse in der Theuerstadt lagen. ${ }^{952}$ Die Canones, die der Obleiherr aus den Einkünften an das Kapitel zu zahlen hatte, betrugen fünf Schillinge an den Obleier. Die erste Erwähnung des Fragments findet sich bereits für das Jahr 1446 in der Obleimatrikel des Stifts St. Gangolf. ${ }^{953}$

Im 16. Jahrhundert lässt sich aus den Urkunden ein Ewigzins von einem Gulden auf einem Haus mit Hof ihn der Mittelsgasen gelegen, das dann von obgedachten hern Michel Stadler als obleyherrn zu zinslehen

${ }^{951}$ Urkunde vom 10. Januar 1474 im Kopialbuch in StABa Stift St. Gangolf, Akten und Bände Nr. 3 Teil I fol. 7-8‘.

952 Fragment „Hintergas alias Huppendorf zu wartz dem Heiligen Grabe“ im Zinsregister von 1538 in StABa Stift St. Gangolf, Akten und Bände Nr. 20 fol. 2; „fragmentum Huppendorf alias Hintergas" im Zinsregister von 1555 in StABa Stift St. Gangolf, Akten und Bände Nr. 23 fol. 65“; „fragmentum Hintergas alias Huppendorferin“ im Zinsregister von 1567 in StABa Stift St. Gangolf, Akten und Bände Nr. 32 fol. 30.

${ }^{953}$ Eintrag in der Obleimatrikel (1433-1663) für das Jahr 1446 in StABa Stift St. Gangolf, Akten und Bände Nr. 192 fol. IV. 
rurendt nachweisen. Die jährliche Abgabe zur Sicherung des Totengedenkens hatten ein Hans Schlainhaufen und dessen Ehefrau Barbara im Jahr 1510 an den Gangolfer Dekan, an das Kapitel und besonders an Michael Stadler, Kanoniker des Stifts St. Gangolf, aus mercklicher unser notturft, nutz und frummens willen verkauft und dafür zehn Gulden erhalten. ${ }^{954}$ Dass diese zusätzlichen Einkünfte dem Fragment Hintergass genannt Huppendorferin zugeordnet wurden, erschließt sich aus der Randnotiz oblegii Mittelgassen betreffend, die offensichtlich später handschriftlich hinzugefügt wurde.

\section{Oblei Curia farinae}

Die Oblei Curia farinae, wörtlich „Mehlhof“, ist keineswegs ein Hinweis auf eine Mühle oder ein anderes mehlverarbeitendes Anwesen in der Theuerstadt. ${ }^{955}$ Vielmehr leitete sich der Name der Oblei von der Familie Mehlmeister ab, welche den besagten Hof bereits weit vor der Mitte des 15. Jahrhundert inne gehabt haben musste. Dies belegt eine Urkunde von 1446, in der vor dem bischöflichen Salgericht zu Bamberg die Klage des Hans Hoffman, Kanoniker des Stifts St. Gangolf, gegen Hans Löffelholz aus Nürnberg ausgetragen wurde, in dem Letzterem vorgeworfen wird, einen Hof zu Teurstat an der Lausach gelegen der etwan dem Meelmeister gewesen ist vom Bischof als freies Mannlehen verliehen bekommen zu haben, obwohl der Hof des gemelten stifts lauter frey eigen obley sey und ihm auch itzlichen ie zu zeiten obleyherrn desselben obleyes jerlichen zinst und gilt und der Löffelholz keine der üblichen Zinsen und Gült bezahlt hätte. Der Schaden beliefe sich auf 400 Gulden. Hoffman führt aus, dass die Löffelholzer

dadurch demselben stieft die eigenschaft entwenden und entfrembden wolten, die doch der obgenant stift vor hundert iaren herbracht und an dem hof gehabt hat, auch so hetten die Meelmeister der solcher hof vor alter gewest war, als lang sie den inne gehabt hetten, einen itzlichen obleyherrn ie zu zeiten deselben hof alle iar ierlichen die zins und gült darum geben und gereicht.

954 Urkunde vom 19. November 1510 im Kopialbuch in StABa Stift St. Gangolf, Akten und Bände Nr. 3 Teil 2 S. 255-257.

${ }^{955}$ Michel Hofmann vermutet fälschlicherweise in der Obleibezeichnung einen Hinweis auf die Zeit der Vita communis und einer gemeinsamen Küche. In Hofmann: Die Bamberger Stifts-Obleien und ihre Namenswelt. 1962. S. 36. 
Das Urteil lautet zugunsten des Stifts. ${ }^{956}$ Will man die Urkunde wörtlich nehmen, so war der Hof der Familie Mehlmeister schon seit der Mitte des 14. Jahrhunderts im Besitz des Stiftes St. Gangolf.

Diese Oblei ist ein gutes Beispiel für die Austauschbarkeit der Klassifizierungen „Oblei“ und „Fragment“. Während die Obleimatrikel für das Jahr 1445 von einem oblegium seu fragmentum magistri farine, seu curie farine spricht, ${ }^{957}$ ordneten die Obleiregister des 16. Jahrhunderts diese Verwaltungseinheit ganz klar als Oblei ein. Besitzungen, die in diese Oblei fallen, sind ein Haus bey dem thor et etiam de prato et agro uf der peundt, ein Haus mit Hof und Garten neben dem Schulgeslein sowie ein Haus mit Hof und Garten der Melbhof genannt den Loffelholzern zustendig und von vier oder funf eckern im Pfaffengeheid. ${ }^{958}$ Die Canonesbelastung der Oblei betrug laut den Obleiregistern zwischen drei Schillingen zweimal jährlich und zehn Schillingen Heller einmal jährlich.

\section{Officium procurationis}

Ob es sich bei dem officium procurationis, wörtlich übersetzt „dem Verwaltungssamt“, um eine Einzeloblei handelte, ist auf den ersten Blick nicht leicht zu beantworten. Auf der einen Seite wird dieses „Amt“ in den meisten Quellen nicht explizit als Oblei oder Fragment klassifiziert. Auf der anderen Seite ist es sowohl in der Obleimatrikel ${ }^{959}$ als auch in den Obleiregistern des 16. Jahrhunderts ${ }^{960}$ in einer Reihe mit all den anderen Einzelobleien aufgeführt und mit Canones von drei Schillingen und 18 Pfund an die anwesenden Gangolfer Kanoniker, von ei-

956 Urkunde vom 25. August 1446 im Kopialbuch in StABa Stift St. Gangolf, Akten und Bände Nr. 3 Teil 2 S. 92-98.

${ }^{957}$ Eintrag in der Obleimatrikel (1433-1663) für das Jahr 1445 in StABa Stift St. Gangolf, Akten und Bände Nr. 192 fol. III.

958 „Oblegium curia farinae“ im Zinsregister von 1518 in StABa Stift St. Gangolf, Akten und Bände Nr. 20 fol. 38-40; Oblei „curia farinae“ im Zinsregister von 1555 in StABa Stift St. Gangolf, Akten und Bände Nr. 23 fol. 9‘-10; „curia farinae“ im Zinsregister von 1567 in StABa Stift St. Gangolf, Akten und Bände Nr. 32 fol. 10-10‘.

${ }^{959}$ Die erste Erwähnung in der Obleimatrikel (1433-1663) für das Jahr 1449 in StABa Stift St. Gangolf, Akten und Bände Nr. 192 fol. IV‘.

960 „Officium procurationis iam oblegium“ im Zinsregister von 1555 in StABa Stift St. Gangolf, Akten und Bände Nr. 23 fol. 1-3; „officium procurationis“ im Zinsregister von 1567 in StABa Stift St. Gangolf, Akten und Bände Nr. 32 fol. 13-14. 
nem Pfund und viereinhalb Schillingen zu zahlen an den Obleier sowie von zwölf Schillingen an das Gangolfer Fabrikamt belastet. ${ }^{961}$ Seine Einkünfte bezog der Inhaber dieser Verwaltungseinheit dabei vorwiegend aus Theuerstädter Besitzungen, und zwar aus 15 Häusern teilweise mit Gärten in der Siechengasse, am Steinweg, in der Mittelgasse, vor dem Gangolfer Tor oder auf dem Hundsbühl, sowie aus mehreren Feldern und Wiesen in Pretzfeld (Lk Forchheim) und Ebermannstadt (Lk Forchheim). Sowohl Besitzungen als auch die Belastung durch die Canones weisen das Officium procurationis als einträgliche Verwaltungseinheit aus, welche schon früh in den Quellen Erwähnung fand. So belegt eine Urkunde von 1332 die Stiftung von mehreren Häusern und Gärten auf dem Hundsbühl samt Erbrecht durch Heinrich von Rotenstein, Kanoniker des Stifts St. Gangolf, an den Dekan und das Kapitel St. Gangolf zur Begehung seines Jahrtages und versah die Schenkung mit dem Zusatz

de quo quodem censu volo et ordino panos triticii, pro praedictos dominos procurari et inter ipsos cuilibet canonicos presentibus tum unus panem distribui.

Dies alles sollen die Beschenkten verobleyen. ${ }^{962}$ Die Bezeichnung des Dekans und der Kanoiker als Herren der Verwaltung (domini procurari) wird hier wohl der Ursprung des Eigennamens der Verwaltungseinheit Officium procurationis sein. Unklar bleibt jedoch, inwieweit sich diese „Verwaltung" von den Verwaltungen der anderen Einzelobleien unterschied.

In der ersten Hälfte des 15. Jahrhunderts kam es zu mehreren Streitfällen zwischen dem Dekan und dem Kapitel des Stifts St. Gangolf, in denen es unter anderem auch um das Officium procurationis ging. So belegt eine Einigung aus dem Jahr 1415 zwischen Heinrich von Rota, Dekan des Stifts (amt. 1412-1416), unter anderem mit Heinrich Forstmeister als Obleier, Johann Künlein als Scholastikus (amt. 1415-1422) und Johann Fere als Keller (amt. 1414-1440):

${ }^{961}$ Diese Canonesangaben sind nur im Zinsregister von $1567 \mathrm{zu}$ finden. In StABa Stift St. Gangolf, Akten und Bände Nr. 32 fol. 14.

962 Urkunde vom 12. Mai 1332 im Kopialbuch in StABa Stift St. Gangolf, Akten und Bände Nr. 3 Teil 2 S. 106-107. 
Item als die hern des capitels dem dechant die procurationis oder die pfleg umb etliche höfe ahn der Lausach entfehlen haben, scheid und sprich das der dechant den herren des capitels seinen offen versigelten brief geben und sich darinnen verschreiben soll, das dieselbige procurationis oder pfleg nicht anhangend und zugefuget sey der dechaney und auch nicht darzu gehöre, sundern des sie des stifts sey und den herren allen zugehore. ${ }^{963}$

Der Dekan schien seinen Einfluss auf diese doch einträgliche Verwaltungseinheit weiter ausgedehnt zu haben, als es bei einem Obleiherren sonst üblich war und strebte gar nach einer Einverleibung in seine Dekanei, sodass sie dem Amt des Dekans, nicht aber dem Kapitel von Nutzen gewesen wäre. In den Folgejahren finden sich weiterhin Gangolfer Dekane als Obleiherren des Officium procurationis, jedoch unter kapitlischer Oberaufsicht. So bekennt Heinrich Jäger, Dekan zu St. Gangolf (amt. 1450), nur wenige Jahre später im Jahr 1450:

das die erbarn meine lieben herren von dem capitel des obgenannten unser lieben frawen zu Teurstat von meiner vleisigen bitt und dinst wegen, die ich hinvor der obgeschrieben kirchen und vermeine zu thun, mir solche freundtschaft wider willen beweist haben, das sie mir gelasen haben die procuration alle iar einzunemen und zufordern gelt, zins und hüner und was anders darvon gefellet, und soll und will ihn davon alle iar ein rechnung thun und sie davon gutlichen bezahlen als herkommen ist. $^{964}$

Auch in dem bereits oben erwähnten Obleiregister von 1555 befindet sich das officium procurationis zwar in der Hand des Dekans Moritz Weißhaupt (amt. 1542-1562), jedoch ist dies eine der wenigen Quellen, in der das Verwaltungsamt deutlich als Oblei bezeichnet wird und auch die Canones, als Beitrag zur Versorgung des Stiftskapitels, Erwähnung finden. ${ }^{965}$

Die Frage nach dem Obleistatus des Officium procurationis sorgte auch bei den Kanonikern des mittelalterlichen Stifts St. Gangolf für Unstimmigkeiten, die mit der Obleiverteilung einhergingen. Im Jahr 1491 gab der Gangolfer Dekan Heinrich Glantz (amt. 1486-1491) sein Amt im Tausch ab, sodass dessen Obleibesitzungen im üblichen Turnus

\footnotetext{
${ }^{963}$ Urkunde vom 28. September 1415 im Kopialbuch in StABa Stift St. Gangolf, Akten und Bände Nr. 3 Teil 1 fol. 19'-21‘.

${ }^{964}$ Urkunde vom 11. November 1450 im Kopialbuch in StABa Stift St. Gangolf, Akten und Bände Nr. 3 Teil 3 S. 6.

965 „Officium procurationis iam oblegium“ im Zinsregister von 1555 in StABa Stift St. Gangolf, Akten und Bände Nr. 23 fol. 1-3.
} 
neu verteilt werden sollten. ${ }^{966}$ Der Kanoniker Konrad Weiß forderte nun das Officium procurationis für sich, da er als nächster im Verteilungsturnus an der Reihe wäre, und weigerte sich dessen Status als Dekansoblei anzuerkennen. Vielmehr betonte er, dass es sich nur um ein officium handeln würde. Das Kapitel legte in einer innerstiftischen Anhörung von dieser Argumentation unabhängig fest,

dass das officium das were ein oblei und er und ander vor im hetten das yetzuzeiten in teilung der obley zu mermalen für obley genomen. ${ }^{967}$

\section{Oblei Lerchgrub}

Die kleine Oblei Lerchgrub bestand aus einer Wiese und einem Acker, gelegen im Piegen oder alias Lichtenheidt, auf welchen Canones von fünf Schillingen lagen. ${ }^{968}$ Obwohl die Güter bereits 1357 als Besitz des Kapitels nachweisbar sind ${ }^{969}$ und auch in der Obleimatrikel für das Jahr 1445 Erwähnung finden, ${ }^{970}$ ist die Identifizierung ihrer genauen Lage schwierig. Zu vermuten sind die Wiese und der Acker in Richtung des heutigen Bamberger Stadtteils Hallstadt, wo noch heute sowohl eine Lichtenhaidestraße als auch eine Biegenhofstraße in ungefährer Nachbarschaft liegen. ${ }^{971}$ Dieses Gebiet befindet sich ähnlich wie die Theuerstadt auf der östlichen Seite der Regnitz, in einer Verlängerung der Siechenstraße, sodass eine Verbindung zum Stift St. Gangolf durchaus denkbar wäre.

\footnotetext{
${ }^{966}$ Näheres zur Vergabepraxis der Obleien im Kapitel 6.4.1.3 Verteilungsmodalitäten der Obleien.

${ }^{967}$ Eintrag in der Obleimatrikel (1433-1663) für das Jahr 1491 in StABa Stift St. Gangolf, Akten und Bände Nr. 192 fol. VII‘.

968 „Oblegium Lerchgrube alias in den pigen“ im Zinsregister von 1538 in StABa Stift St. Gangolf, Akten und Bände Nr. 20 fol. 7‘; Oblei „Lerchgrub“ im Zinsregister von 1548 in StABa Stift St. Gangolf, Akten und Bände Nr. 22 fol. 16; „oblegium Lerchgrub alias in den pigen oder Lichtenheidt“ im Zinsregister von 1567 in StABa Stift St. Gangolf, Akten und Bände Nr. 32 fol. 12،

969 Notiz über die Verleihung der Güter der Oblei Lerchgrub an Herman Gertner und dessen Ehefrau Else durch das Stift St. Gangolf am 4. November 1357 im Zinsregister von 1567 in StABa Stift St. Gangolf, Akten und Bände Nr. 32 fol. 12‘.

${ }^{970}$ Eintrag in der Obleimatrikel (1433-1663) für das Jahr 1445 in StABa Stift St. Gangolf, Akten und Bände Nr. 192 fol. III.

971 Einordnung der Lichtenhaidestraße in Exner/ Ruderich: Theuerstadt und östliche Stadterweiterungen. 2019. S. 951.
} 


\section{Oblei Wattlauben}

Die Oblei Wattlauben bestand streng genommen aus drei Fragmenten, von denen jedes jährlich ein Pfund Zins an seinen Gangolfer Obleiherren zu geben hatte. Diese drei Pfund Zinsen lagen auf einem Haus genannt Wattlauben am Markt in der Stadt Bamberg und wurden durch städtische Bevollmächtigte des Burgerhofes ${ }^{972}$ eingenommen und an das Stift ausgezahlt. ${ }^{973}$ Der Umstand, dass das städtische Bauamt in die Abgabenpraxis des Stiftes eingebunden war, erklärt sich aus der Tatsache, dass das Baumeisteramt zahlreiche Verwaltungsaufgaben umfasste, einschließlich die Verwaltung des städtischen Immobilienbesitzes samt der Mieteinnahmen. ${ }^{974}$ Canones lagen auf dieser Oblei nicht und die Einnahmen aus den drei Obleifragmenten konnten auch einzeln an Kanoniker des Stifts verteilt werden. ${ }^{975}$

Eine erste Erwähnung des Hauses Wattlauben in Bamberg mit Bezug auf das Stift St. Gangolf findet sich in der Abschrift einer Urkunde

972 Der städtische Bauhof „Burgerhof“ am Heumarkt in Bamberg als städtischer Bauhof und Sitz des Stadtschreibers ist spätestens seit dem 15. Jahrhundert nachweisbar und wird heute als Universitätsgebäude genutzt. Näheres zu Lage und Baugeschichte in Breuer/ Gutbier: Stadt Bamberg, Teil 5/1. 1990. S. 313-326.

973 „Oblegium Watlauben“ im Zinsregister von 1538 in StABa Stift St. Gangolf, Akten und Bände Nr. 20 fol. 4; "tria oblegia Watlauben seu fragmenta“ im Zinsregister von 1567 in StABa Stift St. Gangolf, Akten und Bände Nr. 32 fol. 9‘: "Nota sunt tria oblegia sic nuncupata, und ein yeglichs obley hat $1 \mathrm{lb}$ jerlichs zins Martini zu geben, und ist solcher zins gestanden uf des Anthonii Erbeyters behausung am marckt, und ist derselbig zins geschlagen uf der burgerhof zu Bamberg, und ein erbar ratsherren richten solchen zins furbas ewiglich aus, und mit gefordert an paumeister oder schreiber doselbsten, videlicet“. 974 Göldel: Der Bamberger Bauhof. 1987. S. 231-232.

${ }^{975}$ So gehörte dem Gangolfer Kanoniker Johann Himpel in den Jahren 1521 bis 1529 u. a. der Besitz „Watlauben primum dant cives im borgerhof zu Bamberg $1 \mathrm{lb}$ Martini“. Im Zinsregister von 1518 in StABa Stift St. Gangolf, Akten und Bände Nr. 20 fol. 24; dem Gangolfer Dekan Moritz Weißhaupt (amt. 1542-1569) gehörte 1555 u. a. der Besitz "fragmentum Wattlauben tertium“ und er bemerkte dazu, dass der „bauschreiber in burgershof von dem bauhof daselbsten $1 \mathrm{lb}$ Martini“ abzugeben hätte. Außerdem notierte er: „dies fragmentum gibt keine canones“. Im Zinsregister von 1555 in StABa Stift St. Gangolf, Akten und Bände Nr. 23 fol. 3; Und der Gangolfer Scholastikus Johann Sparwasser (amt. 1562-1598) hatte 1564 Ansprüche $u$. a. auf einen Pfund aus der Oblei „Wattlauben primum“, genauer aus einem Hof „cives Bambergenses dant annuatim aus dem burgerhof so der bauhemeyster itzt Adam Halbritter ausricht zu dem ersten Watlauben genant“. Im Zinsregister von 1564 in StABa Stift St. Gangolf, Akten und Bände Nr. 25 fol. 108: 
von 1303, in der der Dekan und das Kapitel das domum nostram iure hereditario in foro Bambergensi sitam, quae vulgariter dicta Watlauben an Siegfried von Kunstadt und dessen Frau Kunigunde verliehen. ${ }^{976}$ Eine spätere Randnotiz dort erwähnt die Zuordnung ad oblegiis Watlauben quondam domo in foro Bambergensis. Die Verwaltungspraxis der Oblei Wattlauben unterschied sich damit in vielerlei Hinsicht von der der anderen Gangolfer Obleien. Eine Besitzung des Stifts St. Gangolf auf der Bamberger Inselstadt am Markt und eine wichtige städtische Amtseinrichtung wie das Burgerhaus, das die Einnahme der Zinsverpflichtungen regelte - der Einfluss der Bürgerstadt Bamberg ist unübersehbar. Doch das Stift hatte noch andere Güter auf der Inselstadt, wie die Oblei Retro sanctum Martinum oder das Fragment In foro, die jedoch in der üblichen Form der Obleiverwaltung organisiert gewesen sind, das heißt mit Canones belastet waren und der alleinigen Zuständigkeit des Obleiherren unterlagen. Es stellt sich die Frage, warum die Verwaltung der Einkünfte dieser Oblei über den städtischen Burgerhof erfolgte. Wurden Baumeister und Stadtschreiber für ihre Dienste bezahlt und, wenn ja, wovon und wieviel erhielten sie? Welchen Nutzen hatte das Stiftskapitel von dieser Oblei, wenn doch keine Canones erhoben wurden? Ging vielleicht der gesamte Betrag von einem Gulden pro Fragment an diese städtischen Ämter, um sie für jährlich anfallende Dienste für das Stift St. Gangolf zu bezahlen? Leider sind die notizhaften Ausführungen in den Zinsregistern dürftig und es fehlen Vergleichspunkte mit anderen Einrichtungen, um das an dieser Stelle umfassend klären zu können.

\section{Fragment In foro}

Nicht weit von dem Haus am Bamberger Markt, das den Zins der Oblei Wattlauben begründete, müssen zwei Häuser gelegen haben, die in einem Gangolfer Fragment mit der Bezeichnung In foro verwaltet wurden. Bereits für das Jahr 1445 erwähnte die Obleimatrikel zwei Häu-

976 Urkunde vom 21. März 1303 im Kopialbuch in StABa Stift St. Gangolf, Akten und Bände Nr. 3 Teil 3 S. 333-334. 
ser, die in dieses Fragment gefallen sind. ${ }^{977}$ Jedoch weist das Fragment nicht die Kontinuität an Besitzbestand und Zahlungsmodalitäten auf, die man bei den anderen Verwaltungseinheiten - ob Oblei oder Fragment - beobachten kann. Schon rund ein Jahrhundert später bestand das Fragment nicht mehr aus zwei Häusern am Markt, sondern aus einem Haus am Hundsbühl in der Theuerstadt. ${ }^{978}$ Die Bezeichnung in foro blieb jedoch erhalten, obwohl nun keine Verbindung mehr zum städtischen Marktplatz bestand.

Auch die Abgabenpflichten, die auf den Grundstücken lagen, erfuhren in dieser Zeit einen Wandel. So findet sich in dem Obleiregister von 1567:

Nota dise behausung gibt jerlich I fl zu die fabrica, davon sol ein obleyer dem obleyhern geben I orth, von wegen des fragments, hat canones vorzyten geben 25 solidi Walpurgis und 25 solidi Martini [...] itzt gibt's nur XXX solidi canones, und nur die fabrica und nicht den obleyher ausrichten.

Desweiteren wird an gleicher Stelle die Güterveränderung erwähnt, jedoch ohne diese näher zu erläutern:

Olim fragmentum in foro, Jorg Zolner und der Zader schuster geben jerlich von irn zweien heusern aneinander vorn am marckt und hinten an unser liben frauen brudercloster gelegen II lb Walpurg II lb Martini oder 60 solidi Thomae alweg fellig gewest. ${ }^{979}$

\section{Oblei Retro sanctum Martinum}

Die erste von den wenigen Nachrichten über die Oblei retro sanctum Martinum stammt aus dem Jahr 1446, festgehalten in der Obleimatrikel des Stifts St. Gangolf, ${ }^{980}$ in der, ganz der Quellengattung entsprechend, nicht mehr als der bloße Name der Oblei genannt wird. Erst in dem Obleiregister von 1567 lässt sich die Spur der Oblei wieder aufnehmen,

\footnotetext{
977 Eintrag in der Obleimatrikel (1433-1663) für das Jahr 1445 in StABa Stift St. Gangolf, Akten und Bände Nr. 192 fol. III.

978 „Oblegium in foro“: ein „haus am hunzpuehel gibt 1 ort Martini“ im Zinsregister von 1555 in StABa Stift St. Gangolf, Akten und Bände Nr. 23 fol. 11; „fragmentum in foro“: Eckhaus „ufm hundspuhel bey den brunnen gelegen“ im Zinsregister von 1567 in StABa Stift St. Gangolf, Akten und Bände Nr. 32 fol. 10.

${ }^{979}$ Zinsregister von 1567 in StABa Stift St. Gangolf, Akten und Bände Nr. 32 fol. 10.

${ }^{980}$ Eintrag in der Obleimatrikel (1433-1663) für das Jahr 1446 in StABa Stift St. Gangolf, Akten und Bände Nr. 192 fol. IV.
} 
jedoch dort bereits mit dem Verweis iam vacat. ${ }^{91}$ Die drei darin genannten Häuser auf dem Schutgraben mit Canones von acht Pfennigen waren demnach wohl nie besonders einträgliche Besitzungen, die trotz ihrer Lage nahe des Stifts St. Gangolf - vermutlich ist mit retro sanctum Martinum das Gebiet zwischen der Bamberger Pfarrkirche St. Martin und dem östlichen Regnitzarm gemeint - nicht leicht zu verwalten waren.

\section{Oblei Longa platea}

Die Oblei longa platea ist ein weiteres Beispiel für Gangolfer Besitzungen in der Bamberger Bürgerstadt, gemäß ihrer Bezeichung in der Langgasse (heute Lange Straße). Eine Urkunde von 1385 belegt, dass der Dekan des Stifts St. Gangolf und das Kapitel mit der Priorin des Klosters Heilig Grab einen Gütertausch vorgenommen hatten, in dessen Umsetzung das Kloster ein Haus das da gelegen ist auf dem Steinweg genseits des wegs erhielt und dem Stift dafür ein Haus mit Hof und Garten das ihn der Langgasen gelegen ist übereignete, welche laut spätere Randnotiz der Oblei Longa platea zugeordnet worden war. ${ }^{982}$ Es ist offentsichtlich, dass das Kloster Heilig Grab bei diesem Tausch Güter nahe ihres Hauptsitzes erhielt, während das Stift St. Gangolf diese Güter auf dem Steinweg wohl auch leichter hätte organisieren können, als die Güter in der Bamberger Langgasse. Doch abgesehen von einzelnen Häusern am Markt, ${ }^{983}$ schien das Stift St. Gangolf Ende des 14. Jahrhunderts bereits mehr als ein Haus in der Langgasse zu besitzen, was eine Urkunde ebenfalls aus dem Jahr 1385 belegt. Darin bestätigten der Schultheiß des Stadtgerichts von Bamberg und dessen Schöffen die Belehnung des Herman Wagner samt Ehefrau und des Albrecht Wagenknecht samt Ehefrau mit mehreren Häusern, Höfen und Gärten in der Langgasse durch den Dekan und das Kapitel von St. Gangolf und bestimmten, dass diese Güter verobleyt

\footnotetext{
981 „Oblegium retro sanctum Martinum“ im Zinsregister von 1567 in StABa Stift St. Gangolf, Akten und Bände Nr. 32 fol. 14'.

982 Urkunde vom 4. April 1385 im Kopialbuch in StABa Stift St. Gangolf, Akten und Bände Nr. 3 Teil 2 S. 110-112.

${ }^{983}$ Näheres dazu in den Unterkapiteln über die Oblei In foro und die Oblei Wattlauben in Kapitel 6.4.1.2 Einzelobleien.
} 
werden sollen und dass die Zuständigkeit bei dem Stadtgericht zu Bamberg liegen solle darynne dasselbe erb ligt. ${ }^{984}$ Die Obleiregister des 16. Jahrhunderts gaben Auskunft, dass es sich um zwei Häuser gehandelt habe, welche nebeneinander lagen, und dessen Obleiherr Canones von fünf Schillingen an den Obleier und einem halben Lammbauch zu Ostern an den Kustos zu zahlen hatte. ${ }^{985}$

\section{Oblei Molendinum}

Die Oblei molendinum bezeichnete Besitzungen, die durch eine Mühle in Hollfeld (Lk Bayreuth) geprägt wurde. Hollfeld als Ort der Pfründengüter des Stifts St. Gangolf beherbergte auch vom Kapitel verwaltete Besitzungen, die vor allem aus der, in den Quellen als Rabenecker mul bezeichneten, Mühle an der Kainach samt Gärten sowie mehreren Äckern zu Ebensfeld (Lk Lichtenfels) bestanden. ${ }^{986}$ Die Canones beliefen sich auf zwei Pfund und fünf Schillinge und auf Geld an das Gangolfer Vikariat St. Blasius, dessen Höhe in den Obleiregistern des 16. Jahrhunderts zwischen 16 Schillingen und 24 Pfennigen schwankte. Die erste Erwähnung der Oblei Molendinum findet sich in der Obleimatrikel für das Jahr 1446. ${ }^{987}$

984 Abschriftliche Überlieferungen der Urkunde vom 28. August 1385 sowohl im Kopialbuch in StABa Stift St. Gangolf, Akten und Bände Nr. 3 Teil 2 S. 189-190; als auch im Zinsregister von 1567 in StABa Stift St. Gangolf, Akten und Bände Nr. 32 fol. 29-29‘.

985 „Oblegium Longa Platea es sind zwey heuser aneinander“ im Zinsregister von 1538 in StABa Stift St. Gangolf, Akten und Bände Nr. 20 fol. 7; „oblegium longa platea es seind zwey heuser aneinander [...] ligen in der Langengas bey dem thor vorn an den wege hinten an des Loffelholz garten [...] an dem wasser ligen das durch die Zinckenwerde brucken fliest, an der statmauern“ im Zinsregister von 1567 unter „oblegium Longa Platea“ in StABa Stift St. Gangolf, Akten und Bände Nr. 32 fol. 28'-29'.

986 Oblei „Holvelth molendinum ibidem di Rabenecker mul genant“ im Zinsregister von 1518 in StABa Stift St. Gangolf, Akten und Bände Nr. 20 fol. 24-33'; Oblei „Oblegium molentinum in Holfeldt“ im Zinsregister von 1564 in StABa Stift St. Gangolf, Akten und Bände Nr. 25 fol. 69-74; „oblegium molendinum in Holfelt cum certis agris prope Ebensfeldt“ im Zinsregister von 1567 in StABa Stift St. Gangolf, Akten und Bände Nr. 32 fol. 23-24.

${ }^{987}$ Eintrag in der Obleimatrikel (1433-1663) für das Jahr 1446 in StABa Stift St. Gangolf, Akten und Bände Nr. 192 fol. IV. 


\section{Oblei Drosendorf}

Die Oblei Drosendorf (Gde Hollfeld, Lk Bayreuth) gehörte mit der Oblei Hundsbühl zu den größten und ertragsreichsten Obleien des Stifts St. Gangolf. Sie ist bereits im 14. Jahrhundert nachweisbar, als der Propst des Stifts St. Gangolf, Otto Imelsdorfer (amt. 1367-1380), dem Dekan und dem Kapitel im Jahr 1368 die Übereignung von Gütern in Drosendorf an einen Bürger von Bamberg als Zinslehen bestätigte. ${ }^{988}$ Diese Gangolfer Oblei ist die einzige, die eine namentliche Erwähnung in den Eintragungen der Anniversarbücher fand. Die Bücher gaben, kalendarisch aufgebaut, den Kanonikern und Vikaren eine Übersicht über die zu begehenden Jahrtagsfeiern und liturgischen Handlungen und darüber hinaus in verkürzter Form Einblicke in Herkunft und Verwendung der Anniversarstiftungen. Jedoch fehlt es in der Regel an einer Zuordnungen der einzelnen Stiftungen zu den betreffenden Obleien. Allein die Oblei Drosendorf wird in den Anniversarbüchern erwähnt. So ist für den 2. Januar festgehalten, dass zum Jahrtagsgedenken eines Herren Geppennius Geld aus den Einkünften der Oblei Drosendorf an die an diesem Tag anwesenden Kanoniker und Vikare verteilt werden sollte. ${ }^{989}$ Für den Jahrtag des Eberhard von Hohenberg (16. Januar), Propst von St. Gangolf (amt. 1360-1363), ${ }^{990}$ und für den Jahrtag des Friedrich von Truhedingen (19. Mai), Bischof zu Bamberg (amt. 13631366), ${ }^{991}$ wurde ebenfalls Geld aus der Oblei Drosendorf aufgewendet.

${ }^{988}$ Urkunde vom 29. Februar 1368 im Kopialbuch in StABa Stift St. Gangolf, Akten und Bände Nr. 3 Teil 1 fol. 42-42“; die Zuordnung als „oblegium Drosendorf“ ist erst von späterer Hand als Randnotiz hinzugefügt.

${ }^{989}$ Eintrag in den Anniversarbüchern für den 2. Januar: "obiit dominus Geppenius in cuius anniversario dantur II $\mathrm{lb}$ hln canonicis vicaryo de oblegio in Drosendorf [...]" in StABa Stift St. Gangolf, Akten und Bände Nr. 128 fol. 1; und „dominus Geppenius, de oblagio in Trosendorf et idem possessor ministratur candelas“ in StABa Stift St. Gangolf, Akten und Bände Nr. 129 fol. 2.

${ }^{990}$ Eintrag in den Anniversarbüchern für den 16. Januar: "obiit dominus Eberhardus de Hohenberg praepositus huius ecclesie in cuius anniversario dantur V lb hln de oblegio in Drosendorf praesentibus canonicis et vicariis et VI sol IIII ${ }^{\text {or }}$ scolaribus IIII sol fratribus sanctum ecclesio I sol et possessor oblegy predicti ministrat II candelas in $\mathrm{VI}^{\mathrm{a}}$ er in missa" in StABa Stift St. Gangolf, Akten und Bände Nr. 128 fol. 2; und „Eberhardus de Hoenberg prepositus huius ecclesie, de obligio in Trosendorf“ in StABa Stift St. Gangolf, Akten und Bände Nr. 129 fol. 4 ‘.

991 Einrag in den Anniversarbüchern für den 19. Mai: „Fredericus de Truhending 
Liturgisch fanden die Einnahmen der Oblei Drosendorf zur Feier der heiligen Anna Verwendung. ${ }^{992}$

Der Besitz, der unter der Oblei Drosendorf verwaltet wurde, umfasste sowohl einen großen Hof (curia) und zwei Häuser in Drosendorf als auch mehrere Güter in der Bamberger Theuerstadt, darunter zwei Häuser mit Garten im Hundsbühl, ein Haus am Egelsee, sieben Gärten hinter den frauen sichen gelegen sowie zwei Höfe mit Gärten im Umfeld des Klosters Heilig Grab. ${ }^{993}$ Die Canones, die der Obleiherr von den Einkünften dieser Besitzungen an das Kapitel abzugeben hatte, sind in den überlieferten Obleiregistern unterschiedlich hoch beziffert. So ist sowohl von 25 Pfund und 28 einhalb Pfennigen ${ }^{994}$ als auch von 14 Pfund und 39 Schillingen ${ }^{995}$ die Rede. Diese Beträge, ob nun der eine oder der andere, waren für die Canonesbelastungen der Gangolfer Obleien im 16. Jahrhundert ungewöhnlich hoch und lassen darauf schließen, dass die Erträge aus den Besitzungen beträchtlich gewesen sein mussten. Die Größe der Oblei sorgte jedoch nicht nur für ansehnliche Einkünfte, sondern auch für eine erschwerte Verwaltungsarbeit, denn

episcopus Bambergensis, de oblegio in Drosendorf“ in StABa Stift St. Gangolf, Akten und Bände Nr. 128 fol. 12'; und „Fridericus de Truchending episcopus Bambergensis, de oblegio in Trosendorf“ in StABa Stift St. Gangolf, Akten und Bände Nr. 129 fol. 33.

992 Eintrag in den Anniversarbüchern für den 26. Juli: „Hodie cantatur hystoria propria de sancta Anna, de domo dicti Werglein auf dem Steynbegk, de oblegio in Drosendorf" in StABa Stift St. Gangolf, Akten und Bände Nr. 128 fol. 18; und „hodie cantatur historia propria de sancta Anna, de domo dicti Weiglein auf dem Steinwege, de oblegia in Drosendorf, dictus Ritter“ in StABa Stift St. Gangolf, Akten und Bände Nr. 129 fol. 47‘.

993 Oblei „Drosendorf“ im Zinsregister von 1548 in StABa Stift St. Gangolf, Akten und Bände Nr. 22 fol. 3-5; „oblegium Drosendorf prope Holveldt“ im Zinsregister von 1564 in StABa Stift St. Gangolf, Akten und Bände Nr. 25 fol. 1-8; „oblegium Drosendorf sub parochia Holfelt" im Zinsregister von 1567 in StABa Stift St. Gangolf, Akten und Bände Nr. 32 fol. 15-17'.

994 Zinsregister von 1564 in StABa Stift St. Gangolf, Akten und Bände Nr. 25 fol. 8.

995 Dieser Betrag errechnete sich aus folgenden Angaben: ein Pfund an dem Jahrtag von "Peringri“ als Kanoniker von St. Stephan in Bamberg, zwei Pfund an dem Jahrtag von Friedrich von Truhendingen als Bischof von Bamberg (amt. 1363-1366), 30 Schillinge „ad historiam sancti Kiliani“, neun Schillinge „ad historiam sancte Annae matris Mariae“, zwei Pfund an dem Jahrtag von Heinrich von Hohenlach als Dompropst, zwei Pfund an dem Jahrtag von Leupold von Bebenburg als Bischof von Bamberg (amt. 1353-1363), zwei Pfund an dem Jahrtag von „domini Geppenii“ und fünf Pfund an dem Jahrtag von Eberhard von Henneberg. Im Zinsregister von 1567 in StABa Stift St. Gangolf, Akten und Bände Nr. 32 fol. 17'. 
alle Lehensleute und Pächter der Güter waren im Auge zu behalten, damit die Einkünfte in die richtigen Taschen flossen. Ein Urteil von 1548, gefällt von Bürgern und Ratsmitgliedern aus Bamberg, gibt darüber Auskunft. ${ }^{996}$ Gerichtet wurde im Streit zwischen dem Dekan und dem Kapitel des Stifts St. Gangolf und speziell zwischen Georg Helmreich als itziger obleyher der obley zu Drosendorf einerseits und Pangraz und Jochum Stiebar zu Buttenheim andererseit, und zwar über zwei Güter auf dem Huntzpuhel bey Bambergk. Der Streitpunkt bestand darin, dass diese zwei aneinanderliegenden Güter getrennt voneinander verliehen und für jedes Gut Handlohn eingenommen worden war. Im Urteil wurde die Unzulässigkeit dieser Praxis festgestellt und betont, dass die zwei Güter zukünftig als Einheit verliehen werden sollten und der überschüssige Handlohn zurückgezahlt werden müsse.

\section{Oblei Weiher}

Die Oblei Weiher umfasste im 16. Jahrhundert eine Hufe genannt der Hutzler, eine Manse genannt der Khornhof, mehrere Äcker und zwei Höfe ${ }^{997}$ in dem Ort Weiher bei Hollfeld (Gde Hollfeld, Lk Bayreuth). ${ }^{998}$ Vor allem die zwei ersten Besitzungen gingen auf die Familie von Aufseß zurück und waren dieser zinspflichtig. Die Canones betrugen im 16. Jahrhundert acht Scheffel Roggen.

Erste Erwähnungen aus dem 15. Jahrhundert nennen die Oblei Weiher nicht selten im Zusammenhang mit der Oblei Gerbersdorf (= Neidenstein, Gde Hollfeld, Lk Bayreuth), welche ebenfalls Güter der Familie von Aufseß umfasste. So urteilte am 8. Juni 1433 Gottfried, Domdekan von Bamberg, als bischöflicher Salrichter in der Differenz zwischen dem Ritter Heinrich von Aufseß, dessen Söhnen Heinz und Christoph von Aufseß einerseits und Johann Schank, Dekan von St. Gangolf (amt. 1430-1441), andererseits von etlicher guter wegen zu Ger-

${ }^{996}$ Urkunde vom 19. September 1548 in StABa A 120 L 131 Nr. 773.

997 „Curiae“.

998 "Weyer oblegium“ im Obleiregister von 1538 in StABa Stift St. Gangolf, Akten und Bände Nr. 20 fol. 2; sowie „oblegium Weyer“ im Obleiregister von 1555 in StABa Stift St. Gangolf, Akten und Bände Nr. 23 fol. 67-67‘; und im Obleiregister von 1567 in StABa Stift St. Gangolf, Akten und Bände Nr. 32 fol. 4-4‘. 
bersdorf und Weyer gelegen und die gülte derselbig stift und capitel zu Teurstat darauf hetten, als von alter herkommen wer zugunsten des Stifts. ${ }^{999}$ Eine Zuordnung zur oblei Gerbersdorf oder Weyer erfolgte durch eine später hinzugefügte Randnotiz im Kopialbuch. Am 15. November 1442 erstritt sich derselbe Dekan erfolgreich die Besitzrechte über zwölf Äcker in Weiher, welche laut einer späteren Randnotiz als zur obley Weyer gehörig benannt wurden. ${ }^{1000}$

\section{Oblei Gerbersdorf}

Das Dorf Gerbersdorf unterhalb der Burg Neidenstein der Familie von Aufseß in der Nähe von Hollfeld wurde oft mit dem Burgnamen betitelt und ist heute unter dem Namen Neidenstein (Gde Hollfeld, Lk Bayreuth) bekannt. ${ }^{1001}$ Die Besitzungen des Stifts St. Gangolf in dieser Gemeinde, bestehend aus einem Hof und einer Hufe, wurden bereits im 16. Jahrhundert des Öfteren unter beiden Ortsnamen geführt. ${ }^{1002}$ Die Canones bestanden im 16. Jahrhundert aus 12 Sümmer Roggen und zehn Schillingen Heller an den Obleier. Erste Erwähnungen finden sich für den Anfang des 15. Jahrhunderts in den bereits für die Oblei Weiher ausgeführten Rechtsstreitigkeiten zwischen dem Gangolfer Dekan und einzelnen Vertretern der Familie von Aufseß für die Jahre 1433 und 1439. ${ }^{1003}$

${ }^{999}$ Urkunde vom 8. Juni 1433 im Kopialbuch in StABa Stift St. Gangolf, Akten und Bände Nr. 3 Teil 1 fol. 77‘-78; Die Streitigkeiten zwischen den zwei Kontrahenten war damit jedoch nicht beigelegt, was ein weiteres Urteil durch Vertreter des Domkapitels in einer kopial überlieferten Urkunde vom 14. März 1439 belegt. Im Kopialbuch in StABa Stift St. Gangolf, Akten und Bände Nr. 3 Teil 3 S. 346-350.

1000 Urkunde vom 15. November 1442 im Kopialbuch in StABa Stift St. Gangolf, Akten und Bände Nr. 3 Teil 3 S. 350-353.

${ }^{1001}$ Fastnacht: Ebermannstadt. 2000. S. 193-195.

1002 „Oblegium Gerbersdorf oder Neydenstein in perochia Holfeldt“ im Obleiregister von 1538 in StABa Stift St. Gangolf, Akten und Bände Nr. 20 fol. 3'; sowie „Oblegium Neydtstein auf Gerbersdorf“ im Obleiregister von 1555 in StABa Stift St. Gangolf, Akten und Bände Nr. 23 fol. 9 und fol. 64; und "Oblegium Gerbersdorf vel Neydstein“ im Obleiregister von 1567 in StABa Stift St. Gangolf, Akten und Bände Nr. 32 fol. 5.

${ }^{1003}$ Urkunde vom 8. Juni 1433 im Kopialbuch in StABa Stift St. Gangolf, Akten und Bände Nr. 3 Teil 1 fol. 77‘-78‘; Eine Zuordnung zur „obleii Gerbersdorf oder Weyer“ erfolgte durch spätere Randnotizen; Urkunde vom 14. März 1439 im Kopialbuch in StABa Stift St. Gangolf, Akten und Bände Nr. 3 Teil 3 S. 346-350. 


\section{Oblei Treppendorf}

In Treppendorf (Gde Hollfeld, Lk Bayreuth) besaß das Stift St. Gangolf laut den Obleiregistern des 16. Jahrhunderts einen Hof mit Äckern, Gewässern und Wiesen, ein Haus mit Stall und einen halben Hof. Dies wurde durch eine Oblei verwaltet, von der der Besitzer Canones in Höhe von 12 Pfennigen an den Obleier zu zahlen hatte. ${ }^{1004}$ Die kleine Oblei hat keinerlei Niederschlag in der Urkundenüberlieferung gefunden. Ihre früheste Spur ist über die Obleimatrikel überliefert, in der berichtet wird, dass im Jahr 1445 nach dem Tod des Nikolaus Vipech, Keller des Stifts (amt. 1440-1443), unter anderem ein oblegium Treppendorf neu verteilt wurde. ${ }^{1005}$

\section{Oblei Wohnsdorf}

Die Zuordnung der in das oblegium Wonsdorf gehörigen Güter des Stifts St. Gangolf zur Ortschaft Wohnsdorf (Gde Hollfeld, Lk Bayreuth) ist aufgrund der verschiedenen Schreibweisen des Ortsnamens in den Quellen schwierig. Diese reichen von Wonsdorf über Wansdorf bis hin zu Watendorf und bezeichneten doch ein und dieselbe Ortschaft. ${ }^{1006}$

Die früheste Erwähnung von Gangolfer Obleibesitzungen in Wohnsdorf findet sich im Umfeld einer abschriftlich überlieferten Gerichtsurkunde, in der im Jahr 1459 Albrecht von Giech, Ritter und obman ihn der hernachgeschrieben sach, in einer Klage des Gangolfer Kanonikers Hans Braun gegen mehrere Brüder zu Watendorf wegen ausstehender Zins und Gült auf dortigen virthalb hub landts und ein virtel gehörendt und ein fragment ist des obgemelten stifts richtete. ${ }^{1007}$ Eine spätere Randnotiz ordnete diesen Fall dem oblegium Wonsdorf zu. Die Aus-

1004 „Oblegium Treppendorf“ im Zinsregister von 1555 in StABa Stift St. Gangolf, Akten und Bände Nr. 23 fol. 3“; „Oblegium Dreppendorf“ im Zinsregister von 1567 in StABa Stift St. Gangolf, Akten und Bände Nr. 32 fol. 6.

1005 Eintrag in der Obleimatrikel (1433-1663) für das Jahr 1445 in StABa Stift St. Gangolf, Akten und Bände Nr. 192 fol. III.

1006 Näheres zu den zahlreichen Schreibvarianten des Ortsnamens Wohnsdorf in Fastnacht: Ebermannstadt. 2000. S. 367-368.

1007 Urkunde vom 19. Dezember 1459 im Kopialbuch in StABa Stift St. Gangolf, Akten und Bände Nr. 3 Teil 3 S. 343-346. 
tauschbarkeit der Klassifizierung als Oblei oder auch als Fragment setzt sich in den späteren Erwähnungen fort, ohne dass eine Erklärung dafür gesucht wurde. ${ }^{1008}$ Laut den Obleiregistern des 16. Jahrhunderts war der Obleibesitzer zur Zahlung von 15 Schillingen als Canones verpflichtet.

\section{Oblei Gutenbiegen}

Bereits im Obleiregister von 1567 als iam vacat bezeichnet und mit nicht mehr als vier Pfennigen und zehn Schillingen Canones belastet, gibt es nur wenige Nachrichten über die kleine Oblei Gutenbiegen. ${ }^{1009}$ Das heute wüstgefallene Schlösslein Gutenbiegen (Gde Waischenfeld, Lk Bayreuth) mit mehreren landwirtschaftlich genutzten Flächen war Sitz der Familie von Wannbach ${ }^{1010}$ und ging um 1400 als Lehen an das Hochstift Bamberg. ${ }^{1011}$ Für das Jahr 1446 sind Einkünfte aus diesem Gutkomplex in der Obleimatrikel des Stifts St. Gangolf als Oblei Gutenbiegen verzeichnet. ${ }^{1012}$

\section{Oblei Kalteneggolsfeld}

Die Oblei Kalteneggolsfeld bestand seit ihrer frühesten überlieferten Erwähnung im 15. Jahrhundert aus nur einem Hof im gleichnamigen Ort Kalteneggolsfeld (Gde Heiligenstadt in Oberfranken, Lk Bamberg), welcher als Schäferei genutzt wurde. An Canones hatte der jeweilige

1008 „Oblegium Wonsdorf“ im Zinsregister von 1538 in StABa Stift St. Gangolf, Akten und Bände Nr. 20 fol. 7‘; „Wansdorf oblegium“ im Zinsregister von 1555 in StABa Stift St. Gangolf, Akten und Bände Nr. 23 fol. 64'; mit der Bemerkung „Wonsdorf oblegium sive fragmentum ist ein hof doeselbst gelegen darein gehortenn IIII hube und ein selden“; „oblegium Wansdorf“ im Zinsregister von 1567 in StABa Stift St. Gangolf, Akten und Bände Nr. 32 fol. 6; mit der Bemerkung „Wonsdorf oblegium sive fragmentum ist ein hof doselbsten zu Watendorf gelegen, darein IIII hublandts und ein virtel gehorend und ein fragment ist".

1009 „Oblegium Gutenbiegen“ im Zinsregister von 1567 in StABa Stift St. Gangolf, Akten und Bände Nr. 32 fol. 14‘.

1010 „Nota Gutenpigen ist ein edelmans sitz sambt etlichen wenig pauers sitzlein darbey, gelegen zwischen Weischenfeld und Lanckendorf im grund, bewonen die vom adel Wampach“ im Zinsregister von 1567 in StABa Stift St. Gangolf, Akten und Bände Nr. 32 fol. $14^{\text {‘. }}$

${ }^{1011}$ Fastnacht: Ebermannstadt. 2000. S. 95.

1012 Eintrag in der Obleimatrikel (1433-1663) für das Jahr 1446 in StABa Stift St. Gangolf, Akten und Bände Nr. 192 fol. IV. 
Obleibesitzer jährlich eineinhalb Pfund, beziehungsweise 45 Pfennige, an den Obleier abzugeben und war darüber hinaus zur Abgabe von Obleibroten verpflichtet, von denen vier dem Dekan des Stifts St. Gangolf, zwei den anwesenden Kanonikern, eins den anwesenden Vikaren und eins dem edituus ${ }^{1013}$ zustanden. ${ }^{1014}$ Die Zugehörigkeit dieses als Oblei verwalteten Hofes zum Stift war jedoch häufig bedroht und musste besonders gegen Ansprüche der Familie von Streitberg verteidigt werden. So urteilte am 16. Februar 1440 Anton, Bischof von Bamberg (amt. 1431-1459), in der Auseinandersetzung zwischen Engelhard von Güsbach, Bamberger Domkanoniker und Scholastikus von St. Gangolf (amt. 1424-1457), als Obleiherr und Erasmus von Streitberg wegen eines Gutes zu Kalteneggolsfeld des genannten stifts freyeigen, und ein obley ist. ${ }^{1015}$ Erasmus von Streitberg behauptete, er hätte das Gut gekauft und wolle nun das Erbrecht daran vom Domkanoniker Güsbach verliehen bekommen. Dies gestand der Bischof ihm auch zu, bestätigte jedoch gleichsam den Status als Oblei des Stifts St. Gangolf. Rochus von Streitberg, ein Erbe des obengenannten Erasmus, entfachte Mitte des 16. Jahrhundert den Streit um den Hof in Kalteneggolsfeld aufs Neue, als man ihn beschuldigte, Äcker aus dem Obleigut herausgezogen und an das Streitberger Gut in Zeckendorf (Gde Scheßlitz, Lk Bamberg) angegliedert zu haben, um es damit in den Besitz seiner Tochter Cordula und deren Ehemann Weigand von Dienheim zu bringen. Im Jahr 1579 erfolgte die Einigung zwischen Johann Sparwasser, Scholastikus des Stifts St. Gangolf (amt. 1569-1598) und Obleiherr von Kalteneggolsfeld,

1013 Obwohl dieses Amt sonst in keiner anderen Quelle beschrieben wird, ist nach seiner Wortbedeutung lat. aedituus - Kirchenaufseher der Küster oder Mesner gemeint.

1014 Oblei „Kaltenebensveldt“ im Zinsregister von 1555 in StABa Stift St. Gangolf, Akten und Bände Nr. 23 fol. 8; „Oblegium Kaltenegensveldt“ im Zinsregister von 1564 in StABa Stift St. Gangolf, Akten und Bände Nr. 25 fol. 108. mit der Bemerkung „das lehen ist des obleyherrn aber juncker Weygandt von Dinheim besetzts mit einem schefer und hat uber inen zu bebieten“; und „Kaltenegensfeldt oblegium“ im Zinsregister von 1567 in StABa Stift St. Gangolf, Akten und Bände Nr. 32 fol. 5‘.

1015 Abschriften der Urkunde vom 16. Februar 1440 in dem Sammelakt „Acta den schäferey antheil, welchen die herrn von Staufenberg der stifts privatobley Kaltenegelsfeld genannt zu lehen tragen betreffen" in StABa Stift St. Gangolf, Akten und Bände Nr. 201 unfoliiert; und im Kopialbuch in StABa Stift St. Gangolf, Akten und Bände Nr. 3 Teil 2 S. 47-50. 
mit Weigand von Dienheim und Heinrich von Aufseß als Lehensmann des Stifts auf diesem Hof, indem die in der bischöflichen Urkunde von 1440 festgelegten rechtlichen Zustände wiederhergestellt wurden. ${ }^{1016}$

\section{Oblei Reckendorf}

Die Oblei Reckendorf (Lk Bamberg) wurde erstmals in der Obleimatrikel für das Jahr 1446 genannt, in der sie noch nicht als Oblei geführt, sondern nur als Reckendorf bezeichnet ist. ${ }^{1017}$ Erst die Obleiregister des 16. Jahrhunderts beschreiben die Reckendorfer Güter einmütig als Oblei und als ligt unter dem schlos Greiffenstein et sunt quatuor mansis mit Canones von zwölf Sümmer Roggen und sechs Schillingen zweimal jährlich. ${ }^{1018}$

\section{Oblei Schederndorf}

Welche Güter die Oblei Schederndorf umfasste, wird in keinem der Obleiregister des 16. Jahrhunderts näher ausgeführt. Dies unterscheidet sich deutlich von der Handhabung anderen Verwaltungseinheiten, bei denen zum Teil die genaue Lage an Straßen und Plätzen angegeben wurde. Für diese Oblei wird lediglich erwähnt, dass es sich um etlich guter zu und umb Schederndorf (Gde Stadelhofen, Lk Bamberg) handelte und Canones von zwei Pfund zweimal jährlich auf dem Besitz lagen. ${ }^{1019}$

Jedoch gibt im Gegenzug eine Anmerkung im Obleiregister von 1567 Auskünfte sowohl über die Herkunft der Schederndorfer Güter als bischöfliche Lehen an das Stift St. Gangolf als auch über Regelungen hinsichtlich dem Einbringen von Zinsabgaben. So hatte einer der Bau-

${ }^{1016}$ Abschrift der Urkunde von 1579 in dem Sammelakt über die Oblei Kalteneggolsfeld in StABa Stift St. Gangolf, Akten und Bände Nr. 201 unfoliiert.

1017 Eintrag in der Obleimatrikel (1433-1663) für das Jahr 1446 in StABa Stift St. Gangolf, Akten und Bände Nr. 192 fol. IV.

1018 „Oblegium Reckendorf“ im Zinsregister von 1538 in StABa Stift St. Gangolf, Akten und Bände Nr. 20 2'-3; "oblegium Reckendorf“ im Zinsregister von 1555 in StABa Stift St. Gangolf, Akten und Bände Nr. 23 fol. 69-69“; „oblegium Reckendorf“ im Zinsregister von 1567 in StABa Stift St. Gangolf, Akten und Bände Nr. 32 fol. 9-9‘.

1019 Oblei „Schederndorf“ im Zinsregister von 1518 in StABa Stift St. Gangolf, Akten und Bände Nr. 20 fol. 34; „oblegium Schederndorf“ im Zinsregister von 1567 in StABa Stift St. Gangolf, Akten und Bände Nr. 32 fol. 12. 
ern, die auf den Gangolfer Gütern in Schederndorf saßen, die jährlichen Zinsen an den Obleiherren nach Bamberg zu liefern und konnte dafür Käse, Brot und Wasser für seine Verpflegung beanspruchen. Dies stand im umgekehrten Fall auch dem Obleiherren zu, wenn er die Zinsen selbst einbringen musste. ${ }^{1020}$ Die Regelungen lassen einen aufwendigen Anfahrtsweg von Schederndorf nach Bamberg vermuten, was die Verwaltung der Güter erschwert haben musste. Diese Annahme wird auch dadurch gestützt, dass es Mitte des 16. Jahrhunderts zu Schwierigkeiten in der Erhebung des Zinses kam:

Item dominus Georgius Helmreich als obleyher hat in dreizehen jahren nichts von solchen zinsen entpfangen, sich schriftlichen beclagt, aber diejenigen dahin zuhalten nicht nachgesetzt sondern lessig gewesen, möchte sie sonsten einpracht. ${ }^{1021}$

Dies ist ein gutes Beispiel für die Schwierigkeiten bei der Verwaltung der Obleien, die als Klein- und Kleinstgüter über weit verstreutes Gebiet verteilt lagen und deren relativ geringe Einkünfte die gewissenhafte Eintreibung von Zinsen für einen Kanoniker oft über Jahre hinweg nicht einträglich erschienen ließen.

\section{Oblei Litzendorf}

Die Besitzungen, die in der Oblei Litzendorf verwaltet wurden, waren nicht ausschließlich Litzendorfer Güter. Zwar lagen im 16. Jahrhundert fünf Häuser mit jeweils einem Hof und mehreren Wiesen und Äckern in Litzendorf (Lk Bamberg), aber dazu kamen eine Wiese und ein Acker in Naisa (Gde Litzendorf, Lk Bamberg) und ein Acker in Lohndorf (Gde Litzendorf, Lk Bamberg). Belastet war die Oblei mit zehn Schillingen für den Obleier. ${ }^{1022}$ Da die Oblei urkundlich nicht fassbar

1020 „Item es ligen etlich guter $\mathrm{zu}$ und umb Schederndorf so reverndissimo episcopo Bambergensi zu lehen rurendt, davon geben die besitzer solcher guter jerlich nachfolgendt zins dem obleyhern, und einer unter inen sol solche zins wie unten folgt einpringen und dem obleyhern uberantworten dargegen man ime kes und prodt und einen trunck geben sol, desgleichen so ein obleyher selbsten darnach zihen will, seind die besizer der guter dem hern auch refectionem schuldig" im Zinsregister von 1567 in StABa Stift St. Gangolf, Akten und Bände Nr. 32 fol. 12.

1021 Zinsregister von 1567 in StABa Stift St. Gangolf, Akten und Bände Nr. 32 fol. 12.

1022 „Oblegium Litzendorf“ im Zinsregister von 1564 in StABa Stift St. Gangolf, Akten und Bände Nr. 25 fol. 37-39“; „oblegium Litzendorf“ im Zinsregister von 1567 in StABa Stift St. Gangolf, Akten und Bände Nr. 32 fol. 18-18‘ mit der Notiz „Item dise obermelte lehen und 
ist, kann deren früheste Erwähnung erst für das Jahr 1445 in der Obleimatrikel des Stifts St. Gangolf nachgewiesen werden. ${ }^{1023}$

\section{Oblei Zeckendorf genannt Zolleisen}

In der Ortschaft Zeckendorf (Gde Scheßlitz, Lk Bamberg) besaß das Stift St. Gangolf mehrere Häuser mit Zugehörungen, die jedoch nicht als eine einzige Verwaltungseinheit geführt, sondern als zwei Obleien und ein Fragment verwaltet wurden. Diese drei Verwaltungseinheiten sind in den Quellen nicht immer eindeutig namentlich unterscheidbar und daher schwer zu identifizieren. So erwähnte beispielsweise die Obleimatrikel für das Jahr 1445 zwei Verwaltungseinheiten Tzechendorf ohne diese durch Zusätze weiter zu spezifizieren. ${ }^{1024}$ Als dann die genaue Aufzählung der Güter der Obleiregister des 16. Jahrhunderts eine Unterschiedung der einzelnen Verwaltungseinheiten nötig machten, wurden sie durch Zusätze spezifiziert, die sich auf die Lehensleute bezogen.

Die größere der beiden Obleien war die Oblei Zeckendorf mit dem Beinamen Zolleisen. Diese, Anfang des 16. Jahrhunderts dem Jobst Zolleisen und später seinem Sohn verliehene Oblei bestand ursprünglich aus einem Haus mit Hof, Acker und Wiesen in Zeckendorf, ${ }^{1025}$ während ab Mitte des 16. Jahrhundert zwei Häuser mit Zugehörungen genannt werden. ${ }^{1026}$ Die Canones, die der Obleibesitzer von den Einkünf-

guter, heuser, höf, ecker, wisen gehen alle einem lehenhern und besitzer der obley Litzendorf zu lehen, und von zehen gulden einem zu handlohn“.

1023 Erwähnung in der Obleimatrikel (1433-1663) für das Jahr 1445 in StABa Stift St. Gangolf, Akten und Bände Nr. 192 fol. III.

1024 Erwähnung in der Obleimatrikel (1433-1663) für das Jahr 1445 in StABa Stift St. Gangolf, Akten und Bände Nr. 192 fol. III.

1025 Oblei „Zochendorf“ dem "Jobst Zolleis" gehörig im Zinsregister von 1518 in StABa Stift St. Gangolf, Akten und Bände Nr. 20 fol. 34'-35; Oblei „Zechendorf“ dem „Hans Zoleis“ gehörig im Zinsregister von 1548 in StABa Stift St. Gangolf, Akten und Bände Nr. 22 fol. 9-9‘.

1026 „Oblegium Zechendorf zolleysen“ im Zinsregister von 1555 in StABa Stift St. Gangolf, Akten und Bände Nr. 23 fol. 10; „oblegium Zegendorf zoleysen genant“ im Zinsregister von 1564 in StABa Stift St. Gangolf, Akten und Bände Nr. 25 fol. 49.-49‘; „oblegium Zechendorf zoleysen dicitur“ mit der Notiz „Dise guter und stucklein alle zu gleich gehen dem besitzer diser obley Zechendorf zu lehen und geben um verkhaufen von zehen gulden einen handlon“ im Zinsregister von 1567 in StABa Stift St. Gangolf, Akten und 
ten an das Kapitel zu zahlen hatte, schwankten zwischen 30 Schillingen und zwei Pfund zweimal jährlich. Die belastbarste Angabe ist die von Canones über drei Pfund jährlich an den Obleier, welche im Obleiregister von 1567 genannt werden.

\section{Oblei Zeckendorf genannt Stretz}

Die zweite Oblei des Stifts St. Gangolf in Zeckendorf (Gde Scheßlitz, Lk Bamberg) wurde durch den Beinamen Stretz spezifiziert, welcher sich ebenfalls auf einen Lehensmann des 16. Jahrhunderts bezog. ${ }^{1027}$ Während der Besitz laut beiden Obleiregistern aus einem Haus mit Hof und Acker sowie aus einem Haus mit Hof und Stall in Zeckendorf bestand, wichen die Canonesbelastungen stark voneinander ab. Im Obleiregister von 1564 wurden jährlich drei Pfund Canones angegeben. Im Obleiregister von 1567 sind es hingegen nur 36 Pfennige, die an der Obleier bezahlt werden mussten. Dies ist verwunderlich, da einerseits die zwei Obleiregister zeitlich unwesentlich voneinander entstanden, und andererseits die Angaben für andere Gangolfer Obleien oft über Jahrhunderte hinweg vergleichbar blieben. Doch Währungen und Geldangaben waren spürbaren Schwankungen unterworfen und die oft stark verkürzten Registervermerke geben keinen Raum für Erläuterungen besonderer Entwicklungen.

\section{Fragment Zeckendorf}

Bestehend aus einem halben Gut mit Haus, Hof, Äcker und Wiesen sowie einem zweiten halben Gut mit Wiesen und Äcker in Zeckendorf (Gde Scheßlitz, Lk Bamberg) war das Fragment Zeckendorf mit 30 Schillingen Canones belastet. ${ }^{1028}$ Das Fragment ist durch eine kopial

Bände Nr. 32 fol. 19.

1027 „Oblegium Zegendorf so Stretz allein innen gehabt“ und „oblegium Zegendorf Stretz genant“ im Zinsregister von 1564 in StABa Stift St. Gangolf, Akten und Bände Nr. 25 fol. 59-61; „oblegium Zechendorf“ im Zinsregister von 1567 in StABa Stift St. Gangolf, Akten und Bände Nr. 32 fol. 22-22'.

1028 „Fragmentum Zechendorf“ im Zinsregister von 1538 in StABa Stift St. Gangolf, Akten und Bände Nr. 20 fol. 4-4"; "fragmentum in Zechendorf" im Zinsregister von 1567 in StABa Stift St. Gangolf, Akten und Bände Nr. 32 fol. 20-21. 
überlieferte Urkunde sogar früher belegt als die zwei weitaus einträglicheren, oben genannten Obleien in Zeckendorf. So vidimiert Jorg Rebhun, Kanoniker und Keller von St. Gangolf (amt. 1441-1484), im Jahr 1453 auf Bitten des Engelhard von Güsbach als Gangolfer Scholastikus (amt. 1424-1457) eine Urkunde vom 23. November 1440 des ehemaligen Gangolfer Kellers Nikolaus Vipech (amt. 1440-1443), in der er für das fragment $z u$ Zechendorf gelegen, das von mir zu lehen geht die Abgaben festlegte. ${ }^{1029}$ Eine spätere Randnotiz spezifiziert die Urkundenabschrift als Zechendorf ein obley oder fragment.

\section{Oblei Laibarös}

Die Oblei Laibarös (Gde Königsfeld, Lk Bamberg) hatte dahingehend einen Sonderstatus unter den Gangolfer Obleien, als dass sie nicht Lehen des Kapitels, sondern des Propstes von St. Gangolf war. Der Rechtssteit, der dieser Regelung zugrunde lag, ist in einer Urkunde kopial überliefert, welche durch spätere Randnotizen dem oblegium Laibrös zugeordnet wurde: Johann von Rota, Kanoniker des Bamberger Stifts St. Stephan, urteilte 1387 in der Auseinandersetzung zwischen Otto von Gauberstadt, Propst des Stifts St. Gangolf (amt. 1393-1397), ${ }^{1030}$ einerseits und Heinrich, Dekan des Stifts (amt. 1387-1395), mit dem Kapitel andererseits, besonders gegen den Keller Hermann (amt. 13811426) wegen des verleihen etlicher gut, die gelegen sein zu Leibrös. Es ging um die Frage, wem die Einkünfte (kuntschaft) zustünden und wer die Lehensleute auswählen dürfe. Alle fünf Zeugen sprachen dem Propst die volle Lehensherrschaft zu. ${ }^{1031}$ Bereits andere Güter in der Ortschaft Laibarös konnten als Pfründengüter nachgewiesen werden, sodass der pröpstische Einfluss in der Ortschaft dominierte. In Drosendorf oder Wohnsdorf sind ebenso sowohl Propstgüter als auch Obleigüter nach-

1029 Vidimus vom 22. Oktober 1453 über eine Urkunde vom 23. November $1440 \mathrm{im}$ Kopialbuch in StABa Stift St. Gangolf, Akten und Bände Nr. 3 Teil 3 S. 388-389.

${ }^{1030}$ Im Jahr 1387 war Heinrich von Brunn (amt. 1380-1388) im Amt des Gangolfer Propstes. Die Unstimmigkeiten lassen sich vermutlich auf die Eigenheiten von kopialer Überlieferung zurückführen.

${ }^{1031}$ Urkunde vom 18. Oktober 1387 im Kopialbuch in StABa Stift St. Gangolf, Akten und Bände Nr. 3 Teil 2 S. 108-110. 
weisbar, jedoch ohne dass dort der Propst auch die Obleigüter als Lehensherr übernahm. Der Grund für diese Sonderregelung bleibt im Dunkeln. Im 16. Jahrhundert bestand die Oblei aus einem Seldengut mit Haus, Hof und Äcker zu Laibarös, welches mit Canones zwischen sieben einhalb Pfennigen bis fünf Schillingen belastet war. ${ }^{1032}$

\section{Fragment Königsfeld}

Die Besitzungen in Königsfeld (Lk Bamberg), die durch das Kapitel verwaltet wurden, sind ein gutes Beispiel für die Wandlungsfähigkeit einer Verwaltungseinheit. Über die Anfänge des Fragments Königsfeld findet sich kein Hinweis in den stiftseigenen Quellen, welche erst für das 16. Jahrhundert Auskunft über die Besitzungen geben. Im Obleiregister von 1518 wird erwähnt, dass es sich bei diesem Fragment um die Überreste eines großen Hofes (curia) zu Königsfeld handele, welcher zerteilt worden war. ${ }^{1033}$ In der Folgezeit kamen durch Schenkungen kleinere Besitzungen hinzu, wie zum Beispiel die Wiesen, Felder und Äcker, die ein Mann namens Welz Reinfalt aus Königsfeld und seine Frau Gerhaus im Jahr 1522 an Johann Wilhelmi, Keller des Stifts St. Gangolf (amt. 1518-1528), als obley- und lehenherrn verkauften und somit die Einküfte des Fragments Königsfeld mehren halfen. ${ }^{1034}$

In dem ausführlichen Obleiregister von 1567 wird deutlich, dass der geteilte Hof zu Königsfeld einst der Kautschhof genannt wurde, welcher die Grundlage der Verwaltungseinheit bildete, in die die später dazugekommenen Schenkungen, wie zwei Güter und ein Holz das Eүchen ge-

1032 Oblei „Leybrös“ als Lehen des Propstes im Zinsregister von 1518 in StABa Stift St. Gangolf, Akten und Bände Nr. 20 fol. 37'; „oblegium Leybrös“ als Lehen des Propstes im Zinsregister von 1564 in StABa Stift St. Gangolf, Akten und Bände Nr. 25 fol. 96-96'; „oblegium Leybrös“ mit der Bemerkund "feudum spectat ad dominum preposito situm ecclesiae sancti Gangolphi” im Zinsregister von 1567 in StABa Stift St. Gangolf, Akten und Bände Nr. 32 fol. 19'.

1033 „Konigsfelt oblegium sive fragmentum in Konigsfelt fuit olim una curia nunc vero divisa“ im Zinsregister von 1518 in StABa Stift St. Gangolf, Akten und Bände Nr. 20 fol. 66 .

${ }^{1034}$ Urkunde vom 5. Mai 1522 im Kopialbuch in StABa Stift St. Gangolf, Akten und Bände Nr. 3 Teil 2 S. 76-89. 
nannt zu Königsfeld, eingeordnet wurden. ${ }^{1035}$ Die Canones beliefen sich auf zehn Sümmer Weizen (unterschieden in fünf Sümmer siligo und fünf Sümmer weitzen) sowie 20 Schillinge Heller. ${ }^{1036}$

\section{Oblei Huppendorf}

Obwohl die Ortschaft Huppendorf (Gde Königsfeld, Lk Bamberg) bereits im 12. Jahrhundert als Besitz des Domkapitels von Bamberg nachweisbar ${ }^{1037}$ und 1445 in der Gangolfer Obleimatrikel als Oblei des Stifts St. Gangolf aufgeführt ist, ${ }^{1038}$ wird sie im 16. Jahrhundert nur von einem Obleiregister erwähnt. Dieses weist die Oblei als aus einem Hof $\mathrm{zu}$ Huppendorf bestehend aus, dessen Obleiinhaber Canones von vier Sümmer Weizen zu entrichten hatten. ${ }^{1039}$

\section{Oblei Wolfsdorf}

In der Ortschaft Wolfsdorf (Gde Bad Staffelstein, Lk Lichtenfels) hatten bereits Mitte des 13. Jahrhunderts sowohl das Kloster Banz als auch das Kloster Langheim Zehntansprüche auf zahlreiche Güter, die unter anderem von Vertretern der Familie Walpot gestiftet worden waren. ${ }^{1040}$ Dies ist Ausdruck der regen Stiftertätigkeit der Ministerialenfamilie, welche zwar rund um die Gründung des Stifts St. Gangolf eine große Rolle als Wohltäter spielte, in den folgenden Jahrhunderten aber keine engeren Beziehungen mehr zum Stift pflegte. ${ }^{1041}$

1035 „Ist vor zeyten eyn hof gewesen, vor etlich vil jahren aber zertheilt worden und ist der kautschenhof genandt, und alle nachfolgende stuck darein gehört, seind alle des obleyhern lehen“ im Zinsregister von 1567 in StABa Stift St. Gangolf, Akten und Bände Nr. 32 fol. $24^{\prime}-25^{\prime}$.

1036 „Konigsfelt oblegium sive fragmentum“ im Zinsregister von 1518 in StABa Stift St. Gangolf, Akten und Bände Nr. 20 fol. 6-6'; Fragment „Kunsfeldt“ im Zinsregister von 1548 in StABa Stift St. Gangolf, Akten und Bände Nr. 22 fol. 3-5; „fragmentum Khönigsfeldt“ im Zinsregister von 1567 in StABa Stift St. Gangolf, Akten und Bände Nr. 32 fol. 24`-25‘

${ }^{1037}$ Fastnacht: Ebermannstadt. 2000. S. 124.

1038 Eintrag in der Obleimatrikel (1433-1663) für das Jahr 1445 in StABa Stift St. Gangolf, Akten und Bände Nr. 192 fol. III.

1039 „Oblegium Huppendorf ufm geburg“ im Zinsregister von 1567 in StABa Stift St. Gangolf, Akten und Bände Nr. 32 fol. 31.

1040 Dorothea Fastnacht: Staffelstein. Ehemaliger Landkreis Staffelstein (Historisches Ortsnamensbuch von Bayern, Bd. 5). München 2007. S. 416-418.

${ }^{1041}$ Näheres im Kapitel 3.1.3.2 Reginold Walpot. 
Bei den Beschreibungen der Besitzungen der Oblei Wolfsdorf gehen die Obleiregister des 16. Jahrhunderts nicht sehr ins Detail. Es handelte sich um mehrere nicht näher beschriebene Güter in Wolfsdorf, welche teils Lehen des Klosters Langheim und teils Lehen des Stifts St. Gangolf waren und Canones von sechs Sümmer Korn und drei Sümmer Weizen abzugeben hatten. ${ }^{1042}$ Bereits eine Urkunde vom 4. April 1337 erwähnte drei Güter in Wolfsdorf, die zum Teil dem Scholastikus des Stifts St. Gangolf zinsten und welche durch eine spätere Randnotiz als zum oblegium Wolfsdorf gehörig identifiziert wurden. ${ }^{1043}$

\section{Oblei Romansthal}

Der Ort Romansthal (Gde Staffelstein, Lk Lichtenfels) ist bereits Anfang des 14. Jahrhunderts in den Urbaren des Bamberger Bischofs aufgeführt und war Sitz einer Vogtei. ${ }^{1044}$ Dass es sich bei dem Quellenbegriff oblegium Ramsta um Besitzungen in der Ortschaft Romansthal handelte, wird weniger aus den Eintragungen in den Gangolfer Obleiregistern des 16. Jahrhunderts ersichtlich, sondern eher aus dem Hinweis in einer kopial überlieferten Urkunde von 1375, in der sich das Stift St. Gangolf mit den bischöflichen Amtsleuten von Lichtenfels über einen Hof und einen Wald zu Ramstal gelegen der ein obley ist des stiefts zu Teurstat zu einigen hatte. Dort schlichtete Lamprecht, Bischof von Bamberg (amt. 1374-1398), den Streit der beiden Parteien, indem er dem Stift St. Gangolf die Erblehenrechte an dem Gut übertrug, während die Amtsleute von Lichtenfels die Vogteirechte weiterhin inne haben sollten. ${ }^{1045}$ Dieser Hinweis auf den Einfluss der bischöflichen Amtsleute in Lichtenfels und auch die Schreibvarianten, die Dorothea Fastnacht für die-

1042 „Oblegium Wolfsdorf” im Zinsregister von 1555 in StABa Stift St. Gangolf, Akten und Bände Nr. 23 fol. 65; „oblegium Wolfsdorf“ im Zinsregister von 1567 in StABa Stift St. Gangolf, Akten und Bände Nr. 32 fol. 7-7‘.

1043 Urkunde vom 4. April 1337 im Kopialbuch in StABa Stift St. Gangolf, Akten und Bände Nr. 3 Teil 3 S. 336-338.

${ }^{1044}$ Fastnacht: Staffelstein. 2007. S. 296-300.

1045 Urkunde vom 3. März 1375 im Kopialbuch in StABa Stift St. Gangolf, Akten und Bände Nr. 3 Teil 3 S. 5-6. 
sen Ort anbietet, lassen vermuten, dass es sich bei Ramstal um das heutige Romansthal handelte. ${ }^{1046}$

Die Besitzungen in Romansthal führt das Obleiregister von 1567 auf und erwähnt Canones von fünf Sümmern Roggen sowie zweieinhalb Sümmern Weizen. ${ }^{1047}$ Von dem Wald, der zu dem Hof gehörte, konnte sich der Lehensmann Brenn- und Bauholz zu eigenen Zwecken nutzen. Den Rest hatte er jedoch dem Obleiherren zur Verfügung zu stellen. ${ }^{1048}$

\section{Oblei Buckendorf}

In der Ortschaft Buckendorf (Gde Weismain, Lk Lichtenfels) besaß das Stift St. Gangolf nur ein Gut, von dessen Einkünften der Obleiinhaber fünf Sümmer Weizen an die Kanonikerhöfe curia Storchsvas und curia Schwanen zu zahlen hatte. ${ }^{1049}$ Keines der anderen Gangolfer Obleiregister des 16. Jahrhunderts erwähnt diese kleine Oblei, obwohl sie bereits im 12. Jahrhundert als Besitzung des Bamberger Bischofs ${ }^{1050}$ und für das Jahr 1445 in der Obleimatrikel des Stifts St. Gangolf nachweisbar ist. ${ }^{1051}$

\section{Oblei Dürrbrunn genannt Tholhorn}

In der Ortschaft Dürrbrunn (Gde Unterleinleiter, Lk Forchheim) waren insgesamt vier Häuser mit Zugehörungen dem Stift St. Gangolf zinspflichtig, welche jedes für sich als eigene Oblei oder als Fragment verwaltet wurden. Da diese Verwaltungseinheiten in den Quellen nicht immer eindeutig unterschieden wurden, sind manche der frühen Hin-

\footnotetext{
${ }^{1046}$ Fastnacht: Staffelstein. 2007. S. 296-300.

1047 „Oblegium Ramstall“ im Zinsregister von 1567 in StABa Stift St. Gangolf, Akten und Bände Nr. 32 fol. 21'.

1048 „Item [...] felt in sich das diser hof der obley lehen sey und ein holtz zu dem hof gehorig, darvon sol ein obleyherr dem besitzer aus dem holtz das zu dem hof gehört, holtz beweysen $\mathrm{zu}$ prenholtz und bauholtz $\mathrm{zu}$ denselben, des andern mag er (der obleyher) genisen, und sein nachkhumen an dem selben obley, als vil sie mugen“ im Zinsregister von 1567 in StABa Stift St. Gangolf, Akten und Bände Nr. 32 fol. 21'.

1049 „Oblegium Buckendorf“ im Zinsregister von 1567 in StABa Stift St. Gangolf, Akten und Bände Nr. 32 fol. 31 .

${ }^{1050}$ George: Lichtenfels. 2008. S. 14-15.

1051 Eintrag in der Obleimatrikel (1433-1663) für das Jahr 1445 in StABa Stift St. Gangolf, Akten und Bände Nr. 192 fol. III.
} 
weise nicht eindeutig einer Oblei oder einem Fragment in Dürrbrunn zuzuorden. So erwähnen zwei Urkunden aus dem Jahr 1332 die Übereignung von jeweils zwei Gütern in Dürrbrunn durch einen diener Ulrich Tapheimer und dessen Ehefrau Kunigunde an den Dekan und das Kapitel des Stifts St. Gangolf. ${ }^{1052}$ Der Hinweis, dass diese Güter als Obleien verwaltet wurden, erfolgte über das Inhaltsverzeichnis des Kopialbuchs, jedoch ohne eine nähere Zuordnung anzubieten. Auch in der Obleimatrikel des Stifts St. Gangolf werden die zwei Einträge Durprunn für das Jahr 1445 nicht spezifiziert. ${ }^{1053}$

Erst in den Obleiregistern des 16. Jahrhunderts schien eine Unterscheidung der einzelnen Obleien und Fragmente in Dürrbrunn aufgrund der detailierten Besitzauflistung nötig geworden zu sein. Die erste so identifizierbare Oblei Dürrbunn besaß daher den Beinamen Tholhorn nach einem ihrer früheren Besitzer. ${ }^{1054}$ Sie umfasste ein Haus mit Hof, Äcker, Wiesen und Wäldern und war belastet mit Canones von jährlich vier Pfund Heller an den Obleier mit der Bedingung, dass ein Pfund davon für Kerzen ausgegeben werden musste. ${ }^{1055}$

\section{Oblei Dürrbrunn}

Die zweite Oblei in Dürrbrunn bekam in den Obleiregistern des 16. Jahrhunderts ebenfalls keinen Beinamen zugewiesen, wurde aber durch ihren langjährigen Besitzer Hans Ber spezifiziert. Sie umfasste ein Haus mit Hof, Stall, Äcker, Wiesen und Wälder in Dürrbrunn. Bei der

1052 Urkunde vom 27. April 1332 im Kopialbuch in StABa Stift St. Gangolf, Akten und Bände Nr. 3 Teil 1 fol. 30; und Urkunde vom 9. Mai 1332 im Kopialbuch in StABa Stift St. Gangolf, Akten und Bände Nr. 3 Teil 1 fol. 30'-31.

1053 Eintrag in der Obleimatrikel (1433-1663) für das Jahr 1445 in StABa Stift St. Gangolf, Akten und Bände Nr. 192 fol. III.

1054 „Conz Tholhorn [...] diser hats wider bebaut, dan es in egerten gelegen“ im Zinsregister von 1567 in StABa Stift St. Gangolf, Akten und Bände Nr. 32 fol. 8.

1055 „Oblegium Turprun Tholhorn nuncupatur quod possidet modo Michel Lauerhas“ im Zinsregister von 1518 in StABa Stift St. Gangolf, Akten und Bände Nr. 20 fol. 37-37; Oblei „Dürbrun“ dem Heinz Lauerhas gehörig im Zinsregister von 1555 in StABa Stift St. Gangolf, Akten und Bände Nr. 23 fol. 7-7‘; „oblegium Durbrun Tholhorn nuncupatur“ im Zinsregister von 1564 in StABa Stift St. Gangolf, Akten und Bände Nr. 25 fol. 98-98; „Durprun oblegium Tholhorn nuncupatur“ im Zinsregister von 1567 in StABa Stift St. Gangolf, Akten und Bände Nr. 32 fol. 8. 
Höhe der Obleibelastung durch Canones sind sich die Obleiregister des 16. Jahrhunderts uneins, sodass die an den Obleier zu zahlenden Angaben dazu von zwei bis vier Pfund Heller jährlich schwankten. ${ }^{1056}$

\section{Fragment Dürrbrunn}

Erst das Obleiregister von 1567 nennt ein fragmentum Durprun mit Besitzungen von einem Gut, genannt das Schmitgut, mit Haus, Hof, Äcker, Wiesen und Wälder in Dürrbrunn. Dieses hatte jährlich zwei Pfund Heller an den Obleier des Stifts St. Gangolf als Canones zu bezahlen. ${ }^{1057}$ Dem Obleiregister beigefügt ist die Abschrift einer Urkunde vom 6. Oktober 1455, in der Konrad Hertlein, Dekan des Stifts St. Gangolf (amt. 1453-1474), und das Kapitel einem Hans Ber (Per) und dessen Ehefrau Christin das guet mit seinen zugehorungen, das do gelegen ist ihn der marck zu Dürrbrunn, es sey zu dorf oder zu veld, wo die gelegen oder wie die genant sein, das dann ein fragment ist verliehen und mit Abgaben von zwei Pfund Hellern, acht Käsen, vier Herbsthühnern, einem Fastnachtshuhn und 40 Eiern zu Ostern belasteten. ${ }^{1058} \mathrm{Ob}$ es sich hierbei um den gleichen Hans Ber handelte, der Anfang des 16. Jahrhundert die zweite Oblei in Dürrbrunn innehatte, mag aufgrund des zwischen beiden Namensnennungen liegenden Zeitraums eher bezweifelt werden. Jedoch scheint die Familie Ber eng mit den Dürrbrunner Besitzungen des Stifts St. Gangolf verbunden gewesen zu sein.

1056 „Oblegium Turnbrun quod possidet Hans Pere“ im Zinsregister von 1518 in StABa Stift St. Gangolf, Akten und Bände Nr. 20 fol. 36'; Oblei „Durbrun“ dem „Hans Bere“ gehörig im Zinsregister von 1555 in StABa Stift St. Gangolf, Akten und Bände Nr. 23 fol. 8; „oblegium Durbrun“ im Zinsregister von 1564 in StABa Stift St. Gangolf, Akten und Bände Nr. 25 fol. 113; „oblegium Durprun“ mit Vorbesitzer „Hans Ber“ im Zinsregister von 1567 in StABa Stift St. Gangolf, Akten und Bände Nr. 32 fol. 8‘.

1057 „Fragmentum Durprun“ im Zinsregister von 1567 in StABa Stift St. Gangolf, Akten und Bände Nr. 32 fol. 26-28.

1058 Diese Lehenurkunde vom 6. Oktober 1455 ist darüber hinaus abschriftlich im Kopialbuch überliefert in StABa Stift St. Gangolf, Akten und Bände Nr. 3 Teil 1 fol. 34-35; eine spätere Randnotiz ordnet den Eintrag dem „Oblegium sine fragmentum Dürrbrunn“ zu. 


\section{Fragment Dürrbrunn genannt Lauerhas}

Das zweite Fragment in Dürrbrunn, das das Obleiregister von 1567 nennt, befand sich von Beginn an im Besitz der Familie Lauerhas, sodass es als Beinamen deren Familiennamen erhielt. Es bestand aus einem Haus mit Äcker und Wiesen und war mit jährlich zwei Pfund Canones belastet. ${ }^{1059}$ Bereits 1538 zählte der Gangolfer Dekan Hieronimus Hirschberger (amt. 1512-1542) in seinem Obleiregister die Oblei Thurnbrun fragmentum unter seine Besitzungen und nennt Michel und Hans Lauerhasen als Besitzer des Gutes. ${ }^{1060}$ Die Bezeichnung einer Gutseinheit durch den Familiennamen ihres Besitzers war also durchaus üblich, obwohl die Zinsregister gleichzeitig beredtes Zeugnis über den regen Wechsel in der Besitzergeschichte eines Gutes ablegen.

\subsubsection{Verteilungsmodalitäten der Obleien}

Obleien wurden den Kanonikern auf Lebenszeit verliehen, solange diese nicht getauscht oder verkauft wurden, was eine Erlaubnis des Kapitels voraussetzte. Die Verleihung beschränkte sich auf stimmberechtigte Kapitularkanoniker. ${ }^{1061}$ Der Propst des Stifts St. Gangolf blieb vom Erhalt einer Stiftsoblei ausgeschlossen. Ein Kanoniker konnte mehrere Obleien auf sich vereinigen und deren Einkünfte beziehen. Dadurch fiel die Anzahl der Obleien eines Kanonikers durchaus sehr unterschiedlich aus, wie auch die Einkünfte der Einzelobleien sehr unterschiedlich waren. So ist bei der Untersuchung der Obleimatrikel des Stifts St. Gangolf beispielhaft für die zweite Hälfte des 15. Jahrhunderts zu beobachten, dass ein Kanoniker von zwei bis zu 17 Obleien innehaben konnte, wobei

1059 „Fragmentum Durprun lauerhas“ dem „Conz, Hans und Michel die Lauerhas“ gehörig im Zinsregister von 1567 in StABa Stift St. Gangolf, Akten und Bände Nr. 32 fol. 30`.

1060 „Thurnbrun fragmentum“ im Zinsregister von 1538 in StABa Stift St. Gangolf, Akten und Bände Nr. 20 fol. 3.

1061 "Statuimus preterea solum canonicos ecclesie nostre capitulares qui praesentes aut de unam nostro capitularii vel maioris partis consensu absentes vel approbatione nostra exempti existatur et vocem capitularem habentes, receptionis oblagiorum ecclesie nostre esse capates." im Statut Nr. 21 im Statutenbuch StABa Stift St. Gangolf, Akten und Bände Nr. 130 fol. 74. Näheres zu dieser Regelung von Kollegiatstiften in Bünz: Oblatio oblagium - Oblei. 2007. S. 38 und S. 43. 
acht bis 11 Obleien die Regel waren. ${ }^{1062}$ Diese Angaben decken sich mit den Untersuchungen von Stefan Nöth zum Domstift Bamberg, der eine Anzahl von meist acht, aber auch 13 bis 17 Obleien als für das Domstift üblich attestierte. ${ }^{1063}$

Starb ein Kanoniker oder gab er sein Amt auf, dann wurden seine Obleien auf die anderen Kanoniker verteilt. Diese Verteilung folgte einer strengen Reihenfolge iuxta seriem stationum in choro et vocum in capitu$10^{1064}$ und konnte in mehreren Durchgängen erfolgen, wenn es mehr Obleien zu verteilen galt als es zahlenmäßig Kanoniker gab. Derjenige, der nach dem letztbedachten Kanoniker im Verteilungsgang an der Reihe gewesen wäre, wurde bei der nächsten Verteilung automatisch als Erster bedacht. ${ }^{1065}$ Der Obleier war damit beauftragt, die Reihenfolge der Kanoniker innerhalb der Verteilungsvorgänge im Auge zu behalten. ${ }^{1066}$

Erstaunlich ist jedoch, dass sich in beiden Quellen, dem Statutenbuch und der Obleimatrikel des Stifts St. Gangolf, kein Hinweis auf eine Durchmischung der Verteilungsmodalitäten findet, die in Bamberg an anderen Häusern durchaus nachweisbar ist - das sogenannte Tukken. ${ }^{1067}$ Bei dieser Praxis des freiwilligen Ausgelassenwerdens innerhalb eines Verteilungsgangs, die für Bamberg bereits Anfang des 14. Jahrhunderts als gängige Praxis des Domstifts nachgewiesen werden kann, dürfte die christliche Idee der Bescheidenheit eine Rolle gespielt haben.

1062 Diese Aufstellung fußt auf den Aufzeichnungen in der Obleimatrikel (1433-1663) für die Jahre 1443 bis 1499 in StABa Stift St. Gangolf, Akten und Bände Nr. 192 fol. III-VIII.

1063 Nöth: Urbare und Wirtschaftsordnungen. 1986. S. 61.

1064 Statut Nr. 21 im Statutenbuch StABa Stift St. Gangolf, Akten und Bände Nr. 130 fol. 74.

1065 Mit dem Beisatz „erit primus in proxima oblegiorum vacatione et divisione in recipiendo" endete jeder Verteilungsvorgang, der in der Obleimatrikel (1433-1663) aufgeführt ist. In StABa Stift St. Gangolf, Akten und Bände Nr. 192.

1066 „Und do der eltesten chorhern einer stirbt, soll er allzeit vleisig aufzeichen wer unter dem capitulhern primus vel secundus in oblegii recipiendis sey." im Regelwerk des Obleiamtes vom 22. Mai 1590 als Anhang eines Register der Anniversarien und Fabrikzinsen (1584-1607) in StABa Stift St. Gangolf, Akten und Bände Nr. 29 fol. 186-187. 1067 „Tukken“ vermutlich im Sinne von sich ducken, neigen oder beugen. Näheres dazu Deutsches Wörterbuch von Jakob und Wilhelm Grimm: Art. „Ducken. 3a“. Bd. 2 (1858). Sp. 1494. 
So wandelten am 26. September 1326 der Dompropst, der Domvizedekan und das Domkapitel von Bamberg nach Absprache mit den Senioren der anderen Bamberger Kollegiatstifte die Consuetudo über das Tukken in ein verbindliches Statut um. ${ }^{1068}$ Dass auch die anderen Bamberger Kollegiatsstifte mit einbezogen wurden, hat Ulrike Siewert für das Stift St. Stephan nachgewiesen, indem sie ausführt, dass die Statuten einem bepfründeten Kanoniker mit Stimmrecht im Kapitel auferlegten, sich beim ersten Durchgang der Obleivergabe „ducken“ zu müssen. ${ }^{1069}$ Warum sich für das Stift St. Gangolf keine derartige Praxis in den Quellen nachweisen lässt, darüber kann nur spekuliert werden. Tatsächlich listet die Obleimatrikel des Stifts konstant die beteiligten Kanoniker und die ihnen zugewiesenen Obleien auf, ohne dass man eine Lücke oder einen ausgelassenen Empfänger ausmachen könnte. Es wäre denkbar, dass die geringere Größe des Stiftes St. Gangolf eine Durchmischung durch das Tukken nicht nötig machte. Interessant bleibt in dem Zusammenhang eine Untersuchung des Bamberger Kollegiatstifts St. Jakob zu diesem Thema, das aufgrund seiner Größe durchaus mit St. Gangolf vergleichbar wäre.

\subsubsection{Andere Anniversarstiftungen und Einkünfte des Kapitels}

Neben den Besitzungen, die in Einzelobleien organisiert waren, lassen sich Einnahmen nachweisen, die zwar eindeutig durch das Kapitel verwaltet wurden und außerhalb des Zugriffes des Propstes lagen, jedoch keiner Obleigruppe zugeordnet werden können. Zum Teil ähneln

1068 "Consuetudinem vulgariter digitur tukken circa oblagiorum ecclesie nostre“ in der Urkunde vom 26. September 1326 in StABa BU 1906; Aufgenommen ebenso in Looshorn: Die Geschichte des Bisthums Bamberg, Bd. 3. 1891. S. 104-105. Näheres zur Praxis des Tukkens im Bamberger Domstift in Nöth: Urbare und Wirtschaftsordnungen. 1986. S. $62-$ 65; und Kunio Nashiro: Über die Oblei im Bistum Bamberg. Naturalabgaben und Geldumlauf mit einem Exkurs zur Entwicklung in Japan und China. In: Rödel, Dieter/ Schneider, Joachim (Hgg.): Strukturen der Gesellschaft im Mittelalter. Interdisziplinäre Mediävistik in Würzburg. Wiesbaden 1996. S. 227-241, hier: 230-231.

${ }^{1069}$ Siewert: Das Bamberger Kollegiatstift Stift St. Stephan. 2007. S. 83-84. Sie identifiziert das Statut Nr. 7 als das besagte, welches man in StABa B 115 Nr. 245, Nr. 246 und Nr. 247. finden könne. 
sie erheblich den Obleien, sind beispielsweise in den Obleiregistern aufgeführt, trugen eine Canonesbelastung oder sind aus Anniversarstiftungen hervorgegangen. Und doch ist die Zuordnung zu einer Einzeloblei schwer möglich, schon allein deshalb, da sie nie explizit als Oblei oder Fragment bezeichnet wurden, und daher gesondert untersucht werden müssen.

Das betrifft zum einen Zinszahlungen aus Einzelbesitzungen, die an Kanonikerhöfe gebunden waren. ${ }^{1070}$ Sie tauchen vereinzelt in den Obleiregistern des 16. Jahrhunderts auf, lassen sich aber in keiner anderen Quellengattung finden und speisen sich in der Regel aus rein Theuerstädter Besitzungen, die sich in der Nähe des Kanonikerhofes befanden. Zum Teil lagen auf ihnen Canonesbelastungen, sodass sie einen Beitrag zur Unterhaltung des Kapitels trugen. Jedoch scheinen sie eher im Besitz einzelner Kanoniker als des Kapitels gewesen zu sein.

Einen größeren Besitzkomplex stellte der Zins der Kustorei dar, der jedoch nur einmal in einem Zinsregister des 16. Jahrhunderts auftaucht, welches durch den Dekan Moritz Weißhaupt (amt. 1542-1569) angelegt wurde. Es könnte sich also durchaus um Einkünfte der Dekanei und weniger des Kapitels handeln, jedoch bleibt diese Annahme unsicher. Allein aufgrund ihres Umfangs ist diese Verwaltungseinheit erwähnenswert. So speiste sich der Zins der Kustorei aus Einkünften von fast 20 Häusern mit Gärten, Wiesen und Feldern in der Bamberger Theuerstadt, einem Gut in Königsfeld (Lk Bamberg), einem Gut mit Garten in Poxdorf (Lk Forchheim) sowie aus den Hollfelder Zolleinnahmen. Darüber hinaus gehörten zu dieser Verwaltungseinheit Einkünfte in Form von Wachs, die der Obleier oder der Gangolfer Vikar von St. Maria Magdalena zu leisten hatten. Weiterhin gab es Einnahmen, die sich aus den Obleien Hundsbühl oder Longa platea speisten, oder gar Einkünfte

1070 Zins des Kanonikerhofes Eckhof: „census ad curiam an der ecken“ im Zinsregister von 1538 in StABa Stift St. Gangolf, Akten und Bände Nr. 20 fol. 2; und „census ad curiam canonicalem der eckhof genant so man in die stat gehet [...] vulgariter zum Schwan“ im Zinsregister von 1567 in StABa Stift St. Gangolf, Akten und Bände Nr. 32 fol. 29; Zins des Kanonikerhofes Kemmett: „curia mea kemmett dictu“ des Dekans Moritz Weißhaupt (amt. 1542-1569) im Zinsregister von 1555 in StABa Stift St. Gangolf, Akten und Bände Nr. 23 fol. 11-11'. 
de provisione capelle s. Gertrudis XII lb Martini, die der Abt des Klosters Michelsberg als Zins der Kustorei bezahlte. ${ }^{1071}$

Diese Beispiele zeigen, dass nicht alle Güter, die durch Anniversarstiftungen an das Stift kamen, in Obleien organisiert wurden. Tatsächlich gab es zahlreiche Güter und Güterkomplexe, die zwar an das Kapitel zinsten oder deren Einkünfte in die Sicherung des liturgischen Gebets eingingen, jedoch keiner Einzeloblei angehörten und wahrscheinlich nicht durch den Obleier verwaltet wurden. Diese Güter lassen sich durch die stiftseigenen Quellen schwer nachweisen. Einzig über die Anniversarbücher sind Spuren von Schenkungen und Stiftungen auszumachen, die nicht in das Raster der Einzelobleien oder Vikarien passen. Über deren Verwaltungsmodalitäten geben diese Quellen jedoch keine dezidierte Auskunft.

1071 „Censum custodie“ im Zinsregister von 1555 in StABa Stift St. Gangolf, Akten und Bände Nr. 23 fol. 42-45. 


\section{Schlussbetrachtung}

Im Mittelpunkt dieser Arbeit steht die Aufarbeitung, Einordnung und Interpretation der zum überwiegenden Teil unedierten Quellen zur Geschichte des Bamberger Kollegiatstifts St. Gangolf. Die daraus resultierende Institutionengeschichte stellt die Organisationsstruktur und die Eigenarten des Stifts heraus und ordnete es in die Stadt- und Kirchenlandschaft Bambergs ein. Dabei zeigt sich eine kirchliche Einrichtung, die zwischen starker Orientierung am Vorbild des Bamberger Domstifts auf der einen Seite und der Identifizierung als Stift rechts der Regnitz auf der anderen Seite schwankte. Letzteres wird besonders an der Bedeutung der Theuerstadt als Bezugspunkt für die Selbst- und Fremdwahrnehmung des Stifts St. Gangolf deutlich.

Die gewichtige Rolle der Theuerstadt ist eines der großen Erkenntnisse der vorliegenden Arbeit. Die Vorstadt war nicht nur Kirchenstandort, Pfarreibezirk, Residenzort der Kanoniker und Zentrum des Gangolfer Obleibesitzes, sondern darüber hinaus ein bedeutender Identifikationspunkt seit der Gründung des Stifts. Während der Bamberger Dom sowie die Stiftskirchen von St. Stephan und St. Jakob westlich der Bürgerstadt gelegen waren, befand sich das Stift St. Gangolf geografisch getrennt östlich der Regnitz. Diese Sonderrolle innerhalb der Bamberger Stiftslandschaft wurde von den Zeitgenossen wahrgenommen, wie sich aus der Analyse der Außendarstellung zeigte. Mittels Siegel, aber auch durch die Selbst- und Fremdbezeichnung innerhalb von Rechtsvorgängen, wurde neben Normen und Werten auch die eigene Identität nach außen sichtbar widergespiegelt. Aufgrund einer feststellbaren Wandelbarkeit der Identität in Reaktion auf Krisen und Umbrüche innerhalb der Gemeinschaft aber auch als Echo auf äußere Gegebenheiten muss das Bild einer innovationsscheuen Klerikergemeinschaft, die allein von den Ägiden des Bamberger Domstifts abhängig war, für das Stift St. Gangolf notwendigerweise relativiert werden. Dabei sind Namensgebung und Siegelgestaltung sicherlich im Sinne einer kontemplativen Hingabe an einen Heiligen und einer religiösen Idee zu verstehen. Sie sind aber ebenso Ausdruck eines Kommunikationsprozesses zwischen dem Stift und seinem sozialen Umfeld. Das nach außen getrage- 
ne Selbstbild richtete sich nicht nur an die anderen geistlichen Institutionen der Region, sondern auch an die laikale Umwelt. Durch die Demonstration der hauseigenen Ideale in Form von Patronagen sollten Laien zu Schenkungen und Stiftungen angeregt werden, welche das Überleben der Institution sicherten. Die Bedeutung der beiden Hauptheiligen war hierbei ebenso alltäglich wahrnehmbar, wie die Patrone der Altäre und die Durchführung der Gottesdienste durch die Kanoniker beziehungsweise der Vikare. Die Wirkung auf die Außenwelt lässt sich durch die historischen Quellen freilich kaum gesichert ermitteln. Durch die Analyse der Gangolfer Urkunden mit ihrem konstanten regionalen und stadtherrlichen Entstehungshintergrund, die diese Arbeit erstmals mit Anspruch einer gewissen Vollständigkeit durchgeführt hat, konnte aber eine Annäherung gewagt werden.

Das erste Siegel, das nachweislich von einem Amtsträger St. Gangolfs geführt wurde, stammt aus dem Jahr 1242 und war das Rechtsinstrument des Dekans. Das Kapitel als siegelndes Organ kann 1295 nachgewiesen werden. Dies fügt sich in die allgemein $\mathrm{zu}$ beobachtende Entwicklung eines gesteigerten korporativen Bewusstseins von Domund Kollegiatstiften nördlich der Alpen ein. Die Außenwirkung heiligen Ordensgründer wurde gezielt durch bildliche und architektonische Medien gefördert und für die Mobilisierung von Stiftungen instrumentalisiert.

Die oft vertretene Behauptung, der Heilige Gangolf sei erst im Spätmittelalter als Patron des Kollegiatstifts aufgetreten und die Gemeinschaft sei damit im Zuge der aufkommenden Gangolfverehrung nördlich der Alpen einem Trend der Zeit gefolgt, konnte mit Hilfe der historischen Quellen widerlegt werden. Spätestens seit dem frühen 12. Jahrhundert prägte der Heilige Gangolf den Bamberger Raum. Obwohl die Motive für eine derart frühe Wahl Gangolfs als Patron unklar bleiben, scheint der Einfluss der rheinischen Gebiete, vor allem Lothringens, auf das Bamberger Gangolfstift ausschlaggebend gewesen zu sein. ${ }^{1072}$ Bereits seit seiner Gründung stand das Stift unter dem Doppel-

1072 Hierbei wird der Argumentation Gerd Zimmermanns gefolgt, in Zimmermann: Sankt 
patrozinium der Gottesmutter Maria und des Ritterheiligen Gangolf. Das bestätigt die Chronik Heimos von St. Jakob ebenso wie die Untersuchung der Stiftsbezeichnungen in den Urkunden. Anders als bisher in der Forschung angenommen, gab es also im Falle des Bamberger Stifts keinen Patrozinienwechsel von Maria zu Gangolf. Aufgrund ikonografischer Analysen der Kapitelsiegel ist jedoch zu konstatieren, dass Maria noch vor Gangolf eine übergeordnete Rolle als Stiftspatronin einnahm. Ob Johannes der Täufer auch bereits seit der Stiftsgründung Mitpatron war, konnte nicht eindeutig geklärt werden, bleibt jedoch aufgrund seines Fehlens auf Siegeln und in Urkundentexten zu bezweifeln. Plausiber erscheint eine Ergänzung der ursprünglichen Marienpatronage um den Heiligen Johannes im 16. Jahrhundert, sodass von einer Patrozinienerweiterung gesprochen werden kann. ${ }^{1073}$

Auf den ersten Blick führt das Zusammenwirken der Heiligen Maria und Gangolf sowie der Theuerstadt auf Siegelabbildungen und Bezeichnungsvarianten zu einer großen Themenvielfalt im Repräsentationsprogramm des Stifts St. Gangolf, die eine gewisse Unstetigkeit vermuten lassen. Jedoch konnten durch die gezielte Untersuchung der chronologisch aufgenommenen Siegeltypen sowie Eigen- und Fremdbezeichnungen Linien aufgezeigt werden, die das Stift St. Gangolf als eine von der Theuerstadt geprägten Kirchengemeinschaft erkennen lässt. Vermutlich schon im Zuge seiner Gründung, ${ }^{1074}$ spätestens jedoch ein halbes Jahrhundert danach, ${ }^{1075}$ tauchte die Theuerstadt als Element der Stiftsbezeichnung auf und bleibt dieser in dem Ausmaß erhalten, als dass sich, unabhängig von den Patronen Gangolf oder Maria, immer die Theuerstadt in der Selbstbezeichnung fand. Häufig genügte die Bezeichnung ecclesia in Teuerstat für eine eindeutige Zuordnung aus. Ordnungsvorstellungen und Herrschaftsverhältnisse wurden auf diese Weise mit einem Raum verknüpft, dessen Grenzen durch den Fluss bereits

Gangolfs Weg von Lothringen nach Bamberg. 1962.

1073 Näheres zum Begriff Patrozinienerweiterung in Zimmermann: Patrozinienwahl und Frömmigkeitswandel. 1958). S. 35.

1074 „Decanus de Duristat“ im Synodialprotokoll vom 13. April 1059 in Jaffé: Acta synodi Bambergensis. 1869. S. 498.

1075 „Prepositus Turstatensis“ in einer Bestätigungsurkunde von 1108 in StABa BU 149. 
vorgegeben waren, dessen Zuordnung zum Stift St. Gangolf aber keinesfalls einheitlich oder konkurrenzlos war. Weitere Kirchen, die in der Theuerstadt lagen, jedoch weitaus weniger selbstverständlich die Theuerstadt als Namensbestandteil führten, waren das Kloster Heilig Grab und die Gertraudkapelle. Der Hof des Bürgerspitals St. Katharina in Theuerstadt oder der Liebfrauen-Siechhof waren ebenfalls in der Theuerstadt ansässig, jedoch weniger durch ihre Ortsteilzugehörigkeit ausgezeichnet. Allein durch das Recht auf Ausübung der Niedergerichtsbarkeit war das Stift St. Gangolf innerhalb seines Immunitätsbezirks tonangebend. Dieser Bezirk kann für das 14. bis 16. Jahrhundert durch die eingängige Analyse der Urkunden des Gangolfer Kellers als rechtssprechender Instanz auf das Gebiet zwischen Wunderburg und Heilig Grab, sowie Peunt und der Kaimsgasse eingegrenzt werden. ${ }^{1076}$ Damit war ein großer Teil der Theuerstadt der niederen Gerichtsbarkeit des Stifts unterstellt. Durch die in den Obleien organisierten Besitzungen hatte das Stift außerdem einen Großteil der Grundstücksrechte unter sich. Sich überlagernde Bezirke aufgrund von Pfarrzugehörigkeiten, Gerichtsrechten oder Steuerräumen mit Interessenunterschieden von mehreren sozialen Gruppen, zum Beispiel gegenüber dem Stadtherrn, prägen nicht nur Bamberg als mittelalterliche Stadt, sondern widerlegen in vielen Bereichen die Vorstellung eines Stadtgefüges als eine im Ganzen wahrgenommene Einheit.

Für die Ansiedelung des Stiftes in der bereits existierenden, ländlich geprägten Theuerstadt im 11. Jahrhundert dürfte sicherlich die relativ gute Erschließung der Gegend um den Hauptsmoorwald und der Wunsch nach Sicherung vor fremden Herrschaftsansprüchen verantwortlich gewesen sein. Allerdings konnte sich an das Gründungsdatum, trotz intensiver Spurensuche, nicht weiter angenähert werden - weitgehend gesichert ist weiterhin nur der Zeitraum zwischen Ostern 1057 und dem 13. April 1059. Die Schriftzeugnisse rund um die Gründung des Stifts St. Gangolf sind rar gesät und eine Gründungsurkunde fehlt völlig. Erste Erwähnungen der Gemeinschaft außerhalb der historiogra-

${ }^{1076}$ Anhang Karte 1: Immunitätsgebiet. 
fischen Quellen finden sich als Fremderwähnungen in den Bamberger Urkunden für das Ende des 11. Jahrhunderts. Die Annäherung an ein bestimmtes Gründungsjahr, wie es schon häufig in der Forschung versucht wurde, kann weiterhin nur vage erfolgen und orientiert sich an den Ausführungen des Erich Freiherrn von Guttenberg, die er in seinen Regesten Anfang des 20. Jahrhunderts dargelegt hat. ${ }^{1077}$ Quellen über die Gründung, die bisher gar nicht oder nur unabhängig der allgemeinen Werke über das Stift gesichtet wurden, sind die stiftsinterne Gründungsnotiz des 17. Jahrhunderts und die sogenannte Reliquienauthentik. Die Gründungsnotiz gibt Einblick in das frühneuzeitliche Wissen über die eigenen Ursprünge. Dieses ist jedoch lückenhaft und vom Selbstverständnis der Hollfelder Propstvögte hinsichtlich ihrer Bedeutung für das Stift geprägt. Abgesehen davon, dass die Entstehungsumstände der zweiten Quelle, der Reliquenauthentik, nur schwer $\mathrm{zu}$ fassen ist, muss sie auch hinsichtlich ihres Bezugs zu Reginold Walpot als Mitbegründer und großzügigem Gönner der Stifts hinterfragt werden. Doch selbst wenn die Reliquienauthentik nicht ungeprüft der Gründungszeit des Stifts zugordnet werden sollte, dann ist sie doch ein beredtes Zeugnis von der Förderung der Reginoldmemoria in der Folgezeit der Stiftsgeschichte. Diese musste sich auf die Person des Reginold als Vertreter seines Geschlechts beschränken, denn während seine umfangreichen Stiftungen an das neugegründete Stift ein persönliches Interesse am Stiftsausbau vermuten lassen könnte, blieb die Bedeutung der Familie der Walpoten für das Stift St. Gangolf in der Folgezeit äußerst gering. So etablierte sich beispielsweise keine Familienmemoria der Walpoten, obwohl die Zuwendungen des Stifters für St. Gangolf existenzbegründend waren.

Auch der Bamberger Bischofs Gunther als historisch verbürgter Initiator der Stiftsgründung spielte in der stiftseigenen Erinnerung, wie beispielsweise der Anniversarüberlieferung, kaum eine Rolle. Das Selbstbild einer Bischofsgründung wurde vom Stift nicht gepflegt. Bedeutung erlangte in den bisherigen Publikationen zum Stift St. Gangolf,

1077 Guttenberg: Die Regesten der Bischöfe und des Domkapitels von Bamberg. 1932. S. 130-131. Nr. 285. 
neben Reginold Walpot nur ein gewisser Eberhard, der in der älteren Forschung als Mitglied der Bamberger Bürgerschaft betrachtet wurde. Die historische Existenz des vermeintlichen Bürgers Eberhards bleibt trotz einer umfangreichen Quellenanalyse fragwürdig. Erwähnt wird Eberhardt erstmals im 15. Jahrhundert, als sich das Domkapitel als Deckelinstitution für die drei Kollegiatstifte einen Parteienkampf mit dem Bamberger Bischof und seiner Bürgerstadt lieferte, und sich dies rückwirkend in der Gründungsgeschichte des Gangolfer Stifts wiederspiegeln sollte.

Verfassung und Verwaltung des Stifts St. Gangolf entsprachen im Wesentlichen den Verhältnissen in den übrigen Bamberger Stiften. Im Gegensatz zu den regulierten Kollegiatstiften oder gar den Klöstern gehörte St. Gangolf zu den weltlichen Kollegiatstiften, was bedeutete, das seinen Mitgliedern Privatbesitz erlaubt war. Mittelpunkt der Gemeischaft bildete das Kapitel. Durch Abhaltung des Kapitelgerichts hielt es die innere Ordnung aufrecht. Dieser Aufgabe trugen die Statuten und Consuetudines Rechnung, wobei sich St. Gangolf stark an den normativen Vorgaben des Bamberger Domkapitels orientierte. Im Unterschied zu den Domkanonikern aber mussten die zwölf vollbepfründeten Kanoniker des Stifts St. Gangolf, wie sie im 15. und 16. Jahrhundert nachweisbar sind, nicht adliger Abstammung sein.

Die Statuten des Stifts St. Gangolf entstanden Anfang des 15. Jahrhunderts und wurden in ihrer ersten Version 1433 von Bischof Anton von Rotenhan verliehen. Ihre Ausfertigung fiel in eine Zeit der angespannten Beziehung zwischen Propst und Stift, welche es nicht nur in St. Gangolf, sondern auch am Domstift zu regulieren galt. Zudem bildeten sie einen rechtssichernden Faktor in den unsicheren Zeiten des Immunitätenstreits. Neben Aufnahme und Bepfründung der Kanoniker regelten die Statuten die Rechte und Pflichten der Inhaber geistlicher Ämter, worunter man bei St. Gangolf den Propst, den Dekan, den Scholastikus, den Kustos, den Keller und den Obleier verstehen muss. Die Consuetudines des Stifts entstanden im Gegensatz zu den Statuten ohne landesherrlichen Einfluss und befassten sich mit Regelung der Liturgie und der allgemeinen Disziplin. 
Als Stadtherr von Bamberg hatte der Bischof die Möglichkeit, etwa durch das Bestätigungsrecht der Statuten, Einfluss auf die Entwicklung des Kollegiatstifts zu nehmen. Daneben bestimmte jedoch vor allem das Domstift die Politik St. Gangolfs sowie der anderen beiden Stifte St. Stephan und St. Jakob. Die aus dieser Interessenvertretung resultierenden Konflikte mit dem bischöflichen Stadtherrn wurden von dem selbstbewussten Domkapitel zur Wahrung der eigenen Machtansprüche mit großer Intensität ausgetragen.

Das Stift St. Stephan hatte innerhalb der Stiftslandschaft eine Vorrangstellung inne, welche vor allem auf dessen Gründungsdatum als ältestes der drei kleineren Bamberger Stifte beruhte. Dies zeigte sich nicht zuletzt durch die Reihenfolge in den urkundlichen Zeugenlisten. Absprachen in rechtlichen Handhabungen und stiftsübergreifenden Bepfründungen sorgten für eine gezielte Abstimmung der Stifte. Bei Rechtsfragen arbeiteten die kirchlichen Einrichtungen Bambergs eng zusammen und traten bei juristischen Konflikten geschlossen auf.

Während sich in Bezug auf die Bürgerstadt durchaus eine personelle Verzahnung von Immunitätsbewohnern und Stadtbewohnern feststellen lässt, blieb ein größerer Niederschlag von Mitgliedern der großen Bürgerfamilien Bambergs in den Kanonikerlisten des Stifts St. Gangolf aus. Auch der innenstädtische Besitz des Stifts blieb überwiegend auf die Theuerstadt beschränkt. Nur vereinzelt sind Güter auf der Inselstadt $\mathrm{zu}$ finden, sodass wenige Aussagen über die Zusammenarbeit mit den bürgerlichen Institutionen getroffen werden können. Allein mit dem Bamberger Bauhof hatte das Stift eine Absprache zur Organisation der Oblei Wattlauben.

Die Verflechtungen St. Gangolfs mit den Kirchen und -gemeinden außerhalb Bambergs waren äußerst gering. So findet sich beispielsweise kein Bischof im Anniversarbuch des Stiftes, der nicht Bamberger Bischof war. Auch durch Gangolfer Kanoniker getätigte Stiftungen für außerstädtische Einrichtungen blieben die Ausnahmen. Allein das 1314 durch Leupold von Hirschberg als Gangolfer Scholastikus gegründete Stift Neunkirchen am Brand ist ein Beispiel für das Engagement einzelner Gangolfer Kanoniker, durch eigene Stiftungen die Kirchenstruktur des Umlandes zu fördern. Jedoch sind in diesem Einzelfall über die 
Person des Gründers hinaus keinerlei Verbindungen zum Stift St. Gangolf nachweisbar.

Das geistige und religiöse Leben am Stift St. Gangolf wird aufgrund der Quellen, die vor allem für das Spätmittelalter und der frühen Neuzeit vorliegen, erst sehr spät greifbar. Insbesondere die stiftseigene Consuetudines-Überlieferung des 16. Jahrhunderts bietet Einblicke in die Organisation der Gottesdienste. Dabei spielte der Dekan als liturgischer Leiter eine wichtige Rolle. Ihm oblag die Sicherung der Disziplin, wodurch mittels einer tadellosen Außenwirkung Stiftungen und damit das Fortbestehen der Gangolfer Gemeinschaft garantiert werden sollten. Die Gottesdienstordnung orientierte sich an der des Bamberger Domstifts und wurde durch lokale Eigenheiten, etwa bei Prozessionen, spezifiziert. Es war gängige Praxis an Bamberger Stiften, Vikariestiftungen zu pflegen und Stuhlbrüder zu unterhalten, wobei sich St. Gangolf stark am Domstift orientierte. Auch hierbei stand die Qualitätssicherung der Gottesdienste im Vordergrund. Was das geistige Leben in St. Gangolf anbelangt, so liegt es größtenteils im Dunkeln. Über die Existenz einer nennenswerten Stiftsbibliothek herrscht in der Forschung weiterhin Unsicherheit. Zwar konnten Hinweise auf einzelne Bücher im Besitz des Stiftes gefunden werden, doch deutet nichts darauf hin, dass sich dieser Bestand in Qualität und Quantität mit dem des Stiftes St. Stephan oder gar des Domstifts hätte messen können. Das spricht für eine eher untergeordnete Rolle des Stiftes St. Gangolf als geistige Einrichtung oder schulische Institution. Das Bild des wohl bekanntesten Gangolfer Schulmeisters, Hugo von Trimberg, muss daher in seiner überregionalen und wegweisenden Bedeutung, zumindest für das Stift St. Gangolf, neu bedacht werden.

Das Kollegiatstift St. Gangolf organisierte seinen Grundbesitz sowohl in Form von Pfründen, die dem Propst unterstanden, als auch in Form von Kapitelsgut, welches der Dekan und das Stiftskapitel verwalteten und worauf der Propst keinen Einfluss hatte. Auch nach der Auflösung der Vita Communis hielt das Stift an der Praxis der Pfründen fest und unterstellte diese dem Propst. Das vom Kapitel verwaltete Gut speiste sich aus verschiedenen Stiftungen, meist zur Begehung des 
Jahrtages, und unterteilte sich in Obleigut, Vikarienstiftungen und anderen Anniversarstiftungen.

Über 130 Besitzverzeichnisse finden sich im Bestand des Stifts St. Gangolf im Staatsarchiv Bamberg und machen damit einen Großteil des gesamten Stiftsnachlasses aus. Durch die gründliche Analyse aller Besitzgruppen und Zugehörigkeiten konnten 39 Orte identifiziert werden, aus denen der Gangolfer Propst im 15. und 16. Jahrhundert seine Einkünfte bezog. Außerdem war es möglich, durch Sichtung der Register und Obleimatrikel die zahlreiche Angaben zur Organisation des Kapitelgutes in 36 Einzelobleien zusammenzufassen. Die klare Trennung zwischen Kapitelgut und Pfründengut des Stifts St. Gangolf fügt sich in das Muster der anderen Bamberger Stifte ein. Für die Verteilung der Pfründen unter die einzelnen Kanoniker war der Keller zuständig, während für die Verteilung und Verwaltung des Kapitelsgutes der Obleier die Verantwortung trug. St. Gangolf vergab nachweislich 14 Vollpfründen, sodass im 15. Jahrhundert von bis zu zwölf Kanonikern ausgegangen werden kann, die das Stift versorgen konnte. Diese Erkenntnis ermöglicht eine vorsichtige Größeneinordnung: Das Domstift vergab 20, das Stift St. Stephan 17 Pfründen. Die Aufteilung der Güter in Einzelpfründen erfolgte also nicht durch den Propst. Dieser gab allein die vereinbarten Abgaben an das Kapitel weiter. Wie viele Pfründen verteilt wurden und wie groß eine Einzelpfründe war, wurde durch die Statuten, also dem Rechtsinstrument des Kapitels, festgelegt. Dies kam den Kanonikern entgegen, da sie so bei größeren Ausfällen von Einnahmen einen Ausgleich durch andere Einnahmen des Propstes verlangen durften. Die Kontrolle des Propstes durch das Kapitel war streng und das Bedürfnis nach der verbindlichen Festlegung der Gütergrenzen groß. Die Analyse der in der Gangolfforschung bisher wenig beachteten Quellen Remissiones und Cautiones als Zugeständnis des Propstes an das Stiftskapitel samt deren Modifizierung konnten wichtige Hinweise auf die Kommunikation zwischen Propst und Kapitel auf der Rechtsebene liefern. Die schriftlich fixierten und durch den Bamberger Bischof abgesegneten Verpflichtungen zwischen beiden Parteien erfuhren dabei eine permanente Umarbeitung und Anpassung an aktuelle Notwendigkeiten. Beide Seiten rangen mittels dieses Instrumentariums um die Einhal- 
tung einstmaliger Zugeständnisse und versuchten auf diese Weise ihre Stellung zu wahren. Der Propst sorgte für die Versorgung der Emanzipaten und der vier Gerichtsschöffen, sowie für den Kustos, den Keller und den Obleier.

Die Güterstreuung des Stifts St. Gangolf war auf ein überschaubares Gebiet beschränkt: dem Pfründengut in und um den Propsthöfen stand das Kapitelgut und da besonders der große, als Obleigut verwaltete Besitzkomplex gegenüber. Dieser lag zu etwa zwei Dritteln im Radenzgau, wenn auch weiter verstreut als es für das Pfründengut nachgewiesen werden konnte, und zu einem Drittel im Bamberger Stadtgebiet. Während die innerstädtische Besitzausdehnung des Domstifts und des Stifts St. Stephan über das gesamte Stadtgebiet verteilt lag, ${ }^{1078}$ beschränkte sich die des Stifts St. Gangolf hauptsächlich auf die Theuerstadt und das Immunitätsgebiet. Einzelne Häuser in der Langen Straße, am Markt und hinter der Stadtpfarrkirche St. Martin bildeten den einzigen Obleibesitzungen im Bamberger Bürgerstadtgebiet. In der Domstadt jenseits des alten Rathauses verfügte das Gangolfer Stift offensichtlich zu keiner Zeit über Eigentum. Dort war die Konkurrenz zu den bereits ansässigen, mächtigeren Institutionen zu groß. Der Landbesitz des Stifts St. Gangolf konzentrierte sich auf die Gebiete um Hollfeld. Entgegen dem großen Wirkungskreis des Bamberger Domstifts, welcher bis nach Kärnten verfolgt werden kann, ist das Gangolfer Kollegiatstift ausschließlich im Radenzgau zwischen Bamberg und Bayreuth vertreten. St. Gangolf hatte daher einen lokal konzentrierten Grundbesitz vorzuweisen, was durch eine gezielte Erwerbspolitik und der Nutzung der alten Villikationsstruktur zusätzlich gefördert wurde.

Obwohl Güter in Hollfeld sowohl als Pfründengut wie auch als Obleigut verwaltet wurden, spielte die Stadt für das Pfründengut eine herausragende Rolle. Hollfeld stand im Mittelpunkt der Pfründenverwaltung und beherbergte eine Kaplanei, die auch in den Statuten des Stifts berücksichtigt wurde. Die Konzentration der vom Propst verwalteten Gebiete auf den Radenzgau um Hollfeld kann

${ }^{1078}$ Schimmelpfennig: Bamberg im Mittelalter. 1964. S. 43. 
durchaus als Spur des Stiftsgründers Reginold Walpot gedeutet werden, dessen Ministerialenfamilie um den Ort Zwernitz begütert war. Deutlich zu erkennen ist die zentrale Rolle des Propsthofverwalters in Hollfeld, der eigene Güterverzeichnisse anlegte und Einkünfte aus eigenen, ihm zugeteilten Gütern bezog. Zusammen mit Gesees nahe Bayreuth bildete Hollfeld einen der wichtigsten Propsteihöfe des Stifts St. Gangolf. An der exponierten Lage dieser Ortschaften lässt sich ablesen, dass es sich hier, neben Verwaltungsstellen, um Außenposten handelte, um die Transportwege zu verkürzen.

Mit der Aufarbeitung der Institutionengeschichte des Kollegiatstifts St. Gangolf anhand der bisher größtenteils unveröffentlichten Quellen zeigt sich ein Bild der Vielfalt in der Lebenswelt der Bamberger Kanoniker, die vom Selbstbild als Dienstleister gottesdienstlicher Spiritualität bis hin zur sozial-wirtschaftlicher Selbstverwaltung geprägt war. Mit dieser Arbeit soll eine Lücke in der Erschließung der Bamberger Kirchengeschichte geschlossen und mittels Impulse weitere Forschungen angeregt werden. 


\section{Abkürzungsverzeichnis}

AEB Archiv des Erzbistums Bamberg

BHVB Berichte des Historischen Vereins Bamberg

BU StABa, Hochstift Bamberg, Bamberger Urkunden

Gde Gemeinde

KMU StABa Kloster Michelsberg, Urkunden

L Lade

LexMA Lexikon des Mittelalters

Lk Landkreis

MGH Monumenta Germaniae Historica

Rep. Repertorium

StABa Staatsarchiv Bamberg

SttABa Stadtarchiv Bamberg

StANu Staatsarchiv Nürnberg

StAWu Staatsarchiv Würzburg

ULF Unserer Lieben Frau

WU StAWu, Hochstift Würzburg, Würzburger Urkunden 


\section{Quellen- und Literaturverzeichnis}

\section{Ungedruckte Quellen}

\section{Staatsarchiv Bamberg}

A 25 Wahlen, Wahlkapitulationen und Erbhuldigungen - L 30 Nr. 42

A 85 Einigungen, Kreisrezesse, Landtagsabschiede, Bündnisse und Staatsverträge

- L 343 Nr. 1396

A 120 Urkunden der Stifte St. Stephan, St. Gangolph und St. Jacob

- L 131 Nr. 720 - L 131 Nr. 753 - L 131 Nr. 770 - L 133 Nr. 879

- L 131 Nr. 721 - L 131 Nr. 754 - L 131 Nr. 771 - L 133 Nr. 880

- L 131 Nr. 722 - L 131 Nr. 755 - L 131 Nr. 772 - L 133 Nr. 881

- L 131 Nr. 724 - L 131 Nr. 756 - L 131 Nr. 773 - L 133 Nr. 882

- L 131 Nr. 725 - L 131 Nr. 757 - L 133 Nr. 851 - L 133 Nr. 883

- L 131 Nr. 726 - L 131 Nr. 758 - L 133 Nr. 867 - L 134 Nr. 899

- L 131 Nr. 727 - L 131 Nr. 760 - L 133 Nr. 870 - L 134 Nr. 902

- L 131 Nr. 728 - L 131 Nr. 761 - L 133 Nr. 871 - L 134 Nr. 905

- L 131 Nr. 729 - L 131 Nr. 762 - L 133 Nr. 872 - L 134 Nr. 906

- L 131 Nr. 730 - L 131 Nr. 763 - L 133 Nr. 873 - L 134 Nr. 918

- L 131 Nr. 731 - L 131 Nr. 764 - L 133 Nr. 874 - L 134 Nr. 919

- L 131 Nr. 732 - L 131 Nr. 765 - L 133 Nr. 875 - L 134 Nr. 922

- L 131 Nr. 750 - L 131 Nr. 766 - L 133 Nr. 876 - L 134 Nr. 935

- L 131 Nr. 751 - L 131 Nr. 767 - L 133 Nr. 877 - L 134 Nr. 936

- L 131 Nr. 752 - L 131 Nr. 769 - L 133 Nr. 878 - L 135 Nr. 1016

A 232/III Hochstift Bamberg, Ämterrechnungen Stifter

- R. $22560(1560 / 61) \quad$ - R. $24797(1597 / 98)$

- R. $24762(1562 / 63) \quad$ - R. $24798(1598 / 99)$

- R. $24790(1590 / 91) \quad$ - R. $24799(1599 / 1600)$ 
- R. $24795(1595 / 96) \quad$ - R. $24800(1600 / 01)$

- R. $24796(1596 / 97) \quad$ - R. $25268(1568 / 69)$

B 86 Rezeßbücher, Literalien und Akten des Domkapitels Bamberg

- Nr. 22

- Nr. 42

- Nr. 263

- Nr. 271

- Nr. 380a

B 113 Kloster Neunkirchen am Brand, Akten und Bände - Nr. 1

K 3 F VIII Regierung von Oberfranken, Kammer des Inneren - Nr. 181

K 202 Säkularisationsakten

- Nr. 452

K 210 Extraditionsakten des Rentamtes Bamberg II

- Nr. 39

K 515 Altregistratur Staatsarchiv Bamberg, Verwaltungsakten - Nr. 662

Geistliche Regierung, Akten und Bände

- Nr. 4567

- Nr. 4568

- Nr. 5488

Hochstift Bamberg, Bamberger Urkunden (BU)

$\begin{array}{llllll}.143 & .411 & .720 & .1872 & .2644 & .3501 \\ .149 & .412 & .689 & .1904 & .2651 & .3599 \\ .156 & .415 & .782 & .1906 & .2670 & .3603 \\ .161 & .427 & .878 & .1947 & .2700 & .3641 \\ & & & 283 & & \end{array}$




$\begin{array}{llllll}.178 & .441 & .881 & .1988 & .2742 & .3726 \\ .223 & .467 & .935 & .2060 & .2806 & .3787 \\ .225 & .471 & .1039 & .2066 & .2835 & .3860 \\ .226 & .473 & .1110 & .2179 & .2913 & .3995 \\ .247 & .475 & .1241 & .2187 & .2940 & .4001 \\ .255 & .476 & .1257 & .2190 & .2964 & .4071 \\ .256 & .478 & .1432 & .2239 & .2969 & .4091 \\ .264 & .485 & .1562 & .2490 & .2985 & .4110 \\ .283 & .600 & .1568 & .2496 & .3022 & .4261 \\ .312 & .607 & .1578 & .2498 & .3075 & .4287 \\ .335 & .613 & .1582 & .2537 & .3076 & .4433 \\ .339 & .614 & .1618 & .2552 & .3114 & .4442 \\ .347 & .618 & .1682 & .2558 & .3115 & .4451 \\ .369 & .645 & .1698 & .2583 & .3130 & .4488 \\ .376 & .660 & .1716 & .2594 & .3240 & .4585 \\ .387 & .671 & .1842 & .2619 & .3261 & .4665 \\ .391 & .688 & .1844 & .2630 & .3296 & .4693 \\ & & .1871 & .2636 & .3332 & .4766\end{array}$

Hochstift Bamberg, Neuverzeichnete Akten

- Nr. 3799

Kloster Langheim, Urkunden

- 1302 XI 10 - 1436 I 23

-1398 VII $12 \quad-1439$ IX 25

- 1406 VIII 28

Kloster Michelsberg, Akten und Bände

- Nr. 46

- Nr. 979

Kloster Michelsberg, Urkunden

- Nr. 16

- Nr. 75

- Nr. 248

- Nr. 545

- Nr. 1419

- Nr. 20

- Nr. 79

- Nr. 294

- Nr. 605

- Nr. 1783

- Nr. 27

- Nr. 80

- Nr. 302

- Nr. 663

- Nr. 1954 


\begin{tabular}{|c|c|c|c|c|}
\hline - Nr. 38 & - Nr. 86 & - Nr. 307 & - Nr. 682 & - Nr. 2023 \\
\hline - Nr. 39 & - N. 110 & - Nr. 318 & - Nr. 704 & - Nr. 2270 \\
\hline - Nr. 41 & - Nr. 141 & - Nr. 321 & - Nr. 733 & - Nr. 2284 \\
\hline - Nr. 46 & - Nr. 154 & - Nr. 503 & - Nr. 738 & - Nr. 2372 \\
\hline - Nr. 73 & - Nr. 169 & - Nr. 507 & - Nr. 970 & - Nr. 2373 \\
\hline \multirow[t]{2}{*}{ - Nr. 74} & - Nr. 174 & - Nr. 527 & - Nr. 1227 & - Nr. 2442 \\
\hline & & & - Nr. 1412 & - Nr. 2443 \\
\hline
\end{tabular}

Stift St. Gangolf, Akten und Bände

- Nr. $2-$ - Nr. $20 \quad$ - Nr. $34 \quad-$ Nr.118 - Nr. $129 \quad$ - Nr. 161

- Nr. 3 - Nr. 22 - Nr. $36 \quad$ - Nr.119 - Nr.130 - Nr. 163

- Nr. $4 \quad$ - Nr. $23 \quad$ - Nr. $40 \quad-$ Nr.120 - Nr. $131 \quad$ - Nr. 168

- Nr. 5 - Nr. $24 \quad$ - Nr. $41 \quad$ - Nr. $121 \quad$ - Nr. $132 \quad$ - Nr. 176

- Nr. 6 - Nr. 25 - Nr. $44 \quad-$ Nr. 122 - Nr. $133 \quad$ - Nr. 191

- Nr. $7 \quad$ - Nr. $27 \quad$ - Nr. $53 \quad$ - Nr. $123 \quad$ - Nr. $134 \quad$ - Nr. 192

- Nr. $10 \quad$ - Nr. $28 \quad$ - Nr. $54 \quad-$ Nr. $124 \quad$ - Nr. $156 \quad$ - Nr. 201

- Nr. $11-$ - Nr. $29 \quad$ - Nr. $56 \quad$ - Nr. 125 - Nr. $157 \quad$ - Nr. 210

- Nr. $12-$ - Nr. $30 \quad-$ Nr. $65 \quad-$ Nr. 126 - Nr. $158 \quad$ - Nr. 211

- Nr. $13 \quad-$ Nr. $31 \quad$ - Nr. $89 \quad-$ Nr. $127 \quad$ - Nr. $159 \quad-$ Nr. 212

- Nr. 235

Stadtarchiv Bamberg

A 21 Urkunden

$\begin{array}{ll}-14-12-1308 & -09-12-1420 \\ -28-03-1335 & -03-02-1440 \\ -27-01-1399 & -25-01-1448 \\ -06-03-1402 & -20-03-1452 \\ -07-01-1416 & -20-02-1458 \\ & -02-05-1491\end{array}$


B 11 Pfründehäuser

- Nr. 100

- Nr. 101

D 3001 HV Rep. 1 Nachlass des Historischen Vereins Bamberg, Urkunden

- Nr. 281

D 3001 HV Rep. 2 Nachlass des Historischen Vereins Bamberg

- Nr. 264

- Nr. 265

- Nr. 522

Archiv des Erzbistums Bamberg

Rep. I Akten des Schlundrepertoriums

- A 121

Rep. I Pfarrei St. Gangolf, Urkunden

- U 818

- U 822

- U 819

- U 823

- U 820

- U 824

- U 821

- U 825

- U 826

Rep. I Pfarrei St. Gertraud, Urkunden

- U 97

- U 102

- U 109

- U 98

- U 103

- U 110

- U 99

- U 104

- U 111

- U 100

- U 105

- U 114

- U 101

- U 107

- U 115

- U 108

- U 116 
Rep. I Pfarrei St. Martin, Urkunden

- U 2

- U 4

- U 16

- U 17

- U 18

Rep. I Pfarrei Unserer lieben Frau, Urkunden

- U 114

- U 121

Rep. 60 Pfarrarchiv St. Gangolf Bamberg

- Nr. 1 - Nr. 119

- Nr. 2 - Nr. 120

- Nr. 3 - Nr. 328

- Nr. 436

Staatsarchiv Würzburg

Kloster Ebrach, Urkunden

- 1205/I - 1290 III 21/II - 1311 VIII 26

- 1285 VII 2/I - 1295 V $25 \quad-1311$ IX 18

- 1285 VII 2/II - 1311 VIII 24/I - 1311 X 1/I

- 1290 I $25 \quad-1311$ VIII 24/II - 1311 X 1/II

- 1312 IV 3

Kloster Langheim, Urkunden

- 1271 XI 10

Kloster St. Stephan Würzburg, Urkunden

$-452$

$-599$

$-600$ 
Mainzer Ingrossaturbücher

- Nr. 43

Hochstift Würzburg, Würzburger Urkunden (WU)

$-65 / 27$

Stift Neumünster, Urkunden

-1245 V 26

Staatsarchiv Nürnberg

Rep. $1 \mathrm{~b}$ Reichsstadt Nürnberg, Päpstliche und fürstliche Privilegien

- Nr. 429

Rep. 8 Reichstadt Nürnberg, Urkunden der Kirchen in Nürnberg - Nr. 58 a

Bayerisches Landesamt für Denkmalpflege, Dienststelle Schloß Seehof

Grabungsbericht 1988 Ausgrabung: Notgrabung bei Ausschachtungsarbeiten für eine Fußbodenheizung, Maßnahme M-2007-31726-1_0; Bamberg, BA: St. Gangolf, G-1988 (Ü-4-6131-0137).

Grabungsbericht 1987 Beobachtung bei Bodeneingriff: Fundbergung und Dokumentation im Zuge von Baumaßnahmen, Maßnahme M2007-31726-3_0; Bamberg, BA: St. Gangolf, FE-1987 (Ü-4-6131-0137).

Grabungsbericht 1980 Ausgrabung: Untersuchung im Zuge der Verlegung einer Fußbodenheizung in der ehemaligen Sepultur der Kirche St. Gangolf, Maßnahme M-2007-31726-2_0; Bamberg, BA: St. Gangolf, G1980 (Ü-4-6131-0137). 


\section{Gedruckte Quellen}

Adalberti vita Heinrici II. imperatoris. In: Pertz, Georg Heinrich (Bearb.): Annales, chronica et historiae aevi Carolini et Saxonici (MGH SS 4). Hannover 1841. S. 792-814.

Annales s. Michaelis Babenbergensis. In: Pertz, Georg Heinrich (Bearb.): Annales et chronica aevi Salici (MGH SS 5). Hannover 1844. S. 910.

Baur, Ludwig (Hg.): Hessische Urkunden, Bd. 2. Darmstadt 1862.

Ebbonis vita Ottonis episcopi Babenbergensis. In: Pertz, Georg Heinrich (Bearb.): Historiae aevi Salici (MGH SS 12). Hannover 1856. S. 822-883.

Excerpta de Ottone ex libris Andreae abbatis s. Michaelis Babenbergensis. In: Pertz, Georg Heinrich (Bearb.): Historiae aevi Salici (MGH SS 12). Hannover 1856. S. 903-909.

Göldel, Caroline: Der Liber feudalis ecclesiae St. Gangolphi 1417-1432. Das älteste Lehnbuch des Kollegiatstiftes St. Gangolf in Bamberg. [o. O.] 1996.

Heisterbach, Caesarius von: Dialogus miraculorum. hg. v. Stange, Joseph. Bd. 1-2. Köln/Bonn/Brüssel 1851.

Holder-Egger, Oswald (Bearb.): Relatio de piis operibus Ottonis episcopi Bambergensis (MGH SS 15/2). Hannover 1888. S. 1151-1166.

Jaffé, Philipp (Hg.): Acta synodi Babenbergensis in epistolae Bambergenses cum aliis monumentis permixtae (Bibliotheca rerum Germanicarum, Bd. 5: Monumenta Bambergensia). Berlin 1869. S. 497-498. 
Jaffé, Philipp (Hg.): Annales s. Michaelis Bambergenses (Bibliotheca rerum Germanicarum, Bd. 5: Monumenta Bambergensia). Berlin 1869. S. 553-554.

Jaffé, Philipp (Hg.): Heimo von St. Jakob: Liber de decurso temporum (Bibliotheca rerum Germanicarum, Bd. 5: Monumenta Bambergensia). Berlin 1869. S. 537-552.

Luther, Bugenhagen, Cruciger und Melanchton an die Pommerschen Räte, Wittenberg 30. Mai 1544. In: D. Martin Luthers Werke. Kritische Gesamtausgabe (Weimarer Ausgabe). Briefwechsel, Bd. 10. Weimar 1947.

Pöhlmann, Thomas: Das Amt Bayreuth im frühen 15. Jahrhundert. Das Landbuch B von 1421/24, eine spätmittelalterliche Quelle mit Erläuterungen (Bayreuther Arbeiten zur Landesgeschichte und Heimatkunde, Bd. 9). Bayreuth 1992.

Schmale, Franz-Josef/ Schmale-Ott, Irene (Hgg.): Frutolfs und Ekkehards Chroniken und die anonyme Kaiserchronik (Ausgewählte Quellen zur deutschen Geschichte des Mittelalters, Bd. 15). Darmstadt 1972.

Sudendorf, Hans Friedrich Georg Julius: Registrum oder merkwürdige Urkunden für die deutsche Geschichte, Bd. 2. Berlin 1851.

Vita sanctae Cunegundis. In: Pertz, Georg Heinrich (Bearb.): Annales, chronica et historiae aevi Carolini et Saxonici (MGH SS 4). Hannover 1841. S. 821-828.

Weitere Briefe Meinhards von Bamberg. In: Erdmann, Carl/ Fickermann, Norbert (Bearb.): Briefsammlung der Zeit Heinrichs IV (MGH Briefe der deutschen Kaiserzeit 5). Weimar 1950. S. 192-248. 
Wikarjak, Jan/ Liman, Kazimierzn (Hgg.): Ebonis vita sancti Ottonis episcopi Babenbergensis (Monumenta Poloniae Historica. Nova Series, Bd. 7,2). Warschau 1969.

Würdtwein, Stephan Alexander: Nova subsidia diplomatica ad selecta juris ecclesiastici Germaniae et historiarum capita elucidanda ex originalibus et authenticis documentis, Bd 1. Heidelberg 1771. S. 197-270.

\section{Literatur}

Acht, Stephan: Studien zum Besitz des Kollegiatstifts Unserer Lieben Frau zur Alten Kapelle in Regensburg. In: Mai, Paul (Hg.): Kollegiatstift Unserer Lieben Frau zur Alten Kapelle in Regensburg 1002-2002. Katalog zur Ausstellung in der Bischöflichen Zentralbibliothek Regensburg, 15. Juli bis 11. Oktober 2002 (Kataloge und Schriften. Bischöfliches Zentralarchiv und Bischöfliche Zentralbibliothek Regensburg, Bd. 17). Regensburg 2002. S. 35-42.

Albrecht, Stephan (Hg.): Der Bamberger Dom im europäischen Kontext (Bamberger interdisziplinäre Mittelalterstudien Vorlesungen und Vorträge, Bd. 4). Bamberg 2015.

Altenhöfer, Edgar: Studien zur Verehrung St. Gangolfs. Insbesondere zur Legende und Sage des Heiligen. Würzburg 1993.

Andraschke, Joachim: Arianische und fränkische Missionierung im Regnitz und Obermaingebiet um 500 bis 800 n. Chr. Ein Sprachgeschichtlicher Beitrag zur Kirchengeschichte Ostfrankens. In: BHVB 135 (1999). S. 89-118.

Angenendt, Arnold: Die liturgische memoria: Hilfe für das Fortleben im Jenseits. In: Berndt, Rainer (Hg.): Wider das Vergessen und für das Seelenheil. Memoria und Totengedenken im Mittelalter (Erudiri Sapientia. Studien zum Mittelalter und zu seiner Rezeptionsgeschichte, Bd. 9). Münster 2013. S. 199-226. 
Angenendt, Arnold: Heilige und Reliquien. Die Geschichte ihres Kultes vom frühen Christentum bis zur Gegenwart. München 1994.

Arlinghaus, Franz-Josef: Konstruktion von Identität mittelalterlicher Korporationen - rechtliche und kulturelle Aspekte. In: Späth, Markus (Hg.): Die Bildlichkeit korporativer Siegel im Mittelalter. Kunstgeschichte und Geschichte im Gespräch (Sensus. Studien zur mittelalterlichen Kunst). Köln/ Weimar/ Wien 2009. S. 33-46.

Arneth, Konrad: M. Martin Hofmann. Ein Bamberger Späthumanist. In: BHVB 110 (1974) S. 39-165

Bedos-Rezak, Brigitte M.: Medieval Identity. A Sign and a Concept. In: American Historical Review 105/5 (2000). S. 1489-1533.

Berndt, Rainer: „Ich habe dich beim Namen gerufen“ (Is 45 3-4). Formen der Selbstwerdung und der Identitätsbildung im lateinischen Mittelalter. In: Berndt, Rainer (Hg.): „Eure Namen sind im Buch des Lebens geschrieben“. Antike und mittelalterliche Quellen als Grundlage moderner prosopographischer Forschung (Erudiri Sapientia. Studien zum Mittelalter und zu seiner Rezeptionsgeschichte, Bd. 11). Münster 2014. S. 25-39.

Berndt, Rainer: „Tuet dies zu meinem Gedächtnis“. Die Eucharistie als Grundlage christlicher memoria in Kirche und Theologie des Mittelalters. In: Berndt, Rainer (Hg.): Wider das Vergessen und für das Seelenheil. Memoria und Totengedenken im Mittelalter (Erudiri Sapientia. Studien zum Mittelalter und zu seiner Rezeptionsgeschichte, Bd. 9). Münster 2013. S. 21-39.

Beyer, Franz-Heinrich: Geheiligte Räume. Theologie, Geschichte und Symbolik des Kirchengebäudes. Darmstadt 2008. 
Braun, Lothar: Musikpflege am Kollegiatstift und an der Pfarrei St. Gangolf in Bamberg im 18. und 19. Jahrhundert. In: Bericht des Historischen Vereins Bamberg, Bd. 155 (2019). S. 241-249.

Braun, Lothar : Von der Stiftspfarrei zur Stadtpfarrei St. Gangolf in Bamberg. In: BHVB 120 (1984). S. 371-398.

Braun, Rainer: Das Benediktinerkloster Michelsberg 1015 - 1525. Eine Untersuchung zur Gründung, Rechtsstellung und Wirtschaftsgeschichte, Bd. 1 (Die Plassenburg. Schriften für Heimatforschung und Kulturpflege in Ostfranken, Bd. 39). Kulmbach 1978.

Braun, Rainer: Das Benediktinerkloster Michelsberg 1015 - 1525. Eine Untersuchung zur Gründung, Rechtsstellung und Wirtschaftsgeschichte, Bd. 2. (Die Plassenburg. Schriften für Heimatforschung und Kulturpflege in Ostfranken, Bd. 39). Kulmbach 1977.

Breuer, Tilmann/ Gutbier, Reinhard: Stadt Bamberg. Teil 5/1: Innere Inselstadt (Die Kunstdenkmäler von Bayern. Regierungsbezirk Oberfranken, Bd. 7). München 1990.

Brügmann, Claus: Das älteste Nekrolog des Stifts St. Peter und Alexander zu Aschaffenburg (Veröffentlichungen des Geschichts- und Kunstvereins Aschaffenburg, Bd. 30). Aschaffenburg 1989.

Bünz, Enno: Oblatio - oblagium - Oblei. Zur Güterorganisation und verwaltung mittelalterlicher Dom- und Kollegiatstifte. In: Lorenz, Sönke/ Meyer, Andreas/ Bauer, Dieter R. (Hgg.): Stift und Wirtschaft. Die Finanzierung geistlichen Lebens im Mittelalter. Fünfte wissenschaftliche Fachtagung zum Stiftskirchenprojekt des Instituts für Geschichtliche Landeskunde und Historische Hilfswissenschaften der Universität Tübingen 2004. Ostfildern 2007. S. 19-44.

Bünz, Enno/ Rödel, Dieter/ Rückert, Peter/ Schöffler, Ekhard (Bearb.): Fränkische Urbare. Verzeichnis der mittelalterlichen urbariellen Quel- 
len im Bereich des Hochstifts Würzburg (Veröffentlichungen der Gesellschaft für fränkische Geschichte. Reihe 10: Quellen zur Rechts- und Wirtschaftsgeschichte Frankens, Bd. 13). Neustadt a. d. Aisch 1998.

Bünz, Enno: Stift Haug in Würzburg. Untersuchungen zur Geschichte eines fränkischen Kollegiatstifts im Mittelalter (Veröffentlichungen des Max-Planck-Instituts für Geschichte, Bd. 128. Studien zur Germania Sacra, Bd. 20). Göttingen 1998.

Bünz, Enno: Probleme der hochmittelalterlichen Urbarüberlieferung. In: Rösener, Werner (Hg.): Grundherrschaft und bäuerliche Gesellschaft im Hochmittelalter (Veröffentlichungen des Max-Planck-Instituts für Geschichte, Bd. 115). Göttingen 1995. S. 31-75.

Chandon, Christian: Die Bevölkerung der Stadt Bamberg um 1525. Eine sozialtopographische Skizze. In: Häberlein, Mark/ Zink, Robert (Hgg.): Soziale Strukturen und wirtschaftliche Konjunkturen (Bamberger Historische Studien, Bd. 10). Bamberg 2013. S. 17-51.

Das Collegiatstift zu U. L. Frau und St. Gangolph in Bamberg. In: Kalender für katholische Christen. Sulzbach 1881. S. 80-91.

Crusius, Irene: Das weltliche Kollegiatstift als Schwerpunkt innerhalb der Germania Sacra. In: Blätter für deutsche Landesgeschichte. Neue Folge des Korrespondenzblattes 120 (1984) S. 241-253.

Deinhardt, Wilhelm: Dedicationes Bambergenses. Weihenotizen und urkunden aus dem mittelalterlichen Bistum Bamberg (Beiträge zur Kirchengeschichte Deutschlands, Heft 1). Freiburg im Breisgau 1936.

Deinhardt, Wilhelm: Frühmittelalterliche Kirchenpatrozinien in Franken. Studien zur Frühgeschichte der Diözesen Bamberg und Würzburg. Nürnberg 1933. 
Dengler-Schreiber, Karin: War Kaiserin Kunigunde die Gründerin von St. Stephan? In: BHVB 156 (2020). S. 89-111.

Deutsches Rechtswörterbuch: Art. „Mandatbrot, Mandatenbrot“. Bd. 9 (1996). Sp. 103.

Deutsches Wörterbuch von Jakob und Wilhelm Grimm: Art. „Vierling. 2c“. Bd. 26 (1951). Sp. 305.

Deutsches Wörterbuch von Jakob und Wilhelm Grimm: Art. „Sümmer“. Bd. 20 (1942). Sp. 1077.

Deutsches Wörterbuch von Jakob und Wilhelm Grimm: Art. „Geischel“. Bd. 5 (1897). Sp. 2607.

Deutsches Wörterbuch von Jakob und Wilhelm Grimm: Art. "Geise“. Bd. 5 (1897). Sp. 2608.

Deutsches Wörterbuch von Jakob und Wilhelm Grimm: Art. "Geisel“. Bd. 5 (1897). Sp. 2618.

Deutsches Wörterbuch von Jakob und Wilhelm Grimm: Art. „Kornbrot“. Bd. 11 (1868). Sp. 1821.

Deutsches Wörterbuch von Jakob und Wilhelm Grimm: Art. „Ducken. 3a“. Bd. 2 (1858). Sp. 1494.

Drossbach, Gisela: Haec sunt statuta. In: Drossbach, Gisela (Hg.): Von der Ordnung zur Norm: Statuten in Mittelalter und Früher Neuzeit. Paderborn 2010. S. 369-385.

Endres, Rudolf: Das Slawenmotiv bei der Gründung des Bistums Bamberg. In: BHVB 109 (1973). S. 161-182. 
Esch, Claudia: Zwischen Institution und Individuum. Bürgerliche Handlungsspielräume im mittelalterlichen Bamberg (Stadt und Region in der Vormoderne, Bd. 4. Veröffentlichungen des Stadtarchivs, Bd. 23). Würzburg 2016.

Esch, Claudia: Topografie und Wirtschaft. Das Verhältnis von Stadtgericht und Immunitäten im mittelalterlichen und frühneuzeitlichen Bamberg im Spiegel der Markt- und Handelsrechte. In: Häberlein, Mark/ Schmölz-Häberlein, Michaela (Hgg.): Handel, Händler und Märkte in Bamberg. Akteure, Strukturen und Entwicklungen in einer vormodernen Residenzstadt (1300-1800) (Stadt und Region in der Vormoderne, Bd. 3. Veröffentlichungen des Stadtarchivs Bamberg, Bd. 21). Würzburg 2015. S. 21-50.

Exner, Matthias/ Ruderich, Peter (Bearb.): Theuerstadt und östliche Stadterweiterungen. 1. Drittelband: Untere Gärtnerei und nordöstliche Stadterweiterung. Teil 1 und 2: Öffentliche Bauten; Straßen und Plätze (Die Kunstdenkmäler von Bayern. Regierungsbezirk Oberfranken, Bd. 9: Stadt Bamberg, Bd. 7/1). Bamberg 2019.

Faber, Arnold: Die staatsrechtliche Stellung des Stifts Sankt Stephan in Bamberg. Sankt Stephan reichsunmittelbar oder bischöfliches Eigenstift? Erlangen 1950.

Farrenkopf, Edmund Karl: Breviarium Eberhardi Cantoris. Die mittelalterliche Gottesdienstordnung des Domes zu Bamberg. Münster 1969.

Fastnacht, Dorothea: Staffelstein. Ehemaliger Landkreis Staffelstein (Historisches Ortsnamensbuch von Bayern, Bd. 5). München 2007.

Fastnacht, Dorothea: Ebermannstadt. Ehemaliger Landkreis Ebermannstadt (Historisches Ortsnamensbuch von Bayern, Bd. 4). München 2000. 
Fickert, Wilhelm: Geldwesen, Kaufkraft und Maßeinheiten im Bereich des Fürstentums Kulmbach-Bayreuth (Gesellschaft für Familienforschung in Franken, Bd. 21). Nürnberg 1989.

Flachenecker, Helmut: Der Zusammenhang zwischen Stiftsschule und Studentenzahlen anhand fränkischer und bayerischer Beispiele. In: Lorenz, Sönke/ Kintzinger, Martin/ Auge, Oliver (Hgg.): Stiftsschulen in der Region. Wissenstransfer zwischen Kirche und Territorium. Ostfildern 2005. S. 167-183.

Flachenecker, Helmut: Lea oder Rachel? Stift oder Kloster am Bischofssitz? In: Lorenz, Sönke/ Zotz, Thomas (Hgg.): Frühformen von Stiftskirchen in Europa. Funktion und Wandel religiöser Gemeinschaft vom 6. bis zum Ende des 11. Jahrhunderts. Festgabe für Dieter Mertens zum 65. Geburtstag (Schriften zur südwestdeutschen Landeskunde, Bd. 54). Leinfelden-Echterdingen 2005. S. 377-392.

Flachenecker, Helmut: Bistum Bamberg. In: Gatz, Erwin (Hg.): Die Bistümer des Heiligen Römischen Reiches von ihren Anfängen bis zur Säkularisation. Freiburg i. B. 2003. S. 70-81.

Flachenecker, Helmut: Patrozinienforschung in Deutschland. In: Concilium Medii Aevi 2 (1999). S. 145-163.

Frank, Hieronymus: Art. „Anniversarium“. In: LThK Bd. 1 (1957). Sp. 577-579.

Fuchs, Margit: Innovation und Pragmatismus. Sankt Stephan in Bamberg als Initialbau der barocken Architektur in Franken (Gesellschaft für fränkische Geschichte, Reihe VIII: Quellen und Darstellungen zur fränkischen Kunstgeschichte, Bd. 18). Stegaurach 2017.

Generaldirektion der Staatlichen Archive Bayerns (Hg.): Königlich Bayerisches Allgemeines Reichsarchiv. Zur Gründung vor 200 Jahren (Bei- 
heft der Ausstellung der Bayerischen Archivschule von Christine Kofer und Johannes Moosdiele, 23. April bis 29. Juni 2012). München 2012.

George, Dieter: Lichtenfels. Der Altlandkreis (Historisches Ortsnamensbuch von Bayern, Bd. 6). München 2008.

Geuder, Irmingard: Auch Bamberg hatte seinen Reformator. Johannes Schwanhauser, Prediger zu St. Gangolf, zum Gedächtnis. Bamberg 1973.

Geyer, Karl: Die öffentliche Armenpflege im kaiserlichen Hochstifts Bamberg mit besonderer Rücksicht der Stadt Bamberg. Bamberg 1909.

Goez, Werner: Kirchenreform und Investiturstreit 910 - 1122. Stuttgart ${ }^{2} 2008$.

Göldel-Kaupper, Caroline: Die Jubiläumsurkunde von 1017. In: Stadt Hollfeld (Hg.): 1000 Jahre Hollfeld Stadt und Land 1017-2017. Hollfeld 2017. S. 9-12.

Göldel, Caroline: Zur Entwicklung der Bamberger Stadtverfassung im 15. Jahrhundert im Spannungsfeld Rat - Gemeinde - Klerus. In: BHVB 135 (1999). S. 7-44.

Göldel, Caroline: Der Bamberger Bauhof und dessen Schriftwesen im 15. Jahrhundert. In: BHVB 123 (1987). S. 223-282.

Goldwitzer, Franz Wenceslaus: Geschichte des Marktes Neunkirchen am Brand und des ehemaligen Klosters mit Rücksicht auf die Pfarrei daselbst nebst einer Topographie. Erlangen 1814.

Göller, Luitgar: Domstift und Kollegiatstifte. In: Göller, Luitgar (Hg.): 1000 Jahre Bistum Bamberg 1007-2007. Unterm Sternenmantel (Katalog der Jubiläumsausstellung). Petersberg 2007. S. 42-49. 
Greipl, Egon Johannes: Art. "Rotenhan, Anton von (um 1390-1459)”. In: Gatz, Erwin (Hg.): Die Bischöfe des Heiligen Römischen Reiches 1448 bis 1648. Ein biographisches Lexikon. Berlin 1996. S. 596.

Greule, Albrecht: Gewässernamensgeschichten im Main-Donau-Raum. In: Bergmann, Rolf/ Stricker, Stefanie (Hgg.): Römer - Baiern - Franken. Archäologie, Namensforschung, Sprachgeschichte im Main-DonauRaum (Bamberger interdisziplinäre Mittelalterstudien. Vorlesungen und Vorträge, Bd. 7). Bamberg 2016. S. 9-23.

Groten, Manfred: Vom Bild zum Zeichen. Die Entstehung korporativer Siegel im Kontext der gesellschaftlichen und intellektuellen Entwicklungen des Hochmittelalters. In: Späth, Markus (Hg.): Die Bildlichkeit korporativer Siegel im Mittelalter. Kunstgeschichte und Geschichte im Gespräch (Sensus. Studien zu mittelalterlichen Kunst, Bd. 1). Köln/ Weimar/ Wien 2009. S. 70-71.

Guerreau, Isabelle: Otto I. von Wohldenberg. Form und Funktion der Selbstdarstellung eines norddeutschen Weltgeistlichen im Spiegel seiner Siegel. In: Signori, Gabriela (Hg.): Das Siegel. Gebrauch und Bedeutung. Darmstadt 2007. S. 45-52.

Gunzelmann, Thomas (Hg.): Stadt Bamberg, Bd. 1: Stadtdenkmal und Denkmallandschaft. 1. Halbband: Stadtentwicklungsgeschichte (Die Kunstdenkmäler von Bayern: Regierungsbezirk Oberfranken, Bd. 3). München/ Bamberg 2012.

Guth, Klaus: Die Verehrung der Bistumspatrone im Mittelalter. In: Göller, Luitgar (Hg.): 1000 Jahre Bistum Bamberg 1007-2007. Unterm Sternenmantel (Katalog der Jubiläumsausstellung). Petersberg 2007. S. 2641.

Guttenberg, Erich Freiherr von: Urbare und Wirtschaftsordnungen des Domstifts zu Bamberg (Veröffentlichungen der Gesellschaft für fränkische Geschichte, Reihe 10: Quellen zur Rechts- und Wirtschaftsge- 
schichte Frankens, Bd. 7,1). hg. von Alfred Wendehorst. Würzburg 1969.

Guttenberg, Erich Freiherr von/ Wendehorst, Alfred: Das Bistum Bamberg 2. Die Pfarreiorganisation (Germania Sacra. Alte Folge Abt. 2: Die Bistümer der Kirchenprovinz Mainz). Berlin/New York 1966.

Guttenberg, Erich Freiherr von: Das Bistum Bamberg (Germania Sacra. Alte Folge Abt. 2: Die Bistümer der Kirchenprovinz Mainz). Berlin 1937 (ND Berlin/New York 1963).

Guttenberg, Erich Freiherr von: Die Regesten der Bischöfe und des Domkapitels von Bamberg (Veröffentlichungen der Gesellschaft für fränkische Geschichte, Bd. 6). Würzburg 1932.

Guttenberg, Erich Freiherr von: St. Nikolaus im alten Bamberg. In: Bamberger Blätter für fränkische Kunst und Geschichte (Beilagen zum Bamberger Volksblatt) 5 (1928). S. 85-87.

Guttenberg, Erich Freiherr von: Territorienbildung am Obermain. In: BHVB 79 (1925). S. 284-287.

Guttenberg, Erich Freiherr von: Peunten in Oberfranken, im Allgäu und in der Steiermark. In: Korrespondenzblatt der Deutschen Gesellschaft für Anthropologie, Ethnologie und Urgeschichte 39 Nr. $4 / 5$ (1908). S. 25-33.

Häberlein, Mark/ Schmölz-Häberlein, Michaela (Hgg.): Handel, Händler und Märkte in Bamberg. Akteure, Strukturen und Entwicklungen in einer vormodernen Residenzstadt (1300-1800) (Stadt und Region in der Vormoderne, Bd. 3. Veröffentlichungen des Stadtarchivs Bamberg, Bd. 21). Würzburg 2015. 
Häberlein, Mark/ Schmölz-Häberlein, Michaela: Stiftungen, Fürsorge und Kreditwesen im frühneuzeitlichen Bamberg (Bamberger Historische Studien, Bd. 13). Bamberg 2015.

Häberlein, Mark: Bamberg im Zeitalter der Aufklärung und der Koalitionskriege (Bamberger Historische Studien, Bd. 12. Veröffentlichungen des Stadtarchivs Bamberg, Bd. 19). Bamberg 2014.

Häberlein, Mark/ Zink, Robert (Hgg.): Soziale Strukturen und wirtschaftliche Konjunkturen im frühneuzeitlichen Bamberg (Bamberger Historische Studien, Bd. 10. Veröffentlichungen des Stadtarchivs Bamberg, Bd. 17). Bamberg 2013.

Häberlein, Mark/ Kech, Kerstin/ Staudenmaier, Johannes: Bamberg in der frühen Neuzeit (Bamberger Historische Studien, Bd. 1. Veröffentlichungen des Stadtarchivs Bamberg, Bd. 11). Bamberg 2008.

Haimerl, Xaver: Das Prozessionswesen des Bistums Bamberg im Mittelalter (Münchener Studien zur historischen Theologie, Bd. 14). München 1937 (ND Hildesheim 1973).

Hallinger, Kassius: Consuetudo. Begriff, Formen, Forschungsgeschichte, Inhalt. In: Max-Planck-Institut für Geschichte (Hg.): Untersuchungen zu Kloster und Stift (Veröffentlichungen des Max-Planck-Instituts für Geschichte, Bd. 68. Studien zur Germania Sacra, Bd. 14). Göttingen 1980. S. 140-166.

Hasselbeck, Johannes: Die Folgen des Deutschen Bauernkriegs im Hochstift Bamberg (Bamberger Historische Studien, Bd. 7. Veröffentlichungen des Stadtarchivs Bamberg, Bd. 14). Bamberg 2012.

Hauck, Albert: Zur Missionsgeschichte Oberfrankens. In: Blätter für bayerische Kirchengeschichte 1 (1888). S. 113-119.

Haupt, Andreas: Bamberger Legenden und Sagen. Bamberg 1842. 
Hawicks, Heike: Xanten im späten Mittelalter. Stift und Stadt im Spannungsfeld zwischen Köln und Kleve. Köln 2007.

Heckmann, Marie-Luise: Art. „Vikar,- iat“. In: LexMA Bd. 8 (1997). Sp. 1662-1664.

Hendges, Gabriele: Maße und Gewichte im Hochstift Würzburg vom 16. bis 19. Jahrhundert. München 1989.

Hetzer, Gerhard: Spannungsfelder und Schnittstellen: Die staatlichen Archive im Königreich Bayern zwischen Verwaltung, Politik und Wissenschaft. In: Sächsisches Staatsarchiv (Hg.): Archivische Facharbeit in historischer Perspektive. Dresden 2009. S. 55-66.

Hien, Hannah: Das Beginenwesen in fränkischen und bayerischen Bischofsstädten (Veröffentlichungen der Gesellschaft für fränkische Geschichte, Reihe IX: Darstellungen aus der fränkischen Geschichte, Bd. 59). Würzburg 2013.

Hiller, Friedrich: Die Kirchenpatrozinien des Erzbistums Bamberg. Bamberg 1931.

Hochedlinger, Michael/ Winkelbauer, Thomas (Hgg.): Herrschaftsverdichtung, Staatsbildung, Bürokratisierung. Verfassungs-, Verwaltungsund Behördengeschichte der Frühen Neuzeit (Veröffentlichungen des Instituts für Österreichische Geschichtsforschung, Bd. 57). Wien u. a. 2010.

Hochholzer, Elmar: Kloster Michaelsberg und sein Totengedenken. In: Jung, Norbert/ Kempkens, Holger (Hgg.): 1000 Jahre Kloster Michaelsberg Bamberg 1015-2015. Im Schutz des Engels (Begleitpublikation zur Sonderausstellung vom 26. Juni bis 4. Oktober 2015). Petersberg 2015. S. 82-93. 
Hoffmann, Martin: Annales Bambergensis episcopatus. In: Ludwig, Johann Peter (Hg.): Novum volumen scriptorum rerum Germanicarum, Bd. 1. Scriptores rerum episcopatus Bambergensis. Frankfurt 1718.

Hofman, Günther: Hollfeld - Holvelt. Ein geschichtlicher Überblick. In: Stadt Hollfeld (Hg.): St. Gangolf. Das Wahrzeichen der Stadt Hollfeld zu neuem Leben erweckt. Hollfeld 2001. S. 5-8.

Hofmann, Michel: Die Bamberger Stifts-Obleien und ihre Namenswelt. In: Fränkische Blätter für Geschichtsforschung und Heimatpflege 9 (1962). S. 33-36.

Holbach, Rudolf: Identitäten von Säkularkanonikern im Mittelalter. In: Kwiatkowski, Stefan/ Mallek, Janusz (Hgg.): Ständische und religiöse Identitäten in Mittelalter und früher Neuzeit. Torun 1998. S. 19-41.

Hörl, Lina: Handwerk in Bamberg. Strukturen, Praktiken und Interaktionen in Stadt und Hochstift (1650-1800) (Stadt und Region in der Vormoderne, Bd. 2. Veröffentlichungen des Stadtarchivs Bamberg, Bd. 20). Würzburg 2015.

Hubel, Achim (Hg.): Neue Forschungen zur mittelalterlichen Bau- und Kunstgeschichte in Franken (Bamberger interdisziplinäre Mittelalterstudien Vorlesungen und Vorträge, Bd. 2). Bamberg 2011.

Hubel, Achim: Kaiser Heinrich II., die Idee einer Roma secunda und die Konkurrenz zwischen Regensburg und Bamberg im 11. Jahrhundert. In: van Eickels, Christine/ van Eickels, Klaus (Hgg.): Das Bistum Bamberg in der Welt des Mittelalters. Vorträge der Ringvorlesung des Zentrums für Mittelalterstudien der Otto-Friedrich-Universität Bamberg im Sommersemester 2007 (Bamberger interdisziplinäre Mittelalterstudien. Vorträge und Vorlesungen, Bd. 1). Bamberg 2007. S. 103-140. 
Jakob, Andreas: Das Kollegiatstift bei St. Martin in Forchheim. Grundlagen zur Geschichte von Stift und Pfarrei in der zweiten Hauptstadt des Hochstiftes Bamberg 1354-1803. Lichtenfels 1998.

Johanek, Peter: Die Mauer und die Heiligen - Stadtvorstellungen im Mittelalter. In: Behringer, Wolfgang/ Roeck, Bernd (Hgg.): Das Bild der Stadt in der Neuzeit. 1400 - 1800. München 1999. S. 26-38.

Jung, Norbert/ Kempkens, Holger (Hgg.): Im Schutz des Engels. 1000 Jahre Kloster Michelsberg Bamberg 1015-2015. Begleitpublikation zur Sonderausstellung vom 26. Juni bis 4. Oktober 2015. Petersberg 2015.

Kaiser, Michael: Art. „Vikar“. In: LThK Bd. 10 (1965). Sp. 791.

Keh, Heribert: Ein Beitrag zur Geschichte des ehem. Kanonikerstiftes St. Gangolf. In: Fränkische Blätter 3 (1951). S. 9.

Kintzinger, Martin: Stiftsschulen und Wissensvermittlung. Einführung in den Forschungsstand. In: Lorenz, Sönke/ Kintzinger, Martin/ Auge, Oliver (Hgg.): Stiftsschulen in der Region. Wissenstransfer zwischen Kirche und Territorium. Ostfildern 2005. S. 1-16.

Kintzinger, Martin: Scholaster und Schulmeister. Funktionsfelder der Wissensvermittlung im späten Mittelalter. In: Schwinges, Rainer Christoph (Hg.): Gelehrte im Reich. Zur Sozial- und Wirkungsgeschichte akademischer Eliten des 14. bis 16. Jahrhunderts (Zeitschrift für Historische Forschung, Beiheft 18). Berlin 1996. S. 349-374.

Kist, Johannes: Die Matrikel der Geistlichkeit des Bistums Bamberg 1400-1556 (Veröffentlichungen der Gesellschaft für Fränkische Geschichte. Reihe IV: Matrikel fränkischer Schulen und Stände, Bd. 7). Würzburg 1955.

Kohlschein, Franz: Die Sankt-Gangolf-Kirche - ein kostbares Vermächtnis für die Pfarrgemeinde heute. In: Albrecht, Alois (Hg.): Pfarrkirche 
St. Gangolf Bamberg. Restaurierung der ältesten Kirche der Stadt 19841990. Bamberg 1990. S. 9-19.

Kolde, Erich: Beiträge, Anregungen und Gedanken zur Geschichte Frankens. Leipzig 1917.

Konrad, Ruprecht: Siedlung und Herrschaft im Hollfelder Land bis zum Hochmittelalter. In: Stadt Hollfeld (Hg.): 1000 Jahre Hollfeld Stadt und Land 1017-2017. Hollfeld 2017. S. 34-42.

Kottje, Raymund: Claustra sine armario? Zum Unterschied von Kloster und Stift im Mittelalter. In: Consuetudines Monasticae. Festgabe für Kassius Hallinger (Studia Anselmiana, Bd. 85). Rom 1982. S. 125-144.

Krug, Wolfgang: Die Münzen des Hochstifts Bamberg 1007 bis 1802 (Süddeutsche Münzkataloge, Bd. 9). Stuttgart 1999.

Krüger, Thomas Michael: Zeugen eines Spannungsverhältnisses? Die mittelalterlichen Siegel des Augsburger Domkapitels und der Augsburger Bürgerschaft. In: Späth, Markus (Hg.): Die Bildlichkeit korporativer Siegel im Mittelalter. Kunstgeschichte und Geschichte im Gespräch. Köln/ Weimar/ Wien 2009. S. 239-260.

Krzenck, Thomas: Die große Heerfahrt der Hussiten 1429-30 und der Bamberger Aufstand im Februar 1430. In: Mediaevalia historica Bohemica 2 (1992). S. 119-141.

Kunde, Holger (Hg.): Zwischen Kathedrale und Welt. 1000 Jahre Bistum Merseburg und Kollegiatstift Zeitz. Aufsätze (Wissenschaftlicher Begleitband zur Ausstellung). Petersberg 2005.

Landau, Peter: Art. „Kirchengut“. In: ThRE Bd. 18 (1989). S. 656.

Landau, Peter: Art. „Beneficium, Benefizium“. In: LexMA Bd. 5 (1980). Sp. 1906. 
Leitschuh, Friedrich: Art. „Oesterreicher, Paul“. In: Allgemeine Deutsche Biographie, Bd. 24 (1887). S. 518-520.

Looshorn, Johannes: Die Geschichte des Bisthums Bamberg, Bde 1-4. Bamberg 1886-1900.

Lorenz, Sönke/ Auge, Oliver/ Hirbodian, Sigrid (Hgg.): Handbuch der Stiftskirchen in Baden-Württemberg. Ostfildern 2019.

Lorenz, Sönke/ Meyer, Andreas/ Bauer, Dieter R. (Hgg.): Stift und Wirtschaft. Die Finanzierung geistlichen Lebens im Mittelalter. Fünfte wissenschaftliche Fachtagung zum Stiftskirchenprojekt des Instituts für Geschichtliche Landeskunde und Historische Hilfswissenschaften der Universität Tübingen 2004 (Schriften zur südwestdeutschen Landeskunde, Bd. 58). Ostfildern 2007.

Lullies, Eckard: Die Fehde der Guttenberg gegen die Vögte und die Adelsfehde gegen Eger. Kulmbach 1999.

Machilek, Franz (Hg.): Die hussitische Revolution. Religiöse, politische und regionale Aspekte (Forschungen und Quellen zur Kirchen- und Kulturgeschichte Ostdeutschlands, Bd. 44). Köln u. a. 2012.

Maierhöfer, Isolde: Bambergs verfassungstopographische Entwicklung vom 15. bis zum 18. Jahrhundert. In: Petri, Franz (Hg.): Bischofs- und Kathedralstädte des Mittelalters und der frühen Neuzeit (Städteforschung, Reihe A: Darstellungen, Bd. 1). Köln 1976. S. 146-162.

Marchal, Guy P.: Weltliches Kollegiatstift und Universität. In: Lorenz, Sönke/ Kintzinger, Martin/ Auge, Oliver (Hgg.): Stiftsschulen in der Region. Wissenstransfer zwischen Kirche und Territorium. Dritte wissenschaftliche Fachtagung zum Stiftskirchenprojekt des Instituts für Geschichtliche Landeskunde. Ostfildern 2005. S. 17-33. 
Marchal, Guy P.: Was war das weltliche Kanonikerinstitut im Mittelalter? Dom- und Kollegiatstifte: Eine Einführung und eine neue Perspektive. Suit et fin. In: Katholische Universität Löwen (Hg.): Revue d'histoire ecclésiastique. Bd. 95. 1. Löwen 2000. S. 7-53.

Marchal, Guy P.: Die Statuten des weltlichen Kollegiatstifts St. Peter in Basel (Quellen und Forschungen zur Basler Geschichte, Bd. 4). Basel 1972.

Marnetté-Kühl, Beatrice: Vom Abt zum Konvent. Eine Etappe in der Geschichte des Ordenssiegels. In: Signori, Gabriela (Hg.): Das Siegel. Gebrauch und Bedeutung. Darmstadt 2007. S. 65-74.

Mayer, Heinrich: Bamberg als Kunststadt (Die Kunst im alten Hochstift Bamberg und in seinen nächsten Einflussgebieten, Bd. 1). Bamberg/ Wiesbaden 1955.

Melville, Gert/ Vorländer, Hans (Hgg.): Geltungsgeschichten. Über die Stabilisierung und Legitimierung institutioneller Ordnungen. Köln/ Weimar/ Wien 2002.

Meyer, Andreas: Das Aufkommen des Nummerus Certus an Dom- und Stiftskirchen. In: Lorenz, Sönke/ Meyer, Andreas/ Bauer, Dieter R. (Hgg.): Stift und Wirtschaft. Die Finanzierung geistlichen Lebens im Mittelalter. Fünfte wissenschaftliche Fachtagung zum Stiftskirchenprojekt des Instituts für Geschichtliche Landeskunde und Historische Hilfswissenschaften der Universität Tübingen 2004. Ostfildern 2007. S. 1-17.

Meyer, Otto: Bambergs Heilige in Hugo von Trimbergs Kalendergedicht. In: Fränkische Blätter für Geschichtsforschung und Heimatpflege 7 (1955). S. 53-55.

Meyer, Otto: Breviarium Eberhardi Cantoris. Zur Überlieferungsgeschichte der mittelalterlichen Gottesdienstordnung des Doms zu Bam- 
berg. In: Monumentum Bambergense (Bamberger Abhandlungen und Forschungen, Bd. 3). München 1955. S. 413-429.

Miekisch, Horst: Das Augustiner-Chorherrenstift Neunkirchen am Brand als Musterkonvent der Raudnitzer Reform in Franken und seine Auflösung in der Reformationszeit. In: Wüst, Wolfgang/ Machilek, Franz (Hgg.): Neunkirchen am Brand. Die Geschichte einer fränkischen Marktgemeinde. St. Ottilien 2019. S. 82-91.

Miekisch, Horst: Pfarrer Leupold - der Gründer des Chorherrenstiftes. In: Wüst, Wolfgang/ Machilek, Franz (Hgg.): Neunkirchen am Brand. Die Geschichte einer fränkischen Marktgemeinde. St. Ottilien 2019. S. 423-424.

Miekisch, Horst: Das Augustinerchorherrenstift Neunkirchen am Brand. Seine Geschichte und seine Bedeutung für die Verbreitung der Raudnitzer Reform. Dissertation, Universität Bamberg 2005.

Moraw, Peter: Über Typologie, Chronologie und Geographie der Stiftskirche im deutschen Mittelalter. In: Max-Planck-Institut für Geschichte (Hg.): Untersuchungen $\mathrm{zu}$ Kloster und Stift (Veröffentlichungen des Max-Planck-Instituts für Geschichte, Bd. 68.; Studien zur Germania Sacra, Bd. 14.). Göttingen 1980. S. 9-37.

Müller, Philipp: Geschichte machen. Historisches Forschen und die Politik der Archive. Göttingen 2019.

Müller, Wilhelm: Der Hummelgau. Ein Beitrag zur geschichtlichen Landschaftskunde Oberfrankens. In: Archiv für Geschichte von Oberfranken 36,1 (1952). S. 81-128.

Murr, Christoph Gottlieb von: Merkwürdigkeiten der Fürstbischöflichen Residenzstadt Bamberg. Nürnberg 1799. 
Nashiro, Kunio: Über die Oblei im Bistum Bamberg. Naturalabgaben und Geldumlauf mit einem Exkurs zur Entwicklung in Japan und China. In: Rödel, Dieter/ Schneider, Joachim (Hgg.): Strukturen der Gesellschaft im Mittelalter. Interdisziplinäre Mediävistik in Würzburg. Wiesbaden 1996. S. 227-241.

Neukam, Wilhelm: Das Hochstift Würzburg und die Errichtung des Bistums Bamberg. In: Würzburger Diözesangeschichtsblätter 14/15 (1952/53). S. 147-172.

Neukam, Wilhelm: Immunitäten und civitas in Bamberg von der Gründung des Bistums 1007 bis zum Ende des Immunitätenstreits 1440. In: BHVB 78 (1922/24). S. 189-369.

Nospickel, Johannes: Das Michelsberger Necrolog. In: Nospickel, Johannes (Hg.): Das Necrolog des Klosters Michelsberg in Bamberg (Monumenta Germaniae Historica: Libri Memoriales et Necrologia Nova Series, Bd. 6). Hannover 2004. S. 51-186.

Nospickel, Johannes: Kalendarische Folge der Einträge und Provenienzregister. In: Nospickel, Johannes (Hg.): Das Necrolog des Klosters Michelsberg in Bamberg (Monumenta Germaniae Historica: Libri Memoriales et Necrologia Nova Series, Bd. 6). Hannover 2004. S. 187-519.

Nöth, Stefan: Urbare und Wirtschaftsordnungen des Domstifts zu Bamberg (Veröffentlichungen der Gesellschaft für fränkische Geschichte, Reihe 10: Quellen zur Rechts- und Wirtschaftsgeschichte Frankens, Bd. 7,2). Neustadt a. d. Aisch 1986.

Paschke, Hans: St. Gangolf zu Bamberg. 900 Jahre Geschichte und Topographie des Kollegiatstiftes und der Pfarrei St. Gangolf in der Theuerstadt zu Bamberg (Studien zur Bamberger Geschichte und Topographie, Heft 18) Bamberg 1959. 
Paschke, Hans: Der Katharinenhof. Beiträge zur Bamberger Häusergeschichte. In: Fränkischer Tag 10 und 12 (1954).

Pfaffenberger, Stefan: Stadtarchäologie in Bamberg 2018 bis 2019. In: BHVB 156 (2020). S. 9-29.

Pfaffenberger, Stefan: Aspekte der Stadtentwicklung Bambergs im frühen und hohen Mittelalter aus archäologischer Sicht (Arbeiten zur Archäologie Süddeutschlands, Bd. 32; Veröffentlichungen des Stadtarchivs Bamberg, Bd. 36). Büchenbach 2020.

Pfaffenberger, Stefan: Stadtarchäologie in Bamberg 2016 bis 2017. In: BHVB 154 (2018). S. 7-36.

Die Pfarreien des Erzbistums Bamberg: Statistische Notizen auf Anordnung Seiner Erzbischöfl. Excellenz revidirt. Bamberg 1888.

Pöhlmann, Thomas: Das Amt Bayreuth im frühen 15. Jahrhundert. Das Landbuch B von 1421/24, eine spätmittelalterliche Quelle mit Erläuterungen (Bayreuther Arbeiten zur Landesgeschichte und Heimatkunde, Bd. 9). Bayreuth 1992.

Reddig, Wolfgang F.: Bürgerspital und Bischofsstadt. Das St. Katharinen- und das St. Elisabethspital in Bamberg vom 13.-18. Jahrhundert (Spektrum Kulturwissenschaft, Bd. 2). Bamberg/ Frankfurt (Oder) 1998.

Reindl, Alwin: Die vier Immunitäten des Domkapitels zu Bamberg. Ein Beitrag ihrer allgemeinen geschichtlichen Entwicklung, Verwaltung und Rechtsprechung. Bamberg 1969.

Rösener, Werner: Agrarwirtschaft, Agrarverfassung und ländliche Gesellschaft im Mittelalter (Enzyklopädie deutscher Geschichte, Bd. 13). München 1992. 
Rothe, Wolfgang F.: Kollegiatkapitel im deutschen Sprachraum. Eine kirchenrechtliche Bestandsaufnahme. In: Zeitschrift der SavignyStiftung für Rechtsgeschichte, Kanonistische Abteilung 93, Bd. 124 (2007). S. 246-278.

Rupprecht, Klaus: Paul Oesterreicher (1767-1839) - Archivar und fränkischer Landeshistoriker. In: Archivalische Zeitschrift 89 (2007). S. 9-43.

Rupprecht, Klaus: Die Säkularisation der Stifts- und Klosterarchive im Hochstift Bamberg. In: Baumgärtel-Fleischmann, Renate (Hg.): Bamberg wird bayerisch. Die Säkularisation des Hochstifts Bamberg 1802/03 (Sammelband zur Ausstellung im Historischen Museum Bamberg, 10. September bis 9. November 2003). Bamberg 2003. S. 223-232.

Rupprecht, Klaus: Der „Fall“ Wunderburg. Zur Beziehung Bischof Georgs von Bamberg (1459-1475) mit Kaiser Friedrich III. (1440-1493). In: Bielmeier, Horst (Hg.): Festgabe Gerd Zimmermann zum 65. Geburtstag (BHVB, Beiheft 23). Bamberg 1989. S. 111-138.

Ruprecht, Konrad: Otnant von Eschenau. Ein salischer Reichsministerialer in Nordostbayern. In: BHVB 148 (2012) S. 45-71.

Rusam, Georg: Die Einführung des Christentums in Oberfranken. In: Blätter für bayerische Kirchengeschichte 8 (1902). S. 241-256.

Scharrer, Werner: Laienbruderschaften in der Stadt Bamberg vom Mittelalter bis zum Ende des Alten Reiches. Geschichte - Brauchtum - Kultobjekte. In: BHVB 126 (1990). S. 21-392.

Schieffer, Rudolf: Die Entstehung von Domkapiteln in Deutschland (Bonner Historische Forschung, Bd. 43). Röhrscheid 1976.

Schimmelpfennig, Bernhard: Bamberg im Mittelalter. Siedelgebiete und Bevölkerung bis 1370 (Historische Studien, Bd. 391). Lübeck 1964. 
Schemmel, Bernhard: Die Säkularisation der Stifts- und Klosterbibliotheken. In: Baumgärtel-Fleischmann, Renate (Hg.): Bamberg wird bayerisch. Die Säkularisation des Hochstifts Bamberg 1802/03. Bamberg 2003. S. 239-250.

Schleß, Monika: Die älteste Urkunde von St. Gangolf im Pfarrarchiv. In: Albrecht, Alois (Hg.): Pfarrkirche St. Gangolf Bamberg. Restaurierung der ältesten Kirche der Stadt 1984-1990 (Festschrift zum Abschluß der Restaurierung Mai 1990). Bamberg 1990. S. 60-62.

Schleß, Monika/ Albrecht, Alois: Pfarrgemeinde St. Gangolf Bamberg. Bamberg 1980.

Schmid, Michael: Augustiner-Chorherren. In: Theologische Realenzyklopädie, Bd. 4. Berlin/ New York 1979. S. 723-728.

Schnapp, Karl: Die historischen Hoheitszeichen der Stadt Bamberg. in: BHVB 109 (1973). S. 55-93.

Schneider, Erich/ Schneidmüller, Bernd (Hgg.): Vor 1000 Jahren - Die Schweinfurter Fehde und die Landschaft am Obermain 1003 (Schweinfurter Museumsschriften, Bd. 118). Schweinfurt 2004.

Schneidmüller, Bernd: Ein Kloster gegen Nordwind. St. Michael, Kaiser Heinrich II. und Bamberg. In: Jung, Norbert/ Kempkens, Holger (Hgg.): 1000 Jahre Kloster Michaelsberg Bamberg 1015-2015. Im Schutz des Engels (Begleitpublikation zur Sonderausstellung vom 26. Juni bis 4. Oktober 2015). Petersberg 2015. S. 26-39.

Schneidmüller, Bernd: "Tausend Jahre sind für dich wie der Tag, der gestern vergangen ist". Die Gründung des Bistums Bamberg 1007. In: van Eickels, Christine/ van Eickels, Klaus (Hgg.): Das Bistum Bamberg in der Welt des Mittelalters. Vorträge der Ringvorlesung des Zentrums für Mittelalterstudien der Otto-Friedrich-Universität Bamberg im Som- 
mersemester 2007 (Bamberger interdisziplinäre Mittelalterstudien. Vorträge und Vorlesungen, Bd. 1). Bamberg 2007. S. 15-32.

Schneidmüller, Bernd: Verfassung und Güterordnungen weltlicher Kollegiatstifte im Hochmittelalter. In: Zeitschrift der Savigny-Stiftung für Rechtsgeschichte. Kanonistische Abteilung (1986) 103. S. 118-119.

Schöpplein, Roman: Die hochmittelalterliche Stadtmauer der Bamberger Inselstadt unter besonderer Berücksichtigung der Ergebnisse der Ausgrabung „Am Kranen 14“ (Forschungen des Instituts für Archäologie, Denkmalkunde und Kunstgeschichte- Bereich Archäologie, Bd. 3. Veröffentlichungen des Stadtarchivs Bamberg, Bd. 26). Bamberg 2016.

Schubert, Michael Heinrich: Historischer Versuch über die geistliche und weltliche Staats- und Gerichtsverfassung des Hochstifts Bamberg. Ein Beytrag zur deutschen insonderheit ostfränkischen Geschichte. Erlangen 1792.

Schubert, Michael Heinrich: Dissertatio inauguralis de origine et conditione ecclesiarum collegiatarum in genere et ecclesiae collegiatae ad b. virginem et s. Gangolphum Bambergae in specie. Bamberg 1768.

Schweitzer, Caspar Anton: Vollständiger Auszug aus den vorzüglichsten Calendarien des ehemaligen Fürstenthums Bamberg. In: BHVB 7 (1844). S. 67-319.

Siegel, Wolfram: Der Heilige Gangolf in Münchenlohra an der Hainleite. Basilika, Kloster und karolingische Vorgeschichte (HarzForschungen, Bd. 20). Wernigerode/ Berlin 2005.

Siegel, Wolfram: Der heilige Gangolf in Hollfeld und das Geschlecht der Walpoten. In: Stadt Hollfeld (Hg.): St. Gangolf. Das Wahrzeichen der Stadt Hollfeld zu neuem Leben erweckt. Hollfeld 2001. S. 9-12. 
Siegel, Wolfram: Der heilige Gangolf im Raum um den Harz und die Zeit der Sachsenkriege Karls des Großen. In: Harz-Zeitschrift 45/2 (2000).

Siegel, Wolfram: Der heilige Gangolf an Donau und Lech. In: Zeitschrift des Historischen Vereins für Schwaben 84 (1991). S. 7-43.

Siegwart, Josef: Die Chorherren- und Chorfrauengemeinschaften in der deutschsprachigen Schweiz vom 6. Jahrhundert bis 1160. Mit einem Überblick über die deutsche Kanonikerreform des 10. und 11. Jahrhunderts (Studia Friburgensia NF, Bd. 30). Freiburg 1962.

Siewert, Ulrike: Die Bamberger Bistumsgründung und die Entstehung einer sakralen Landschaft. Die Bedeutung des Nebenstifts St. Stephan in der Bamberger Kirchenlandschaft. In: Jahrbuch für fränkische Landesforschung 71 (2011). S. 1-19.

Siewert, Ulrike: Das Bamberger Kollegiatstift St. Stephan. Säkularkanoniker in einer mittelalterlichen Bischofsstadt. Bamberg 2007.

Skambraks, Tanja: Das Kinderbischofsfest im Mittelalter. Florenz 2014.

Späth, Markus: Die Bildlichkeit korporativer Siegel im Mittelalter. Perspektiven eines interdisziplinären Austauschs. In: Späth, Markus (Hg.): Die Bildlichkeit korporativer Siegel im Mittelalter. Kunstgeschichte und Geschichte im Gespräch (Sensus. Studien zu mittelalterlichen Kunst, Bd. 1). Köln/ Weimar/ Wien 2009. S. 9-29.

Späth, Markus: Mikroarchitektur zwischen Repräsentation und Identitätsstiftung. Die Siegelbilder englischer Klöster und Kathedralkapitel im 13. Jahrhundert. In: Albrecht, Uwe/ Kratzke, Christine (Hgg.): Mikroarchitektur im Mittelalter. Ein gattungsübergreifendes Phänomen zwischen Realität und Imagination. Leipzig 2008. S. 253-277. 
Stieldorf, Andrea: Helden oder Heilige. Überlegungen zur Motivwahl reichsfürstlicher Münzen und Siegel. In: Archiv für Diplomatik 62 (2016). S. 107-136.

Stieldorf, Andrea: Die Selbstdarstellung rheinischer Hochadeliger auf Siegeln und Münzen. In: Rheinische Vierteljahresblätter 79 (2015). S. 68-103.

Stieldorf, Andrea: Heilige Patrone und weltliche Stifter. Zur Selbstdarstellung und Selbstdeutung mittelalterlicher Universitäten. In: Archiv für Diplomatik 56 (2010). S. 317-361.

Stieldorf, Andrea: Siegelkunde (Hahnsche Historische Hilfswissenschaften, Bd. 2). Hannover 2004.

Störmer, Wilhelm: Die konradinisch-babenbergische Fehde um 900. Ursachen, Anlass, Folgen. In: Goetz, Hans-Werner (Hg.): Konrad I. auf dem Weg zum „Deutschen Reich“? Bochum 2006. S. 169-183.

Straub, Heinrich: Die geistliche Gerichtsbarkeit des Domdekans im alten Bistum Bamberg von den Anfängen bis zum Ende des 16. Jhds. Eine rechtsgeschichtliche Untersuchung (Münchener theologische Studien, Bd. 3, 9). München 1957.

Tausendpfund, Walter: Oberfranken und der Hussitensturm im 15. Jahrhundert. In: Archiv für Geschichte von Oberfranken 86 (2006). S. 109-134.

Thiel, Matthias: Das St. Emmeraner Register von 1275 in Clm 12992, seine Vorstufen und Nachläufer. Ein Beitrag zum klösterlichen Registerwesen und dessen Anfängen. In: Zeitschrift für bayerische Landesgeschichte 33 (1970). S. 85-134 und S. 542-635. 
Tischer, Roman: Bischof Gunther von Bamberg (gest. 1065). Ein Pontifikat im Zeichen des Umbruchs. In: Bericht des Historischen Vereins Bamberg, Bd. 155 (2019). S. 71-94.

Übungsbuch Deutsche Schriftkunde. Schriftbeispiele des 12. bis 20 . Jahrhunderts aus bayerischen staatlichen Archiven (Sonderveröffentlichung der Staatlichen Archive Bayerns, Bd. 11). München 2015.

Unger, Ludwig: Auf der Suche nach der rechten Lebensweise. Die Hirsauer und die Bursfelder Reform auf dem Michaelsberg. In: Jung, Norbert/ Kempkens, Holger (Hgg.): 1000 Jahre Kloster Michaelsberg Bamberg 1015-2015. Im Schutz des Engels (Begleitpublikation zur Sonderausstellung vom 26. Juni bis 4. Oktober 2015). Petersberg 2015. S. 94109.

Ussermann, Ämilian P.: Episcopatus Bambergensis sub sede apostolica chronologice ac diplomatice illustratus. [St. Blasius] 1802.

van Eickels, Christine/ van Eickels, Klaus (Hgg.): Das Bistum Bamberg in der Welt des Mittelalters. Vorträge der Ringvorlesung des Zentrums für Mittelalterstudien der Otto-Friedrich-Universität Bamberg im Sommersemester 2007 (Bamberger interdisziplinäre Mittelalterstudien. Vorträge und Vorlesungen, Bd. 1). Bamberg 2007.

van Eickels, Klaus: Bistumsgründungen um das Jahr 1000. In: van Eickels, Christine/ van Eickels, Klaus (Hgg.): Das Bistum Bamberg in der Welt des Mittelalters. Vorträge der Ringvorlesung des Zentrums für Mittelalterstudien der Otto-Friedrich-Universität Bamberg im Sommersemester 2007 (Bamberger interdisziplinäre Mittelalterstudien Vorträge und Vorlesungen, Bd. 1). Bamberg 2007. S. 33-64.

van Eickels, Klaus: Bamberger Bischofswahlen im Mittelalter. In: Göller, Luitgar (Hg.): 1000 Jahre Bistum Bamberg 1007-2007. Unterm Sternenmantel (Katalog der Jubiläumsausstellung). Petersberg 2007. S. 126133. 
van Eickels, Klaus: Das Preisgedicht Gerhards von Seeon auf die Bamberger Kirche. In: BHVB 138 (2002). S. 123-137.

Verhulst, Adriaan: Aspekte der Grundherrschaftsentwicklung des Hochmittelalters aus westeuropäischer Sicht. In: Rösener, Werner (Hg.): Grundherrschaft und bäuerliche Gesellschaft im Hochmittelalter (Veröffentlichungen des Max-Planck-Instituts für Geschichte, Bd. 115). Göttingen 1995. S. 16-30.

Voit, Gustav: Die Walpoten. Auf den Spuren des ältesten Adelsgeschlechtes der Fränkischen Schweiz (Die Fränkische Schweiz - Heimatkundliche Beiträge, Bd. 11). Erlangen/ Jena 1996.

Wachter, Friedrich: Sankt Gangolfs Ring. In: Alt-Bamberg. Rückblicke auf Bambergs Vergangenheit 12 (1912/13). S. 3-15.

Wachter, Friedrich: General-Personal-Schematismus der Erzdiözese Bamberg 1007 - 1907. Bamberg 1908.

Weigand, Rudolf Kilian: Der 'Renner' des Hugo von Trimberg. Überlieferung, Quellenabhängigkeit und Struktur einer spätmittelalterlichen Lehrdichtung (Wissensliteratur im Mittelalter, Bd. 35). Wiesbaden 2000.

Weigel, Georg: Die Wahlkapitulationen der Bamberger Bischöfe 13281693. Eine historische Untersuchung. Bamberg 1909.

Weinfurter, Stefan: Eichstätt im Mittelalter. Kloster - Bistum - Fürstentum. Regensburg 2010.

Weiß, Dieter J.: Das exemte Bistum Bamberg 4: Die Bamberger Bischöfe von 1693 bis 1802 (Germania Sacra. Dritte Folge, Bd. 12). Berlin/ Boston 2015. 
Weiß, Dieter J.: Das Kloster Michelsberg und die Stadt Bamberg. In: van Eickels, Christine/ van Eickels, Klaus (Hgg.): Das Bistum Bamberg in der Welt des Mittelalters. Vorträge der Ringvorlesung des Zentrums für Mittelalterstudien der Otto-Friedrich-Universität Bamberg im Sommersemester 2007 (Bamberger interdisziplinäre Mittelalterstudien. Vorträge und Vorlesungen, Bd. 1). Bamberg 2007. S. 227-245.

Weiß, Dieter J.: Das exemte Bistum Bamberg 3/1: Die Bischofsreihe von 1522 bis 1693 (Germania Sacra. Neue Folge, Bd. 38). Berlin/ New York 2000 .

Wendehorst, Alfred: Stadt und Kirche. In: Wagner, Ulrich (Hg.): Geschichte der Stadt Würzburg. Bd. 1: Von den Anfängen bis zum Ausbruch des Bauernkrieges. Stuttgart 2001. S. 255-271.

Wendehorst, Alfred/ Benz, Stefan: Verzeichnis der Säkularkanonikerstifte der Reichskirche (Schriften des Zentralinstituts für fränkische Landeskunde und allgemeine Regionalforschung an der Universität Erlangen-Nürnberg, Bd. 35). Neustadt an der Aisch 1997.

Witowski, Lisa: Adlige Exklusivität. Aufschwörbuch des Bamberger Domkapitels. In: Original! Pracht und Vielfalt aus den Staatlichen Archiven Bayerns (Ausstellung der Staatlichen Archive Bayerns im Bayerischen Hauptstaatsarchiv). München 2017. S. 146-149.

Witowski, Lisa: Die Bedeutung Hollfelds für das mittelalterliche Kollegiatstift St. Gangolf in Bamberg. In: Stadt Hollfeld (Hg.): 1000 Jahre Hollfeld Stadt und Land 1017-2017. Hollfeld 2017. S. 48-52.

Witowski, Lisa: Urkunden des Bamberger Klosters Michelsberg erschlossen und digitalisiert. In: Nachrichten aus den Staatlichen Archiven Bayerns 68 (2015). S. 50-52.

Wollasch, Joachim: Art. „Nekrologien“. In: LThK Bd. 7 (1998). Sp. 720 721. 
Wollasch, Joachim: Art. „Necrolog“. In: LexMA Bd. 6 (1993). Sp. 10781079.

Wollasch, Joachim: Die Wahl des Papstes Nikolaus II. In: Fleckenstein, Josef/ Schmid, Karl (Hgg.): Adel und Kirche (Festschrift für Gerd Tellenbach). Freiburg/ Basel/ Wien 1968. S. 205-220.

Zimmermann, Gerd: Sankt Gangolf in Bamberg. Ehem. Stiftskirche, seit 1806 Pfarrkirche (Schnell Kunstführer, Nr. 1172). Regensburg ${ }^{2} 1998$.

Zimmermann, Gerd: Die Gangolfskirche als Spiegel der Frömmigkeit seit über 925 Jahren. In: Albrecht, Alois (Hg.): Pfarrkirche St. Gangolf Bamberg. Restaurierung der ältesten Kirche der Stadt 1984-1990. Bamberg 1990. S. 20-33.

Zimmermann, Gerd: Sankt Gangolfs Weg von Lothringen nach Bamberg. Studie zur Gründung und frühen Geschichte des Stiftes in der Theuerstadt zu Bamberg. In: Jahrbuch für Fränkische Landesforschung 22 (1962). S. 443-461.

Zimmermann, Gerd: Patrozinienwahl und Frömmigkeitswandel im Mittelalter. Dargestellt an Beispielen aus dem alten Bistum Würzburg. In: Würzburger Diözesan-Geschichtsblätter 20 (1958). S. 24-126. und 21 (1959). S. 5-124.

Zink, Robert: St. Theodor in Bamberg 1157-1554. Ein Nonnenkloster im mittelalterlichen Franken. Bamberg 1978. 


\section{Anhang}

Abbildungen

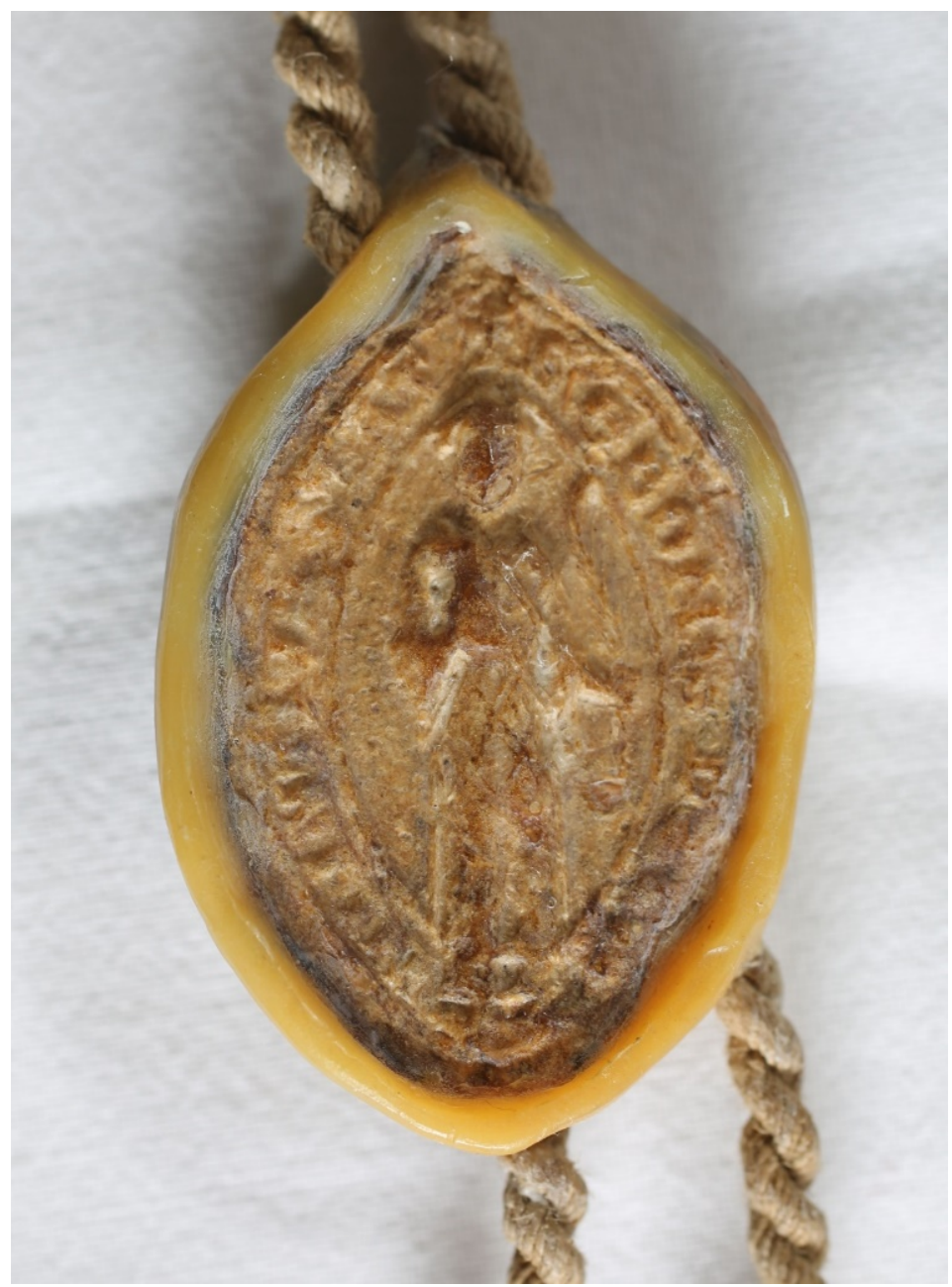

Abbildung 1: Ältestes nachweisbares Siegel des Stifts St. Gangolf. Personales Amtssiegel des Ebo, Dekan des Stifts St. Gangolf, von 1242. StABa BU 613. (Anhang Tabelle 1: Siegel Nr. 1) 


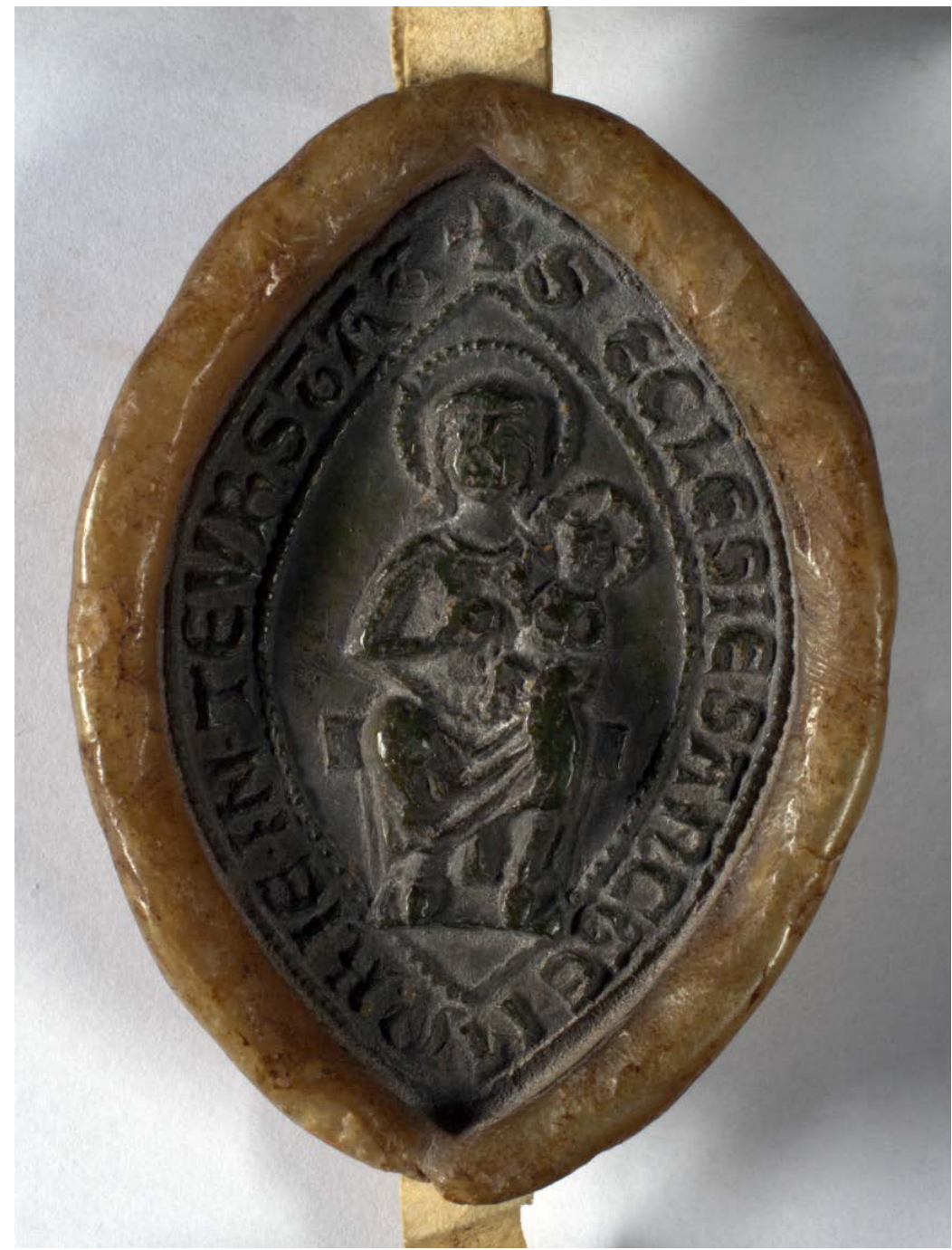

Abbildung 2: Kapitelsiegel des Stifts St. Gangolf vom älteren Typ aus dem Jahr 1390. StABa BU 4261. (Anhang Tabelle 1: Siegel Nr. 23) 


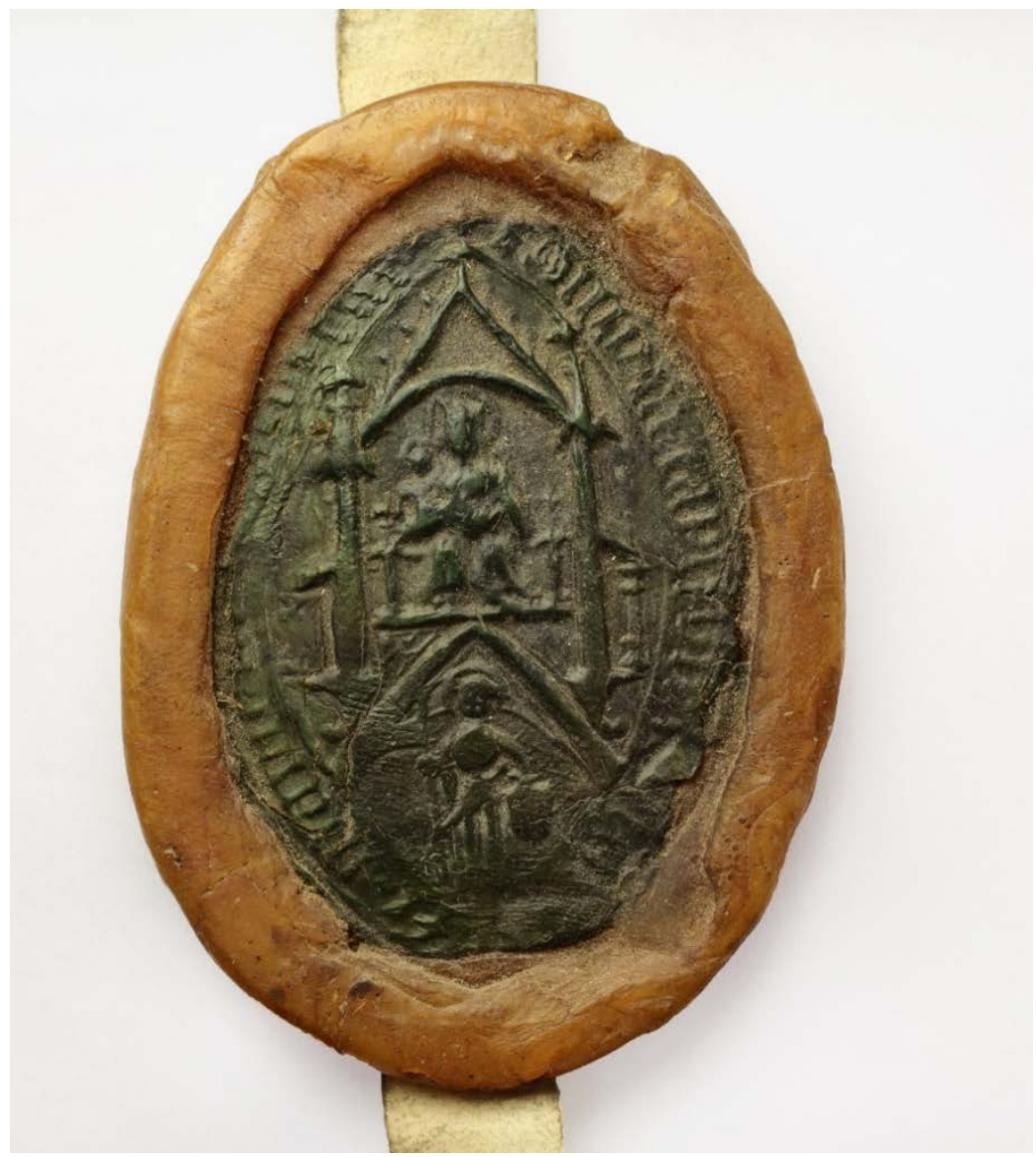

Abbildung 3: Kapitelsiegel des Stifts St. Gangolf vom neueren Typ aus dem Jahr 1534. AEB Rep. I Pfarrei St. Gangolf U 822. (Anhang Tabelle 1: Siegel Nr. 65) 


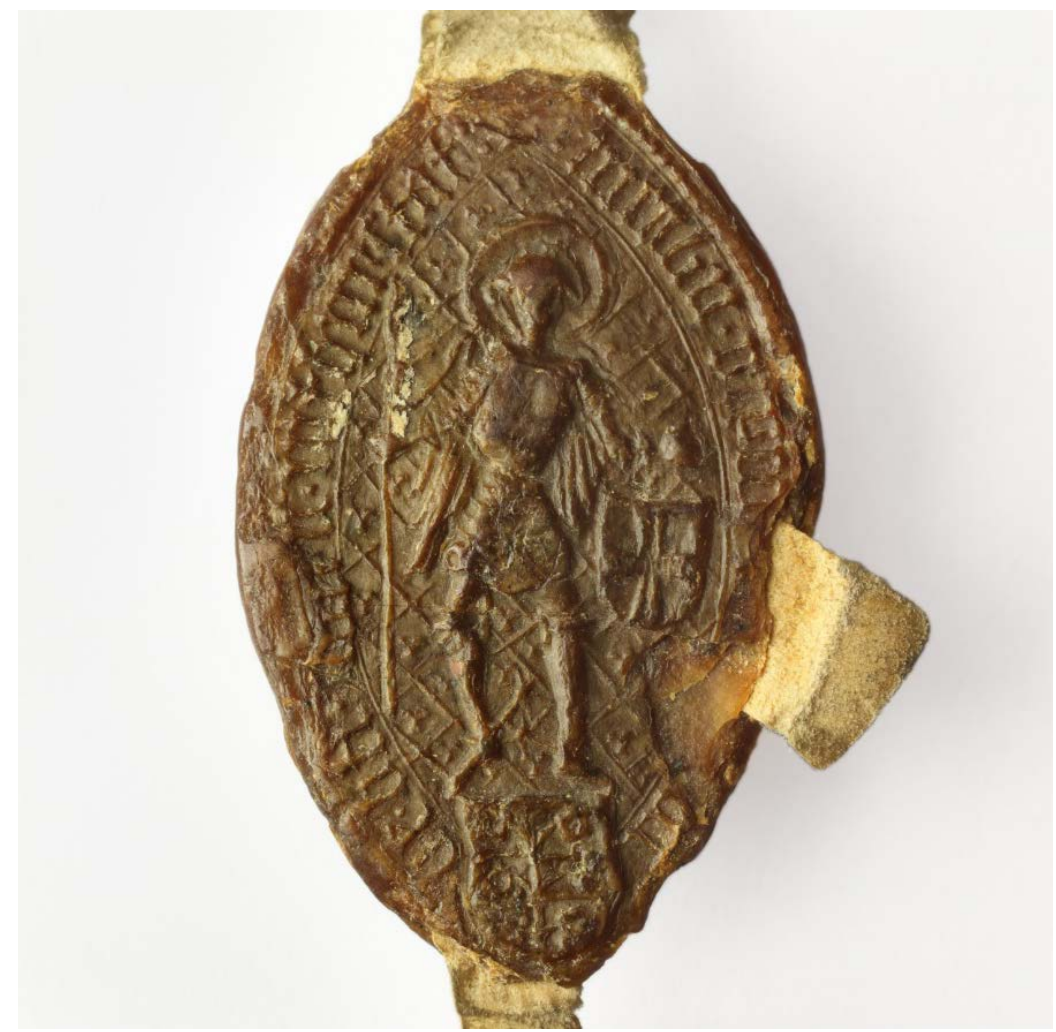

Abbildung 4: Personales Amtssiegel des Nikolaus Vipech, Keller des Stifts St. Gangolf, von 1440. AEB Rep. I Pfarrei St. Gertraud U 102. (Anhang Tabelle 1: Siegel Nr. 42) 


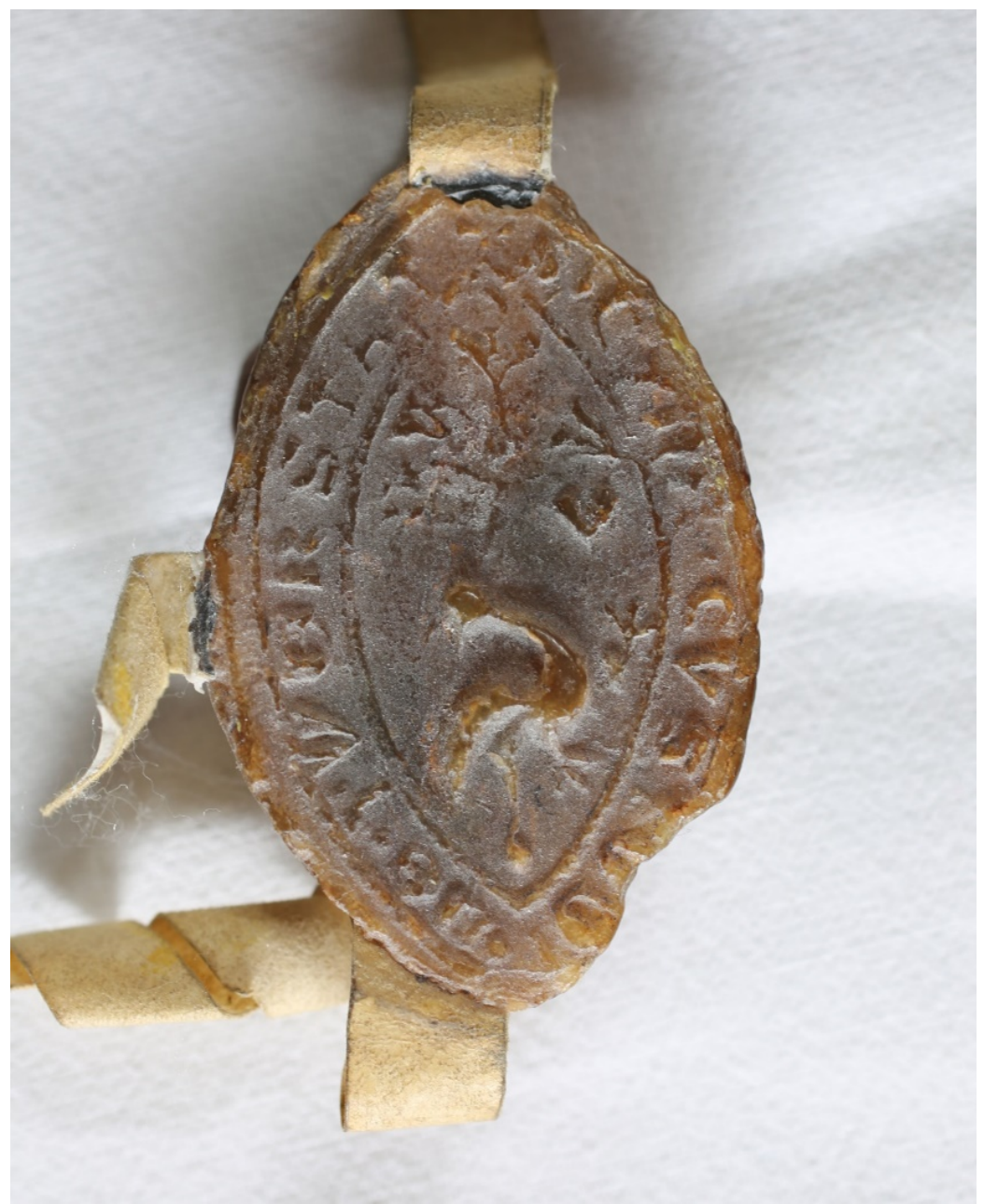

Abbildung 5: Personales Amtssiegel des Konrad, Kustos des Stifts St. Gangolf, von 1329. StABa BU 1988. (Anhang Tabelle 1: Siegel Nr. 13) 


\section{Karten}

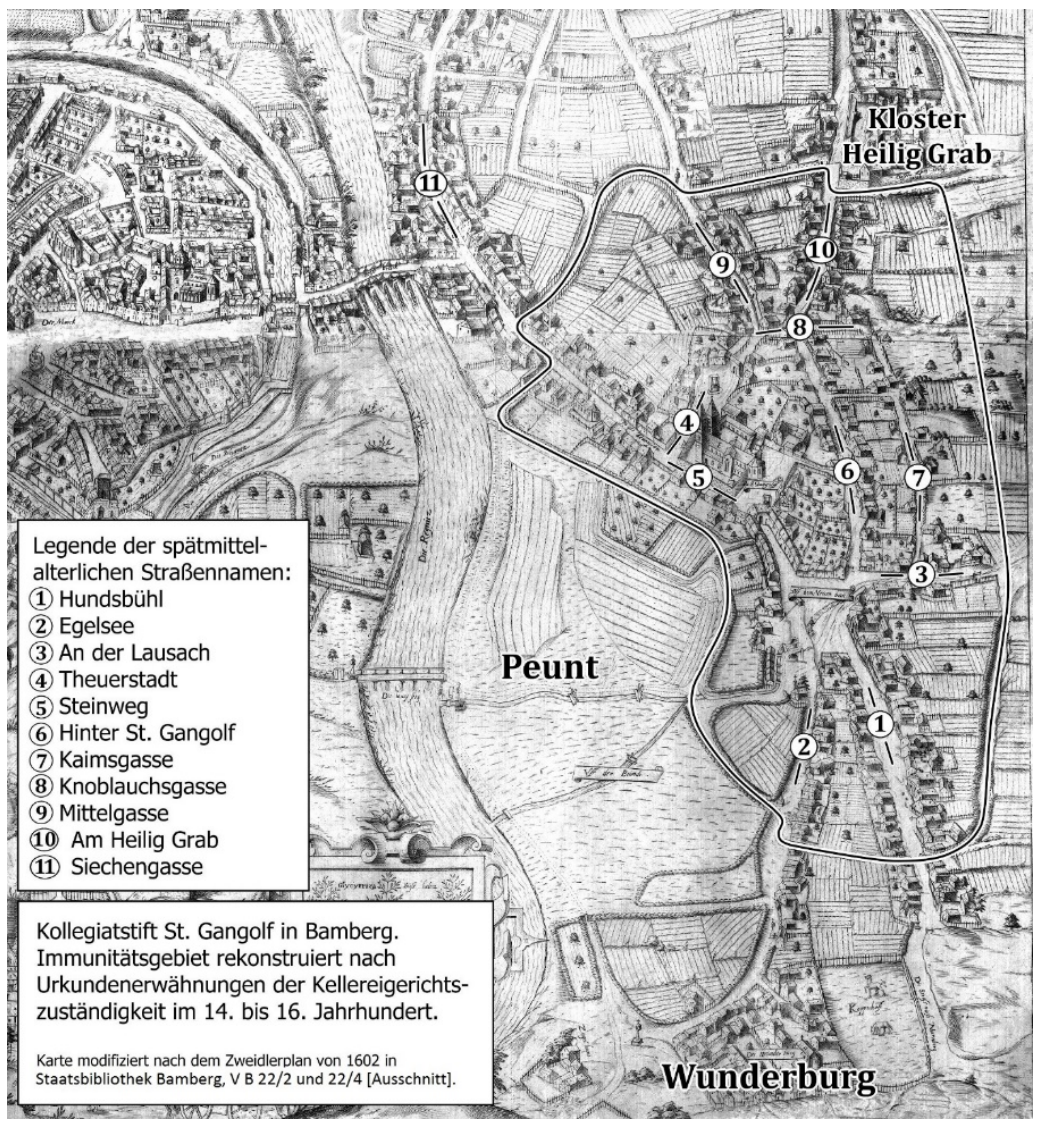

Karte 1: Immunitätsgebiet des Stifts St. Gangolf anhand der Erwähnungen der Kellereizuständigkeit in den Urkunden vom 14. bis 16. Jahrhundert. 


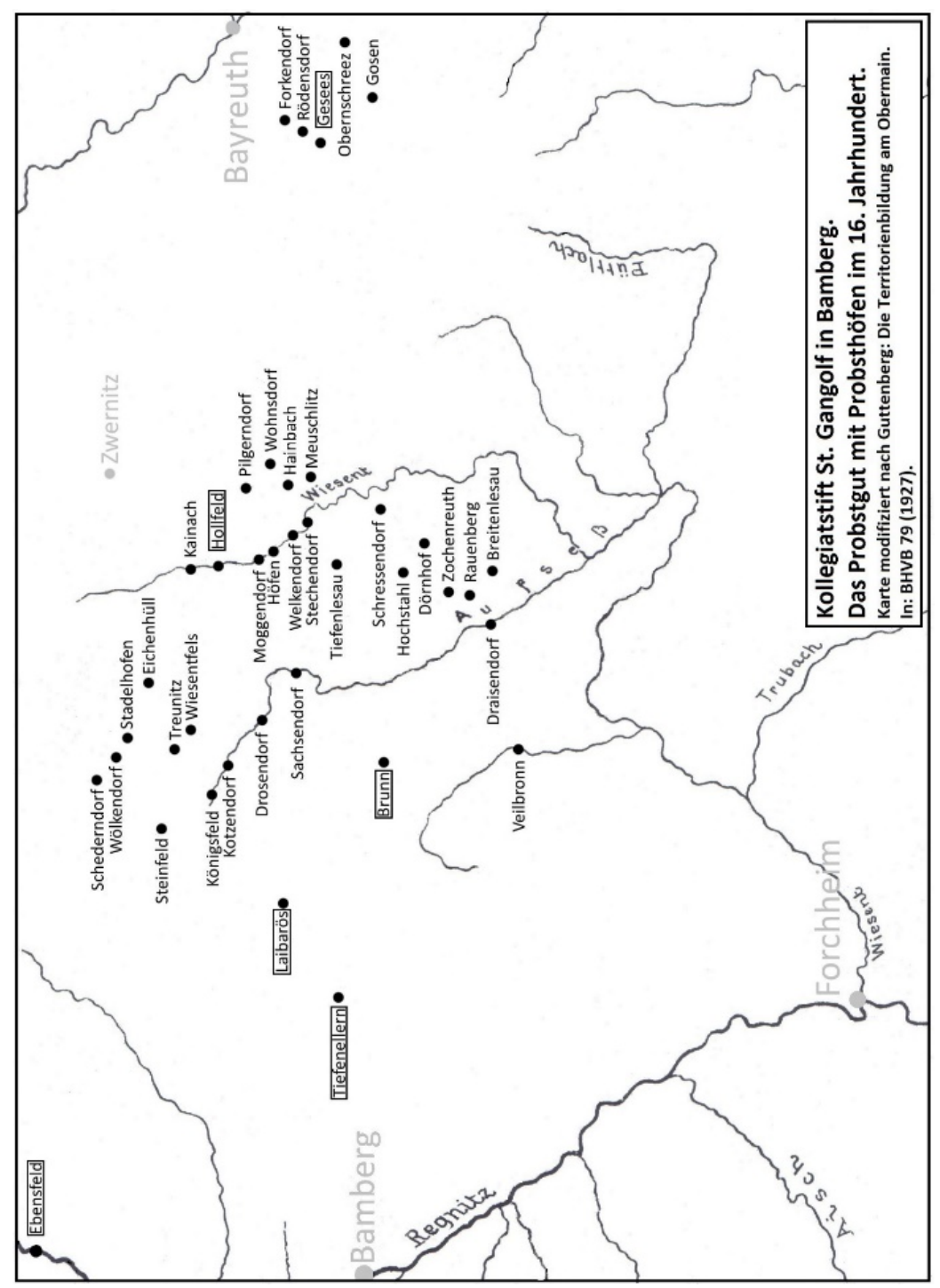

Karte 2: Ortschaften des Probstguts des Stifts St. Gangolfs, identifiziert anhand der stiftseigenen Güterverzeichnisse des 16. Jahrhunderts aus dem Staatsarchiv Bamberg. 


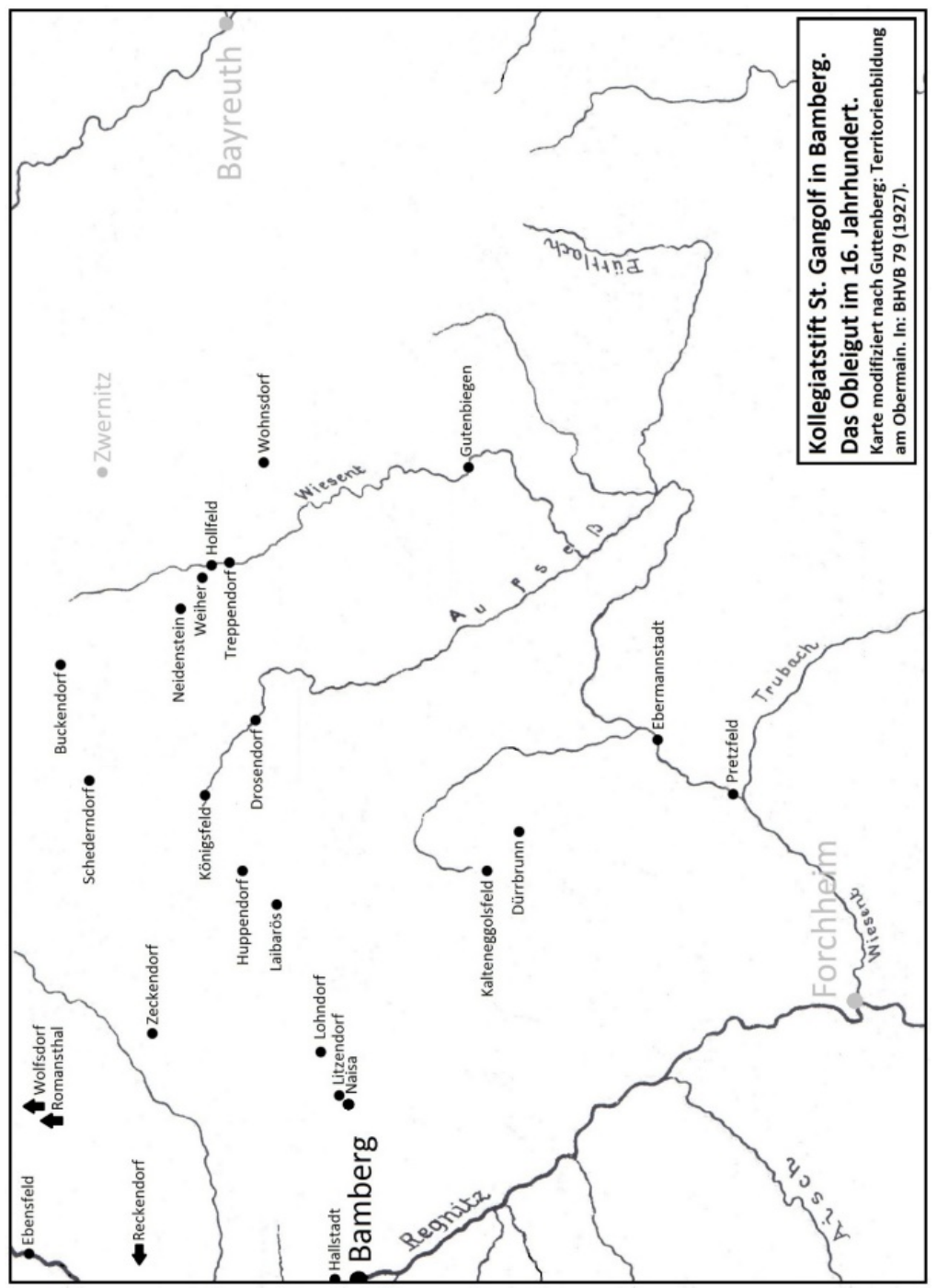

Karte 3: Ortschaften des Obleiguts des Stifts St. Gangolfs, identifiziert anhand der stiftseigenen Güterverzeichnisse des 16. Jahrhunderts aus dem Staatsarchiv Bamberg. 


\section{Tabellen}

\section{Siegel}

Aufgelistet sind alle Siegel des Stifts St. Gangolf, die anhand stiftseigener und stiftsfremder Urkunden im Staatsarchiv Bamberg, im Archiv des Erzbistums Bamberg, im Stadtarchiv Bamberg und im Staatsarchiv Würzburg identifiziert werden konnten. Die Datierung bezieht sich auf das Ausstellungsdatum der Urkunde, sodass sie nicht zwingend Auskunft darüber gibt, wann der Abdruck gemacht oder in welchem Zeitraum das Typar verwendet wurde. Hinsichtlich der Methodologie der Siegelbeschreibung wurde sich an der Herangehensweise von Andrea Stieldorf ${ }^{1079}$ orientiert.

\begin{tabular}{|l|l|l|}
\hline 1.1242 & $\begin{array}{l}\text { Personales Amtssiegel des Ebo, Dekan des Stifts } \\
\text { St. Gangolf; spitzoval aus hellem Wachs; anhän- } \\
\text { gend an geflochtenen Leinenschnüren; Größe: } 30 \\
\text { x } 45 \text { mm; abgenutzt; Umschrift: S(IGILLUM) } \\
\text { EBONIS D[ECA]NI IN TURSTAT; Siegelfeld zeigt } \\
\text { nicht identifizierten Heiligen oder Siegler selbst } \\
\text { (stehende Ganzfigur) in bodenlangem Gewand mit } \\
\text { einem kleinen runden Gegenstand in der rechten } \\
\text { Hand und einem Palmenwedel oder einer Lilie } \\
\text { (Lilie als ikonografisches Heiligenattribut der } \\
\text { Jungfräulichkeit eventuell Hinweis auf Maria) in } \\
\text { der linken. StABa BU 613. (Abb. 1) }\end{array}$ \\
\hline 2.1275 IV 23 & $\begin{array}{l}\text { Personales Amtssiegel des Albert Graf von } \\
\text { Schlüsselberg, Propst des Stifts St. Gangolf; spitz- } \\
\text { oval aus dunklem Wachs; anhängend an Perga- } \\
\text { mentstreifen; Größe: } 30 \text { x 45 mm; unbeschädigt; } \\
\text { Umschrift: S(IGILLUM) ALB(ER)TI }\end{array}$ \\
\hline
\end{tabular}

${ }^{1079}$ Stieldorf: Siegelkunde. 2004. S. 17-19. 


\begin{tabular}{|l|l|l|}
\hline & & $\begin{array}{l}\text { P(RAE)PO(SIT)I S(AN)C(T)E MARIE } \\
\text { BABENB(ER)GEN(SIS); Siegelfeld zeigt eventuell } \\
\text { Siegler selbst (stehende Ganzfigur) vor architekto- } \\
\text { nischem Hintergrund in bodenlangem Gewand } \\
\text { betend mit beiden Händen vor der Brust. StABa } \\
\text { BU 881. }\end{array}$ \\
\hline 3. & 1285 VII 2 & $\begin{array}{l}\text { Personales Amtssiegel des Leupold von Grindlach, } \\
\text { Propst des Stifts St. Gangolf; spitzoval aus dunk- } \\
\text { lem Wachs; anhängend an rot-gelber Wollschnur; } \\
\text { Größe: 27 x 40 mm; leicht beschädigt; Umschrift: } \\
\text { S(IGILLUM) LUPOLDI PREPOSITI [...]; Siegelfeld } \\
\text { zeigt heilige Maria (Brustbild) mit Kind auf dem } \\
\text { linken Arm, darunter kniet betend der Siegelfüh- } \\
\text { rer im Profil (Adorantensiegel). StAWu Kloster } \\
\text { Ebrach, Urkunden 1285 VII 2/I. }\end{array}$ \\
\hline 4. & $\begin{array}{l}\text { Korporatives Siegel des Kapitels St. Gangolf; } \\
\text { spitzoval aus dunklem Wachs; anhängend an Per- } \\
\text { gamentstreifen; Größe: 47 x 71 mm; unbeschädigt; } \\
\text { Umschrift: S(IGILLUM) EC(C)LESIE SANCTE } \\
\text { MARIE IN TEURSTAT; Siegelfeld zeigt heilige } \\
\text { Maria sitzend auf einer schlichten Bank (sitzende } \\
\text { Ganzfigur) mit Kind auf dem linken Arm, in der } \\
\text { rechten Hand einen nicht identifizierten Gegen- } \\
\text { stand. StAWu Kloster Ebrach, Urkunden 1295 V } \\
\text { 25. }\end{array}$ \\
\hline 5. & $\begin{array}{l}\text { Personales Amtssiegel des Marquard, Dekan des } \\
\text { Stifts St. Gangolf; spitzoval aus dunklem Wachs; } \\
\text { anhängend an Pergamentstreifen; Größe: 30 x 45 } \\
\text { mm; leicht beschädigt und restauriert; Umschrift: } \\
\text { [...] MARQUARD VIRGINIS ECC(LESIE) [...]; } \\
\text { Siegelfeld zeigt heilige Maria (sitzende Ganzfigur) } \\
\text { mit Kind auf dem linken Arm vor architektoni- } \\
\text { schem Hintergrund, darunter kniet betend der } \\
\text { Siegelführer im Profil (Adorantensiegel). StAWu }\end{array}$ \\
\hline
\end{tabular}




\begin{tabular}{|c|c|c|}
\hline & & Kloster Ebrach, Urkunden 1295 V 25. \\
\hline 6. & $1302 \times 27$ & $\begin{array}{l}\text { Personales Amtssiegel des Friedrich von Truhen- } \\
\text { dingen, Propst des Stifts St. Gangolf; spitzoval aus } \\
\text { dunklem Wachs; anhängend an Pergamentstrei- } \\
\text { fen; Größe: } 40 \text { x } 60 \text { mm; beschädigt und restau- } \\
\text { riert; Umschrift: [S(IGILLUM) F]RID(ERICI) D(E) } \\
\text { TRUHEDI(N)GE[N...] D(E) TURSTAT EX BA- } \\
\text { BE(N)BE[RG]; Siegelfeld zeigt heilige Maria } \\
\text { (Brustbild) mit Kind auf dem rechten Arm, Wap- } \\
\text { penschild. StABa Kloster Michelsberg, Urkunden } \\
\text { Nr. 141. }\end{array}$ \\
\hline 7. & 1311 VIII 24 & $\begin{array}{l}\text { Personales Amtssiegel des Friedrich von Truhen- } \\
\text { dingen, Propst des Stifts St. Gangolf; spitzoval aus } \\
\text { hellem Wachs; anhängend an Pergamentstreifen; } \\
\text { Größe: } 40 \text { x } 60 \text { mm; schwer beschädigt und restau- } \\
\text { riert; Umschrift: [F]RID(ERICUS) D(E) } \\
\text { TRUEDI(N)GE[N] [...] [TEU]RSTAT EX } \\
\text { BAB(EN)BE[RG]; Siegelfeld zeigt heilige Maria } \\
\text { (Brustbild) mit Kind auf dem rechten Arm, Wap- } \\
\text { penschild. StAWu Urkunden Kloster Ebrach } 1311 \\
\text { VIII 24/I. }\end{array}$ \\
\hline 8. & 1311 VIII 24 & $\begin{array}{l}\text { Korporatives Siegel des Kapitels St. Gangolf; } \\
\text { spitzoval aus hellem Wachs; anhängend an Per- } \\
\text { gamentstreifen; Größe: } 50 \text { x } 70 \text { mm; schwer be- } \\
\text { schädigt und restauriert; Umschrift: [...] } \\
\text { EC(C)LE(SIE) SANCTE MARIE IN TEV[ERSTAT]; } \\
\text { Siegelfeld zeigt heilige Maria sitzend auf einer } \\
\text { schlichten Bank (sitzende Ganzfigur) mit Kind auf } \\
\text { dem linken Arm. StAWu Kloster Ebrach, Urkun- } \\
\text { den } 1311 \text { VIII 24/I. }\end{array}$ \\
\hline 9. & 1311 VIII 26 & $\begin{array}{l}\text { Personales Amtssiegel des Friedrich von Truhen- } \\
\text { dingen, Propst des Stifts St. Gangolf; spitzoval aus } \\
\text { dunklem Wachs; abhängend an Pergamentstrei- }\end{array}$ \\
\hline
\end{tabular}




\begin{tabular}{|l|l|l|}
\hline \multirow{1}{*}{} & & $\begin{array}{l}\text { fen; Größe: 40 x 60 mm; schwer beschädigt und } \\
\text { abgenutzt; Umschrift: [F]RID(ERICUS) D(E) } \\
\text { TRUEDI(N)GE[N] IN TIRSTAT EX } \\
\text { BAB(EN)BE[RG]; Siegelfeld zeigt heilige Maria } \\
\text { (Brustbild) mit Kind auf dem rechten Arm, Wap- } \\
\text { penschild. StAWu Kloster Ebrach, Urkunden 1311 } \\
\text { VIII 26. }\end{array}$ \\
\hline 10. & $\begin{array}{l}\text { Personales Amtssiegel des Friedrich von Truhen- } \\
\text { dingen, Propst des Stifts St. Gangolf; spitzoval aus } \\
\text { hellem Wachs; anhängend an Pergamentstreifen; } \\
\text { Größe: 35 x 55 mm; schwer beschädigt und restau- } \\
\text { riert, nur oberstes Drittel erhalten; Umschrift: } \\
\text { S(IGILLUM) FRID(ERICUS) D(E) [...] } \\
\text { BAB(EN)BERG; Siegelfeld zeigt heilige Maria (nur } \\
\text { Kopf erhalten) mit Kind auf dem rechten Arm. } \\
\text { StAWu Kloster Ebrach, Urkunden 1311 X 1/I. }\end{array}$ \\
\hline 11. & $\begin{array}{l}\text { Korporatives Siegel des Kapitels St. Gangolf; } \\
\text { spitzoval aus hellem Wachs; anhängend an Per- } \\
\text { gamentstreifen; Größe: 50 x 70 mm; schwer be- } \\
\text { schädigt und restauriert; Umschrift: [...] (SA)NCTE } \\
\text { MARIE IN TEU(E)RS[TAT]; Siegelfeld zeigt heilige } \\
\text { Maria sitzend auf einer schlichten Bank (sitzende } \\
\text { Ganzfigur) mit Kind auf dem linken Arm, in der } \\
\text { rechten Hand einen nicht identifizierten Gegen- } \\
\text { stand. StAWu Kloster Ebrach, Urkunden 1311 X } \\
\text { 1/II. }\end{array}$ \\
\hline $\begin{array}{l}\text { Personales Amtssiegel des Friedrich Graf von } \\
\text { Hohenlohe, Propst des Stifts St. Gangolf; spitzoval } \\
\text { aus dunklem Wachs; anhängend an Pergament- } \\
\text { streifen; Größe: 30 x 50 mm; beschädigt; Um- } \\
\text { schrift: [S(IGILLUM) F]RIDERICI [DE] HOHEN- } \\
\text { LOC(H)E P(RAE)P(OSI)TI ECC(LESI)E S(ANCTE) } \\
\text { MARIE I(N) TUERST[AT]; Siegelfeld zeigt heilige } \\
\text { Maria mit Kind (stehende Ganzfigur im Halbpro- }\end{array}$ \\
\hline 1329
\end{tabular}




\begin{tabular}{|c|c|c|}
\hline & & $\begin{array}{l}\text { fil) vor architektonischem Hintergrund, links vor } \\
\text { ihr kniet betend eine Figur (Adorantensiegel) mit } \\
\text { Spruchband, Wappenschild. StABa BU } 1988 .\end{array}$ \\
\hline 13. & 1329 & $\begin{array}{l}\text { Personales Amtssiegel des Konrad, Kustos des } \\
\text { Stifts St. Gangolf; spitzoval aus dunklem Wachs; } \\
\text { anhängend an Pergamentstreifen; Größe: } 30 \text { x } 50 \\
\text { mm; beschädigt und abgenutzt; Umschrift: } \\
\text { S(IGILLUM) CINR(ADUI) CUSTODI DE TUER- } \\
\text { STAT; Siegelfeld zeigt einen laufenden, langhälsi- } \\
\text { gen Vogel und Geäst. StABa BU 1988. (Abb. 5) }\end{array}$ \\
\hline 14. & 1331 VII 18 & $\begin{array}{l}\text { Personales Amtssiegel des Walter Gundloch, De- } \\
\text { kan des Stifts St. Gangolf; spitzoval aus hellem } \\
\text { Wachs; anhängend an Pergamentstreifen; Größe: } \\
35 \text { x } 50 \text { mm; stark beschädigt und restauriert; Um- } \\
\text { schrift: [S(IGILLUM) W]ALTE[R...TEUE]RSTAT; } \\
\text { Siegelfeld zeigt heiligen Gangolf (stehende Ganz- } \\
\text { figur) mit Lanze oder Fahne in der rechten Hand } \\
\text { und gekreuztem Schild in der linken Hand, rechts } \\
\text { von ihm kniet betend eine Figur im Halbprofil } \\
\text { (Adorantensiegel). StABa BU 2060. }\end{array}$ \\
\hline 15. & 1331 VII 18 & $\begin{array}{l}\text { Personales Amtssiegel des Herman von Mühlhau- } \\
\text { sen (in der Urkunde: Heinrich von Mühlhausen), } \\
\text { Keller des Stifts St. Gangolf; spitzoval aus hellem } \\
\text { Wachs; anhängend an Pergamentstreifen; Größe: } \\
30 \text { x } 45 \text { mm; schwer beschädigt und restauriert; } \\
\text { Umschrift: [...] MILL [...]; Siegelfeld zeigt den heili- } \\
\text { gen Gangolf (kniende Ganzfigur im Profil) betend } \\
\text { zu einer Taube oder einem Engel, eine zum Schlag } \\
\text { ausholende Person mit spitzem Hut (Judenhut) zu } \\
\text { seiner Linken (Erzählsiegel). StABa BU 2060. }\end{array}$ \\
\hline 16. & 1342 XII 13 & $\begin{array}{l}\text { Personales Amtssiegel des Walter Gundloch, De- } \\
\text { kan des Stifts St. Gangolf; spitzoval aus dunklem } \\
\text { Wachs; anhängend an Pergamentstreifen; Größe: }\end{array}$ \\
\hline
\end{tabular}




\begin{tabular}{|c|c|c|}
\hline & & $\begin{array}{l}40 \text { x } 60 \text { mm; schwer beschädigt und restauriert; } \\
\text { Umschrift: [...] TEWER[...]; Siegelfeld zeigt heiligen } \\
\text { Gangolf (stehende Ganzfigur) in fließenden Ge- } \\
\text { wändern, in der rechten Hand eine Lanze oder } \\
\text { Fahne. StABa Kloster Michelsberg, Urkunden Nr. } \\
294 .\end{array}$ \\
\hline 17. & 1344 IV 26 & $\begin{array}{l}\text { Personales Amtssiegel des Walter Gundloch, De- } \\
\text { kan des Stifts St. Gangolf; spitzoval aus dunklem } \\
\text { Wachs; anhängend an Pergamentstreifen; Größe: } \\
40 \text { x } 55 \text { mm; beschädigt und abgenutzt; Umschrift: } \\
\text { [...] WALTERI [...EC]C(LESI)E S(AN)C(T)E MARIE } \\
\text { IN TEWERSTAT; Siegelfeld zeigt heiligen Gangolf } \\
\text { (stehende Ganzfigur) in fließenden Gewändern, in } \\
\text { der rechten Hand eine Lanze oder Fahne, in der } \\
\text { linken ein gekreuztes Schild, rechts von ihm eine } \\
\text { betende Figur an im Profil (Adorantensiegel). } \\
\text { StABa Kloster Michelsberg, Urkunden Nr. 302. }\end{array}$ \\
\hline 18. & 1347 III 18 & $\begin{array}{l}\text { Personales Amtssiegel des Heinrich, Keller des } \\
\text { Stifts St. Gangolf; spitzoval aus rotem Wachs; an- } \\
\text { hängend an Pergamentstreifen; Größe: } 30 \text { x } 45 \\
\text { mm; beschädigt; Umschrift: [S(IGILLUM) } \\
\text { HE]INRICI CELLERARII EC(C)L(LES)IE } \\
\text { TEUE[RSTAT]; Siegelfeld zeigt heiligen Gangolf } \\
\text { (kniende Ganzfigur im Profil) betend zu einer } \\
\text { Taube oder einem Engel, eine zum Schlag ausho- } \\
\text { lende Person mit spitzem Hut (Judenhut) zu sei- } \\
\text { ner Linken (Erzählsiegel). StABa BU 2583. }\end{array}$ \\
\hline 19. & 1349 XI 23 & $\begin{array}{l}\text { Personales Amtssiegel des Heinrich, Keller des } \\
\text { Stifts St. Gangolf; spitzoval aus hellem Wachs; } \\
\text { anhängend an Pergamentstreifen; Größe: } 30 \text { x } 50 \\
\text { mm; beschädigt; Umschrift: [S(IGILLUM)] HEIN- } \\
\text { RICI CELLERARII EC(C)L(LES)IE TEUE[RSTAT]; } \\
\text { Siegelfeld zeigt heiligen Gangolf (kniende Ganzfi- } \\
\text { gur im Profil) betend zu einer Taube oder einem }\end{array}$ \\
\hline
\end{tabular}




\begin{tabular}{|c|c|c|}
\hline & & $\begin{array}{l}\text { Engel, eine zum Schlag ausholende Person mit } \\
\text { spitzem Hut (Judenhut) zu seiner Linken (Erzähl- } \\
\text { siegel). StABa BU } 2670 .\end{array}$ \\
\hline 20. & 1356 XII 5 & $\begin{array}{l}\text { Personales Amtssiegel des Seifrid, Keller des Stifts } \\
\text { St. Gangolf; spitzoval aus dunklem Wachs; abhän- } \\
\text { gend an Pergamentstreifen; Größe: } 30 \text { x } 60 \text { mm; } \\
\text { stark beschädigt und abgenutzt, nur obere Hälfte } \\
\text { erhalten; Umschrift nicht erhalten; Siegelfeld zeigt } \\
\text { eine weibliche Person mit Krone (eventuell sitzen- } \\
\text { de Ganzfigur) mit Speichenrad (als ikonografi- } \\
\text { sches Attribut eventuell Hinweis auf heilige Katha- } \\
\text { rina) in der rechten Hand, in der linken Hand ein } \\
\text { Schwert. AEB Rep. I Pfarrei St. Martin U } 2 \text {. }\end{array}$ \\
\hline 21. & $1374 \mathrm{~V} 15$ & $\begin{array}{l}\text { Personales Amtssiegel des Otto von Aufseß, Keller } \\
\text { des Stifts St. Gangolf; spitzoval aus dunklem } \\
\text { Wachs; anhängend an Pergamentstreifen; Größe: } \\
30 \text { x } 55 \text { mm; beschädigt und abgenutzt; Umschrift: } \\
\text { S(IGILLUM) OTTO(N)I(U)S DE AU(FSESS) [...] } \\
\text { TEW(ER)STAT; Siegelfeld zeigt heiligen Gangolf } \\
\text { in wehenden Gewändern (stehende Ganzfigur) mit } \\
\text { Fahne in der rechten Hand, ein gekreuzter Schild } \\
\text { in der Linken, Wappenschild. AEB Rep. I Pfarrei } \\
\text { St. Martin U 4. }\end{array}$ \\
\hline 22. & 1376 & $\begin{array}{l}\text { Korporatives Siegel des Kapitels St. Gangolf; } \\
\text { spitzoval aus hellem Wachs; anhängend an Per- } \\
\text { gamentstreifen; Größe: } 50 \text { x } 70 \text { mm; abgenutzt; } \\
\text { Umschrift: S(IGILLUM) ECCLESIE SANCTE } \\
\text { MARIE IN TEURSTAT; Siegelfeld zeigt heilige } \\
\text { Maria sitzend auf einer schlichten Bank (sitzende } \\
\text { Ganzfigur) mit Kind auf dem linken Arm, in der } \\
\text { rechten Hand einen nicht identifizierten Gegen- } \\
\text { stand. StABa BU } 3726 .\end{array}$ \\
\hline 23. & 1390 VIII 5 & Korporatives Siegel des Stifts St. Gangolf (Siegel- \\
\hline
\end{tabular}




\begin{tabular}{|c|c|c|}
\hline & & $\begin{array}{l}\text { führer laut Urkunde: Heinrich Kaulberger, Dekan } \\
\text { des Stifts St. Gangolf); spitzoval aus dunklem } \\
\text { Wachs; anhängend an Pergamentstreifen; Größe: } \\
50 \text { x } 70 \text { mm; unbeschädigt; Umschrift: } \\
\text { S(IGILLUM) EC(C)LESIE SANCTE MARIE IN } \\
\text { TEURSTAT; Siegelfeld zeigt heilige Maria sitzend } \\
\text { auf einer schlichten Bank (sitzende Ganzfigur) mit } \\
\text { Kind auf dem linken Arm, in der rechten Hand } \\
\text { einen nicht identifizierten Gegenstand. StABa BU } \\
4261 \text {. (Abb. 2) }\end{array}$ \\
\hline 24. & 1391 IV 23 & $\begin{array}{l}\text { Personales Amtssiegel des Herman Willich, Keller } \\
\text { des Stifts St. Gangolf; spitzoval aus dunklem } \\
\text { Wachs; anhängend an Pergamentstreifen; Größe: } \\
30 \text { x } 50 \text { mm; beschädigt; Umschrift: [S(IGILLUM)] } \\
\text { HERMANN WILLICH CELLERARII ECC(LESI)E } \\
\text { S(ANCTE) MAR(IE) TEW(ER)STAT; Siegelfeld } \\
\text { zeigt heiligen Gangolf (stehende Ganzfigur) in } \\
\text { Rüstung mit Lanze oder Fahne in der rechten } \\
\text { Hand und die linke auf dem Schwert am Gürtel, } \\
\text { Wappenschild. StABa BU } 4287 .\end{array}$ \\
\hline 25. & 1399 I 27 & $\begin{array}{l}\text { Personales Amtssiegel des Herman Willich, Keller } \\
\text { des Stifts St. Gangolf; spitzoval aus dunklem } \\
\text { Wachs; anhängend an Pergamentstreifen; Größe: } \\
30 \text { x } 50 \text { mm; schwer beschädigt, nur unterste Spit- } \\
\text { ze erhalten, teilweise lose; Umschrift: } \\
\text { [S(IGILLUM) HERMANN WILLI]CH CELLERA- } \\
\text { RII ECC[...]; Siegelfeld zeigt heiligen Gangolf (ste- } \\
\text { hende Ganzfigur) mit Lanze oder Fahne in der } \\
\text { rechten Hand und die linke auf dem Schwert am } \\
\text { Gürtel, Wappenschild. SttABa A } 21 \text { 27-01-1399. }\end{array}$ \\
\hline 26. & 1399 III 17 & $\begin{array}{l}\text { Personales Amtssiegel des Herman Willich, Keller } \\
\text { des Stifts St. Gangolf; spitzoval aus dunklem } \\
\text { Wachs; anhängend an Pergamentstreifen; Größe: } \\
30 \text { x } 50 \text { mm; leicht beschädigt, gebrochen; Um- }\end{array}$ \\
\hline
\end{tabular}




\begin{tabular}{|l|l|l|}
\hline & schrift: S(IGILLUM) HERMANN WILLICH CEL- \\
& LERARII ECC(LESIA)E S(ANCTAE) MAR(IAE) \\
TEW(ER)STAT; Siegelfeld zeigt heiligen Gangolf \\
(stehende Ganzfigur) in Rüstung mit Lanze oder \\
Fahne in der rechten Hand und die linke auf dem \\
Schwert am Gürtel, Wappenschild. StABa BU \\
4693.
\end{tabular}




\begin{tabular}{|c|c|c|}
\hline & & Schwert, Wappenschild. SttABa A 21 06-03-1402. \\
\hline 30. & 1403 XI 26 & $\begin{array}{l}\text { Personales Amtssiegel des Herman Willich, Keller } \\
\text { des Stifts St. Gangolf; spitzoval aus hellem Wachs; } \\
\text { anhängend an Pergamentstreifen; Größe: } 30 \text { x } 50 \\
\text { mm; abgenutzt; Umschrift: S(IGILLUM) HER- } \\
\text { MAN WILLICH CELLERAR IN ECC(LESIA)E } \\
\text { S(ANCTAE) MARI TEW(ER)STAT; Siegelfeld zeigt } \\
\text { heiligen Gangolf (stehende Ganzfigur) in Rüstung } \\
\text { mit Fahne in der rechten Hand, in der linken ein } \\
\text { Schwert, Wappenschild. AEB Rep. I Pfarrei St. } \\
\text { Martin U 17. }\end{array}$ \\
\hline 31. & 1406 VIII 28 & $\begin{array}{l}\text { Korporatives Siegel des Kapitels St. Gangolf; } \\
\text { spitzoval aus dunklem Wachs; anhängend an Per- } \\
\text { gamentstreifen; Größe: } 40 \text { x } 60 \text { mm; beschädigt, } \\
\text { beschmutzt und abgenutzt; Umschrift: SIGILLUM } \\
\text { CAPITULI ECCLESIE BEATE MARIE IN TE- } \\
\text { WERSTAT; Siegelfeld zeigt vor architektonischem } \\
\text { Hintergrund in der oberen Hälfte heilige Maria } \\
\text { sitzend auf einer verzierten Bank (sitzende Ganz- } \\
\text { figur) mit Kind auf dem rechten Arm, und in der } \\
\text { unteren Hälfte den heiligen Gangolf (stehende } \\
\text { Ganzfigur) mit Schwert und Lanze oder Fahne in } \\
\text { der rechten Hand, ein Schild in der linken. StABa } \\
\text { Kloster Langheim, Urkunden } 1406 \text { VIII } 28 .\end{array}$ \\
\hline 32. & 1406 XII 20 & $\begin{array}{l}\text { Personales Amtssiegel des Herman Willich, Keller } \\
\text { des Stifts St. Gangolf; spitzoval aus dunklem } \\
\text { Wachs; anhängend an Pergamentstreifen; Größe: } \\
30 \text { x } 50 \text { mm; abgenutzt; Umschrift: S(IGILLUM) } \\
\text { HERMAN WILLICH CELLERAR IN ECC(LESIA)E } \\
\text { S(ANCTAE) MARI TEW(ER)STAT; Siegelfeld zeigt } \\
\text { heiligen Gangolf (stehende Ganzfigur) in Rüstung } \\
\text { mit Fahne in der rechten Hand, in der linken ein } \\
\text { Schwert, Wappenschild. AEB Rep. I Pfarrei St. } \\
\text { Martin U 18. }\end{array}$ \\
\hline
\end{tabular}




\begin{tabular}{|l|l|l|}
\hline 33.1408 V 21 & $\begin{array}{l}\text { Personales Amtssiegel des Herman Willich, Keller } \\
\text { des Stifts St. Gangolf; spitzoval aus dunklem } \\
\text { Wachs; anhängend an Pergamentstreifen; Größe: } \\
\text { 35 x 60 mm; beschädigt; Umschrift: S(IGILLIUM) } \\
\text { HERMAN [WILLICH] [...] MAR[...] TEUERSTAT; } \\
\text { Siegelfeld zeigt heiligen Gangolf (stehende Ganz- } \\
\text { figur) mit Helm, Schwert und Rüstung, eine Lanze } \\
\text { oder Fahne in der rechten Hand, Wappenschild. } \\
\text { AEB Rep. I Pfarrei St. Gertraud U 97. }\end{array}$ \\
\hline 34. 1416 I 7 & $\begin{array}{l}\text { Personales Amtssiegel des Johann Fere, Keller des } \\
\text { Stifts St. Gangolf; spitzoval aus dunklem Wachs; } \\
\text { anhängend an Pergamentstreifen; Größe: 30 x 50 } \\
\text { mm; leicht beschädigt; Umschrift: S(IGILLUM) } \\
\text { IOHANIS FER CELLERARI ECC(LESI)E S MA- } \\
\text { RIE IN TEWER; Siegelfeld zeigt heiligen Gangolf } \\
\text { (stehende Ganzfigur) mit Lanze oder Fahne in der } \\
\text { rechten Hand und in der linken einem gekreuzten } \\
\text { Schild, Wappenschild. SttABa A 21 07-01-1416. }\end{array}$ \\
\hline 36. & $\begin{array}{l}\text { Personales Amtssiegel des Johann Fere, Keller des } \\
\text { Stifts St. Gangolf; spitzoval aus dunklem Wachs; } \\
\text { anhängend an Pergamentstreifen; Größe: 30 x 50 } \\
\text { mm; schwer beschädigt, mehrfach gebrochen; } \\
\text { Umschrift: [...] HAN [...] ECCE [...] TAT; Siegelfeld } \\
\text { zeigt heiligen Gangolf (stehende Ganzfigur) mit } \\
\text { Lanze oder Fahne in der rechten Hand, Wappen- } \\
\text { schild. AEB Rep. I Pfarrei St. Gertraud U 99. }\end{array}$ \\
\hline 1419 & $\begin{array}{l}\text { Personales Amtssiegel des Johann Fere, Keller des } \\
\text { Stifts St. Gangolf; spitzoval aus dunklem Wachs; } \\
\text { anhängend an Pergamentstreifen; Größe: 30 x 50 } \\
\text { mm; schwer beschädigt, nur untere Hälfte erhal- } \\
\text { ten; Umschrift: [S(IGILLUM) IOHANIS] FERE } \\
\text { CELLERARII ECC(LESI)E S MAR[...]; Siegelfeld } \\
\text { zeigt heiligen Gangolf (stehende Ganzfigur) mit } \\
\text { Lanze oder Fahne in der rechten Hand und in der }\end{array}$ \\
\hline
\end{tabular}




\begin{tabular}{|l|l|l|}
\hline & & $\begin{array}{l}\text { linken einem gekreuzten Schild, Wappenschild. } \\
\text { SttABa A 21 09-12-1420. }\end{array}$ \\
\hline 37. & 1424 IV 9 & $\begin{array}{l}\text { Personales Amtssiegel des Johann Fere, Keller des } \\
\text { Stifts St. Gangolf; spitzoval aus hellem Wachs; } \\
\text { anhängend an Pergamentstreifen; Größe: 30 x 50 } \\
\text { mm; schwer beschädigt und abgenutzt, nur die } \\
\text { untere Hälfte erhalten; Umschrift: [...] FERE CEL- } \\
\text { LERAR ECCL(ES)IE B(EATE) MAR[...]; Siegelfeld } \\
\text { zeigt heiligen Gangolf (stehende Ganzfigur) mit } \\
\text { Lanze oder Fahne in der rechten Hand und in der } \\
\text { linken einem gekreuzten Schild, Wappenschild. } \\
\text { StABa A 120 L 131 Nr. 750. }\end{array}$ \\
\hline 38. & $\begin{array}{l}\text { Personales Amtssiegel (laut Urkunde: des Hein- } \\
\text { rich Forstmeister, Dekan des Stifts St. Gangolf); } \\
\text { spitzoval aus dunklem Wachs; anhängend an Per- } \\
\text { gamentstreifen; Größe: 30 x 45 mm; abgenutzt; } \\
\text { Umschrift: [...]ANT ECCE [...]; Siegelfeld zeigt } \\
\text { heilige Maria (stehende Ganzfigur) in fließenden } \\
\text { Gewändern mit Kind auf dem rechten Arm. StABa } \\
\text { Kloster Michelsberg, Urkunden Nr. 704. }\end{array}$ \\
\hline 39. 1435 XI 22 & $\begin{array}{l}\text { Personales Amtssiegel des Johann Schanck, De- } \\
\text { kan des Stifts St. Gangolf; spitzoval aus dunklem } \\
\text { Wachs; anhängend an Pergamentstreifen; Größe: } \\
\text { 30 x 50 mm; beschädigt; Umschrift: S(IGILLUM) } \\
\text { IOHANIS SCHANCK [...] DEC[...] ECC[LES]IE } \\
\text { B(EA)TE MARIE IN TEWERSTAT; Siegelfeld zeigt } \\
\text { heilige Maria (stehende Ganzfigur) mit Krone im } \\
\text { Strahlenkranz in fließenden Gewändern mit Kind } \\
\text { auf dem linken Arm, Wappenschild. StABa A 120 } \\
\text { L 133 Nr. 871. }\end{array}$ \\
\hline $\begin{array}{l}\text { Personales Amtssiegel des Johann Fere, Keller des } \\
\text { Stifts St. Gangolf; spitzoval aus dunklem Wachs; } \\
\text { anhängend an Pergamentstreifen; Größe: 30 x 50 }\end{array}$ \\
\hline I439 VI 1
\end{tabular}




\begin{tabular}{|l|l|l|}
\hline & $\begin{array}{l}\text { mm; schwer beschädigt, nur obere Hälfte erhalten; } \\
\text { Umschrift: S(IGILLUM) IOHANIS [...] EURSTAT; } \\
\text { Siegelfeld zeigt heiligen Gangolf (wahrscheinlich } \\
\text { stehende Ganzfigur) mit Lanze oder Fahne in der } \\
\text { rechten Hand. AEB Rep. I Pfarrei St. Gertraud U } \\
101 .\end{array}$ \\
\hline 41.1440 II 3 & $\begin{array}{l}\text { Personales Amtssiegel des Johann Fere, Keller des } \\
\text { Stifts St. Gangolf; spitzoval aus dunklem Wachs; } \\
\text { anhängend an Pergamentstreifen; Größe: 30 x 50 } \\
\text { mm; beschädigt und beschmutzt; Umschrift: } \\
\text { S(IGILLUM) IOHANIS FER CELLERARII } \\
\text { ECC(LESI)E S MARIE IN TEWER; Siegelfeld zeigt } \\
\text { heiligen Gangolf (stehende Ganzfigur) mit Lanze } \\
\text { oder Fahne in der rechten Hand und in der linken } \\
\text { einem gekreuzten Schild, Wappenschild. SttABa A } \\
\text { 21 03-02-1440. }\end{array}$ \\
\hline 42. 1440 IV 4 & $\begin{array}{l}\text { Personales Amtssiegel des Nikolaus Vipech, Keller } \\
\text { des Stifts St. Gangolf; spitzoval aus dunklem } \\
\text { Wachs; anhängend an Pergamentstreifen; Größe: } \\
\text { 30 x 50 mm; leicht beschädigt; Umschrift: } \\
\text { S(IGILLUM) NICOLAI VIPECH [...] NCE M } \\
\text { ECC(LES)IE IN THURSTAT; Siegelfeld zeigt hei- } \\
\text { ligen Gangolf (stehende Ganzfigur) mit Umhang, } \\
\text { Lanze oder Fahne in der rechten Hand und in der } \\
\text { linken einem gekreuzten Schild, Wappenschild. } \\
\text { AEB Rep. I Pfarrei St. Gertraud U 102. (Abb. 4) }\end{array}$ \\
\hline 1440 V 9 & $\begin{array}{l}\text { Personales Amtssiegel des Nikolaus Vipech, Keller } \\
\text { des Stifts St. Gangolf; spitzoval aus dunklem } \\
\text { Wachs; anhängend an Pergamentstreifen; Größe: } \\
\text { 30 x 50 mm; schwer beschädigt, nur unteres Vier- } \\
\text { tel erhalten; Umschrift: [...] ECCL(ES)IE [...]; Sie- } \\
\text { gelfeld ist abgesehen vom Wappenschild nicht } \\
\text { erhalten. AEB Rep. I Pfarrei St. Gertraud U 103. }\end{array}$ \\
\hline
\end{tabular}




\begin{tabular}{|c|c|c|}
\hline 44. & 1442 VI 4 & $\begin{array}{l}\text { Personales Amtssiegel des Nikolaus Vipech, Keller } \\
\text { des Stifts St. Gangolf; spitzoval aus dunklem } \\
\text { Wachs; anhängend an Pergamentstreifen; Größe: } \\
30 \text { x } 50 \text { mm; leicht beschädigt; Umschrift: [...] } \\
\text { NICOLAI VIPECH [...] E[...] IN TEUR[ERSTAT]; } \\
\text { Siegelfeld zeigt heiligen Gangolf (stehende Ganz- } \\
\text { figur) mit Umhang, Lanze oder Fahne in der rech- } \\
\text { ten Hand und in der linken einem gekreuzten } \\
\text { Schild, Wappenschild. AEB Rep. I Pfarrei St. Ger- } \\
\text { traud U } 104 .\end{array}$ \\
\hline 45. & $1443 \times 21$ & $\begin{array}{l}\text { Personales Amtssiegel des Nikolaus Vipech, Keller } \\
\text { des Stifts St. Gangolf; spitzoval aus dunklem } \\
\text { Wachs; anhängend an Pergamentstreifen; Größe: } \\
30 \text { x } 55 \text { mm; schwer beschädigt, nur untere Hälfte } \\
\text { erhalten; Umschrift; [...] CELERAR ECC[LESIE } \\
\text { MAR]IE [...]; Siegelfeld zeigt heiligen Gangolf (ste- } \\
\text { hende Ganzfigur) mit Lanze oder Fahne in der } \\
\text { rechten Hand und in der linken einem gekreuzten } \\
\text { Schild, Wappenschild. AEB Rep. I Pfarrei St. Ger- } \\
\text { traud U 105. }\end{array}$ \\
\hline 46. & 1445 VI 14 & $\begin{array}{l}\text { Personales Amtssiegel des Johann Schank, Keller } \\
\text { des Stifts St. Gangolf; spitzoval aus dunklem } \\
\text { Wachs; anhängend an Pergamentstreifen; Größe: } \\
35 \text { x } 55 \text { mm; beschädigt; Umschrift: S(IGILLUM) } \\
\text { IOHANIS SCHANK CELER ECCL(ESI)E IN } \\
\text { TEURSTAT; Siegelfeld zeigt heiligen Gangolf } \\
\text { (stehende Ganzfigur) vor architektonischem Hin- } \\
\text { tergrund mit einer Lanze oder Fahne in der rech- } \\
\text { ten Hand und in der linken einem gekreuzten } \\
\text { Schild, Wappenschild. AEB Rep. I Pfarrei St. Ger- } \\
\text { traud U } 107 .\end{array}$ \\
\hline 47. & 1448 I 25 & $\begin{array}{l}\text { Personales Amtssiegel des Jorg Rephun, Keller } \\
\text { des Stifts St. Gangolf; spitzoval aus dunklem } \\
\text { Wachs; anhängend an Pergamentstreifen; Größe: }\end{array}$ \\
\hline
\end{tabular}




\begin{tabular}{|c|c|c|}
\hline & & $\begin{array}{l}35 \text { x } 55 \text { mm; beschädigt und restauriert, mehrfach } \\
\text { gebrochen; Umschrift: S(IGILLUM) GEORG } \\
\text { REPHUN CELLERARII ECCL(ES)IE B(EA)TE } \\
\text { MARIE I TEWRSTAT; Siegelfeld zeigt heiligen } \\
\text { Gangolf (stehende Ganzfigur) in Rüstung mit } \\
\text { einer Lanze oder Fahne in der rechten Hand und } \\
\text { in der linken einem gekreuzten Schild, Wappen- } \\
\text { schild. SttABa A } 21 \text { 25-01-1448. }\end{array}$ \\
\hline 48. & 1449 VIII 18 & $\begin{array}{l}\text { Personales Amtssiegel des Jorg Rephun, Keller } \\
\text { des Stifts St. Gangolf; spitzoval aus dunklem } \\
\text { Wachs; anhängend an Pergamentstreifen; Größe: } \\
35 \text { x } 55 \text { mm; beschädigt; Umschrift: [...] EORG } \\
\text { REP[...] B(EA)TE MARIE I TEWRSTAT; Siegelfeld } \\
\text { zeigt heiligen Gangolf (stehende Ganzfigur) mit } \\
\text { einer Lanze oder Fahne in der rechten Hand und } \\
\text { in der linken einem gekreuzten Schild, Wappen- } \\
\text { schild. AEB Rep. I Pfarrei St. Gertraud U 108. }\end{array}$ \\
\hline 49. & 1449 XI 8 & $\begin{array}{l}\text { Korporatives Siegel des Kapitels St. Gangolf; } \\
\text { spitzoval aus dunklem Wachs; anhängend an Per- } \\
\text { gamentstreifen; Größe: } 40 \text { x } 60 \text { mm; schwer be- } \\
\text { schädigt, nur in Teilen erhalten, mehrfach gebro- } \\
\text { chen; Umschrift: [SIGILLUM CAPI]TULI ECCLE- } \\
\text { SIE B[EATE MARIE IN TEWERSTAT]; Siegelfeld } \\
\text { zeigt vor architektonischem Hintergrund in der } \\
\text { oberen Hälfte heilige Maria sitzend auf einer ver- } \\
\text { zierten Bank (sitzende Ganzfigur) mit Kind auf } \\
\text { dem rechten Arm, und in der unteren Hälfte den } \\
\text { heiligen Gangolf (stehende Ganzfigur) mit } \\
\text { Schwert und Lanze oder Fahne in der rechten } \\
\text { Hand, ein Schild in der linken. StABa A } 120 \text { L } 131 \\
\text { Nr. } 753 .\end{array}$ \\
\hline 50. & 1452 III 20 & $\begin{array}{l}\text { Personales Amtssiegel des Georg Rephun, Keller } \\
\text { des Stifts St. Gangolf; spitzoval aus dunklem } \\
\text { Wachs; anhängend an Pergamentstreifen; Größe: }\end{array}$ \\
\hline
\end{tabular}




\begin{tabular}{|c|c|c|}
\hline & & $\begin{array}{l}35 \text { x } 50 \text { mm; beschädigt; Umschrift: [...] GEORG } \\
\text { REPHUN CELLERARII ECCL(ES)IE B(EA)TE } \\
\text { MARIE I TEWRSTAT; Siegelfeld zeigt heiligen } \\
\text { Gangolf (stehende Ganzfigur) in detaillierter Rüs- } \\
\text { tung mit einer Lanze oder Fahne in der rechten } \\
\text { Hand und in der linken einem gekreuzten Schild, } \\
\text { Wappenschild. SttABa A } 21 \text { 20-03-1452. }\end{array}$ \\
\hline 51. & 1458 II 20 & $\begin{array}{l}\text { Personales Amtssiegel (laut Urkunde: des Georg } \\
\text { Rephun, Keller des Stifts St. Gangolf); spitzoval } \\
\text { aus dunklem Wachs; anhängend an Pergament- } \\
\text { streifen; Größe: } 35 \text { x } 50 \text { mm; stark beschädigt, } \\
\text { mehrfach gebrochen, teilweise lose; Umschrift } \\
\text { nicht erhalten; Siegelfeld zeigt den heiligen Gan- } \\
\text { golf (stehende Ganzfigur) in detaillierter Rüstung } \\
\text { mit einer Lanze oder Fahne in der rechten Hand } \\
\text { und in der linken einem gekreuzten Schild, Wap- } \\
\text { penschild. SttABa A } 21 \text { 20-02-1458. }\end{array}$ \\
\hline 52. & 1466 V 30 & $\begin{array}{l}\text { Korporatives Siegel des Kapitels St. Gangolf; } \\
\text { spitzoval aus dunklem Wachs; anhängend an Per- } \\
\text { gamentstreifen; Größe: } 40 \text { x } 60 \text { mm; schwer be- } \\
\text { schädigt, nur rechte Seite erhalten, mehrfach ge- } \\
\text { brochen; Umschrift: SIGILLUM CAPITULI } \\
\text { ECCLESIE BEATE [MARIE IN TEWERSTAT]; } \\
\text { Siegelfeld zeigt vor architektonischem Hinter- } \\
\text { grund in der oberen Hälfte heilige Maria sitzend } \\
\text { auf einer verzierten Bank (sitzende Ganzfigur) mit } \\
\text { Kind auf dem rechten Arm, und in der unteren } \\
\text { Hälfte den heiligen Gangolf (stehende Ganzfigur) } \\
\text { mit Schwert und Lanze oder Fahne in der rechten } \\
\text { Hand, ein Schild in der linken. StABa A } 120 \text { L } 131 \\
\text { Nr. } 724 \text {. }\end{array}$ \\
\hline 53. & 1466 VI 16 & $\begin{array}{l}\text { Korporatives Siegel des Kapitels St. Gangolf; } \\
\text { spitzoval aus dunklem Wachs; anhängend an Per- } \\
\text { gamentstreifen; Größe: } 40 \text { x } 60 \text { mm; schwer be- }\end{array}$ \\
\hline
\end{tabular}




\begin{tabular}{|c|c|c|}
\hline & & $\begin{array}{l}\text { schädigt, nur mittlerer Teil erhalten; Umschrift: } \\
\text { [SIGILLUM] CAPITULI ECCL[ESIE BEATE } \\
\text { MAR]IE IN TE[WERSTAT]; Siegelfeld zeigt vor } \\
\text { architektonischem Hintergrund in der oberen } \\
\text { Hälfte heilige Maria sitzend auf einer verzierten } \\
\text { Bank (sitzende Ganzfigur) mit Kind auf dem rech- } \\
\text { ten Arm, und in der unteren Hälfte den heiligen } \\
\text { Gangolf (stehende Ganzfigur) mit Schwert und } \\
\text { Lanze oder Fahne in der rechten Hand, ein Schild } \\
\text { in der linken. StABa A } 120 \text { L } 131 \text { Nr. } 757 \text {. }\end{array}$ \\
\hline 54. & 1468 VIII 22 & $\begin{array}{l}\text { Korporatives Siegel des Kapitels St. Gangolf; } \\
\text { spitzoval aus dunklem Wachs; anhängend an Per- } \\
\text { gamentstreifen; Größe: } 40 \text { x } 60 \text { mm; schwer be- } \\
\text { schädigt; Umschrift nicht erhalten; Siegelfeld zeigt } \\
\text { vor architektonischem Hintergrund in der oberen } \\
\text { Hälfte heilige Maria sitzend auf einer verzierten } \\
\text { Bank (sitzende Ganzfigur) mit Kind auf dem rech- } \\
\text { ten Arm, und in der unteren Hälfte den heiligen } \\
\text { Gangolf (stehende Ganzfigur) mit Schwert und } \\
\text { Lanze oder Fahne in der rechten Hand, ein Schild } \\
\text { in der linken. StABa A } 120 \text { L } 133 \text { Nr. } 879 \text {. }\end{array}$ \\
\hline 55. & 1470 I 5 & $\begin{array}{l}\text { Personales Amtssiegel des Konrad Hartung, De- } \\
\text { kan des Stifts St. Gangolf; spitzoval aus rotem } \\
\text { Wachs; anhängend an weißer Seidenschnur; Grö- } \\
\text { ße: } 33 \text { x } 50 \text { mm; beschädigt; Umschrift: } \\
\text { S(IGILLUM) CUNRAD HARTUNG DECAN [...] } \\
\text { STAT; Siegelfeld zeigt heilige Maria (stehende } \\
\text { Ganzfigur) vor architektonischem Hintergrund } \\
\text { mit Kind auf dem linken Arm, Wappenschild. } \\
\text { StAWU WU 65/27. }\end{array}$ \\
\hline 56. & 1475 VI 19 & $\begin{array}{l}\text { Personales Amtssiegel des Georg Rephun, Keller } \\
\text { des Stifts St. Gangolf; spitzoval aus dunklem } \\
\text { Wachs; anhängend an Pergamentstreifen; Größe: } \\
35 \text { x } 50 \text { mm; beschädigt; Umschrift: GEORGI }\end{array}$ \\
\hline
\end{tabular}




\begin{tabular}{|c|c|c|}
\hline & & $\begin{array}{l}\text { REPHUN CELLERAR ECCL(ES)IE [...]EWER[...]; } \\
\text { Siegelfeld zeigt heiligen Gangolf (stehende Ganz- } \\
\text { figur) in Rüstung mit Lanze oder Fahne in der } \\
\text { rechten Hand und in der linken einem gekreuzten } \\
\text { Schild, Wappenschild. StABa A } 120 \text { L } 131 \text { Nr. } 760 .\end{array}$ \\
\hline 57. & 1477 IV 14 & $\begin{array}{l}\text { Personales Amtssiegel des Georg Rephun, Keller } \\
\text { des Stifts St. Gangolf; spitzoval aus dunklem } \\
\text { Wachs; anhängend an Pergamentstreifen; Größe: } \\
35 \text { x } 50 \text { mm; beschädigt und abgenutzt; Umschrift: } \\
\text { S(IGILLUM) JORG REPHUN CELLERAR } \\
\text { ECCL(ESIAE) B(EA)TE MARIE I(N) } \\
\text { TEW(E)RSTAT; Siegelfeld zeigt heiligen Gangolf } \\
\text { (stehende Ganzfigur) in Rüstung mit Lanze oder } \\
\text { Fahne in der rechten Hand und in der linken ei- } \\
\text { nem gekreuzten Schild, Wappenschild. AEB Rep. I } \\
\text { Pfarrei Unserer lieben Frau U } 114 \text {. }\end{array}$ \\
\hline 58. & 1489 III 16 & $\begin{array}{l}\text { Personales Amtssiegel des Andreas Herzog, Keller } \\
\text { des Stifts St. Gangolf; spitzoval aus dunklem } \\
\text { Wachs; anhängend an Pergamentstreifen; Größe: } \\
35 \text { x } 60 \text { mm; leicht abgenutzt; Umschrift: } \\
\text { S(IGILLUM) ANDREE HERZOG CELLERARII } \\
\text { ECCL(ES)IE S(AN)CTE M[ARI]E IN TEUERSTAT; } \\
\text { Siegelfeld zeigt heiligen Gangolf (stehende Ganz- } \\
\text { figur) in Rüstung mit Lanze oder Fahne in der } \\
\text { rechten Hand und in der linken einem gekreuzten } \\
\text { Schild, Wappenschild. StABa Kloster Michelsberg, } \\
\text { Urkunden Nr. 1412. }\end{array}$ \\
\hline 59. & 1491 V 2 & $\begin{array}{l}\text { Personales Amtssiegel des Andreas Herzog, Keller } \\
\text { des Stifts St. Gangolf; spitzoval aus dunklem } \\
\text { Wachs; anhängend an Pergamentstreifen; Größe: } \\
35 \text { x } 60 \text { mm; schwer beschädigt, mittig gebrochen; } \\
\text { Umschrift: S(IGILLUM) ANDREE HERZ[...]RARII } \\
\text { ECCL(ES)IE S(AN)CTE M[ARI]E IN TEUERSTAT; } \\
\text { Siegelfeld zeigt heiligen Gangolf (stehende Ganz- }\end{array}$ \\
\hline
\end{tabular}




\begin{tabular}{|c|c|c|}
\hline & & $\begin{array}{l}\text { figur) mit Lanze oder Fahne in der rechten Hand } \\
\text { und in der linken einem gekreuzten Schild, Wap- } \\
\text { penschild. SttABa A } 21 \text { 02-05-1491. }\end{array}$ \\
\hline 60. & 1491 VIII 8 & $\begin{array}{l}\text { Personales Amtssiegel des Andreas Herzog, Keller } \\
\text { des Stifts St. Gangolf; spitzoval aus dunklem } \\
\text { Wachs; anhängend an Pergamentstreifen; Größe: } \\
35 \text { x } 60 \text { mm; schwer beschädigt, nur untere Hälfte } \\
\text { erhalten; Umschrift: [...] ECCL(ES)IE MARIE [...]; } \\
\text { Siegelfeld zeigt heiligen Gangolf (stehende Ganz- } \\
\text { figur) mit Lanze oder Fahne in der rechten Hand } \\
\text { und in der linken einem gekreuzten Schild, Wap- } \\
\text { penschild. AEB Rep. I Pfarrei St. Gertraud U } 114 .\end{array}$ \\
\hline 61. & 1492 II 27 & $\begin{array}{l}\text { Personales Amtssiegel des Andreas Herzog, Keller } \\
\text { des Stifts St. Gangolf; spitzoval aus dunklem } \\
\text { Wachs; anhängend an Pergamentstreifen; Größe: } \\
35 \text { x } 60 \text { mm; schwer beschädigt, gebrochen; Um- } \\
\text { schrift: [...] HER[Z]OG CELLER(AR) ECCL(ESIAE) } \\
\text { B(E)ATE MARIE [...]STAT; Siegelfeld zeigt heili- } \\
\text { gen Gangolf (stehende Ganzfigur) in Rüstung und } \\
\text { Schwert mit Fahne in der rechten Hand und in der } \\
\text { linken einem gekreuzten Schild, Wappenschild. } \\
\text { AEB Rep. I Pfarrei Unserer lieben Frau U 121. }\end{array}$ \\
\hline 62. & 1502 XII 19 & $\begin{array}{l}\text { Personales Amtssiegel des Amandus Korber, Kel- } \\
\text { ler des Stifts St. Gangolf; spitzoval aus dunklem } \\
\text { Wachs; anhängend an Pergamentstreifen; Größe: } \\
30 \text { x } 50 \text { mm; schwer beschädigt, nur rechte Seite } \\
\text { erhalten; Umschrift: [...]NDI KORBER CELERAR } \\
\text { [...]; Siegelfeld zeigt heiligen Gangolf (stehende } \\
\text { Ganzfigur) mit gekreuztem Schild und Schwert an } \\
\text { der linken Seite, Wappenschild. StABa A } 120 \text { L } 131 \\
\text { Nr. } 766 .\end{array}$ \\
\hline 63. & 1524 V 1 & $\begin{array}{l}\text { Korporatives Siegel des Kapitels St. Gangolf; } \\
\text { spitzoval aus dunklem Wachs; anhängend an Per- }\end{array}$ \\
\hline
\end{tabular}




\begin{tabular}{|l|l|l|}
\hline | & gamentstreifen; Größe: 40 x 60 mm; leicht abge- \\
nutzt; Umschrift: SIGILLUM CAPITULI ECCLE- \\
SIE BEATE MARIE IN TEWERSTAT; Siegelfeld \\
zeigt vor architektonischem Hintergrund in der \\
oberen Hälfte heilige Maria sitzend auf einer ver- \\
zierten Bank (sitzende Ganzfigur) mit Kind auf \\
dem rechten Arm, und in der unteren Hälfte den \\
heiligen Gangolf (stehende Ganzfigur) mit \\
Schwert und Lanze oder Fahne in der rechten \\
Hand, ein Schild in der linken. StABa Kloster Mi- \\
chelsberg, Urkunden Nr. 2023.
\end{tabular}




\begin{tabular}{|c|c|c|}
\hline & & Rep. I Pfarrei St. Gangolf U 822. (Abb. 3) \\
\hline 66. & 1559 III 1 & $\begin{array}{l}\text { Personales Amtssiegel des Paul Neidecker, Propst } \\
\text { des Stifts St. Gangolf; rund; aufgedruckt unter } \\
\text { Papier; Durchmesser: } 30 \text { mm; unbeschädigt; Um- } \\
\text { schrift: PAUL NEIDECKER PREPOS; Siegelfeld } \\
\text { zeigt heilige Maria (Brustbild) mit Kind auf dem } \\
\text { rechten Arm, Wappenschild. StABa Kloster Mi- } \\
\text { chelsberg, Urkunden Nr. } 2442 \text {. }\end{array}$ \\
\hline 67. & 1559 III 1 & $\begin{array}{l}\text { Personales Amtssiegel des Paul Neidecker, Propst } \\
\text { des Stifts St. Gangolf; rund; aufgedruckt unter } \\
\text { Papier; Durchmesser: } 30 \text { mm; unbeschädigt; Um- } \\
\text { schrift: PAUL NEIDECKER PREPOS; Siegelfeld } \\
\text { zeigt heilige Maria (Brustbild) mit Kind auf dem } \\
\text { rechten Arm, Wappenschild. StABa Kloster Mi- } \\
\text { chelsberg, Urkunden Nr. 2443. }\end{array}$ \\
\hline
\end{tabular}




\section{Stiftsbezeichnungen}

Aufgelistet sind Selbst- und Fremdbezeichnungen des Stifts St. Gangolf ${ }^{1080}$ anhand stiftseigener und stiftsfremder Urkunden im Staatsarchiv Bamberg, im Archiv des Erzbistums Bamberg, im Stadtarchiv Bamberg und im Staatsarchiv Würzburg, aber auch anhand des Bamberger Synodialprotokolls von 1059 und anhand der Chronik Liber de decurso temporum des Heimo von St. Jakob von vor 1139. Die Klassifizierung als Selbst- oder Fremdbezeichnung ist davon abhängig, ob der oder die Aussteller dem Stift St. Gangolf angehörten und somit Einfluss auf die Stiftsbezeichnung nehmen konnten. Unterschiedliche Mehrfachnennungen innerhalb einer Quelle wurden aufgenommen, um im Falle einer verkürzten Betitelung in Folge einer Wiederholung die interne Bedeutung einzelner Namensbestandteile für die Identifizierung des Stifts deutlich zu machen. Buchstabendoppelungen, die der modernen Schreibweise widersprechen, wurden als Schmuckwerk eingestuft und nicht in die Transkription aufgenommen. Hochgeschriebene Buchstaben wurden gemäß den modernen Umlauten hinter den Hauptbuchstaben gestellt $(\stackrel{\mathrm{u}}{=} \mathrm{uo}$ ) und $\mathrm{v}$ wurde als $\mathrm{u}$ transkribiert.

\begin{tabular}{|l|l|l|}
\hline Datierung & Bezeichnung & Quelle \\
\hline 1059 IV 13 & decanus de Duristat & $\begin{array}{l}\text { Fremdbezeichnung; } \\
\text { Synodialprotokoll vom } \\
\end{array}$ \\
& & $\begin{array}{l}\text { 13. April 1059 (Zeugen- } \\
\text { liste) in: Jaffé: Acta sy- } \\
\text { nodi. 1869. S. 498. Nr. 8. }\end{array}$ \\
\hline 1093 V 6 & fratres de sancta Maria & $\begin{array}{l}\text { Fremdbezeichnung; } \\
\text { StABa BU 143. }\end{array}$ \\
\hline 1108 V 19 & prepositus Turstatensis & $\begin{array}{l}\text { Fremdbezeichnung; } \\
\text { StABa BU 149. }\end{array}$ \\
\hline 1127 & & Fremdbezeichnung; \\
\hline
\end{tabular}

1080 Näheres zur Auswertung der Selbst- und Fremdbezeichnungen im Kapitel 3.2.5 Selbstbezeichnungen in den Urkunden. 


\begin{tabular}{|c|c|c|}
\hline & & StABa BU 156. \\
\hline 1127 & decanus de Tuirstat & $\begin{array}{l}\text { Fremdbezeichnung; } \\
\text { StABa BU } 178 .\end{array}$ \\
\hline vor 1139 & $\begin{array}{l}\text { ecclesia in honore sancte } \\
\text { Mariae matris Domini et sanc- } \\
\text { ti Gengolfi martiris extra ur- } \\
\text { bem versus orientem in loco } \\
\text { Tierstat }\end{array}$ & $\begin{array}{l}\text { Fremdbezeichnung; } \\
\text { Jaffé: Heimo von St. } \\
\text { Jakob: Liber de decurso } \\
\text { temporum. 1869. S. } 546 .\end{array}$ \\
\hline $1142 \times 28$ & praepositus sancte Marie & $\begin{array}{l}\text { Fremdbezeichnung; } \\
\text { StABa Kloster Michels- } \\
\text { beg, Urk. Nr. } 27 .\end{array}$ \\
\hline 1142 & praepositus sancte Marie & $\begin{array}{l}\text { Fremdbezeichnung; } \\
\text { StABa BU } 223 .\end{array}$ \\
\hline 1143 & praepositus sancte Marie & $\begin{array}{l}\text { Fremdbezeichnung; } \\
\text { StABa BU } 226 .\end{array}$ \\
\hline 1149 & praepositus sancte Marie & $\begin{array}{l}\text { Fremdbezeichnung; } \\
\text { StABa BU } 247 .\end{array}$ \\
\hline 1151 IV 10 & praepositus de Tuerstat & $\begin{array}{l}\text { Fremdbezeichnung; } \\
\text { StABa BU } 255 .\end{array}$ \\
\hline 1151 & praepositus sancti Gangolfi & $\begin{array}{l}\text { Fremdbezeichnung; } \\
\text { StABa Kloster Michels- } \\
\text { berg, Urk. Nr. } 38 .\end{array}$ \\
\hline 1152 II 14 & $\begin{array}{l}\text { praepositus sancti Gingolfi } \\
\text { Babenbergensis }\end{array}$ & $\begin{array}{l}\text { Fremdbezeichnung; } \\
\text { StABa Kloster Michels- } \\
\text { berg, Urk. Nr. } 39 .\end{array}$ \\
\hline 1178 IV 6 & praepositus sancti Gingulfi & $\begin{array}{l}\text { Fremdbezeichnung; } \\
\text { StABa BU } 335 .\end{array}$ \\
\hline$(1180)$ & praepositus sancte Marie & $\begin{array}{l}\text { Fremdbezeichnung; } \\
\text { StABa BU } 347 .\end{array}$ \\
\hline 1187 & praepositus sancti Gingolfi & $\begin{array}{l}\text { Fremdbezeichnung; } \\
\text { StABa BU } 376 .\end{array}$ \\
\hline$(1190)$ & $\begin{array}{l}\text { praepositus sancte Marie in } \\
\text { Duorstat; vicarius de Tuorstat }\end{array}$ & $\begin{array}{l}\text { Fremdbezeichnung; } \\
\text { StABa BU } 387 .\end{array}$ \\
\hline
\end{tabular}




\begin{tabular}{|c|c|c|}
\hline 1192 & praepositus s. Marie & $\begin{array}{l}\text { Fremdbezeichnung; } \\
\text { StABa BU } 391 .\end{array}$ \\
\hline 1199 & $\begin{array}{l}\text { decanus sancte Marie in } \\
\text { Tuwerstat }\end{array}$ & $\begin{array}{l}\text { Fremdbezeichnung; } \\
\text { StABa BU } 411 .\end{array}$ \\
\hline 1205 & $\begin{array}{l}\text { prepositus sancte Marie in } \\
\text { Tiurstat }\end{array}$ & $\begin{array}{l}\text { Fremdbezeichnung; } \\
\text { StAWu Kloster Ebrach, } \\
\text { Urk. 1205/I. }\end{array}$ \\
\hline 1206 & praepositus sancte Marie & $\begin{array}{l}\text { Fremdbezeichnung; } \\
\text { StABa BU } 441 .\end{array}$ \\
\hline 1216 & praepositus in Tuoerstat & $\begin{array}{l}\text { Fremdbezeichnung; } \\
\text { StABa BU } 473 .\end{array}$ \\
\hline 1217 & $\begin{array}{l}\text { praepositus in Tuorstat; deca- } \\
\text { nus in Turstat }\end{array}$ & $\begin{array}{l}\text { Fremdbezeichnung; } \\
\text { StABa Kloster Michels- } \\
\text { berg, Urk. Nr. } 75 .\end{array}$ \\
\hline (1217) & turstatensis praepositus & $\begin{array}{l}\text { Fremdbezeichnung; } \\
\text { StABa BU } 485 .\end{array}$ \\
\hline 1221 & in Tuoerstat canonicus & $\begin{array}{l}\text { Fremdbezeichnung; } \\
\text { StABa Kloster Michels- } \\
\text { berg, Urk. Nr. } 79 .\end{array}$ \\
\hline 1221 & canonicus in Tuoerstat & $\begin{array}{l}\text { Fremdbezeichnung; } \\
\text { StABa Kloster Michels- } \\
\text { berg, Urk. Nr. } 80 .\end{array}$ \\
\hline 1233 & praepositus in Tuerstat & $\begin{array}{l}\text { Fremdbezeichnung; } \\
\text { StABa Kloster Michels- } \\
\text { berg, Urk. Nr. } 86 .\end{array}$ \\
\hline $\begin{array}{l}1240 \mathrm{VII} \\
10\end{array}$ & decanus in Turstat & $\begin{array}{l}\text { Fremdbezeichnung; } \\
\text { StABa BU 600. }\end{array}$ \\
\hline 1242 & $\begin{array}{l}\text { sancte Marie in Tyrstat deca- } \\
\text { nus; custos in Tyrstat }\end{array}$ & $\begin{array}{l}\text { Fremdbezeichnung; } \\
\text { StABa BU } 613 .\end{array}$ \\
\hline 1242 & $\begin{array}{l}\text { custodia in Tiwerstat; canoni- } \\
\text { ci in Tuwerstat }\end{array}$ & $\begin{array}{l}\text { Fremdbezeichnung; } \\
\text { StABa BU 614. }\end{array}$ \\
\hline $1245 \mathrm{~V} 26$ & $\begin{array}{l}\text { decanus in Turstat Babinber- } \\
\text { gensis; decanus de Turstat }\end{array}$ & $\begin{array}{l}\text { Fremdbezeichnung; } \\
\text { StAWu Stift Neumüns- }\end{array}$ \\
\hline
\end{tabular}




\begin{tabular}{|c|c|c|}
\hline & Babinbergensis & ter, Urk. 1245 V 26. \\
\hline 1246 & scolaricus in Twerstat & $\begin{array}{l}\text { Fremdbezeichnung; } \\
\text { StABa BU } 645 .\end{array}$ \\
\hline 1250 & $\begin{array}{l}\text { decanus sancte Marie in Tu- } \\
\text { orstat }\end{array}$ & $\begin{array}{l}\text { Fremdbezeichnung; } \\
\text { StABa BU } 688 .\end{array}$ \\
\hline (um 1250) & $\begin{array}{l}\text { decanus sancte Marie in Ti- } \\
\text { werstat }\end{array}$ & $\begin{array}{l}\text { Fremdbezeichnung; } \\
\text { StABa BU } 689 .\end{array}$ \\
\hline 1255 I 9 & canonicus Tirstatensis & $\begin{array}{l}\text { Fremdbezeichnung; } \\
\text { StABa BU } 720 .\end{array}$ \\
\hline 1261 VI 13 & $\begin{array}{l}\text { decanus sancte Marie in } \\
\text { Twerstat }\end{array}$ & $\begin{array}{l}\text { Fremdbezeichnung; } \\
\text { StABa BU } 782 .\end{array}$ \\
\hline 1271 XI 10 & de sancto Gangolfo & $\begin{array}{l}\text { Fremdbezeichnung; } \\
\text { StAWu Kloster Lang- } \\
\text { heim, Urk. } 1271 \text { XI } 10 .\end{array}$ \\
\hline 1275 II 1 & $\begin{array}{l}\text { praepostius sancte Marie in } \\
\text { Thuerstat }\end{array}$ & $\begin{array}{l}\text { Fremdbezeichnung; } \\
\text { StABa BU } 878 .\end{array}$ \\
\hline 1275 IV 23 & $\begin{array}{l}\text { praepositus sancte Marie in } \\
\text { Teurstat }\end{array}$ & $\begin{array}{l}\text { Fremdbezeichnung; } \\
\text { StABa BU } 881 .\end{array}$ \\
\hline 1280 I 28 & $\begin{array}{l}\text { canonicus sancte Marie in } \\
\text { Tuwerstat }\end{array}$ & $\begin{array}{l}\text { Fremdbezeichnung; } \\
\text { StABa BU } 935 .\end{array}$ \\
\hline 1285 VII 2 & $\begin{array}{l}\text { prepositus sancte Marie in } \\
\text { Tewerstat; prepositus in Tew- } \\
\text { erstat }\end{array}$ & $\begin{array}{l}\text { Fremdbezeichnung; } \\
\text { StAWu Kloster Ebrach, } \\
\text { Urk. } 1285 \text { VII 2/I. }\end{array}$ \\
\hline 1285 VII 2 & $\begin{array}{l}\text { prepositus sancte Marie in } \\
\text { Tewerstat }\end{array}$ & $\begin{array}{l}\text { Fremdbezeichnung; } \\
\text { StAWu Urk Kloster E- } \\
\text { brach } 1285 \text { VII 2/II. }\end{array}$ \\
\hline 1290 I 25 & de Turstat Babenbergensis & $\begin{array}{l}\text { Fremdbezeichnung; } \\
\text { StAWu Kloster Ebrach, } \\
\text { Urk. } 1290 \text { I } 25 .\end{array}$ \\
\hline 1290 III 21 & $\begin{array}{l}\text { rector scolarum sancti Gan- } \\
\text { golfi }\end{array}$ & $\begin{array}{l}\text { Fremdbezeichnung; } \\
\text { StAWu Kloster Ebrach, } \\
\text { Urk. } 1290 \text { III 21/II. }\end{array}$ \\
\hline $1295 \mathrm{~V} 25$ & decanus totusque capitulum & Selbstbezeichnung; \\
\hline
\end{tabular}




\begin{tabular}{|c|c|c|}
\hline & $\begin{array}{l}\text { in Tiurstat Babenbergensis; } \\
\text { decanus nostre in Tiurstat; } \\
\text { ecclesia nostra in Tiurstat; } \\
\text { decanus in Tiurstat }\end{array}$ & $\begin{array}{l}\text { StAWu Kloster Ebrach, } \\
\text { Urk. } 1295 \text { V } 25 .\end{array}$ \\
\hline $1302 \times 27$ & $\begin{array}{l}\text { prepositus sancte Marie in } \\
\text { Tuerstat }\end{array}$ & $\begin{array}{l}\text { Fremdbezeichnung; } \\
\text { StABa Kloster Michels- } \\
\text { berg, Urk. Nr. } 41 .\end{array}$ \\
\hline 1302 XI 10 & $\begin{array}{l}\text { praepositus sancte Marie in } \\
\text { Thuerstat extra muros Baben- } \\
\text { bergenses }\end{array}$ & $\begin{array}{l}\text { Selbstbezeichnung; } \\
\text { StABa Kloster Langheim, } \\
\text { Urk. } 1302 \text { XI } 10 .\end{array}$ \\
\hline 1308 IV 5 & $\begin{array}{l}\text { decanus sancte Marie in Tu- } \\
\text { erstat }\end{array}$ & $\begin{array}{l}\text { Fremdbezeichnung; } \\
\text { StABa Kloster Michels- } \\
\text { berg, Urk. Nr. } 154 .\end{array}$ \\
\hline $\begin{array}{l}1308 \text { VII } \\
22\end{array}$ & $\begin{array}{l}\text { custos sancte Marie in Tuers- } \\
\text { tat }\end{array}$ & $\begin{array}{l}\text { Fremdbezeichnung; } \\
\text { StABa BU } 1432 .\end{array}$ \\
\hline $\begin{array}{l}1311 \text { VIII } \\
24\end{array}$ & $\begin{array}{l}\text { capitulum ecclesie sancte } \\
\text { Marie in Teuwerstat extra } \\
\text { muros civitatis Babenbergen- } \\
\text { ses }\end{array}$ & $\begin{array}{l}\text { Selbstbezeichnung; } \\
\text { StAWu Kloster Ebrach, } \\
\text { Urk. } 1311 \text { VIII 24/I. }\end{array}$ \\
\hline $\begin{array}{l}1311 \text { VIII } \\
24\end{array}$ & $\begin{array}{l}\text { decanus et capitulum ecclesie } \\
\text { sancte Marie in Tewerstat } \\
\text { extra muros civitatis nostre } \\
\text { Babembergenses }\end{array}$ & $\begin{array}{l}\text { Fremdbezeichnung; } \\
\text { StAWu Kloster Ebrach, } \\
\text { Urk. } 1311 \text { VIII 24/II. }\end{array}$ \\
\hline $\begin{array}{l}1311 \text { VIII } \\
26\end{array}$ & $\begin{array}{l}\text { prepositus ecclesie in Tiur- } \\
\text { stat; ecclesia in Tiurstat }\end{array}$ & $\begin{array}{l}\text { Selbstbezeichnung; } \\
\text { StAWu Kloster Ebrach, } \\
\text { Urk. } 1311 \text { VIII } 26 .\end{array}$ \\
\hline 1311 IX 18 & $\begin{array}{l}\text { decanus et capitulum ecclesie } \\
\text { in Turstat extra muros Ba- } \\
\text { bembergenses }\end{array}$ & $\begin{array}{l}\text { Fremdbezeichnung; } \\
\text { StAWu Kloster Ebrach, } \\
\text { Urk. } 1311 \text { IX } 18 . \\
\end{array}$ \\
\hline 1311 X 1 & $\begin{array}{l}\text { ecclesie sancte Marie in Tuer- } \\
\text { stat extra muros Babenber- } \\
\text { genses }\end{array}$ & $\begin{array}{l}\text { Selbstbezeichnung; } \\
\text { StAWu Kloster Ebrach, } \\
\text { Urk. } 1311 \text { X 1/I und } \\
1311 \text { X 1/II. }\end{array}$ \\
\hline
\end{tabular}




\begin{tabular}{|c|c|c|}
\hline 1312 IV 3 & $\begin{array}{l}\text { decanus ecclesie sancte Marie } \\
\text { in Theurstat prope muros } \\
\text { Bambergenses }\end{array}$ & $\begin{array}{l}\text { Fremdbezeichnung; } \\
\text { StAWu Kloster Ebrach, } \\
\text { Urk. } 1312 \text { IV } 3 .\end{array}$ \\
\hline $\begin{array}{l}1312 \text { XII } \\
22\end{array}$ & $\begin{array}{l}\text { decanus ecclesie sancte Marie } \\
\text { in Tewerstat }\end{array}$ & $\begin{array}{l}\text { Fremdbezeichnung; } \\
\text { StABa Kloster Michels- } \\
\text { berg, Urk. Nr. } 169 .\end{array}$ \\
\hline 1314 II 15 & $\begin{array}{l}\text { canonicus ecclesie sancte } \\
\text { Marie in Tewerstat }\end{array}$ & $\begin{array}{l}\text { Fremdbezeichnung; } \\
\text { StABa BU } 1582 .\end{array}$ \\
\hline 1314 III 5 & $\begin{array}{l}\text { canonicus ecclesie sancte } \\
\text { Marie in Teurstat }\end{array}$ & $\begin{array}{l}\text { Fremdbezeichnung; } \\
\text { StABa Kloster Michels- } \\
\text { berg, Urk. Nr. } 174 .\end{array}$ \\
\hline 1315 VI 11 & $\begin{array}{l}\text { canonici ecclesie sancte Marie } \\
\text { in Teurstat extra muros Bam- } \\
\text { bergenses }\end{array}$ & $\begin{array}{l}\text { Fremdbezeichnung; } \\
\text { StABa BU } 1618 .\end{array}$ \\
\hline 1317 IX 7 & $\begin{array}{l}\text { praepositus ecclesie sancte } \\
\text { Marie in Tewerstat }\end{array}$ & $\begin{array}{l}\text { Fremdbezeichnung } \\
\text { (aber Propst von St. } \\
\text { Gangolf ist Mitausstel- } \\
\text { ler); StABa BU } 1682 .\end{array}$ \\
\hline 1318 II 25 & $\begin{array}{l}\text { custos ecclesie sancte Marie } \\
\text { in Thuerstat; vicarii ecclesie in } \\
\text { Thuerstat }\end{array}$ & $\begin{array}{l}\text { Selbstbezeichnung; } \\
\text { StABa BU } 1698 .\end{array}$ \\
\hline $\begin{array}{l}1318 \text { XII } \\
13\end{array}$ & $\begin{array}{l}\text { probst des gotzhaus ze Te- } \\
\text { werstat auzzerhalb der mawer } \\
\text { der stat ze Babemberch; chor- } \\
\text { here ze Tewerstat }\end{array}$ & $\begin{array}{l}\text { Fremdbezeichnung; } \\
\text { StABa BU } 1716 .\end{array}$ \\
\hline 1324 I 24 & $\begin{array}{l}\text { sancte Marie in Teustat Bam- } \\
\text { bergensis }\end{array}$ & $\begin{array}{l}\text { Fremdbezeichnung; } \\
\text { StABa BU } 1842 .\end{array}$ \\
\hline 1324 I 29 & $\begin{array}{l}\text { prepositus ecclesie sancte } \\
\text { Marie in Tewerstat propre } \\
\text { muros Babenbergenses }\end{array}$ & $\begin{array}{l}\text { Fremdbezeichnung; } \\
\text { StABa BU } 1844 .\end{array}$ \\
\hline 1328 VI 13 & korher ze Teuerstat & $\begin{array}{l}\text { Fremdbezeichnung; } \\
\text { StABa BU } 1947 .\end{array}$ \\
\hline 1329 & custos ecclesie sancte Marie & Fremd- und Selbstbe- \\
\hline
\end{tabular}




\begin{tabular}{|c|c|c|}
\hline & $\begin{array}{l}\text { in Tewerstat extra muros } \\
\text { Bambergenses; prefate eccle- } \\
\text { sie sancte Marie in Tewerstat }\end{array}$ & $\begin{array}{l}\text { zeichnung (Vidimus); } \\
\text { StABa BU } 1988 .\end{array}$ \\
\hline $\begin{array}{l}1331 \mathrm{VII} \\
18\end{array}$ & $\begin{array}{l}\text { canonici ecclesie sancte Marie } \\
\text { in Teurstat; custodia ecclesie } \\
\text { in Teurstat }\end{array}$ & $\begin{array}{l}\text { Fremdbezeichnung; } \\
\text { StABa BU } 2060 .\end{array}$ \\
\hline $1331 \times 25$ & $\begin{array}{l}\text { custos ecclesie sancte Marie } \\
\text { in Teuerstat }\end{array}$ & $\begin{array}{l}\text { Fremdbezeichnung; } \\
\text { StABa BU } 2066 .\end{array}$ \\
\hline 1335 III 28 & $\begin{array}{l}\text { der techant und daz capitel } \\
\text { gemeine des gotsheus unser } \\
\text { vrauwen zu Teuerstat }\end{array}$ & $\begin{array}{l}\text { Selbstbezeichnung; } \\
\text { StABa BU } 2179 .\end{array}$ \\
\hline 1336 XII 9 & $\begin{array}{l}\text { ecclesie sancte Marie in Teu- } \\
\text { erstat extra muros civitatis } \\
\text { Babnbergensis; ecclesia sancte } \\
\text { Marie }\end{array}$ & $\begin{array}{l}\text { Fremdbezeichnung; } \\
\text { AEB Rep. I Pfarrei St. } \\
\text { Gangolf, U } 818 .\end{array}$ \\
\hline 1344 IV 26 & techant zuo Teurstat & $\begin{array}{l}\text { Fremdbezeichnung; } \\
\text { StABa Kloster Michels- } \\
\text { berg, Urk. Nr. } 302 .\end{array}$ \\
\hline 1344 V 19 & $\begin{array}{l}\text { cellerarius ecclesie sancte } \\
\text { Marie in Tewrstat sacerdos }\end{array}$ & $\begin{array}{l}\text { Fremdbezeichnung; } \\
\text { StABa BU } 2490 .\end{array}$ \\
\hline 1344 VIII 5 & kelner zu Tuerstat & $\begin{array}{l}\text { Fremdbezeichnung; } \\
\text { StABa BU } 2498 .\end{array}$ \\
\hline 1345 XI 28 & techant zu Thewrstat & $\begin{array}{l}\text { Fremdbezeichnung; } \\
\text { StABa BU } 2537 .\end{array}$ \\
\hline 1347 III 18 & $\begin{array}{l}\text { kelner des gotzhaus zu } \\
\text { Theurstat auzzerhalb der } \\
\text { mauern zu Babenberg }\end{array}$ & $\begin{array}{l}\text { Selbstbezeichnung; } \\
\text { StABa BU } 2583 .\end{array}$ \\
\hline $\begin{array}{l}1348 \text { XII } \\
20\end{array}$ & $\begin{array}{l}\text { canonicus ecclesie sancte } \\
\text { Marie in Tewerstat extra mu- } \\
\text { ros Babenbergenses }\end{array}$ & $\begin{array}{l}\text { Selbstbezeichnung; } \\
\text { StABa BU } 2636 .\end{array}$ \\
\hline 1349 IV 3 & $\begin{array}{l}\text { korhere zu sant Gangolf zu } \\
\text { Teurstat zu Babenberch }\end{array}$ & $\begin{array}{l}\text { Selbstbezeichnung; } \\
\text { StABa BU } 2651 .\end{array}$ \\
\hline 1349 XI 23 & kelner und richter in der & Fremdbezeichnung; \\
\hline
\end{tabular}




\begin{tabular}{|c|c|c|}
\hline & $\begin{array}{l}\text { muntat ze sant Gangolf zu } \\
\text { Tuerstat }\end{array}$ & StABa BU 2670. \\
\hline $\begin{array}{l}1353 \text { VIII } \\
12\end{array}$ & $\begin{array}{l}\text { das gerichte zu Teuerstat; } \\
\text { unterrichter zu Teuerstat }\end{array}$ & $\begin{array}{l}\text { Fremdbezeichnung; } \\
\text { StABa BU } 2806 .\end{array}$ \\
\hline 1356 XI 16 & $\begin{array}{l}\text { ecclesia sancte Marie in Teur- } \\
\text { stat extra muros Bambergen- } \\
\text { ses }\end{array}$ & $\begin{array}{l}\text { Fremdbezeichnung; } \\
\text { StABa BU } 2913 .\end{array}$ \\
\hline 1356 XII 5 & $\begin{array}{l}\text { kelner und auch rihter in der } \\
\text { muntat zu Tewerstat }\end{array}$ & $\begin{array}{l}\text { Selbstbezeichnung; AEB } \\
\text { Rep. I Pfarrei St. Martin, } \\
\text { U } 2 \text {. }\end{array}$ \\
\hline $1360 \mathrm{~V} 18$ & $\begin{array}{l}\text { kelner und auch richter in der } \\
\text { muntat zu Tewerstat }\end{array}$ & $\begin{array}{l}\text { Selbstbezeichnung; } \\
\text { StABa BU } 3075 .\end{array}$ \\
\hline 1364 IV 21 & $\begin{array}{l}\text { techant zu unser frawen } \mathrm{zu} \\
\text { Tewerstat }\end{array}$ & $\begin{array}{l}\text { Fremdbezeichnung; } \\
\text { StABa BU } 3240 .\end{array}$ \\
\hline 1371 IV 28 & $\begin{array}{l}\text { chorher zu Tewerstat auzzer- } \\
\text { halben der maur ze Bamberg }\end{array}$ & $\begin{array}{l}\text { Selbstbezeichnung; } \\
\text { StABa BU } 3501 .\end{array}$ \\
\hline 1374 V 15 & $\begin{array}{l}\text { chorher und kelner ze unser } \\
\text { frawen zu Tewerstat und rih- } \\
\text { ter in der muntat }\end{array}$ & $\begin{array}{l}\text { Selbstbezeichnung; AEB } \\
\text { Rep. I Pfarrei St. Martin, } \\
\text { U } 4 .\end{array}$ \\
\hline 1376 XII 4 & stift zu Teurstat & $\begin{array}{l}\text { Fremdbezeichnung; } \\
\text { StABa BU } 3726 .\end{array}$ \\
\hline $\begin{array}{l}1387 \text { V } 25 \\
\text { (Abschrift) }\end{array}$ & $\begin{array}{l}\text { vicareyen zu Teuerstat in un- } \\
\text { ser lieben frawen munster }\end{array}$ & $\begin{array}{l}\text { Fremdbezeichnung; } \\
\text { StABa A } 120 \text { L } 134 \text { Nr. } \\
922 .\end{array}$ \\
\hline 1390 VIII 5 & $\begin{array}{l}\text { canonici et vicarii beate Marie } \\
\text { in Tewerstat; decanus et capi- } \\
\text { tulum beate Marie in Tewers- } \\
\text { tat; sancte Marie in Tewrstat } \\
\text { canonicus }\end{array}$ & $\begin{array}{l}\text { Fremdbezeichnung; } \\
\text { StABa BU } 4261 .\end{array}$ \\
\hline 1391 IV 23 & $\begin{array}{l}\text { chorher und oberster kelner } \\
\text { des stifts zu unser liben fra- } \\
\text { wen zu Tewerstat auzzerhalb } \\
\text { der mawer der stat }\end{array}$ & $\begin{array}{l}\text { Selbstbezeichnung; } \\
\text { StABa BU } 4287 .\end{array}$ \\
\hline
\end{tabular}




\begin{tabular}{|c|c|c|}
\hline $\begin{array}{l}1395 \text { VIII } \\
23\end{array}$ & $\begin{array}{l}\text { Nycolaus sancte Marie in } \\
\text { Tewerstat }\end{array}$ & $\begin{array}{l}\text { Fremdbezeichnung } \\
\text { (aber Stift St. Gangolf ist } \\
\text { Mitaussteller); StABa BU } \\
4488 .\end{array}$ \\
\hline $\begin{array}{l}1398 \mathrm{VII} \\
12\end{array}$ & probst zu Tewerstat & $\begin{array}{l}\text { Fremdbezeichnung; } \\
\text { StABa KLangheimU } \\
1398 \text { VII } 12 .\end{array}$ \\
\hline 1398 XI 27 & $\begin{array}{l}\text { praepositus sancte Marie in } \\
\text { Teurstad }\end{array}$ & $\begin{array}{l}\text { Fremdbezeichnung; } \\
\text { StABa BU } 4665 .\end{array}$ \\
\hline 1399 I 27 & $\begin{array}{l}\text { korherre und oberster kelner } \\
\text { dez stiftz zu unser liben fra- } \\
\text { wen zu Tewrstad auzzerhal- } \\
\text { ben der mawr der stat zu } \\
\text { Bamberg und richter an der } \\
\text { muntat daselbst }\end{array}$ & $\begin{array}{l}\text { Selbstbezeichnung; } \\
\text { SttABa A } 21 \text { 27-01-1399. }\end{array}$ \\
\hline 1399 III 17 & $\begin{array}{l}\text { korherre und oberster kelner } \\
\text { dez stifts zu unser liben fra- } \\
\text { wen zu Tewerstat auzzerhalb } \\
\text { der mauer der stat zu Bam- } \\
\text { berg }\end{array}$ & $\begin{array}{l}\text { Fremdbezeichnung; } \\
\text { StABa BU } 4693 .\end{array}$ \\
\hline 1400 I 17 & $\begin{array}{l}\text { probst ze Tewrstat; techant zu } \\
\text { Tewrstat }\end{array}$ & $\begin{array}{l}\text { Selbstbezeichnung; } \\
\text { StABa Kloster Michels- } \\
\text { berg, Urk. Nr. } 605 .\end{array}$ \\
\hline $1400 \times 18$ & $\begin{array}{l}\text { chorherr und oberster kelner } \\
\text { des stiftz zu unser liben fra- } \\
\text { wen zu Tewerstat auzzerhal- } \\
\text { ben der mawer der stat zu } \\
\text { Bamberg und richter in der } \\
\text { muntat daselbst }\end{array}$ & $\begin{array}{l}\text { Selbstbezeichnung; } \\
\text { StABa BU } 4766 .\end{array}$ \\
\hline 1401 VII 4 & $\begin{array}{l}\text { chorher und oberster kelner } \\
\text { des stifts zu unser liben fra- } \\
\text { wen zu Tewerstat auserhalben } \\
\text { der mawer der stat zu Bam- }\end{array}$ & $\begin{array}{l}\text { Selbstbezeichnung; AEB } \\
\text { Rep. I Pfarrei St. Martin, } \\
\text { U } 16 .\end{array}$ \\
\hline
\end{tabular}




\begin{tabular}{|c|c|c|}
\hline & $\begin{array}{l}\text { berg und richter in der muntat } \\
\text { daselbst }\end{array}$ & \\
\hline 1402 III 6 & $\begin{array}{l}\text { chorher und oberster kelner } \\
\text { des stifts zu unser liben fra- } \\
\text { wen zu Tewerstat auserhalben } \\
\text { der mawer der stat zu Bam- } \\
\text { berg und richter in der muntat } \\
\text { daselbst }\end{array}$ & $\begin{array}{l}\text { Selbstbezeichnung; } \\
\text { SttABa A } 21 \text { 06-03-1402. }\end{array}$ \\
\hline 1403 XI 26 & $\begin{array}{l}\text { chorher und oberster kelner } \\
\text { des stifts zu unser liben fra- } \\
\text { wen zu Tewerstat auserhalben } \\
\text { der mawer der stat zu Bam- } \\
\text { berg und richter in der muntat } \\
\text { daselbst }\end{array}$ & $\begin{array}{l}\text { Selbstbezeichnung; AEB } \\
\text { Rep. I Pfarrei St. Martin, } \\
\text { U } 17 .\end{array}$ \\
\hline $\begin{array}{l}1406 \text { VIII } \\
28\end{array}$ & $\begin{array}{l}\text { techant und daz gemein capi- } \\
\text { tel zu unser lieben frawen zu } \\
\text { Tewerstat }\end{array}$ & $\begin{array}{l}\text { Selbstbezeichnung; } \\
\text { StABa Kloster Langheim, } \\
\text { Urk. } 1406 \text { VIII } 28 .\end{array}$ \\
\hline $\begin{array}{l}1406 \text { XII } \\
20\end{array}$ & $\begin{array}{l}\text { korher und oberster kelner } \\
\text { des stifts zu unser liben fra- } \\
\text { wen zu Tewerstat auserhalb } \\
\text { der mawer der stat zu Bam- } \\
\text { berg und richter in der muntat } \\
\text { daselbst }\end{array}$ & $\begin{array}{l}\text { Selbstbezeichnung; AEB } \\
\text { Rep. I Pfarrei St. Martin, } \\
\text { U } 18 .\end{array}$ \\
\hline 1408 V 21 & $\begin{array}{l}\text { chorher und oberster kelner } \\
\text { dez stifts zu unser lieben fra- } \\
\text { wen zu Tewerstat auserhalben } \\
\text { der mawer der stat zu Bam- } \\
\text { berg und rihter in der muntat } \\
\text { da selbst; vicarier zu unser } \\
\text { lieben frawen zu Tewerstat }\end{array}$ & $\begin{array}{l}\text { Selbstbezeichnung; AEB } \\
\text { Rep. I Pfarrei St. Ger- } \\
\text { traud, U } 97\end{array}$ \\
\hline 1415 III 1 & $\begin{array}{l}\text { chorher und oberster kelner } \\
\text { des stifts zu unser lieben fra- } \\
\text { wen zu Tewerstat auswendig }\end{array}$ & $\begin{array}{l}\text { Selbstbezeichnung; } \\
\text { StABa Kloster Michels- } \\
\text { berg, Urk. Nr. } 663 .\end{array}$ \\
\hline
\end{tabular}




\begin{tabular}{|c|c|c|}
\hline & $\begin{array}{l}\text { der mawer der stat zu Bam- } \\
\text { berg }\end{array}$ & \\
\hline 1415 V 24 & probstey gein Teuerstatt & $\begin{array}{l}\text { Fremdbezeichnung; } \\
\text { StABa A } 120 \text { L } 134 \text { Nr. } \\
919 .\end{array}$ \\
\hline $\begin{array}{l}1415 \mathrm{VII} \\
15\end{array}$ & $\begin{array}{l}\text { stift unser liben frawen zu } \\
\text { Tewerstat zu Babenberg; } \\
\text { probst dez stiftes unser liben } \\
\text { frawen zu Tewerstat zu Bam- } \\
\text { berg }\end{array}$ & $\begin{array}{l}\text { Fremdbezeichnung; } \\
\text { StABa A } 120 \text { L } 134 \text { Nr. } \\
902 .\end{array}$ \\
\hline 1416 I 7 & $\begin{array}{l}\text { chorher und oberster kelner } \\
\text { des stifts zu unser liben fra- } \\
\text { wen zu Tewerstat ausserhal- } \\
\text { ben der mawer der stat zu } \\
\text { Bamberg und richter in der } \\
\text { muntat daselbst }\end{array}$ & $\begin{array}{l}\text { Selbstbezeichnung; } \\
\text { SttABa A } 21 \text { 07-01-1416. }\end{array}$ \\
\hline $\begin{array}{l}1419 \text { VII } \\
31\end{array}$ & $\begin{array}{l}\text { chorher und oberster kelner } \\
\text { dez stifts zu unser liben fra- } \\
\text { wen zu Tewerstat ausserhal- } \\
\text { ben der mawer der stat zu } \\
\text { Bamberg und rihter in der } \\
\text { muntat da selbst }\end{array}$ & $\begin{array}{l}\text { Selbstbezeichnung; AEB } \\
\text { Rep. I Pfarrei St. Ger- } \\
\text { traud, U } 98 .\end{array}$ \\
\hline 1419 & $\begin{array}{l}\text { chorher unde oberster kelner } \\
\text { dez stifts zu unser liben fra- } \\
\text { wen zu Tewerstat ausserhal- } \\
\text { ben der mawer der stat zu } \\
\text { Bamberg und rihter in der } \\
\text { muntat da selbst }\end{array}$ & $\begin{array}{l}\text { Selbstbezeichnung; AEB } \\
\text { Rep. I Pfarrei St. Ger- } \\
\text { traud, U } 99 .\end{array}$ \\
\hline 1420 XII 9 & $\begin{array}{l}\text { chorherre und oberster kelner } \\
\text { des styfts zu unser lieben } \\
\text { frauwen zu Tewerstat aus- } \\
\text { erhalben der mawer der stat } \\
\text { zu Bambergk und richter in }\end{array}$ & $\begin{array}{l}\text { Selbstbezeichnung; } \\
\text { SttABa A } 21 \text { 09-12-1420. }\end{array}$ \\
\hline
\end{tabular}




\begin{tabular}{|c|c|c|}
\hline & der muntat daselbest & \\
\hline 1423 VI 15 & $\begin{array}{l}\text { praepositus ecclesie beate } \\
\text { Marie in Teurstat extra muros } \\
\text { Bambergenses }\end{array}$ & $\begin{array}{l}\text { Fremdbezeichnung; } \\
\text { StABa Kloster Michels- } \\
\text { berg, Urk. Nr. } 970 .\end{array}$ \\
\hline 1424 IV 9 & $\begin{array}{l}\text { korherre und oberster kelner } \\
\text { des stiftes zu unser liben } \\
\text { frauwen zu Tewerstat aus- } \\
\text { erhalben der mawer der stat } \\
\text { zu Bamberg und richter in der } \\
\text { muntat daselbest }\end{array}$ & $\begin{array}{l}\text { Selbstbezeichnung; } \\
\text { StABa A } 120 \text { L } 131 \text { Nr. } \\
750 .\end{array}$ \\
\hline 1428 I 12 & $\begin{array}{l}\text { techant des stifts unserer lie- } \\
\text { ben frawen zu Tewerstat }\end{array}$ & $\begin{array}{l}\text { Fremdbezeichnung; } \\
\text { StABa Kloster Michels- } \\
\text { berg, Urk. Nr. } 704 .\end{array}$ \\
\hline 1434 III 19 & $\begin{array}{l}\text { chorheren zu unser lieben } \\
\text { frawen zu Tewerstat }\end{array}$ & $\begin{array}{l}\text { Fremdbezeichnung; } \\
\text { StABa Kloster Michels- } \\
\text { berg, Urk. Nr. } 733 .\end{array}$ \\
\hline 1434 XI 3 & $\begin{array}{l}\text { brobste des stiftes unser lie- } \\
\text { ben frawen zu Teuerstat bey } \\
\text { Bamberg }\end{array}$ & $\begin{array}{l}\text { Fremdbezeichnung; } \\
\text { StABa A } 120 \text { L } 133 \text { Nr. } \\
870 .\end{array}$ \\
\hline 1435 XI 22 & $\begin{array}{l}\text { techand unser liben frawen } \\
\text { stifts zu Teurstat }\end{array}$ & $\begin{array}{l}\text { Selbstbezeichnung; } \\
\text { StABa A } 120 \text { L } 133 \text { Nr. } \\
871 .\end{array}$ \\
\hline 1436 I 23 & $\begin{array}{l}\text { brobst des stiftes unser lieben } \\
\text { frawen zu Teurstat bey Bam- } \\
\text { berg }\end{array}$ & $\begin{array}{l}\text { Selbstbezeichnung; } \\
\text { StABa Kloster Michels- } \\
\text { berg, Urk. Nr. } 738 .\end{array}$ \\
\hline 1436 I 23 & $\begin{array}{l}\text { probste des stiftes unserer } \\
\text { lieben frawen zu Teurstat bey } \\
\text { Bamberg }\end{array}$ & $\begin{array}{l}\text { Selbstbezeichnung; } \\
\text { StABa Kloster Langheim, } \\
\text { Urk. } 1436 \text { I } 23 .\end{array}$ \\
\hline 1436 XI 12 & $\begin{array}{l}\text { brobste des stiftes unser lie- } \\
\text { ben frawen zu Teurstat bey } \\
\text { Bamberg }\end{array}$ & $\begin{array}{l}\text { Fremdbezeichnung; } \\
\text { StABa A } 120 \text { L } 133 \text { Nr. } \\
872 \text { und Nr. } 873 .\end{array}$ \\
\hline $\begin{array}{l}1437 \text { VII } \\
28\end{array}$ & $\begin{array}{l}\text { probste des stiftes unser lie- } \\
\text { ben frawen zu Tewerstat bey }\end{array}$ & $\begin{array}{l}\text { Fremdbezeichnung; } \\
\text { StABa A } 120 \text { L } 134 \text { Nr. }\end{array}$ \\
\hline
\end{tabular}




\begin{tabular}{|c|c|c|}
\hline & Bamberg & 906. \\
\hline 1439 VI 1 & $\begin{array}{l}\text { chorher und oberster kellner } \\
\text { des stifts zu unser liben fra- } \\
\text { wen zu Tewerstat auserhalben } \\
\text { der mauer der stat zu Bam- } \\
\text { berg und richter in der muntat } \\
\text { daselbst }\end{array}$ & $\begin{array}{l}\text { Selbstbezeichnung; AEB } \\
\text { Rep. I Pfarrei St. Ger- } \\
\text { traud, U } 101 .\end{array}$ \\
\hline 1439 VI 3 & $\begin{array}{l}\text { corherre } \mathrm{zu} \text { unser liben fra- } \\
\text { wen } \mathrm{zu} \text { Tewrstat auswendig } \\
\text { der statmawer } \mathrm{zu} \text { Bamberg; } \\
\text { gemein capitel desselben sif- } \\
\text { tes } \mathrm{zu} \text { unser liben frawen zu } \\
\text { Tewrstat }\end{array}$ & $\begin{array}{l}\text { Selbstbezeichnung; } \\
\text { StABa A } 120 \text { L } 131 \text { Nr. } \\
721 .\end{array}$ \\
\hline 1439 IX 25 & $\begin{array}{l}\text { chorherre des stiftes unser } \\
\text { lieben frawen zu Tewrstat bey } \\
\text { Bamberg }\end{array}$ & $\begin{array}{l}\text { Selbstbezeichnung; } \\
\text { StABa Kloster Langheim, } \\
\text { Urk. } 1439 \text { IX } 25 .\end{array}$ \\
\hline 1440 II 3 & $\begin{array}{l}\text { chorher und oberster kelner } \\
\text { des stifts zu unser liben fra- } \\
\text { wen } \mathrm{zu} \text { Tewerstat ausserhal- } \\
\text { ben der mauer der stat zu } \\
\text { Bamberg und richter in der } \\
\text { muntat daselbst }\end{array}$ & $\begin{array}{l}\text { Selbstbezeichnung; } \\
\text { SttABa A } 21 \text { 03-02-1440. }\end{array}$ \\
\hline 1440 IV 4 & $\begin{array}{l}\text { chorher und oberster kelner } \\
\text { des stifts zu unser liben fra- } \\
\text { wen zu Tewerstat ausserthalbe } \\
\text { der mawer der stat zu Bam- } \\
\text { berg und richter in der muntat } \\
\text { daselbst }\end{array}$ & $\begin{array}{l}\text { Selbstbezeichnung; AEB } \\
\text { Rep. I Pfarrei St. Ger- } \\
\text { traud, U } 102 .\end{array}$ \\
\hline $1440 \mathrm{~V} 9$ & $\begin{array}{l}\text { chorher und oberster kelner } \\
\text { des stifts zu unser liben fra- } \\
\text { wen zu Tewerstat ausserthal- } \\
\text { ben der mawer der stat zu } \\
\text { Bamberg und richter in der }\end{array}$ & $\begin{array}{l}\text { Selbstbezeichnung; AEB } \\
\text { Rep. I Pfarrei St. Ger- } \\
\text { traud, U } 103 .\end{array}$ \\
\hline
\end{tabular}




\begin{tabular}{|l|l|l|}
\hline & $\begin{array}{l}\text { muntat daselbst; des genanten } \\
\text { stifts zu unser liben frawen zu } \\
\text { Tewerstat }\end{array}$ & \\
\hline 1442 VI 4 & $\begin{array}{l}\text { chorher und oberster kelner } \\
\text { des stifts unser liben frawen } \\
\text { zu Tewerstat ausserthalben } \\
\text { der mawer der stat zu Bam- } \\
\text { berg und richter in der muntat } \\
\text { daselbst }\end{array}$ & $\begin{array}{l}\text { Selbstbezeichnung; AEB } \\
\text { Rep. I Pfarrei St. Ger- } \\
\text { traud, U 104. }\end{array}$ \\
\hline 1443 X 21 & $\begin{array}{l}\text { chorher und oberster kellner } \\
\text { dez stifts unser lieben frawen } \\
\text { zu Tewerstat ausserhalben der } \\
\text { mawer der stat zu Bamberg } \\
\text { und richter in der muntat } \\
\text { daselbenst }\end{array}$ & $\begin{array}{l}\text { Selbstbezeichnung; AEB } \\
\text { Rep. I Pfarrei St. Ger- } \\
\text { traud, U 105. }\end{array}$ \\
\hline 1444 XII 2 & $\begin{array}{l}\text { capitulum ecclesie beate Ma- } \\
\text { rie in Tewrstat extra muros } \\
\text { civitatis nostre Bambergensis }\end{array}$ & $\begin{array}{l}\text { Fremdbezeichnung; } \\
\text { StABa A 120 L 131 Nr. } \\
\text { 722. }\end{array}$ \\
\hline 1445 VI 14 & $\begin{array}{l}\text { stieft unser lieben frawen } \\
\text { kirchen zu Tewrstat bey unser } \\
\text { stat Bamberg; probstey zu } \\
\text { Tewrstat; capitel zu Tewrstat; } \\
\text { stieft zu Tewrstat }\end{array}$ & $\begin{array}{l}\text { Fremdbezeichnung; } \\
\text { StABa A 120 L 133 Nr. } \\
\text { 874. }\end{array}$ \\
\hline probste zu unser lieben fra- \\
wen zu Tewerstat pey Bam- \\
berg
\end{tabular}




\begin{tabular}{|c|c|c|}
\hline & $\begin{array}{l}\text { des stiffts unser lieben frawen } \\
\text { zu Tewerstat ausserhalben der } \\
\text { mawer der stat zu Bamberg } \\
\text { und richter in der muntat } \\
\text { daselbenst }\end{array}$ & $\begin{array}{l}\text { StABa A } 120 \text { L } 131 \text { Nr. } \\
751 .\end{array}$ \\
\hline 1447 VI 3 & brobst zu Teurstat & $\begin{array}{l}\text { Fremdbezeichnung; } \\
\text { StABa A } 120 \text { L } 131 \text { Nr. } \\
752 .\end{array}$ \\
\hline 1448 I 25 & $\begin{array}{l}\text { chorherre und oberster kelner } \\
\text { des stifts unser lieben frawen } \\
\text { zu Tewrstat auserhalb der } \\
\text { mawer der stat Bamberg und } \\
\text { richter in der muntat daselbst }\end{array}$ & $\begin{array}{l}\text { Selbstbezeichnung; } \\
\text { SttABa A } 21 \text { 25-01-1448. }\end{array}$ \\
\hline $1448 \times 7$ & $\begin{array}{l}\text { probst unser lieben frawen } \\
\text { stieftes zu Tewerstat bey unser } \\
\text { stad Bamberg }\end{array}$ & $\begin{array}{l}\text { Fremdbezeichnung; } \\
\text { StABa A } 120 \text { L } 133 \text { Nr. } \\
851 .\end{array}$ \\
\hline $\begin{array}{l}1449 \text { VIII } \\
18\end{array}$ & $\begin{array}{l}\text { chorherr und oberster kelner } \\
\text { des stifts zu unser lieben } \\
\text { frawn zu Theurstat ausserhal- } \\
\text { ben der maur der stat zu } \\
\text { Bamberg und richter in der } \\
\text { munthat doselbst }\end{array}$ & $\begin{array}{l}\text { Selbstbezeichnung; AEB } \\
\text { Rep. I Pfarrei St. Ger- } \\
\text { traud, U } 108 .\end{array}$ \\
\hline $\begin{array}{l}1449 \text { VIII } \\
20\end{array}$ & $\begin{array}{l}\text { ecclesie beate Marie in Tewrs- } \\
\text { tat extra muros Bambergenses }\end{array}$ & $\begin{array}{l}\text { Fremdbezeichnung; } \\
\text { AEB Rep. I Pfarrei St. } \\
\text { Gangolf, U } 820 .\end{array}$ \\
\hline 1449 XI 8 & stifte zu Tewrstad & $\begin{array}{l}\text { Fremdbezeichnung; } \\
\text { StABa A } 120 \text { L } 131 \text { Nr. } \\
753 .\end{array}$ \\
\hline 1449 XI 17 & $\begin{array}{l}\text { stift zu unser lieben frawen } \\
\text { zu Teurstat auswendig unnser } \\
\text { stat Bamberg; capitel zu Teur- } \\
\text { stat }\end{array}$ & $\begin{array}{l}\text { Fremdbezeichnung; } \\
\text { StABa A } 120 \text { L } 133 \text { Nr. } \\
876 .\end{array}$ \\
\hline 1452 III 20 & chorherr und obirster kelner & Selbstbezeichnung; \\
\hline
\end{tabular}




\begin{tabular}{|c|c|c|}
\hline & $\begin{array}{l}\text { des stifts zu unser lieben } \\
\text { frawn und sanct Gangolfs } \\
\text { kirchen zu Teurstat asserhal- } \\
\text { ben der mawrn der stat zu } \\
\text { Bamberg und richter in der } \\
\text { munthat doselbst }\end{array}$ & SttABa A 21 20-03-1452. \\
\hline $\begin{array}{l}1452 \text { VII } \\
28\end{array}$ & $\begin{array}{l}\text { corher des stiefts unserer } \\
\text { frawen zu Tewerstad in unser } \\
\text { stad Bamberg }\end{array}$ & $\begin{array}{l}\text { Fremdbezeichnung; } \\
\text { StABa A } 120 \text { L } 131 \text { Nr. } \\
755 .\end{array}$ \\
\hline $\begin{array}{l}1452 \text { VIII } \\
14\end{array}$ & $\begin{array}{l}\text { probst des wirdigen stifts zu } \\
\text { sant Gangolf zu Tewrstat pei } \\
\text { Bamberg }\end{array}$ & $\begin{array}{l}\text { Fremdbezeichnung; } \\
\text { StABa A } 120 \text { L } 133 \text { Nr. } \\
877 .\end{array}$ \\
\hline $\begin{array}{l}1453 \mathrm{VII} \\
30\end{array}$ & $\begin{array}{l}\text { corher und oberster kellner } \\
\text { des stifts unser liben frawen } \\
\text { zu Tewerstat ausserhalben der } \\
\text { mawer der stat zu Bamberg } \\
\text { und richter in der muntat } \\
\text { daselbst }\end{array}$ & $\begin{array}{l}\text { Selbstbezeichnung; } \\
\text { StABa A } 120 \text { L } 131 \text { Nr. } \\
754 .\end{array}$ \\
\hline 1453 XI 12 & $\begin{array}{l}\text { corher und oberster kellner } \\
\text { des stifts unser lieben frawen } \\
\text { zu Tewerstat ausserhalben der } \\
\text { mawer der stat zu Bamberg } \\
\text { und richter in der muntat } \\
\text { daselbst }\end{array}$ & $\begin{array}{l}\text { Selbstbezeichnung; AEB } \\
\text { Rep. I Pfarrei St. Ger- } \\
\text { traud, U } 109 .\end{array}$ \\
\hline 1456 IX 22 & $\begin{array}{l}\text { dechant und der herr des } \\
\text { capitels gemeniglich des stifts } \\
\text { unser lieben frauen und sanct } \\
\text { Gangolf zu Teuerstatt bey } \\
\text { Bamberg; dechant und das } \\
\text { gantz capitel gemeniglich des } \\
\text { stifts unser lieben frauen und } \\
\text { sanct Gangolph zu Teuerstatt } \\
\text { bey der statt Bamberg }\end{array}$ & $\begin{array}{l}\text { Fremdbezeichnung; } \\
\text { StABa A } 120 \text { L } 131 \text { Nr. } \\
756 .\end{array}$ \\
\hline
\end{tabular}




\begin{tabular}{|c|c|c|}
\hline 1458 II 20 & $\begin{array}{l}\text { corherr und oberster kellner } \\
\text { des stifts unser lieben frawen } \\
\text { zu Tewerstat bey Bamberg } \\
\text { gelegen und richter in der } \\
\text { muntat daselbst }\end{array}$ & $\begin{array}{l}\text { Selbstbezeichnung; } \\
\text { SttABa A } 21 \text { 20-02-1458. }\end{array}$ \\
\hline 1463 IV 27 & $\begin{array}{l}\text { sancti Gangolfi in Dewerstat } \\
\text { Bambergensis }\end{array}$ & $\begin{array}{l}\text { Fremdbezeichnung; } \\
\text { StAWu Kloster St. Ste- } \\
\text { phan Würzburg, Urk. } \\
452 .\end{array}$ \\
\hline 1466 V 30 & $\begin{array}{l}\text { dechant und das capitel ge- } \\
\text { meiniglich des stifts unser } \\
\text { lieben frauen zu Teurstat } \\
\text { auswendig der stadmaurn } \\
\text { Bamberg }\end{array}$ & $\begin{array}{l}\text { Selbstbezeichnung; } \\
\text { StABa A } 120 \text { L } 131 \text { Nr. } \\
724 .\end{array}$ \\
\hline 1466 VI 16 & $\begin{array}{l}\text { probst des stifts unser liben } \\
\text { frawen und sant Gangolfs zu } \\
\text { Tewerstat in unser stat Bam- } \\
\text { berg }\end{array}$ & $\begin{array}{l}\text { Fremdbezeichung; StA- } \\
\text { Ba A } 120 \text { L } 131 \text { Nr. } 757 .\end{array}$ \\
\hline 1466 XI 11 & $\begin{array}{l}\text { techant und das gemeyn capi- } \\
\text { tel des stifts unser liben frau- } \\
\text { en zu Teuerstat auserhalben } \\
\text { der statmauern Bambergs }\end{array}$ & $\begin{array}{l}\text { Selbstbezeichnung; } \\
\text { StABa A } 120 \text { L } 131 \text { Nr. } \\
758 .\end{array}$ \\
\hline $\begin{array}{l}1468 \text { VIII } \\
22\end{array}$ & $\begin{array}{l}\text { probst des stifts unser lieben } \\
\text { frauwen und sant Gangolfs zu } \\
\text { Teuwerstadt; capitel des stifts } \\
\text { unser lieben frauwen zu Te- } \\
\text { werstat }\end{array}$ & $\begin{array}{l}\text { Selbstbezeichnung; } \\
\text { StABa A } 120 \text { L } 133 \text { Nr. } \\
879 .\end{array}$ \\
\hline $\begin{array}{l}1468 \text { VIII } \\
24\end{array}$ & $\begin{array}{l}\text { probst des stifts unser lieben } \\
\text { frauwen und sant Gangolfs zu } \\
\text { Tewerstadt bey Bamberg; stift } \\
\text { zu Tewerstat }\end{array}$ & $\begin{array}{l}\text { Selbstbezeichnung; } \\
\text { StABa A } 120 \text { L } 120 \text { Nr. } \\
878 .\end{array}$ \\
\hline 1468 XI 19 & $\begin{array}{l}\text { ecclesia collegiata beate Marie } \\
\text { virginis in Thewerstadt }\end{array}$ & $\begin{array}{l}\text { Fremdbezeichnung; } \\
\text { StABa A } 120 \text { L } 135 \text { Nr. }\end{array}$ \\
\hline
\end{tabular}




\begin{tabular}{|c|c|c|}
\hline & & 1016. \\
\hline 1470 & $\begin{array}{l}\text { ecclesia beate Marie virginis } \\
\text { in Tewerstat extra muros dicte } \\
\text { civitate Bamberg }\end{array}$ & $\begin{array}{l}\text { Fremdbezeichnung; } \\
\text { AEB Rep. I Pfarrei St. } \\
\text { Gertraud, U } 111 .\end{array}$ \\
\hline 1470 I 5 & $\begin{array}{l}\text { decanus ecclesie beate Marie } \\
\text { virginis in Tewrstat extra mu- } \\
\text { ros Bambergenses; ecclesia } \\
\text { beate Marie in Tewrstat; eccle- } \\
\text { sia beate virginis in Tewrstat }\end{array}$ & $\begin{array}{l}\text { Selbstbezeichnung; } \\
\text { StAWu WU 65/27. }\end{array}$ \\
\hline 1472 XI 6 & $\begin{array}{l}\text { probst des stifts unser liben } \\
\text { frawen und sant Ganngolfs zu } \\
\text { Tewerstat auswendig der ma- } \\
\text { wer unser stat Bamberg }\end{array}$ & $\begin{array}{l}\text { Fremdbezeichnung; } \\
\text { StABa A } 120 \text { L } 133 \text { Nr. } \\
880 .\end{array}$ \\
\hline 1474 V 21 & $\begin{array}{l}\text { brobst unser liben frawen } \\
\text { und sant Gangolfs zu Thewer- } \\
\text { stat bey Bamberg; probstey } \\
\text { unser lieben frawen und sant } \\
\text { Gangolfs }\end{array}$ & $\begin{array}{l}\text { Fremdbezeichnung; } \\
\text { StABa A } 120 \text { L } 133 \text { Nr. } \\
881 .\end{array}$ \\
\hline $\begin{array}{l}1474 \text { XII } \\
26\end{array}$ & $\begin{array}{l}\text { stift unser lieben frawen } \mathrm{zu} \\
\text { Thewerstat aushalben der stat } \\
\text { mawern zu Bambergk }\end{array}$ & $\begin{array}{l}\text { Selbstbezeichnung; } \\
\text { StABa A } 120 \text { L } 134 \text { Nr. } \\
936 .\end{array}$ \\
\hline 1475 VI 19 & $\begin{array}{l}\text { chorherr und oberster kellner } \\
\text { des stifts unserer lieben fra- } \\
\text { wen und sandt Gangolfs zu } \\
\text { Teurstat ausserhalben der } \\
\text { statmauern bey Bamberg und } \\
\text { richter in der muntat daselbst }\end{array}$ & $\begin{array}{l}\text { Selbstbezeichnung; } \\
\text { StABa A } 120 \text { L } 131 \text { Nr. } \\
760 .\end{array}$ \\
\hline 1477 IV 14 & $\begin{array}{l}\text { oberster kellner des stifts } \\
\text { unser lieben frawen und sandt } \\
\text { Gangolfs zu Teurstat aus- } \\
\text { serhalb der statmaurn bey } \\
\text { Bamberg und richter in der } \\
\text { muntat daselbst }\end{array}$ & $\begin{array}{l}\text { Selbstbezeichnung; AEB } \\
\text { Rep. I Pfarrei Unserer } \\
\text { lieben Frau, U } 114 .\end{array}$ \\
\hline
\end{tabular}




\begin{tabular}{|c|c|c|}
\hline 1479 III 16 & $\begin{array}{l}\text { prepositus ecclesie beate Ma- } \\
\text { rie virginis in Teuerstat Bam- } \\
\text { bergensis diocesis }\end{array}$ & $\begin{array}{l}\text { Fremdbezeichnung; } \\
\text { StABa A } 120 \text { L } 131 \text { Nr. } \\
725 .\end{array}$ \\
\hline $\begin{array}{l}1479 \text { VIII } \\
19\end{array}$ & zu sant Gangolf corherr & $\begin{array}{l}\text { Fremdbezeichnung; } \\
\text { StABa Kloster Michels- } \\
\text { berg, Urk. Nr. } 1227 .\end{array}$ \\
\hline 1489 III 16 & $\begin{array}{l}\text { chorher und oberster kelner } \\
\text { des stifts unser lieben frawen } \\
\text { und sant Gangolfs zu Tewrstat } \\
\text { ausserhalben der statmaurn } \\
\text { bei Bamberg richter in der } \\
\text { muntat doselbst und dersel- } \\
\text { ben kelnereimuntatgerichts }\end{array}$ & $\begin{array}{l}\text { Selbstbezeichnung; } \\
\text { StABa Kloster Michels- } \\
\text { berg, Urk. Nr. } 1412 .\end{array}$ \\
\hline 1489 VI 1 & $\begin{array}{l}\text { dechant des stifts unser lie- } \\
\text { ben frawen zu Tewerstat aus- } \\
\text { serhalb Bamberg gelegen zu } \\
\text { sandt Gangolf gnant }\end{array}$ & $\begin{array}{l}\text { Selbstbezeichnung; } \\
\text { StABa Kloster Michels- } \\
\text { berg, Urk. Nr. } 1419 .\end{array}$ \\
\hline 1491 V 2 & $\begin{array}{l}\text { chorhere und oberster kellner } \\
\text { des stifts unser lieben frawen } \\
\text { und sant Gangolfs zu Tewers- } \\
\text { tat ausserhalb der statmauern } \\
\text { bey Bamberg richter in der } \\
\text { muntat doselbst }\end{array}$ & $\begin{array}{l}\text { Selbstbezeichnung; } \\
\text { SttABa A } 21 \text { 02-05-1491. }\end{array}$ \\
\hline 1491 VIII 8 & $\begin{array}{l}\text { chorhern und obersten kelner } \\
\text { des stifts unser lieben frawen } \\
\text { und sant Gangolfs zu Tewrstat } \\
\text { ausserhalb der statmauern bey } \\
\text { Bamberg richter zu der mun- } \\
\text { tat daselbst; zu sant Gangolf }\end{array}$ & $\begin{array}{l}\text { Selbstbezeichnung; AEB } \\
\text { Rep. I Pfarrei St. Ger- } \\
\text { traud, U } 114 .\end{array}$ \\
\hline 1491 X 31 & $\begin{array}{l}\text { chorher und oberster kelner } \\
\text { des stifts unser lieben frawen } \\
\text { und sant Gangolfs zu Tewers- } \\
\text { tat ausserhalb der statmauern }\end{array}$ & $\begin{array}{l}\text { Selbstbezeichnung; } \\
\text { StABa A } 120 \text { L } 131 \text { Nr. } \\
761 .\end{array}$ \\
\hline
\end{tabular}




\begin{tabular}{|c|c|c|}
\hline & $\begin{array}{l}\text { bey Bamberg richter in der } \\
\text { muntat daselbst }\end{array}$ & \\
\hline 1492 II 27 & $\begin{array}{l}\text { chorhere und oberster kellner } \\
\text { des stifts unser lieben frawen } \\
\text { und sant Gangolfs zu Tewers- } \\
\text { tat ausserhalb der statmauern } \\
\text { bey Bamberg richter in der } \\
\text { muntat doselbst }\end{array}$ & $\begin{array}{l}\text { Selbstbezeichnung; AEB } \\
\text { Rep. I Pfarrei Unserer } \\
\text { lieben Frau, U } 121 .\end{array}$ \\
\hline $1492 \times 12$ & $\begin{array}{l}\text { brobstey zu sant Gangolf aus- } \\
\text { serhalb der stat Bamberg }\end{array}$ & $\begin{array}{l}\text { Fremdbezeichnung; } \\
\text { StABa A } 120 \text { L } 134 \text { Nr. } \\
905 .\end{array}$ \\
\hline 1493 III 18 & $\begin{array}{l}\text { chorher und oberster kelner } \\
\text { des stifts unser liben frawen } \\
\text { und sant Gangolfs zw The- } \\
\text { werstat auserhalb der stat- } \\
\text { mawrn bey Bamberg richter } \\
\text { in der munthat doselbst }\end{array}$ & $\begin{array}{l}\text { Selbstbezeichnung; Sta- } \\
\text { Ba A } 120 \text { L } 131 \text { Nr. } 762 .\end{array}$ \\
\hline 1493 VI 11 & $\begin{array}{l}\text { chorher und oberster kelner } \\
\text { des stifts unser liben frawen } \\
\text { und sand Gangolfs zw The- } \\
\text { werstatt auserhalb der stat- } \\
\text { mawrn bey Bamberg richter } \\
\text { inn der munthat doselbst }\end{array}$ & $\begin{array}{l}\text { Fremdbezeichnung; } \\
\text { StaBa A } 120 \text { L } 131 \text { Nr. } \\
763 .\end{array}$ \\
\hline 1493 VII 1 & $\begin{array}{l}\text { probst des stifts unser lieben } \\
\text { frawen zue Tewerstat aus- } \\
\text { serhalb der mawern der stat } \\
\text { Bamberg; stieft unser lieben } \\
\text { frawen; stift unser lieben fra- } \\
\text { wen zue Tewerstat ausserhal- } \\
\text { ben der mauern der stat Bam- } \\
\text { berg }\end{array}$ & $\begin{array}{l}\text { Fremdbezeichnung; } \\
\text { StABa A } 120 \text { L } 133 \text { Nr. } \\
882 .\end{array}$ \\
\hline $\begin{array}{l}1493 \text { XII } \\
11\end{array}$ & $\begin{array}{l}\text { beate Marie in Duerstat extra } \\
\text { muros Bambergenses }\end{array}$ & $\begin{array}{l}\text { Fremdbezeichnung; } \\
\text { StAWu Kloster St. Ste- }\end{array}$ \\
\hline
\end{tabular}




\begin{tabular}{|c|c|c|}
\hline & & $\begin{array}{l}\text { phan Würzburg, Urkun- } \\
\text { den } 599 \text { und } 600 \text {. }\end{array}$ \\
\hline 1496 IX 12 & $\begin{array}{l}\text { dechand und das capitel ge- } \\
\text { meyniglich des stifts unserer } \\
\text { lieben frauen und sandt Gan- } \\
\text { golfs zu Tewerstat auserhalb } \\
\text { der statmawern bey Bambergk }\end{array}$ & $\begin{array}{l}\text { Selbstbezeichnung; Sta- } \\
\text { Ba A } 120 \text { L } 131 \text { Nr. } 764 .\end{array}$ \\
\hline $\begin{array}{l}1497 \mathrm{VII} \\
17\end{array}$ & $\begin{array}{l}\text { ecclesie sancti Gangolfi extra } \\
\text { muros Bambergense praeposi- } \\
\text { tus }\end{array}$ & $\begin{array}{l}\text { Fremdbezeichnung; } \\
\text { StABa A } 120 \text { L } 131 \text { Nr. } \\
765 .\end{array}$ \\
\hline $\begin{array}{l}1502 \text { XII } \\
19\end{array}$ & $\begin{array}{l}\text { chorher und oberster kelner } \\
\text { des stifts unser lieben frawen } \\
\text { und sand Gangolfs zu Tewers- } \\
\text { tat auserhalb der statmawern } \\
\text { bey Bamberg richter in der } \\
\text { muntat doselbst }\end{array}$ & $\begin{array}{l}\text { Fremdbezeichnung; } \\
\text { StABa A } 120 \text { L } 131 \text { Nr. } \\
766 .\end{array}$ \\
\hline 1503 VI 27 & $\begin{array}{l}\text { stift unser lieben frawen und } \\
\text { sandt Gangolfs ausserhalb der } \\
\text { mawern Bamberg; sandt Gan- } \\
\text { golfs stift }\end{array}$ & $\begin{array}{l}\text { Fremdbezeichnung; } \\
\text { StABa A } 120 \text { L } 134 \text { Nr. } \\
918 .\end{array}$ \\
\hline 1507 IV 9 & $\begin{array}{l}\text { chorhere des stiefts zw sandt } \\
\text { Gangolf bey Bamberg }\end{array}$ & $\begin{array}{l}\text { Fremdbezeichnung; } \\
\text { StABa Kloster Michels- } \\
\text { berg, Urk. Nr. } 1783 .\end{array}$ \\
\hline 1515 III 19 & $\begin{array}{l}\text { sant Gangolfs stift; des mun- } \\
\text { tatgerichts zu sant Gangolfs } \\
\text { insigel }\end{array}$ & $\begin{array}{l}\text { Fremdbezeichnung; } \\
\text { AEB Rep. I Pfarrei St. } \\
\text { Getraud, U } 115 .\end{array}$ \\
\hline $\begin{array}{l}1516 \text { VII } \\
30\end{array}$ & $\begin{array}{l}\text { brobst des stifts unser liben } \\
\text { frawen und sanct Gangolfs zu } \\
\text { Tewerstat ausserhalb der stat } \\
\text { Bamberg }\end{array}$ & $\begin{array}{l}\text { Selbstbezeichnung; AEB } \\
\text { Rep. I Pfarrei St. Gan- } \\
\text { golf, U } 826 .\end{array}$ \\
\hline 1517 I 10 & $\begin{array}{l}\text { vicarier sandt Gangolfs stift } \\
\text { zw Bamberg; chorher obge- } \\
\text { nanten stifts unser lieben }\end{array}$ & $\begin{array}{l}\text { Selbstbezeichnung; } \\
\text { StABa A } 120 \text { L } 131 \text { Nr. } \\
720 .\end{array}$ \\
\hline
\end{tabular}




\begin{tabular}{|c|c|c|}
\hline & $\begin{array}{l}\text { frawen und sandt Gangolfs zw } \\
\text { Teuerstadt auserhalb der } \\
\text { statmauerin zw Bamberg }\end{array}$ & \\
\hline 1519 II 26 & $\begin{array}{l}\text { dechant und capitel gemeinig- } \\
\text { lich unser lieben frawen und } \\
\text { sant Gangolfs stifts zu Tewrs- } \\
\text { tat bey Bamberg }\end{array}$ & $\begin{array}{l}\text { Fremdbezeichnung; } \\
\text { StABa Kloster Michels- } \\
\text { berg, Urk. Nr. } 1954 .\end{array}$ \\
\hline 1524 V 1 & $\begin{array}{l}\text { techant und gemeyn capitel } \\
\text { im stift zu sanct Gangolfi } \\
\text { Bamberg }\end{array}$ & $\begin{array}{l}\text { Fremdbezeichnung; } \\
\text { StABa Kloster Michels- } \\
\text { berg, Urk. Nr. } 2023 .\end{array}$ \\
\hline 1526 III 5 & $\begin{array}{l}\text { chorherr und oberster kelnere } \\
\text { des stifts unser liben frauen } \\
\text { und sanct Gangolf zu Teuern- } \\
\text { stat ausserhalb der statmauren } \\
\text { bey Bamberg richter in der } \\
\text { munthat doselbst; oblei zu } \\
\text { sanct Gangolf }\end{array}$ & $\begin{array}{l}\text { Fremdbezeichnung; } \\
\text { StABa A } 120 \text { L } 131 \text { Nr. } \\
767 .\end{array}$ \\
\hline 1526 IV 25 & $\begin{array}{l}\text { dechant und ein gemein capi- } \\
\text { tel unser lieben frawen und } \\
\text { sant Gangolfs stieft auserhalb } \\
\text { Bamberg zw Teuerstat genant; } \\
\text { gemelts sant Gangolfs stift }\end{array}$ & $\begin{array}{l}\text { Sebstbezeichnung; StA- } \\
\text { Ba A } 120 \text { L } 131 \text { Nr. } 726 .\end{array}$ \\
\hline 1526 VI 27 & $\begin{array}{l}\text { ecclesie sancti Gangolfi Bam- } \\
\text { bergensis canonicus }\end{array}$ & $\begin{array}{l}\text { Fremdbezeichnung; } \\
\text { AEB Rep. I Pfarrei St. } \\
\text { Gangolf, U } 821 .\end{array}$ \\
\hline $\begin{array}{l}1527 \text { VII } \\
31\end{array}$ & $\begin{array}{l}\text { probst des stiefts zu sant } \\
\text { Gangolf bey Bamberg }\end{array}$ & $\begin{array}{l}\text { Fremdbezeichnung; } \\
\text { StABa A } 120 \text { L } 134 \text { Nr. } \\
899 .\end{array}$ \\
\hline 1528 IX 25 & $\begin{array}{l}\text { custorey unser lieben frawen } \\
\text { und sant Gangolfs unsers } \\
\text { stifts zu Teuerstat bey unser } \\
\text { stat Bamberg; stift sant Gan- } \\
\text { golfs; custor sant Gangolfs }\end{array}$ & $\begin{array}{l}\text { Fremdbezeichnung; } \\
\text { StABa A } 120 \text { L } 133 \text { Nr. } \\
867 .\end{array}$ \\
\hline
\end{tabular}




\begin{tabular}{|c|c|c|}
\hline & $\begin{array}{l}\text { stift; dechant und capitel sant } \\
\text { Gangolfs stift }\end{array}$ & \\
\hline $1530 \mathrm{~V} 20$ & $\begin{array}{l}\text { dechant zu unser lieben frau- } \\
\text { en und sanct Gangolfs stieft } \\
\text { zu Teuernstat ausserhalbn der } \\
\text { statmauern bey Bamberg; } \\
\text { obleyern zu sanct Gangolfs } \\
\text { stieft; stift zu sanct Gangolf }\end{array}$ & $\begin{array}{l}\text { Selbstbezeichnung; } \\
\text { StABa A } 120 \text { L } 131 \text { Nr. } \\
769 .\end{array}$ \\
\hline 1531 VI 30 & $\begin{array}{l}\text { vicarier senior sancti Nicolai } \\
\text { des stiefts unser lieben frawen } \\
\text { und sanct Gangolfs zu Tewer- } \\
\text { stat auserhalb der statmauer } \\
\text { bey Bamberg }\end{array}$ & $\begin{array}{l}\text { Selbstbezeichnung; } \\
\text { StABa A } 120 \text { L } 131 \text { Nr. } \\
727 .\end{array}$ \\
\hline 1533 VI 27 & $\begin{array}{l}\text { decanus sancti Gangolphi } \\
\text { Bambergensis; decanus sancti } \\
\text { Gangolphi }\end{array}$ & $\begin{array}{l}\text { Fremdbezeichnung; } \\
\text { StABa A } 120 \text { L } 131 \text { Nr. } \\
772 .\end{array}$ \\
\hline 1534 III 5 & $\begin{array}{l}\text { chorherr sant Gangolfs stifts } \\
\text { bey Bamberg }\end{array}$ & $\begin{array}{l}\text { Selbstbezeichnung; } \\
\text { StABa A } 120 \text { L } 131 \text { Nr. } \\
728 .\end{array}$ \\
\hline 1534 V 31 & $\begin{array}{l}\text { dechant und gemayn capitel } \\
\text { unserer lieben frawen und } \\
\text { sant Gangolfs stiefte zw } \\
\text { Theuerstatt auserhalb der } \\
\text { mauer bey Bamberg }\end{array}$ & $\begin{array}{l}\text { Selbstbezeichnung; AEB } \\
\text { Rep. I Pfarrei St. Gan- } \\
\text { golf, U } 822 \text {. }\end{array}$ \\
\hline 1534 IX 27 & $\begin{array}{l}\text { ecclesie sancti Gangolphi } \\
\text { Bambergense }\end{array}$ & $\begin{array}{l}\text { Fremdbezeichnung; } \\
\text { StABa A } 120 \text { L } 131 \text { Nr. } \\
770 .\end{array}$ \\
\hline 1536 & $\begin{array}{l}\text { vicarier des stifts unser lieben } \\
\text { frauen und s. Gangolfs zu } \\
\text { Teuerstat auserhalben der } \\
\text { statmauern bei Bamberg }\end{array}$ & $\begin{array}{l}\text { Selbstbezeichnung; AEB } \\
\text { Rep. I Pfarrei St. Gan- } \\
\text { golf, U } 823 .\end{array}$ \\
\hline 1539 IV 30 & $\begin{array}{l}\text { vicarier des stiefts unser lie- } \\
\text { ben frauen und sand Gangolfs }\end{array}$ & $\begin{array}{l}\text { Selbstbezeichnung; } \\
\text { StABa A } 120 \text { L } 131 \text { Nr. }\end{array}$ \\
\hline
\end{tabular}




\begin{tabular}{|c|c|c|}
\hline & $\begin{array}{l}\text { zu Teuerstatt auserhalb der } \\
\text { stattmauer bey Bamberg; be- } \\
\text { melts sand Gangolfs stieft }\end{array}$ & 729. \\
\hline 1540 IX 12 & $\begin{array}{l}\text { vicarier des stifts unser lieben } \\
\text { frauen und sand Gangolfs zu } \\
\text { Teuerstat ausserhalb der } \\
\text { statmauer bey Bamberg }\end{array}$ & $\begin{array}{l}\text { Selbstbezeichnung; } \\
\text { StABa A } 120 \text { L } 131 \text { Nr. } \\
730 .\end{array}$ \\
\hline 1541 II 25 & $\begin{array}{l}\text { probst unsers stiefts zu sant } \\
\text { Gangolf alhie bey unser stat } \\
\text { Bamberg; probstey gemelts } \\
\text { sant Gangolfs stieft; sant } \\
\text { Gangolfs stiefts probstey; } \\
\text { stieft zu sant Gangolf; sant } \\
\text { Gangolfs stieft }\end{array}$ & $\begin{array}{l}\text { Fremdbezeichnung; } \\
\text { StABa A } 120 \text { L } 133 \text { Nr. } \\
883 .\end{array}$ \\
\hline 1542 IV 17 & $\begin{array}{l}\text { clericus Bambergensis dioce- } \\
\text { sis canonicus ecclesie colle- } \\
\text { giate beate Marie virginis ad } \\
\text { sanctum Gangolphum prope } \\
\text { et extra muros Bambergenses; } \\
\text { canonicatus et prebenda eccle- } \\
\text { sie collegiate beate Marie vir- } \\
\text { ginis prope et extra muros } \\
\text { Bambergenses; prepositus } \\
\text { dicte ecclesie beate Marie } \\
\text { virginis; prebenda dicte eccle- } \\
\text { sie beate Marie virginis; capit- } \\
\text { ulum dicte ecclesie beate Ma- } \\
\text { rie virginis; constitutio dicte } \\
\text { ecclesie beate Marie virginis; } \\
\text { canonicatus et prebanda dicte } \\
\text { ecclesie beate Marie virginis; } \\
\text { statutae et consuetudines dicte } \\
\text { ecclesie beate Marie virginis }\end{array}$ & $\begin{array}{l}\text { Fremdbezeichnung; } \\
\text { AEB Rep. I Pfarrei St. } \\
\text { Gangolf, U } 824 .\end{array}$ \\
\hline
\end{tabular}




\begin{tabular}{|c|c|c|}
\hline 1544 IX 9 & $\begin{array}{l}\text { styft zu sant Gangolf; styft zu } \\
\text { sant Gangolf }\end{array}$ & $\begin{array}{l}\text { Fremdbezeichnung; } \\
\text { StABa A } 120 \text { L } 131 \text { Nr. } \\
771 .\end{array}$ \\
\hline 1546 II 22 & chorher sanct Gangolfs stifts & $\begin{array}{l}\text { Fremdbezeichnung; } \\
\text { StABa Kloster Michels- } \\
\text { berg, Urk. Nr. } 2270 .\end{array}$ \\
\hline 1547 X 1 & $\begin{array}{l}\text { dechant und das capitel gem- } \\
\text { einlich unser lieben frauen } \\
\text { und sanct Gangolfs stift in der } \\
\text { Teurstat ausserhalb Bamberg }\end{array}$ & $\begin{array}{l}\text { Fremdbezeichnung; } \\
\text { StABa Kloster Michels- } \\
\text { berg, Urk. Nr. } 2284 .\end{array}$ \\
\hline 1548 II 24 & $\begin{array}{l}\text { vicarier des stifts zu sant } \\
\text { Gangolf }\end{array}$ & $\begin{array}{l}\text { Fremdbezeichnung; } \\
\text { StABa A } 120 \text { L } 134 \text { Nr. } \\
935 .\end{array}$ \\
\hline 1548 IX 19 & $\begin{array}{l}\text { dechent und gemein capitel } \\
\text { zu unser lieben frawen zu } \\
\text { Theuerstat bey Bambergk; zu } \\
\text { unser lieben frauen zu Theu- } \\
\text { erstat; stieft unser lieben fra- } \\
\text { wen zu Deuerstat }\end{array}$ & $\begin{array}{l}\text { Fremdbezeichnung; } \\
\text { StABa A } 120 \text { L } 131 \text { Nr. } \\
773 .\end{array}$ \\
\hline 1551 XI 16 & $\begin{array}{l}\text { dechant und das capitel gem- } \\
\text { einlich sanct Gangolfs stifts in } \\
\text { der Teurstatt ausserhalb Bam- } \\
\text { berg }\end{array}$ & $\begin{array}{l}\text { Fremdbezeichnung; } \\
\text { StABa Kloster Michels- } \\
\text { berg, Urk. Nr. } 2373 .\end{array}$ \\
\hline 1551 XI 16 & $\begin{array}{l}\text { dechant und das capitel gem- } \\
\text { einlich sanct Gangolfs stifts in } \\
\text { der Teurstat ausserhalb Bam- } \\
\text { berg }\end{array}$ & $\begin{array}{l}\text { Fremdbezeichnung; } \\
\text { StABa Kloster Michels- } \\
\text { berg, Urk. Nr. } 2372 .\end{array}$ \\
\hline 1554 I 11 & $\begin{array}{l}\text { decanus totiumque capitulum } \\
\text { collegiatae ecclesiae nostrae } \\
\text { sancti Gangolphi prope civi- } \\
\text { tatem nostrem Bambergensis }\end{array}$ & $\begin{array}{l}\text { Fremdbezeichnung; } \\
\text { AEB Rep. I Pfarrei St. } \\
\text { Gangolf, U } 825 .\end{array}$ \\
\hline $1556 \mathrm{~V} 7$ & $\begin{array}{l}\text { chorher des stiefts unser lie- } \\
\text { ben frauen und sant Gangolfs }\end{array}$ & $\begin{array}{l}\text { Selbstbezeichnung; } \\
\text { StABa A } 120 \text { L } 131 \text { Nr. }\end{array}$ \\
\hline
\end{tabular}




\begin{tabular}{|l|l|l|}
\hline & $\begin{array}{l}\text { kirchen zu Teuerstat aus- } \\
\text { serhalb der stadtmauernn zu } \\
\text { Bamberg; itzgenant unser } \\
\text { lieben frauen stieft }\end{array}$ & 731. \\
\hline 1559 III 1 & $\begin{array}{l}\text { probst sanct Gangolfs stieft } \\
\text { bey Bamberg }\end{array}$ & $\begin{array}{l}\text { Selbstbezeichnung; } \\
\text { StABa Kloster Michels- } \\
\text { berg, Urk. Nr. 2442. }\end{array}$ \\
\hline 1559 III 1 & $\begin{array}{l}\text { probst sanct Gangolfs stieft } \\
\text { zw Bamberg }\end{array}$ & $\begin{array}{l}\text { Selbstbezeichnung; } \\
\text { StABa Kloster Michels- } \\
\text { berg, Urk. Nr. 2443. }\end{array}$ \\
\hline 1565 I 27 & $\begin{array}{l}\text { probst des stifts unsers lieben } \\
\text { frawen und sanct Gangolfs zu } \\
\text { Tewerstatt ausserhalb der statt } \\
\text { Bambergk; propst des stifts zu } \\
\text { sant Gangolf obgemelt }\end{array}$ & $\begin{array}{l}\text { Selbstbezeichnung; } \\
\text { StABa A 120 L 131 Nr. } \\
\text { 732. }\end{array}$ \\
\hline
\end{tabular}




\section{Theuerstadtbezeichnung}

Aufgelistet sind die Bezeichnungen der Theuerstadt in ihrer zeitgenössischen Schreibweise anhand stiftseigener und stiftsfremder Urkunden im Staatsarchiv Bamberg, im Archiv des Erzbistums Bamberg und im Staatsarchiv Würzburg, aber auch anhand des Bamberger Synodialprotokolls von 1059 und anhand der Chronik Liber de decurso temporum des Heimo von St. Jakob von vor 1139. Unterschiedliche Mehrfachnennungen innerhalb einer Quelle wurden aufgenommen und Lesevarianten sind mit einem Querstrich getrennt. Buchstabendoppelungen, die der modernen Schreibweise widersprechen, wurden als Schmuckwerk eingestuft und nicht in die Transkription aufgenommen. Hochgeschriebene Buchstaben wurden gemäß den modernen Umlauten hinter den Hauptbuchstaben gestellt $(\stackrel{\circ}{\mathrm{u}}=\mathrm{uo})$ und v wurde als $\mathrm{u}$ transkribiert.

\begin{tabular}{|l|l|l|}
\hline Datierung & Bezeichnung & Quelle \\
\hline 1059 IV 13 & Duristat & $\begin{array}{l}\text { Synodialprotokoll vom 13. } \\
\text { April 1059 (Zeugenliste) in: } \\
\text { Jaffé: Acta synodi. 1869. S. } \\
\text { 498. Nr. 8. }\end{array}$ \\
\hline 1108 V 19 & prepositus Turstatensis & StABa BU 149. \\
\hline 1127 & Tuirstat & StABa BU 156. \\
\hline$(1127)$ & Tuirstat & StABa BU 178. \\
\hline 1223 & Twrstat/Tuirstat & StABa BU 161. \\
\hline$(1142)$ & Tuirstat & StABa BU 225. \\
\hline 1151 IV 10 & Tuerstat & StABa BU 255. \\
\hline 1157 VI & Thuirstat & StABa Kloster Michelsberg, \\
& & Urkunden Nr. 46. \\
\hline$(1179)$ & Tiurstat/Tuirstat & StABa BU 339. \\
\hline 1185 & villa Tuorstat & StABa BU 369. \\
\hline$(1190)$ & Duorstat, Tuorstat & StABa BU 387. \\
\hline 1199 & Tuwerstat & StABa BU 411. \\
\hline
\end{tabular}




\begin{tabular}{|c|c|c|}
\hline 1205 & Tiurstat & $\begin{array}{l}\text { StAWu Kloster Ebrach, } \\
\text { Urkunden 1205/I. }\end{array}$ \\
\hline$(1215)$ & Tuoerstat & StABa BU 471. \\
\hline$(1215)$ & Turstat & $\begin{array}{l}\text { StABa Kloster Michelsberg, } \\
\text { Urkunden Nr. } 73 .\end{array}$ \\
\hline 1216 & Tuoerstat & StABa BU 473. \\
\hline 1216 & Tuoristat & $\begin{array}{l}\text { StABa Kloster Michelsberg, } \\
\text { Urkunden Nr. } 74 .\end{array}$ \\
\hline 1217 & Tuorstat; Turstat & $\begin{array}{l}\text { StABa Kloster Michelsberg, } \\
\text { Urkunden Nr. } 75 .\end{array}$ \\
\hline (1217) & Turstatensis praepositus & StABa BU 485. \\
\hline 1221 & Tuoerstat & $\begin{array}{l}\text { StABa Kloster Michelsberg, } \\
\text { Urkunden Nr. } 79 .\end{array}$ \\
\hline 1221 & Tuoerstat & $\begin{array}{l}\text { StABa Kloster Michelsberg, } \\
\text { Urkunden Nr. } 80 .\end{array}$ \\
\hline (1223) & Twrstat & StABa BU 161. \\
\hline 1233 & Tuerstat & $\begin{array}{l}\text { StABa Kloster Michelsberg, } \\
\text { Urkunden Nr. } 86 .\end{array}$ \\
\hline 1240 VII 10 & Turstat & StABa BU 600. \\
\hline 1242 & Tyrstat & StABa BU 613. \\
\hline 1242 & Tiwerstat; Tuwerstat & StABa BU 614. \\
\hline $1245 \mathrm{~V} 26$ & Turstat Babinbergensis & $\begin{array}{l}\text { StAWu Stift Neumünster, } \\
\text { Urkunden } 1245 \text { V } 26 .\end{array}$ \\
\hline 1246 XI 8 & Twerstat & StABa BU 645. \\
\hline 1250 & Tuorstat & StABa BU 688. \\
\hline$(1250)$ & Tiwerstat & StABa BU 689. \\
\hline 1255 I 9 & canonicus Tirstatensis & StABa BU 720. \\
\hline 1261 VI 13 & Twerstat & StABa BU 782. \\
\hline 1275 II 1 & Thuerstat & StABa BU 878. \\
\hline 1275 IV 23 & Teurstat & StABa BU 881. \\
\hline 1280 I 28 & Tuwerstat & StABa BU 935. \\
\hline 1285 VII 2 & Tewerstat & $\begin{array}{l}\text { StAWu Kloster Ebrach, } \\
\text { Urkunden } 1285 \text { VII 2/I. }\end{array}$ \\
\hline
\end{tabular}




\begin{tabular}{|c|c|c|}
\hline 1285 VII 2 & Tewerstat & $\begin{array}{l}\text { StAWu Kloster Ebrach, } \\
\text { Urkunden } 1285 \text { VII 2/II. }\end{array}$ \\
\hline 1290 I 25 & Turstat Babenbergensis & $\begin{array}{l}\text { StAWu Kloster Ebrach, } \\
\text { Urkunden } 1290 \text { I } 25 .\end{array}$ \\
\hline $\begin{array}{l}1292 \text { VIII } \\
14\end{array}$ & Tuerstat & StABa BU 1110. \\
\hline $1295 \mathrm{~V} 25$ & $\begin{array}{l}\text { Tiurstat Babenbergensis; } \\
\text { Tiurstat }\end{array}$ & $\begin{array}{l}\text { StAWu Kloster Ebrach, } \\
\text { Urkunden } 1295 \text { V } 25 .\end{array}$ \\
\hline $1302 \times 27$ & Tuerstat & $\begin{array}{l}\text { StABa Kloster Michelsberg, } \\
\text { Urkunden Nr. } 141 .\end{array}$ \\
\hline 1302 XI 10 & $\begin{array}{l}\text { Thuerstat extra muros } \\
\text { Babenbergenses }\end{array}$ & $\begin{array}{l}\text { StABa Kloster Langheim, } \\
\text { Urkunden } 1302 \text { XI } 10 .\end{array}$ \\
\hline 1308 IV 5 & Tuerstat & $\begin{array}{l}\text { StABa Kloster Michelsberg, } \\
\text { Urkunden Nr. } 154 .\end{array}$ \\
\hline 1308 VII 22 & Tuerstat & StABa BU 1432. \\
\hline $\begin{array}{l}1311 \text { VIII } \\
24\end{array}$ & $\begin{array}{l}\text { Teuwerstat extra muros } \\
\text { civitatis Babenbergenses }\end{array}$ & $\begin{array}{l}\text { StAWU Kloster Ebrach, } \\
\text { Urkunden } 1311 \text { VIII 24/I. }\end{array}$ \\
\hline $\begin{array}{l}1311 \text { VIII } \\
24\end{array}$ & $\begin{array}{l}\text { Tewerstat extra muros } \\
\text { civitatis nostre Ba- } \\
\text { bembergenses }\end{array}$ & $\begin{array}{l}\text { StAWu Kloster Ebrach, } \\
\text { Urkunden } 1311 \text { VIII 24/II. }\end{array}$ \\
\hline $\begin{array}{l}1311 \text { VIII } \\
26\end{array}$ & Tiurstat & $\begin{array}{l}\text { StAWu Kloster Ebrach, } \\
\text { Urkunden } 1311 \text { VIII } 26 .\end{array}$ \\
\hline 1311 IX 18 & $\begin{array}{l}\text { Turstat extra muros Ba- } \\
\text { bembergenses }\end{array}$ & $\begin{array}{l}\text { StAWu Kloster Ebrach, } \\
\text { Urkunden } 1311 \text { IX } 18 .\end{array}$ \\
\hline $1311 \times 1$ & $\begin{array}{l}\text { Tuerstat extra muros } \\
\text { Babenbergenses }\end{array}$ & $\begin{array}{l}\text { StAWu Kloster Ebrach, } \\
\text { Urkunden } 1311 \text { X 1/I und } \\
1311 \text { X 1/II. }\end{array}$ \\
\hline 1312 IV 3 & $\begin{array}{l}\text { Theurstat prope muros } \\
\text { Bambergenses }\end{array}$ & $\begin{array}{l}\text { StAWu Kloster Ebrach, } \\
\text { Urkunden } 1312 \text { IV } 3 .\end{array}$ \\
\hline 1312 XII 22 & Tewerstat & $\begin{array}{l}\text { StABa Kloster Michelsberg, } \\
\text { Urkunden Nr. } 169 .\end{array}$ \\
\hline 1314 II 15 & Tewerstat & StABa BU 1582. \\
\hline 1314 III 5 & Teurstat & StABa Kloster Michelsberg, \\
\hline
\end{tabular}




\begin{tabular}{|c|c|c|}
\hline & & Urkunden Nr. 174. \\
\hline 1315 VI 11 & $\begin{array}{l}\text { Teurstat extra muros } \\
\text { Bambergenses }\end{array}$ & StABa BU 1618. \\
\hline 1317 IX 7 & Tewerstat & StABa BU 1682. \\
\hline 1318 II 25 & Thuerstat & StABa BU 1698. \\
\hline 1318 XII 13 & $\begin{array}{l}\text { Tewerstat auzzerhalb der } \\
\text { mawer der stat ze Babem- } \\
\text { berch; Tewerstat }\end{array}$ & StABa BU 1716. \\
\hline 1324 I 24 & Teustat Bambergensis & StABa BU 1842. \\
\hline 1324 I 29 & $\begin{array}{l}\text { Tewerstat propre muros } \\
\text { Babenbergenses }\end{array}$ & StABa BU 1844. \\
\hline 1325 I 29 & Tewerstat & StABa BU 1871. \\
\hline 1325 I 29 & Tewerstat & StABa BU 1872. \\
\hline 1329 & $\begin{array}{l}\text { Tewerstat extra muros } \\
\text { Bambergenses; Tewerstat }\end{array}$ & StABa BU 1988. \\
\hline 1331 VII 18 & Teurstat & StABa BU 2060. \\
\hline $1331 \times 25$ & Teuerstat & StABa BU 2066. \\
\hline 1333 VII 14 & Turstat & $\begin{array}{l}\text { StABa Kloster Michelsberg, } \\
\text { Urkunden Nr. } 248 .\end{array}$ \\
\hline 1335 III 28 & Teuerstat; Teurstat & StABa BU 2179. \\
\hline $1335 \mathrm{~V} 3$ & Thuerstat & StABa BU 2187. \\
\hline $1335 \mathrm{~V} 19$ & Tewerstat & StABa BU 2190. \\
\hline 1336 VII 26 & Thuerstat & StABa BU 2239. \\
\hline 1336 XII 9 & $\begin{array}{l}\text { Teuerstat extra muros } \\
\text { civitatis Babnbergensis }\end{array}$ & $\begin{array}{l}\text { AEB Rep. I Pfarrei St. Gan- } \\
\text { golf, U } 818 \text {. }\end{array}$ \\
\hline 1440 II 15 & Tewrstat & $\begin{array}{l}\text { AEB Rep. I Pfarrei St. Gan- } \\
\text { golf, U } 819 .\end{array}$ \\
\hline 1344 IV 26 & Teurstat & $\begin{array}{l}\text { StABa Kloster Michelsberg, } \\
\text { Urkunden Nr. } 302 .\end{array}$ \\
\hline $1344 \mathrm{~V} 19$ & Tewrstat & StABa BU 2490. \\
\hline 1344 VII 26 & $\begin{array}{l}\text { Tewrstat; in loco dicto } \\
\text { Tewrstat }\end{array}$ & StABa BU 2496. \\
\hline 1344 VIII 5 & Tuerstat & StABa BU 2498. \\
\hline
\end{tabular}




\begin{tabular}{|c|c|c|}
\hline 1345 XI 28 & Thewrstat & StABa BU 2537. \\
\hline 1346 III 6 & Teurstat & $\begin{array}{l}\text { StABa Kloster Michelsberg, } \\
\text { Urkunden Nr. } 307 .\end{array}$ \\
\hline 1346 III 7 & Teurstat & StABa BU 2552. \\
\hline 1346 V 26 & Teurstat & StABa BU 2558. \\
\hline 1347 III 18 & $\begin{array}{l}\text { Theurstat auzzerhalb der } \\
\text { mauern zu Babenberg; } \\
\text { Thewrstat; Theurstat }\end{array}$ & StABa BU 2583. \\
\hline $\begin{array}{l}1347 \text { VIII } \\
30\end{array}$ & Thuerstat & StABa BU 2594. \\
\hline 1348 VI 27 & Thuerstat & StABa BU 2619. \\
\hline $1348 \times 27$ & Theurstat & StABa BU 2630. \\
\hline 1348 XII 20 & $\begin{array}{l}\text { Tewerstat extra muros } \\
\text { Babenbergenses }\end{array}$ & StABa BU 2636. \\
\hline 1349 III 10 & Teurstat & StABa BU 2644. \\
\hline 1349 IV 3 & Teurstat zu Babenberch & StABa BU 2651. \\
\hline 1349 IX 17 & Teurstat & $\begin{array}{l}\text { StABa Kloster Michelsberg, } \\
\text { Urkunden Nr. } 318 .\end{array}$ \\
\hline 1349 XI 23 & Tuerstat & StABa BU 2670. \\
\hline 1350 II 10 & Tewerstat & $\begin{array}{l}\text { StABa Kloster Michelsberg, } \\
\text { Urkunden Nr. } 321 .\end{array}$ \\
\hline 1350 VI 3 & Teurstat & StABa BU 2700. \\
\hline 1351 VI 14 & Teurstat & StABa BU 2742. \\
\hline $\begin{array}{l}1353 \text { VIII } \\
12\end{array}$ & Teuerstat & StABa BU 2806. \\
\hline 1354 VI 26 & Teurstat & StABa BU 2835. \\
\hline 1356 XI 16 & $\begin{array}{l}\text { Teurstat extra muros } \\
\text { Bambergenses }\end{array}$ & StABa BU 2913. \\
\hline 1356 XII 5 & Tewerstat & $\begin{array}{l}\text { AEB Rep. I Pfarrei St. Mar- } \\
\text { tin, U } 2 .\end{array}$ \\
\hline 1357 IV 13 & Teurstat bei Babenberch & StABa BU 2940. \\
\hline 1357 X 10 & Teurstat & StABa BU 2964. \\
\hline 1357 XI 6 & Teurstat & StABa BU 2969. \\
\hline
\end{tabular}




\begin{tabular}{|c|c|c|}
\hline 1358 III 22 & Teurstat & StABa BU 2985. \\
\hline 1359 VI 7 & Teurstat & StABa BU 3022. \\
\hline $1360 \mathrm{~V} 18$ & Tewerstat & StABa BU 3075. \\
\hline $1360 \mathrm{~V} 23$ & Teuerstat ze Babenberch & StABa BU 3076. \\
\hline 1361 IV 20 & Teuerstat & StABa BU 3114. \\
\hline 1361 IV 29 & $\begin{array}{l}\text { Teurstat ze Babenberg; } \\
\text { Teurstat }\end{array}$ & StABa BU 3115. \\
\hline 1361 VIII 5 & $\begin{array}{l}\text { Teurstat; Teurstat bei } \\
\text { Babenberch }\end{array}$ & StABa BU 3130. \\
\hline 1364 IV 21 & Tewerstat & StABa BU 3240. \\
\hline $\begin{array}{l}1364 \text { VIII } \\
29\end{array}$ & $\begin{array}{l}\text { Tewerstat; Teurstat; Teu- } \\
\text { erstat }\end{array}$ & StABa BU 3261. \\
\hline 1365 IX 5 & Tewrstat & StABa BU 3296. \\
\hline 1366 VII 17 & Tewerstat & StABa BU 3332. \\
\hline 1371 IV 28 & $\begin{array}{l}\text { Tewerstat auzzerhalben } \\
\text { der maur ze Bamberg }\end{array}$ & StABa BU 3501. \\
\hline 1374 II 9 & Tewrstat & StABa BU 3599. \\
\hline $1374 \mathrm{~V} 5$ & Tewerstat & StABa BU 3603. \\
\hline $1374 \mathrm{~V} 15$ & Tewerstat & $\begin{array}{l}\text { AEB Rep. I Pfarrei St. Mar- } \\
\text { tin, U } 4 .\end{array}$ \\
\hline $1375 \mathrm{~V} 16$ & Tewerstat & StABa BU 3641. \\
\hline 1376 III 17 & Tewerstat & $\begin{array}{l}\text { StABa Kloster Michelsberg, } \\
\text { Urkunden Nr. } 503 .\end{array}$ \\
\hline 1376 VII 24 & Tewerstat & $\begin{array}{l}\text { StABa Kloster Michelsberg, } \\
\text { Urkunden Nr. } 507 .\end{array}$ \\
\hline 1376 XII 4 & Teurstat & StABa BU 3726. \\
\hline 1378 V 7 & $\begin{array}{l}\text { Tewerstat; Tewerstat ze } \\
\text { Babemberg }\end{array}$ & StABa BU 3787. \\
\hline 1380 II 14 & Tewerstat & StABa BU 3860. \\
\hline 1380 XI 5 & Tewrstat & $\begin{array}{l}\text { StABa Kloster Michelsberg, } \\
\text { Urkunden Nr. } 527 .\end{array}$ \\
\hline 1382 IV 22 & $\begin{array}{l}\text { Tewrstat in der vorstat ze } \\
\text { Babemberch }\end{array}$ & $\begin{array}{l}\text { StABa Kloster Michelsberg, } \\
\text { Urkunden Nr. } 545 .\end{array}$ \\
\hline
\end{tabular}




\begin{tabular}{|c|c|c|}
\hline 1383 XI 29 & Tewrstat & StABa BU 3995. \\
\hline 1384 II 8 & Tewrstat & StABa BU 4001. \\
\hline $1385 \times 16$ & Tewerstat & StABa BU 4071. \\
\hline 1386 IV 9 & Tewrstat & StABa BU 4091. \\
\hline 1386 IX 13 & Tewerstat & StABa BU 4110. \\
\hline $\begin{array}{l}1387 \text { V } 25 \\
\text { (Abschrift) }\end{array}$ & Teuerstat & StABa A 120 L 134 Nr. 922. \\
\hline 1390 VIII 5 & Tewerstat; Tewrstat & StABa BU 4261. \\
\hline 1391 VI 23 & $\begin{array}{l}\text { Tewerstat auzzerhalb der } \\
\text { mawer der stat }\end{array}$ & StABa BU 4287. \\
\hline 1394 V 19 & Tewrstat & StABa BU 4433. \\
\hline $\begin{array}{l}1395 \text { VIII } \\
23\end{array}$ & Tewerstat & StABa BU 4488. \\
\hline 1397 IX 16 & Tewrstat & StABa BU 4585. \\
\hline 1398 VII 12 & Tewerstat & $\begin{array}{l}\text { StABa Kloster Langheim, } \\
\text { Urkunden } 1398 \text { VII } 12 .\end{array}$ \\
\hline 1398 XI 27 & Teurstad & StABa BU 4665. \\
\hline 1399 I 27 & $\begin{array}{l}\text { Tewrstad auzzerhalben der } \\
\text { mawr der stat zu Bamberg }\end{array}$ & SttABa A 21 27-01-1399. \\
\hline 1399 III 17 & $\begin{array}{l}\text { Tewerstat auzzerhalb der } \\
\text { mauer der stat zu Bam- } \\
\text { berg }\end{array}$ & StABa BU 4693. \\
\hline 1400 I 17 & Tewrstat & $\begin{array}{l}\text { StABa Kloster Michelsberg, } \\
\text { Urkunden Nr. } 605 .\end{array}$ \\
\hline $1400 \times 18$ & $\begin{array}{l}\text { Tewerstat auzzerhalben } \\
\text { der mawer der stat zu } \\
\text { Bamberg; Tewerstat }\end{array}$ & StABa BU 4766. \\
\hline 1401 VII 4 & $\begin{array}{l}\text { Tewerstat auserhalben der } \\
\text { mawer der stat zu Bam- } \\
\text { berg }\end{array}$ & $\begin{array}{l}\text { AEB Rep. I Pfarrei St. Mar- } \\
\text { tin, U } 16 .\end{array}$ \\
\hline 1402 III 6 & $\begin{array}{l}\text { Tewerstat auserhalben der } \\
\text { mawer der stat zu Bam- } \\
\text { berg }\end{array}$ & SttABa A 21 06-03-1402. \\
\hline
\end{tabular}




\begin{tabular}{|c|c|c|}
\hline 1403 XI 26 & $\begin{array}{l}\text { Tewerstat auserhalben der } \\
\text { mawer der stat zu Bam- } \\
\text { berg }\end{array}$ & $\begin{array}{l}\text { AEB Rep. I Pfarrei St. Mar- } \\
\text { tin, U } 17 .\end{array}$ \\
\hline $\begin{array}{l}1406 \text { VIII } \\
28\end{array}$ & Tewerstat & $\begin{array}{l}\text { StABa Kloster Langheim } \\
\text { Urkunden } 1406 \text { VIII } 28 .\end{array}$ \\
\hline 1406 XII 20 & $\begin{array}{l}\text { Tewerstat auserhalb der } \\
\text { mawer der stat zu Bam- } \\
\text { berg }\end{array}$ & $\begin{array}{l}\text { AEB Rep. I Pfarrei St. Mar- } \\
\text { tin, U } 18 .\end{array}$ \\
\hline 1408 V 21 & $\begin{array}{l}\text { Tewerstat auserhalben der } \\
\text { mawer der stat zu Bam- } \\
\text { berg; Tewerstat }\end{array}$ & $\begin{array}{l}\text { AEB Rep. I Pfarrei St. Ger- } \\
\text { traud, U } 97 .\end{array}$ \\
\hline 1415 III 1 & $\begin{array}{l}\text { Tewerstat auswendig der } \\
\text { mawer der stat zu Bam- } \\
\text { berg }\end{array}$ & $\begin{array}{l}\text { StABa Kloster Michelsberg, } \\
\text { Urkunden Nr. } 663 .\end{array}$ \\
\hline 1415 V 24 & Teuerstatt & StABa A 120 L 134 Nr. 919. \\
\hline 1415 VII 15 & $\begin{array}{l}\text { Tewerstat zu Babenberg; } \\
\text { Tewerstat zu Bamberg }\end{array}$ & StABa A 120 L 134 Nr. 902. \\
\hline 1416 I 7 & $\begin{array}{l}\text { Tewerstat ausserhalben } \\
\text { der mawer der stat zu } \\
\text { Bamberg }\end{array}$ & SttABa A 21 07-01-1416. \\
\hline 1419 VII 31 & $\begin{array}{l}\text { Tewerstat ausserhalben } \\
\text { der mawer der stat zu } \\
\text { Bamberg }\end{array}$ & $\begin{array}{l}\text { AEB Rep. I Pfarrei St. Ger- } \\
\text { traud, U } 98 .\end{array}$ \\
\hline 1419 & $\begin{array}{l}\text { Tewerstat ausserhalben } \\
\text { der mawer der stat zu } \\
\text { Bamberg }\end{array}$ & $\begin{array}{l}\text { AEB Rep. I Pfarrei St. Ger- } \\
\text { traud, U } 99 .\end{array}$ \\
\hline 1420 XII 9 & $\begin{array}{l}\text { Tewerstat auserhalben der } \\
\text { mawer der stat zu Bam- } \\
\text { bergk }\end{array}$ & SttABa A 21 09-12-1420. \\
\hline 1423 VI 15 & $\begin{array}{l}\text { Teurstat extra muros } \\
\text { Bambergenses }\end{array}$ & $\begin{array}{l}\text { StABa Kloster Michelsberg, } \\
\text { Urkunden Nr. } 970 .\end{array}$ \\
\hline 1424 IV 9 & $\begin{array}{l}\text { Tewerstat auserhalben der } \\
\text { mawer der stat zu Bam- }\end{array}$ & StABa A 120 L 131 Nr. 750. \\
\hline
\end{tabular}




\begin{tabular}{|c|c|c|}
\hline & berg; Tewerstat & \\
\hline 1428 I 12 & Tewerstat & $\begin{array}{l}\text { StABa Kloster Michelsberg, } \\
\text { Urkunden Nr. } 704 .\end{array}$ \\
\hline 1434 III 19 & Tewerstat & $\begin{array}{l}\text { StABa Kloster Michelsberg, } \\
\text { Urkunden Nr. } 733 .\end{array}$ \\
\hline 1434 XI 3 & Teuerstat bey Bamberg & StABa A 120 L 133 Nr. 870. \\
\hline 1435 XI 22 & Teurstat & StABa A 120 L 133 Nr. 871. \\
\hline 1436 I 23 & Teurstat bey Bamberg & $\begin{array}{l}\text { StABa Kloster Michelsberg, } \\
\text { Urkunden Nr. } 738 .\end{array}$ \\
\hline 1436 I 23 & Teurstat bey Bamberg & $\begin{array}{l}\text { StABa Kloster Langheim, } \\
\text { Urkunden } 1436 \text { I } 23 .\end{array}$ \\
\hline 1436 XI 12 & Teurstat bey Bamberg & $\begin{array}{l}\text { StABa A } 120 \text { L } 133 \text { Nr. } 872 \\
\text { und Nr. } 873 .\end{array}$ \\
\hline 1437 VII 28 & Tewerstat bey Bamberg & StABa A 120 L 134 Nr. 906. \\
\hline 1439 VI 1 & $\begin{array}{l}\text { Tewerstat auserhalben der } \\
\text { mauer der stat zu Bam- } \\
\text { berg }\end{array}$ & $\begin{array}{l}\text { AEB Rep. I Pfarrei St. Ger- } \\
\text { traud, U } 101 .\end{array}$ \\
\hline 1439 VI 3 & $\begin{array}{l}\text { Tewrstat auswendig der } \\
\text { statmawer zu Bamberg; } \\
\text { Tewrstat }\end{array}$ & StABa A 120 L 131 Nr. 721. \\
\hline 1439 IX 25 & Tewrstat bey Bamberg & $\begin{array}{l}\text { StABa Kloster Langheim, } \\
\text { Urkunden } 1439 \text { IX } 25 .\end{array}$ \\
\hline 1440 II 3 & $\begin{array}{l}\text { Tewerstat ausserhalben } \\
\text { der mauer der stat zu } \\
\text { Bamberg }\end{array}$ & SttABa A 21 03-02-1440. \\
\hline 1440 IV 4 & $\begin{array}{l}\text { Tewerstat ausserthalbe der } \\
\text { mawer der stat zu Bam- } \\
\text { berg }\end{array}$ & $\begin{array}{l}\text { AEB Rep. I Pfarrei St. Ger- } \\
\text { traud, U } 102 .\end{array}$ \\
\hline $1440 \mathrm{~V} 9$ & $\begin{array}{l}\text { Tewerstat ausserthalben } \\
\text { der mawer der stat zu } \\
\text { Bamberg; Tewerstat }\end{array}$ & $\begin{array}{l}\text { AEB Rep. I Pfarrei St. Ger- } \\
\text { traud, U } 103 .\end{array}$ \\
\hline 1442 VI 4 & $\begin{array}{l}\text { Tewerstat ausserthalben } \\
\text { der mawer der stat zu }\end{array}$ & $\begin{array}{l}\text { AEB Rep. I Pfarrei St. Ger- } \\
\text { traud, U } 104 .\end{array}$ \\
\hline
\end{tabular}




\begin{tabular}{|c|c|c|}
\hline & Bamberg & \\
\hline $1443 \times 21$ & $\begin{array}{l}\text { Tewerstat ausserhalben } \\
\text { der mawer der stat zu } \\
\text { Bamberg }\end{array}$ & $\begin{array}{l}\text { AEB Rep. I Pfarrei St. Ger- } \\
\text { traud, U } 105 .\end{array}$ \\
\hline $\begin{array}{l}1444 \text { XII } 2 \\
\text { (in Ab- } \\
\text { schrift) }\end{array}$ & $\begin{array}{l}\text { Tewrstat extra muros civi- } \\
\text { tatis nostre Bambergensis }\end{array}$ & StABa A 120 L 131 Nr. 722. \\
\hline 1445 I 26 & $\begin{array}{l}\text { Tewrstat bey unser stat } \\
\text { Bamberg; Tewrstat }\end{array}$ & StABa A 120 L 133 Nr. 874. \\
\hline 1445 II 14 & Tewerstat pey Bamberg & StABa A 120 L 133 Nr. 875. \\
\hline 1445 VI 14 & $\begin{array}{l}\text { Tewerstat ausserhalben } \\
\text { der mawer der stat zu } \\
\text { Bamberg; Tewerstat }\end{array}$ & $\begin{array}{l}\text { AEB Rep. I Pfarrei St. Ger- } \\
\text { traud, U } 107 .\end{array}$ \\
\hline 1445VI 14 & $\begin{array}{l}\text { Tewerstat ausserhalben } \\
\text { der mawer der stat zu } \\
\text { Bamberg }\end{array}$ & StABa A 120 L 131 Nr. 751. \\
\hline 1447 VI 3 & Teurstat & StABa A 120 L 131 Nr. 752. \\
\hline 1448 I 25 & $\begin{array}{l}\text { Tewrstat auserhalb der } \\
\text { mawer der stat Bamberg }\end{array}$ & SttABa A 21 25-01-1448. \\
\hline $1448 \times 7$ & $\begin{array}{l}\text { Tewerstat bey unser stad } \\
\text { Bamberg }\end{array}$ & StABa A 120 L 133 Nr. 851. \\
\hline $\begin{array}{l}1449 \text { VIII } \\
18\end{array}$ & $\begin{array}{l}\text { Theurstat ausserhalben } \\
\text { der maur der stat zu Bam- } \\
\text { berg }\end{array}$ & $\begin{array}{l}\text { AEB Rep. I Pfarrei St. Ger- } \\
\text { traud, U } 108 .\end{array}$ \\
\hline $\begin{array}{l}1449 \text { VIII } \\
20\end{array}$ & $\begin{array}{l}\text { Tewrstat extra muros } \\
\text { Bambergenses }\end{array}$ & $\begin{array}{l}\text { AEB Rep. I Pfarrei St. Gan- } \\
\text { golf, U } 820 \text {. }\end{array}$ \\
\hline 1449 XI 17 & $\begin{array}{l}\text { Teurstat auswendig unser } \\
\text { stat Bamberg; Teurstat }\end{array}$ & StABa A 120 L 133 Nr. 876. \\
\hline 1449 XI 8 & Tewrstad; Teurstad & StABa A 120 L 131 Nr. 753. \\
\hline 1452 III 20 & $\begin{array}{l}\text { Teurstat asserhalben der } \\
\text { mawrn der stat zu Bam- } \\
\text { berg }\end{array}$ & SttABa A 21 20-03-1452. \\
\hline 1452 VII 28 & Tewerstad in unser stad & StABa A 120 L 131 Nr. 755. \\
\hline
\end{tabular}




\begin{tabular}{|c|c|c|}
\hline & Bamberg; Tewerstad & \\
\hline $\begin{array}{l}1452 \text { VIII } \\
14\end{array}$ & Tewrstat pei Bamberg & StABa A 120 L 133 Nr. 877. \\
\hline 1453 VII 30 & $\begin{array}{l}\text { Tewerstat ausserhalben } \\
\text { der mawer der stat zu } \\
\text { Bamberg }\end{array}$ & StABa A 120 L 131 Nr. 754. \\
\hline 1453 XI 12 & $\begin{array}{l}\text { Tewerstat ausserhalben } \\
\text { der mawer der stat zu } \\
\text { Bamberg }\end{array}$ & $\begin{array}{l}\text { AEB Rep. I Pfarrei St. Ger- } \\
\text { traud, U } 109 .\end{array}$ \\
\hline $\begin{array}{l}1456 \text { IX } 22 \\
\text { (Abschrift) }\end{array}$ & $\begin{array}{l}\text { Teuerstatt bey Bamberg; } \\
\text { Teuerstatt bey der statt } \\
\text { Bamberg }\end{array}$ & StABa A 120 L 131 Nr. 756. \\
\hline 1458 II 20 & $\begin{array}{l}\text { Tewerstat bey Bamberg } \\
\text { gelegen }\end{array}$ & SttABa A 21 20-02-1458. \\
\hline 1463 IV 27 & Dewerstat Bambergensis & $\begin{array}{l}\text { StAWu Kloster St. Stephan } \\
\text { Würzburg, Urkunden } 452 .\end{array}$ \\
\hline 1466 V 30 & $\begin{array}{l}\text { Teurstat auswendig der } \\
\text { stadmaurn Bamberg }\end{array}$ & StABa A 120 L 131 Nr. 724. \\
\hline 1466 VI 16 & $\begin{array}{l}\text { Tewerstat in unser stat } \\
\text { Bamberg }\end{array}$ & StABa A 120 L 131 Nr. 757. \\
\hline 1466 XI 11 & $\begin{array}{l}\text { Teuerstat auserhalben der } \\
\text { statmauern Bambergs }\end{array}$ & StABa A 120 L 131 Nr. 758. \\
\hline $\begin{array}{l}1468 \text { VIII } \\
22\end{array}$ & Teuwerstadt; Tewerstat & StABa A 120 L 133 Nr. 879. \\
\hline $\begin{array}{l}1468 \text { VIII } \\
24\end{array}$ & $\begin{array}{l}\text { Tewerstadt bey Bamberg; } \\
\text { Tewerstat }\end{array}$ & StABa A 120 L 133 Nr. 878. \\
\hline 1468 XI 19 & $\begin{array}{l}\text { Thewerstadt; trans pontem } \\
\text { Sesprucken [...] in The- } \\
\text { werstadt }\end{array}$ & $\begin{array}{l}\text { StABa A } 120 \text { L } 135 \text { Nr. } \\
1016 .\end{array}$ \\
\hline 1470 & $\begin{array}{l}\text { Tewerstat extra muros } \\
\text { dicte civitate Bamberg }\end{array}$ & $\begin{array}{l}\text { AEB Rep. I Pfarrei St. Ger- } \\
\text { traud, U } 111 .\end{array}$ \\
\hline 1470 I 5 & Tewrstat & StAWu WU 65/27. \\
\hline 1472 XI 6 & Tewerstat auswendig der & StABa A 120 L 133 Nr. 880. \\
\hline
\end{tabular}




\begin{tabular}{|c|c|c|}
\hline & mawer unser stat Bamberg & \\
\hline 1474 V 21 & Thewerstat bey Bamberg & StABa A 120 L 133 Nr. 881. \\
\hline 1474 XII 26 & $\begin{array}{l}\text { Thewerstat aushalben der } \\
\text { stat mawern zu Bambergk }\end{array}$ & StABa A 120 L 134 Nr. 936. \\
\hline 1475 VI 19 & $\begin{array}{l}\text { Teurstat ausserhalben der } \\
\text { statmauern bey Bamberg }\end{array}$ & StABa A 120 L 131 Nr. 760. \\
\hline 1477 IV 14 & $\begin{array}{l}\text { Teurstat ausserhalb der } \\
\text { statmaurn bey Bamberg }\end{array}$ & $\begin{array}{l}\text { AEB Rep. I Pfarrei Unserer } \\
\text { lieben Frau, U } 114 .\end{array}$ \\
\hline 1479 III 16 & $\begin{array}{l}\text { Teuerstat Bambergensis } \\
\text { diocesis }\end{array}$ & StABa A 120 L 131 Nr. 725. \\
\hline 1489 III 16 & $\begin{array}{l}\text { Tewrstat ausserhalben der } \\
\text { statmaurn bei Bamberg }\end{array}$ & $\begin{array}{l}\text { StABa Kloster Michelsberg, } \\
\text { Urkunden Nr. } 1412 .\end{array}$ \\
\hline 1489 VI 1 & $\begin{array}{l}\text { Tewerstat ausserhalb } \\
\text { Bamberg }\end{array}$ & $\begin{array}{l}\text { StABa Kloster Michelsberg, } \\
\text { Urkunden Nr. } 1419 .\end{array}$ \\
\hline $1491 \mathrm{~V} 2$ & $\begin{array}{l}\text { Tewerstat ausserhalb der } \\
\text { statmauern bey Bamberg }\end{array}$ & SttABa A 21 02-05-1491. \\
\hline 1491 VIII 8 & $\begin{array}{l}\text { Tewrstat ausserhalb der } \\
\text { statmauern bey Bamberg }\end{array}$ & $\begin{array}{l}\text { AEB Rep. I Pfarrei St. Ger- } \\
\text { traud, U } 114 .\end{array}$ \\
\hline $1491 \times 31$ & $\begin{array}{l}\text { Tewerstat ausserhalb der } \\
\text { statmauern bey Bamberg }\end{array}$ & StABa A 120 L 131 Nr. 761. \\
\hline 1492 II 27 & $\begin{array}{l}\text { Tewerstat ausserhalb der } \\
\text { statmauern bey Bamberg }\end{array}$ & $\begin{array}{l}\text { AEB Rep. I Pfarrei Unserer } \\
\text { lieben Frau, U } 121 .\end{array}$ \\
\hline 1493 III 18 & $\begin{array}{l}\text { Thewerstat auserhalb der } \\
\text { statmawrn bey Bamberg }\end{array}$ & StABa A 120 L 131 Nr. 762. \\
\hline 1493 VI 11 & $\begin{array}{l}\text { Thewerstatt auserhalb der } \\
\text { statmawrn bey Bamberg }\end{array}$ & StABa A 120 L 131 Nr. 763. \\
\hline 1493 VII 1 & $\begin{array}{l}\text { Tewerstat ausserhalb der } \\
\text { mawern der stat Bamberg }\end{array}$ & StABa A 120 L 133 Nr. 882. \\
\hline 1493 XII 11 & $\begin{array}{l}\text { Duerstat extra muros } \\
\text { Bambergenses }\end{array}$ & $\begin{array}{l}\text { StAWu Kloster St. Stephan } \\
\text { Würzburg, Urkunden } 599 \\
\text { und } 600 .\end{array}$ \\
\hline 1496 IX 12 & $\begin{array}{l}\text { Tewerstat auserhalb der } \\
\text { statmawern bey Bambergk }\end{array}$ & StABa A 120 L 131 Nr. 764. \\
\hline
\end{tabular}




\begin{tabular}{|c|c|c|}
\hline 1502 XII 19 & $\begin{array}{l}\text { Tewerstat auserhalb der } \\
\text { statmawern bey Bamberg }\end{array}$ & StABa A 120 L 131 Nr. 766. \\
\hline 1516 VII 30 & $\begin{array}{l}\text { Tewerstat ausserhalb der } \\
\text { stat Bamberg }\end{array}$ & $\begin{array}{l}\text { AEB Rep. I Pfarrei St. Gan- } \\
\text { golf, U } 826 \text {. }\end{array}$ \\
\hline 1517 I 10 & $\begin{array}{l}\text { Teuerstadt auserhalb der } \\
\text { statmauerin zw Bamberg }\end{array}$ & StABa A 120 L 131 Nr. 720. \\
\hline 1519 II 26 & Tewrstat bey Bamberg & $\begin{array}{l}\text { StABa Kloster Michelsberg, } \\
\text { Urkunden Nr. } 1954 .\end{array}$ \\
\hline 1526 III 5 & $\begin{array}{l}\text { Teuernstat ausserhalb der } \\
\text { statmauren bey Bamberg }\end{array}$ & StABa A 120 L 131 Nr. 767. \\
\hline 1526 IV 25 & $\begin{array}{l}\text { auserhalb Bamberg zw } \\
\text { Teuerstat }\end{array}$ & StABa A 120 L 131 Nr. 726. \\
\hline 1528 IX 25 & $\begin{array}{l}\text { Teuerstat bey unser stat } \\
\text { Bamberg }\end{array}$ & StABa A 120 L 133 Nr. 867. \\
\hline $1530 \mathrm{~V} 20$ & $\begin{array}{l}\text { Teuernstat ausserhalbn } \\
\text { der statmauern bey Bam- } \\
\text { berg }\end{array}$ & StABa A 120 L 131 Nr. 769. \\
\hline 1531 VI 30 & $\begin{array}{l}\text { Tewerstat auserhalb der } \\
\text { statmauer bey Bamberg }\end{array}$ & StABa A 120 L 131 Nr. 727. \\
\hline 1534 V 31 & $\begin{array}{l}\text { Theuerstatt auserhalb der } \\
\text { mauer bey Bamberg }\end{array}$ & $\begin{array}{l}\text { AEB Rep. I Pfarrei St. Gan- } \\
\text { golf, U } 822 \text {. }\end{array}$ \\
\hline 1536 & $\begin{array}{l}\text { Teuerstat auserhalben der } \\
\text { statmauern bei Bamberg }\end{array}$ & $\begin{array}{l}\text { AEB Rep. I Pfarrei St. Gan- } \\
\text { golf, U } 823 \text {. }\end{array}$ \\
\hline 1539 IV 30 & $\begin{array}{l}\text { Teuerstatt auserhalb der } \\
\text { stattmauer bey Bamberg }\end{array}$ & StABa A 120 L 131 Nr. 729. \\
\hline 1540 IX 12 & $\begin{array}{l}\text { Teuerstat ausserhalb der } \\
\text { statmauer bey Bamberg }\end{array}$ & StABa A 120 L 131 Nr. 730. \\
\hline $1547 \times 1$ & $\begin{array}{l}\text { Teurstat ausserhalb Bam- } \\
\text { berg }\end{array}$ & $\begin{array}{l}\text { StABa Kloster Michelsberg, } \\
\text { Urkunden Nr. } 2284 .\end{array}$ \\
\hline 1548 IX 19 & $\begin{array}{l}\text { Theuerstat bey Bambergk; } \\
\text { Theuerstat; Deuerstat }\end{array}$ & StABa A 120 L 131 Nr. 773. \\
\hline 1551 XI 16 & $\begin{array}{l}\text { Teurstatt ausserhalb Bam- } \\
\text { berg }\end{array}$ & $\begin{array}{l}\text { StABa Kloster Michelsberg, } \\
\text { Urkunden Nr. } 2373 .\end{array}$ \\
\hline
\end{tabular}




\begin{tabular}{|l|l|l|}
\hline 1551 XI 16 & $\begin{array}{l}\text { Teurstat ausserhalb Bam- } \\
\text { berg }\end{array}$ & $\begin{array}{l}\text { StABa Kloster Michelsberg, } \\
\text { Urkunden Nr. 2372. }\end{array}$ \\
\hline 1556 V 7 & $\begin{array}{l}\text { Teuerstat ausserhalb der } \\
\text { stadtmauern zu Bamberg }\end{array}$ & StABa A 120 L 131 Nr. 731. \\
\hline 1565 I 27 & $\begin{array}{l}\text { Tewerstatt ausserhalb der } \\
\text { statt Bambergk }\end{array}$ & StABa A 120 L 131 Nr. 732. \\
\hline
\end{tabular}




\section{Amtsträger}

Bereits Hans Paschke hat eine umfassende Liste der Gangolfer Amtsträger (ohne Obleier) vorgelegt, ${ }^{1081}$ die sich vorrangig auf die Arbeiten von Friedrich Wachter ${ }^{1082}$ und Johannes Kist ${ }^{1083}$ stützt. Diese Liste, geordnet nach den frühesten nachweisbaren Erwähnung der Person in dem jeweiligen Amt, wurde im Folgenden bereinigt und bis zum Jahr 1600 um Quellenfunde ergänzt, welche die Existenz des betreffenden Amtsträger in der vorrangig innerstiftischen Überlieferung belegen. Die Angaben aus Wachter dienen der Orientierung hinsichtlich der Karriere in geistlichen Ämtern des Betreffenden. Wenn nicht näher erläutert, handelt es sich bei den erwähnten Ämtern um Ämter in Bamberg.

\section{Propst}

\begin{tabular}{|c|c|c|}
\hline 1100 & Friedrich & $\begin{array}{l}\text { Wachter Nr. 2729: „abbas St. Mariae in } \\
\text { Turstatt“ }\end{array}$ \\
\hline 1108 & Eberhard & $\begin{array}{l}1108 \text { V } 19 \text { in StABa BU } 149 \text { (beglaubigte } \\
\text { Abschrift von } 1883 \text { II 10); Wachter Nr. } \\
\text { 1843: } 1087 \text { Domkanoniker, } 1108 \text { Dom- } \\
\text { propst, resign. } 1115 \text {, gest. } 1143 \text { VI } 26\end{array}$ \\
\hline 1116 & Sigfried & Wachter Nr. 9582: Domkanoniker \\
\hline 1123 & Ruzelin & $\begin{array}{l}\text { Propstliste von } 1802 \text { in Ussermann: } \\
\text { Episcopatus Bambergensis. 1802. S. } \\
\text { 274; Wachter Nr. 8432: 1099 Domherr, } \\
\text { 1142 oder } 1145 \text { Propst von St. Stephan, } \\
\text { gest. } 1147 \text { I } 22\end{array}$ \\
\hline 1139 & Egilbert & Wachter Nr. 1979: 1109 Domkanoniker, \\
\hline
\end{tabular}

${ }^{1081}$ Paschke: St. Gangolf zu Bamberg. 1959. S. 23-31.

1082 Wachter: General-Personal-Schematismus der Erzdiözese Bamberg. 1908.

1083 Johannes Kist: Die Matrikel der Geistlichkeit des Bistums Bamberg 1400-1556 (Veröffentlichungen der Gesellschaft für Fränkische Geschichte. Reihe IV: Matrikel fränkischer Schulen und Stände, Bd. 7). Würzburg 1955. 


\begin{tabular}{|c|c|c|}
\hline & & $\begin{array}{l}1121 \text { Domdekan, } 1128 \text { Patriarch in } \\
\text { Aquileia, } 1139 \text { Bischof, gest. } 1146 \text { V } 29\end{array}$ \\
\hline 1140 & Udalrich & $\begin{array}{l}1142 \text { X } 28 \text { in StABa KMU Nr. 27; } 1142 \\
\text { in StABa BU 223; } 1143 \text { in StABa BU } \\
\text { 226; Wachter Nr. 10361: } 1114 \text { Domka- } \\
\text { noniker, } 1144 \text { Dompropst, res. 1144, } \\
\text { gest. } 1164 \text { I } 3\end{array}$ \\
\hline 1144 & Eberhard & Wachter Nr. 1844 \\
\hline 1146 & $\begin{array}{l}\text { Konrad von Mem- } \\
\text { melsdorf }\end{array}$ & $\begin{array}{l}1149 \text { in StABa BU 247; } 1151 \text { IV } 10 \text { in } \\
\text { StABa BU 255; } 1151 \text { in StABa KMU Nr. } \\
\text { 38; } 1152 \text { III } 27 \text { in StABa BU 264; } 1152 \text { II } \\
14 \text { in StABa KMU Nr. 39; Wachter Nr. } \\
\text { 6629: } 1123 \text { Domkustos, gest. } 1164\end{array}$ \\
\hline 1147 & Ludwig & $\begin{array}{l}\text { Propstliste von } 1802 \text { in Ussermann: } \\
\text { Episcopatus Bambergensis. 1802. S. } \\
274 .\end{array}$ \\
\hline 1155 & $\begin{array}{l}\text { Hermann von } \\
\text { Aurach }\end{array}$ & $\begin{array}{l}1157 \text { in StABa BU 283; Wachter Nr. 314: } \\
\text { Domkanoniker, } 1145 \text { Domkeller, } 1163 \\
\text { Domdekan, } 1170 \text { Bischof, gest. } 1177 \text { VI } \\
12\end{array}$ \\
\hline 1158 & $\begin{array}{l}\text { Konrad von Schein- } \\
\text { feld }\end{array}$ & $\begin{array}{l}1153 \text { in Propstliste von } 1802 \text { in Usser- } \\
\text { mann: Episcopatus Bambergensis. } \\
\text { 1802. S. 274; Wachter Nr. 8645: Dom- } \\
\text { kanoniker von Bamberg und Würzburg }\end{array}$ \\
\hline 1174 & Burchhard & $\begin{array}{l}1178 \text { IV } 6 \text { in StABa BU 335; um } 1180 \text { in } \\
\text { StABa BU 347; } 1187 \text { in StABa BU 376; } \\
\text { um } 1190 \text { in StABa BU 387; um } 1190 \text { in } \\
\text { StABa BU 387; Wachter Nr. 1297: } 1165 \\
\text { Domkanoniker, } 1186 \text { Propst von St. } \\
\text { Jakob, gest. } 1190 \text { IX } 7\end{array}$ \\
\hline 1185 & $\begin{array}{l}\text { Ulrich von He- } \\
\text { roldsbach }\end{array}$ & $\begin{array}{l}\text { Wachter Nr. 4234: } 1165 \text { Domkanoniker, } \\
\text { gest. } 1190\end{array}$ \\
\hline 1190 & Poppo von Andechs- & Wachter Nr. 173: 1187 Propst von St. \\
\hline
\end{tabular}




\begin{tabular}{|c|c|c|}
\hline & Meranien & $\begin{array}{l}\text { Jakob, } 1190 \text { Propst von St. Stephan, } \\
1206 \text { Dompropst, gest. } 1245 \text { XII } 2\end{array}$ \\
\hline 1192 & $\begin{array}{l}\text { Eckbert von An- } \\
\text { dechs-Meranien }\end{array}$ & $\begin{array}{l}1192 \text { in StABa BU } 391 \text { 1192; Propstliste } \\
\text { von } 1802 \text { in Ussermann: Episcopatus } \\
\text { Bambergensis. 1802. S. 274; Wachter } \\
\text { Nr. 171: } 1195 \text { Dompropst, } 1203 \text { Bischof, } \\
\text { gest. } 1237 \text { VI } 5\end{array}$ \\
\hline 1203 & $\begin{array}{l}\text { Siegfried Graf von } \\
\text { Oettingen }\end{array}$ & $\begin{array}{l}1205 \text { in StAWu Kloster Ebrach, Urkun- } \\
\text { den 1205/I; } 1206 \text { in StABa BU 441; } 1216 \\
\text { in StABa BU 473; } 1217 \text { in StABa KMU } \\
\text { Nr. 75; um } 1217 \text { in StABa BU 485; } 1233 \\
\text { in StABa KMU Nr. 86; Propstliste von } \\
1802 \text { in Ussermann: Episcopatus Bam- } \\
\text { bergensis. 1802. S. 274; Wachter Nr. } \\
\text { 7250: } 1216 \text { Domkanoniker, } 1237 \text { Bi- } \\
\text { schof, gest. } 1237 \text { XI } 18\end{array}$ \\
\hline 1236 & $\begin{array}{l}\text { Martin von Lichten- } \\
\text { stein }\end{array}$ & $\begin{array}{l}\text { Propstliste von } 1802 \text { in Ussermann: } \\
\text { Episcopatus Bambergensis. 1802. S. } \\
\text { 274; Wachter Nr. } 6142\end{array}$ \\
\hline 1248 & Albert von Kastell & $\begin{array}{l}\text { Wachter Nr. 5011: } 1237 \text { Domkanoniker, } \\
\text { gest. } 1258 \text { IV } 19\end{array}$ \\
\hline 1264 & $\begin{array}{l}\text { Eberhard von } \\
\text { Hirschberg }\end{array}$ & Wachter Nr. 4368: 1248 Domkanoniker \\
\hline 1268 & $\begin{array}{l}\text { Albert Graf von } \\
\text { Schlüsselberg }\end{array}$ & $\begin{array}{l}1275 \text { II } 1 \text { in StABa BU 878; } 1275 \text { IV } 23 \\
\text { in StABa BU 881; Propstliste von } 1743 \\
\text { in StABa Stift St. Gangolf, Akten und } \\
\text { Bände Nr. } 160 \text { fol. 77'; Propstliste von } \\
1802 \text { in Ussermann: Episcopatus Bam- } \\
\text { bergensis. } 1802 . \text { S. 274; Wachter Nr. } \\
\text { 8834: } 1261 \text { Domkanoniker }\end{array}$ \\
\hline 1285 & $\begin{array}{l}\text { Leupold von Grind- } \\
\text { lach }\end{array}$ & $\begin{array}{l}1285 \text { VII } 2 \text { in StAWu Kloster Ebrach, } \\
\text { Urkunden } 1285 \text { VII 2/I und } 1285 \text { VII } \\
\text { 2/II; Wachter Nr. 3381: Domkanoniker }\end{array}$ \\
\hline
\end{tabular}




\begin{tabular}{|c|c|c|}
\hline & & $\begin{array}{l}\text { von Bamberg und Würzburg, } 1272 \\
\text { Propst von St. Stephan }\end{array}$ \\
\hline 1302 & $\begin{array}{l}\text { Friedrich Graf von } \\
\text { Truhendingen }\end{array}$ & $\begin{array}{l}1302 \text { X } 27 \text { in StABa KMU Nr. 141; } 1302 \\
\text { XI } 10 \text { in StABa Kloster Langheim, Ur- } \\
\text { kunden } 1302 \text { XI 10; } 1311 \text { VIII } 24 \text { in } \\
\text { StAWu Kloster Ebrach, Urkunden } 1311 \\
\text { VIII 24/I; } 1311 \text { VIII } 26 \text { in StAWu Klos- } \\
\text { ter Ebrach, Urkunden } 1311 \text { VIII 26; } \\
1311 \text { X } 1 \text { in StAWu Urkunden Kloster } \\
\text { Ebrach } 1311 \text { X 1/I und 1311 X 1/II ; } \\
1317 \text { IX } 7 \text { in StABa BU 1682; 1318 XII } \\
13 \text { in StABa BU 1716; Propstliste von } \\
1743 \text { in StABa Stift St. Gangolf, Akten } \\
\text { und Bände Nr. } 160 \text { fol. 77;; Propstliste } \\
\text { von } 1802 \text { in Ussermann: Episcopatus } \\
\text { Bambergensis. } 1802 . \text { S. 274; Wachter } \\
\text { Nr. } 10305: 1286 \text { Domkanoniker, gest. } \\
1318\end{array}$ \\
\hline 1323 & $\begin{array}{l}\text { Friedrich Graf von } \\
\text { Hohenlohe }\end{array}$ & $\begin{array}{l}\text { 1324 I } 29 \text { in StABa BU 1844; } 1329 \text { in } \\
\text { StABa BU 1988; } 1331 \text { X } 25 \text { in StABa BU } \\
\text { 2066; Propstliste von } 1743 \text { in StABa Stift } \\
\text { St. Gangolf, Akten und Bände Nr. } 160 \\
\text { fol. 77'; Propstliste von } 1802 \text { in Usser- } \\
\text { mann: Episcopatus Bambergensis. } \\
\text { 1802. S. 274; Wachter Nr. 4559: } 1319 \\
\text { Domkanoniker, } 1323 \text { Domscholaster } \\
\text { und Propst von St. Jakob, } 1325 \text { Domde- } \\
\text { kan, gest. } 1351 \text { V } 18\end{array}$ \\
\hline 1360 & $\begin{array}{l}\text { Eberhard von Ho- } \\
\text { henberg }\end{array}$ & $\begin{array}{l}\text { StABa Stift St. Gangolf, Akten und Bän- } \\
\text { de Nr. } 128 \text { fol. } 2 \text { (Jahrtag laut Annivers- } \\
\text { arbuch 16. Januar); Propstliste von } 1743 \\
\text { in StABa Stift St. Gangolf, Akten und } \\
\text { Bände Nr. } 160 \text { fol. 77'; Wachter Nr. } \\
\text { 4548: } 1315 \text { Domscholaster, } 1338 \text { Gene- }\end{array}$ \\
\hline
\end{tabular}




\begin{tabular}{|c|c|c|}
\hline & & $\begin{array}{l}\text { ralvikar, } 1360 \text { Kaplan und Sekretär Kai- } \\
\text { ser Karls IV., gest. } 1363 \text { I } 13\end{array}$ \\
\hline 1367 & $\begin{array}{l}\text { Otto von Immels- } \\
\text { dorf }\end{array}$ & $\begin{array}{l}1368 \text { II } 29 \text { (Abschrift) in StABa Stift St. } \\
\text { Gangolf, Akten und Bände Nr. } 3 \text { Teil } 1 \\
\text { fol. 42; Wachter Nr. 4847: Domkanoni- } \\
\text { ker }\end{array}$ \\
\hline 1380 & Heinrich von Brunn & $\begin{array}{l}\text { Wachter Nr. 1189: Domkanoniker in } \\
\text { Bamberg und Speyer, } 1380 \text { Propst von } \\
\text { St. Jakob, } 1388 \text { Propst von St. Stephan, } \\
\text { gest. } 1388 \text { VI } 23\end{array}$ \\
\hline 1384 & $\begin{array}{l}\text { Otto von Gauber- } \\
\text { stadt }\end{array}$ & $\begin{array}{l}1394 \text { (Abschrift) in StABa A 120 L } 133 \\
\text { Nr. 869; } 1394 \text { XI } 3 \text { (Abschrift) in StABa } \\
\text { Stift St. Gangolf, Akten und Bände Nr. } \\
168 \text { fol. 26; Propstliste von } 1743 \text { in StA- } \\
\text { Ba Stift St. Gangolf, Akten und Bände } \\
\text { Nr. } 160 \text { fol. 77‘; Propstliste von } 1802 \text { in } \\
\text { Ussermann: Episcopatus Bambergensis. } \\
\text { 1802 S. 274; Wachter Nr. 2933: } 1377 \\
\text { Domkanoniker, gest. } 1397 \text { V } 10\end{array}$ \\
\hline 1398 & $\begin{array}{l}\text { Friedrich Stiebar } \\
\text { von Buttenheim }\end{array}$ & $\begin{array}{l}1398 \text { VII } 12 \text { in StABa Kloster Langheim, } \\
\text { Urkunden } 1398 \text { VII 12; } 1398 \text { XI } 27 \text { in } \\
\text { StABa BU 4665; } 1400 \text { I } 17 \text { in StABa } \\
\text { KMU Nr. 605; } 1408 \text { II } 2 \text { (Abschrift) in } \\
\text { StABa Stift St. Gangolf, Akten und Bän- } \\
\text { de Nr. } 168 \text { fol. 95; Propstliste von } 1743 \\
\text { in StABa Stift St. Gangolf, Akten und } \\
\text { Bände Nr. } 160 \text { fol. 77'; Propstliste von } \\
1802 \text { in Ussermann: Episcopatus Bam- } \\
\text { bergensis. 1802. S. 274; Wachter Nr. } \\
\text { 9901: } 1391 \text { Domkanoniker, } 1409 \\
\text { Domdekan, gest. } 1412 \text { I } 13\end{array}$ \\
\hline 1410 & $\begin{array}{l}\text { Hermann Graf von } \\
\text { Henneberg }\end{array}$ & $\begin{array}{l}1415 \text { VII } 15 \text { in StABa A } 120 \text { L } 134 \text { Nr. } \\
\text { 902; Propstliste von } 1743 \text { in StABa Stift }\end{array}$ \\
\hline
\end{tabular}




\begin{tabular}{|c|c|c|}
\hline & & $\begin{array}{l}\text { St. Gangolf, Akten und Bände Nr. } 160 \\
\text { fol. 77'; Propstliste von } 1802 \text { in Usser- } \\
\text { mann: Episcopatus Bambergensis. } \\
\text { 1802. S. 274; Wachter Nr. 4117: Dom- } \\
\text { kanoniker, } 1398 \text { Generalvikar, gest. } \\
1416\end{array}$ \\
\hline 1417 & $\begin{array}{l}\text { Thomas Graf von } \\
\text { Wertheim }\end{array}$ & $\begin{array}{l}1417 \text { (Abschrift) in StABa Stift St. Gan- } \\
\text { golf, Akten und Bände Nr. } 118 \text { fol. 1; } \\
1417 \text { (Abschrift) in StABa Stift St. Gan- } \\
\text { golf, Akten und Bände Nr. } 119 \text { fol. 1; } \\
\text { Propstliste von } 1743 \text { in StABa Stift St. } \\
\text { Gangolf, Akten und Bände Nr. } 160 \text { fol. } \\
\text { 77‘; Propstliste von } 1802 \text { in Ussermann: } \\
\text { Episcopatus Bambergensis. } 1802 . \text { S. } \\
\text { 274; Wachter Nr. 10993: 1409 Domka- } \\
\text { noniker von Bamberg und Würzburg, } \\
\text { abgesetzt } 1431 \text { I 14, gest. } 1444\end{array}$ \\
\hline 1433 & Stephan Beheim & $\begin{array}{l}1433 \text { (Abschrift) in StABa Stift St. Gan- } \\
\text { golf, Akten und Bände Nr. } 119 \text { fol. 1; } \\
\text { 1434 XI } 3 \text { in StABa A } 120 \text { L } 133 \text { Nr. 870; } \\
1434 \text { XI } 3 \text { (Abschrift) in StABa Stift St. } \\
\text { Gangolf, Akten und Bände Nr. } 168 \text { fol. } \\
\text { 30; } 1435 \text { XI } 22 \text { in StABa A } 120 \text { L } 133 \text { Nr. } \\
\text { 871; } 1435 \text { (Abschrift) in StABa Stift St. } \\
\text { Gangolf, Akten und Bände Nr. } 168 \text { fol. } \\
\text { 41; } 1436 \text { I } 23 \text { in StABa Kloster Lang- } \\
\text { heim, Urkunden } 1436 \text { I 23; } 1436 \text { I } 23 \text { in } \\
\text { StABa A } 136 \text { L } 223 \text { Nr. 789; } 1436 \text { XI } 12 \\
\text { in StABa A } 120 \text { L } 133 \text { Nr. } 872 \text { und Nr. } \\
\text { 873; } 1437 \text { VII } 28 \text { in StABa A } 120 \text { L } 134 \\
\text { Nr. } 906 \text {; Propstliste von 1743 in StABa } \\
\text { Stift St. Gangolf, Akten und Bände Nr. } \\
\text { 160 fol. 77'; Propstliste von } 1802 \text { in } \\
\text { Ussermann: Episcopatus Bambergensis. }\end{array}$ \\
\hline
\end{tabular}




\begin{tabular}{|c|c|c|}
\hline & & $\begin{array}{l}\text { 1802. S. 274; Wachter Nr. 642: Dr. the- } \\
\text { ol., } 1425 \text { Kanoniker von St. Stephan, } \\
\text { resign. 1441, gest. } 1444\end{array}$ \\
\hline 1441 & $\begin{array}{l}\text { Heinrich von Streit- } \\
\text { berg }\end{array}$ & $\begin{array}{l}\text { Wachter Nr. 10002: 1408 Domkanoni- } \\
\text { ker, resign. } 1442 \text { V 27, gest. } 1451\end{array}$ \\
\hline 1442 & Stephan Beheim & $\begin{array}{l}\text { Wachter Nr. 642: Dr. theol., } 1425 \text { Kano- } \\
\text { niker von St. Stephan, resign. 1441, } \\
\text { gest. } 1444\end{array}$ \\
\hline 1444 & Johann Kautsch & $\begin{array}{l}1445 \text { I } 26 \text { in StABa A } 120 \text { L } 133 \text { Nr. 874; } \\
1445 \text { II } 14 \text { in StABa A } 120 \text { L } 133 \text { Nr. 875; } \\
1447 \text { VI } 3 \text { in StABa A } 120 \text { L } 131 \text { Nr. 752; } \\
\text { 1449 XI } 8 \text { in StABa A } 120 \text { L } 131 \text { Nr. 753; } \\
\text { 1449 XI } 17 \text { in StABa A } 120 \text { L } 133 \text { Nr. } \\
\text { 876; } 1452 \text { VIII } 14 \text { in StABa A } 120 \text { L } 133 \\
\text { Nr. 877; } 1454 \text { (Abschrift) in StABa Stift } \\
\text { St. Gangolf, Akten und Bände Nr. } 120 \\
\text { fol. 0; } 1466 \text { VI } 16 \text { (bereits verstorben) in } \\
\text { StABa A } 120 \text { L } 131 \text { Nr. } 757 \text {; StABa Stift } \\
\text { St. Gangolf, Akten und Bände Nr. } 128 \\
\text { fol. } 18 \text { (Jahrtag laut Anniversarbuch 19. } \\
\text { Juli); Propstliste von } 1743 \text { in StABa Stift } \\
\text { St. Gangolf, Akten und Bände Nr. } 160 \\
\text { fol. } 77 \text {; Propstliste von } 1802 \text { in Usser- } \\
\text { mann: Episcopatus Bambergensis. } \\
\text { 1802. S. 274; Wachter Nr. } 5053 \text { : Dr. jur., } \\
\text { 1440 Dekan von St. Stephan, gest. } 1462 \\
\text { VII } 19\end{array}$ \\
\hline 1462 & $\begin{array}{l}\text { Philipp Graf von } \\
\text { Henneberg }\end{array}$ & $\begin{array}{l}\text { Propstliste von } 1743 \text { in StABa Stift St. } \\
\text { Gangolf, Akten und Bände Nr. } 160 \text { fol. } \\
\text { 77'; Propstliste von } 1802 \text { in Ussermann: } \\
\text { Episcopatus Bambergensis. 1802. S. } \\
\text { 274; Wachter Nr. } 4122: 1444 \text { Domkano- } \\
\text { niker, } 1475 \text { Bischof, gest. } 1487 \text { I } 26\end{array}$ \\
\hline
\end{tabular}




\begin{tabular}{|c|c|c|}
\hline 1466 & Gumpert Fabri & 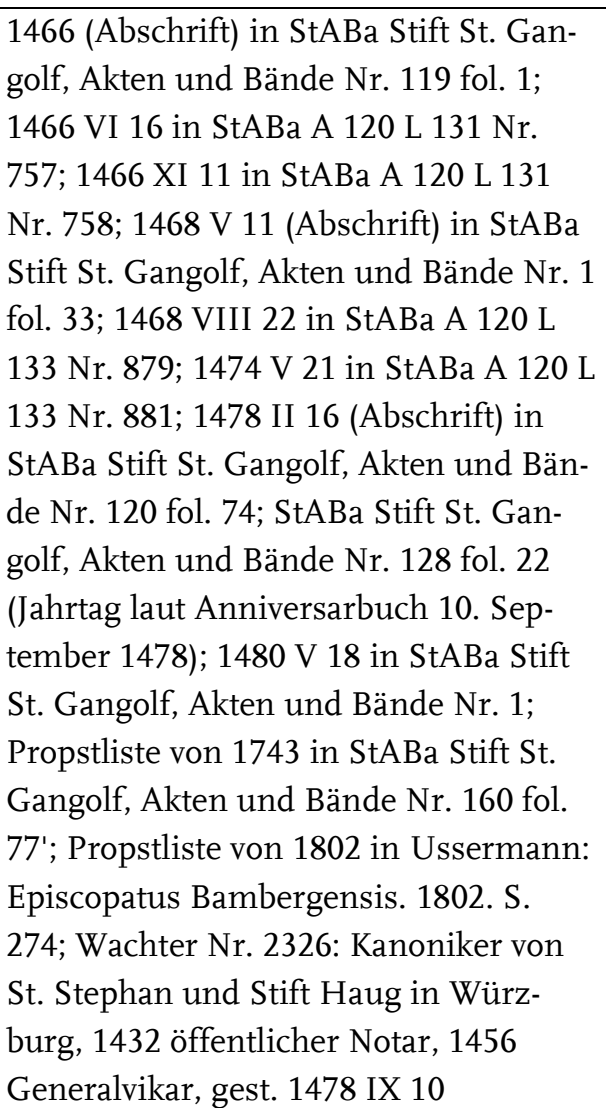 \\
\hline 1479 & $\begin{array}{l}\text { Berthold Graf von } \\
\text { Henneberg }\end{array}$ & $\begin{array}{l}\text { 1479 (Abschrift) in StABa Stift St. Gan- } \\
\text { golf, Akten und Bände Nr. } 119 \text { fol. 1‘; } \\
\text { 1479 III } 16 \text { in StABa A } 120 \text { L } 131 \text { Nr. } \\
\text { 725; Propstliste von } 1743 \text { in StABa Stift } \\
\text { St. Gangolf, Akten und Bände Nr. } 160 \\
\text { fol. 77'; Propstliste von } 1802 \text { in Usser- } \\
\text { mann: Episcopatus Bambergensis. } \\
\text { 1802. S. 274; Wachter Nr. 4113: Dom- } \\
\text { kanoniker von Bamberg, Würzburg, } \\
\text { Köln und Straßburg, } 1470 \text { Propst von } \\
\text { St. Stephan, } 1475 \text { Domkantor, gest. }\end{array}$ \\
\hline
\end{tabular}




\begin{tabular}{|l|l|l|}
\hline & & 1495 IV 20 \\
\hline 1486 & Johann von & Propstliste von 1743 in StABa Stift St. \\
& Bleuningen & Gangolf, Akten und Bände Nr. 160 fol. \\
& & 77'; Propstliste von 1802 in Ussermann: \\
& & Episcopatus Bambergensis. 1802. S. \\
274; Wachter Nr. 931
\end{tabular}




\begin{tabular}{|c|c|c|}
\hline & Buttenheim & $\begin{array}{l}\text { de Nr. } 129 \text { fol. 37' (Jahrtag laut Anniver- } \\
\text { sarbuch } 1515 \text { VI 8); Propstliste von } 1743 \\
\text { in StABa Stift St. Gangolf, Akten und } \\
\text { Bände Nr. } 160 \text { fol. 77'; Propstliste von } \\
1802 \text { in Ussermann: Episcopatus Bam- } \\
\text { bergensis. 1802. S. 275; Wachter Nr. } \\
\text { 9902: Domkanoniker, } 1505 \text { Domdekan } \\
\text { und Propst von St. Jakob, gest. } 1515 \text { VI } \\
8\end{array}$ \\
\hline 1512 & $\begin{array}{l}\text { Andreas Fuchs von } \\
\text { Dornheim }\end{array}$ & $\begin{array}{l}\text { Propstliste von } 1743 \text { in StABa Stift St. } \\
\text { Gangolf, Akten und Bände Nr. } 160 \text { fol. } \\
\text { 77'; Propstliste von } 1802 \text { in Ussermann: } \\
\text { Episcopatus Bambergensis. 1802. S. } \\
\text { 275; Wachter Nr. 2834: Domkanoniker } \\
\text { in Bamberg, Augsburg und Würzburg, } \\
1515 \text { Domdekan, gest. } 1543 \text { X } 5\end{array}$ \\
\hline 1516 & Paul Neydecker & $\begin{array}{l}\text { 1516 VII } 30 \text { in AEB Rep. I Pfarrei St. } \\
\text { Gangolf, U 826; 1527 VII } 31 \text { in StABa A } \\
\text { 120 L } 134 \text { Nr. 899; } 1528 \text { IX } 25 \text { in StABa } \\
\text { A } 120 \text { L } 133 \text { Nr. 867; } 1541 \text { II } 25 \text { in StABa } \\
\text { A } 120 \text { L } 133 \text { Nr. 883; } 1543 \text { in StABa Stift } \\
\text { St. Gangolf, Akten und Bände Nr. } 192 \\
\text { fol. 16'; } 1559 \text { III } 1 \text { in StABa A } 136 \text { L } 222 \\
\text { Nr. } 753 \text { und Nr. 754; Propstliste von } \\
\text { 1743 in StABa Stift St. Gangolf, Akten } \\
\text { und Bände Nr. } 160 \text { fol. 77'; Propstliste } \\
\text { von } 1802 \text { in Ussermann: Episcopatus } \\
\text { Bambergensis. 1802. S. 275; Wachter } \\
\text { Nr. } 7111 \text { : Dr. theol., Dr. jur., fürstbi- } \\
\text { schöflicher Rat, Kanoniker von St. Ste- } \\
\text { phan, resign. 1563, gest. 1565 I } 24\end{array}$ \\
\hline 1565 & $\begin{array}{l}\text { Erasmus von Neus- } \\
\text { tetter gen. Stürmer }\end{array}$ & $\begin{array}{l}1565 \text { I } 27 \text { in StABa A } 120 \text { L } 131 \text { Nr. 732; } \\
1565 \text { in StABa Stift St. Gangolf, Akten } \\
\text { und Bände Nr. } 7 \text { und Nr. 12; Propstliste }\end{array}$ \\
\hline
\end{tabular}




\begin{tabular}{|c|c|c|}
\hline & & $\begin{array}{l}\text { von } 1743 \text { in StABa Stift St. Gangolf, } \\
\text { Akten und Bände Nr. } 160 \text { fol. 77'; } \\
\text { Propstliste von } 1802 \text { in Ussermann: } \\
\text { Episcopatus Bambergensis. 1802. S. } \\
\text { 275; Wachter Nr. 7087: } 1545 \text { Domkano- } \\
\text { niker in Würzburg, } 1555 \text { Propst am Stift } \\
\text { Haug in Würzburg, } 1561 \text { Domkanoni- } \\
\text { ker, } 1564 \text { Domdekan in Würzburg, gest. } \\
\text { 1594 XII } 3\end{array}$ \\
\hline 1595 & $\begin{array}{l}\text { Wolfgang Albrecht } \\
\text { von Würtzburg }\end{array}$ & $\begin{array}{l}\text { Propstliste von } 1743 \text { in StABa Stift St. } \\
\text { Gangolf, Akten und Bände Nr. } 160 \text { fol. } \\
\text { 78; Propstliste von } 1802 \text { in Ussermann: } \\
\text { Episcopatus Bambergensis. } 1802 . \text { S. } \\
\text { 275; Wachter Nr. 11293: } 1558 \text { Domka- } \\
\text { noniker, } 1560 \text { Domkanoniker in Würz- } \\
\text { burg, } 1591 \text { Propst von St. Stephan, } 1591 \\
\text { Dompropst, gest. } 1610 \text { III } 24\end{array}$ \\
\hline 1610 & \multicolumn{2}{|c|}{ Wolf Heinrich von Redtwitz } \\
\hline 1617 & \multicolumn{2}{|c|}{ Hector von Kotzau } \\
\hline 1619 & \multicolumn{2}{|c|}{ Johann Kaspar von Lammersheim } \\
\hline 1627 & \multicolumn{2}{|c|}{ Franz von Hatzfeld } \\
\hline 1633 & \multicolumn{2}{|c|}{ Ludwig Konrad von Thüngen } \\
\hline 1636 & \multicolumn{2}{|c|}{ Hieronymus von Würtzburg } \\
\hline 1651 & \multicolumn{2}{|c|}{ Philipp Valentin Voit von Rieneck } \\
\hline 1658 & \multicolumn{2}{|c|}{ Franz Conrad von Stadion } \\
\hline 1685 & \multicolumn{2}{|c|}{ Veit Dietrich von Erthal } \\
\hline 1687 & \multicolumn{2}{|c|}{ Carl Sigismund Freiherr von Aufsess } \\
\hline 1715 & \multicolumn{2}{|c|}{ Johann Franz Karl Graf von Ostein } \\
\hline 1718 & \multicolumn{2}{|c|}{ Franz Peter Freiherr von Sickingen } \\
\hline 1736 & \multicolumn{2}{|c|}{ Karl Dietrich Freiherr von Aufsess } \\
\hline 1742 & \multicolumn{2}{|c|}{ Carl Dietrich Freiherr von Kunsberg } \\
\hline 1745 & \multicolumn{2}{|c|}{ Adam Friedrich Graf von Seinsheim } \\
\hline 1757 & \multicolumn{2}{|c|}{ Philiph Ernst Heinrich Carl Anton Leonhard Veit von Salzburg } \\
\hline
\end{tabular}




\begin{tabular}{|l|l|}
\hline 1782 & Johann Carl Dietrich Josef Freiherr von Guttenberg \\
\hline 1786 & Johann Philipp Graf von Stadion \\
\hline 1801 & Franz Erwein Carl Kaspar Graf von der Leyen \\
\hline
\end{tabular}

\section{Dekan}

\begin{tabular}{|c|c|c|}
\hline 1058 & Adalbero & $\begin{array}{l}\text { 1059 IV } 13 \text { (Synodialprotokoll Bischof } \\
\text { Gunther) in Jaffé: Acta synodi. 1869. S. } \\
498 \text { Nr. 8; } 1059 \text { IX 22; "Adalbero presby- } \\
\text { ter s. Gyngolfi" in StBB Lit. } 144 \text { fol. 95r } \\
\text { (Nekrolog des Kloster Michelsberg aus } \\
\text { 12. Jhd, Zuordnung zu den Jahren } 1059 \\
\text { und } 1087 \text { durch Nospickel: Das Necro- } \\
\text { log des Klosters Michelsberg. 2004. S. } \\
\text { 445); Dekanliste von } 1802 \text { in Usser- } \\
\text { mann: Episcopatus Bambergensis. } \\
\text { 1802. S. 276; Wachter Nr. 22: Domka- } \\
\text { noniker }\end{array}$ \\
\hline 1109 & Gumpo & Wachter Nr. 3534 \\
\hline 1127 & Gerung & $\begin{array}{l}1127 \text { in StABa BU 156; [1127] (undat.) } \\
\text { in StABa BU 178; Dekanliste von } 1802 \\
\text { in Ussermann: Episcopatus Bamber- } \\
\text { gensis. 1802. S. 276; Wachter Nr. } 3054\end{array}$ \\
\hline 1164 & Wilhelm & $\begin{array}{l}\text { Dekanliste von } 1802 \text { in Ussermann: } \\
\text { Episcopatus Bambergensis. 1802. S. } \\
\text { 276; Wachter Nr. } 11083\end{array}$ \\
\hline 1185 & Otto von Hersbruck & Wachter Nr. 7322 \\
\hline 1195 & Gottschalk & $\begin{array}{l}1199 \text { in StABa BU 411; Wachter Nr. } \\
3264\end{array}$ \\
\hline 1208 & Johann & $\begin{array}{l}\text { Dekanliste von } 1802 \text { in Ussermann: } \\
\text { Episcopatus Bambergensis. 1802. S. } 276\end{array}$ \\
\hline 1215 & Gundeloch & Wachter Nr. 3548 \\
\hline 1217 & Heinrich Raab & $\begin{array}{l}1217 \text { in StABa KMU Nr. 75; Dekanliste } \\
\text { von } 1802 \text { in Ussermann: Episcopatus }\end{array}$ \\
\hline
\end{tabular}




\begin{tabular}{|c|c|c|}
\hline & & $\begin{array}{l}\text { Bambergensis. 1802. S. 276; Wachter } \\
\text { Nr. 7682b }\end{array}$ \\
\hline 1221 & $\begin{array}{l}\text { Krafto von Her- } \\
\text { dingsberg }\end{array}$ & $\begin{array}{l}\text { Wachter Nr. } 4164 \text { und 5603: Domkano- } \\
\text { niker, } 1218 \text { Propst der alten Kapelle in } \\
\text { Regensburg, } 1227 \text { Domdekan }\end{array}$ \\
\hline 1221 & Albert, Vizedekan & Wachter Nr. 96 \\
\hline 1240 & Ebo & $\begin{array}{l}1240 \text { VII } 10 \text { in StABa BU 600; } 1242 \text { in } \\
\text { StABa BU 613; } 1242 \text { in StABa BU 614; } \\
1250 \text { in StABa KMU Nr. 102; Wachter } \\
\text { Nr. } 1908\end{array}$ \\
\hline 1241 & $\begin{array}{l}\text { Heinrich Stör von } \\
\text { Ostrach }\end{array}$ & Wachter Nr. 9946: 1237 Domkanoniker \\
\hline 1261 & Hiltebold & $\begin{array}{l}1261 \text { VI } 13 \text { in StABa BU 782; Wachter } \\
\text { Nr. 4348: Domkanoniker }\end{array}$ \\
\hline 1268 & Otto & $\begin{array}{l}\text { Dekanliste von } 1802 \text { in Ussermann: } \\
\text { Episcopatus Bambergensis. 1802. S. } \\
\text { 276; Wachter Nr. 7325: Pfarrer in Hal- } \\
\text { lerndorf, außerdem Keller von St. Gan- } \\
\text { golf }\end{array}$ \\
\hline 1271 & Peter, Vizedekan & Wachter Nr. 7396 \\
\hline 1279 & Johann Kiessling & $\begin{array}{l}\text { Dekanliste von } 1802 \text { in Ussermann: } \\
\text { Episcopatus Bambergensis. 1802. S. } \\
\text { 276; Wachter Nr. } 5184\end{array}$ \\
\hline 1291 & Jodokus Walter & $\begin{array}{l}\text { Dekanliste von } 1802 \text { in Ussermann: } \\
\text { Episcopatus Bambergensis. 1802. S. } \\
\text { 276; Wachter Nr. } 10684\end{array}$ \\
\hline 1294 & Marquard & $\begin{array}{l}1295 \text { V } 25 \text { in StAWu Kloster Ebrach, } \\
\text { Urkunden } 1295 \text { V 25; Dekanliste bei: } \\
\text { Ussermann Episcopatus Bambergensis } \\
1802 \text { S. 276; Wachter Nr. } 6431\end{array}$ \\
\hline 1303 & Albert, Vizedekan & $\begin{array}{l}1303 \text { III } 31 \text { (Abschrift) in StABa Stift St. } \\
\text { Gangolf, Akten und Bände Nr. 3; Wach- } \\
\text { ter Nr. } 105\end{array}$ \\
\hline
\end{tabular}




\begin{tabular}{|c|c|c|}
\hline 1308 & Friedrich & 1308 IV 5 in StABa KMU Nr. 154 \\
\hline 1310 & Heinrich Tunne & $\begin{array}{l}\text { Dekanliste von } 1802 \text { in Ussermann: } \\
\text { Episcopatus Bambergensis. 1802. S. } 276\end{array}$ \\
\hline 1311 & Friedrich & $\begin{array}{l}\text { 1311 VIII } 24 \text { in StAWu Urkunden Klos- } \\
\text { ter Ebrach } 1311 \text { VIII 24/I und } 1311 \text { VIII } \\
\text { 24/II; } 1311 \text { X } 1 \text { in StAWu Kloster E- } \\
\text { brach, Urkunden } 1311 \text { X 1/I und } 1311 \text { X } \\
\text { 1/II; } 1312 \text { XII } 22 \text { in StABa KMU Nr. } \\
\text { 170; } 1315 \text { VI } 11 \text { in StABa BU 1618; } 1317 \\
\text { XII } 20 \text { (Abschrift) in StABa Stift St. } \\
\text { Gangolf, Akten und Bände Nr. } 1 \text { fol. 20; } \\
1318 \text { V } 14 \text { (Abschrift) in StABa Stift St. } \\
\text { Gangolf, Akten und Bände Nr. } 1 \text { fol. 47; } \\
\text { Dekanliste von } 1802 \text { in Ussermann: } \\
\text { Episcopatus Bambergensis. } 1802 . \text { S. } 276\end{array}$ \\
\hline 1320 & Eberhard & Wachter Nr. 1870 \\
\hline 1326 & Konrad & $\begin{array}{l}\text { Dekanliste von } 1802 \text { in Ussermann: } \\
\text { Episcopatus Bambergensis. 1802. S. } 276\end{array}$ \\
\hline 1331 & Walter Gundloch & $\begin{array}{l}1331 \text { VII } 18 \text { in StABa BU 2060; } 1331 \text { X } \\
25 \text { in StABa BU 2066; } 1333 \text { VIII } 27 \text { (Ab- } \\
\text { schrift) in StABa Stift St. Gangolf, Akten } \\
\text { und Bände Nr. } 1 \text { fol. 19'; } 1335 \text { III } 28 \text { in } \\
\text { StABa BU 2179; } 1342 \text { XII } 13 \text { in StABa } \\
\text { KMU 294; } 1340 \text { (Abschrift) in SttABa B } \\
11 \text { Nr. } 100 \text { fol. 27'-28; } 1344 \text { IV } 26 \text { in } \\
\text { StABa KMU Nr. 302; } 1345 \text { XI } 28 \text { in } \\
\text { StABa BU 2537; 1348 XII } 20 \text { in StABa } \\
\text { BU 2636; } 1357 \text { III } 5 \text { in StABa Stift St. } \\
\text { Gangolf, Akten und Bände Nr. } 1 \text { fol. 32; } \\
1364 \text { IV } 21 \text { in StABa BU 3240; StABa } \\
\text { Stift St. Gangolf, Akten und Bände Nr. } \\
129 \text { fol. 18 (Jahrtag laut Anniversarbuch } \\
1370 \text { III 15); Dekanliste von 1802 in }\end{array}$ \\
\hline
\end{tabular}




\begin{tabular}{|c|c|c|}
\hline & & $\begin{array}{l}\text { Ussermann: Episcopatus Bambergensis. } \\
\text { 1802. S. 276; Wachter Nr. 3550: gest. } \\
1370 \text { III } 15\end{array}$ \\
\hline 1354 & Nikolaus Henlin & $\begin{array}{l}\text { Dekanliste von } 1802 \text { in Ussermann: } \\
\text { Episcopatus Bambergensis. 1802. S. } \\
\text { 276; Wachter Nr. } 4109\end{array}$ \\
\hline 1362 & Wick & Wachter Nr. 11027 \\
\hline 1362 & Heinrich Bletzner & $\begin{array}{l}1362 \text { I } 17 \text { (Abschrift) in StABa Stift St. } \\
\text { Gangolf, Akten und Bände Nr. 1; } 1376 \\
\text { XII } 4 \text { in StABa BU 3726; } 1387 \text { V } 25 \\
\text { (Abschrift) in StABa A 120 L } 134 \text { Nr. } \\
\text { 922; StABa Stift St. Gangolf, Akten und } \\
\text { Bände Nr. } 128 \text { fol. 21' (Todestag laut } \\
\text { Anniversarbuch 1386 VIII 30); Dekan- } \\
\text { liste von } 1802 \text { in Ussermann: Episco- } \\
\text { patus Bambergensis. 1802. S. 276; } \\
\text { Wachter Nr. 930: gest. } 1386 \text { VIII } 10\end{array}$ \\
\hline 1387 & $\begin{array}{l}\text { Heinrich Kaulber- } \\
\text { ger }\end{array}$ & $\begin{array}{l}1388 \text { II } 6 \text { (Abschrift) in StABa Stift St. } \\
\text { Gangolf, Akten und Bände Nr. } 1 \text { fol. 4; } \\
1390 \text { in StABa BU 4261; StABa Stift St. } \\
\text { Gangolf, Akten und Bände Nr. } 128 \text { fol. } \\
31 \text { (Todestag laut Anniversarbuch } 1405 \\
\text { XII 25); Dekanliste von } 1802 \text { in Usser- } \\
\text { mann: Episcopatus Bambergensis. } \\
\text { 1802. S. 276; Wachter Nr. 5040: } 1367 \\
\text { Kustos von St. Gangolf, res. 1395, gest. } \\
1405 \text { XII } 25\end{array}$ \\
\hline 1395 & Nikolaus & $\begin{array}{l}1395 \text { VIII } 23 \text { (Abschrift) in StABa Stift } \\
\text { St. Gangolf, Akten und Bände Nr. } 1 \text { fol. } \\
\text { 6; } 1397 \text { XI } 9 \text { (Abschrift) in StABa Stift } \\
\text { St. Gangolf, Akten und Bände Nr. } 1 \text { fol. } \\
\text { 52; Dekanliste von } 1802 \text { in Ussermann: } \\
\text { Episcopatus Bambergensis. 1802. S. }\end{array}$ \\
\hline
\end{tabular}




\begin{tabular}{|c|c|c|}
\hline & & $\begin{array}{l}\text { 276; Wachter Nr. 7144: Kanoniker von } \\
\text { St. Ägidius in Nürnberg, res. } 1397 \text { XI } 9\end{array}$ \\
\hline 1397 & $\begin{array}{l}\text { Ulrich von Onolz- } \\
\text { bach, Vizedekan }\end{array}$ & $\begin{array}{l}1397 \text { XI } 9 \text { (Abschrift) in StABa Stift St. } \\
\text { Gangolf, Akten und Bände Nr. } 1 \text { fol. 52; } \\
\text { StABa Stift St. Gangolf, Akten und Bän- } \\
\text { de Nr. } 129 \text { fol. 64' (Todestag laut Anni- } \\
\text { versarbuch } 1427 \text { X 3; Wachter Nr. } 7271\end{array}$ \\
\hline 1398 & Konrad Raben & $\begin{array}{l}1400 \text { I } 17 \text { in StABa BU 4743; } 1406 \text { VIII } \\
28 \text { in StABa Kloster Langheim, Urkun- } \\
\text { den } 1406 \text { VIII 28; Dekanliste von } 1802 \\
\text { in Ussermann: Episcopatus Bamber- } \\
\text { gensis. } 1802 . \text { S. 276; Wachter Nr. 7697: } \\
1390 \text { Pfarrer von St. Martin, gest. } 1407\end{array}$ \\
\hline 1410 & Konrad Leuchner & $\begin{array}{l}\text { Dekanliste von } 1802 \text { in Ussermann: } \\
\text { Episcopatus Bambergensis. 1802. S. } \\
\text { 276; Wachter Nr. } 6103\end{array}$ \\
\hline 1412 & $\begin{array}{l}\text { Heinrich Jäger von } \\
\text { Rotha }\end{array}$ & $\begin{array}{l}\text { StABa Stift St. Gangolf, Akten und Bän- } \\
\text { de Nr. } 128 \text { fol. } 8 \text { (Jahrtag laut Annivers- } \\
\text { arbuch 26. März); Dekanliste von } 1802 \\
\text { in Ussermann: Episcopatus Bamber- } \\
\text { gensis. 1802. S. 276; Wachter Nr. 4800: } \\
\text { gest. } 1416 \text { III } 26\end{array}$ \\
\hline 1416 & $\begin{array}{l}\text { Heinrich Forstmeis- } \\
\text { ter }\end{array}$ & $\begin{array}{l}1418 \text { XI } 11 \text { (Abschrift) in StABa Stift St. } \\
\text { Gangolf, Akten und Bände Nr. } 1 \text { fol. 37; } \\
1428 \text { I } 12 \text { in StABa A } 136 \text { L } 227 \text { Nr. } \\
\text { 1069; StABa Stift St. Gangolf, Akten } \\
\text { und Bände Nr. } 128 \text { fol. 20' (Todestag } \\
\text { laut Anniversarbuch } 1428 \text { VIII 22); De- } \\
\text { kanliste von } 1802 \text { in Ussermann: Epis- } \\
\text { copatus Bambergensis. 1802. S. 276; } \\
\text { Wachter Nr. 2625: gest. } 1428 \text { VIII } 28\end{array}$ \\
\hline 1426 & Nikolaus Pistorius & $\begin{array}{l}1426 \text { I } 27 \text { (Abschrift) in StABa Stift St. } \\
\text { Gangolf, Akten und Bände Nr. } 1 \text { fol. 38'; }\end{array}$ \\
\hline
\end{tabular}




\begin{tabular}{|c|c|c|}
\hline & & $\begin{array}{l}\text { Dekanliste von } 1802 \text { in Ussermann: } \\
\text { Episcopatus Bambergensis. 1802. S. } \\
\text { 276; Wachter Nr. } 7518\end{array}$ \\
\hline 1430 & Johann Schank & $\begin{array}{l}1433 \text { in StABa Stift St. Gangolf, Akten } \\
\text { und Bände Nr. } 192 \text { fol.1; } 1435 \text { XI } 22 \text { in } \\
\text { StABa A } 120 \text { L } 133 \text { Nr. 871; } 1435 \text { (Ab- } \\
\text { schrift) in StABa Stift St. Gangolf, Akten } \\
\text { und Bände Nr. } 168 \text { fol. 41; Dekanliste } \\
\text { von } 1802 \text { in Ussermann: Episcopatus } \\
\text { Bambergensis. 1802. S. 276; Wachter } \\
\text { Nr. 8564: } 1422 \text { Pfarrer in Etzelskirchen, } \\
\text { 1430 Hofkaplan, res. 1441, gest. } 1447 \text { X } \\
\text { 9, außerdem Keller von St. Gangolf }\end{array}$ \\
\hline 1441 & $\begin{array}{l}\text { Konrad Vachdorfer, } \\
\text { Vizedekan }\end{array}$ & $\begin{array}{l}\text { Dekanliste von } 1802 \text { in Ussermann: } \\
\text { Episcopatus Bambergensis. 1802. S. } \\
\text { 276; Wachter Nr. 10443: öffentlicher } \\
\text { Notar, Kanoniker von St. Stephan, } 1450 \\
\text { Generalvikar, gest. } 1456 \text { IX } 14\end{array}$ \\
\hline 1442 & Heinrich Klinghart & $\begin{array}{l}\text { 1444 XII } 2 \text { (Abschrift) in StABa A } 120 \\
\text { Nr. 722; } 1449 \text { in StABa Stift St. Gangolf, } \\
\text { Akten und Bände Nr. } 192 \text { fol. 4; Dekan- } \\
\text { liste von } 1802 \text { in Ussermann: Episco- } \\
\text { patus Bambergensis. 1802. S. 276; } \\
\text { Wachter Nr. 5273: gest. 1449 VIII } 16\end{array}$ \\
\hline 1450 & $\begin{array}{l}\text { Heinrich Konrad } \\
\text { Jäger }\end{array}$ & $\begin{array}{l}\text { Dekanliste von } 1802 \text { in Ussermann: } \\
\text { Episcopatus Bambergensis. 1802. S. } \\
\text { 276; Wachter Nr. } 4801\end{array}$ \\
\hline 1450 & $\begin{array}{l}\text { Johann Spangen- } \\
\text { berger }\end{array}$ & $\begin{array}{l}1467 \text { in StABa Stift St. Gangolf, Akten } \\
\text { und Bände Nr. } 192 \text { fol. 5; Wachter Nr. } \\
\text { 9649: Domvikar, res. } 1453\end{array}$ \\
\hline 1453 & $\begin{array}{l}\text { Conrad Hertlein } \\
\text { (Hartung) }\end{array}$ & $\begin{array}{l}1456 \text { IX } 22 \text { in StABa A } 120 \text { L } 131 \text { Nr. } \\
\text { 756; } 1466 \text { V } 30 \text { in StABa A } 120 \text { L } 131 \text { Nr. } \\
\text { 724; } 1466 \text { VI } 16 \text { in StABa A } 120 \text { L } 131\end{array}$ \\
\hline
\end{tabular}




\begin{tabular}{|c|c|c|}
\hline & & $\begin{array}{l}\text { Nr. 757; 1466 XI } 11 \text { in StABa A } 120 \text { L } \\
131 \text { Nr. 758; } 1468 \text { V } 11 \text { (Abschrift) in } \\
\text { StABa Stift St. Gangolf, Akten und Bän- } \\
\text { de Nr. } 1 \text { fol. 33; } 1468 \text { VIII } 22 \text { in StABa A } \\
120 \text { L } 133 \text { Nr. 879; } 1470 \text { I } 5 \text { in StAWu } \\
\text { WU 65/27; } 1472 \text { XI } 6 \text { in StABa A } 120 \text { L } \\
133 \text { Nr. 880; } 1474 \text { I } 10 \text { (Abschrift) in } \\
\text { StABa Stift St. Gangolf, Akten und Bän- } \\
\text { de Nr. } 1 \text { fol. 16'; } 1474 \text { in StABa Stift St. } \\
\text { Gangolf, Akten und Bände Nr. } 192 \text { fol. } \\
\text { 5'; StABa Stift St. Gangolf, Akten und } \\
\text { Bände Nr. } 128 \text { fol. 5' (Jahrtag laut Anni- } \\
\text { versarbuch } 24 . \text { Februar); Dekanliste von } \\
\text { 1802 in Ussermann: Episcopatus Bam- } \\
\text { bergensis. } 1802 . \text { S. } 276 \text {; Wachter Nr. } \\
\text { 3792: gest. } 1474 \text { II } 24\end{array}$ \\
\hline 1474 & Michael Kautsch & $\begin{array}{l}1480 \text { V } 18 \text { (Abschrift) in StABa Stift St. } \\
\text { Gangolf, Akten und Bände Nr. } 1 \text { fol. 11'; } \\
1482 \text { in StABa Stift St. Gangolf, Akten } \\
\text { und Bände Nr. } 192 \text { fol. 6; StABa Stift St. } \\
\text { Gangolf, Akten und Bände Nr. } 128 \text { fol. } \\
29 \text { (Todestag laut Anniversarbuch } 1482 \\
\text { XII 2); Dekanliste von } 1802 \text { in Usser- } \\
\text { mann: Episcopatus Bambergensis. } \\
\text { 1802. S. 276; Wachter Nr. 5055: gest. } \\
1482 \text { XII } 4\end{array}$ \\
\hline 1482 & Konrad Würtwein & $\begin{array}{l}\text { Dekanliste von } 1802 \text { in Ussermann: } \\
\text { Episcopatus Bambergensis. 1802. S. } 276\end{array}$ \\
\hline 1486 & Heinrich Glantz & $\begin{array}{l}1486 \text { in StABa Stift St. Gangolf, Akten } \\
\text { und Bände Nr. } 192 \text { fol. 7; 1489 VI } 1 \text { in } \\
\text { StABa A } 136 \text { L } 213 \text { Nr. 86; Dekanliste } \\
\text { von } 1802 \text { in Ussermann: Episcopatus } \\
\text { Bambergensis. 1802. S. 276; Wachter } \\
\text { Nr. 3114: } 1491 \text { Domvikar, gest. } 1500\end{array}$ \\
\hline
\end{tabular}




\begin{tabular}{|c|c|c|}
\hline 1491 & Nikolaus Pistorius & $\begin{array}{l}1495 \text { XI } 27 \text { (Abschrift) in StABa Stift St. } \\
\text { Gangolf, Akten und Bände Nr. } 1 \text { fol. 42; } \\
1496 \text { IX } 12 \text { in StABa A } 120 \text { L } 131 \text { Nr. } \\
\text { 764; } 1502 \text { in StABa Stift St. Gangolf, } \\
\text { Akten und Bände Nr. } 192 \text { fol. 8; Dekan- } \\
\text { liste von } 1802 \text { in Ussermann: Episco- } \\
\text { patus Bambergensis. 1802. S. 276; } \\
\text { Wachter Nr. 7519: gest. } 1502 \text { v } 29\end{array}$ \\
\hline 1502 & Heinrich Schroll & $\begin{array}{l}\text { Dekanliste von } 1802 \text { in Ussermann: } \\
\text { Episcopatus Bambergensis. 1802. S. } \\
\text { 276; Wachter Nr. 9187: gest. } 1510\end{array}$ \\
\hline 1510 & Konrad Glantz & $\begin{array}{l}\text { Dekanliste von } 1802 \text { in Ussermann: } \\
\text { Episcopatus Bambergensis. 1802. S. } \\
\text { 276; Wachter Nr. 3115: gest. } 1510\end{array}$ \\
\hline 1510 & Wolfgang Held & $\begin{array}{l}1512 \text { in StABa Stift St. Gangolf, Akten } \\
\text { und Bände Nr. } 192 \text { fol. 9; StABa Stift St. } \\
\text { Gangolf, Akten und Bände Nr. } 129 \text { fol. } \\
\text { 19' (Todestag laut Anniversarbuch } 1512 \\
\text { III 20); Dekanliste von } 1802 \text { in Usser- } \\
\text { mann: Episcopatus Bambergensis. } \\
\text { 1802. S. 276; Wachter Nr. 4053: gest. } \\
1512 \text { III } 22\end{array}$ \\
\hline 1512 & $\begin{array}{l}\text { Hieronymus } \\
\text { Hirschberger }\end{array}$ & $\begin{array}{l}\text { 1511-1538 in StABa Stift St. Gangolf, } \\
\text { Akten und Bände Nr. 191; 1515-1540 in } \\
\text { StABa Stift St. Gangolf, Akten und Bän- } \\
\text { de Nr. } 192 \text { fol. 9'-15; } 1517 \text { I } 10 \text { in StABa } \\
\text { A } 120 \text { L } 131 \text { Nr. 720; } 1521 \text { III } 4 \text { (Ab- } \\
\text { schrift) in StABa Stift St. Gangolf, Akten } \\
\text { und Bände Nr. } 1 \text { fol. 41; 1526 IV } 25 \text { in } \\
\text { StABa A } 120 \text { L } 131 \text { Nr. 726; } 1526 \text { XII } 14 \\
\text { (Abschrift) in StABa Stift St. Gangolf, } \\
\text { Akten und Bände Nr. } 1 \text { fol. 43'; } 1528 \text { IX } \\
14 \text { (Abschrift) in StABa Stift St. Gangolf, }\end{array}$ \\
\hline
\end{tabular}




\begin{tabular}{|c|c|c|}
\hline & & $\begin{array}{l}\text { Akten und Bände Nr. } 1 \text { fol. 45'; } 1528 \text { IX } \\
25 \text { in StABa A } 120 \text { L } 133 \text { Nr. 867; } 1530 \text { V } \\
20 \text { in StABa A } 120 \text { L } 131 \text { Nr. 769; } 1531 \\
\text { VI } 30 \text { in StABa A } 120 \text { L } 131 \text { Nr. 727; } \\
1533 \text { VI } 27 \text { in StABa A } 120 \text { L 131 Nr. } \\
\text { 772; } 1534 \text { V } 31 \text { in AEB Rep. I Pfarrei St. } \\
\text { Gangolf, U 822; } 1539 \text { IV } 30 \text { in StABa A } \\
\text { 120 L } 131 \text { Nr. 729; } 1542 \text { in StABa Stift } \\
\text { St. Gangolf, Akten und Bände Nr. } 192 \\
\text { fol. 15'; StABa Stift St. Gangolf, Akten } \\
\text { und Bände Nr. } 130 \text { fol. } 26 \text { (Todestag laut } \\
\text { Anniversarbuch } 21 . \text { Juli); Dekanliste von } \\
\text { 1802 in Ussermann: Episcopatus Bam- } \\
\text { bergensis. } 1802 . \text { S. } 276 \text {; Wachter Nr. } \\
\text { 4370: gest. } 1542 \text { VII 22 }\end{array}$ \\
\hline 1542 & Moritz Weisshaupt & $\begin{array}{l}1547 \text { X } 1 \text { in StABa A } 136 \text { L } 223 \text { Nr. 834; } \\
1548 \text { IX } 19 \text { in StABa A } 120 \text { L } 131 \text { Nr. } \\
\text { 773; } 1550-1566 \text { in StABa Stift St. Gan- } \\
\text { golf, Akten und Bände Nr. 191; } 1542 \text { in } \\
\text { StABa Stift St. Gangolf, Akten und Bän- } \\
\text { de Nr. } 192 \text { fol. 15'; } 1551 \text { XI } 16 \text { in StABa } \\
\text { A } 136 \text { L } 219 \text { Nr. } 564 \text { und Nr. 565; } 1564 \\
\text { in StABa Stift St. Gangolf, Akten und } \\
\text { Bände Nr. } 192 \text { fol. 18; } 1564 \text { in SttABa D } \\
3001 \text { HV Rep. } 2 \text { Nr. } 264 \text { fol. 1; } 1569 \text { in } \\
\text { StABa Stift St. Gangolf, Akten und Bän- } \\
\text { de Nr. } 192 \text { fol. 19'; Dekanliste von } 1802 \\
\text { in Ussermann: Episcopatus Bamber- } \\
\text { gensis. } 1802 . \text { S. 276; Wachter Nr. } 10898 \text { : } \\
\text { außerdem Kustos von St. Gangolf, gest. } \\
\text { 1569 VIII }\end{array}$ \\
\hline 1569 & $\begin{array}{l}\text { Hieronymus Stör } \\
\text { von Ostrach }\end{array}$ & $\begin{array}{l}\text { Wachter Nr. 9947: Dr. theol., Dr. jur., } \\
\text { Kanoniker von St. Stephan, Kanoniker } \\
\text { in Augsburg, Generalvikar, Propst von }\end{array}$ \\
\hline
\end{tabular}




\begin{tabular}{|c|c|c|}
\hline & & $\begin{array}{l}\text { St. Gertraud in Augsburg, gest. 1614 XI } \\
5\end{array}$ \\
\hline 1569 & Georg Judas & $\begin{array}{l}1569 \text { VIII } 31 \text { in StABa Stift St. Gangolf, } \\
\text { Akten und Bände Nr. } 192 \text { fol. 20; } 1590 \text { V } \\
22 \text { in StABa Stift St. Gangolf, Akten und } \\
\text { Bände Nr. } 29 \text { fol. 187; } 1592 \text { in StABa } \\
\text { Stift St. Gangolf, Akten und Bände Nr. } \\
192 \text { fol. 24; StABa Stift St. Gangolf, } \\
\text { Akten und Bände Nr. } 129 \text { fol. } 76 \text { (Todes- } \\
\text { tag laut Anniversarbuch } 1596 \text { XI 26); } \\
\text { 1597 in StABa Stift St. Gangolf, Akten } \\
\text { und Bände Nr. } 192 \text { fol. 25; Dekanliste } \\
\text { von } 1802 \text { in Ussermann: Episcopatus } \\
\text { Bambergensis. } 1802 . \text { S. 276; Wachter } \\
\text { Nr. } 4911: 1549 \text { Domvikar, gest. } 1597 \text { XI } \\
26\end{array}$ \\
\hline 1571 & Pangratz Holzschuh & $\begin{array}{l}\text { Wachter Nr. 4619: Dr. jur., fürstbischöf- } \\
\text { licher Rat, } 1610 \text { Amtmann der Dom- } \\
\text { propstei, gest. } 1610 \mathrm{~V}\end{array}$ \\
\hline 1577 & Johann Schaller & $\begin{array}{l}\text { StABa Stift St. Gangolf, Akten und Bän- } \\
\text { de Nr. } 129 \text { fol. } 74 \text { (Todestag laut Anni- } \\
\text { versarbuch } 1600 \text { XI 17); Dekanliste von } \\
1802 \text { in Ussermann: Episcopatus Bam- } \\
\text { bergensis. 1802. S. 276; Wachter Nr. } \\
\text { 8557: } 1563 \text { Domvikar, } 1565 \text { Pfarrer in } \\
\text { Weißmain, Pfarrer in Stadtsteinach, } \\
\text { gest. } 1600 \text { XI } 17\end{array}$ \\
\hline 1583 & Kaspar Hartmann & $\begin{array}{l}\text { 1583-1607 in StABa Stift St. Gangolf, } \\
\text { Akten und Bände Nr. } 192 \text { fol. 22'-26'; } \\
1590 \text { V } 22 \text { in StABa Stift St. Gangolf, } \\
\text { Akten und Bände Nr. } 29 \text { fol. 187; 1622 } \\
\text { in StABa Stift St. Gangolf, Akten und } \\
\text { Bände Nr. } 192 \text { fol. 28; Dekanliste von }\end{array}$ \\
\hline
\end{tabular}




\begin{tabular}{|l|l|l|}
\hline & & $\begin{array}{l}1802 \text { in Ussermann: Episcopatus Bam- } \\
\text { bergensis. 1802. S. 276; Wachter Nr. } \\
\text { 3779: gest. 1622 II 2 }\end{array}$ \\
\hline 1622 & Johann Murmann \\
\hline 1656 & Neithard Gampert \\
\hline 1661 & Johann Georg Ringer \\
\hline 1690 & Georg Haller \\
\hline 1694 & Johann Ignatz Eppenauer \\
\hline 1739 & Franz Joseph Hahn \\
\hline 1748 & Johann Jakob Anton Boxberger \\
\hline 1764 & Heinrich Joseph von Nitschke \\
\hline 1778 & Johann Andreas Nieser \\
\hline 1790 & Michael Heinrich Schubert \\
\hline
\end{tabular}

\section{Scholastikus}

\begin{tabular}{|c|c|c|}
\hline 1185 & Herbord & Wachter Nr. 4148 \\
\hline 1246 & Berthold & $\begin{array}{l}1246 \text { XI } 8 \text { in StABa BU 645; Wachter } \\
\text { Nr. } 734\end{array}$ \\
\hline 1295 & Dietrich & $\begin{array}{l}1295 \text { V } 25 \text { in StAWu Kloster Ebrach, } \\
\text { Urkunden } 1295 \text { V 25; Wachter Nr. } 1539\end{array}$ \\
\hline 1298 & $\begin{array}{l}\text { Leupold von } \\
\text { Hirschberg }\end{array}$ & $\begin{array}{l}1311 \text { X } 1 \text { in StAWu Kloster Ebrach, } \\
\text { Urkunden } 1311 \text { X 1/I; Wachter Nr. } \\
\text { 4369: Pfarrer in Neunkirchen am } \\
\text { Brand, gest. } 1328 \text { IX } 11\end{array}$ \\
\hline 1328 & Hermann Kiessling & $\begin{array}{l}1337 \text { IV } 4 \text { (Abschrift) in StABa Stift St. } \\
\text { Gangolf, Akten und Bände Nr. } 3 \text { Teil } 3 \\
\text { S. 336; Wachter Nr. } 5183\end{array}$ \\
\hline 1348 & Hermann & 1348 XII 20 in StABa BU 2636 \\
\hline 1357 & $\begin{array}{l}\text { Wolfgang Wolfstei- } \\
\text { ner }\end{array}$ & $\begin{array}{l}\text { StABa Stift St. Gangolf, Akten und Bän- } \\
\text { de Nr. } 128 \text { fol. 2' (Todestag laut Anni- } \\
\text { versarbuch } 1365 \text { I 23); Wachter Nr. } \\
\text { 11266: gest. } 1365 \text { I } 25\end{array}$ \\
\hline 1370 & Heinrich Kuptzer & Wachter Nr. 5861: gest. 1392 IV 22 \\
\hline
\end{tabular}




\begin{tabular}{|c|c|c|}
\hline 1397 & Albert von Sachsen & $\begin{array}{l}1397 \text { XI } 9 \text { (Abschrift) in StABa Stift St. } \\
\text { Gangolf, Akten und Bände Nr. } 1 \text { fol. 52; } \\
\text { StABa Stift St. Gangolf, Akten und Bän- } \\
\text { de Nr. } 128 \text { fol. 12' (Todestag laut Anni- } \\
\text { versarbuch } 1401 \text { V 24); Wachter Nr. } \\
\text { 8444: gest. } 1401 \text { V } 24\end{array}$ \\
\hline 1402 & Andreas Wurm & Wachter Nr. 11315 \\
\hline 1415 & Johann Kühnlein & $\begin{array}{l}1415 \text { IX } 28 \text { (Abschrift) in StABa Stift St. } \\
\text { Gangolf, Akten und Bände Nr. } 1 \text { fol. 34; } \\
1418 \text { XI } 11 \text { (Abschrift) in StABa Stift St. } \\
\text { Gangolf, Akten und Bände Nr. } 1 \text { fol. 37; } \\
\text { Wachter Nr. } 5793\end{array}$ \\
\hline 1422 & Johann Rampusch & $\begin{array}{l}1422 \text { II } 15 \text { (Abschrift) in StABa Stift St. } \\
\text { Gangolf, Akten und Bände Nr. } 3 \text { S. 690; } \\
\text { StABa Stift St. Gangolf, Akten und Bän- } \\
\text { de Nr. } 128 \text { fol. } 8 \text { (Todestag laut Anniver- } \\
\text { sarbuch } 1432 \text { III 29) }\end{array}$ \\
\hline 1426 & Johann Strumpf & $\begin{array}{l}1426 \text { I } 27 \text { (Abschrift) in StABa Stift St. } \\
\text { Gangolf, Akten und Bände Nr. } 1 \text { fol. 38' } \\
\text { (zu dieser Zeit bereits verstorben) }\end{array}$ \\
\hline 1431 & Konrad Rudhart & $\begin{array}{l}\text { StABa Stift St. Gangolf, Akten und Bän- } \\
\text { de Nr. } 129 \text { fol. 50' (Todestag laut Anni- } \\
\text { versarbuch } 1434 \text { VIII 9); Wachter Nr. } \\
\text { 8330: gest. } 1434 \text { VIII } 9\end{array}$ \\
\hline 1440 & $\begin{array}{l}\text { Engelhard von } \\
\text { Güssbach }\end{array}$ & $\begin{array}{l}1440 \text { (Abschrift) in StABa Stift St. Gan- } \\
\text { golf, Akten und Bände Nr. 201; } 1444 \text { XII } \\
2 \text { (Abschrift) in StABa A } 120 \text { L } 131 \text { Nr. } \\
722 ; 1457 \text { in StABa Stift St. Gangolf, } \\
\text { Akten und Bände Nr. } 192 \text { fol. 4'; StABa } \\
\text { Stift St. Gangolf, Akten und Bände Nr. } \\
128 \text { fol. } 5 \text { (Jahrtag laut Anniversarbuch } \\
1462 \text { II 19); Wachter Nr. 3503: gest. } \\
1457 \text { II } 19\end{array}$ \\
\hline
\end{tabular}




\begin{tabular}{|c|c|c|}
\hline 1470 & Johann Stumpf & $\begin{array}{l}1491 \text { in StABa Stift St. Gangolf, Akten } \\
\text { und Bände Nr. } 192 \text { fol. 8; } 1495 \text { in StABa } \\
\text { Stift St. Gangolf, Akten und Bände Nr. } \\
192 \text { fol. 8'; } 1496 \text { IX } 12 \text { in StABa A } 120 \text { L } \\
131 \text { Nr. 764; StABa Stift St. Gangolf, } \\
\text { Akten und Bände Nr. } 128 \text { fol. 23' (To- } \\
\text { destag laut Anniversarbuch } 1495 \text { IX 28); } \\
\text { Wachter Nr. } 10065 \text { : öffentlicher Notar, } \\
\text { gest. } 1495 \text { IX } 26\end{array}$ \\
\hline 1495 & Georg Federmann & $\begin{array}{l}1518 \text { in StABa Stift St. Gangolf, Akten } \\
\text { und Bände Nr. 191; StABa Stift St. Gan- } \\
\text { golf, Akten und Bände Nr. } 129 \text { fol. } 33 \\
\text { (Jahrtag laut Anniversar } 1522 \text { V 17); } \\
\text { Wachter Nr. 2375: Dr. theol., gest. } 1518\end{array}$ \\
\hline 1529 & $\begin{array}{l}\text { Nikolaus Scher- } \\
\text { baum }\end{array}$ & $\begin{array}{l}1529 \text { und } 1530 \text { in StABa Stift St. Gan- } \\
\text { golf, Akten und Bände Nr. 191; } 1533 \text { in } \\
\text { StABa Stift St. Gangolf, Akten und Bän- } \\
\text { de Nr. } 192 \text { fol. 14; StABa Stift St. Gan- } \\
\text { golf, Akten und Bände Nr. } 129 \text { fol. 44' } \\
\text { (Todestag laut Anniversarbuch am } 1533 \\
\text { VI 13); Wachter Nr. 8704: gest. } 1553 \text { VII } \\
12\end{array}$ \\
\hline 1542 & Georg Helmreich & $\begin{array}{l}1542 \text { in StABa Stift St. Gangolf, Akten } \\
\text { und Bände Nr. } 192 \text { fol. 15'; 1542-1543 in } \\
\text { StABa Stift St. Gangolf, Akten und Bän- } \\
\text { de Nr. } 192 \text { fol. 16-16';1548 IX } 19 \text { in StA- } \\
\text { Ba A } 120 \text { L } 131 \text { Nr. } 773 ; 1556 \text { in SttABa } \\
\text { D } 3001 \text { HV Rep. } 2 \text { Nr. } 264 \text { fol. 5; } 1564 \text { in } \\
\text { StABa Stift St. Gangolf, Akten und Bän- } \\
\text { de Nr. } 192 \text { fol. 18; Wachter Nr. 4085: } \\
\text { geb. } 1496 \text {, gest. vor } 1562\end{array}$ \\
\hline 1573 & Johann Sparwasser & $\begin{array}{l}1579 \text { (Abschrift) in StABa Stift St. Gan- } \\
\text { golf, Akten und Bände Nr. 201; } 1580 \text { in }\end{array}$ \\
\hline
\end{tabular}




\begin{tabular}{|c|c|c|}
\hline & & $\begin{array}{l}\text { StABa Stift St. Gangolf, Akten und Bän- } \\
\text { de Nr. } 192 \text { fol. 21; } 1590 \text { V } 22 \text { in StABa } \\
\text { Stift St. Gangolf, Akten und Bände Nr. } \\
29 \text { fol. 187; } 1592 \text { in StABa Stift St. Gan- } \\
\text { golf, Akten und Bände Nr. } 192 \text { fol. 24; } \\
1598 \text { in StABa Stift St. Gangolf, Akten } \\
\text { und Bände Nr. } 192 \text { fol. 25'; StABa Stift } \\
\text { St. Gangolf, Akten und Bände Nr. } 129 \\
\text { fol. } 59 \text { ' (Todestag laut Anniversarbuch } \\
\text { 1598 X 15); Wachter Nr. } 9655: 1562 \\
\text { Vikar von St. Stephan, gest. } 1598 \text { X } 15\end{array}$ \\
\hline 1650 & \multicolumn{2}{|l|}{ Neithart Gampert } \\
\hline 1656 & \multicolumn{2}{|l|}{ Jakob Koch } \\
\hline 1661 & \multicolumn{2}{|l|}{ Johann Rephuhn } \\
\hline 1696 & \multicolumn{2}{|c|}{ Wolfgang Franz Pymer } \\
\hline 1699 & \multicolumn{2}{|c|}{ Johann August Gerber } \\
\hline 1710 & \multicolumn{2}{|c|}{ Johann Friedrich Eppenauer } \\
\hline 1717 & \multicolumn{2}{|c|}{ Johann Heinrich Karl Batz } \\
\hline 1762 & \multicolumn{2}{|c|}{ Karl Adolf Heinrich Boxberger } \\
\hline 1780 & \multicolumn{2}{|c|}{ Johann Michael Heinrich Schubert } \\
\hline 1796 & \multicolumn{2}{|c|}{ Melchior Ignatz Stenglein } \\
\hline
\end{tabular}

\section{Kustos}

\begin{tabular}{|l|l|l|}
\hline 1185 & Friedrich & Wachter Nr. 2737 \\
\hline 1242 & Ulrich & $\begin{array}{l}1242 \text { in StABa BU 613; } 1242 \text { in StABa } \\
\text { BU 614; Wachter Nr. 10376 }\end{array}$ \\
\hline 1253 & Hartwig & $\begin{array}{l}\text { Wachter Nr. 3798: Leibarzt von Herzog } \\
\text { Otto II. von Bayern (4798) }\end{array}$ \\
\hline 1295 & Egelolf & $\begin{array}{l}\text { 1295 V 25 in StAWu Kloster Ebrach, } \\
\text { Urkunden 1295 V 25; Wachter Nr. 1966 }\end{array}$ \\
\hline 1307 & $\begin{array}{l}\text { Konrad Pfaffenhof- } \\
\text { er }\end{array}$ & $\begin{array}{l}\text { 1308 VII 22 in StABa BU 1432; 1311 X 1 } \\
\text { in StAWu Kloster Ebrach, Urkunden } \\
1311 \text { X 1/I; 1318 II 25 in StABa BU }\end{array}$ \\
\hline
\end{tabular}




\begin{tabular}{|c|c|c|}
\hline & & $\begin{array}{l}\text { 1698; } 1329 \text { in StABa BU 1988; } 1331 \text { VII } \\
18 \text { (bereits verstorben) in StABa BU } \\
\text { 2060; } 1331 \text { X } 25 \text { in StABa BU 2066; } \\
1336 \text { XII } 9 \text { in AEB Rep. I Pfarrei St. } \\
\text { Gangolf, U 818; Wachter Nr. } 5505 \text { und } \\
\text { 7426: gest. } 1331 \text { IV } 9\end{array}$ \\
\hline 1331 & Eberhard & $\begin{array}{l}\text { Wachter Nr. } 1869 \text { und 1873: gest. } 1353 \text { I } \\
25\end{array}$ \\
\hline 1346 & $\begin{array}{l}\text { Friedrich von Weis- } \\
\text { senburg }\end{array}$ & Wachter Nr. 10885: gest. 1377 \\
\hline 1367 & $\begin{array}{l}\text { Heinrich Kaulber- } \\
\text { ger }\end{array}$ & $\begin{array}{l}\text { StABa Stift St. Gangolf, Akten und Bän- } \\
\text { de Nr. } 128 \text { fol. } 31 \text { (Todestag laut Anni- } \\
\text { versarbuch } 1405 \text { XII 25); Wachter Nr. } \\
\text { 5040: außerdem Dekan von St. Gangolf, } \\
\text { gest. } 1405 \text { XII } 25\end{array}$ \\
\hline 1418 & Johann Rampusch & $\begin{array}{l}1418 \text { XI } 11 \text { (Abschrift) in StABa Stift St. } \\
\text { Gangolf, Akten und Bände Nr. } 1 \text { fol. } 37\end{array}$ \\
\hline 1422 & Heinrich Teuerlein & Wachter Nr. 10136: gest.1443 III 31 \\
\hline 1443 & $\begin{array}{l}\text { Nikolaus von } \\
\text { Viepech }\end{array}$ & $\begin{array}{l}\text { StABa Stift St. Gangolf, Akten und Bän- } \\
\text { de Nr. } 128 \text { fol. } 29 \text { (Todestag laut Anni- } \\
\text { versarbuch } 1443 \text { XII 3); Wachter Nr. } \\
\text { 10469: außerdem Keller von St. Gan- } \\
\text { golf, gest. } 1443 \text { XII } 4\end{array}$ \\
\hline 1444 & Konrad Wurm & $\begin{array}{l}1444 \text { XII } 2 \text { (Abschrift) in StaBA A } 120 \text { L } \\
131 \text { Nr. } 722 ; 1445 \text { VI } 14 \text { in AEB Rep. I } \\
\text { Pfarrei St. Gertraud, U 107; } 1448 \text { in } \\
\text { StABa Stift St. Gangolf, Akten und Bän- } \\
\text { de Nr. } 192 \text { fol. 4; Wachter Nr. 11316: } \\
\text { Pfarrer in Bayreuth }\end{array}$ \\
\hline 1448 & Johann Dornpeck & $\begin{array}{l}1448 \text { in StABa Stift St. Gangolf, Akten } \\
\text { und Bände Nr. } 192 \text { fol. 4; } 1458 \text { in StABa } \\
\text { Stift St. Gangolf, Akten und Bände Nr. } \\
192 \text { fol. 5; Wachter Nr. 1697: Pfarrer in }\end{array}$ \\
\hline
\end{tabular}




\begin{tabular}{|c|c|c|}
\hline & & Bayreuth, gest. 1458 III 21 \\
\hline 1466 & Johann Kohler & $\begin{array}{l}\text { 1466 VI } 16 \text { in StABa A } 120 \text { L } 131 \text { Nr. } \\
\text { 757; Wachter Nr. 5449: } 1445 \text { Obleier } \\
\text { und Vikar von St. Stephan, } 1466 \text { Kano- } \\
\text { niker, gest. } 1490\end{array}$ \\
\hline 1481 & Johann Schreiner & Wachter Nr. 9166 \\
\hline 1509 & $\begin{array}{l}\text { Johann Schwanhau- } \\
\text { sen }\end{array}$ & $\begin{array}{l}\text { StABa Stift St. Gangolf, Akten und Bän- } \\
\text { de Nr. } 129 \text { fol. } 3 \text { (Jahrtag laut Annivers- } \\
\text { arbuch 1509); } 1511 \text { in StABa Stift St. } \\
\text { Gangolf, Akten und Bände Nr. 191; } \\
\text { Wachter Nr. 9325: Anhänger Luthers, } \\
\text { gest. } 1528 \text { IX } 1\end{array}$ \\
\hline 1538 & $\begin{array}{l}\text { Matteus Meyerher- } \\
\text { man }\end{array}$ & $\begin{array}{l}1538 \text { in StABa Stift St. Gangolf, Akten } \\
\text { und Bände Nr. } 191\end{array}$ \\
\hline 1538 & Moritz Weisshaupt & $\begin{array}{l}1538 \text { in StABa Stift St. Gangolf, Akten } \\
\text { und Bände Nr. 191; Wachter Nr. 10898: } \\
\text { außerdem Dekan von St. Gangolf, gest. } \\
1569 \text { VIII }\end{array}$ \\
\hline 1577 & Johann Zwirner & $\begin{array}{l}1577 \text { in StABa Stift St. Gangolf, Akten } \\
\text { und Bände Nr. } 192 \text { fol. 21; StABa Stift } \\
\text { St. Gangolf, Akten und Bände Nr. } 129 \\
\text { fol. 46' (Jahrtag laut Anniversarbuch am } \\
\text { 22. Juli) }\end{array}$ \\
\hline 1609 & \multicolumn{2}{|l|}{ Johann Hartmann } \\
\hline 1612 & \multicolumn{2}{|l|}{ Alexander Schwartz } \\
\hline 1615 & \multicolumn{2}{|c|}{ Johann Friedrich Hummel } \\
\hline 1618 & \multicolumn{2}{|l|}{ Johann Hartmann } \\
\hline 1636 & \multicolumn{2}{|l|}{ Andreas Rödel } \\
\hline 1645 & \multicolumn{2}{|l|}{ Neithart Gampert } \\
\hline 1655 & \multicolumn{2}{|l|}{ Andreas Kastner } \\
\hline 1658 & \multicolumn{2}{|l|}{ Johann Rephuhn } \\
\hline 1662 & \multicolumn{2}{|l|}{ Peter Krummer } \\
\hline 1667 & \multicolumn{2}{|c|}{ Friedrich Hiltenperger } \\
\hline
\end{tabular}




\begin{tabular}{|l|l|}
\hline 1673 & Joahnn Georg Friedrich Ullrich \\
\hline 1682 & Georg Haller \\
\hline 1684 & Georg Andreas Beyer \\
\hline 1688 & Johann Nikolaus Kell \\
\hline 1688 & Johann Wolfgang Hüls \\
\hline 1703 & Johann Friedrich Eppenauer \\
\hline 1706 & Johann Georg Panschab \\
\hline 1713 & Johann Michael Wolfrom \\
\hline 1746 & Franz Georg Ditterich \\
\hline 1762 & Karl Josef Ignatz Gislenus Dittrich von Schönhofen \\
\hline 1773 & Konrad Joseph Herzog \\
\hline
\end{tabular}

\section{Keller}

\begin{tabular}{|c|c|c|}
\hline 1242 & Egelolf & 1242 in StABa BU 614 \\
\hline 1256 & Hermann Steiner & Wachter Nr. 9829 \\
\hline 1264 & Otto & $\begin{array}{l}\text { Wachter Nr. 7325: Pfarrer in Hallern- } \\
\text { dorf, außerdem Dekan von St. Gangolf }\end{array}$ \\
\hline 1302 & Poppo Gross & $\begin{array}{l}1311 \text { X } 1 \text { in StAWu Kloster Ebrach, } \\
\text { Urkunden } 1311 \text { X 1/I; } 1314 \text { (Abschrift) } \\
\text { in SttABa B } 11 \text { Nr. } 100 \text { fol. 26; Wachter } \\
\text { Nr. 3415: gest. } 1330\end{array}$ \\
\hline 1328 & $\begin{array}{l}\text { Hermann von } \\
\text { Mühlhausen }\end{array}$ & $\begin{array}{l}1331 \text { VII } 18 \text { in StABa BU 2060; } 1331 \text { X } \\
25 \text { in StABa BU 2066; } 1340 \text { (Abschrift) } \\
\text { in SttABa B } 11 \text { Nr. } 100 \text { fol. 28; StABa } \\
\text { Stift St. Gangolf, Akten und Bände Nr. } \\
128 \text { fol. } 3 \text { (Todestag laut Anniversarbuch } \\
1344 \text { I 26); Wachter Nr. 6806: gest. } 1344 \\
\text { I } 26\end{array}$ \\
\hline 1344 & $\begin{array}{l}\text { Heinrich von Rat- } \\
\text { telsdorf }\end{array}$ & $\begin{array}{l}1344 \text { V } 19 \text { in StABa BU 2490; } 1344 \text { VIII } \\
5 \text { in StABa BU 2498; } 1347 \text { III } 18 \text { in StA- } \\
\text { Ba BU 2583; } 1348 \text { XII } 20 \text { in StABa BU } \\
\text { 2636; } 1349 \text { XI } 23 \text { in StABa BU 2670; } \\
\text { Wachter Nr. } 4019 \text { und 7751: gest. } 1356\end{array}$ \\
\hline
\end{tabular}




\begin{tabular}{|c|c|c|}
\hline & & III 30 \\
\hline 1356 & $\begin{array}{l}\text { Seifried von Weis- } \\
\text { senburg }\end{array}$ & $\begin{array}{l}1356 \text { XII } 5 \text { in AEB Rep. I Pfarrei St. } \\
\text { Martin, U 2; } 1360 \text { V } 18 \text { in StABa BU } \\
\text { 3075; StABa Stift St. Gangolf, Akten } \\
\text { und Bände Nr. } 128 \text { fol. } 29^{\prime} \text { (Todestag } \\
\text { laut Anniversarbuch } 1363 \text { XII 7) }\end{array}$ \\
\hline 1367 & Otto von Aufsees & $\begin{array}{l}1374 \text { V } 15 \text { in AEB Rep. I Pfarrei St. Mar- } \\
\text { tin, U 4; Wachter Nr. } 297\end{array}$ \\
\hline 1380 & Hermann Willich & $\begin{array}{l}1380 \text { IV } 4 \text { (Abschrift) in StABa Stift St. } \\
\text { Gangolf, Akten und Bände Nr. } 1 \text { fol. 49'; } \\
1384 \text { X } 3 \text { (Abschrift) in StABa Stift St. } \\
\text { Gangolf, Akten und Bände Nr. } 1 \text { fol. 2'; } \\
1386 \text { VII } 25 \text { (Abschrift) in StABa Stift St. } \\
\text { Gangolf, Akten und Bände Nr. } 1 \text { fol. 3; } \\
1390 \text { in StABa BU 4261; } 1391 \text { in StABa } \\
\text { BU } 4287 ; 1399 \text { III } 17 \text { in StABa BU 4693; } \\
1398 \text { V } 31 \text { (Abschrift) in StABa Stift St. } \\
\text { Gangolf, Akten und Bände Nr. } 1 \text { fol. 50'; } \\
1399 \text { XII } 15 \text { (Abschrift) in StABa Stift St. } \\
\text { Gangolf, Akten und Bände Nr. } 1 \text { fol. 7; } \\
1400 \text { X } 18 \text { in StABa BU } 4766 ; 1401 \text { VII } 4 \\
\text { in AEB Rep. I Pfarrei St. Martin, U 16; } \\
\text { 1403 XI } 26 \text { in AEB Rep. I Pfarrei St. } \\
\text { Martin, U 17; } 1406 \text { XII } 20 \text { in AEB Rep. I } \\
\text { Pfarrei St. Martin, U 18; } 1408 \text { V } 21 \text { in } \\
\text { AEB Rep. I Pfarrei St. Gertraud, U 97; } \\
\text { Wachter Nr. } 11111\end{array}$ \\
\hline 1414 & Johann Fere & $\begin{array}{l}1415 \text { III } 1 \text { in StABa A } 136 \text { L } 216 \text { Nr. 292; } \\
1415 \text { IX } 28 \text { (Abschrift) in StABa Stift St. } \\
\text { Gangolf, Akten und Bände Nr. } 1 \text { fol. 34; } \\
1418 \text { XI } 11 \text { (Abschrift) in StABa Stift St. } \\
\text { Gangolf, Akten und Bände Nr. } 1 \text { fol. 36'; } \\
1419 \text { in AEB Rep. I Pfarrei St. Gertraud, }\end{array}$ \\
\hline
\end{tabular}




\begin{tabular}{|c|c|c|}
\hline & & $\begin{array}{l}\text { U 99; } 1419 \text { VII } 31 \text { in AEB Rep. I Pfarrei } \\
\text { St. Gertraud, U 98; } 1419 \text { XII } 24 \text { (Ab- } \\
\text { schrift) in StABa Stift St. Gangolf, Akten } \\
\text { und Bände Nr. } 1 \text { fol. 37'; } 1424 \text { IV } 9 \text { in } \\
\text { StABa A } 120 \text { L } 131 \text { Nr. 750; } 1439 \text { VI } 1 \text { in } \\
\text { AEB Rep. I Pfarrei St. Gertraud, U 101; } \\
\text { 1439 VI } 3 \text { in StABa A } 120 \text { L } 131 \text { Nr. 721; } \\
\text { Wachter Nr. 2409: gest. } 1440\end{array}$ \\
\hline 1440 & $\begin{array}{l}\text { Nikolaus von } \\
\text { Viepech }\end{array}$ & $\begin{array}{l}\text { 1440 IV } 4 \text { in AEB Rep. I Pfarrei St. Ger- } \\
\text { traud, U 102; } 1440 \text { V } 9 \text { in AEB Rep. I } \\
\text { Pfarrei St. Gertraud, U 103; } 1442 \text { VI } 4 \text { in } \\
\text { AEB Rep. I Pfarrei St. Gertraud, U 104; } \\
1443 \text { X } 21 \text { in AEB Rep. I Pfarrei St. Ger- } \\
\text { traud, U 105; } 1443 \text { in StABa Stift St. } \\
\text { Gangolf, Akten und Bände Nr. } 192 \text { fol. } \\
\text { 3; StABa Stift St. Gangolf, Akten und } \\
\text { Bände Nr. } 128 \text { fol. } 29 \text { (Todestag laut } \\
\text { Anniversarbuch } 1443 \text { XII 3); Wachter } \\
\text { Nr. 10469: gest. } 1443 \text { XII } 4\end{array}$ \\
\hline 1441 & Johann Schank & $\begin{array}{l}1444 \text { XII } 2 \text { (Abschrift) in StABa A } 120 \text { L } \\
131 \text { Nr. 722; } 1445 \text { VI } 14 \text { in StABa A } 120 \\
\text { L } 131 \text { Nr. 751; } 1445 \text { VI } 14 \text { in AEB Rep. I } \\
\text { Pfarrei St. Gertraud, U 107; } 1446 \text { in } \\
\text { StABa Stift St. Gangolf, Akten und Bän- } \\
\text { de Nr. } 192 \text { fol. 4; StABa Stift St. Gan- } \\
\text { golf, Akten und Bände Nr. } 128 \text { fol. 24' } \\
\text { (Todestag laut Anniversarbuch 1446 X } \\
\text { 9); Wachter Nr. 8564: 1419 Vikar von St. } \\
\text { Stephan, Pfarrer in Etzelskirchen und } \\
\text { Amlingstadt, } 1427 \text { Generalkommissar } \\
\text { und Hofkaplan von Bischof Friedrich, } \\
\text { außerdem Dekan von St. Gangolf, gest. } \\
\text { 1447 X } 9\end{array}$ \\
\hline 1448 & Georg Rephuhn & 1449 VIII 18 in AEB Rep. I Pfarrei St. \\
\hline
\end{tabular}




\begin{tabular}{|c|c|c|}
\hline & & $\begin{array}{l}\text { Gertraud, U 108; } 1453 \text { VII } 30 \text { in StABa } \\
\text { A } 120 \text { L } 131 \text { Nr. 754; } 1453 \text { XI } 12 \text { in AEB } \\
\text { Rep. I Pfarrei St. Gertraud, U 109; } 1456 \\
\text { II } 8 \text { (Abschrift) in StABa Stift St. Gan- } \\
\text { golf, Akten und Bände Nr. } 1 \text { fol. 39'; } \\
1468 \text { V } 11 \text { (Abschrift) in StABa Stift St. } \\
\text { Gangolf, Akten und Bände Nr. } 1 \text { fol. 33; } \\
\text { 1474 I } 10 \text { (Abschrift) in StABa Stift St. } \\
\text { Gangolf, Akten und Bände Nr. } 1 \text { fol. 16'; } \\
\text { 1475 VI } 19 \text { in StABa A } 120 \text { L } 131 \text { Nr. } \\
\text { 760; } 1476 \text { IV } 24 \text { (Abschrift) in StABa } \\
\text { Stift St. Gangolf, Akten und Bände Nr. } 1 \\
\text { fol. } 21 \text { '; } 1477 \text { IV } 14 \text { in AEB Rep. I Pfarrei } \\
\text { ULF, U } 114 ; 1484 \text { in StABa Stift St. } \\
\text { Gangolf, Akten und Bände Nr. } 192 \text { fol. } \\
\text { 6'; StABa Stift St. Gangolf, Akten und } \\
\text { Bände Nr. } 128 \text { fol. 10' (Jahrtag laut An- } \\
\text { niversarbuch am 26. April); Wachter Nr. } \\
\text { 7809: gest. } 1484\end{array}$ \\
\hline 1481 & $\begin{array}{l}\text { Johann Riemen- } \\
\text { schneider }\end{array}$ & Wachter Nr. 8073: gest. 1483 XI 19 \\
\hline 1488 & Andreas Herzog & $\begin{array}{l}1491 \text { VIII } 8 \text { in AEB Rep. I Pfarrei St. } \\
\text { Gertraud, U 114; } 1491 \text { X } 31 \text { in StABa A } \\
120 \text { L } 131 \text { Nr. 761; } 1491 \text { in StABa Stift } \\
\text { St. Gangolf, Akten und Bände Nr. } 192 \\
\text { fol. 8; } 1492 \text { II } 27 \text { in AEB Rep. I Pfarrei } \\
\text { ULF, U 121; } 1493 \text { III } 18 \text { in StABa A } 120 \\
\text { L } 131 \text { Nr. 762; } 1493 \text { VI } 11 \text { in StABa L } \\
131 \text { Nr. 763; } 1495 \text { und } 1499 \text { in StABa } \\
\text { Stift St. Gangolf, Akten und Bände Nr. } \\
192 \text { fol. 8‘ } 1496 \text { IX } 12 \text { in StABa A 120 L } \\
131 \text { Nr. 764; StABa Stift St. Gangolf, } \\
\text { Akten und Bände Nr. } 128 \text { fol. } 23 \text { (Todes- } \\
\text { tag laut Anniversarbuch } 1499 \text { IX 22); }\end{array}$ \\
\hline
\end{tabular}




\begin{tabular}{|c|c|c|}
\hline & & Wachter Nr. 4261: gest. 1499 IX 23 \\
\hline 1499 & Nikolaus Schäfer & $\begin{array}{l}1517 \text { in StABa Stift St. Gangolf, Akten } \\
\text { und Bände Nr. } 192 \text { fol. 10'; StABa Stift } \\
\text { St. Gangolf, Akten und Bände Nr. } 128 \\
\text { fol. } 16 \text { (Todestag laut Anniversarbuch } \\
\text { 1517 VI 29); Wachter Nr. 7274: Dr. the- } \\
\text { ol., Kanoniker von St. Ulrich in Augs- } \\
\text { burg, } 1500 \text { Pfarrer in Burgebrach, gest. } \\
1517 \text { VI } 29\end{array}$ \\
\hline 1502 & Amand Körber & $\begin{array}{l}1502 \text { XII } 19 \text { in StABa A } 120 \text { L } 131 \text { Nr. } \\
\text { 766; } 1526 \text { in StABa Stift St. Gangolf, } \\
\text { Akten und Bände Nr. } 192 \text { fol. 12'; } 1526 \\
\text { IV } 25 \text { in StABa A } 120 \text { L } 131 \text { Nr. 726; } \\
1526 \text { VI } 27 \text { in AEB Rep. I Pfarrei St. } \\
\text { Gangolf, U 821; StABa Stift St. Gangolf, } \\
\text { Akten und Bände Nr. } 128 \text { fol. } 25 \text { (Todes- } \\
\text { tag laut Anniversarbuch } 1526 \text { X 12); } \\
\text { Wachter Nr. 5413: gest. } 1526 \text { X } 9\end{array}$ \\
\hline 1515 & $\begin{array}{l}\text { Erhard Götzendor- } \\
\text { fer }\end{array}$ & $\begin{array}{l}1518 \text { in StABa Stift St. Gangolf, Akten } \\
\text { und Bände Nr. } 192 \text { fol. 11; StABa Stift } \\
\text { St. Gangolf, Akten und Bände Nr. } 128 \\
\text { fol. 25' (Todestag laut Anniversarbuch } \\
\text { 1518 X 22); } 1519 \text { II } 26 \text { (bereits verstor- } \\
\text { ben) in StABa A } 136 \text { L } 219 \text { Nr. 545; } \\
\text { Wachter Nr. } 3202 \text { : Pfarrer in Hirschaid, } \\
\text { gest. } 1519 \text { X } 24\end{array}$ \\
\hline 1518 & Johann Wilhelmi & $\begin{array}{l}1521 \text { in StABa Stift St. Gangolf, Akten } \\
\text { und Bände Nr. 18; } 1521 \text { in StABa Stift } \\
\text { St. Gangolf, Akten und Bände Nr. } 192 \\
\text { fol. 11; } 1522 \text { in StABa Stift St. Gangolf, } \\
\text { Akten und Bände Nr. } 192 \text { fol. 11'; } 1526 \\
\text { III } 5 \text { in StABa A 120 L } 131 \text { Nr. 767; } 1528 \\
\text { in StABa Stift St. Gangolf, Akten und }\end{array}$ \\
\hline
\end{tabular}




\begin{tabular}{|c|c|c|}
\hline & & $\begin{array}{l}\text { Bände Nr. } 192 \text { fol. 13; StABa Stift St. } \\
\text { Gangolf, Akten und Bände Nr. } 128 \text { fol. } \\
\text { 11' (Jahrtag laut Anniversarbuch } 1528 \text { V } \\
\text { 7); Wachter Nr. 11089: gest. } 1528 \text { V } 7\end{array}$ \\
\hline 1519 & Heinrich Neydecker & $\begin{array}{l}\text { 1530 V } 20 \text { in StABa A } 120 \text { L } 131 \text { Nr. 769; } \\
\text { 1531-1534 in StABa Stift St. Gangolf, } \\
\text { Akten und Bände Nr. 191; } 1534 \text { III } 5 \text { in } \\
\text { StABa A } 120 \text { L } 131 \text { Nr. 728; } 1537 \text { in } \\
\text { StABa Stift St. Gangolf, Akten und Bän- } \\
\text { de Nr. } 192 \text { fol. 14'; Wachter Nr. 7100: } \\
\text { gest. } 1537 \text { XI } 9\end{array}$ \\
\hline 1528 & Sebastian Wegner & $\begin{array}{l}1540 \text { IX } 12 \text { in StABa A } 120 \text { L } 131 \text { Nr. } \\
\text { 730; } 1543 \text { in StABa Stift St. Gangolf, } \\
\text { Akten und Bände Nr. } 192 \text { fol. 16; Wach- } \\
\text { ter Nr. 10784: gest. } 1543 \text { XI } 11\end{array}$ \\
\hline 1540 & $\begin{array}{l}\text { Heinrich Götzen- } \\
\text { dorfer }\end{array}$ & $\begin{array}{l}\text { Wachter Nr. 3204: öffentlicher Notar, } \\
\text { Pfarrer in Güßbach und Buttenheim, } \\
\text { Kanoniker von St. Stephan, außerdem } \\
\text { Dekan von St. Gangolf }\end{array}$ \\
\hline 1550 & $\begin{array}{l}\text { Eustach Schwan- } \\
\text { hausen }\end{array}$ & $\begin{array}{l}1556 \text { in SttABa D } 3001 \text { HV Rep. } 2 \text { Nr. } \\
264 \text { fol. 5; } 1564 \text { in StABa Stift St. Gan- } \\
\text { golf, Akten und Bände Nr. } 192 \text { fol. 18'; } \\
\text { StABa Stift St. Gangolf, Akten und Bän- } \\
\text { de Nr. } 129 \text { fol. 52' (Todestag laut Anni- } \\
\text { versarbuch } 1564 \text { XII 24); Wachter Nr. } \\
\text { 9324: } 1529 \text { öffentlicher Notar, Domvi- } \\
\text { kar, Pfarrer in Scheßlitz, gest. } 1564 \text { XII } \\
12\end{array}$ \\
\hline 1569 & Albert Wolf & $\begin{array}{l}\text { 1563-66 in StABa Stift St. Gangolf, Ak- } \\
\text { ten und Bände Nr. 191; } 1564 \text { in StABa } \\
\text { Stift St. Gangolf, Akten und Bände Nr. } \\
192 \text { fol. 17'; } 1569 \text { in StABa Stift St. Gan- } \\
\text { golf, Akten und Bände Nr. } 192 \text { fol. 20; }\end{array}$ \\
\hline
\end{tabular}




\begin{tabular}{|c|c|c|}
\hline & & $\begin{array}{l}1580 \text { in StABa Stift St. Gangolf, Akten } \\
\text { und Bände Nr. } 192 \text { fol. 21; StABa Stift } \\
\text { St. Gangolf, Akten und Bände Nr. } 129 \\
\text { fol. 52' (Todestag laut Anniversarbuch } \\
\text { 1580 VIII 17); Wachter Nr. 11210: } 1535 \\
\text { Vikar von St. Jakob, gest. } 1580 \text { VIII } 15\end{array}$ \\
\hline 1580 & Nikolaus Grosskopf & $\begin{array}{l}1580 \text { in StABa Stift St. Gangolf, Akten } \\
\text { und Bände Nr. } 192 \text { fol. 21; } 1588 \text { in StA- } \\
\text { Ba Stift St. Gangolf, Akten und Bände } \\
\text { Nr. } 192 \text { fol. 23'; Wachter Nr. 3440: gest. } \\
1588 \text { VII } 12\end{array}$ \\
\hline 1588 & Andreas Schwarz & $\begin{array}{l}1590 \text { V } 22 \text { in StABa Stift St. Gangolf, } \\
\text { Akten und Bände Nr. } 29 \text { fol. 187; } 1592 \\
\text { in StABa Stift St. Gangolf, Akten und } \\
\text { Bände Nr. } 192 \text { fol. 24; } 1596 \text { in StABa } \\
\text { Stift St. Gangolf, Akten und Bände Nr. } \\
192 \text { fol. 25; StABa Stift St. Gangolf, } \\
\text { Akten und Bände Nr. } 129 \text { fol. } 68 \text { (Todes- } \\
\text { tag laut Anniversarbuch } 1596 \text { X 20); } \\
\text { Wachter Nr. } 9329 \text { : Vikar von St. Ste- } \\
\text { phan, gest. } 1606 \text { X } 20\end{array}$ \\
\hline 1612 & \multicolumn{2}{|l|}{ Johann Leo Baunach } \\
\hline 1624 & \multicolumn{2}{|l|}{ Johann Murmann } \\
\hline 1648 & \multicolumn{2}{|l|}{ Johann Hiltenberger } \\
\hline 1654 & \multicolumn{2}{|c|}{ Johann Christoph Geyer } \\
\hline 1683 & \multicolumn{2}{|c|}{ Georg Haller } \\
\hline 1690 & \multicolumn{2}{|c|}{ Wolfgang Franz Pymer } \\
\hline 1696 & \multicolumn{2}{|c|}{ Johann August Gerber } \\
\hline 1699 & \multicolumn{2}{|c|}{ Johann Wilhelm Hönicke } \\
\hline 1729 & \multicolumn{2}{|c|}{ Johann Jakob Anton Boxberger } \\
\hline 1748 & \multicolumn{2}{|c|}{ Johann Andreas Nieser } \\
\hline 1768 & \multicolumn{2}{|c|}{ Karl Ignatz Josef Gislenus Ditterich von Schönhofen } \\
\hline 1783 & \multicolumn{2}{|c|}{ Johann Michael Heinrich Schubert (Abschaffung des geistli- } \\
\hline
\end{tabular}


